\title{
Annex 47 Report 3: Commissioning Cost-Benefit and Persistence of Savings
}

\author{
Hannah Friedman \\ Marti Frank \\ Kristin Heinemeier \\ Kim Crossman \\ Eliot Crowe \\ David Claridge \\ Cory Toole \\ Daniel Choinière \\ Natascha Milesi Ferretti
}

http://dx.doi.org/10.6028/NIST.TN.1727

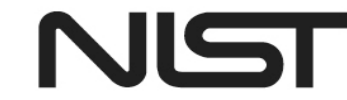




\section{Annex 47 Report 3: Commissioning Cost-Benefit and Persistence of Savings}

Hannah Friedman Marti Frank

Kristin Heinemeier

Kim Crossman

Eliot Crowe

Portland Energy Conservation Inc.

David Claridge

Cory Toole

Texas A\&M University

Daniel Choinière

Natural Resources Canada

CanmetENERGY

Energy Technology Centre

Natascha Milesi Ferretti

National Institute of Standards and Technology

Engineering Laboratory

http://dx.doi.org/10.6028/NIST.TN.1727

December 2011

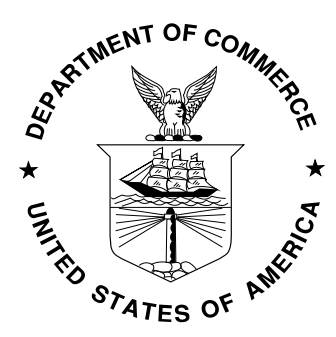

U.S. Department of Commerce Rebecca Blank, Acting Secretary 
Certain commercial entities, equipment, or materials may be identified in this document in order to describe an experimental procedure or concept adequately. Such identification is not intended to imply recommendation or endorsement by the National Institute of Standards and Technology, nor is it intended to imply that the entities, materials, or equipment are necessarily the best available for the purpose.

National Institute of Standards and Technology Technical Note 1727 Natl. Inst. Stand. Technol. Tech. Note 1727, 252 pages (December 2011) http://dx.doi.org/10.6028/NIST.TN.1727 CODEN: NTNOEF 


\section{CITATION}

Friedman, H. et al. "Annex 47 Report 3: Commissioning Cost-Benefit and Persistence of Savings”, National Institute of Standards and Technology, Technical Note 1727. December 2011.

This publication was simultaneously published by Natural Resources Canada as Friedman, H. et al. “Annex 47 Report 3: Commissioning Cost-Benefit and Persistence of Savings”, a Report of Cost-Effective Commissioning of Existing and Low Energy Buildings. December 2011.

Copies of this report may be obtained from the Annex 47 web site at: http://www.ieaannex47.org , the NIST website at: http://www.nist.gov, or from the IEA/ECBCS Bookshop at: www.ecbcs.org.

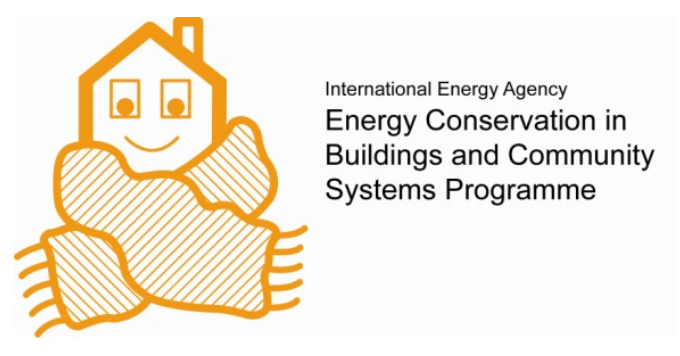




\section{Preface}

\section{International Energy Agency}

The International Energy Agency (IEA) was established in 1974 within the framework of the Organization for Economic Co-operation and Development (OECD) to implement an international energy program. A basic aim of the IEA is to foster co-operation among the twentyeight IEA participating countries and to increase energy security through energy conservation, development of alternative energy sources and energy research, development and demonstration (RD\&D).

\section{Energy Conservation in Buildings and Community Systems}

The IEA coordinates research and development in a number of areas related to energy. The mission of one of those areas, the Energy Conservation for Building and Community Systems Program (ECBCS) is to develop and facilitate the integration of technologies and processes for energy efficiency and conservation into healthy, low emission, and sustainable buildings and communities, through innovation and research.

The research and development strategies of the ECBCS Program [1] are derived from research drivers, national programs within IEA countries, and the IEA Future Building Forum Think Tank Workshop, held in March 2007. The R\&D strategies represent a collective input of the Executive Committee members to exploit technological opportunities to save energy in the buildings sector, and to remove technical obstacles to market penetration of new energy conservation technologies. The R\&D strategies apply to residential, commercial, office buildings and community systems, and will impact the building industry in three focus areas of R\&D activities:

- Dissemination;

- Decision-making; and

- Building products and systems.

Participating countries in ECBCS: Australia, Austria, Belgium, Canada, P.R. China, Czech Republic, Denmark, Finland, France, Germany, Greece, Italy, Japan, Republic of Korea, the Netherlands, New Zealand, Norway, Poland, Portugal, Spain, Sweden, Switzerland, Turkey, United Kingdom and the United States of America.

\section{The Executive Committee}

Overall control of the program is maintained by an Executive Committee, which not only monitors existing projects but also identifies new areas where collaborative effort may be 
beneficial. To date the following projects have been initiated by the executive committee on Energy Conservation in Buildings and Community Systems (completed projects are identified by $(*)$ ):

Annex 1: $\quad$ Load Energy Determination of Buildings (*)

Annex 2: $\quad$ Ekistics and Advanced Community Energy Systems $\left(^{*}\right)$

Annex 3: $\quad$ Energy Conservation in Residential Buildings (*)

Annex 4: $\quad$ Glasgow Commercial Building Monitoring $(*)$

Annex 5: $\quad$ Air Infiltration and Ventilation Centre

Annex 6: $\quad$ Energy Systems and Design of Communities $(*)$

Annex 7: $\quad$ Local Government Energy Planning $(*)$

Annex 8: $\quad$ Inhabitants Behaviour with Regard to Ventilation $(*)$

Annex 9: $\quad$ Minimum Ventilation Rates (*)

Annex 10: $\quad$ Building HVAC System Simulation $(*)$

Annex 11: $\quad$ Energy Auditing $(*)$

Annex 12: $\quad$ Windows and Fenestration $(*)$

Annex 13: $\quad$ Energy Management in Hospitals $(*)$

Annex 14: Condensation and Energy $(*)$

Annex 15: $\quad$ Energy Efficiency in Schools $(*)$

Annex 16: $\quad$ BEMS 1- User Interfaces and System Integration (*)

Annex 17: $\quad$ BEMS 2- Evaluation and Emulation Techniques (*)

Annex 18: Demand Controlled Ventilation Systems (*)

Annex 19: $\quad$ Low Slope Roof Systems $(*)$

Annex 20: $\quad$ Air Flow Patterns within Buildings $(*)$

Annex 21: $\quad$ Thermal Modelling $(*)$

Annex 22: $\quad$ Energy Efficient Communities $(*)$

Annex 23: $\quad$ Multi Zone Air Flow Modelling (COMIS) $\left({ }^{*}\right)$

Annex 24: Heat, Air and Moisture Transfer in Envelopes (*)

Annex 25: $\quad$ Real-time HVAC Simulation $(*)$

Annex 26: Energy Efficient Ventilation of Large Enclosures (*)

Annex 27: Evaluation and Demonstration of Domestic Ventilation Systems (*) 
Annex 28: $\quad$ Low Energy Cooling Systems (*)

Annex 29: $\quad$ Daylight in Buildings (*)

Annex 30: $\quad$ Bringing Simulation to Application (*)

Annex 31: Energy-Related Environmental Impact of Buildings $(*)$

Annex 32: $\quad$ Integral Building Envelope Performance Assessment $(*)$

Annex 33: $\quad$ Advanced Local Energy Planning $(*)$

Annex 34: $\quad$ Computer-Aided Evaluation of HVAC System Performance (*)

Annex 35: Design of Energy Efficient Hybrid Ventilation (HYBVENT) $(*)$

Annex 36: $\quad$ Retrofitting of Educational Buildings $(*)$

Annex 37: Low Exergy Systems for Heating and Cooling of Buildings (LowEx) (*)

Annex 38: $\quad$ Solar Sustainable Housing $\left({ }^{*}\right)$

Annex 39: High Performance Insulation Systems (*)

Annex 40: $\quad$ Building Commissioning to Improve Energy Performance $(*)$

Annex 41: Whole Building Heat, Air and Moisture Response (MOIST-ENG) $\left({ }^{*}\right)$

Annex 42: The Simulation of Building-Integrated Fuel Cell and Other Cogeneration Systems (FC+COGEN-SIM) $(*)$

Annex 43: $\quad$ Testing and Validation of Building Energy Simulation Tools (*)

Annex 44: Integrating Environmentally Responsive Elements in Buildings

Annex 45: $\quad$ Energy Efficient Electric Lighting for Buildings $\left(^{*}\right)$

Annex 46: Holistic Assessment Tool-kit on Energy Efficient Retrofit Measures for Government Buildings (EnERGo)

Annex 47: Cost-Effective Commissioning for Existing and Low Energy Buildings

Annex 48: Heat Pumping and Reversible Air Conditioning

Annex 49: $\quad$ Low Exergy Systems for High Performance Buildings and Communities

Annex 50: Prefabricated Systems for Low Energy Renovation of Residential Buildings

Annex 51: Energy Efficient Communities

Annex 52: Towards Net Zero Energy Solar Buildings

Annex 53: Total Energy Use in Buildings: Analysis \& Evaluation Methods

Annex 54: $\quad$ Analysis of Micro-Generation \& Related Energy Technologies in Buildings 
Annex 55: Reliability of Energy Efficient Building Retrofitting - Probability Assessment of Performance \& Cost (RAP-RETRO)

Annex 56: $\quad$ Energy and Greenhouse Gas Optimised Building Renovation

Working Group - Energy Efficiency in Educational Buildings (*)

Working Group - Indicators of Energy Efficiency in Cold Climate Buildings (*)

Working Group - Annex 36 Extension: The Energy Concept Adviser (*)

Working Group - Energy Efficient Communities

\section{Annex 47}

The objectives of Annex 47 were to enable the effective commissioning of existing and future buildings in order to improve their operating performance and to advance the state-of-the-art of building commissioning by:

Extending previously developed methods and tools to address advanced systems and low energy buildings, utilizing design data and the buildings’ own systems in commissioning;

Automating the commissioning process to the extent practicable;

Developing methodologies and tools to improve operation of buildings in use, including identifying the best energy saving opportunities in HVAC system renovations; and

Quantifying and improving the costs and benefits of commissioning, including the persistence of benefits and the role of automated tools in improving persistence and reducing costs without sacrificing other important commissioning considerations.

To accomplish these objectives Annex 47 has conducted research and development in the framework of the following three areas:

\section{Initial Commissioning of Advanced and Low Energy Building Systems}

This area addressed what can be done for (the design of) future buildings to enable cost-effective commissioning. The focus was set on the concept, design, construction, acceptance, and early operation phase of buildings.

\section{Commissioning and Optimization of Existing Buildings}

This area addressed needs for existing buildings and systems to conduct cost-effective commissioning. The focus here was set on existing buildings where the commissioning process must be performed with incomplete or out-of-date documentation.

\section{Commissioning Cost-Benefits and Persistence}

This area addressed how the cost-benefit situation can be represented. Key answers were provided by developing international consensus methods for evaluating commissioning cost- 
benefit and persistence. The methods were implemented in a cost-benefit and persistence database using field data.

Annex 47 was an international joint effort conducted by 50 organizations in 11 countries:

\begin{tabular}{|c|c|}
\hline Belgium & $\begin{array}{ll}\text { - } & \text { KaHo St-Lieven } \\
\text { - } & \text { Ghent University } \\
\text { - } & \text { Passive House Platform } \\
\text { - } & \text { Katholieke de Liège } \\
\end{array}$ \\
\hline Canada & $\begin{array}{ll} & \text { Natural Resources Canada (CETC-Varennes) } \\
\text { - } & \text { Public Works and Governmental Services Canada } \\
\text { - } \quad \text { Palais de Congres de Montreal } \\
\text { - } & \text { Hydro Quebec }\end{array}$ \\
\hline Czech Republic & - Czech Technical University \\
\hline Finland & $\begin{array}{l}\text { - VTT Technical Research Centre of Finland } \\
\text { - Helsinki University of Technology }\end{array}$ \\
\hline Germany & $\begin{array}{ll} & \text { Ebert-Baumann Consulting Engineers } \\
\text { - } & \text { Institute of Building Services and Energy Design } \\
\text { - } & \text { Fraunhofer Institute for Solar Energy Systems }\end{array}$ \\
\hline Hong Kong/China & - $\quad$ Hong Kong Polytechnic University \\
\hline Hungary & - University of Pécs \\
\hline Japan & 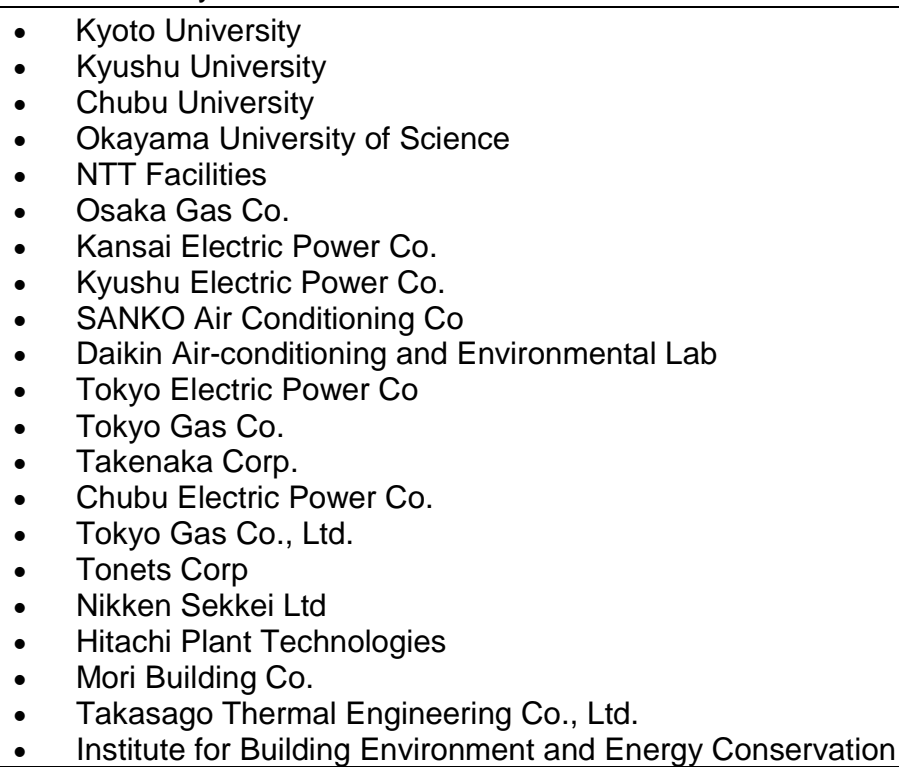 \\
\hline Netherlands & $\begin{array}{l}\text { - TNO Environment and Geosciences } \\
\text { - University of Delft }\end{array}$ \\
\hline Norway & $\begin{array}{l}\text { - } \quad \text { Norwegian University of Science and Technology } \\
\text { - SINTEF }\end{array}$ \\
\hline USA & $\begin{array}{l}\text { - } \quad \text { National Institute of Standards and Technology } \\
\text { - } \quad \text { Texas A\&M University } \\
\text { - } \quad \text { Cortland Energy Conservation Inc. } \\
\text { - } \quad \text { Johnson Contlon University } \\
\text { - } \quad \text { Siemens } \\
\text { - Lawrence Berkeley National Laboratory }\end{array}$ \\
\hline
\end{tabular}




\section{FOREWORD}

This report summarizes part of the work of IEA-ECBCS Annex 47 Cost-Effective Commissioning of Existing and Low Energy Buildings. It is based on the research findings from the participating countries. The publication is an official Annex 47 report.

Report 1, 'Commissioning Overview' can be considered as an introduction to the commissioning process.

Report 2, 'Commissioning Tools for Existing and Low Energy Buildings' provides general information on the use of tools to enhance the commissioning of low energy and existing buildings, summarizes the specifications for tools developed in the Annex and presents building case studies.

Report 3, 'Commissioning Cost Benefit and Persistence' presents a collection of data that would be of use in promoting commissioning of new and existing buildings and defines methods for determining costs, benefits, and persistence of commissioning, The report also highlights national differences in the definition of commissioning.

Report 4, 'Flowcharts and Data Models for Initial Commissioning of Advanced and Low Energy Building Systems' provides a state of the art description of the use of flow charts and data models in the practice and research of initial commissioning of advanced and low energy building systems.

In many countries, commissioning is still an emerging activity and in all countries, advances are needed for greater formalization and standardization. We hope that this report will be useful to promote best practices, to advance its development and to serve as the basis of further research in this growing field.

Natascha Milesi Ferretti and Daniel Choinière

Annex 47 Co-Operating Agents 


\section{ACKNOWLEDGEMENT}

The material presented in this publication has been collected and developed within an Annex of the IEA implementing agreement on Energy Conservation in Buildings and Community Systems, Annex 47, “Cost-Effective Commissioning of Existing and Low Energy Buildings”.

This report, together with three companion Annex reports are the result of an international joint effort conducted in ten countries. All those who have contributed to the project are gratefully acknowledged.

On behalf of all participants, the members of the Executive Committee of IEA Energy

Conservation in Building and Community Systems Implementing Agreement as well as the funding bodies are also gratefully acknowledged.

A list of participating countries, institutes, and people can be found at the end of this report.

\section{REPORT EDITORS:}

Hannah Friedman (Portland Energy Conservation, Inc)

David Claridge (Texas A\&M University)

Daniel Choinière (Natural Resources Canada)

Natascha Milesi Ferretti (NIST, USA) 


\section{TABLE OF CONTENTS}

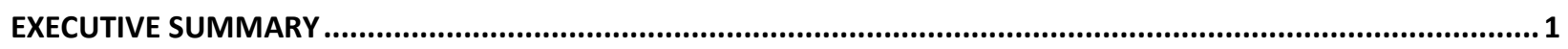

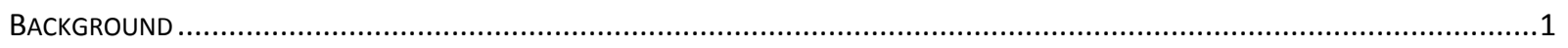

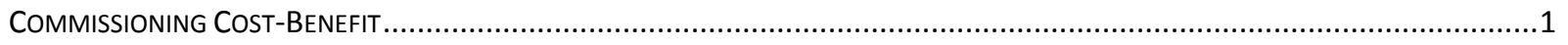

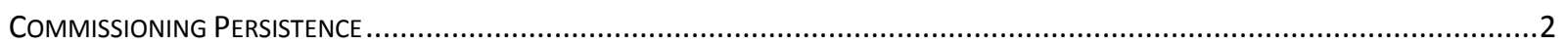

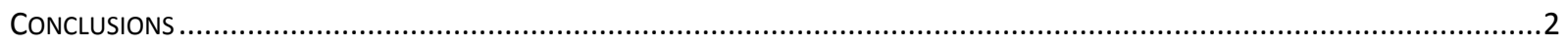

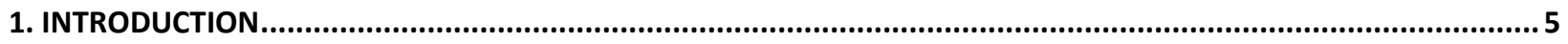

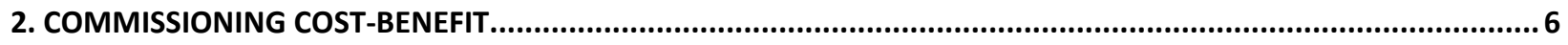

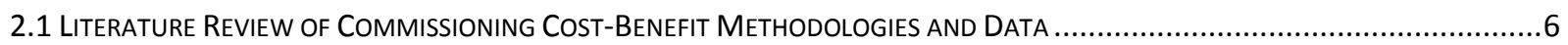

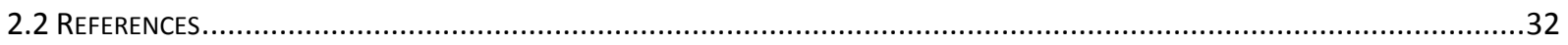

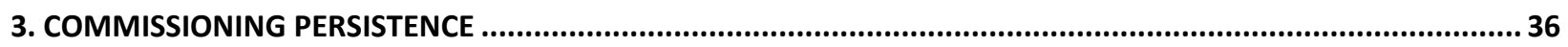

3.1 Methodologies for Determining PeRsistence of Commissioning Benefits .........................................................36

3.2 ReView of Literature on the Persistence of Commissioning Benefits in NeW And Existing BuILDings......................41

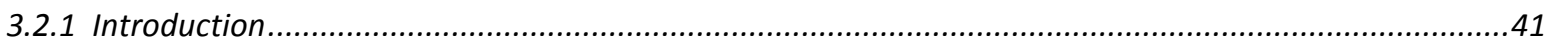

3.2.2 Persistence of Commissioning Measures in Existing Buildings...........................................................

3.2.3. Persistence of Commissioning Measures in New Buildings .............................................................54

3.2.4. Strategies for Improving Persistence in New and Existing Buildings..................................................57

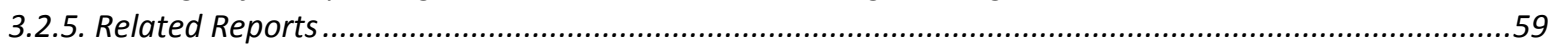

3.2.6. Methodologies for Determining Persistence of Commissioning Measures and Energy Benefits of

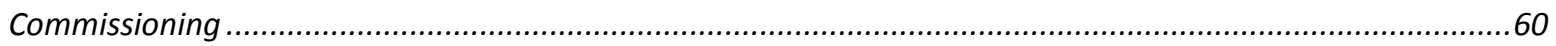

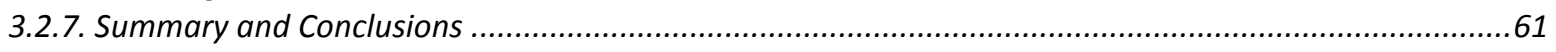

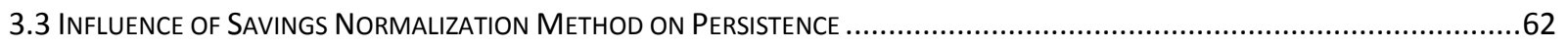

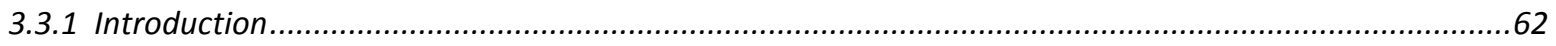

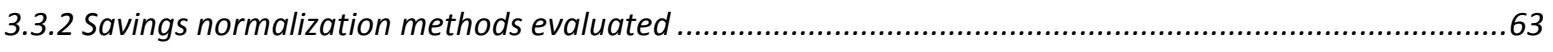

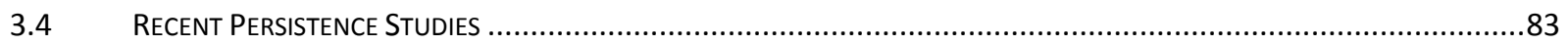

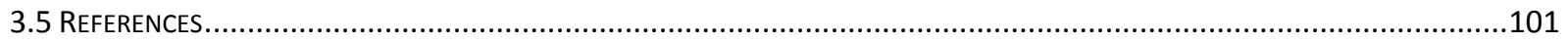

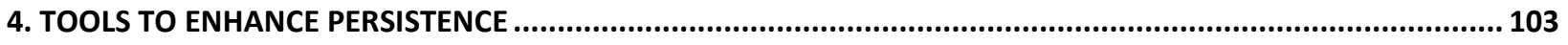

4.1 AN AUtOMATEd BUILDING COMmisSIONING ANALYSIS TOOL (ABCAT) ..................................................................103

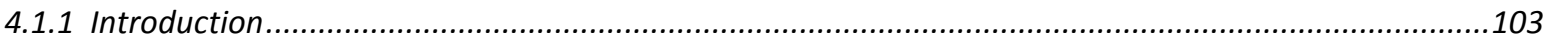

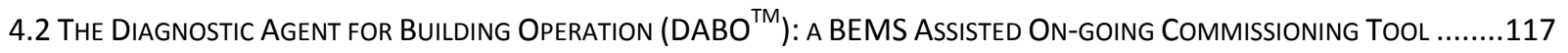

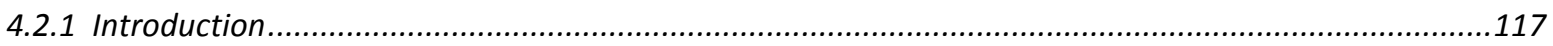

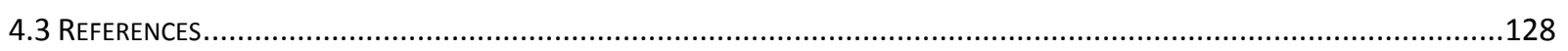

5. INTERNATIONAL COMMISSIONING COST-BENEFIT AND PERSISTENCE DATABASE ........................................ 130

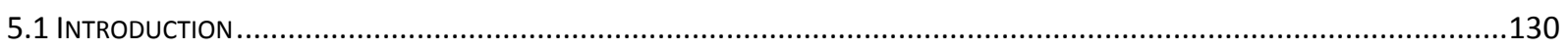

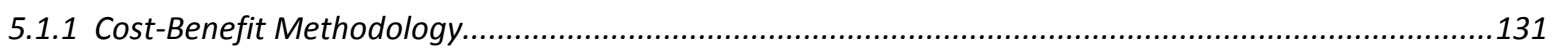

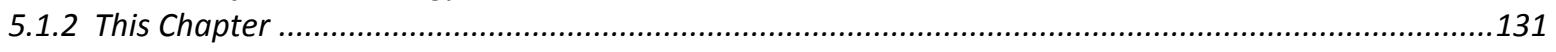

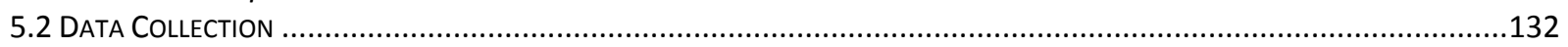

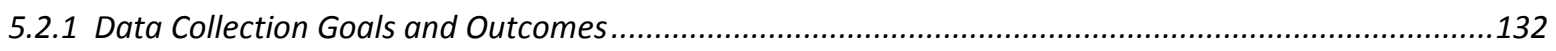

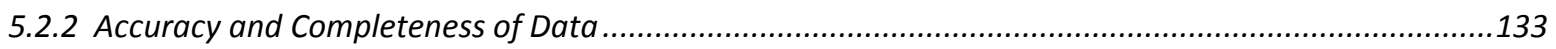

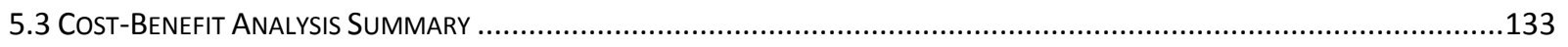

5.3.2 Existing Building Commissioning $(E B C X)$...................................................................................138

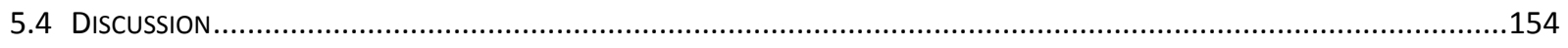

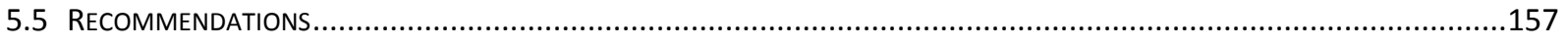

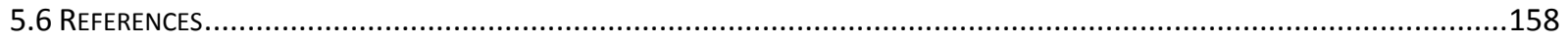


APPENDIX A: COMMISSIONING COST-BENEFIT DATABASE ................................................................. 161

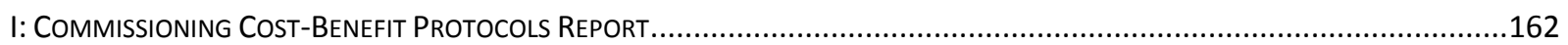

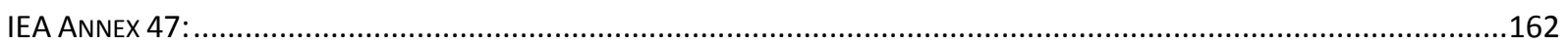

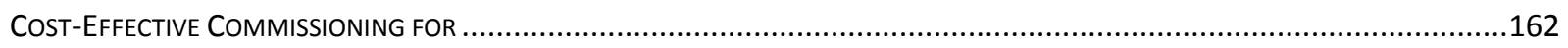

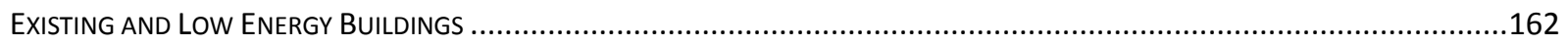

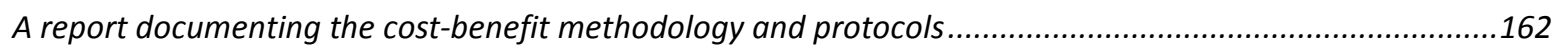

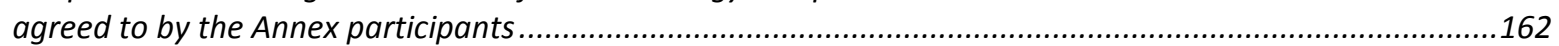

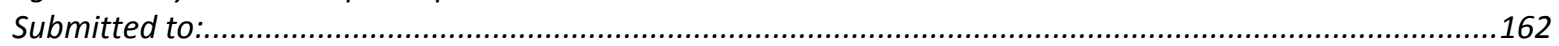

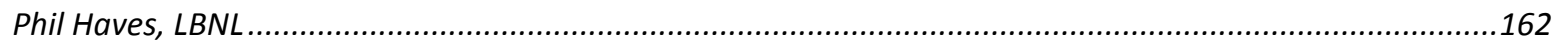

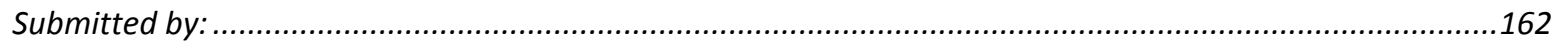

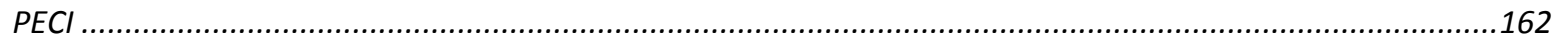

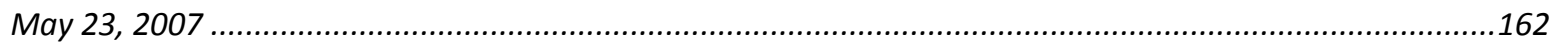

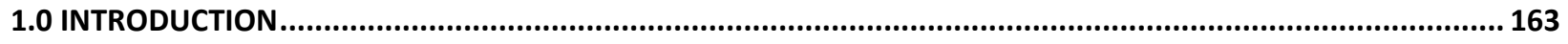

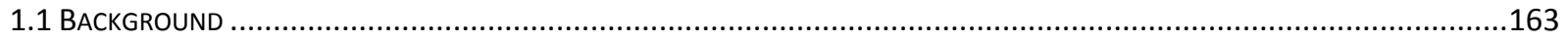

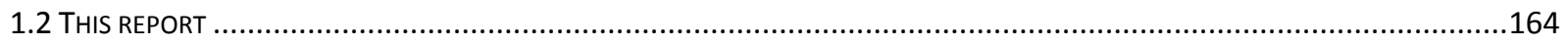

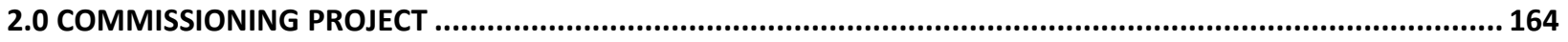

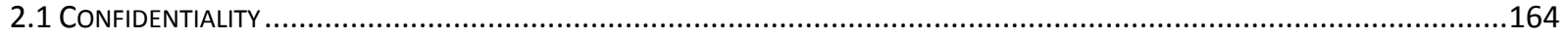

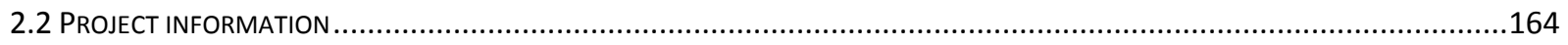

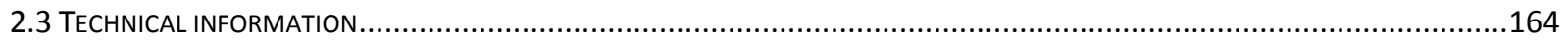

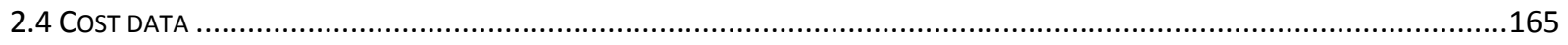

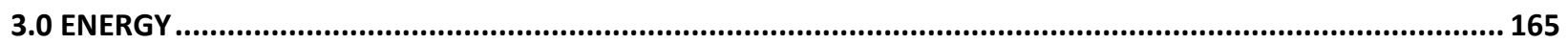

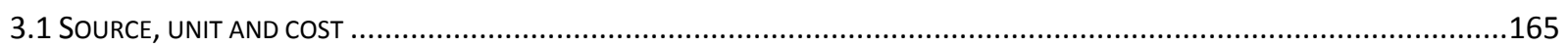

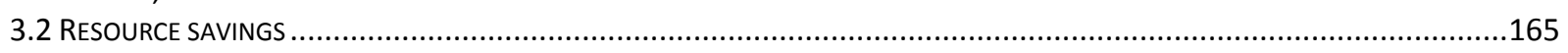

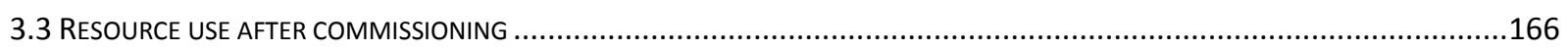

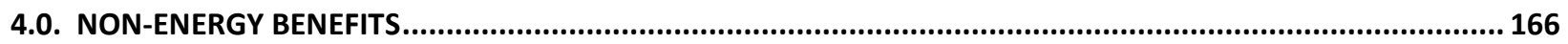

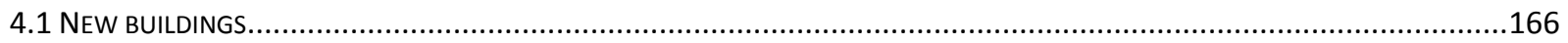

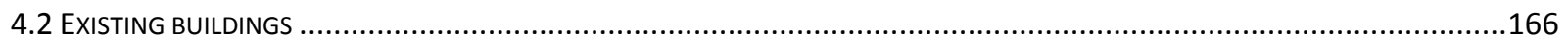

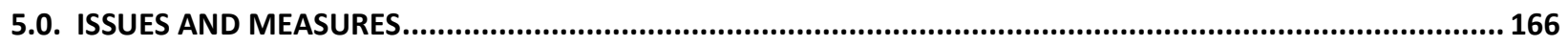

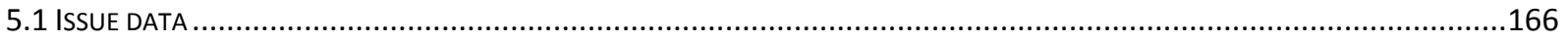

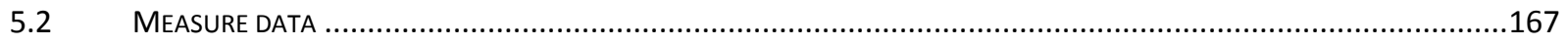

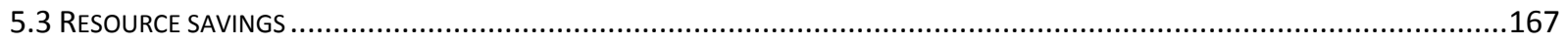

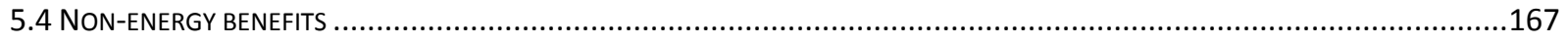

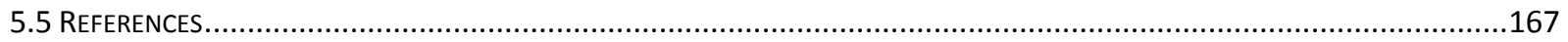

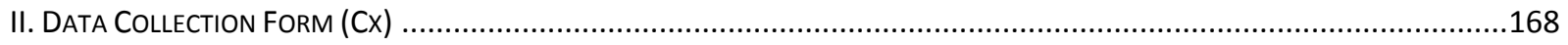

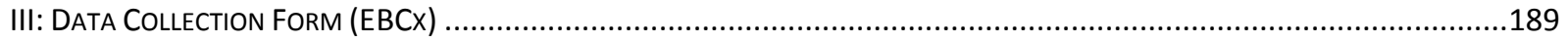

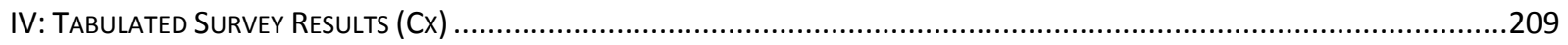

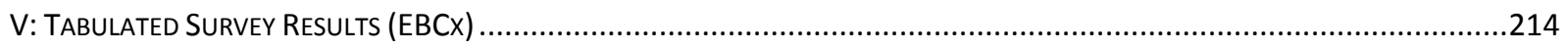

APPENDIX B: THE STATE OF BUILDING SYSTEMS COMMISSIONING ................................................... 224

APPENDIX C: RELEVANT PAPERS AND PRESENTATIONS .....................................................................232

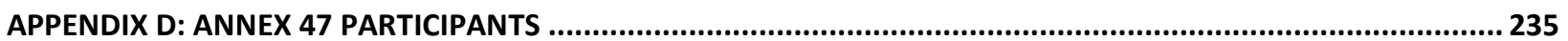




\section{EXECUTIVE SUMMARY}

\section{Background}

Commissioning $(\mathrm{Cx})$ of new and existing buildings has been shown to reduce energy usage and can also produce non-energy related benefits such as improved occupant comfort. When compared with other initiatives such as installation of high efficiency equipment or installing photovoltaic systems, commissioning is highly cost-effective, resulting in short investment payback periods.

Despite the proven benefits, commissioning is not "business as usual," and this is generally attributed to the following factors:

1. The costs and benefits of commissioning are not clearly understood by the decision-makers in the commercial buildings industry.

2. This (Point 1 ) is further complicated due to the lack of a single definition of what the commissioning process includes.

3. Commissioning focuses on the operation of systems and their interactions, and there is a perception that operational improvements may not persist over time.

4. While commissioning can be explained as a logical sequence of steps, the details are complex and the outcomes aren't tangible in the same way that, for example, high efficiency lighting is. That means it takes time for the buildings industry to become familiar and comfortable with the process.

This report is the result of an international research project that collected data to help overcome the barriers listed in items 1, 2, and 3.

The core purpose of this report was to collect data that would be of use in promoting commissioning of new and existing buildings. A secondary purpose was to define methods for determining costs, benefits, and persistence of commissioning along with understanding national differences in the definition of commissioning.

Research was grouped under two broad headings: Commissioning Cost-Benefit, and Commissioning Persistence.

\section{Commissioning Cost-Benefit}

\section{Literature Review of Commissioning Cost-Benefit Methodologies}

Twelve studies were summarized, focused on studies where the cost-benefit methodologies were known. The majority were research studies of multiple buildings, and the studies ranged from research reports, databases, and marketing literature. These studies are summarized in three main aspects:

1. Author, year, format, audience, caveats and considerations,

2. Quantitative data - number of buildings, costs, benefits, payback, and

3. Methodologies used to determine quantitative data - subdivided into simple, moderate and complex.

\section{Creation of an International Cost-Benefit Database}

Financial and technical data was collected and analyzed from ten new building commissioning projects and 44 existing building commissioning projects, from seven countries.

This subtask commenced with efforts to determine what key data was to be collected (divided into "required" and "optional" data), and to develop the data collection forms. These data to be collected included:

1. Description of what was included in the commissioning process,

2. Commissioning cost,

3. Energy and cost savings from commissioning, 
4. What problems were found, and the solutions, and

5. Non-energy benefits.

Collected data was collated in spreadsheets for analysis and generation of charts of the key findings.

\section{Commissioning Persistence}

\section{Literature Review on the Persistence of Commissioning Benefits}

This review summarized the findings from five studies encompassing 37 commissioning projects from across the USA. Persistence of savings was expressed as a percentage of the original claimed savings, after a specified time has elapsed after the project (e.g., $75 \%$ after five years). In addition to evaluating project savings, the studies covered persistence at the level of specific measures, including the reasons for measures not persisting.

\section{Impact of Savings Normalization Method on Commissioning Persistence}

This study reviewed two weather normalization methods that are used in calculating energy savings from commissioning, and compared their impact on commissioning persistence claims. The two methods evaluated were:

\section{International Performance Measurement and Verification Protocol (IPMVP)}

A baseline regression model (or calibrated simulation model) is created based on the precommissioning energy use and recorded temperature/humidity. In the post-commissioning period, weather data is collected, and the regression model is used to predict what the energy use would have been if commissioning hadn't occurred. The actual energy use is subtracted from the modeled prediction, and this constitutes the energy saved.

\section{Normalized Annual Consumption (NAC)}

Similar basic principle to the IPMVP; a regression model (or calibrated simulation model) is created using baseline data. This model is applied to a standardized 'average' weather year based on the site location in order to calculate baseline annual energy use. In the postcommissioning period the regression model is recreated using post-energy and post-weather data, and this regression model is applied to the same 'average' weather year. The difference between the two modeled average years constitutes the savings.

\section{Examples of Tools for Enhancing Persistence of Commissioning Benefits}

There are a number of data collection and analysis tools that may be used for monitoring the persistence of commissioning improvements. This study described two such tools:

\section{Automated Building Commissioning Analysis Tool (ABCAT)}

This tool collects and compares whole-building energy use to modeled 'optimal' energy use, and identifies anomalies that point towards operational problems.

\section{Diagnostic Agent for Building Operation (DABO ${ }^{T M}$ )}

This tool is an add-on module that uses the Building Automation System (BAS) to monitor performance at the sub-system level. It is designed as an aid for Ongoing Commissioning.

The basic architecture and functionality of each of these systems is described, along with case study examples of projects where they identified system problems and contributed to their solutions.

\section{Conclusions}

\section{Commissioning Cost-Benefit}

The data collected through this research project begins to characterize the various types of commissioning processes that are occurring in Annex member countries internationally. While data was often difficult to obtain, we expanded our knowledge in two key areas:

- The scope of the Cx process employed for new and existing buildings, and 
- Characterization of issues discovered through the Cx process including system type, likely origin of issue (design, construction/installation, Operations and Maintenance (O\&M), or capital improvement), issue type, and measures implemented.

While the project results begin to develop a qualitative picture for how commissioning is evolving internationally, quantitative results were less apparent. For example, data on commissioning costs and energy savings were highly variable. Falling short of the data collection goals set by Annex member country representatives, it was not possible to make strong conclusions about the cost-effectiveness of Cx internationally. However, progress was made towards understanding and categorizing the state of the commissioning industry for new and existing buildings in Annex member countries. While all countries have $\mathrm{Cx}$ research occurring, the majority of countries are in an early adopter phase of industry development. Only a few countries can be categorized as having a developing commissioning industry in which services are becoming more commonly obtained by owners.

New Construction Cx costs ranged from 0.06 US $\$ / \mathrm{ft}^{2}$ to $2.57 \mathrm{US} \$ / \mathrm{ft}^{2},\left(0.64 \mathrm{US} \$ / \mathrm{m}^{2}\right.$ to $\left.27.63 \mathrm{US} \$ / \mathrm{m}^{2}\right)$ suggesting the $C x$ process varied significantly and/or the way costs were attributed varies. Savings values were either not reported or considered unreliable as reference values, and so payback values were not calculated for New Construction Cx.

For Existing Building Cx, calculating simple payback results in a small data set (19 samples) but this can serve to illustrate a typical range of values (see following chart).

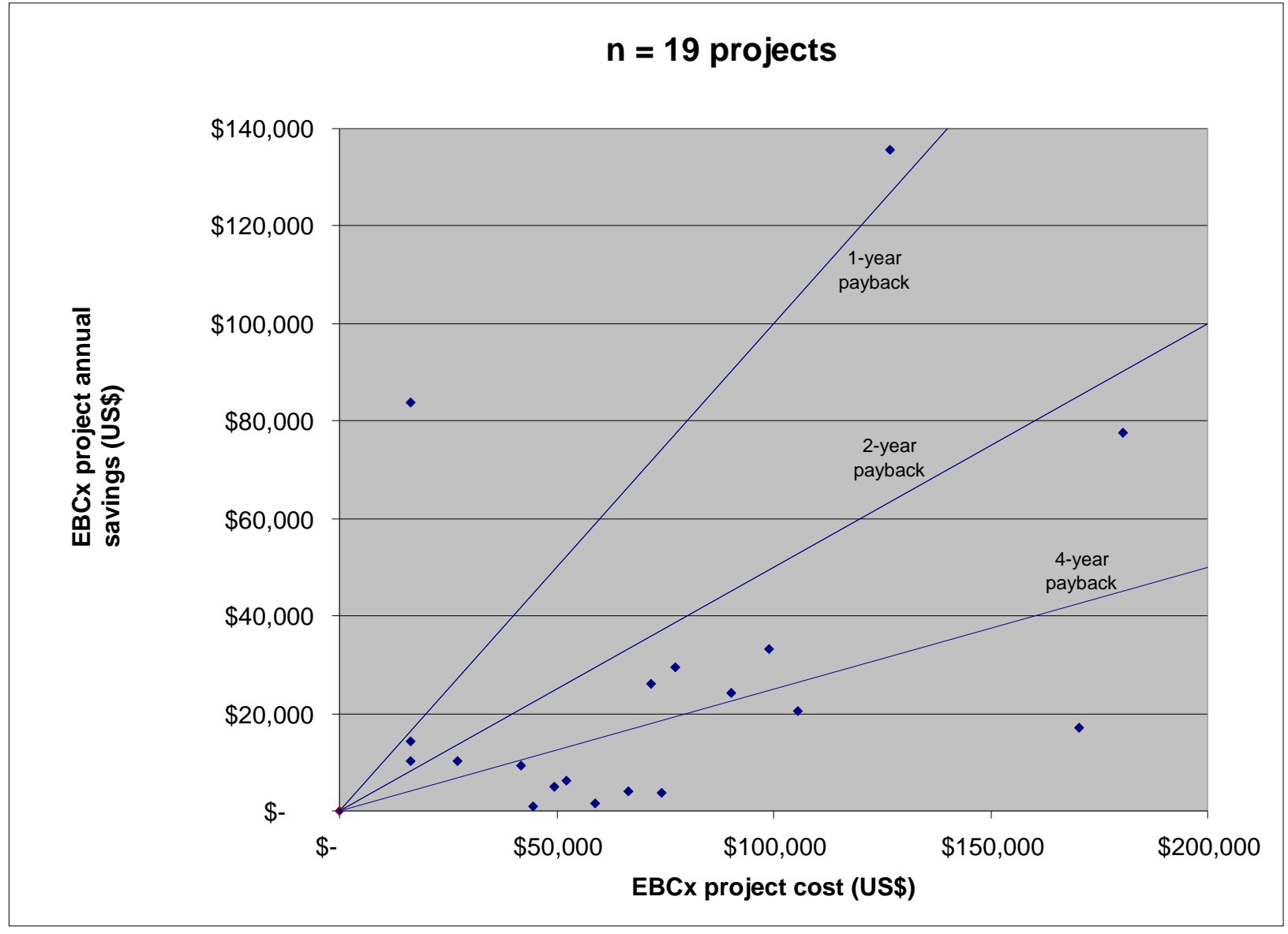

EBCx project costs vs. annual savings estimates 
Project simple payback values ranged from 0.9 years to 45.7 years, with a median value of 3.7 years. Nine out of the 19 projects had a payback of greater than four years, and six had payback of between two and four years.

Higher payback is the result of either relatively high EBCx costs or relatively low resultant cost savings. For cases where payback was greater than four years in this study, the savings were relatively low (based on savings $\$ / \mathrm{m}^{2}\left(\$ / \mathrm{ft}^{2}\right)$, as opposed the costs being relatively high.

\section{Persistence of Commissioning Benefits}

Current information on persistence of commissioning energy savings in existing buildings may be summarized as:

- Savings persistence at the time of the study (3 years to 20 years after commissioning) ranged from about $50 \%$ to $100 \%$ in all but a handful of buildings.

- Average savings persistence at the time of the study was about $75 \%$ of the original savings.

- The most dramatic savings degradation was caused by undetected mechanical or control component failures.

- Follow-up when needed has demonstrated persistence of commissioning savings for 7 years to 20 years in a small number of buildings. ABCAT and $\mathrm{DABO}{ }^{\mathrm{TM}}$ have demonstrated the benefits of having tools to support persistence.

- Determination of savings using a "normalized annual consumption" as the basis for savings determination produced less variation in savings and persistence than found when the actual weather during the baseline and post-commissioning periods was used. It also suggested that use of calibrated simulation for baseline determination may provide more stable results. 


\section{INTRODUCTION}

Building Commissioning ${ }^{1}$ is a quality assurance process for the design, construction and operation of buildings. The formalized concept of commissioning originated in the UK in the 1960's and developed in Hong Kong and Canada in the 1980's. The process has been refined in individual countries and researchers are working with the building industry to merge the commissioning process with existing best practices to develop a more complete and streamlined approach to ensure that buildings operate as intended. Internationally, partnerships and collaborations to promote the commissioning process have accelerated awareness and adoption [Appendix B]. Although it is recognized as a valuable means to ensure that buildings reach their operating potential, the process is not widely adopted.

The principle barrier to market penetration is the perception of high cost of commissioning. Documenting the costs and the benefits, and disseminating that information is widely seen as critical to increasing the uptake of commissioning. The increased use of innovative, interacting, systems in low or zero energy buildings both increases the importance of commissioning and requires the development of commissioning methods and procedures for these systems. Furthermore, it is crucial that the benefits gained through commissioning persist over time so that building owners maximize their benefits.

The development of standardized methodologies for quantifying costs and benefits of commissioning and the evaluation of persistence of savings are seen as means to further increase market adoption of. This report presents the lessons learned in key studies, gathers and develops new information, and distills the information into a format that can useful in the development of a plan for future work.

This report summarizes the work completed between 2005 and 2009 through the International Energy Agency Annex 47 Subtask C: Cost-Benefit and Persistence of Savings, and is organized as follows:

\section{Chapter 2: Commissioning Cost-Benefit}

This chapter includes a literature review of existing cost-benefit methodologies, including recommendations for improvements.

\section{Chapter 3: Commissioning Persistence}

This chapter discusses methodologies for measuring persistence of commissioning benefits, summarizes example projects from a literature review, and reports results of persistence studies performed by Annex participants.

\section{Chapter 4: Tools to Enhance Persistence}

This chapter describes two tools that have been developed for the purpose of tracking persistence of building performance - ABCAT and DABO.

\section{Chapter 5: International Commissioning Cost-Benefit and Persistence Report}

This chapter summarizes the results of the Annex 47 cost-benefit data collection efforts with discussion of findings and recommendations for future work.

\section{Chapter 6: Conclusions on Commissioning Cost-Benefit and Persistence}

\footnotetext{
${ }^{1}$ Commissioning- Clarifying Owner's Project Requirements (OPR) from viewpoints of environment, energy and facility usage, and auditing and verifying different judgments, actions and documentations in the Commissioning Process (CxP) in order to realize a performance of building system requested in the OPR through the life of the building. Initial Commissioning, Re-commissioning, Existing Building Commissioning, and Ongoing Commissioning are defined in the Glossary of Terms produced by ECBCS Annex 40.
} 


\section{COMMISSIONING COST-BENEFIT}

\subsection{Literature Review of Commissioning Cost-Benefit Methodologies and Data}

\subsubsection{Introduction}

This chapter summarizes findings from a review of 12 commissioning cost-benefit studies. The chapter focuses specifically on the methodologies used to determine the costs and benefits of commissioning (See Appendix A for report on methodology). In order to maintain this focus, only studies that make their methodologies explicit have been included. The majority of methodologies that were analyzed are research studies of multiple buildings, and only a few are case studies of just one or two buildings. A more exhaustive list of studies that include cost and benefit data, but not an extensive methodological discussion, can be found in the bibliography.

These 12 studies represent a variety of formats and intentions, which were each created to meet the funder's goal. Among them are research reports, databases of cost-benefit information and a glossy, marketing-style brochure. Most of the research reports were undertaken to produce data to support utility and research programs and to help owners and commissioning providers gather the financial justification needed to implement New Building Commissioning (Cx) or Existing Building Commissioning (EBCx).

There is a significant difference in methodological framework between studies implemented as "one-time" or "snapshot" analyses, and those set up to continually collect and incorporate new data. It is probably true that any methodology can be implemented on a continuous basis if its funding is also continuous. However, data collection methodologies that facilitate data entry by allowing respondents to easily enter their own data and use an automated or semi-automated analysis tool are better positioned for ongoing analysis.

Table 2.1 summarizes the key cost and benefits as derived from the 12 studies. This indicates the minimum and maximum average values stated in the studies, rather than the complete range of values for all individual projects (which would have a larger range of values). 
Table 2.1 Summary of average costs and benefits from 12 studies ${ }^{i}$

\begin{tabular}{|c|c|c|}
\hline & $\begin{array}{c}\text { New construction } \\
\text { US } \$ / \mathrm{m}^{2} \\
\left(\mathrm{US} \$ / \mathrm{ft}^{2}\right)\end{array}$ & 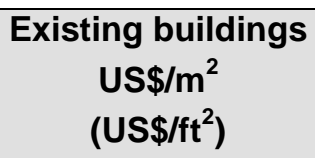 \\
\hline Cx / EBCx cost & $\begin{array}{l}\$ 2.05 \text { to } \$ 10.76 \\
(\$ 0.19 \text { to } \$ 1.00)\end{array}$ & $\begin{array}{l}\$ 0.86 \text { to } \$ 4.31 \\
(\$ 0.08 \text { to } \$ 0.40)\end{array}$ \\
\hline Energy benefits & $\begin{array}{c}\$ 0.54 \text { to } \$ 6.89 \\
(\$ 0.05 \text { to } \$ 0.64)\end{array}$ & $\begin{array}{l}\$ 1.18 \text { to } \$ 2.80 \\
(\$ 0.11 \text { to } \$ 0.26)\end{array}$ \\
\hline Non-energy benefits & $\begin{array}{l}\$ 1.40 \text { to } \$ 22.60 \\
(\$ 0.13 \text { to } \$ 2.10)\end{array}$ & $\begin{array}{c}\$ 1.18 \text { to } \$ 1.94 \\
(\$ 0.11 \text { to } \$ 0.18)\end{array}$ \\
\hline Simple payback & 4.8 years to 6.5 years & 0.7 years to 3.2 years \\
\hline
\end{tabular}

Costs and benefits are presented as ranges to demonstrate the variances in the studies examined. Median or average values are not presented because underlying methodologies differ widely and such figures would not reflect actual costs and benefits experienced by building owners.

Table 2.2 describes the studies, including their format, expected use and audience, and any caveats and considerations that might affect how their conclusions are interpreted. Four of the studies were originally conducted as research projects, funded by government agencies and a non-profit corporation. ${ }^{2}$ Ten reported their findings in published conference papers ${ }^{3}$ of the two that were never published as conference papers, one is a glossy brochure produced for marketing purposes and the other is an article written for subscribers to an energy research and information service. ${ }^{4}$

Table 2.2 also provides a side-by-side comparison of the studies' data and findings. They represent a wide range of methodological approaches and resulting data on the costs and benefits of commissioning. Their data ranges from case studies of one to six buildings to more extensive analyses of 16 to 21 buildings to two meta-analyses of data collected and analyzed by others, one of 44 buildings and the other of 175 buildings. Among building projects studied there is wide range in building size and type and in findings.

\footnotetext{
${ }^{2}$ Funders were: U.S. Department of Energy, U.S. Environmental Protection Agency, Lawrence Berkeley National Laboratory, Northwest Energy Efficiency Alliance.

${ }^{3}$ Conferences were: American Council for an Energy Efficient Economy Summer Study, National Conference on Building Commissioning.

${ }^{4}$ Energy information service is ESource.
} 
Table 2.2. Description of cost-benefit studies (continued on next two pages)

\begin{tabular}{|c|c|c|c|}
\hline Studylauthor & Format & Uselaudience & Caveats and considerations \\
\hline $\begin{array}{l}\text { Stum, } \\
\text { ECM Cx } \\
(1994)\end{array}$ & Conference paper & Research & $\begin{array}{l}\text { - Only energy conservation measure (ECM) commissioning is studied - not whole } \\
\text { building commissioning. } \\
\text { - } \quad \text { Utility program costs are included as a cost of commissioning. } \\
\text { - } \quad \text { This early study does not address non-energy benefits (NEBs). }\end{array}$ \\
\hline $\begin{array}{l}\text { Piette, } \\
\text { Energy Edge Cx } \\
(1995)\end{array}$ & Technical report & $\begin{array}{l}\text { This was one of the first studies } \\
\text { to show savings concretely, and } \\
\text { audience is program planners, } \\
\text { technology developers. }\end{array}$ & $\begin{array}{l}\text { - The study is focused on commissioning of ECMs in new construction, although } \\
\text { additional unrelated deficiencies were reported. } \\
\text { - Some of the data collection and analysis were associated with a broader } \\
\text { evaluation project. }\end{array}$ \\
\hline $\begin{array}{l}\text { Haasl, } \\
5 \text { Building Study } \\
(1996)\end{array}$ & Conference Paper & $\begin{array}{l}\text { Funded by the U.S. } \\
\text { Environmental Protection } \\
\text { Agency, Global Change Division, } \\
\text { and the U.S. Department of } \\
\text { Energy to help formulate energy } \\
\text { conservation policy and } \\
\text { programs. }\end{array}$ & $\begin{array}{l}\text { - The study was an "Operations and Maintenance (O\&M) investigative case } \\
\text { study." } \\
\text { - No detail provided on the standard energy calculations or modeling scope. } \\
\text { - } \quad \text { NEB analysis was still in progress. } \\
\text { - Stated objective was to "demonstrate that energy saving opportunities exist... } \\
\text { and can be realized through improvements in O\&M." }\end{array}$ \\
\hline $\begin{array}{l}\text { PECI/DOE, } \\
\text { Deficiency } \\
\text { Database (1996) }\end{array}$ & Research report & $\begin{array}{l}\text { DOE-funded to document } \\
\text { deficiencies found through } \mathrm{Cx} \\
\text { and EBCx. }\end{array}$ & $\begin{array}{l}\text { - While technically not a cost-benefit methodology itself, this method offers insight } \\
\text { into the value of incorporating a detailed deficiency database into any cost- } \\
\text { benefit methodology. } \\
\text { - Savings data only available for } 35 \text { deficiencies. } \\
\text { - A deficiency database may be a lower cost version of a cost-benefit } \\
\text { methodology. Typically Cx reports have some detail on measures at a findings } \\
\text { level through an issues log or punchlists. Cx reports do not always have } \\
\text { comparable detail regarding quantification of energy savings or non-energy } \\
\text { savings and a cost accounting procedure. A deficiency database leads to an } \\
\text { understanding of where the most common problems lie. }\end{array}$ \\
\hline $\begin{array}{l}\text { Gregerson, EBCx } \\
(1997)\end{array}$ & $\begin{array}{l}\text { Report for } \\
\text { members of } \\
\text { ESource }\end{array}$ & $\begin{array}{l}\text { Audience was ESource members } \\
\text { (utilities, ESCOs, Cx providers, } \\
\text { researchers), to quantify a new } \\
\text { field of efficiency opportunity }\end{array}$ & $\begin{array}{l}\text { - Few reports cited measure costs and savings. Savings may be estimated, or as } \\
\text { with the Texas LoanSTAR program ( } 75 \% \text { of square footage in the study sample) } \\
\text { per-building costs were estimated. } \\
\text { - The first major summary report on EBCx. }\end{array}$ \\
\hline $\begin{array}{l}\text { PECI, Brochure } \\
\text { (1997) }\end{array}$ & Glossy brochure & $\begin{array}{l}\text { Audience was owners and Cx } \\
\text { providers, for marketing. }\end{array}$ & $\begin{array}{l}\text { - } \quad \text { Summary metrics by sector, Cx and EBCx mixed. } \\
\text { - } \quad \text { Original data not available. }\end{array}$ \\
\hline $\begin{array}{l}\text { Altweis } \\
(2001)\end{array}$ & $\begin{array}{l}\text { Conference paper } \\
\text { documenting } \\
\text { methodology and } \\
\text { detailed } \\
\text { assumptions }\end{array}$ & $\begin{array}{l}\text { Paper's audience was Cx } \\
\text { providers, to encourage them to } \\
\text { collect and report such data. } \\
\text { Audience for data is owners and } \\
\text { prospective customers. }\end{array}$ & $\begin{array}{l}\text { - } \quad \text { Very small sample size, suitable for case studies or research projects. } \\
\text { - } \quad \text { - wide range in savings reported, due to highly varying assumptions (scenarios). } \\
\text { Savings calculation methodology will vary from Cx Agent to Cx Agent, no } \\
\text { standard calculation provided (although the methodology is conceptually well } \\
\text { defined). } \\
\text { - No discussion of costs. }\end{array}$ \\
\hline
\end{tabular}

Page 8 of 239 


\begin{tabular}{|c|c|c|c|}
\hline Studylauthor & Format & Uselaudience & Caveats and considerations \\
\hline $\begin{array}{l}\text { Mills, } \\
\text { Meta-analysis } \\
(2004)\end{array}$ & $\begin{array}{l}\text { Excel database, } \\
\text { Research report }\end{array}$ & $\begin{array}{l}\text { Statistical analysis for U.S. Dept. } \\
\text { of Energy }\end{array}$ & $\begin{array}{l}\text { - Largest Cx cost-benefit study to date. Focused on obtaining large number of } \\
\text { projects to get a high-level view of Cx metrics. } \\
\text { - } \quad \text { Relied on availability, quality, and comparability of different primary data } \\
\text { sources. } \\
\text { - Majority of building information comes from a few sources, especially for EBCx. } \\
\text { Merits of Cx should be assessed based on the cost-effectiveness of the } \\
\text { proposed measures, not necessarily only on what was implemented. } \\
\text { May inappropriately attribute or not attribute costs to the Cx process since cost } \\
\text { - } \text { accounting conventions are not always followed. } \\
\text { May underestimate benefits because energy savings from all measures are not } \\
\text { captured in Cx reports, NEBs are not usually expressed in monetary terms, and } \\
\text { financial benefits in terms of increased net operating income (NOI) are rarely } \\
\text { determined. Furthermore, in a few projects studied, measured savings } \\
\text { exceeded predicted savings. } \\
\text { Time consuming to gather project information from secondary sources and } \\
\text { interpret it, as opposed to having the cost-benefit data entered by the people } \\
\text { involved with the project. }\end{array}$ \\
\hline $\begin{array}{l}\text { SBW, Northwest Cx } \\
\text { \& EBCx } \\
(2004)\end{array}$ & Research report & Utility program evaluation & $\begin{array}{l}\text { - Cost calculations include many costs associated with Cx, so figures may be } \\
\text { higher than other studies. } \\
\text { - NEBs calculations based on opinion of team members (willingness to pay and/or } \\
\text { perceived value). }\end{array}$ \\
\hline $\begin{array}{l}\text { California } \\
\text { Commissioning } \\
\text { Collaborative's } \\
\text { Cxdatabase.com } \\
(2004)\end{array}$ & $\begin{array}{l}\text { SQL database, } \\
\text { exportable to Excel } \\
\text { One-page } \\
\text { "datasheet" on } \\
\text { each project } \\
\text { Conference paper } \\
\text { describing } \\
\text { database }\end{array}$ & $\begin{array}{l}\text { Researchers - data that supports } \\
\text { Cx research and utility incentive } \\
\text { programs } \\
\text { Owners - defining the value of } \\
\text { Cx to their business through data } \\
\text { and case studies } \\
\text { Providers - third party source } \\
\text { from which to give owners } \\
\text { information. Help raise the bar } \\
\text { for Cx documentation of results }\end{array}$ & $\begin{array}{l}\text { - Data was stored as-entered by respondents - no analysis performed unless } \\
\text { brought in by outside researchers } \\
\text { - } \text { Datasheet was a one-page summary form automatically populated by data } \\
\text { entered by respondents. } \\
\text { - Little population as of February, } 2006 \text { - database is no longer online, and is not } \\
\text { actively updated. } \\
\text { While the original vision for this data included creation of case studies, none } \\
\text { were created. }\end{array}$ \\
\hline
\end{tabular}




\begin{tabular}{|c|c|c|c|}
\hline Study/Author & Format & Use/Audience & Caveats and considerations \\
\hline $\begin{array}{l}\text { Moore et al. } \\
\text { California EBCx } \\
\text { programs lessons } \\
\text { learned } \\
(2008)\end{array}$ & $\begin{array}{l}\text { Presentation paper } \\
\text { for ACEEE } \\
\text { Summer Study } \\
\text { (pdf) }\end{array}$ & $\begin{array}{l}\text { Energy efficiency program } \\
\text { implementers }\end{array}$ & $\begin{array}{l}\text { - Report-out on } 4 \text { California EBCx Programs, covering } 60 \text { million square feet of } \\
\text { - } \quad \text { Describes program process experiences as well as presenting quantitative data } \\
\text { - } \quad \begin{array}{r}\text { Reports on: } \\
\text { kWh savings recommended after investigation, compared with } \\
\text { savings from measures selected by owner for investigation } \\
\text { o } \quad \begin{array}{l}\text { Simple payback for uncovered measures and measures selected } \\
\text { by owner for implementation }\end{array} \\
\text { o } \quad \text { Breakdown of savings by measure type } \\
\text { o Simple payback by measure type } \\
\text { o Savings by building type } \\
\text { o Relationship between building EUI and EBCx savings }\end{array} \\
\text { - All programs were managed by PECl under the same basic program design, so } \\
\text { scope of work and approach to energy savings calculations are consistent } \\
\text { across all programs. Commissioning provider costs and driven by the utility } \\
\text { program design/budget, and so are consistent across the dataset. } \\
\text { Much of the data is based on outcomes of EBCx investigations; at the time the } \\
\text { paper was created, a high proportion of the projects had not completed } \\
\text { implementation }\end{array}$ \\
\hline $\begin{array}{l}\text { PECI \& Summit } \\
\text { Building } \\
\text { Engineering } \\
2007 \text { California } \\
\text { EBCx Market } \\
\text { Characterization } \\
(2008)\end{array}$ & $\begin{array}{l}\text { Report available } \\
\text { from California } \\
\text { Commissioning } \\
\text { Collaborative } \\
\text { www.cacx.org }\end{array}$ & Program implementers, providers & $\begin{array}{l}\text { Estimates of potential costs and savings for EBCx in California, along with an } \\
\text { assessment of how many EBCx providers would be required to fulfill that } \\
\text { potential } \\
\text { - Projects used for the study were all under California utility programs, and so } \\
\text { savings calculation approaches are quite consistent across the whole data set } \\
\text { - Forecasts based on a very large number of ongoing projects under utility } \\
\text { programs; only a small number of these projects were complete at the time of } \\
\text { the report. }\end{array}$ \\
\hline
\end{tabular}




\subsubsection{Data Collection Strategies}

By far the most common data collection method is the Researcher-Driven Model, in which a researcher was tasked with collecting and analyzing data. In more than $90 \%$ of the studies a researcher was wholly or partially responsible for collecting documentation and data produced by others. In the handful that differed from this model, data collection was usually done "in house," because the researcher also served as the commissioning provider on the projects that were studied. In two cases, however, data collection was accomplished through use of a database allowing providers and owners to submit data independent of the researcher. In two cases, data came from databases created for utility existing building commissioning programs, where project data was entered by program administrators as a part of the normal program process. A comparison of the data collection methodologies used in 13 different studies reviewed here is presented in Table 2.3. The discussion of the three cost methodology types (simple, moderate, and complex) shown in Table 2.3 is presented in Sec. 2.1.3.

\section{The Researcher-Driven Model}

In 10 of the 13 studies, the data collection strategy was driven by a researcher who collected commissioning project information and produced a cost-benefit report. In eight of those ten, the researchers relied heavily on project documentation, primarily the commissioning provider's Final Report. Other documentation consulted included construction documents (for new buildings), issue logs and change orders. In more than half of the studies, other types of information were used to supplement written documentation. They include telephone surveys with key team members (two studies) and onsite inspection and monitoring (three studies).

When telephone surveys or interviews were employed, they were often used to gather data on nonenergy benefits (NEBs). This is logical, given that NEBs are hardest to measure using commissioning or building documentation because they depend most on the experiences of the people who manage and occupy the building. In fact, there are two studies in which researchers were only interested in NEBs and in which the only source of data were telephone surveys and detailed interviews - no project documentation was collected (Haasl 1996; Bicknell 2004).

Among the ten studies that employed the researcher-driven model, there is much variation in the amount of data studied and level of detail collected, the logistics of obtaining documentation, and in the supplemental types of data and the data collection strategies.

- Quantity of data varies from case studies of a single project to mid-range studies of five, six, 21 and 44 projects to two large studies of 175 projects each.

- Level of detail ranges from whole-project level metrics to metrics for individual issues.

- Logistics of obtaining documentation includes submission by a utility that collected all the documentation and turned it over to the researcher, submission by owners and providers directly to the researcher, and the gathering of documentation by the researchers from commissioning providers and other researchers.

- Supplemental data includes telephone surveys and onsite inspections.

In the researcher-driven model, data collection almost always takes place after the commissioning projects are complete and documentation finished. As a result, the effort required and the data quality depends almost entirely on the diligence of the parties responsible for producing the documentation (usually the commissioning provider, general contractor or testing and balancing agent). Time is also an issue. The closer the study is to project close-out, the more likely it is that project documentation will be available and in good condition, and that the important parties will be able to answer any questions.

\section{The Provider-Driven Model}

In two studies, the researcher and commissioning provider were one and the same. As a result, their studies were able to utilize very detailed data collected throughout the commissioning project. However, 
only a few projects were included, leading to these studies' designation as case studies rather than statistically significant research studies (Haasl 1996; Altweis 2001).

\section{The Research Database Model}

In two studies, researchers created interactive databases to collect commissioning project data. In one, the database was created through a collaborative effort in which multiple researchers and commissioning providers helped define required and minimum inputs. The database itself was created as an online application, meaning it was accessible on the Internet. Thus once it was released, commissioning providers could use it to enter information about their projects in real-time ${ }^{5}$. In the other, a database of categories deficiencies was developed (PECI/DOE 1996).

A significant advantage to the database model of data collection is the ability of the researcher's needs to influence the commissioning provider's data retention efforts. Because providers know up-front what data the researcher wants, it can be supplied immediately while the documents are still available and the project is fresh in the provider's mind. On the negative side, a database alone is incapable of performing analysis, and this model requires funding for several things: design and programming of the database, a researcher to analyze the data or work with programmers to build analysis functionality into the database, marketing of the database to the provider audience, ongoing database maintenance and support, and perhaps even funding to compensate providers for entering data.

\section{The Utility Program Database Model}

In two cases, data came from databases created for utility EBCx programs, where project data was entered by program administrators as a part of the normal program process. Data entry came from two sources: 1) Data entered directly into database by program administrators (including EBCx provider costs) and 2) Data uploaded from each project's Master list of Findings, which lists descriptions, savings, and costs for each individual measure. EBCx providers enter data into the Master list of Findings spreadsheet, and program administrators upload this spreadsheet to the program database. Each project's Master List of Findings, undergoes program review (along with all supporting documentation, collected data and energy savings calculations).

The main advantages of this data are:

- Cost and savings information is available for each individual measure.

- All data underwent a rigorous quality control process that maximized consistency across the dataset

- Data is available for a high quantity of projects within a single U.S. state.

The main disadvantages of this data are:

- There is no non-energy benefits data included in the utility program databases.

- Data available at the time the two reference reports were created was predominantly based on unfinished projects, so it does not include much data on installed measures (only measures selected for implementation by building owners). Data on installed measures for the California projects should be available by the end of 2009 .

- EBCx provider costs are driven by utility program designs/budgets. This is not necessarily a disadvantage, but it does artificially influence the overall project costs.

\section{Explanation of Estimated Effort}

Table 2.4 includes a column for "Estimated effort need to obtain and enter data." The amount of time and difficulty required to both collect and submit project data is estimated as either low, medium, high, or variable. These rankings are not independently defined. Rather, they reflect the authors' estimate of the relative effort required to gather data according to the study's methodology, as compared to the other studies in this report. Thus a study with a "high" effort ranking was judged to employ a more time- and effort-intensive collection methodology than those deemed "low" or "medium."

\footnotetext{
${ }^{5}$ This database is no longer online, and is not being maintained.
} 
Table 2.3. Cost and benefit data (continued on next 2 pages) ${ }^{6}$

\begin{tabular}{|c|c|c|c|c|c|c|c|c|c|c|}
\hline \multirow[t]{2}{*}{ Studyl Year } & \multirow[t]{2}{*}{$\begin{array}{l}\text { \# of } \\
\text { buildings }\end{array}$} & \multirow{2}{*}{$\begin{array}{l}\text { Total and } \\
\text { median } \\
\text { bldg. size }\end{array}$} & \multicolumn{2}{|c|}{ Costs (US\$) } & \multicolumn{2}{|c|}{ Energy benefits } & \multicolumn{2}{|c|}{$\begin{array}{c}\text { Non-energy benefits } \\
\text { (NEBs) }\end{array}$} & \multicolumn{2}{|c|}{ Cost effectiveness } \\
\hline & & & Cx & EBCX & Cx & EBCX & Cx & EBCX & Cx & EBCX \\
\hline $\begin{array}{l}\text { Stum, } \\
\text { ECM Cx } \\
(1994)\end{array}$ & 6 & $\begin{array}{l}218722 \mathrm{ft}^{2} \\
20320 \mathrm{~m}^{2}\end{array}$ & & $\begin{array}{l}\$ 3060 \\
\text { overall } \\
\$ 0.041 / \\
\mathrm{ECM} \\
\$ 0.08 / \mathrm{ft}^{2} \\
\$ 0.86 / \mathrm{m}^{2} \\
\text { Simple }\end{array}$ & & $\begin{array}{l}37412 \mathrm{kWh} / \mathrm{y} \\
5.3 \% \text { of orig. } \\
\text { ECM } \\
\text { Unrealized: } \\
7.9 \% \\
\text { Moderate }\end{array}$ & & $\mathrm{N} / \mathrm{A}$ & & $\begin{array}{l}\text { Recovered } \\
\text { savings: } \\
\text { \$0.033/kWh } \\
\text { Recovered + } \\
\text { unrealized } \\
\text { savings: } \\
\$ 0.02 / \mathrm{kWh}\end{array}$ \\
\hline $\begin{array}{l}\text { Piette, } \\
\text { Energy Edge } \\
\text { Cx (1995) }\end{array}$ & 16 & $\begin{array}{l}849800 \mathrm{ft}^{2} \\
78949 \mathrm{~m}^{2} \\
27000 \mathrm{ft}^{2} \\
\text { (median) } \\
2508 \mathrm{~m}^{2} \\
\text { (median) }\end{array}$ & $\begin{array}{l}\$ 0.19 / \mathrm{ft}^{2} \\
\$ 2.05 / \mathrm{m}^{2} \\
\text { Simple }\end{array}$ & $\mathrm{N} / \mathrm{A}$ & $\begin{array}{l}9.48 \\
\mathrm{kWh} / \mathrm{ft}^{2} \cdot \mathrm{y} \\
102.04 \\
\mathrm{kWh} / \mathrm{m}^{2} \\
\$ 0.64 / \mathrm{ft}^{2} \cdot \mathrm{y} \\
\$ 6.89 / \mathrm{m}^{2} \mathrm{y} \\
\text { Complex }\end{array}$ & $\mathrm{N} / \mathrm{A}$ & $\begin{array}{l}\text { not } \\
\text { quantified }\end{array}$ & $\mathrm{N} / \mathrm{A}$ & $\begin{array}{l}\text { Simple } \\
\text { payback: } \\
\text { average } \\
13.7 \mathrm{y} ; \\
\text { median: } \\
6.5 \mathrm{y}\end{array}$ & $N / A$ \\
\hline $\begin{array}{l}\text { Haasl, } \\
5 \text { Building } \\
\text { Study } \\
(1996)\end{array}$ & 5 & $\begin{array}{l}837000 \mathrm{ft}^{2} \\
77760 \mathrm{~m}^{2} \\
1313197 \mathrm{ft}^{2} \\
\text { (median) } \\
122000 \mathrm{~m}^{2} \\
\text { (median) }\end{array}$ & N/A & $\begin{array}{l}\$ 0.11 / \mathrm{ft}^{2} \\
\$ 1.18 \mathrm{~m}^{2} \\
\text { Simple }\end{array}$ & $\mathrm{N} / \mathrm{A}$ & $\begin{array}{l}\$ 0.11 / \mathrm{ft}^{2} \\
\$ 1.18 \mathrm{~m}^{2} \\
\text { Simple }\end{array}$ & N/A & $\begin{array}{l}\text { Not } \\
\text { quantified }\end{array}$ & N/A & $\begin{array}{l}\text { Simple } \\
\text { payback: } 10 \\
\text { months }\end{array}$ \\
\hline $\begin{array}{l}\text { PECI/DOE, } \\
\text { Deficiency } \\
\text { Database } \\
(1996)\end{array}$ & $\begin{array}{l}16 \mathrm{Cx} \\
28 \mathrm{EBCx} \\
(44 \text { total) }\end{array}$ & $\begin{array}{l}4 \text { million } \mathrm{ft}^{2} \\
367896 \mathrm{~m}^{2} \\
67000 \mathrm{ft}^{2} \\
6224 \mathrm{~m}^{2} \\
\text { (median) }\end{array}$ & $\mathrm{N} / \mathrm{A}$ & $\mathrm{N} / \mathrm{A}$ & $\begin{array}{l}83 \% \text { of all } \\
\text { deficiencies } \\
\text { related to } \\
\text { energy }\end{array}$ & $\begin{array}{l}92 \% \text { of } \\
\text { operational } \\
\text { deficiencies } \\
\text { impact } \\
\text { energy. } \\
\text { Avg savings/ } \\
\text { deficiency = } \\
\text { \$892/y } \\
\text { Moderate }\end{array}$ & $\begin{array}{l}51 \% \text { of all } \\
\text { deficiencies } \\
\text { related to } \\
\text { reliability and } \\
\text { maintenance }\end{array}$ & $\begin{array}{l}25 \% \text { of } \\
\text { deficiencies } \\
\text { related to } \\
\text { comfort }\end{array}$ & $\mathrm{N} / \mathrm{A}$ & $\mathrm{N} / \mathrm{A}$ \\
\hline
\end{tabular}

\footnotetext{
${ }^{6}$ Dollar amounts have not been normalized to a common year. Methodological complexity listed in bold.
} 


\begin{tabular}{|c|c|c|c|c|c|c|c|c|c|c|}
\hline \multirow[t]{2}{*}{ Studyl Year } & \multirow[t]{2}{*}{$\begin{array}{l}\text { \# of } \\
\text { buildings }\end{array}$} & \multirow[t]{2}{*}{$\begin{array}{l}\text { Total and } \\
\text { median } \\
\text { bldg. size }\end{array}$} & \multicolumn{2}{|c|}{ Costs (US\$) } & \multicolumn{2}{|c|}{ Energy benefits } & \multicolumn{2}{|c|}{$\begin{array}{c}\text { Non-energy benefits } \\
\text { (NEBs) }\end{array}$} & \multicolumn{2}{|c|}{ Cost effectiveness } \\
\hline & & & Cx & EBCX & Cx & EBCX & Cx & EBCX & Cx & EBCX \\
\hline $\begin{array}{l}\text { Gregerson, } \\
\text { EBCx (1997) }\end{array}$ & 44 & $\begin{array}{l}9 \text { million } \mathrm{ft}^{2} \\
836127 \mathrm{~m}^{2}\end{array}$ & $\mathrm{~N} / \mathrm{A}$ & $\begin{array}{l}\text { Approx } \\
\$ 20000 \\
\$ 0.19 / \mathrm{ft}^{2} \\
\$ 2.05 / \mathrm{m}^{2} \\
\text { Simple }\end{array}$ & $\mathrm{N} / \mathrm{A}$ & $\begin{array}{l}\text { Avg } \$ 98000 \\
\text { Med: } \$ 41000 \\
19.2 \% \text { avg } \\
\text { savings } \\
\$ 0.49 / \mathrm{ft}^{2} \\
\$ 5.27 / \mathrm{m}^{2} \\
\text { Moderate }\end{array}$ & $\mathrm{N} / \mathrm{A}$ & $\begin{array}{l}\text { Not } \\
\text { assessed }\end{array}$ & $\mathrm{N} / \mathrm{A}$ & $\begin{array}{l}\text { Simple } \\
\text { payback: } \\
0.9 \text { years }\end{array}$ \\
\hline $\begin{array}{l}\text { PECI, } \\
\text { Brochure } \\
(1997)\end{array}$ & $\begin{array}{l}75 \\
\text { Cx and } \\
\text { EBCx not } \\
\text { separated }\end{array}$ & Not available & \multicolumn{2}{|l|}{$\begin{array}{l}\text { Median: } \\
\$ 0.15 / \mathrm{ft}^{2} \\
\$ 1.61 / \mathrm{m}^{2}\end{array}$} & \multicolumn{2}{|c|}{ No standardized metric } & \multicolumn{2}{|c|}{$\begin{array}{l}\text { Improved ( } \% \text { of buildings): } \\
\text { Thermal comfort: } 42 \% \\
\text { System function: } 44 \% \\
\text { Indoor air quality: } 23 \% \\
\text { O\&M: } 42 \% \\
\text { Simple }\end{array}$} & \multicolumn{2}{|c|}{ Not assessed } \\
\hline $\begin{array}{l}\text { Altweis } \\
(2001)\end{array}$ & 1 & $\begin{array}{l}14350 \mathrm{ft}^{2} \\
1333 \mathrm{~m}^{2}\end{array}$ & $\begin{array}{l}\text { Not } \\
\text { reported }\end{array}$ & $\mathrm{N} / \mathrm{A}$ & $\begin{array}{l}\text { Up to } \\
\$ 0.13 / \mathrm{ft}^{2} \cdot \mathrm{y} \\
\$ 1.40 / \mathrm{m}^{2}\end{array}$ & $\mathrm{~N} / \mathrm{A}$ & $\begin{array}{l}\$ 0.17 \text { to } \\
\$ 2.10 / \mathrm{ft}^{2} \cdot \mathrm{y} \\
\$ 1.83 \text { to } \\
\$ 22.60 / \mathrm{m}^{2} \mathrm{y} \\
\text { Moderate }\end{array}$ & $\mathrm{N} / \mathrm{A}$ & $\begin{array}{l}\text { Not } \\
\text { reported }\end{array}$ & N/A \\
\hline $\begin{array}{l}\text { Heinemeier, } \\
\text { Schools Cx } \\
(2004)\end{array}$ & 1 & $\begin{array}{l}\text { N/A: } \\
\text { methodology } \\
\text { but no } \\
\text { results. }\end{array}$ & N/A & $\mathrm{N} / \mathrm{A}$ & N/A & $\mathrm{N} / \mathrm{A}$ & N/A & $\mathrm{N} / \mathrm{A}$ & N/A & N/A \\
\hline
\end{tabular}

\footnotetext{
${ }^{7}$ Energy intensive buildings and even most of the efficient buildings had paybacks of less than two years.
} 


\begin{tabular}{|c|c|c|c|c|c|c|c|c|c|c|}
\hline \multirow[t]{2}{*}{ Study/ Year } & \multirow[t]{2}{*}{$\begin{array}{l}\text { \# of } \\
\text { buildings }\end{array}$} & \multirow{2}{*}{$\begin{array}{l}\text { Total and } \\
\text { median } \\
\text { bldg. size }\end{array}$} & \multicolumn{2}{|c|}{ Costs (US\$) } & \multicolumn{2}{|c|}{ Energy benefits } & \multicolumn{2}{|c|}{$\begin{array}{c}\text { Non-energy benefits } \\
\text { (NEBs) }\end{array}$} & \multicolumn{2}{|c|}{ Cost effectiveness } \\
\hline & & & $\mathbf{C x}$ & EBCX & Cx & EBCX & Cx & EBCx & $\mathrm{Cx}$ & EBCX \\
\hline $\begin{array}{l}\text { Mills, } \\
\text { Meta- } \\
\text { analysis } \\
(2004)\end{array}$ & $\begin{array}{l}175 \\
\text { projects } \\
\text { EBCx: } 106 \\
\text { Cx: } 69\end{array}$ & $\begin{array}{l}30400000 \mathrm{ft}^{2} \\
2824252 \mathrm{~m}^{2} \\
\text { total } \\
69500 \mathrm{ft}^{2} \\
6457 \mathrm{~m}^{2} \\
(\text { median Cx }) \\
151000 \mathrm{ft}^{2} \\
14028 \mathrm{~m}^{2} \\
\text { (median } \\
\text { EBCx) }\end{array}$ & $\begin{array}{l}\$ 74267 \\
\$ 1.00 / \mathrm{ft}^{2} \\
\$ 10.76 / \mathrm{m}^{2} \\
{[0.6 \%} \\
\text { construc- } \\
\text { tion cost] } \\
\text { Moderate }\end{array}$ & $\begin{array}{l}\$ 33696 \\
\$ 0.27 / \mathrm{ft}^{2} \\
\$ 2.90 \mathrm{~m}^{2} \\
\text { Moderate }\end{array}$ & $\begin{array}{l}\$ 2533 / \mathrm{y} \\
\$ 0.05 / \mathrm{ft}^{2} \cdot \mathrm{y} \\
\$ 0.54 / \mathrm{m}^{2} \cdot \mathrm{y} \\
\quad \text { Moderate }\end{array}$ & $\begin{array}{l}\$ 44629 / \mathrm{y} \\
\$ 0.26 / \mathrm{ft}^{2} \cdot \mathrm{y} \\
\$ 2.80 \mathrm{~m}^{2} \cdot \mathrm{y} \\
\text { Moderate }\end{array}$ & $\begin{array}{l}\$ 51000 / y \\
\$ 1.24 / \mathrm{ft}^{2} \cdot \mathrm{y} \\
\$ 13.35 \mathrm{~m}^{2} \cdot \mathrm{y} \\
\text { Moderate }\end{array}$ & $\begin{array}{l}\$ 17000 / y \\
\$ 0.18 / \mathrm{ft}^{2} \cdot y \\
\$ 1.94 \mathrm{~m}^{2} \cdot y \\
\text { Moderate }\end{array}$ & $\begin{array}{l}\text { Simple } \\
\text { payback: } \\
4.8 y^{8}\end{array}$ & $\begin{array}{l}\text { Simple } \\
\text { payback: } \\
0.7 \mathrm{y}^{9}\end{array}$ \\
\hline $\begin{array}{l}\text { SBW, } \\
\text { Northwest } \\
\text { Cx \& EBCx } \\
(2004)\end{array}$ & 21 & $\begin{array}{l}2.2 \text { million } \mathrm{ft}^{2} \\
204386 \mathrm{~m}^{2}\end{array}$ & $\begin{array}{l}\$ 71791^{10} \\
\$ 0.85 / \mathrm{ft}^{2} \\
\$ 9.15 / \mathrm{m}^{2} \\
\text { Complex }\end{array}$ & $\begin{array}{l}\$ 22053 \\
\$ 0.31 / \mathrm{ft}^{2} \\
\$ 3.34 / \mathrm{m}^{2} \\
\text { Complex }\end{array}$ & $\begin{array}{l}\$ 9856 / y \\
\$ 0.09 / \mathrm{ft}^{2} \cdot y \\
\$ .97 / \mathrm{m}^{2} \cdot y \\
\text { Complex }\end{array}$ & $\begin{array}{l}\$ 13678 / \text { year } \\
\$ 0.14 / \mathrm{ft}^{2} \cdot y \\
\$ 1.51 \mathrm{~m}^{2} \cdot y \\
\text { Complex }\end{array}$ & $\begin{array}{l}\begin{array}{l}\$ 13609 \\
\text { (one-time) }\end{array} \\
\$ 0.13 / \mathrm{ft}^{2} \\
\$ 1.40 / \mathrm{m}^{2} \text {. } \\
\text { Complex }\end{array}$ & $\begin{array}{l}\$ 10534 \\
\text { (one-time) } \\
\$ 0.11 / \mathrm{ft}^{2} \\
\$ 1.18 / \mathrm{m}^{2} \\
\text { Complex }\end{array}$ & $\begin{array}{l}\text { Direct pay- } \\
\text { back: } 7.5 \text { y } \\
\text { Total simple } \\
\text { payback: } \\
6.1 \text { y }\end{array}$ & $\begin{array}{l}\text { Direct pay- } \\
\text { back: } 4.0 \text { y } \\
\text { Total simple } \\
\text { payback: } \\
3.2 \text { y }\end{array}$ \\
\hline $\begin{array}{l}\text { Moore et al. } \\
(2008)\end{array}$ & 21 & $\begin{array}{l}\text { Not stated, } \\
\text { but } 21 \\
\text { projects total } \\
\text { approx. } 9 \\
\text { million kWh } \\
\text { annual } \\
\text { savings } \\
\text { forecast }\end{array}$ & & $\begin{array}{l}\text { Not } \\
\text { reported }\end{array}$ & & $\begin{array}{l}\text { Average } 6.9 \\
\% \\
\text { Complex }\end{array}$ & & Not reported & & $\begin{array}{l}84 \% \text { of } \\
\text { savings with } \\
<2-y e a r \\
\text { payback } \\
\text { (owner's } \\
\text { implementa- } \\
\text { tion costs } \\
\text { only) }\end{array}$ \\
\hline
\end{tabular}

\footnotetext{
${ }^{8}$ Standard energy prices corrected for inflation. Data normalized to $\$ 2003$.

9 Standard energy prices corrected for inflation Data normalized to $\$ 2003$.

${ }^{10}$ Costs for this study include only Cx provider fees - although payback information includes additional costs, for example, costs to other parties.
} 


\begin{tabular}{|c|c|c|c|c|c|c|c|c|c|c|}
\hline \multirow[t]{2}{*}{ Studyl Year } & \multirow[t]{2}{*}{$\begin{array}{l}\text { \# of } \\
\text { buildings }\end{array}$} & \multirow{2}{*}{$\begin{array}{l}\text { Total and } \\
\text { median } \\
\text { bldg. size }\end{array}$} & \multicolumn{2}{|c|}{ Costs } & \multicolumn{2}{|c|}{ Energy benefits } & \multicolumn{2}{|c|}{$\begin{array}{c}\text { Non-energy benefits } \\
\text { (NEBs) }\end{array}$} & \multicolumn{2}{|c|}{ Cost effectiveness } \\
\hline & & & Cx & EBCX & Cx & EBCX & Cx & EBCx & Cx & EBCX \\
\hline $\begin{array}{l}\text { PECI \& Summit } \\
\text { Building } \\
\text { Engineering } \\
\text { (2008) }\end{array}$ & \multicolumn{2}{|c|}{$\begin{array}{l}\text { Market characterization } \\
\text { study forecasts } 70 \text { million } \\
\mathrm{ft}^{2} \text { annual potential for } \\
\text { EBCx in California ( } 6.5 \\
\text { million). } \mathrm{m}^{2}\end{array}$} & & $\begin{array}{l}\$ 0.39 / \mathrm{ft}^{2} \\
\$ 4.20 / \mathrm{m}^{2} \\
\text { Complex }\end{array}$ & & $\begin{array}{l}0.96 \mathrm{kWh} / \mathrm{ft}^{2} \cdot \mathrm{y} \\
10.3 \mathrm{kWh} / \mathrm{m}^{2} \cdot \mathrm{y} \\
\text { Complex }\end{array}$ & & Not reported & & $\begin{array}{l}\text { Mean 3-year } \\
\text { payback } \\
\text { forecast }\end{array}$ \\
\hline $\begin{array}{l}\text { California } \\
\text { Commissioning } \\
\text { Collaborative's } \\
\text { Cxdatabase.com } \\
(2004)\end{array}$ & \multicolumn{10}{|c|}{ Two surveys were completed and five were in progress. Not assessed at this time due to lack of data and funding. } \\
\hline
\end{tabular}


Table 2.4 Comparison of data collection methodology (continued on next page)

\begin{tabular}{|c|c|c|c|c|c|c|}
\hline Study/Author & Level of detail & Data sources & $\begin{array}{l}\text { Collection } \\
\text { process }\end{array}$ & $\begin{array}{l}\text { Timing of data } \\
\text { collection }\end{array}$ & Data storage & $\begin{array}{l}\text { Estimated effort } \\
\text { needed to obtain } \\
\text { and enter data }\end{array}$ \\
\hline $\begin{array}{l}\text { Stum, } \\
\text { ECM Cx } \\
(1994)\end{array}$ & $\begin{array}{l}\text { Only looked at ECMs } \\
\text { meriting greater } \\
\text { resources (i.e., VFDs, } \\
\text { economizers) }\end{array}$ & $\begin{array}{l}\text { Inspection reports, } \\
\text { onsite inspection of } \\
\text { ECMs in small } \\
\text { comm. and retail }\end{array}$ & $\begin{array}{l}\text { Reports provided by } \\
\text { utility, onsite work } \\
\text { done by authors. }\end{array}$ & $\begin{array}{l}\text { Concurrent with and } \\
\text { immediately } \\
\text { following Cx } \\
\text { activities }\end{array}$ & $\mathrm{N} / \mathrm{A}$ & $\begin{array}{l}\text { Medium } \\
\text { Onsite inspections but } \\
\text { only of a few measures }\end{array}$ \\
\hline $\begin{array}{l}\text { Piette, } \\
\text { Energy Edge Cx } \\
(1995)\end{array}$ & $\begin{array}{l}\text { Very detailed data } \\
\text { collection on building } \\
\text { characteristics to } \\
\text { develop models, }\end{array}$ & $\begin{array}{l}\text { Commissioning } \\
\text { report, on-site data } \\
\text { collection. }\end{array}$ & $\begin{array}{l}\text { Extensive evaluation } \\
\text { project. }\end{array}$ & $\begin{array}{l}\text { Within one or two } \\
\text { years after } \\
\text { construction. }\end{array}$ & $\begin{array}{l}\text { Unix-based } \\
\text { database. }\end{array}$ & $\begin{array}{l}\text { High } \\
\text { Data for simulation. }\end{array}$ \\
\hline $\begin{array}{l}\text { Haasl, } \\
5 \text { Building Study } \\
(1996)\end{array}$ & $\begin{array}{l}\text { Data required for } \\
\text { standard calculations } \\
\text { and simulations. }\end{array}$ & Provider collected. & $\begin{array}{l}\text { Data collected } \\
\text { through EBCx } \\
\text { process, including } \\
\text { two weeks of } \\
\text { monitored data on } \\
\text { key systems. }\end{array}$ & $\begin{array}{l}\text { Collected during } \\
\text { EBCx process. }\end{array}$ & Not described. & $\begin{array}{l}\text { Medium } \\
\text { Building and system } \\
\text { characteristic data } \\
\text { needed for modeling } \\
\text { and calculation, and } \\
\text { monitored data. }\end{array}$ \\
\hline $\begin{array}{l}\text { PECI/DOE, } \\
\text { Deficiency } \\
\text { Database (1996) }\end{array}$ & Findings level detail. & $\begin{array}{l}\text { Half of data directly } \\
\text { entered by Cx } \\
\text { provider. Half by } \\
\text { researcher (paid). }\end{array}$ & $\begin{array}{l}\text { Review of final } \\
\text { commissioning } \\
\text { reports and issues } \\
\text { logs. }\end{array}$ & Retrospective. & Database (Excel) & $\begin{array}{l}\text { Variable } \\
\text { Depends on availability } \\
\text { and organization of } \\
\text { necessary info in Cx } \\
\text { documentation. }\end{array}$ \\
\hline $\begin{array}{l}\text { Gregerson, EBCx } \\
(1997)\end{array}$ & $\begin{array}{l}\text { No detail other than } \\
\text { metrics on a project- } \\
\text { level. No measure- } \\
\text { level detail. }\end{array}$ & $\begin{array}{l}\text { Four Cx providers. } \\
70 \% \text { from TAMU } \\
\text { and } 25 \% \text { from } \\
\text { PECl }\end{array}$ & $\begin{array}{l}\text { Building } \\
\text { characteristics, EUI, } \\
\text { and cost and energy } \\
\text { savings figures } \\
\text { requested from Cx } \\
\text { provider by } \\
\text { researcher. }\end{array}$ & $\begin{array}{l}\text { Retrospective from } \\
\text { final Cx reports. }\end{array}$ & Not specified. & $\begin{array}{l}\text { Low } \\
\text { Very minimal data } \\
\text { collected (although } \\
\text { retroactive so it may be } \\
\text { difficult to obtain.) }\end{array}$ \\
\hline $\begin{array}{l}\text { PECI, Brochure } \\
\text { (1997) }\end{array}$ & High level metrics & Cx provider & Phone interviews & Retrospective & Not specified & $\begin{array}{l}\text { Low } \\
\text { Minimal data collected } \\
\text { (although retroactive so } \\
\text { it may be difficult to } \\
\text { obtain) }\end{array}$ \\
\hline
\end{tabular}




\begin{tabular}{|c|c|c|c|c|c|c|}
\hline Study/Author & Level of detail & Data sources & $\begin{array}{l}\text { Collection } \\
\text { process }\end{array}$ & $\begin{array}{l}\text { Timing of data } \\
\text { collection }\end{array}$ & Data storage & $\begin{array}{l}\text { Estimated effort } \\
\text { needed to obtain } \\
\text { and enter data }\end{array}$ \\
\hline $\begin{array}{l}\text { Altweis } \\
(2001)\end{array}$ & $\begin{array}{l}\text { Case study level data. } \\
\text { Extensive detailed } \\
\text { information required } \\
\text { from project. Not } \\
\text { difficult for the } \\
\text { commissioning agent } \\
\text { to obtain. } \\
\end{array}$ & $\begin{array}{l}\text { Commissioning } \\
\text { agent collected } \\
\text { information and } \\
\text { conducted benefits } \\
\text { analysis. }\end{array}$ & $\begin{array}{l}\text { Commissioning } \\
\text { provider review of } \\
\text { notes and project } \\
\text { documents. }\end{array}$ & $\begin{array}{l}\text { Throughout the } \\
\text { project. }\end{array}$ & Not specified. & $\begin{array}{l}\text { Low, for commissioning } \\
\text { provider. } \\
\text { High for anyone else. }\end{array}$ \\
\hline $\begin{array}{l}\text { Heinemeier, } \\
\text { Schools Cx (2004) }\end{array}$ & $\begin{array}{l}\text { Report showed a } \\
\text { great deal of detail, } \\
\text { but the intent is to } \\
\text { define metrics that are } \\
\text { easily gathered, from } \\
\text { review of construction } \\
\text { documents. } \\
\end{array}$ & $\begin{array}{l}\text { Complete } \\
\text { construction } \\
\text { documents. }\end{array}$ & $\begin{array}{l}\text { Researcher obtained } \\
\text { a copy of and } \\
\text { reviewed all } \\
\text { construction } \\
\text { documents. }\end{array}$ & $\begin{array}{l}\text { After the project was } \\
\text { complete. }\end{array}$ & Not specified. & $\begin{array}{l}\text { Medium } \\
\text { Somewhat time- } \\
\text { consuming to review all } \\
\text { documents. }\end{array}$ \\
\hline $\begin{array}{l}\text { Mills, } \\
\text { Meta-analysis } \\
(2004)\end{array}$ & $\begin{array}{l}\text { Based on the } \\
\text { documentation } \\
\text { available. Where little } \\
\text { available, at minimum, } \\
\text { project-level info was } \\
\text { entered. }\end{array}$ & $\begin{array}{l}\text { A few Cx providers } \\
\text { and researchers } \\
\text { entered many } \\
\text { projects (paid). } \\
\text { Smaller number of } \\
\text { projects from } \\
\text { unpaid Cx } \\
\text { providers. }\end{array}$ & $\begin{array}{l}\text { Review of past } \\
\text { studies and final Cx } \\
\text { reports/issues logs. }\end{array}$ & $\begin{array}{l}\text { Projects completed } \\
\text { between } 1993 \text { and } \\
2004 \\
\text { Retrospective from } \\
\text { final Cx reports and } \\
\text { previous studies. }\end{array}$ & Excel spreadsheet & $\begin{array}{l}\text { Variable } \\
\text { Depends on availability } \\
\text { and organization of } \\
\text { necessary info in Cx } \\
\text { documentation. }\end{array}$ \\
\hline $\begin{array}{l}\text { SBW, Northwest } \\
\text { Cx \& EBCx } \\
(2004)\end{array}$ & $\begin{array}{l}\text { Identified all } \\
\text { issues/findings, } \\
\text { selected only } \\
\text { significant and } \\
\text { resolved issues } \\
\end{array}$ & $\begin{array}{l}\text { Extensive project } \\
\text { documentation } \\
\text { and surveys } \\
\text { (both unpaid). }\end{array}$ & $\begin{array}{l}\text { Project materials } \\
\text { submitted by owner } \\
\text { and telephone } \\
\text { surveys with team. }\end{array}$ & $\begin{array}{l}\text { While projects } \\
\text { underway and within } \\
1 \text { year after close- } \\
\text { out (early 2003) }\end{array}$ & $\begin{array}{l}\text { Database (no } \\
\text { specific software } \\
\text { identified) }\end{array}$ & High \\
\hline $\begin{array}{l}\text { Moore et al. } \\
(2008)\end{array}$ & $\begin{array}{l}\text { High level utility } \\
\text { program data } \\
\text { reported. }\end{array}$ & $\begin{array}{l}\text { Utility program } \\
\text { databases }\end{array}$ & $\begin{array}{l}\text { Paper created by } \\
\text { program } \\
\text { administrator with } \\
\text { direct access to all } \\
\text { programs' data } \\
\end{array}$ & $\begin{array}{l}\text { Data compiled } \\
\text { Summer } 2008\end{array}$ & $\begin{array}{l}\text { Excel spreadsheet } \\
\text { downloaded from } \\
\text { program databases }\end{array}$ & $\begin{array}{l}\text { Medium } \\
\text { Data is readily available } \\
\text { (but need to filter data } \\
\text { for non-standard } \\
\text { projects) }\end{array}$ \\
\hline $\begin{array}{l}\text { PECI \& Summit } \\
\text { Building } \\
\text { Engineering } \\
(2008)\end{array}$ & $\begin{array}{l}\text { High level forecasts of } \\
\text { market potential }\end{array}$ & $\begin{array}{l}\text { Data collected from } \\
\text { various California } \\
\text { utility program } \\
\text { implementers }\end{array}$ & $\begin{array}{l}\text { Data requests to all } \\
\text { implementers. Data } \\
\text { then adjusted for } \\
\text { easier cross- } \\
\text { comparison }\end{array}$ & Early 2008 & Spreadsheet & High \\
\hline
\end{tabular}




\begin{tabular}{|c|c|c|c|c|c|c|}
\hline StudylAuthor & Level of detail & Data sources & $\begin{array}{l}\text { Collection } \\
\text { process }\end{array}$ & $\begin{array}{l}\text { Timing of data } \\
\text { collection }\end{array}$ & Data storage & $\begin{array}{l}\text { Estimated effort } \\
\text { needed to obtain } \\
\text { and enter data }\end{array}$ \\
\hline $\begin{array}{l}\text { California } \\
\text { Commissioning } \\
\text { Collaborative's } \\
\text { Cxdatabase.com } \\
(2004)\end{array}$ & $\begin{array}{l}\text { Three findings } \\
\text { required, can } \\
\text { accommodate } \\
\text { unlimited number }\end{array}$ & $\begin{array}{l}\text { Cx provider or } \\
\text { owner. (unpaid, but } \\
\text { funding for entering } \\
\text { data desired, } \\
\text { requirement was } \\
\text { written into scope } \\
\text { of some projects) }\end{array}$ & $\begin{array}{l}\text { Respondent gathers } \\
\text { data and enters into } \\
\text { online forms. }\end{array}$ & $\begin{array}{l}\text { Intended to be } \\
\text { completed during } \\
\text { project or } \\
\text { immediately after } \\
\text { completion. Can be } \\
\text { completed at any } \\
\text { time, if data is } \\
\text { available. }\end{array}$ & $\begin{array}{l}\text { Custom-built online } \\
\text { database - project } \\
\text { took several months } \\
\text { at a cost of approx. } \\
\$ 20,000 \text {. } \\
\text { (www.Cxdatabase.o } \\
\text { rg) }\end{array}$ & $\begin{array}{l}\text { Variable } \\
\text { Depends on whether } \\
\text { respondent was aware } \\
\text { of data requirements } \\
\text { during the project and } \\
\text { the quality of } \\
\text { documentation. }\end{array}$ \\
\hline
\end{tabular}




\subsubsection{Methodologies for Determining Costs, Energy Benefits and Non-Energy Benefits}

\section{Commissioning Costs}

There is no widely used methodology for determining commissioning costs. To assist in the evaluation process, this report distinguishes three levels of complexity in cost methodologies: simple, moderate and complex.

Table 2.5 summarizes their differences in terms of which costs are included and if the costs are validated.

Table 2.5 Comparison of cost methodologies

\begin{tabular}{|l|c|c|c|c|}
\hline & Cx provider's fee & $\begin{array}{c}\text { Resolution costs } \\
\text { (EBCx) }\end{array}$ & $\begin{array}{c}\text { Costs to other } \\
\text { parties }\end{array}$ & $\begin{array}{c}\text { Validation } \\
\text { method }\end{array}$ \\
\hline Simple & $\mathrm{X}$ & $\mathrm{X}$ & & \\
\hline Moderate & $\mathrm{X}$ & $\mathrm{X}$ & $\mathrm{X}$ & \\
\hline Complex & $\mathrm{X}$ & $\mathrm{X}$ & $\mathrm{x}$ & $\mathrm{X}$ \\
\hline
\end{tabular}

Of the 12 studies examined, all include the commissioning provider's fee as a cost of commissioning. Some include additional costs, for example, costs to other parties, although each study defines these costs differently. Only one study, with a complex methodology, makes an attempt to validate cost data by checking the respondent's data for consistency and to make sure cost figures fell within what researchers defined as a "reasonable range." (SBW Consulting 2004)

In general, the average cost of commissioning per square foot increases as the study's cost methodology increases in complexity. As Table 2.6 shows, in existing buildings the cost of commissioning steps upward as the methodology becomes more complex. In the case of new buildings, the cost of commissioning has a generally higher trend; however, complex methodologies returned an average cost per square foot $\left({ }^{\mathrm{m} 2}\right.$ ) slightly lower than moderate methodologies. Although not conclusive, it seems likely that the reported cost increases because complex methodologies account for costs incurred by several parties, whereas simple methodologies usually only account for the commissioning provider's fee.

Table 2.6 Average cost of commissioning by methodological complexity

\begin{tabular}{|c|c|c|c|c|}
\hline & \multicolumn{2}{|c|}{ Existing buildings } & \multicolumn{2}{c|}{ New buildings } \\
\hline Methodology & \# of buildings & $\begin{array}{c}\text { Average cost } \\
\text { (US\$) }\end{array}$ & \# of buildings & $\begin{array}{c}\text { Average } \\
\text { cost(US } \$ \text { ) }\end{array}$ \\
\hline Complex & 8 & $\begin{array}{c}\$ 0.31 / \mathrm{ft}^{2} \\
\$ 3.34 / \mathrm{m}^{2}\end{array}$ & 13 & $\begin{array}{c}\$ 0.85 / \mathrm{ft}^{2} \\
\$ 9.15 / \mathrm{m}^{2}\end{array}$ \\
\hline Moderate & 106 & $\begin{array}{l}\$ 0.27 / \mathrm{ft}^{2} \\
\$ 2.91 / \mathrm{m}^{2}\end{array}$ & 69 & $\$ 1.00 / \mathrm{ft}^{2}$ \\
& 50 & $\$ 0.18 / \mathrm{ft}^{2}$ & 16 & $\$ 10.76 / \mathrm{m}^{2}$ \\
\hline Simple & $51.90 / \mathrm{m}^{2}$ & & $\$ 0.19 / \mathrm{ft}^{2}$ \\
& & & & \\
\hline
\end{tabular}


A more detailed discussion of cost methodology types, with examples, follows.

Simple. A simple methodology uses only one or two cost categories to arrive at the overall cost of commissioning. Usually these cost figures are relatively easy to obtain. Examples include the commissioning provider's fee and the cost to resolve an issue. In simple methodologies, these cost figures are self-reported and the study makes little or no attempt to validate the data.

An example of a simple methodology can be found in two early studies: Piette (1995) and Stum (1994). Piette calculated the cost of commissioning by taking a percentage of the overall energy efficiency measure cost. Stum defined the cost of commissioning as the self-reported commissioning provider's fee plus the administrative costs of the utility commissioning program that funded the projects.

Moderate. A moderately complex methodology uses more than two cost categories to arrive at the overall cost of commissioning. For example, cost categories could include incremental costs to all parties, travel costs, and negative impacts like increased change orders. Moderately complex methodologies include a broader array of costs in the cost of commissioning than a simple methodology, although the study stops short of applying a validation process to the data. The methodology may include differences in cost accounting between $\mathrm{Cx}$ and EBCx.

An example of a moderate methodology can be found in Mills et al. (2004) and in Cxdatabase.com (2004). Mills et al.'s cost definition includes several figures: the provider fee, the coordination costs incurred by other parties and on EBCx projects, the resolution costs. Cxdatabase.com's cost definition includes the provider fee, incremental costs incurred by other parties, the cost of O\&M staff participation (if specified by the owner) and on EBCx projects, the resolution costs. Neither Mills et al. nor Cxdatabase.com makes any attempt to verify the cost figures reported in project documentation or by respondents.

Complex. Like a moderate methodology, a complex methodology differentiates several categories of commissioning costs. However, studies employing complex methodologies do attempt to validate cost figures.

An example of a complex methodology is found in SBW Consulting (2004). Cost includes the provider fee, incremental fee increases for other parties, travel expenses and resolution costs. Researchers used a telephone survey to ask key commissioning team members 1 ) if they increased their bid for the project to account for commissioning activities and 2) if there were any significant non-labor costs associated with commissioning. Respondents were then asked to attach a dollar amount to each. If the respondent was unable to provide a dollar figure, researchers asked them to estimate the additional labor hours and provide a labor rate, from which researchers calculated the incremental cost to that respondent. As a quality assurance measure, researchers also evaluated whether the data supplied by respondents "were consistent and fell within reasonable ranges" (SBW Consulting 2004).

\section{Energy Savings}

There are a variety of methods for determining energy savings from commissioning. This study evaluates energy benefit methodologies, like cost methodologies, according to their level of complexity. 
Table 2.7 Comparison of energy savings methodologies

\begin{tabular}{|l|c|c|c|c|c|c|}
\hline & $\begin{array}{c}\text { Issues ID } \\
\text { and/or } \\
\text { baseline } \\
\text { comparison } \\
11\end{array}$ & $\begin{array}{c}\text { Energy } \\
\text { calcula- } \\
\text { tions }\end{array}$ & $\begin{array}{c}\text { Energy } \\
\text { modeling }\end{array}$ & $\begin{array}{c}\text { Normaliza- } \\
\text { tion of } \\
\text { energy data }\end{array}$ & $\begin{array}{c}\text { Attention to } \\
\text { measure } \\
\text { interactions }\end{array}$ & $\begin{array}{c}\text { Validation } \\
\text { method }\end{array}$ \\
\hline Simple & $\mathrm{x}$ & & & & & \\
\hline Moderate & $\mathrm{x}$ & $I$ & $I$ & $I$ & & $I$ \\
\hline Complex & $\mathrm{x}$ & $\mathrm{x}$ & $\mathrm{x}$ & $\mathrm{x}$ & $\mathrm{x}$ & $\mathrm{x}$ \\
\hline
\end{tabular}

Key: $\mathrm{X}=$ always present; $/$ = sometimes, but not always present

Of the 12 studies examined, all used either an issues identification or baseline comparison method to determine energy savings. Moderate methodologies employed some form of energy calculations, modeling, or data normalization. Only complex methodologies were attentive to measure interactions and data validation.

The following is a more detailed discussion of energy benefit methodology types, with examples.

Simple. In existing buildings, simple methodologies compare before and after energy consumption without normalization of data. They may also obtain information directly from the building owner or manager regarding energy savings or comparisons of performance.

Examples of simple energy benefit methodologies are found in Cxdatabase.com (2004) and Heinemeier (2004). Cxdatabase.com asked survey respondents to provide energy savings numbers for each reported finding. Respondents were asked to also provide the calculations they used to arrive at the figures, but this information was not required. No standardized process for calculating energy savings was created. In Heinemeier's methodology, energy use per square foot of commissioned buildings was compared to those that were not commissioned. Building pairs were of similar size and type, and monthly utility bills were used to gather energy use data. Commissioned building energy use was also compared against standardized benchmarks.

Moderate. Moderately complex methodologies use project documentation to identify significant commissioning findings/issues that have been resolved, and then use engineering calculations or parametric modeling to determine the energy benefit. A validation process using measured data may be, but is not necessarily, applied. Moderately complex methodologies may also apply normalization techniques to before and after energy consumption.

An example of a moderately complex energy benefit methodology is found in the SBW Consulting (2004). Researchers used a three-step process, shown in Fig. 2.1, to identify issues that resulted in a "stream" of energy and/or non-energy benefits. First they used project documentation to identify all issues. Then they determined which issues were "significant" relative to their affect on total building area or occupants, resolution cost and/or long term impact. (SBW Consulting 2004) Of significant issues, they determined through documentation and/or telephone surveys which issues had been or would likely be resolved. Energy and non-energy benefits were only calculated for issues deemed significant and resolved.

\footnotetext{
${ }^{11}$ Two methods for determining energy (and non-energy) savings are issue identification and baseline comparison. In issue identification energy savings are determined first at the issue level and then added to arrive at the total savings for the project. The baseline comparison method looks only at whole-building energy benefits. The researcher establishes the building's "baseline" energy use and then compares it to energy use after commissioning. This method can be a more straightforward process in existing building projects, where there is a "before" snapshot. In new construction it is more difficult because the "baseline" is hypothetical and must be simulated.
} 


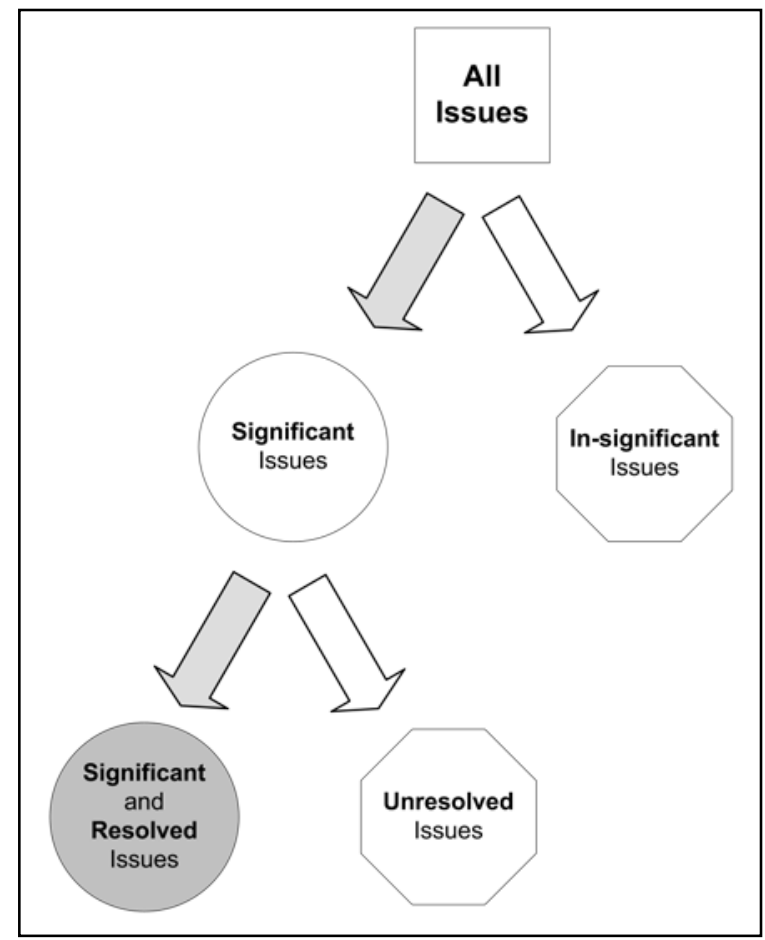

Figure 2.1 Sample issue identification methodology (SBW Consulting, 2004)

Complex. Studies utilizing complex methodologies employ detailed engineering calculations or models to estimate energy savings. Examples range from detailed building simulations that require extensive information about building characteristics to very detailed engineering calculations based on measured data. Complex methodologies for new construction commissioning benefits address nuances such as the range of assumptions that go into the hypothetical baseline (i.e., what is assumed to have occurred without commissioning). More complex methods also address the interaction between commissioning measures, and the interaction with related activities like energy retrofits. Results can be reported per measure, or for a whole building (which is not simply the sum of individual measures).

An example of a complex energy benefit methodology is found in Altweis (2001). This study used engineering calculations to estimate energy use both with and without identified findings/issues. Researchers developed both a "most likely" and a "least cost solution" scenario, depending on assumptions about what would have occurred in the absence of commissioning.

\section{Non-Energy Benefits (NEBs)}

In the assessment of non-energy benefits there is a great diversity of methodologies in use. Here again, in Table 2.8, non-energy benefit methodologies are classified according to their complexity.

Table 2.8 Comparison of non-energy benefit methodologies

\begin{tabular}{|l|c|c|c|}
\hline & $\begin{array}{c}\text { Monetary value } \\
\text { NOT assigned }\end{array}$ & $\begin{array}{c}\text { Monetary value } \\
\text { assigned }\end{array}$ & $\begin{array}{c}\text { Monetary value } \\
\text { validated }\end{array}$ \\
\hline Simple & $\mathrm{x}$ & & \\
\hline Moderate & & $\mathrm{x}$ & $\mathrm{x}$ \\
\hline Complex & & $\mathrm{x}$ & \\
\hline
\end{tabular}


Of the 12 studies examined, 5 do not assign a monetary value to NEBs. Those that do use methodologies ranging from simple processes that do not employ standard calculations or checks on respondents' information to a highly complex system in which NEB dollar values are calculated several different ways and the most conservative number selected. Here too, only the most complex methodologies attempt to validate the data.

Contrary to the direct relationship between methodological complexity and commissioning costs, with NEBs there appears to be an inverse relationship: the more complex the methodology the lower the monetary benefit reported. This holds true for both new and existing building commissioning.

It is apparent that methodology significantly impacts reported non-energy benefits. The study employing avoided cost calculations (a moderate methodology) returned higher savings than the study that determined the owner's perceived value of the benefit (a complex methodology). This is due to a fundamental difference between these two methodologies. Although both methods are hypothetical, avoided cost calculations estimate the full cost that would have been incurred, had the benefit not been received. Whereas the owner's perceived value is the amount the owner is willing to pay for the benefit often less than the avoided cost. Further study in this area is clearly needed to determine how the nonenergy benefit valuation method relates to the goals of the cost-benefit methodology.

Table 2.9 NEBs of commissioning by methodological complexity ${ }^{i}$

\begin{tabular}{|c|c|c|c|c|}
\hline & \multicolumn{2}{|c|}{ New Buildings } & \multicolumn{2}{c|}{ Existing Buildings } \\
\hline \multirow{2}{*}{ Methodology } & $\begin{array}{c}\text { Number of } \\
\text { Buildings }\end{array}$ & $\begin{array}{c}\text { Average NEB Savings } \\
\text { (US\$) }\end{array}$ & $\begin{array}{c}\text { Number of } \\
\text { Buildings }\end{array}$ & $\begin{array}{c}\text { Average NEB } \\
\text { Savings (US\$) }\end{array}$ \\
\hline Complex & 13 & $\$ 0.13 / \mathrm{ft}^{2}$ & 8 & $\$ 0.11 / \mathrm{ft}^{2}$ \\
& & $\$ 1.40 / \mathrm{m}^{2}$ & 10 & $\$ 1.18 / \mathrm{m}^{2}$ \\
\hline Moderate & 23 & $\$ 0.17 / \mathrm{ft}^{2}-\$ 6.96 / \mathrm{ft}^{2}$ & $\$ 0.10 / \mathrm{ft}^{2}-\$ 0.45 / \mathrm{ft}^{2}$ \\
& & $\$ 1.83 / \mathrm{m}^{2}-\$ 74.92 / \mathrm{m}^{2}$ & & $\$ 1.08 / \mathrm{m}^{2}-$ \\
& & & & \\
\hline
\end{tabular}

${ }^{\mathrm{i}}$ Moderate data is presented as a range because a validation method was not employed.

The following is a more detailed discussion of non-energy benefit methodology types, with examples.

Simple. An example of a simple methodology for assessing non-energy benefits is found in Cxdatabase.com (2004). Here, respondents are asked to identify which benefits they received and have the option, but not the requirement, to supply a dollar value for the benefit. No standardized calculations are employed, and there is no process for evaluating the dollar values supplied by respondents.

Moderate. An example of a moderately complex methodology for calculating NEBs is found in Mills et al. (2004). Here, the researcher arrived at the NEB dollar value by adding the first-cost dollar value of nonenergy savings and the ongoing labor cost savings, estimated as labor hours saved. Other NEBs were accounted for using a Yes/No checklist with an estimated dollar value supplied optionally.

Complex. An example of a complex methodology for assessing NEBs is found in SBW Consulting (2004), see Fig. 2.2. Researchers developed three different ways to assign a dollar value to a "stream" of 
benefits flowing from a specific finding/issue, and then used the most conservative (lowest dollar value) estimate. All three calculations were based on the responses of key commissioning team members given in telephone surveys. (See Table 2.10 for additional details).

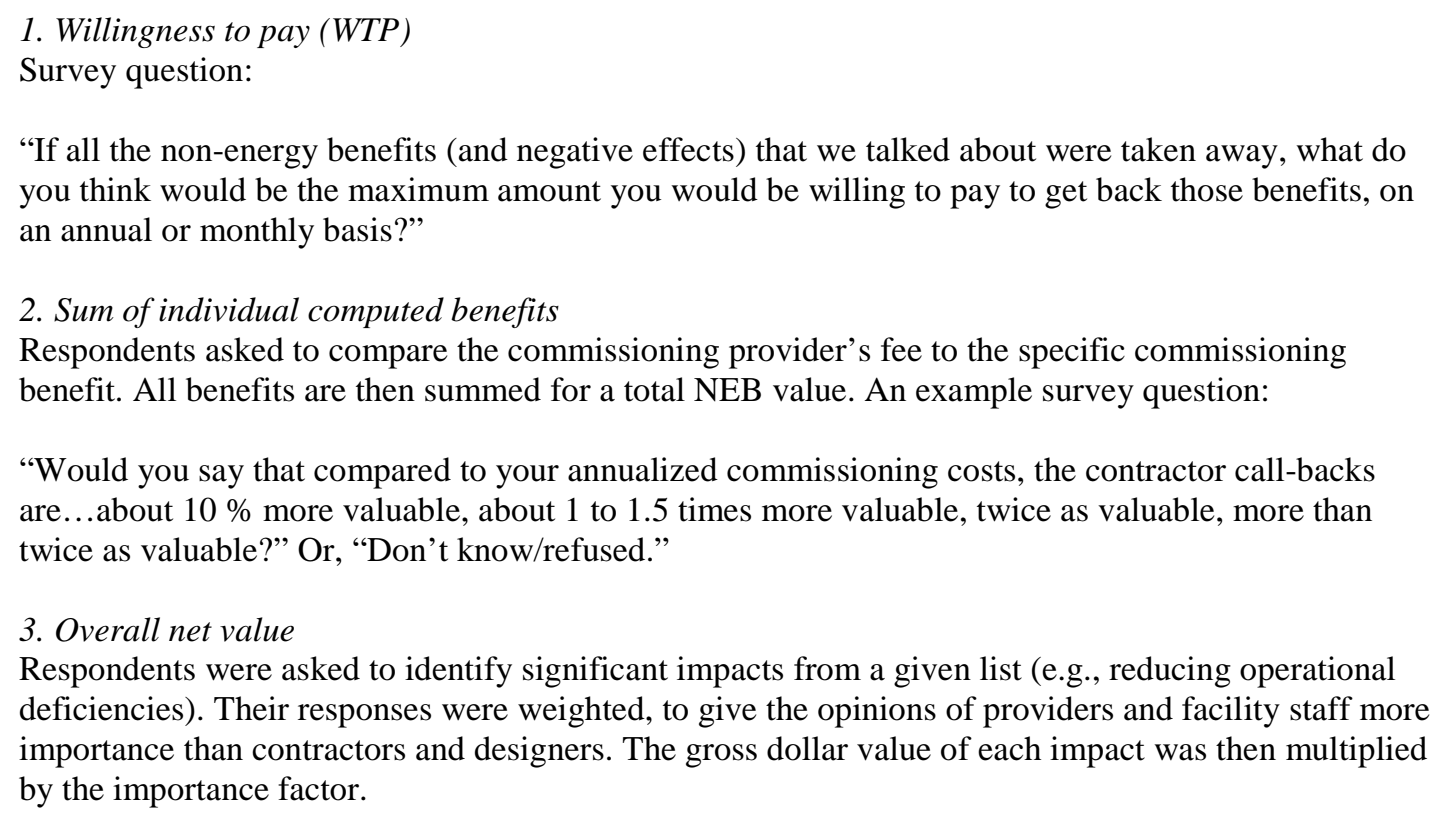

3. Overall net value

Respondents were asked to identify significant impacts from a given list (e.g., reducing operational deficiencies). Their responses were weighted, to give the opinions of providers and facility staff more importance than contractors and designers. The gross dollar value of each impact was then multiplied by the importance factor.

Figure 2.2 Sample complex NEB methodology (SBW Consulting, 2004) 
Table 2.10 Overview of cost-benefit evaluation methodologies (continued on next 3 pages)

\begin{tabular}{|c|c|c|c|c|c|c|c|c|}
\hline \multirow{2}{*}{$\begin{array}{l}\text { StudylAuthor } \\
\text { Stum, } \\
\text { ECM Cx } \\
(1994)\end{array}$} & \multicolumn{2}{|r|}{ Costs } & \multicolumn{2}{|c|}{ Energy Benefits } & \multicolumn{2}{|c|}{ Non-energy Benefits (NEBs) } & \multicolumn{2}{|c|}{ Persistence Assumptions } \\
\hline & Simple & $\begin{array}{l}\text { Cost of Cx } \\
\text { provider services } \\
+ \text { program } \\
\text { administration } \\
\text { costs }\end{array}$ & Moderate & $\begin{array}{l}\text { Engineering calculations } \\
\text { and computer simulations } \\
\text { from original ECM savings } \\
\text { predictions }\end{array}$ & $\mathrm{N} / \mathrm{A}$ & & $N / A$ & \\
\hline $\begin{array}{l}\text { Piette, } \\
\text { Energy Edge } \\
\text { Cx (1995) }\end{array}$ & Simple & $\begin{array}{l}\text { Percent of overall } \\
\text { energy efficiency } \\
\text { measure cost, } \\
\text { costs by energy- } \\
\text { efficiency } \\
\text { measure are } \\
\text { used when } \\
\text { available. }\end{array}$ & Complex & $\begin{array}{l}\text { Used deficiency } \\
\text { identification and post- } \\
\text { construction utility data to } \\
\text { tune as-built simulation } \\
\text { models. Deficiencies were } \\
\text { "removed" from the } \\
\text { models to determine } \\
\text { savings. Deficiencies } \\
\text { categorized as Directly, } \\
\text { Indirectly, and Un-related } \\
\text { to the ECM, and Static or } \\
\text { Dynamic. }\end{array}$ & Simple & $\begin{array}{l}\text { Categorized as control, } \\
\text { indoor environmental } \\
\text { quality (IEQ), equipment } \\
\text { life, O\&M. No value } \\
\text { assigned. }\end{array}$ & $\begin{array}{l}\text { Simple (but } \\
\text { the } \\
\text { modeling } \\
\text { itself was } \\
\text { not simple) }\end{array}$ & $\begin{array}{l}\text { "Low" and "High" } \\
\text { lifetime scenarios } \\
\text { defined in the } \\
\text { modeling. }\end{array}$ \\
\hline $\begin{array}{l}\text { Haasl, } \\
5 \text { Building } \\
\text { Study (1996) }\end{array}$ & N/A & N/A & Simple & $\begin{array}{l}\text { Categorize deficiencies } \\
\text { into deficiency type } \\
\text { (maintenance, } \\
\text { documentation, training, } \\
\text { operations, installation, } \\
\text { design); HVAC } \\
\text { subsystem; and affected } \\
\text { component. Additional } \\
\text { categorization for controls } \\
\text { related findings. }\end{array}$ & Simple & $\begin{array}{l}\text { All deficiencies were } \\
\text { categorized, including non- } \\
\text { energy related } \\
\text { deficiencies. In total (Cx } \\
\text { and EBCx), } 51 \% \text { of all } \\
\text { deficiencies related to } \\
\text { reliability and maintenance } \\
(25 \% \text { significantly } \\
\text { related). In total (Cx and } \\
\text { EBCx), } 25 \% \text { of all } \\
\text { deficiencies related to } \\
\text { comfort ( } 13 \% \text { significantly } \\
\text { related). }\end{array}$ & $\mathrm{N} / \mathrm{A}$ & \\
\hline
\end{tabular}




\begin{tabular}{|c|c|c|c|c|c|c|c|c|}
\hline StudylAuthor & \multicolumn{2}{|c|}{ Costs } & \multicolumn{2}{|c|}{ Energy Benefits } & \multicolumn{2}{|c|}{ Non-energy Benefits (NEBs) } & \multicolumn{2}{|c|}{ Persistence Assumptions } \\
\hline $\begin{array}{l}\text { PECI/DOE, } \\
\text { Deficiency } \\
\text { Database } \\
(1996)\end{array}$ & Moderate & $\begin{array}{l}\text { Categorized as } \\
\text { Assessment or } \\
\text { Implementa- } \\
\text { tion. Included } \\
\text { consultant, } \\
\text { contractor, and } \\
\text { building staff } \\
\text { time, as well } \\
\text { as parts and } \\
\text { lease costs for } \\
\text { monitoring } \\
\text { equipment. } \\
\text { Did not include } \\
\text { "research" } \\
\text { related costs. }\end{array}$ & Moderate & $\begin{array}{l}\text { "Potential" energy } \\
\text { savings reported. A } \\
\text { combination of } \\
\text { standard engineering } \\
\text { calculations and DOE2 } \\
\text { building simulations, } \\
\text { with short-term } \\
\text { diagnostic monitored } \\
\text { data used to inform the } \\
\text { calculations or model. }\end{array}$ & Moderate & $\begin{array}{l}\text { Only includes extended } \\
\text { equipment life, which is } \\
\text { the most easily quantified } \\
\text { effect. Categorized as } \\
\text { extended equipment life } \\
\text { through reduced hours of } \\
\text { operation and through } \\
\text { reduced short cycling. } \\
\text { Calculated based on } \\
\text { assumptions of reduced } \\
\text { hours, reduced lifetime } \\
\text { through short cycling, and } \\
\text { nominal life. }\end{array}$ & $\mathrm{N} / \mathrm{A}$ & N/A \\
\hline $\begin{array}{l}\text { Gregerson, } \\
\text { EBCX (1997) }\end{array}$ & Simple & $\begin{array}{l}\text { Costs reported } \\
\text { or estimated } \\
\text { by each Cx } \\
\text { provider. } \\
\text { Costs include } \\
\text { Cx fee, } \\
\text { monitoring } \\
\text { costs, and the } \\
\text { cost of } \\
\text { implementing } \\
\text { measures } \\
\text { except for in- } \\
\text { house facility } \\
\text { staff time } \\
\text { during normal } \\
\text { working hours. }\end{array}$ & Moderate & $\begin{array}{l}\text { Project documentation } \\
\text { may have utilized } \\
\text { engineering } \\
\text { calculations, models, or } \\
\text { pre- and post- } \\
\text { consumption } \\
\text { measurement to } \\
\text { quantify savings. } \\
\text { Report notes that rigor } \\
\text { with which energy } \\
\text { savings were } \\
\text { calculated varies } \\
\text { significantly. }\end{array}$ & $\mathrm{N} / \mathrm{A}$ & & $\mathrm{N} / \mathrm{A}$ & \\
\hline $\begin{array}{l}\text { PECI, Brochure } \\
\text { (1997) }\end{array}$ & Simple & $\begin{array}{l}\text { Cost range } \\
\text { and median } \\
\text { cost. }\end{array}$ & Simple & $\begin{array}{l}\text { Savings range by } \\
\text { building type. } \\
\text { Conducted phone } \\
\text { interviews. }\end{array}$ & Moderate & $\begin{array}{l}\text { Identified NEB } \\
\text { quantitatively for many } \\
\text { different categories }\end{array}$ & $\mathrm{N} / \mathrm{A}$ & \\
\hline
\end{tabular}




\begin{tabular}{|c|c|c|c|c|c|c|c|}
\hline Study/Author & Costs & \multicolumn{2}{|r|}{ Energy Benefits } & \multicolumn{2}{|c|}{ Non-energy Benefits (NEBs) } & \multicolumn{2}{|c|}{ Persistence Assumptions } \\
\hline $\begin{array}{l}\text { Altweis } \\
(2001)\end{array}$ & $\mathrm{N} / \mathrm{A}$ & Complex & $\begin{array}{l}\text { Used engineering } \\
\text { calculations to estimate } \\
\text { energy used with and } \\
\text { without identified } \\
\text { deficiencies. Provided Most } \\
\text { Likely and Least Cost } \\
\text { Solution scenarios, } \\
\text { depending on assumptions } \\
\text { for what would have } \\
\text { occurred absent } \\
\text { commissioning. }\end{array}$ & Moderate & $\begin{array}{l}\text { Used simple calculations } \\
\text { and extensive assumptions } \\
\text { to estimate impacts to } \\
\text { factors such as lost } \\
\text { productivity, lost sales due } \\
\text { to late building completion } \\
\text { and equipment } \\
\text { replacement. Provided } \\
\text { Most Likely and Least Cost } \\
\text { Solution scenarios, } \\
\text { depending on assumptions } \\
\text { for what would have } \\
\text { occurred absent } \\
\text { commissioning. }\end{array}$ & Simple & $\begin{array}{l}\text { Lifetime assumed } \\
\text { by measure and } \\
\text { benefit (most are } \\
\text { first-year impacts or } \\
\text { flat over assumed } \\
\text { lifetime). }\end{array}$ \\
\hline $\begin{array}{l}\text { Heinemeier, } \\
\text { Schools Cx } \\
(2004)\end{array}$ & N/A. & Simple & $\begin{array}{l}\text { Comparison of monthly } \\
\text { utility bills (electricity and } \\
\text { gas (kBtu) per square foot), } \\
\text { between commissioned and } \\
\text { uncommissioned buildings } \\
\text { (well matched pair or large } \\
\text { sample size } \\
\text { recommended), also } \\
\text { comparing commissioned } \\
\text { buildings with benchmarks } \\
\text { (e.g., CBECS). }\end{array}$ & Moderate & $\begin{array}{l}\text { Comparison of well-defined } \\
\text { metrics collected during } \\
\text { construction and operation } \\
\text { phases, between } \\
\text { commissioned and } \\
\text { uncommissioned buildings } \\
\text { (well matched pair or large } \\
\text { sample size } \\
\text { recommended). }\end{array}$ & Simple & $\begin{array}{l}\text { Many benefits are } \\
\text { first year. } \\
\text { Persistence not } \\
\text { addressed. }\end{array}$ \\
\hline
\end{tabular}




\begin{tabular}{|c|c|c|c|c|c|c|c|c|}
\hline \multirow{2}{*}{$\begin{array}{l}\text { Study/Author } \\
\text { Mills, } \\
\text { Meta-analysis } \\
(2004)\end{array}$} & \multicolumn{2}{|r|}{ Costs } & \multicolumn{2}{|c|}{ Energy Benefits } & \multicolumn{2}{|c|}{ Non-energy Benefits (NEBs) } & \multicolumn{2}{|c|}{ Persistence Assumptions } \\
\hline & Moderate & $\begin{array}{l}\text { Cx and EBCx: includes } \\
\text { Cx provider fee, Cx } \\
\text { coordination costs of } \\
\text { other parties } \\
\text { Cx: Does not include } \\
\text { resolution cost for } \\
\text { "quality assurance" } \\
\text { findings or cost to fix } \\
\text { design flaws } \\
\text { EBCx: Includes } \\
\text { resolution cost }\end{array}$ & Moderate & $\begin{array}{l}\text { Project documentation } \\
\text { may have utilized } \\
\text { engineering } \\
\text { calculations, models, or } \\
\text { pre- and post- } \\
\text { consumption } \\
\text { measurement to } \\
\text { quantify savings. } 58 \% \\
\text { of EBCx and } 28 \% \text { of Cx } \\
\text { projects verified } \\
\text { measures to be } \\
\text { implemented. }\end{array}$ & Moderate & $\begin{array}{l}\text { First cost non-energy } \\
\text { savings }(\$), \text { and ongoing } \\
\text { labor cost savings (type, } \\
\text { labor hours saved), and } \\
\text { includes a list of other } \\
\text { NEBs }(\mathrm{Y} / \mathrm{N}, \$)\end{array}$ & $\begin{array}{l}\text { Simple } \\
\text { (number } \\
\text { taken from } \\
\text { other } \\
\text { studies, } \\
\text { which are } \\
\text { more } \\
\text { complex) }\end{array}$ & $\begin{array}{l}\text { Persistence data } \\
\text { collected where } \\
\text { available from other } \\
\text { studies (LBNL, } \\
\text { TAMU)). Used their } \\
\text { methodology (see } \\
\text { Persistence chapter } \\
\text { of this report). } \\
\text { For the majority of } \\
\text { buildings, } \\
\text { persistence or } \\
\text { measure life was } \\
\text { not addressed. }{ }^{12}\end{array}$ \\
\hline $\begin{array}{l}\text { SBW, Northwest } \\
\text { Cx \& EBCx } \\
(2004)\end{array}$ & Complex & $\begin{array}{l}\text { Includes incremental } \\
\text { fee increases, travel } \\
\text { expenses, and } \\
\text { resolution costs to each } \\
\text { party, as reported by } \\
\text { respondents. }\end{array}$ & Moderate & $\begin{array}{l}\text { Used project } \\
\text { documentation to } \\
\text { identified significant and } \\
\text { resolved issues, then } \\
\text { used standard } \\
\text { engineering calculations } \\
\text { or parametric modeling } \\
\text { to get savings. }\end{array}$ & Complex & $\begin{array}{l}\text { Dollar value estimated } \\
\text { three different ways } \\
\text { based on telephone } \\
\text { survey data with most } \\
\text { conservative figure used. }\end{array}$ & $\mathrm{N} / \mathrm{A}$ & \\
\hline $\begin{array}{l}\text { California } \\
\text { Commissioning } \\
\text { Collaborative's } \\
\text { Cxdatabase.com } \\
(2004)\end{array}$ & Moderate & $\begin{array}{l}\text { Includes minor capital } \\
\text { improvements as a cost } \\
\text { of EBCx. } 13 \\
\text { Includes incremental } \\
\text { costs to other parties }\end{array}$ & Simple & $\begin{array}{l}\text { Respondent provides } \\
\text { info for energy-savings } \\
\text { calculations for each } \\
\text { finding, not required to } \\
\text { perform calculation. } \\
\text { Persistence and } \\
\text { avoided cost info } \\
\text { optional. No } \\
\text { standardized } \\
\text { calculations for energy } \\
\text { savings. }\end{array}$ & Simple & $\begin{array}{l}\text { Respondents asked to } \\
\text { identify which benefits } \\
\text { they received, and given } \\
\text { the option of entering a } \\
\text { dollar value for the } \\
\text { estimated avoided cost. } \\
\text { No standardized } \\
\text { calculations for avoided } \\
\text { costs. }\end{array}$ & $\begin{array}{l}\text { Not } \\
\text { assessed }\end{array}$ & \\
\hline
\end{tabular}

\footnotetext{
12 The fast payback times for Cx measures are most likely shorter than the period of erosion of savings.

${ }^{13}$ Allows owner to specify whether O\&M staff participation is a cost or a benefit. Does not include resolution costs for "quality assurance" findings as reported by respondents.
} 


\begin{tabular}{|c|c|c|c|c|c|c|c|}
\hline \multirow{2}{*}{$\begin{array}{l}\text { StudylAuthor } \\
\begin{array}{l}\text { Moore et al. } \\
(2008)\end{array}\end{array}$} & \multicolumn{2}{|r|}{ Costs } & \multicolumn{2}{|c|}{ Energy Benefits } & Non-energy Benefits (NEBs) & \multicolumn{2}{|c|}{ Persistence Assumptions } \\
\hline & $\mathrm{n} / \mathrm{a}$ & $\begin{array}{l}\text { Only provides payback } \\
\text { based on owner's costs. }\end{array}$ & Complex & $\begin{array}{l}\text { Complex spreadsheet } \\
\text { calculations, quality- } \\
\text { checked by utility } \\
\text { program administrators }\end{array}$ & $\mathrm{n} / \mathrm{a}$ & $\mathrm{n} / \mathrm{a}$ & \\
\hline $\begin{array}{l}\text { PECI \& Summit } \\
\text { Building } \\
\text { Engineering } \\
(2008)\end{array}$ & Complex & $\begin{array}{l}\text { EBCx provider costs } \\
\text { and implementation } \\
\text { costs included. }\end{array}$ & Complex & $\begin{array}{l}\text { Based on utility } \\
\text { programs' data, which } \\
\text { uses detailed energy } \\
\text { calculations and a } \\
\text { rigorous review }\end{array}$ & $\mathrm{n} / \mathrm{a}$ & $\mathrm{n} / \mathrm{a}$ & \\
\hline
\end{tabular}




\subsubsection{Recommendations and Decision Points}

Table 2.10 displays the 12 diverse studies reviewed in this report. The studies represent a large range of data collection, costs, energy benefit and non-energy benefit methodologies. Although this makes generalizations difficult, their collective efforts point to several recommendations moving forward, and several decision points to which any new study must attend.

\section{Recommendations}

1. Building commissioning data should be greatly diversified. In the majority of these studies, building information comes from only a few sources, like a handful of commissioning providers or a large university research department. It is thus unclear how well the findings of these studies will apply to the worldwide commissioning industry. Moving forward, an attempt should be made to gather building data from a much broader base. To date, it has been difficult to collect data from diverse projects because owners do not tend to ask for (or pay for) this kind of data on their own projects, and commissioning providers therefore do not gather it. Collecting commissioning data in a consistent way requires artificial injection of a research project or program to help standardize the way data is gathered and reported by market actors.

2. A complex cost-benefit methodology may require continuous data collection throughout the commissioning project, extensive interviews, or both, to acquire a sufficiently detailed reporting of costs. The data required for complex, and sometimes even moderate, cost methodologies will be difficult to obtain with a retroactive data collection methodology relying solely on documentation. It is nearly impossible to determine from documentation costs that are not explicitly defined during the project. For example, a study may want to include in its cost calculation the cost to the contractor of coordinating with the commissioning provider. If this cost is not defined either during or immediately after the commissioning process it will not be included in documentation (although it may be obtained through a timely interview). As a result, retroactive studies relying mostly on project documentation are often forced to "take what they can get," a methodology which does not lead itself to a consistent definition of commissioning costs. A study employing a complex cost methodology should facilitate accurate data entry by using a collection methodology that allows easy entry of data and thus helps avoid the need for retrospective information-gathering based on project documentation.

3. Data validation is an important aspect of any cost-benefit methodology. In cases where data is not verified, the accuracy of the cost-benefit results may be at risk.

\section{Decision Points in Creating a Cx/EBCx Cost-Benefit Methodology}

Creating an appropriate and feasible commissioning cost-benefit methodology that achieves the goals of the project requires careful planning around some key decision points. Ultimately, these decisions lead to a methodology that can have a range of levels of effort to collect and analyze data, as is shown in this chapter. The following key decision points emerged during this analysis of cost-benefit methodologies.

\section{General}

- What is the goal of data collection and who is the expected audience?

- What data and formats are appropriate to the study goals and audience?

- What resources do researchers have available to them? This includes both financial resources as well as current and potential data sources.

- How important is verification of data? (Possible levels: reasonableness check, oversight of energy and non-energy benefits calculations, and verification for persistence.) 


\section{Data Collection}

- Will the study be a one-time event that looks retrospectively at past projects, or will data collection and analysis occur continuously with current and future projects?

\section{Costs}

- $\quad$ Should the cost to resolve problems identified by the commissioning provider be counted as a cost of commissioning? If these resolutions are major design changes, should they be counted as a cost of commissioning?

- Should the commissioning-related costs of designers, contractors, and operating staff be counted as costs of commissioning?

- Are tasks performed by a commissioning provider that is out of the scope of commissioning counted as a cost of commissioning? For example, designers are generally tasked with developing the design intent documents. If the designer does not complete these documents, but the commissioning provider must have a complete set to functionally test the systems against, then often the commissioning provider will complete the task.

- Are costs treated differently for new construction commissioning and existing building commissioning?

\section{Energy Benefits}

- Will the methodology be whole building or measure-based?

- Will the methodology require monitored data or rely on calculations, and will calculations be validated by monitored data?

- How will measured data be collected (e.g., utility bills, dataloggers, or trends from the building automation system)?

- How will it be tracked that identified measures are implemented?

- Will standardized calculations be used, or guidelines for calculations or modeling?

- What standardized documentation must be collected to support modeling or calculation?

- How will persistence of savings be estimated or verified?

\section{Non-Energy Benefits}

- Will an attempt be made to quantify the financial consequences of non-energy benefits?

- If not, how will non-energy benefits be reported and verified?

- If so, will the financial non-energy benefit be self-reported, or will a verification methodology be employed?

\subsection{References}

Altwies, Joy and Ian B. D. McIntosh. 2001. "Quantifying the Cost Benefits of Commissioning" in Proceedings of the 9th National Conference on Building Commissioning. PECl.

Friedman, Hannah, Tudi Haasl, and Ken Gillespie. 2004. "Creating California's Online Commissioning Case Study Database: Case Studies Go High Tech" " in Proceedings of the ACEEE 2004 Summer Study on Energy Efficiency in Buildings, 3-64 - 3-75, Washington, DC: ACEEE.

Gregerson, Joan. 1997. Commissioning Existing Buildings. E Source TU-97-3. Boulder, CO: E Source, Inc. 
Haasl, Tudi, K. Stum, and M. Arney. 1996. "Better Buildings through Improved O\&M - A Five Building Case Study." in Proceedings of the 5th National Conference on Building Commissioning.

Heinemeier, Kristin, Michael Martin, Balaji Santhanakrishnan, Anita Ledbetter, Jim Shoop, Wes Harvey, Joseph Martin, and Frank Thomas. 2004. "Commissioning of New Schools: A State Funded Study of Costs and Benefits" in Proceedings of the ACEEE 2004 Summer Study on Energy Efficiency in Buildings, 3-88 -3-99, Washington, DC: ACEEE.

Mills, Evan, Hannah Friedman, Tehesia Powell, Norman Bourassa, David Claridge, Tudi Haasl and Mary Ann Piette. 2004. "The Cost-Effectiveness of Commercial-Building Commissioning." LBNL - 56637, December, 2004.

Moore, Emily, 2008. "California Retrocommissioning Programs: Lessons Learned", Proceedings of the 14th biennial ACEEE Summer Study on Energy Efficiency in Buildings, Pacific Grove, California.

Piette, Mary Ann, B. Nordman, and S. Greenberg. 1995. "Commissioning of Energy-Efficiency Measures: Costs and Benefits for 16 Buildings." LBNL - 36448, April.

Piette, Mary Ann and Bruce Nordman. 1995. "Energy and Cost Savings from Commissioning Efficiency Measures in 16 Buildings" in Proceedings of the 4th National Conference on Building Commissioning.

Portland Energy Conservation, Inc. (PECI). 1997. "What Can Commissioning Do for Your Building?"

PECI. 1996. "Building Systems Deficiency Database." Report to the U.S. Environmental Protection Agency/U.S. Department of Energy under Assistance Agreement CX822837-01-0, December, 1996.

PECI and Summit Building Engineering, "2007 California RCx Market Characterization", Report prepared for the California Commissioning Collaborative.

SBW Consulting. 2004. "Cost-Benefit Analysis for the Commissioning in Public Buildings Project," submitted to the Northwest Energy Efficiency Alliance, posted May, 2004.

Tso, Bing, Marc Schuldt, and Jun Quan. 2004. "The Costs and Benefits of Achieving Silver LEED for Two Seattle Municipal Buildings" in Proceedings of the ACEEE 2004 Summer Study on Energy Efficiency in Buildings, 3-338 -3-350, Washington, DC: ACEEE.

Tso, Bing, Michael Baker, and Andrzej Pekalski. 2002. "The Costs and Benefits of Commissioning Oregon Public Buildings" in: Proceedings of the ACEEE 2002 Summer Study on Energy Efficiency in Buildings, 3.373-3.384, Washington, DC: ACEEE. An earlier version is also included, from the Proceedings of the 8th National Conference on Building Commissioning, 2000. PECl. (Based on SBW Consulting. "Cost-Benefit Analysis for the Commissioning in Public Buildings Project")

Stum, Karl, Tudi Haasl and Dan Krebs. 1994. "Costs and Savings of ECM Commissioning and Inspection - Case Studies from One Utility" in Proceedings of the 2nd National Conference on Building Commissioning, PECl.

\section{Additional Cost-Benefit Studies}

Bicknell, Charles and Liza Skumatz. 2004. "Non-Energy Benefits (NEBs) in the Commercial Sector: Results from Hundreds of Buildings" in Proceedings of the ACEEE 2004 Summer Study on Energy Efficiency in Buildings, 4-10 - 4-22, Washington, DC: ACEEE.

Bushell, Christopher, Jack Wolpert, Mandeep Singh, and William Burns. 2002. "Retro Commissioning at Chicago Public Schools" in Proceedings of the 10th National Conference on Building Commissioning, PECl. 
Chao, Mark and David B. Goldstein. 1998. "Commissioning, Energy Efficiency, and the Asset Value of Commercial Properties: Perspectives from Appraisers and Financial Stakes for Owners" in Proceedings of the 6th National Conference on Building Commissioning, PECl.

Claridge, David E., Charles H. Culp, Song Deng, W.D. Turner, J.S. Haberl, and Mingsheng Liu. 2000. "Continuous Commissioning of a University Campus" in Proceedings of the 8th National Conference on Building Commissioning, PECl.

Cohan, David and Phil Willems. 2001. "Construction Costs and Commissioning" in Proceedings of the 9th National Conference on Building Commissioning, PECl.

Coleman, James D. 1998. "Three Building Tune-Up Case Studies" in Proceedings of the 6th National Conference on Building Commissioning, PECl.

Cox, Robert and April Williams. 2000. "Quantifying Costs \& Benefits of Commissioning" in Proceedings of the 8th National Conference on Building Commissioning, PECl.

Deall, Jerry H., Jack S. Wolpert, Mandeep Singh, and James Kelley. 2002. "Savings Due to Commissioning at the King Center, (Performing Arts Building)" in Proceedings of the 10th National Conference on Building Commissioning, PECl.

Dorgan, Chad, Robert Cox, and Charles Dorgan. 2002. "The Value of the Commissioning Process: Costs and Benefits." The Austin Papers: Best of the 2002 International Green Building Conference, Compiled by Environmental Building News, pp. 25-30.

Khan, Aleisha. 2002. "Retrocommissioning of Two Long-Term Care Facilities in California. Institute for Market Transformation 2002, available online at www.imt.org/papers.

Kumar, Satish and William J. Fisk. 2002. "IEQ and the Impact on Building Occupants" in the ASHRAE Journal.

Kumar, Satish and William J. Fisk. 2002. "The Role of Emerging Energy-Efficient Technology in Promoting Workplace Productivity and Health: Final Report" Publication source unknown. February 13, 2002.

Martinez, Mark S. 1999. "Energy Efficient Retrofit Commissioning - Tricks of the Trade to Avoid Claims and Unhappy Customers" in Proceedings of the 7th National Conference on Building Commissioning, PECl.

McHugh, Jonathon, Lisa Heschong, Nehemiah Stone, Abby Vogen, Daryl Mills, and Cosimina Panetti. 2002. "Non-Energy Benefits as a Market Transformation Driver" in Proceedings of the ACEEE 2002 Summer Study on Energy Efficiency in Buildings, 6.209-6.220, Washington, DC: ACEEE.

Milton, Donald K. 2002. "IEQ and the Impact on Employee Sick Leave" in the ASHRAE Journal, 2002.

Nelson, Norman L. 1999. "Avoiding Litigation through Proper Commissioning: My Experience as an Expert Witness" in Proceedings of the 7th National Conference on Building Commissioning, $\mathrm{PECl}$.

Nicholls, Andrew, Sean McDonald, and John D. Ryan. 2002. "Estimating the Benefits from Building Technologies: Issues, Challenges, and Lessons Learned from Blue Ribbon Panel Reviews" in Proceedings of the ACEEE 2002 Summer Study on Energy Efficiency in Buildings, 10.221-10.236, Washington, DC: ACEEE. 
Parker, Gretchen and Mark Chao. 1999. "Management and Documentation of Building Energy Performance by Real Estate Investment Trusts" in Proceedings of the 7th National Conference on Building Commissioning, PECl.

Parker, Gretchen, Mark Chao, and Ken Gillespie. 2000. "Energy-related Practices and Investment Criteria of Corporate Decision-Makers" in Proceedings of the ACEEE 2000 Summer Study on Energy Efficiency in Buildings. Washington, DC: ACEEE.

Parks, Jim, Mazin Kellow, Debby Dodds, and Greg Cunningham. 2001. "Getting the Most Out of Your Building: SMUD's Commissioning Program" in Proceedings of the ACEEE 2000 Summer Study on Energy Efficiency in Buildings, 4.247 - 4.256, Washington, DC: ACEEE; also published as “SMUD's Retrocommissioning Program: Improving With Time" in Proceedings of the 9th National Conference on Building Commissioning, PECl.

Tseng, Paul. 1998. "Building Commissioning: Benefits and Costs." Heating/Piping/Air Conditioning, April, 1998, pp. 51-59.

Veltri, Anthony. 2002. "Development of an Integrated Commissioning Strategy and Cost Model" in Proceedings of the 10th National Conference on Building Commissioning, $\mathrm{PECl}$.

Wei, Guanghua, Mingsheng Liu, Martha J. Hewett, and Mark W. Hancock. 2001. "Continuous Commissioning of a Hospital Complex" in Proceedings of the 9th National Conference on Building Commissioning, PECl.

Wilkinson, Ronald J. 2000. "Establishing Commissioning Fees" ASHRAE Journal. February 2000, pp. 4151. 


\section{COMMISSIONING PERSISTENCE}

\subsection{Methodologies for Determining Persistence of Commissioning Benefits}

\subsubsection{Commissioning Benefits}

The benefits of $C x$ and $E B C x$ are normally verified as part of the project, whether they are energy-related benefits or non-energy benefits (NEBs). How those benefits last over time is a subject of much study and discussion, in two principle areas:

- How will certain Cx/EBCx measure types persist over time (typically measured as percentage degradation over certain time periods in years),

- The robustness of methods used to ascertain measure persistence.

The one-time, or inherently persistent benefits normally reduce construction costs directly or indirectly. Table 3.1 lists a number of reported benefits of commissioning (Mills et al. 2005, Friedman et al. 2002, Liu et al., 2002) that appear to generally fall in the category of inherently persistent benefits. They have been grouped as design benefits, construction benefits, early occupancy benefits, and "other", primarily based on when they occur in the design/construction process. The benefit from design improvements inherently occurs once, but this benefit persists until the building is renovated or equipment fails and is replaced. Many more design benefits than those listed may result from commissioning. The benefits that speed up or make the construction process flow more smoothly will clearly provide a one-time benefit. The benefits that make early occupancy a more seamless process will generally be one-time benefits, though the items related to safety and liability may be viewed as on-going benefits.

The role of commissioning in qualifying a building for a Leadership in Energy and Environmental Design (LEED) rating or participation in a utility program may provide long-term benefits, but are treated as inherently persisting. A thorough EBCx process can be a significant enabling factor for a thorough building retrofit.

Whether viewed as one-time benefits, or as longer term, the commissioning benefits shown in Table 3.1 will not be considered among those that may degrade over time. Hence they will be assumed to be inherently persistent in the context of the persistence methodology presented here.

The benefits listed in Table 3.2 have also been reported as commissioning benefits (Mills et al. 2005, Friedman et al. 2002, Liu et al., 2002), but these are items related to the operation of the building that are thought to be more likely to change over time, particularly if they are the result of the implementation of practices that are not widely understood by the community of building operators. Hence these benefits are treated as commissioning benefits that may not persist. 
Table 3.1 Inherently persistent benefits of commissioning

\begin{tabular}{|c|c|}
\hline Design Benefits \\
\hline - & Equipment right-sizing \\
\hline Construction Benefits \\
\hline - & Improved project schedule \\
- & Clarified delineation of responsibilities among team members \\
- & Lews disangreement among contractors \\
- & Reduced contractor call-backs \\
- & More vigilant contractor behavior (knowing that Cx will follow their \\
- & Reduced testing and balancing (TAB) costs \\
\hline Early Occupancy Benefits \\
\hline - Smoother process and turnover \\
- Less disruption to occupancy and operations during turnover \\
- $\quad$ Improved safety \\
- Reduced liability \\
\hline Other \\
\hline - $\quad$ Compliance with LEED or other sustainability rating system \\
- Qualification for rebate, financing or other services \\
- An enabling factor for comprehensive system overhaul \\
\hline
\end{tabular}

Table 3.2 Commissioning benefits that may not persist

\begin{tabular}{|l|}
\hline Easier to Quantify \\
\hline Reduced energy consumption \\
\hline Ensured or improve indoor environment /occupant comfort \\
\hline Ensured adequate indoor air quality \\
\hline Improved water utilization \\
\hline More Difficult to Quantify \\
\hline Repaired or accelerate repair of a problem \\
\hline Avoided premature equipment failure \\
\hline Reduced operations and maintenance costs \\
\hline Increased occupant productivity \\
\hline Improved documentation \\
\hline Increased in-house staff skills, knowledge, awareness \\
\hline Improved operational efficacy \\
\hline Provided sustainable engineering solutions to operational problems \\
\hline $\begin{array}{l}\text { Ensured proper system performance (energy and non-energy } \\
\text { systems) }\end{array}$ \\
\hline
\end{tabular}




\subsubsection{Measures of Benefit Persistence}

The first four items shown in Table 3.2 are commissioning benefits that may be quantified if suitable baselines for comparison are available. The International Performance Measurement and Verification Protocol (IPMVP 2001) is widely used to determine savings in energy and water resulting from either retrofits or operational changes. It provides procedures that may also be applied to new buildings if the impact of commissioning measures implemented can be accurately assessed in a simulation. Comfort has been widely studied, and measures of comfort such as dry bulb temperature and relative humidity can be measured and logged. Likewise, $\mathrm{CO}_{2}$ and other measures of indoor air quality may be measured. It is assumed that new buildings will provide comfort and quality indoor air, so it will be difficult to document commissioning benefits to comfort or indoor air quality in new buildings. However, when commissioning is carried out in an existing building, these changes can be documented with appropriate measurements before and after commissioning. These measurements are most likely to be made if a serious comfort and/or air quality problem provides a significant part of the motivation for commissioning the building.

The remaining items listed in Table 3.2 are much more difficult to document, beyond the documentation of specific commissioning measures that have been implemented and verification that these measures are still in place months or years later. Hence the only further treatment of these benefits within the proposed methodology will be through documentation of specific measures related to these benefits.

Given this context, and based on a review of the existing literature on persistence of commissioning benefits (Frank et al. 2005), the proposed methodology for determining persistence of commissioning benefits will specifically treat the persistence of the energy, water, comfort, and indoor air quality benefits of commissioning in a quantitative manner. It will treat all other benefits through examination of the persistence of specific commissioning measures that have been implemented.

\subsubsection{Persistence of Energy Benefits from Commissioning}

The energy benefits of commissioning will initially be determined using an appropriate methodology from the International Performance Measurement and Verification Protocol (IPMVP 2001). This protocol provides a general approach that compares measured energy use or demand before and after implementation of an energy savings program using the equation:

Energy Savings $=$ Base year Energy Use - Post-Retrofit Energy Use \pm Adjustments

The "Adjustments" term brings energy use in the two time periods to the same set of conditions by adjusting for differences in weather, occupancy, plant throughput, and equipment operations. These adjustments are made routinely for weather changes, or as needed for occupancy changes, scheduling changes, etc.

Four basic options are presented for determining energy savings within the IPMVP. These options are briefly described in Table 3.3. Within the context of this methodology, the only option that is considered appropriate for determining the energy savings from commissioning of a new building is Option $D$, Calibrated Simulation. This permits the calibration of a simulation to the measured consumption of the building following commissioning, followed by simulation of the changes made during commissioning. For existing buildings that are commissioned, energy savings from comprehensive commissioning projects may be evaluated using either Options $C$ or $D$. If the savings from the commissioning process are too small to evaluate in one of these ways or only one or two measures are expected to result in energy savings, then Option B may be appropriate. Option A will rarely be appropriate. The detailed procedures in the protocol are to be used.

Following determination of energy savings in multiple years using the selected procedure, savings from each year in which savings are determined will be further normalized to a common weather year to eliminate bias in the persistence determination from weather differences in the different years. Other adjustments may also be made when warranted by known conditions. 
Table 3.3 The four IPMVP energy savings options

Source: IPMVP 2001

\begin{tabular}{|c|c|c|}
\hline M\&V Option & $\begin{array}{l}\text { How Savings Are } \\
\text { Calculated }\end{array}$ & Typical Applications \\
\hline $\begin{array}{l}\text { A. Partially Measured Retrofit Isolation } \\
\text { Savings are determined by partial field measurement of } \\
\text { the energy use of the system(s) to which an ECM was } \\
\text { applied, separate from the energy use of the rest of the } \\
\text { facility. Measurements may be either short-term or } \\
\text { continuous. } \\
\text { Partial measurement means that some but not all } \\
\text { parameter(s) may be stipulated, if the total impact of } \\
\text { possible stipulation error(s) is not significant to the } \\
\text { resultant savings. Careful review of ECM design and } \\
\text { installation will ensure that stipulated values fairly } \\
\text { represent the probable actual value. Stipulations should } \\
\text { be shown in the M\&V Plan along with analysis of the } \\
\text { significance of the error they may introduce. }\end{array}$ & $\begin{array}{l}\text { Engineering } \\
\text { calculations usingshort } \\
\text { term or continuous } \\
\text { post-retrofit } \\
\text { measurements and } \\
\text { stipulations. }\end{array}$ & $\begin{array}{l}\text { Lighting retrofit where power draw is } \\
\text { measured periodically. Operating hours } \\
\text { of the lights are assumed to be one half } \\
\text { hour per day longer than store open } \\
\text { hours. }\end{array}$ \\
\hline $\begin{array}{l}\text { B. Retrofit Isolation } \\
\text { Savings are determined by field measurement of the } \\
\text { energy use of the systems to which the ECM was } \\
\text { applied, separate from the energy use of the rest of the } \\
\text { facility. Short-term or continuous measurements are } \\
\text { taken throughout the post-retrofit period. }\end{array}$ & $\begin{array}{l}\text { Engineering } \\
\text { calculations usingshort } \\
\text { term or continuous } \\
\text { measurements }\end{array}$ & $\begin{array}{l}\text { Application of controls to vary the load } \\
\text { on a constant speed pump using a variable } \\
\text { speed drive. Electricity use is measured } \\
\text { by a kWhmeter installed on the electrical } \\
\text { supply to the pump motor. In the baseyear } \\
\text { this meter is in place for a week to verify } \\
\text { constant loading. The meter is in place } \\
\text { throughout the post-retrofit period to } \\
\text { track variations in energy use. }\end{array}$ \\
\hline $\begin{array}{l}\text { C. Whole Facility } \\
\text { Savings are determined by measuring energy use at the } \\
\text { whole facility level. Short-term or continuous } \\
\text { measurements are taken throughout the post-retrofit } \\
\text { period. }\end{array}$ & $\begin{array}{l}\text { Analysis of whole } \\
\text { facility utility meter or } \\
\text { sub-meter data using } \\
\text { techniques from simple } \\
\text { comparison to } \\
\text { regression analysis. }\end{array}$ & $\begin{array}{l}\text { Multifaceted energy management } \\
\text { program affecting many systems in a } \\
\text { building. Energy use is measured by the } \\
\text { gas and electric utility meters for a twelve } \\
\text { month baseyear period and throughout } \\
\text { the post-retrofit period. }\end{array}$ \\
\hline $\begin{array}{l}\text { D. Calibrated Simulation } \\
\text { Savings are determined through simulation of the } \\
\text { energy use of components or the whole facility. } \\
\text { Simulation routines must be demonstrated to } \\
\text { adequately model actual energy performance measured } \\
\text { in the facility. This option usually requires } \\
\text { considerable skill in calibrated simulation. }\end{array}$ & $\begin{array}{l}\text { Energy use simulation, } \\
\text { calibrated with hourly } \\
\text { or monthly utility } \\
\text { billing data and/or end- } \\
\text { use metering. }\end{array}$ & $\begin{array}{l}\text { Multifaceted energy management } \\
\text { program affecting many systems in a } \\
\text { building but where no baseyear data are } \\
\text { available. Post-retrofit period energy use } \\
\text { is measured by the gas and electric utility } \\
\text { meters. Baseyear energy use is } \\
\text { determined by simulation using a model } \\
\text { calibrated by the post-retrofit period } \\
\text { utility data. }\end{array}$ \\
\hline
\end{tabular}




\subsubsection{Persistence of Water Savings Benefits from Commissioning}

The IPMVP methodologies for determining water savings are the same as those used to determine energy savings. In these cases, it becomes important to consider precipitation if the building water consumption includes water uses for exterior landscaping.

\subsubsection{Persistence of Commissioning Measures}

In some cases, appropriate metering is not installed or baseline information needed to determine energy savings is not available. In other cases, the measures of interest may not impact energy consumption, but may impact other benefits of commissioning as discussed in the section on "Measures of Benefit Persistence." In these cases, persistence shall be determined by comparing a list of documented commissioning measures that were implemented during the commissioning process with the measures that are subsequently documented as being in place or operational during the time when persistence is being checked.

When used to evaluate measures that impact energy consumption, the most comprehensive systematic listing of measures that may be considered is probably that of Mills et al. (2005). They used a matrix that included the specific commissioning measures in the four categories listed in Table 3.4. These measures were then considered as being applied to deficiencies in the areas or systems shown in Table 3.5.

Table 3.4 Specific commissioning measures

\begin{tabular}{|c|c|}
\hline Design, Installation, Retrofit, Replacement \\
\hline$\bullet$ & Design change \\
\hline$\bullet$ & Installation modifications \\
\hline$\bullet$ & Retrofit/equipment replacement \\
\hline Operations and Control \\
\hline$\bullet \quad$ Implement advanced reset \\
\hline$\bullet$ & Start/stop (environmentally determined) \\
\hline$\bullet$ & Scheduling (occupancy determined) \\
\hline$\bullet$ & Modify setpoint(s) \\
\hline$\bullet$ & Equipment staging \\
\hline$\bullet$ & Modify sequence of operations \\
\hline$\bullet$ & Loop tuning \\
\hline$\bullet$ & Behavior modification/manual changes to operations \\
\hline$\bullet$ & Other \\
\hline Maintenance \\
\hline$\bullet$ & Calibration \\
\hline$\bullet$ & Mechanical fix \\
\hline$\bullet$ & Heat transfer maintenance \\
\hline$\bullet$ & Filtration maintenance \\
\hline$\bullet$ & Other \\
\hline Miscellaneous \\
\hline$\bullet$ & Deficiency unmatched to specific measure \\
\hline
\end{tabular}


Table 3.5 Areas or systems in which measures correct deficiencies

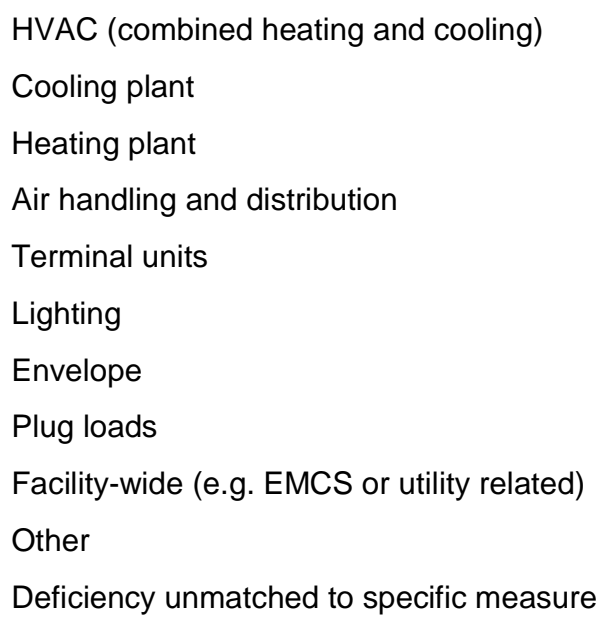

\subsection{Review of Literature on the Persistence of Commissioning Benefits in New and Existing Buildings}

\subsubsection{Introduction}

In recent years the topic of persistence of benefits has gained more interest both for existing building and new building commissioning. Several studies have been performed and published examining both aspects of this topic. This review will summarize the key results of these studies. The categories presented are persistence of commissioning measures in existing buildings, persistence of commissioning measures in new buildings, strategies for improving persistence in new and existing buildings, and related reports. This topic is relatively new, and the only relevant projects identified in the literature to date involve a total of 37 buildings:

- 10 Existing Buildings Commissioned at Texas A\&M University - Turner et al. (2001) and Claridge et al. $(2002,2004)$

- 8 Existing Buildings Commissioned in Sacramento, California - Bourassa et al. (2004)

- 8 Existing Buildings Commissioned in Oregon - Peterson (2005)

- 1 Existing Building Commissioned in Colorado - Selch and Bradford (2005)

- 10 New Buildings Commissioned - Friedman et al. (2002, 2003a, 2003b)

Since the total literature identified consists of published papers and reports from only five projects directly related to persistence, the summaries presented for each project are considerably more detailed than is customary in a literature review. 


\title{
3.2.2 Persistence of Commissioning Measures in Existing Buildings
}

\author{
Texas A\&M: Ten Buildings at Texas A\&M University
}

A study was performed in 2000 to evaluate the persistence of savings in ten buildings on a university campus three years after the buildings participated in existing building commissioning (Turner et al. 2001). The objectives of the study were to determine quantitatively how much savings degradation occurred and the major causes of any observed degradation. The investigation did not focus on the detailed measures implemented in each building but rather on the degree to which the measures implemented in the EBCx process had been maintained, as indicated by examination of energy use data, the EBCx reports, and the control settings in place on the main energy management control system.

The study was conducted in five major parts. First, buildings were selected to be studied. Second, savings calculations were performed based on energy usage data from the different periods needed. Third, field examination and commissioning follow-up was conducted on two buildings in which major savings degradation occurred. Fourth, operational and controls changes that could have contributed to changes in building performance after commissioning were identified. And fifth, calibrated simulations of some of the buildings were performed to verify the effects of the identified changes on energy consumption.

A preliminary group of 20 buildings which had been commissioned in 1996 or 1997 was initially selected. An office review of information on the EBCx measures implemented and available information on operating parameters before and after existing building commissioning was then conducted. Based on this review, the ten buildings with the most complete information concerning the EBCx process and energy consumption data were selected. None of the buildings in this group received capital retrofits during the period of 1996 to 2000. Five buildings were commissioned in 1996 and the other five were finished in 1997. In each of these buildings, commissioning measures were identified by the EBCx provider and then implemented by the provider, after receiving the concurrence of the building owner's representative. Since all ten buildings were located on a university campus, they primarily consisted of classrooms, laboratories, and offices, with one volleyball arena.

The energy usage data for these buildings had been monitored and was obtained beginning with the period shortly before EBCx and ending in 2000 when the study was performed. For comparison purposes, all of the energy data was normalized to a single year of weather data. Because the weather data for the year 1995 most closely approximated average weather conditions for the years studied, it was chosen as the baseline year. Energy use before and after the EBCx process were compared. In this study savings from the EBCx process were determined by using Option $C$ of the International Performance Measurement and Verification Protocol, which determines savings using measured energy use at the whole facility level. This required that baseline models of the consumption be formulated for each major source of energy use in each building. Chilled water and hot water energy consumption were measured for each year, and three-parameter or four-parameter change-point models of cooling and heating consumption were determined as functions of ambient temperature using a modeling program.

The process of calculating the yearly savings required the development of five separate chilled water models and five hot water models for each building, one for each year, including the baseline model. The consumption and savings for each year were then normalized to 1995 weather by using the models for each year's data with the 1995 temperature data to determine the savings for each year. Electricity savings were determined without normalization since the buildings did not have chillers, and electricity consumption is not appreciably affected by ambient temperature.

Follow-up was performed on two buildings with significant savings degradation. This was done primarily through a field investigation of the buildings to determine what changes had occurred that would produce the changes. Equipment performance and Energy Management Control System (EMCS) control settings were examined to evaluate possible causes for degradation. 
Information was then gathered on controls and operational changes that had occurred in the buildings during the period studied. This was done by examining the EBCx reports and interviewing the engineers and maintenance personnel who had responsibility for each building. These interviews provided identifiable reasons for many of the changes in savings seen in the buildings.

In order to quantify the effect of each operational or control change identified, it was decided that the energy usage of the buildings would be modeled using a computer simulation program. The rough simulations would then be calibrated until they provided accurate representations of the actual energy use. These simulations would then demonstrate how much of an effect each control or operational change had on the building energy use.

\section{Texas A\&M: Results}

All ten buildings showed significantly reduced chilled water and hot water energy consumption since EBCX, although the savings generally decreased somewhat with time. Eight buildings had larger HW savings in 1998 than in 1997 as a consequence of hot water loop optimization conducted in 1997 and final EBCx actions. Overall the electricity consumption remained fairly constant, with three buildings showing small increases in consumption (negative savings). The average electricity savings for the ten buildings from 1997 to 2000 were $10.8 \%$. Figure 3.1 and Figure 3.2 show the chilled water and hot water savings trends for the years following the building EBCX.

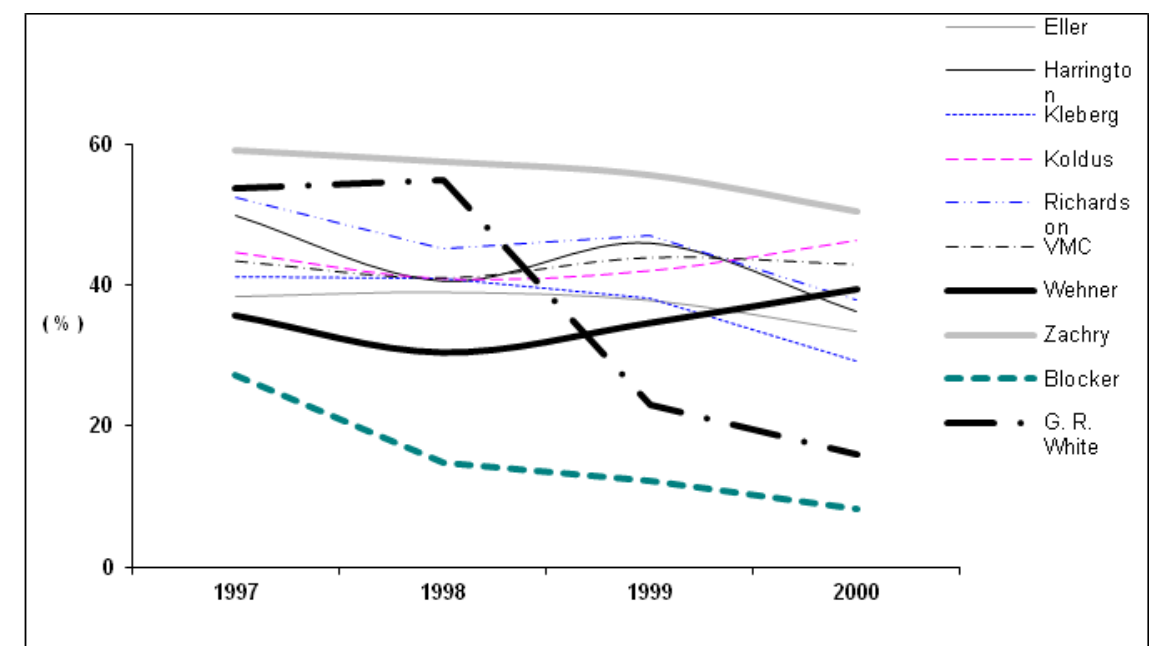

Figure 3.1 Chilled water savings persistence after EBCx.

Overall, chilled water savings for the three years following EBCx averaged $39.3 \%$ of the precommissioning baseline. Eight of the buildings showed good persistence of savings for chilled water (less than $15 \%$ change during the three to four years after EBCx), while the other two displayed significant degradation. The Blocker building had $19 \%$ degradation, and the G. R. White Coliseum had a dramatic savings degradation of $38 \%$.

Hot water consumption was reduced significantly in the years following EBCx, but the savings fluctuated widely from year to year. Savings increased from 1997 to 1998 in most buildings due to optimization in the hot water loop in 1997 and some ongoing EBCx work. The ten buildings averaged hot water savings of $65.0 \%$ after EBCx. 


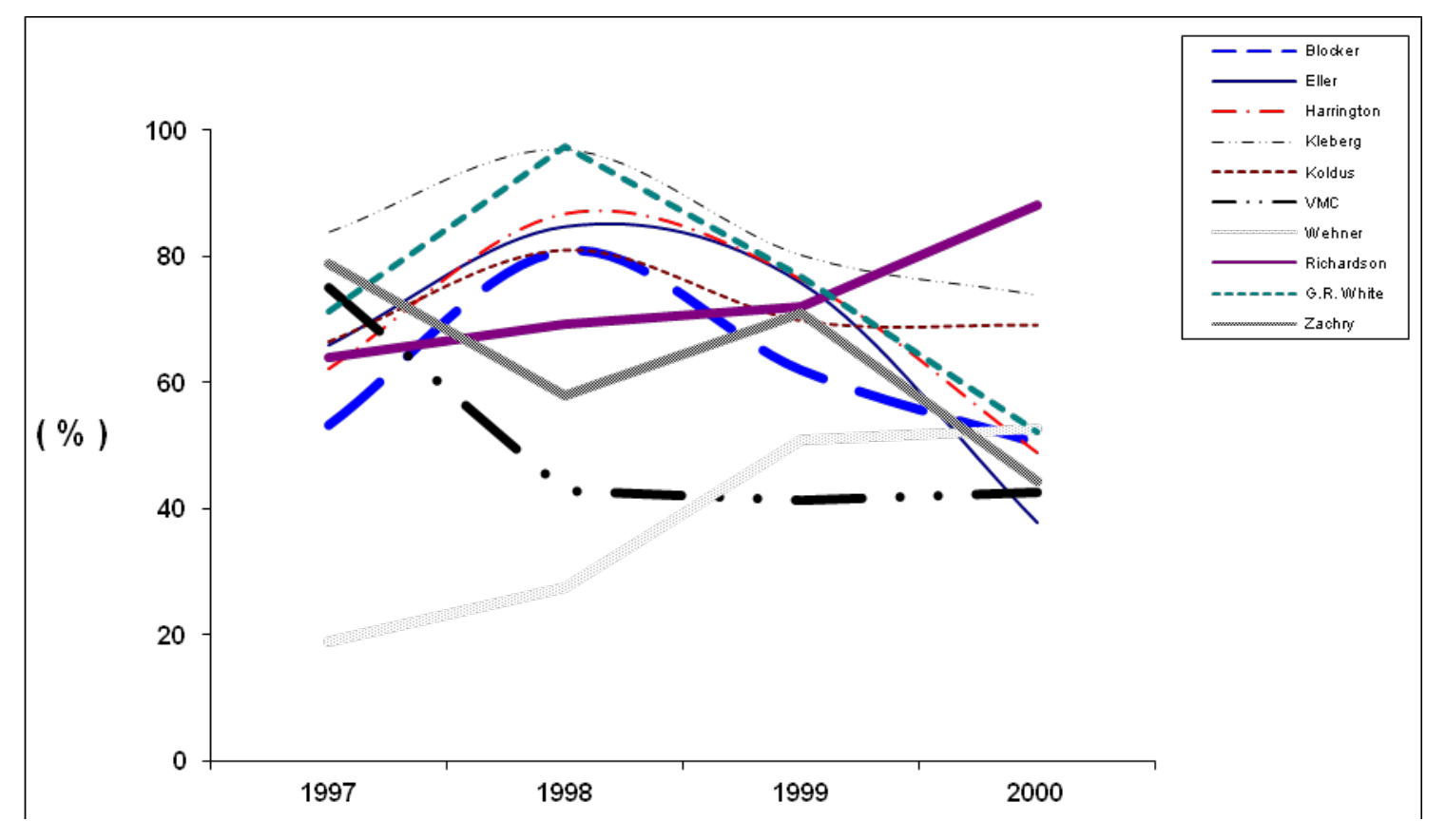

Figure 3.2 Hot water savings persistence after EBCx.

Based on the historic campus energy costs of $\$ 4.42 / \mathrm{GJ}$ (\$4.67/MMBtu) for chilled water, $\$ 4.50 / \mathrm{GJ}$ (\$4.75/MMBtu) for hot water, and $\$ 0.02788 / \mathrm{kWh}$ for electricity, the cumulative savings from EBCx in these ten buildings were $\$ 4439000$ for the period of 1997 to 2000 . Only three buildings had year 2000 savings greater than 1998 savings, and the increase in two of these was approximately $2 \%$ of baseline consumption, which is well within the range of normal year-to-year variation. The savings of the other buildings decreased.

Follow-up investigations of the two buildings with significant savings degradations revealed serious equipment malfunction and controls failure. In the Kleberg building, two chilled water control valves were found to be leaking badly, and combined with a failed electronic to pneumatic switch and high water pressure, caused low discharge temperatures and continuous reheat operation. In addition, failed sensors caused the outside air dampers to remain fully open, and leaking damper actuators in a number of VAV boxes resulted in simultaneous heating and cooling. The G. R. White Coliseum was found to have a controls malfunction resulting in simultaneous heating and cooling, with two of the thirteen air handling units operating in heating mode, while the rest operated in cooling mode. These equipment and controls problems in these two buildings were the primary causes of the savings degradation observed. Because these problems did not result in comfort problems in the buildings, they may have gone undetected had the energy consumption not been monitored and compared with previous data.

The energy management control system settings were evaluated for the buildings to determine why the changes in savings occurred. Three major control settings were examined: cold deck or cooling discharge temperatures, hot deck temperatures, and static pressure settings. The cold deck or cooling coil discharge temperatures were reset during EBCx to save chilled water consumption. It was found that for eight of the ten buildings in 2000 , the temperatures had been lowered and were requiring more cooling. This led to chilled water savings degradation, particularly in the Blocker building. Five of the ten buildings had dual duct systems, and of these five, three of the hot deck temperature set points were at different values in 2000 than they had been upon completion of EBCx. This resulted in more hot water consumption. Static pressure set points affected chilled water, hot water, and electricity consumption. Of the nine buildings with variable air volume systems, only one (Koldus) still had the same static pressure set point in 2000 that it had been set to during EBCX. The other buildings were requiring more static 
pressure, and therefore using more energy. It is worth noting that the Koldus building showed no serious savings degradation of any kind in this study.

Data were gathered from engineers and maintenance personnel to attempt to verify the controls changes and explain them. It was found that the G. R. White Coliseum, which saw significant savings degradation in chilled water and hot water savings, had experienced malfunctions in air handling unit controls that caused simultaneous heating and cooling to occur throughout the year. Almost all of the savings degradation for this building could safely be attributed to these problems. It was also found that the Kleberg building had experienced some significant equipment problems that could explain some of the degradation in savings that occurred. No other building was reported to have experienced equipment problems of the same caliber as these two cases, but controls changes in the other buildings were verified through investigation. With the assembly of this type of information, simulated calibrations could be made for the buildings. Lack of data and other problems such as the one mentioned for the G. R. White Coliseum. G.R. White allowed only five of the ten buildings to be simulated. Three simulations were performed for each of these buildings, one for the pre-commissioning period, one for the year after EBCx, and one for the year 2000. Factors considered in the simulations included control settings changes, operator overrides on the controls, and physical changes in the system such as broken or repaired valves, sensors, etc. Detailed simulations of the control changes in Eller O\&M, Harrington Tower, VMC Addition and Wehner showed that the RMS difference between the changes observed between the post-commissioning periods and year 2000 was only $1.1 \%$, suggesting that the changes in savings for these buildings were almost entirely due to the control changes identified.

Overall, equipment malfunction and changes made in cold deck and hot deck temperature settings following EBCx were the major reasons for changes in chilled water and hot water energy consumption and savings after EBCX.

Table 3.6 is a summary of the money saved in the year 1998 as compared with the money saved in the year 2000 for each of the ten buildings examined. 
Table 3.6 Cost savings calculations for the year 1998 and the Year 2000.

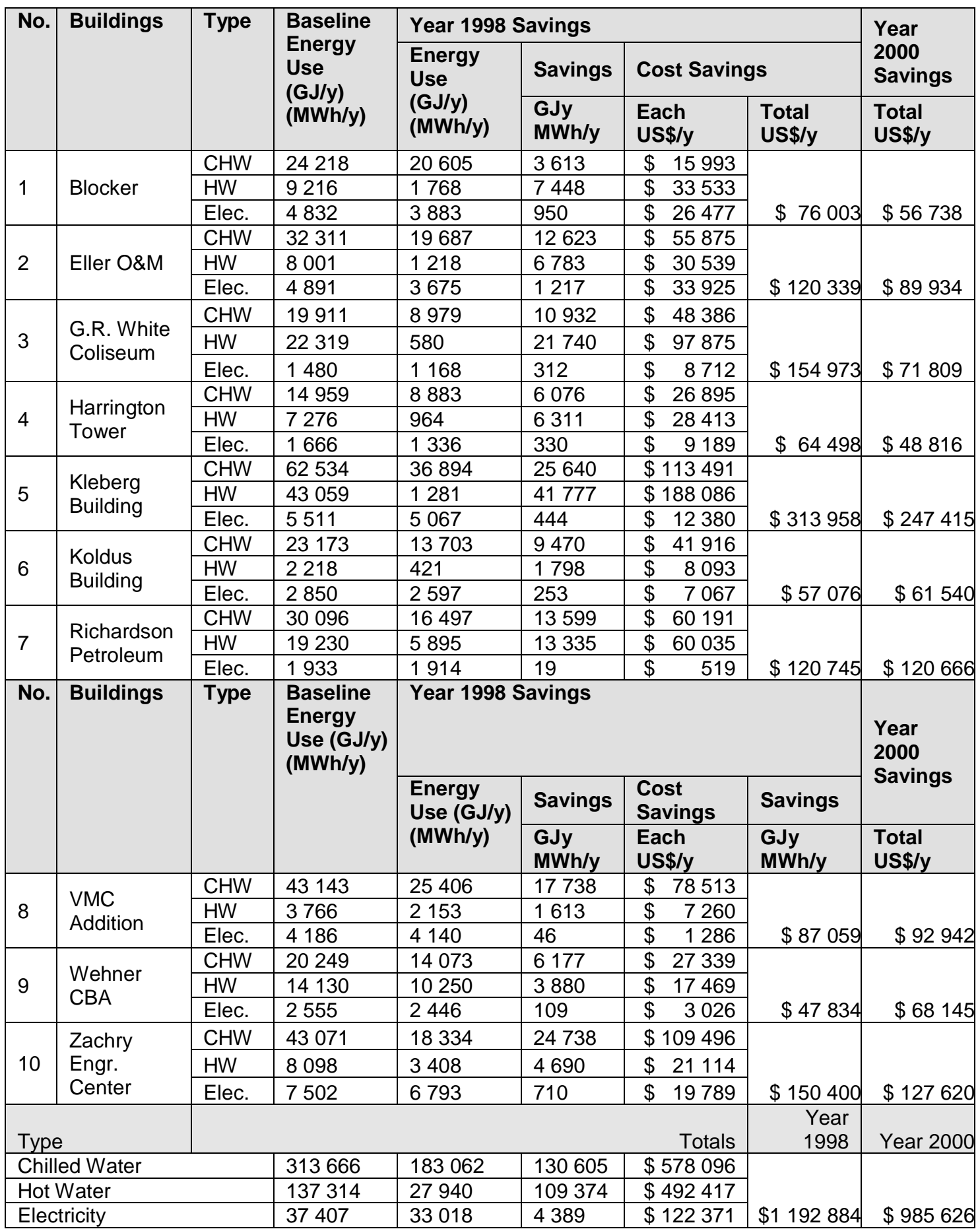

* The baseline energy use data for two buildings were created based on the average savings of the other buildings because they did not have enough data.

**To obtain MMBtu/yr, multiply the number of GJ/yr by 0.9478 . 


\section{Texas A\&M: Conclusions}

Table 3.7 summarizes the savings history of this group of ten buildings. The savings in 1998 following initial retro commissioning corresponded to average energy cost savings of $39 \%$ for the ten buildings. Savings decreased to $32.3 \%$ over the next two years - still a highly significant level of savings.

Table 3.7 Summary of savings history in ten retro-commissioned buildings at Texas A\&M

\begin{tabular}{|l|r|r|r|}
\hline & $\begin{array}{l}\text { Baseline use } \\
\text { (US\$/y) }\end{array}$ & $\begin{array}{l}\text { 1998 Cx savings } \\
\text { (US\$/y) }\end{array}$ & $\begin{array}{l}\text { Persistence of } \\
\text { savings in 2000 } \\
\text { (US\$/y) }\end{array}$ \\
\hline 10 Buildings & $\$ 3049487$ & $\begin{array}{r}\$ 1192000 \\
(39.1 \%)\end{array}$ & $\begin{array}{r}\$ 984516 \\
(32.3 \%)\end{array}$ \\
\hline 8 Buildings & $\$ 2195307$ & $\$ 723376$ & $\begin{array}{r}\$ 666108 \\
(32.3 \%)\end{array}$ \\
\hline 2 Buildings & $\$ 854180$ & $\begin{array}{l}\$ 468624 \\
(55 \%)\end{array}$ & $\begin{array}{r}\$ 314408 \\
(37 \%)\end{array}$ \\
\hline
\end{tabular}

Investigation showed that two of the buildings, G. R. White Coliseum and Kleberg, accounted for 3/4 of the total savings degradation, and both had experienced major equipment and controls malfunctions which were the primary causes of their degradation. Following correction of these problems, savings were restored to earlier levels. In the remaining eight buildings, savings changes were rather small, declining from $32.9 \%$ to $30.3 \%$ in aggregate.

All but one of eight buildings had experienced at least some changes in EMCS control settings. To verify the impact of the EMCS changes on energy consumption, the calibrated simulation process was performed on the four buildings with the most complete data sets. Simulation was conducted for a precommissioning period, a post-commissioning period soon after EBCx and for the year 2000 for each building. It was found that the changes in consumption observed following EBCx in these buildings were consistent with those due to the identified controls changes, with an RMS difference of only $1.1 \%$. Control changes accounted for the savings increase observed in the Wehner Building as well as the decreases observed in the other three buildings. This suggests that the changes in savings these four were almost entirely due to the control changes.

Based on the results of this study of ten buildings, it was concluded that:

- Basic existing building commissioning measures are quite stable,

- Savings should be monitored to determine the need for follow-up, and

- Steps should be taken to inform operators of the impact of planned/implemented control changes.

\section{SMUD: Eight Buildings in SMUD Program in Sacramento}

In 2003, a study was performed by the Lawrence Berkley National Laboratory (LBNL) on eight buildings that had undergone EBCx through the Sacramento Municipal Utility District (SMUD) EBCx program (Bourassa et al. 2004). The objective of the study was to determine the extent to which EBCx measures were implemented, and the magnitude and persistence of energy savings achieved. Another objective was to see if the two primary goals of the SMUD EBCx program had been met: reduced overall annual building energy consumption, and improved energy efficiency awareness and focus in the customer. The eight buildings selected for the study consisted of six office buildings, one laboratory, and one hospital. Four of the buildings participated in EBCx in 1999, and the other four in 2000. In this program, the EBCx provider worked with the building operators to develop the recommended measures. The measures selected for adoption were subsequently implemented by the building staff and/or contractors over a period of up to two years. 


\section{SMUD: Energy Analysis}

The energy savings obtained in the years following EBCx were determined and compared. In order to be able to compare energy savings in the different buildings over the years examined, baseline energy consumption was established for each building based on pre-EBCx energy use. Electricity use data were collected from monthly utility bills for each building. Four buildings also had metered data recorded at 15 minute intervals. Gaps in utility bills were filled from site records or regression analysis.

The energy consumption data were normalized to a common weather year and to a common billing cycle of $30.5 \mathrm{~d}$. The savings were calculated using spreadsheets, based on the normalized data, which allowed for a simpler and more robust statistical comparison. Another set of savings was also calculated, based on the EBCx report predictions. Adjustments were made for a capital retrofit in one of the buildings. The cost of EBCx was also estimated for each of the buildings, based on three categories: SMUD's EBCX costs, the site's EBCx costs, and the EBCx measure implementation costs. Based on the estimated costs and savings, simple payback periods for EBCX at each of the sites were calculated and compared.

The electrical savings observed for each building over the years following EBCx are shown in Fig. 3.3

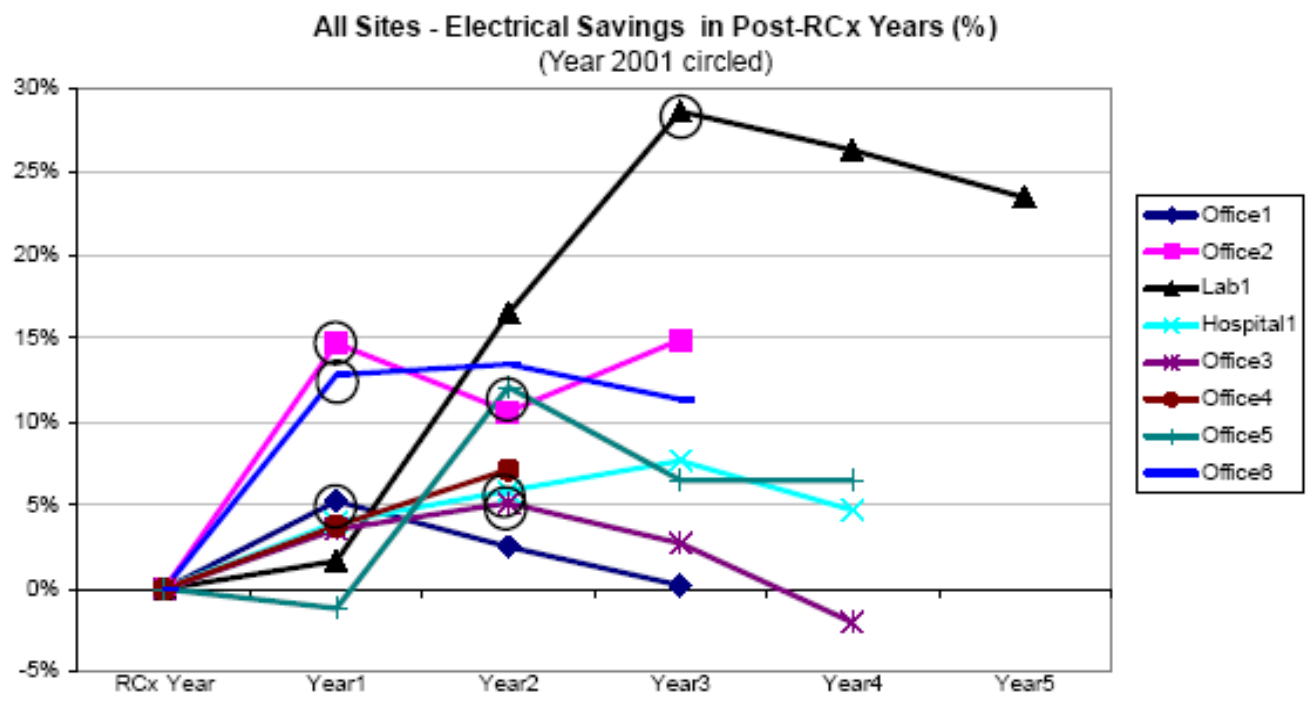

Figure 3.3 Electrical savings following EBCx for each of the buildings.

The aggregate savings for the sites are shown in Fig. 3.4. The buildings are grouped together according to the number of years of data available after EBCx. Note that the "two-year" line includes data for all buildings for the first two years following EBCX, that the "three-year" line includes data for all buildings having three years of data following EBCX, and the "four-year" line includes data for all buildings having four or more years of data following EBCx. Comparison with the data in Fig. 3.3 suggests that the peak in year 3 may be largely due to the one building whose savings peaked in year 3 . 
Aggregate Electricity Savings in Post-RCx Years (MWh/yr)

$\sim$ Sum -8 Sites w/ 2 Years $\Rightarrow \square$ Sum -7 Sites w/ 3 Years $\rightarrow$-Sum -4 Sites w/ 4 Years

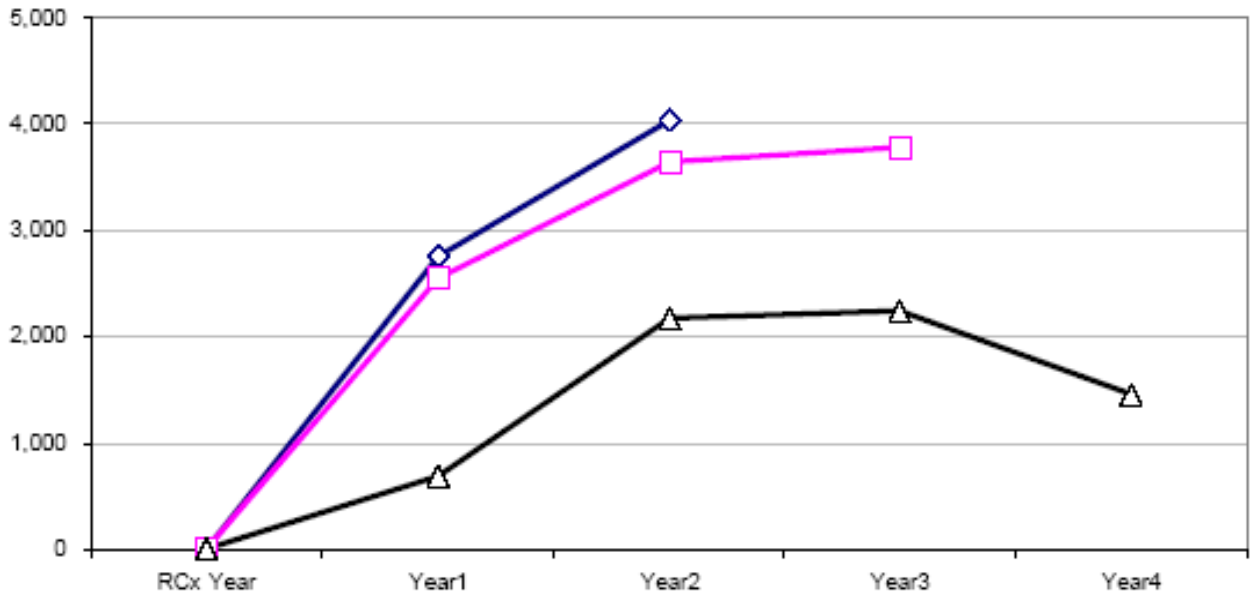

Figure 3.4 Plot of aggregate post-EBCx electricity savings.

These plots demonstrate the observed trend in energy savings for the commissioned buildings. During the first two years the savings generally increased. This was expected because of the length of time needed for the EBCx measures to be implemented. In the third year the savings began to level off, and the fourth year generally showed a declination in the electricity savings. A comparison with the predicted savings estimated in the EBCx reports revealed that on average these reports underestimated the savings by $27.5 \%$.

The average electricity savings for all the sites over all the years was $7.3 \%$ per year. Natural gas usage could only be obtained for four of the buildings. The savings for natural gas were considerably lower, but since Sacramento is dominated by cooling needs, the lower natural gas savings only reduced the average total energy savings in these four buildings to $6.1 \%$ per year.

The payback periods for the EBCx projects all proved to be attractive, with the longest period being 2.3 years. Table 3.8 lists the estimated costs, annual savings, and payback period for each site, as well as a price per square foot of the building. 
Table 3.8 Costs, energy savings, and payback periods for the eight sites studied.

\begin{tabular}{|c|c|c|c|c|c|c|c|c|}
\hline Building & $\begin{array}{l}\text { EBCx } \\
\text { study } \\
\text { costs } \\
\text { (agent } \\
\text { cost } 25 \mathrm{k} \text {, } \\
\text { balance } \\
\text { incurred } \\
\text { by site) }\end{array}$ & $\begin{array}{l}\text { Estimated } \\
\text { measure } \\
\text { implmen- } \\
\text { tation } \\
\text { costs }\end{array}$ & $\begin{array}{l}\text { Predicted } \\
\text { average } \\
\text { annual } \\
\text { savings } \\
\text { (\$) }\end{array}$ & $\begin{array}{l}\text { Post } \\
\text { EBCx } \\
\text { average } \\
\text { annual } \\
\text { savings } \\
\text { (\$) }\end{array}$ & $\begin{array}{l}\text { Predicted } \\
\text { simple } \\
\text { pay-back }\end{array}$ & $\begin{array}{l}\text { Post } \\
\text { EBCx } \\
\text { simple } \\
\text { pay- } \\
\text { back }\end{array}$ & $\begin{array}{l}\text { EBCX } \\
\text { study } \\
\text { costs } \\
\left(\$ / \mathrm{m}^{2}\right)\end{array}$ & $\begin{array}{l}\text { EBCX } \\
\text { study \& } \\
\text { implement. } \\
\text { costs } \\
\left(\$ / \mathrm{m}^{2}\right)\end{array}$ \\
\hline Office 1 & $\$ 28000$ & $\$ 1710$ & $\$ 24500$ & $\$ 13000$ & 1,2 & 2,3 & 2,05 & 2,15 \\
\hline Office 2 & $\$ 26500$ & $\$ 20500$ & $\$ 21900$ & $\$ 27900$ & 2,1 & 1,7 & 0,75 & 1,29 \\
\hline Lab 1 & $\$ 26000$ & $\$ 12370$ & $\$ 64800$ & $\$ 40100$ & 0,6 & 1,0 & 3,01 & 4,41 \\
\hline Hospital & $\$ 28300$ & $\$ 11180$ & $\$ 35200$ & $\$ 30900$ & 1,1 & 1,3 & 1,18 & 1,61 \\
\hline Office 3 & $\$ 25400$ & $\$ 150$ & $\$ 6400$ & $\$ 22400$ & 4,0 & 1,1 & 0,65 & 0,65 \\
\hline Office 4 & $\$ 26817$ & $\$ 8380$ & $\$ 8400$ & $\$ 22600$ & 4,3 & 1,6 & 0,86 & 1,18 \\
\hline Office 5 & $\$ 26817$ & $\$ 4350$ & $\$ 9100$ & $\$ 15800$ & 3,4 & 2,0 & 0,86 & 0,97 \\
\hline Office 6 & $\$ 26700$ & $\$ 3000$ & $\$ 11200$ & $\$ 48600$ & 2,7 & 0,6 & 0,97 & 1,08 \\
\hline $\begin{array}{l}\text { All sites } \\
\text { total }\end{array}$ & $\$ 214533$ & $\$ 61650$ & $\$ 181600$ & $\$ 221200$ & 1,5 & 1,2 & 0,97 & 1,29 \\
\hline
\end{tabular}

${ }^{*}$ To obtain costs in $\$ / \mathrm{ft}^{2}$, multiply the number of $\$ / \mathrm{m}^{2}$ by 0.0929 .

\section{SMUD: Measure Persistence Analysis}

A series of interviews and site visits were used to determine the persistence in the EBCx measures recommended. The eight EBCx reports recommended a total of 81 corrective measures, of which 48 were implemented. Of these 48 , it was found that $81 \%$ had persisted, in that they were still in effect at the time of the study. It was discovered that four of the measures had been abandoned completely, all of which were air distribution component recommendations. Five of the measures had undergone evolution by the building engineers because the original measures had not resolved the problems.

Surveys were given at the sites to determine attitudes regarding the EBCx process, as well as its benefits. All of the sites reported that $\mathrm{EBCx}$ was a worthy process. Four of the sites listed training as the primary non-energy benefit from EBCx. The most cited downside to EBCx was the time intensive nature of the process. All of the sites came out of the EBCx process with ideas on how to retain the commissioning benefits over time, the most common solutions being preventative maintenance plans. All of the sites would undertake EBCx again, but only two had potential internal funding.

\section{SMUD: Conclusions}

Some important EBCx process factors that this study identified were:

- The commissioning authority is most effective when he is both an expert and a teacher.

- Building engineers prefer to evolve the settings on a recommendation that doesn't work, rather than revert to the previous condition.

- $\quad E B C x$ appears to raise energy efficiency awareness.

- $\quad E B C x$ funds are constrained within building management budgets.

The energy analysis results showed: 
- Analyses should not emphasize first-year savings because savings typically take two to three years to fully manifest.

- Energy savings persist to four years or more, although some degradation begins in the third year.

- The EBCx energy savings predictions were reasonably accurate.

- Building managers lack tools for tracking energy performance.

- EBCx cost pay back was shorter than the apparent savings persistence.

- EBCx focused mostly on electricity savings and some natural gas tradeoffs in the savings occurred.

The study suggested several recommendations for the SMUD EBCx program:

- Develop measure implementation tracking agreements, possibly with inspections.

- Explore methods to conduct a three year post-EBCx energy consumption analysis using the billing history.

- Develop simple Performance Tracking Tools for the building operators.

- Develop an extension to the program whereby participants are eligible for new incentives in year 4 to evaluate and update the EBCx as necessary.

On the whole, the SMUD EBCx program's two broad goals were met at the eight sites. Aggregate postEBCx savings were strong, peaking at approximately $4420 \mathrm{MWh}$ and the program helped educate site staff about energy efficiency and the role operations and maintenance plays.

\section{Oregon: Oregon Case Study}

A study performed in Oregon in 2004 examined eight Intel buildings that had been retro-commissioned in 1999 and 2000 (Peterson 2005). The buildings were located on the Intel Jones Farm and Hawthorn Farms campuses. Kaplan Engineering and $\mathrm{PECl}$ performed the $\mathrm{EBCx}$ for these buildings through funding from Portland General Electric (PGE). At the time EBCx occurred, it was estimated that electricity savings of nearly 3.5 million kWh annually would result from the low cost energy efficiency measures (EEMs) proposed. The purpose of this study was to examine the energy usage of the buildings to determine what percentage of the original savings was still being achieved four years later. At the same time, it was desired to determine how many of the EEMs proposed were still being utilized.

Three of the buildings studied were located on the Hawthorn Farms Campus (HF), and were designated $\mathrm{HF} 1,2$, and 3 . The buildings combined for a total of $59457 \mathrm{~m}^{2}\left(640000 \mathrm{ft}^{2}\right)$, and were served by a central chiller and boiler plant. HF1 had Direct Digital Controls (DDC) interfaced with pneumatic actuators, and the other two buildings were upgraded to DDC control in 2000 . The remaining five buildings studied were located on the Jones Farm Campus (JF). They combined for a total of $130063 \mathrm{~m}^{2}$ $\left(1400000 \mathrm{ft}^{2}\right)$, with over 40 major air handling systems served by two central chiller plants and two hot water boiler plants. Most of the spaces on both campuses were served by variable air volume (VAV) systems.

Three reports generated at the time of EBCx were examined to determine what measures had been implemented. The current status of these measures was determined through random sampling, with functional testing or trending being used as appropriate. For HF1, the terminal reheat units were serviced at the time of EBCx to ensure proper damper motion. At the time of this study, random sampling discovered no noticeable damper movement from full cooling to full heating in $60 \%$ of the units. The savings for this measure did not persist, probably due to the aging pneumatic system. For HF 1,2 , and 3 , EBCx had modified outside air intake controls to allow for the economizing cycle to function. At the time of the study, random sampling revealed this measure to still be functioning. For the HF chillers, EBCx had lowered the condenser water set point from $23.9^{\circ} \mathrm{C}\left(75^{\circ} \mathrm{F}\right)$ to $21.1{ }^{\circ} \mathrm{C}\left(70{ }^{\circ} \mathrm{F}\right)$, while raising the chilled water set point from $5.6{ }^{\circ} \mathrm{C}\left(42^{\circ} \mathrm{F}\right)$ to $7.2^{\circ} \mathrm{C}\left(45^{\circ} \mathrm{F}\right)$. This measure was also found to be in operation at the time of this study.

For the JF buildings, air handling units and terminal boxes were scheduled at the time of EBCx to reflect occupancy patterns, scheduling unoccupied hours as 6 PM to 6 AM on weekdays and all day on 
weekends. At the time of this study, JF3 was evaluated, and the control was found to be working fairly well, with only a couple of override issues. Additional savings opportunities for the JF buildings were also identified in this study, including air flow and scheduling opportunities and control overrides that needed adjustment. For the HF chillers, the leaving condenser water set point was lowered as part of the EBCx project.

Overall at the Hawthorn Farms campus the EEMs were found to have been maintained, with the exception of the terminal unit reheat optimization in HF1. Of the original projected savings in the three buildings at Hawthorn Farms, $89 \%$ of the electric savings and $0 \%$ of the natural gas savings were still being achieved at the time of this study. In the five buildings at Jones Farm, the results were more mixed and less quantifiable. The recommended scheduling changes were still programmed at a high level, but it appeared that numerous control overrides at a zone or box level had been made. Some overrides may have been due to changes in space use (such as conversion to a lab), but in many instances conference and training rooms were maintaining occupied modes around the clock. The trending done on some of the variable speed air handlers showed little difference between day and nighttime airflow suggesting that terminal box scheduling was not having an impact on overall airflow.

\section{Oregon: Summary}

Of the eight EBCx projects studied in Oregon in 1999 and 2000 quantitative findings were reported for three buildings and qualitative findings for the other five. For the three buildings on the Hawthorn Farms campus, totaling $60000 \mathrm{~m}^{2}$ in floor area, $89 \%$ of the original electric savings were achieved in 2004 and $0 \%$ of the natural gas savings were achieved in 2004. For the five buildings on the Jones Farm campus with $130000 \mathrm{~m}^{2}$ of floor area, the results were mixed and less quantifiable. It was found that scheduling changes were still programmed at a high level, but numerous control overrides at a zone or box level had been made.

\section{Colorado: Office Building in Colorado}

A study completed in 2005 evaluated the persistence of EBCx savings in a large office building in Colorado (Selch 2005). Of the studies of this kind done to date, this study appears to have chosen the largest window of time over which to look at persistence. The office building was commissioned in 1995, which resulted in verified savings of $14 \%$ in electrical demand, $25 \%$ in electrical use, and $74 \%$ in gas use. In 2003, the building was again commissioned, at which time the status of the energy conservation measures implemented in the initial commissioning effort was evaluated.

The computation of savings was done in two ways. The overall energy use of the building for each year was obtained from utility bills. These data were then normalized to account for factors such as weather differences, changing occupancy patterns in the building, and added construction in the building. In this way the yearly energy use could be accurately compared to the baseline, pre-commissioned energy use. The other savings calculation method was an individual measure evaluation. Specific measures that impacted individual HVAC system components were examined. To perform the calculations, Options B \& $C$ of the International Performance Measurement and Verification Protocol (IPMVP 2001) were employed, Option B being used for individual measure evaluation, and Option C for whole building usage comparison.

Table 3.9 summarizes the results of the individual measures evaluation. Using the same baseline, the savings achieved from the 1996 commissioning effort (20\%) are compared with savings achieved in $2003(17 \%)$. It was supposed that the persistence of savings was represented by the difference in achieved savings between the two commissioning efforts. Therefore, , the 2003 savings was calculated as a percentage of the original 1996 savings (i.e., $(1,330,000 / 1,600,000) \star 100)$ to represent the persistence of savings (83 \%).

As noted in Table 3.9, it was calculated that $83 \%$ of the electrical use savings had persisted, while $86 \%$ of the electrical demand savings had persisted. The results of the whole building energy use comparison appear in Figure 3.5 and Figure 3.6. The left chart in each figure represents the raw values, while the right chart displays adjusted, normalized values. 
Table 3.9 Electric savings persistence summary

\begin{tabular}{|c|c|c|c|}
\hline & Baseline use & 1996 savings & 2003 savings \\
\hline Electricity & $(80,000,000$ kWh $)$ & $\begin{array}{l}20 \% \\
(1,600,000 \mathrm{kWh})\end{array}$ & $\begin{array}{l}83 \% \text { persistence } \\
\text { (17\% savings) } \\
(1,330,000 \mathrm{kWh})\end{array}$ \\
\hline Demand & $(1564 \mathrm{~kW})$ & $\begin{array}{l}14 \% \\
(219 \mathrm{~kW})\end{array}$ & $\begin{array}{l}86 \% \text { persistence } \\
12 \% \text { savings } \\
(188 \mathrm{~kW})\end{array}$ \\
\hline Gas & - & $74 \%$ & Complete persistence \\
\hline
\end{tabular}
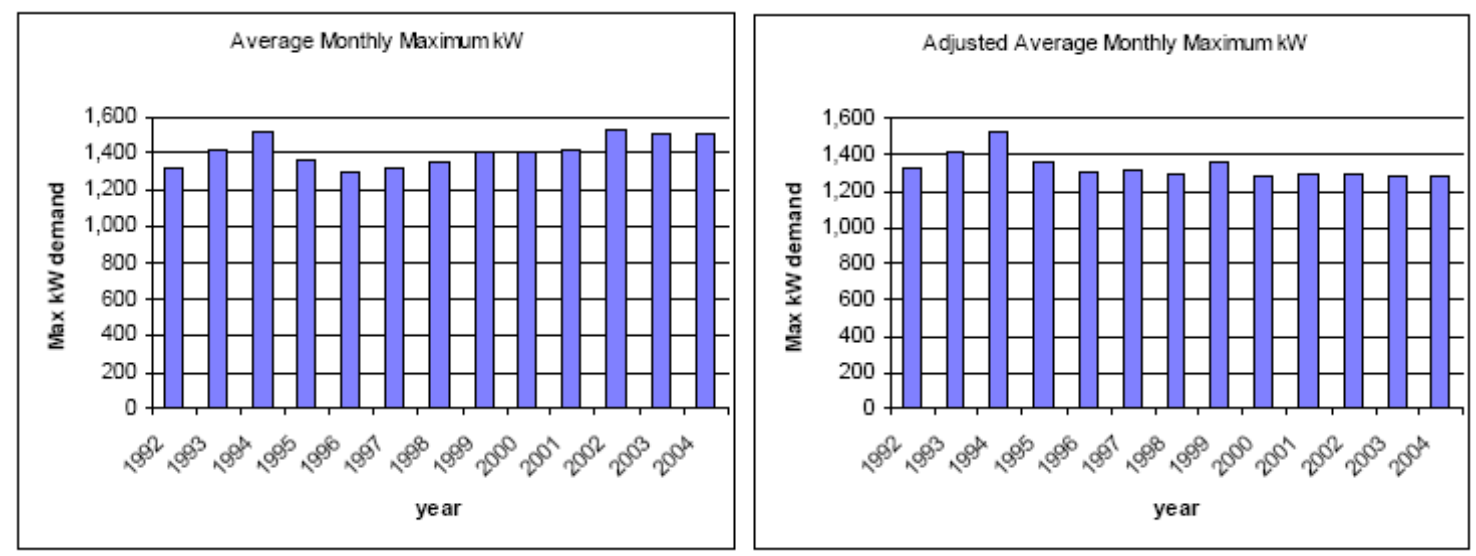

Figure 3.5 Annual electrical demand, raw and adjusted.
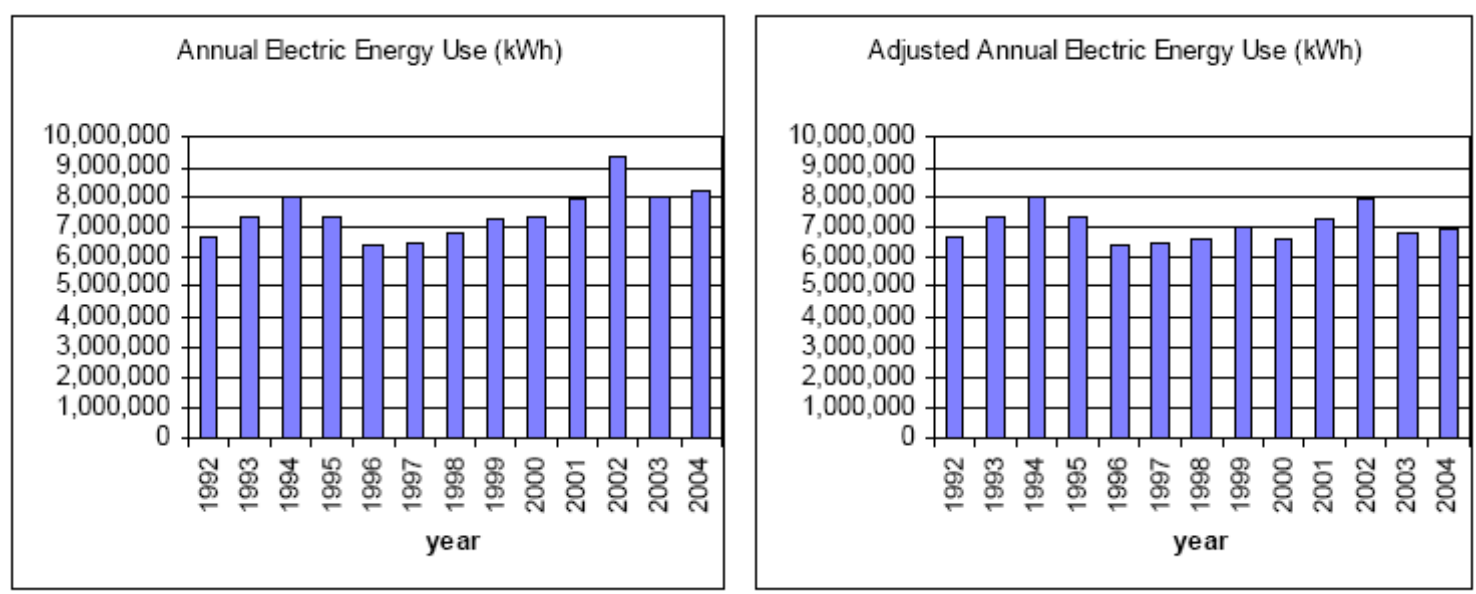

Figure 3.6 Annual electrical use, raw and adjusted.

The annual demand and consumption values that were adjusted to account for changing conditions indicated that the savings achieved from EBCx had largely persisted. This was concluded with greater confidence due to the corroboration of the independent measure analysis. 
The study reported that a large majority of the energy savings measures implemented in the original commissioning effort had persisted, as had their resultant energy savings. This was in spite of changing conditions in the building, including a complete change in operation staff. It was concluded that ECMs of this nature can persist for at least eight years even with limited support from operators and staff. However, it was noted that continued, on-going support to the building staff as part of the original commissioning effort probably would have resulted in complete persistence of the savings achieved.

\subsubsection{Persistence of Commissioning Measures in New Buildings}

\section{PECI PIER Study}

In the summer of 2002, a study was completed that had begun in the fall of 2001 under a California Energy Commission Public Interest Energy Research (PIER) project (Friedman et al. 2003). The purpose of the study was to examine ten buildings that were commissioned at building start-up in order to address the persistence of benefits from the commissioning process. This study drew qualitative conclusions about the persistence of new building commissioning, focusing on three issues: how well the benefits of commissioning persisted, the reasons for declining performance, and the methods that can be used to improve the persistence of benefits achieved through commissioning. A quantitative assessment of persistence by measure ("this measure has an expected persistence of X years") was outside the scope of this project, since a large number of buildings would have been required to determine the figures for each measure.

To evaluate the persistence of commissioning benefits on new buildings, the buildings first had to be selected. To qualify for the study, the facility needed to have been commissioned as a new building or major retrofit between two and eight years prior to the study. Due to the difficulty in finding such buildings with adequate commissioning documentation in California, five buildings were selected in the Pacific Northwest, and five more in California. It was not feasible to limit the study to buildings that followed the full commissioning process, from pre-design through final acceptance and post-occupancy, as described in ASHRAE Guideline 1 (ASHRAE 1996). The most completely commissioned and documented buildings were sought, but these typically did not include design-phase commissioning.

For each building, three to eight items were identified that were documented to have been fixed during commissioning. The changes and repairs made during commissioning generally fell into three categories: hardware, control system, and documentation improvements. Due to the focus on energy savings measures in the study, the hardware and control system changes with the greatest energy implications were of highest interest, as well as measures dealing with comfort and reliability. The amount of documentation available for each measure was also a driving force in measure selection. It was necessary to only evaluate those measures that had actually been implemented and documented. Routine maintenance issues or measures deemed static once corrected (such as equipment disconnected from the power supply) were not looked at. With the limited amount of time and funding for the study, it was necessary to focus on measures whose current status could easily be compared to the as-commissioned status and which would affect energy consumption. Because of the bias in selecting these measures, and the underestimation of savings persistence due to the limited number of measures considered, the results of the study were presented qualitatively.

For purposes of the study, it was decided that if the measure resulted in better performance than the precommissioning condition, then the measure was said to have persisted, even if it had been adapted to meet real operating conditions of the building. In some cases the persistence of a measure was somewhat subjective.

The people with the most knowledge about the control system at each site were interviewed. Some sites were identified for site visits, and for the others a second interview was conducted to discuss the current status of the commissioning measures. Six of the buildings were visited, during which the persistence of the selected commissioning measures was investigated, and the work environment and resources available to the operations staff were evaluated. 


\section{PECI PIER - Results}

It was found that the process of finding qualified buildings for the study in California was difficult. Qualified buildings were located more easily in Oregon, most likely because of the longer history of new building commissioning in the Pacific Northwest. California had numerous existing buildings involved in EBCx projects, but new buildings having undergone commissioning at least two years earlier were sparse. For many of the commissioned buildings considered for the study, commissioning reports had not been written, so the information that could have been used by operations personnel to more efficiently operate the building essentially was lost. Often times in lieu of a report, the commissioning activities would simply be placed on a "punch list" for maintenance personnel to work on, who, when they had completed them usually did not document the changes. In other buildings the reports had been written, but were not readily available to the operations staff, having been filed away in storage and not easily accessible. In many cases where documentation did exist, it was not clear when or if the commissioning measures had been implemented, as they were noted as "recommendations" or "pending." These issues led to the conclusion that the term "commissioning" had been applied to a variety of different activities, including troubleshooting items and checklists, indicating a lack of consistency in the way the term was being applied.

Table 3.10 summarizes the commissioning measures studied and their level of persistence. A light gray square indicates that the measure persisted, while a black square indicates that the measure did not persist. A square split in half horizontally indicates that more than one measure was investigated in the category. 
Table 3.10 Persistence of equipment and controls fixed during commissioning.

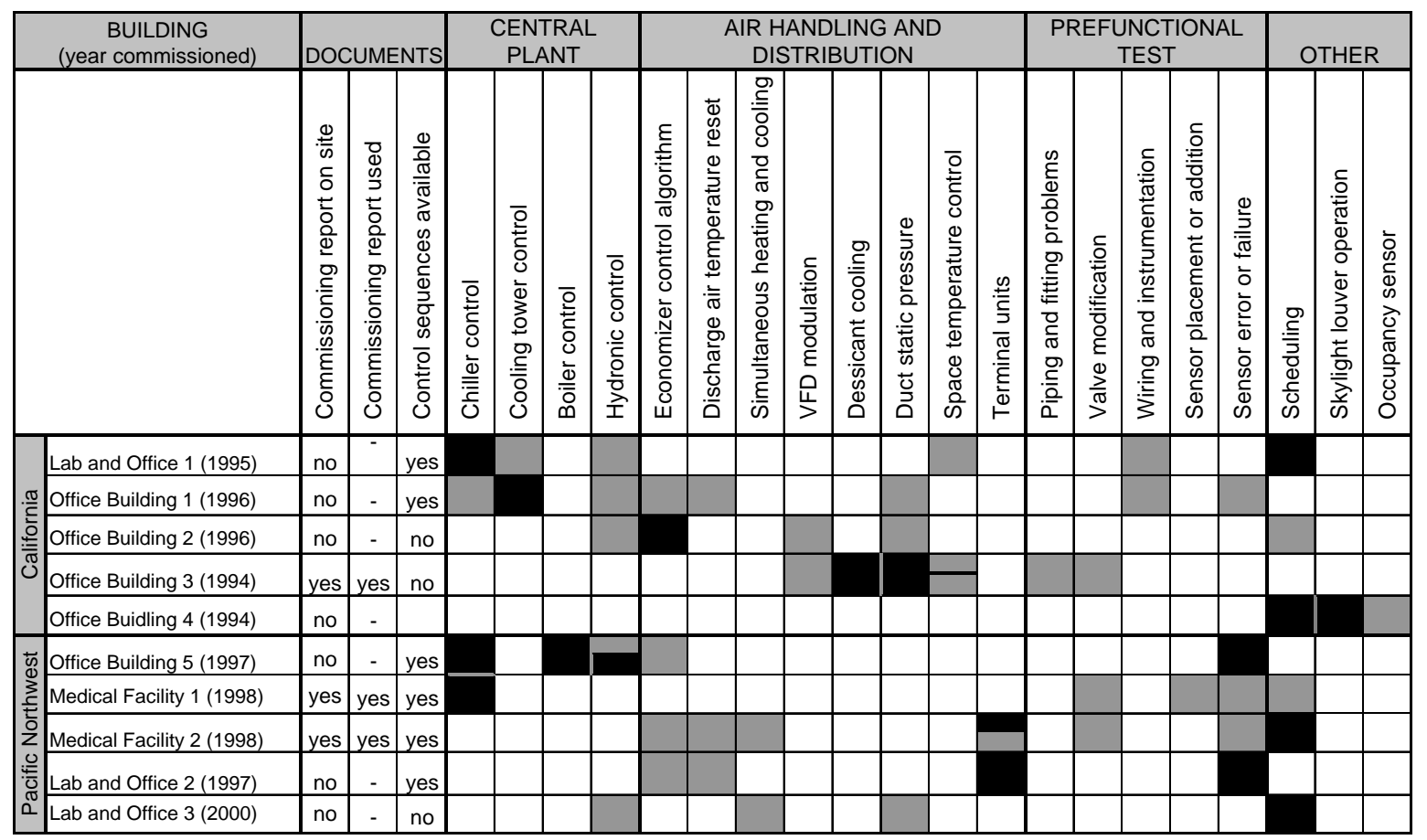

Key to shading:

\begin{tabular}{|l|l|}
\hline & Black cell: Measure did not persist \\
\hline & Grey cell: Measure persisted \\
\hline & Split cells indicate multiple measures \\
\hline
\end{tabular}

Across the ten buildings studied, patterns about the types of commissioning fixes that persisted emerged. For the 56 commissioning fixes selected, well over half of the measures persisted. It was not surprising that hardware fixes, such as moving a sensor or adding a valve, persisted. Furthermore, when control algorithm changes were reprogrammed, these fixes often persisted, especially when comfort was not compromised. Many design phase fixes may have persisted in a similar way, but these were not able to be studied since only one building was commissioned in the design phase.

The types of measures that tended not to persist were the control strategies that could easily be changed, such as occupancy schedules, reset schedules, and chiller staging. Four out of six occupancy schedules did not persist. Chiller control strategies did not persist in three out of four cases, most likely due to the complex nature of control in chilled water systems. The study of sensor issues was limited to major sensor problems that were corrected during commissioning, such as sensor failure or excessively faulty readings. With this selection bias applied, two out of five sensor repairs did not persist.

Among the commissioning measures implemented, a few cases involved technologies that were new or different from normal practice. Due to lack of documentation, these measures were not included in this study, but it was observed during the investigation that these measures generally did not persist. This was attributed to a lack of operator training for the technologies.

\section{PECI PIER - Discussion}

The study suggested three possible reasons for lack of persistence among some measures. The first was limited operator support and high operator turnover rates. Operators often did not receive the 
training necessary or they did not have sufficient time or guidance for assessing energy use, and the training given new operators who came in after the commissioning was usually inadequate. The second reason involved poor information transfer from the commissioning process. For nearly every case studied, the commissioning report was either difficult to locate, or was not even located on site, which reduced the ability of building operators to review commissioning measures implemented. The third reason for lack of persistence was a lack of systems to help track performance. Operators spent most of their time responding to complaints and troubleshooting problems, leaving little time to focus on assessing system efficiency. Aside from this, lack of information and knowledge impeded the efficiency assessment by building operators.

The persistence of commissioning benefits was found to be highly dependent on the working environment for building engineers and maintenance staff. A working environment that was supportive of persistence included adequate operator training, dedicated operations staff with the time to study and optimize building operation, and an administrative focus on building performance and energy costs. Trained operators were found to be knowledgeable about how the systems should run and, with adequate time and motivation to study the system operation, these operators evaluated and improved building performance. In five buildings, operators participated in the commissioning process and came away with a good understanding of their systems. In addition, good system documentation in the form of a system manual served as a troubleshooting resource for operators at two buildings. It was noted that administrative staff can help enable a supportive working environment by placing high priority on energy efficient systems and operator training. Only a few of the buildings studied seemed to operate in this environment, and the measures investigated at these facilities had the highest rate of persistence.

Some of the measures simply persisted by default - no maintenance being required to keep them operational. If comfort issues were not a factor, or the measure involved programming buried deep within code, the measures tended to persist.

The study recommended four methods for improving persistence. First, operators should be provided with training and support. Especially with high operator turnover, adequate training is needed for benefits to persist, and a working environment with energy efficiency as a high priority is also beneficial. Second, a complete systems manual should be provided at the end of the commissioning process. This will serve as a reference for building operators, and will allow the systems knowledge gained from the commissioning process to be available over the long term. Third, building performance should be tracked. New building commissioning efforts should help to implement mechanisms for performance tracking, including what information to track, how often to check it, and the magnitude of deviations to address. Fourth, commissioning should begin in the design phase to prevent nagging design problems. Changes made on paper before construction has begun tend to be more cost effective and have higher levels of persistence.

The study concluded with a recommendation that more in-depth, quantitative studies be performed to investigate the life of commissioning measures and carry out cost-benefit analyses for new building commissioning. It was further recommended that a manual of guidelines for improving persistence be developed to give guidance and direction to building operators with regard to energy efficiency.

\subsubsection{Strategies for Improving Persistence in New and Existing Buildings}

As a follow-up to the study of persistence of commissioning benefits for new buildings performed in California and Oregon, and the study of persistence of EBCx benefits done at Texas A\&M (both described previously), a report was issued in July 2003 addressed to building owners, managers, and operators suggesting methods for improving the persistence of commissioning benefits for both new and existing buildings (Mills et al. 2004). The report began by summarizing the key conclusions of both studies, namely that many commissioning benefits tend to persist fairly well, but that significant opportunities still exist for improving overall savings persistence. The report then proposed that an emphasis on certain key elements of energy analysis and efficiency would pave the way for long-term success in building operation and energy use. In particular, seven recommendations were discussed at length: design review, building documentation, operator training, building benchmarking, energy use 
tracking, trend data analysis, and EBCx. A summary of the discussion of each of these topics is presented here.

\section{Design Review}

As much as one-third of major commissioning problems can be traced back to the design phase of the project, and these problems often plague building operators throughout the life of the building. Allowing professional engineers to review the design while it still in the design phase, is a cost-effective way to prevent future problems. Correcting design problems on paper is easier and less costly than attempting to correct them once the building is completed. Some of the issues to be considered in reviewing a design are test port location, equipment accessibility, load calculations and minimum flow settings, control system sequences and point lists, and standard design details. The process of design review should begin as soon as possible to allow opportunity for correction.

\section{Building Documentation}

Good system documentation is not a common practice currently in the construction environment. While it may seem like a costly and time-consuming effort, this documentation is the best way to ensure that the knowledge base obtained during design, construction, and commissioning of the building is preserved, and will aid in maintaining commissioning benefits. The three most vital items to document are the final design intent, the sequences of operation, and the system diagrams. Other important documents include the operator's log, commissioning summary report, general description of facility and systems, as-built documents, detailed description of each system, location of all control sensors and test ports, and capabilities and conventions of the DDC system. The best time for this documentation to occur is during the construction phase of the building. For existing buildings, a good time is during a retrofit or EBCX. The documentation should be compiled into a systems manual that is readily accessible.

\section{Operator Training}

Effective operator training will allow the benefits of building commissioning to persist, and will aid in preventing problems. Training opportunities exist for building operators during the commissioning process, through manufacturers and vendors, in operator certification programs, and using building documentation. It is also essential that new operators be trained sufficiently so that the knowledge gained by the previous operator is not lost. Some suggested training topics include: descriptions of equipment, equipment start-up and shut-down procedures, operation and adjustment of controls, review of system documentation, common troubleshooting problems, maintenance requirements and schedules, health and safety issues, special tools and spare parts inventory, and emergency procedures.

\section{Building Benchmarking}

Benchmarking refers to measuring the energy use of a building relative to other buildings, and provides a way to track energy use over time and compare it with the competition. This will allow building owners and operators to prioritize initiatives and improve energy efficiency. Several tools exist to aid in the benchmarking process. Two of these are the ENERGY STAR ${ }^{\circledR}$ Portfolio Manager, which uses a number of factors to make meaningful comparisons with other buildings under different conditions, and the CalArch Building Energy Reference Tool, which is a quick and simple tool for comparing energy use per square foot.

\section{Energy Use Tracking}

Tracking utility bills or metered data is an effective method for recognizing energy use problems that may not result in comfort problems, and therefore might not be noticed any other way. It is essential for continued energy efficiency and persistence in commissioning benefits. The energy use curves should be compared for different years to look for patterns, anomalies, and peaks and valleys. An Energy Information System (EIS) is a useful tool for automating utility tracking. It saves time, provides immediate feedback, can gather additional data, and can allow access over the Internet. 


\section{Trend Data Analysis}

DDC systems allow points to be trended over time. Knowing how to interpret these trended data is essential for identifying and correcting problems in building energy consumption and performance. The data should be examined regularly to determine if the system and its individual components are functioning as desired. Automated diagnostic tools exist to aid in this process, having automated capabilities in the following categories: data acquisition, archiving and pre-processing, detection, and diagnosis. Two tools available are ENFORMA and PACRAT. PACRAT can be used as an ongoing diagnostic tool.

\section{Re-commissioning ${ }^{14}$}

The process of re-commissioning, especially when it draws on building documentation and previous commissioning activities, is very effective in maintaining commissioning benefits. The time to consider recommissioning largely depends on the effectiveness of operations and maintenance strategies and overall building performance. Commissioning can be performed by an outside commissioning provider when an outsider's view is considered helpful, or it may be done in house. In-house commissioning increases the knowledge level of those participating with regards to building operation. Continuous Commissioning ${ }^{\circledR}$ is an ongoing commissioning process developed by the Energy Systems Laboratory at Texas A\&M University that has the same general goal as EBCX, but focuses strongly on the persistence of commissioning benefits.

The report concluded by reiterating the need to pursue the topics addressed during and after the commissioning process to maintain the benefits of commissioning over the long-term.

\subsubsection{Related Reports}

A report was compiled in 2004 that evaluated the cost effectiveness of commissioning in new and existing buildings (Mills et al. 2004). The largest study of its kind to date, it examined the results of commissioning for 224 buildings across 21 states. Among the existing buildings commissioned, a median payback period for commissioning was reported to be 0.7 years. For new buildings, this value was found to be 4.8 years. Both of these figures excluded non-energy benefits, which would increase the savings experienced.

While persistence of savings was not the primary focus of the study, it was examined briefly since it plays a role in determining overall savings. Figure 3.7 shows the persistence of savings results for 20 of the buildings in the study, with a four year period following commissioning in each building. The savings are indexed by a comparison of the year's consumption to the pre-commissioning baseline consumption. The savings are compared by category: electricity, fuel, chilled water, and steam/hot water.

\footnotetext{
${ }^{14}$ Re-commissioning is a term sometimes applied when EBCx is carried out on a building that was commissioned as part of the construction process. Some organizations use the term EBCx irrespective of whether or not the building was previously commissioned.
} 


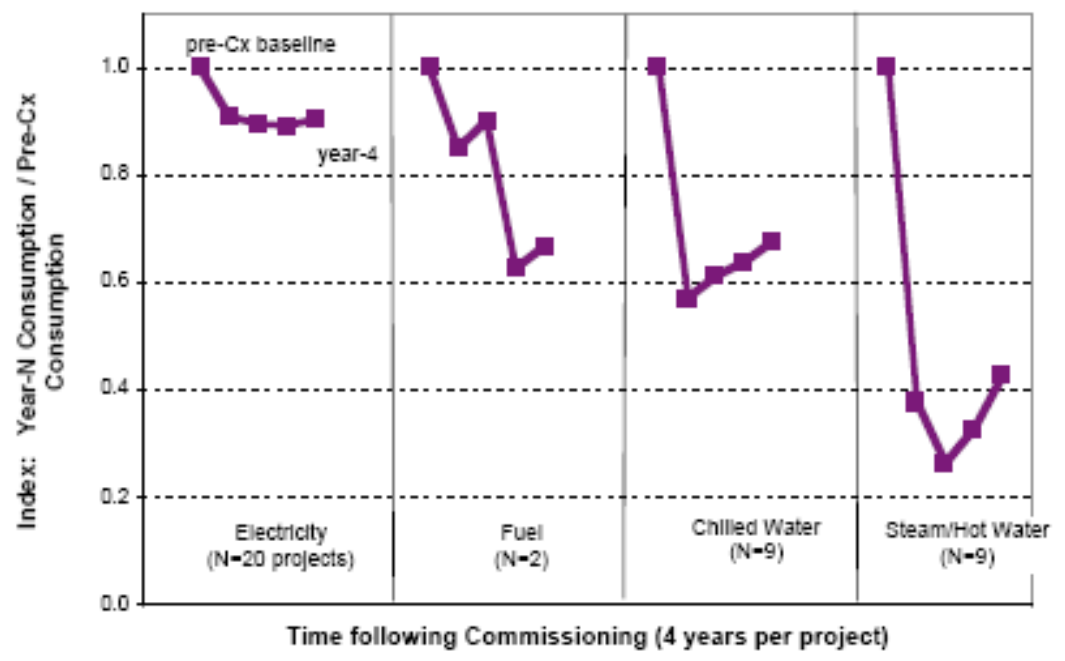

Figure 3.7 Emergence and persistence of energy savings (weather normalized).

An important factor noted in the report was the fact that in many cases of commissioning, the recommended measures were implemented gradually; indicating that the first year after commissioning was not the best year for calculating savings. On the other hand, it was also observed that after time some of the savings began to degrade due to changing building conditions, operations, or aging. As seen in the figure, the maximum value for savings was reached and subsequently savings began to degrade. This effect was smallest for electricity, but much more noticeable for chilled and hot water and steam.

With regard to persistence of commissioning benefits, the report concluded that tracking energy consumption for evidence of significant consumption increases is the most important means of determining the need for follow-up commissioning, and that while controls changes by building operators account for a portion of savings degradation, hidden component failures are perhaps the greatest culprit in persistence problems.

\subsubsection{Methodologies for Determining Persistence of Commissioning Measures and Energy Benefits of Commissioning}

The EBCx studies that provided a quantitative evaluation of the persistence of energy benefits of commissioning, used variations on two different approaches to evaluate the persistence of energy benefits.

The study of ten Texas buildings (Turner et al. 2001) used a variation on Option C of the IPMVP that normalized for weather differences between years by selecting a "normal" year of weather data in the sequence available that most closely met long-term norms. A suitable three-parameter or four-parameter regression model of the baseline year was created along with models of the performance of the building in each year evaluated.

Then the annual consumption for each year was determined by running the appropriate model with the appropriate year of weather data. The study of eight SMUD buildings (Bourassa 2004) used the same methodology, except that they used a long-term average weather year instead of selecting one of the available years of weather data. The Colorado study used a different approach, evaluating savings persistence with IPMVP Option C with baseline adjustments and IPMVP "Option B" was used to determine savings for specific measures in operation. The Oregon study did not specify how savings were evaluated. 
The study of eight buildings in Oregon (Peterson 2005) and the Colorado building (Selch and Bradford 2005) used a different approach. These studies examined each of the measures that had been implemented and determined whether the measures were still in place and functioning. Peterson found that in three of the buildings, she could quantify the savings associated with measures that had been disabled after four years. It was found that numerous measures implemented in the other five buildings were still in place, but there were also numerous overrides and changes that had occurred as well. It was not possible to quantify the degree of persistence in these buildings. Selch and Bradford (2005) found that they were able to quantify the savings associated with measures that had been disabled.

The study of ten new buildings that had been commissioned in Oregon and Washington (Friedman et al. 2003b) used a methodology that quantified the number of measures that were still in place, but it did not seem appropriate to try to quantify the energy savings associated with these measures. The four EBCX studies all discussed the measures found to be still operating and those that had been changed. The Texas study used calibrated simulation to evaluate measures that had been changed. The other studies were not explicit in the methods used to evaluate the impact of measure changes.

\subsubsection{Summary and Conclusions}

The results of studies from five projects related to commissioning, either in new or existing buildings, described represent the extent of research that has been performed with regard to the persistence of commissioning benefits over time.

The savings in the buildings that were retro-commissioned generally showed some degradation with time. In retro-commissioned buildings, savings generally decreased with time, but there is wide variation from building to building. For the buildings where savings persistence was quantified:

- Savings persistence at the time of the study ( 3 years to 8 years after commissioning) ranged from about $50 \%$ to $100 \%$ in all but one or two buildings.

- Average savings at the time of the study were about $75 \%$ of the original savings.

- The most dramatic savings degradation was caused by undetected mechanical or control component failures.

For the new buildings, well over half of the 56 commissioning fixes persisted. Hardware fixes, such as moving a sensor or adding a valve, and control algorithm changes that were reprogrammed generally persisted. Control strategies that could easily be changed, such as occupancy schedules, reset schedules, and chiller staging tended not to persist. It was also found that the extent to which persistence occurs is also related to operator training.

As is evident, the number of buildings studied in all of the papers described here represents a very small portion of commercial buildings that have undergone commissioning or EBCx. More research is needed to:

- Develop a uniform methodology for determining commissioning persistence.

- Determine the persistence of savings from a broader sample of buildings.

- Develop simple tools for tracking performance of commissioning measures.

- Develop practical methods for owners and operators to better maintain commissioning savings. 


\subsection{Influence of Savings Normalization Method on Persistence}

\subsubsection{Introduction}

There are several different existing building commissioning processes including existing building commissioning (EBCX) and Continuous Commissioning ${ }^{\circledR}\left(\mathrm{CC}^{\circledR}\right)$. The purpose of commissioning as detailed by ASHRAE is to ensure proper operation of a building according to the design intent (ASHRAE,1996). Existing building commissioning often involves making retrofits and optimizing building operation to achieve greater energy efficiency and energy savings.

The means used to determine these savings vary in both complexity and ease of performance. The International Performance Measurement and Verification Protocol (IPMVP) defines acceptable approaches for determining energy savings in buildings that have undergone energy conservation measures (ECMs) such as those carried out during commissioning (IPMVP 2002). Under the IPMVP there are four separate savings determination methods, Options A-D. Option A and Option B are not appropriate for determining whole building commissioning savings.

Option C of the IPMVP uses whole building data to develop consumption models such as regression models while Option $D$ uses calibrated simulations to determine building energy consumption. Regression models are a quick way to relate heating and cooling consumption to the outside dry bulb temperature for a specific time period using that period's consumption data. Calibrated simulations require a series of inputs to a simulation tool that are adjusted, or calibrated, until the simulated consumption closely matches the heating and cooling data as a function of the outside dry bulb temperature. Calibrated simulations are valuable because they can identify and verify potential causes for changes in consumption from year to year but are much more time consuming than regression models.

Once an energy consumption model (regression model or calibrated simulation) that determines consumption as a function of outside dry bulb temperature has been obtained for baseline and postcommissioning periods, commissioning savings can be determined by two different weather normalization approaches:

- The standard International Performance Measurement and Verification Protocol (IPMVP) weather normalization approach (IPMVP 2002)

- $\quad$ The Normalized Annual Consumption (NAC) weather normalization approach (Fels 1986).

The standard IPMVP weather normalization approach calculates actual savings as the difference between the post-commissioning energy consumption determined by the pre-commissioning baseline model when using the post-commissioning weather data and the measured energy consumption during the post-commissioning period. In contrast, energy consumption models can be weather-normalized to "normal" or average weather conditions to mitigate the effects of varying weather from year to year. The common term for the annual consumption under the "normal" weather year is Normalized Annual Consumption or NAC (Fels 1986). Under the NAC weather normalization approach, each of the energy consumption models uses the "normal" weather year and savings are determined by the difference in the baseline and post-commissioning consumption.

Since the reported savings from commissioning are essential in telling the success of a commissioned building, it is important to know in some terms how the savings and persistence of savings results of one savings determination procedure compare to the other. In particular, it is useful to know whether use of the NAC weather normalization approach provides less variability in the persistence of commissioning savings than use of the standard IPMVP weather normalization approach when using a set of different weather years. Likewise, it is valuable to identify whether use of Option C of the IPMVP with regression modeling provides less variability in the persistence of commissioning savings than use of Option D of the IPMVP when using a set of different weather years. Persistence of savings refers to the degree to which post-commissioning savings are maintained from year-to-year. Specifically, the persistence of savings is 
the absence of change in savings between the first post-commissioning period and any later subsequent post-commissioning period.

Using the weather normalization approaches and IPMVP savings determination methods, about 30 existing buildings have been analyzed in previous studies to quantify savings persistence and identify reasons for changes in savings from year to year after commissioning has been performed. Similarly, over 100 buildings that have undergone major retrofits have been analyzed to quantify savings persistence.

Additional commissioned and retrofitted buildings have been previously analyzed where savings results are given without persistence results. Further research on additional buildings is important because a larger set of buildings documenting savings persistence can help identify ways to make commissioning savings persist longer and encourage more to take advantage of the benefits of this energy saving process.

The objectives of this chapter are to determine:

- Whether use of the NAC weather normalization approach provides less variability in commissioning savings and the persistence of commissioning savings than use of the standard IPMVP weather normalization approach, and to quantify any difference observed.

- Whether use of Option C of the IPMVP with regression modeling provides less variability in commissioning savings and the persistence of commissioning savings than use of Option D of the IPMVP, and to quantify any difference observed.

\subsubsection{Savings normalization methods evaluated}

Pre- and post-commissioning data were collected from the Civil Engineering/Texas Transportation Institute (CE/TTI) Building on the Texas A\&M University campus. CE/TTI is used to compare the savings variability of the NAC and the standard IPMVP weather normalization approaches, and to compare the savings variability of Option $C$ with regression modeling and Option D of the IPMVP. Only chilled and hot water results are used. Electricity results are not analyzed because electricity consumption is assumed to be mostly constant, independent of outside air temperature for the buildings on the Texas A\&M University chilled and hot water campus loops.

Hourly chilled water and hot water data are used to calculate daily average consumption. For days in which 19 or more of the hours of data exist, the average from those hours is used as the daily average. This number is recommended by the Energy Systems Laboratory (ESL) data analysis group based on their experience. For days in which 18 or fewer hours of data exist, the daily average is determined by linear interpolation from daily averages of prior and subsequent days. Energy balance plots are used to screen the daily consumption data (Shao 2005). Note that this data screening method requires electricity, chilled water, and hot water data. Electricity data is used to screen for poor chilled water and hot water data but is not analyzed for reasons previously mentioned. Data identified as potentially erroneous are discarded. If one or more of the three data streams has poor data quality for a particular day then the other streams of data are discarded since the energy balance data screening method can only indicate good data quality for all or none of the three streams.

Review of the pre-commissioning data for CE/TTI shows very little accuracy or availability. In order to create an accurate pre-commissioning baseline, the commissioning report (Chen et al. 2004) is used to document key building and HVAC system parameters essential for creating a simulation for the precommissioning period by changing inputs of the calibrated simulation from the first post-commissioning period.

\section{IPMVP Savings Methods}

Once consumption data has been screened, Option $\mathrm{C}$ with regression models and Option D of the IPMVP can be used to determine savings. These savings methods use regression models and calibrated simulations to obtain a relationship for energy consumption as a function of the outside air dry bulb 
temperature. Three-parameter change-point (3P CP or PRISM) and four-parameter change-point (4P CP) regression models are used to model cooling and heating consumption. Using AirModel (Liu 1995), calibrated simulations are created that model chilled and hot water consumption.

Data for CE/TTI are separated into pre- and post-commissioning periods. Where possible, consumption data periods are divided into full calendar years. In some cases, however, periods are modified to be either shorter or longer than one calendar year where large periods of data are missing or of poor quality, or when the commissioning process takes place in the middle of a year. Katipamula et al. (1995) concluded that regression modeling of large commercial buildings can be accurate and reliable with at least three to six months of daily data. This data length requirement is met for all models and care is given to ensure that data spans a broad temperature range when less than a year of data is available. This process maximizes the amount of data that can be used for the study. As a result, each building has different pre- and post-commissioning period lengths. Consumption from each model is annualized by using a full weather year's temperature data, making comparison between periods of different lengths possible. A description of the weather data used in conjunction with the weather normalization approaches utilized follows the discussion of Options C and D.

Regression models are created for each of the post-commissioning periods using CE/TTI data. Calibrated simulations are also performed for each of CE/TTI's pre- and post-commissioning periods using AirModel. Since there are insufficient pre-commissioning data available to adequately model building chilled and hot water consumption, the first post-commissioning period consumption is simulated according to building and system characteristics stated in the commissioning report. After calibrating this simulation, the inputs are adjusted to reflect the pre-commissioning operation of the HVAC systems as documented in the commissioning report. In this manner, baseline consumption models are obtained for chilled and hot water. A regression model is also created from the calibrated simulation baseline output for both chilled and hot water to determine savings with Option C of the IPMVP.

\section{Option C with Regression Models}

The regression models used under Option $C$ of the IPMVP to determine consumption in this study use four-parameter change point models. These models find energy consumption expressions as a function of daily average temperature. Chilled and hot water typically employ a three- or four-parameter change point model in commercial buildings.

Equation 1 expresses the functional form of four parameter models.

$E=a+b_{1} *\left(T_{O A}-T_{C P}\right)^{-}+b_{2} *\left(T_{O A}-T_{C P}\right)^{+}$

where $a$ is the energy use at the change point temperature, $T_{c p}$, and $b$ is the slope. $T_{O A}$ is the ambient temperature. The notation ()$^{+-}$indicates that the quantities within the parenthesis should be positive or negative as the sign indicates; otherwise they are set to zero.

\section{Option D}

Option D of the IPMVP uses calibrated simulations to determine energy savings. When using AirModel to simulate building energy consumption, the user must specify two files, the input file and the weather source file. The input file includes specific quantities for the building and system parameters and characteristics such as conditioned floor area, room temperature, cold deck temperature, total and outside air flow settings, and night-time setback schedules. For this study, the weather file includes daily averaged values for dry bulb temperature and dew point temperature, although AirModel has the option of entering hourly values.

After running the AirModel simulation, the simulated output must be calibrated to the measured consumption data. The basis of the simulation inputs for CE/TTI comes mainly from commissioning reports, building blue prints, and trips to the building for assessment. A brief description of the calibration 
process is given here. A more detailed procedure of the simulation calibration process is given by Claridge et al. (2003) and Wei et al. (1998).

The term "calibration signature" (Claridge et al. 2003) is defined as follows:

$$
\text { CalibrationSignature }=\frac{- \text { residual }}{\text { MaxiumumMeasuredEnergy }} \times 100 \%
$$

where

$$
\text { residual }=\text { SimulatedConsumption }- \text { MeasuredConsumption }
$$

The maximum measured energy is the maximum heating or cooling energy use recorded over the temperature range of the particular data file being used. The calibration signature is a normalized plot of the difference between measured energy use and simulated energy use over a specified temperature range. For each temperature, a measured energy use value and a simulated energy value exist. The difference in these values for each point is divided by the maximum measured energy use and multiplied by $100 \%$. These values are then plotted versus temperature.

The calibration signature is now compared to published characteristic signatures of the given HVAC system type in the given climate. A characteristic signature is identical to a calibration signature, except that instead of comparing simulated and measured values, it compares two simulations. One simulation is taken to be the baseline or "measured" value. Then, by varying parameters one by one, signatures can be plotted and compared. Characteristic signatures (Claridge et al. 2003) are defined as:

$$
\text { CharacteristicSignature }=\frac{\text { ChangeInEnergyConsumption }}{\text { MaximumEnergyConsumption }} \times 100 \%
$$

As mentioned, the baseline model is treated as the "measured" case, and maximum energy consumption comes from this model.

Characteristic signatures can be generated for each HVAC system type. The majority of the CE/TTI building's HVAC systems are single-duct variable-air-volume (SDVAV), thus making it most practical to refer to SDVAV characteristic signatures when calibrating simulations. The parameters of major importance for which characteristic signatures should be generated include minimum air flow rate (VAV systems), floor area, preheat temperature, internal gains, outside air flow rate, room temperature, envelope U-value, and economizer.

Two indices used for evaluating the accuracy of a simulation are the "Root Mean Square Error" and the "Mean Bias Error." The Root Mean Square Error (RMSE) is defined as:

$$
R M S E=\sqrt{\frac{\sum_{i=1}^{n} \text { residual }_{i}^{2}}{n-2}}
$$

where $\mathrm{n}$ is the number of total data points. The RMSE is a good measure of the overall magnitude of the errors, but does not give any reflection of bias, since no indication is made as to whether the errors are positive or negative. A good simulation minimizes the RMSE and can achieve $10 \%$ to $20 \%$ CV-RMSE (IPMVP 2002). It is generally difficult to reduce this to smaller than $5 \%$ to10 \% CV-RMSE (Claridge et al. 2003). The Mean Bias Error (MBE) is defined as:

$$
M B E=\frac{\sum_{i=1}^{n} \text { residual }_{i}}{n}
$$


where $\mathrm{n}$ is the number of data points. The MBE is an overall measure of how biased the data is, since positive and negative errors cancel each other out. The MBE should be minimized in calibrating a simulation and should be less than $\pm 20 \%$ of the mean consumption (IPMVP 2002).

Calibration signatures combined with characteristic signatures are used to quickly calibrate a simulation. The calibration signatures for heating and cooling generated for the simulation are compared with the characteristic signatures from the corresponding system and climate type, to see which change of parameter or parameters most closely resembles the calibration signature. Normally one parameter is changed at a time in the correct direction and according to the magnitude needed. For example, if the calibration signature is in the range of $20 \%$ for low temperatures, and a similar characteristic signature shows the same trend, but is in the range of only $5 \%$, the parameter adjustment would need to be significantly greater than what was done to get the characteristic signature in order to increase the magnitude. The adjustment is of course limited by reasonable values.. Once the parameter has been decided on, it is changed and the simulation is run again. The RMSE is calculated again, and calibration signatures are again generated and compared with the characteristic signatures. This process is repeated until the RMSE is minimized, and the calibration signature is flat and settled around zero. At this point, the simulation can be considered to be calibrated to the measured data. In most cases, however, it is difficult to obtain a completely flat calibration signature for both cooling and heating consumption. A well calibrated simulation has a CV-RMSE of $10 \%$ to $20 \%$ (Claridge et al. 2003) and the MBE should be less than $20 \%$ of the mean consumption (IPMVP 2002).

\section{Weather Normalization Approaches}

The energy consumption models are now used to determine savings with two weather normalization approaches-NAC and standard IPMVP. In order to obtain a measure of variability in commissioning savings between the two weather normalization approaches, a set of different weather years is obtained to drive the energy consumption models. A set of different savings results is then obtained with both the NAC and standard IPMVP weather normalization approaches.

The weather year's data representing College Station, TX and used to create a set of savings results for the NAC and standard IPMVP weather normalization approaches were obtained from a few sources, depending on the year. For years 1973 to 2005, hourly weather data from the Easterwood Airport weather station was retrieved from the National Climatic Data Center (NCDC) weather database. For the years 1997 through June of 2004, NCDC data is used in conjunction with weather data from the Energy Systems Laboratory (ESL) database to fill in any missing data points.

As with the energy consumption data, hourly dry bulb and dew point temperature data are used to calculate daily average values. For days in which 19 or more of the hours of data exist, the average from those hours is used as the daily average. For days in which 18 or fewer hours of data exist, the daily average is determined by linear interpolation from daily averages of prior and succeeding days.

Additionally, daily average weather data from all available weather years are averaged to form a longterm average weather year. Each day's data of this long-term average weather year represents the average of all weather years' data for that day. For example, the daily average data for January 21 of the long-term average weather year is the average of all January 21 data from the existing weather years' data.

\section{NAC Weather Normalization Approach}

The NAC weather normalization approach determines savings as the difference between pre- and postcommissioning model consumption during a "normal" weather year. By using the same weather across all pre- and post-commissioning models, the variation in the consumption due to different weather patterns from year to year is minimized. Generally, long-term average weather data is used as the "normal" weather year when using the NAC weather normalization approach. This study, however, uses each of 29 different College Station, Texas weather years obtained from NCDC as the "normal" weather year. Each of these 29 weather years is used with every one of CE/TTI's pre- and post-commissioning energy consumption models (both regression models and calibrated simulations) to obtain 29 sets of 
normalized annual consumption. The savings are then determined in each of the post-commissioning periods for each weather year used.

\section{Standard IPMVP Weather Normalization Approach}

The standard IPMVP weather normalization approach employed to determine actual savings from commissioning activities calculates the difference between post-commissioning energy consumption determined by the baseline model with the post-commissioning period weather and the measured energy consumption taken from the post-commissioning period. In order to annualize the measured energy consumption, the model created from consumption data is used to determine the annual measured energy consumption by using the full weather year's ambient temperature data to drive the model. A more typical procedure in cases where there is missing data in a post-commissioning time period is to use the post-commissioning model to generate any missing data to add to the actual measured data. This approach is not used in this study, however, due to the necessity of using post-commissioning time periods of less or greater than one year in several instances.

Since the standard IPMVP weather normalization approach uses the measured post-commissioning energy consumption to determine savings, there is just one set of savings for each post-commissioning period. In order to form a larger sample size of savings results from the standard IPMVP weather normalization approach to compare to the NAC weather normalization approach, a method is employed that randomly selects a College Station weather year from the NCDC weather years retrieved as the $1^{\text {st }}$ post-commissioning year, another as the $2^{\text {nd }}$ post-commissioning year, yet another as the $3^{\text {rd }}$ postcommissioning year, and so forth. As an example of this methodology, assume that a random run of weather years selected to find savings for the six CE/TTI post-commissioning periods are 1984, 1976, $1999,1998,1993$, and 1974 . The $1^{\text {st }}$ post-commissioning period savings under the standard IPMVP weather normalization approach would be determined by subtracting the "measured" 1st postcommissioning period consumption determined by the period's model normalized to 1984 weather from the consumption of the baseline model normalized to 1984 weather. The $2^{\text {nd }}$ post-commissioning period savings under the standard IPMVP weather normalization approach would be determined by subtracting the "measured" $2^{\text {nd }}$ post-commissioning period consumption determined by the period's model normalized to 1976 weather from the consumption of the baseline model normalized to 1976 weather. The 1999 , 1998,1993 , and 1974 weather years would similarly be used to determine the savings of the $3^{\text {rd }}, 4^{\text {th }}, 5^{\text {th }}$, and $6^{\text {th }}$ post-commissioning periods, respectively. Other sets of random runs of weather years are used to obtain a set of savings results to determine whether the NAC weather normalization approach provides less variability in the persistence of commissioning savings than the standard IPMVP weather normalization approach. The 29 specific sets of random runs are given in Table 3.11. It should be reemphasized that the baseline regression model for CE/TTI used here is created from the synthetic "data" of the baseline calibrated simulation output. 
Table 3.11 Sequence of College Station weather years for 29 different random runs used with both Option D and Option $C$ with regression models in conjunction with the standard IPMVP weather normalization approach.

\begin{tabular}{|l|l|l|l|l|l|l|}
\hline Run & $\mathbf{1 9 9 7}$ & $\mathbf{1 9 9 8}$ & $\begin{array}{l}\mathbf{1 / 1 9 9 9 -} \\
\mathbf{4 / 2 0 0 0}\end{array}$ & $\mathbf{2 0 0 1}$ & $\begin{array}{l}\mathbf{1 / 2 0 0 2 -} \\
\mathbf{1 1 / 2 0 0 2}\end{array}$ & $\begin{array}{l}\mathbf{9 / 2 0 0 3 -} \\
\mathbf{6 / 2 0 0 4}\end{array}$ \\
\hline $\mathbf{1}$ & 1993 & 1993 & 1980 & 1985 & 1984 & 2001 \\
\hline $\mathbf{2}$ & 1984 & 1976 & 1999 & 1998 & 1993 & 1974 \\
\hline $\mathbf{3}$ & 1977 & 1998 & 2001 & 1984 & 1991 & 1999 \\
\hline $\mathbf{4}$ & 1979 & 2005 & 1978 & 2005 & 1978 & 1991 \\
\hline $\mathbf{5}$ & 1992 & 1981 & 2003 & 2005 & 1998 & 1998 \\
\hline $\mathbf{6}$ & 1980 & 1996 & 1975 & 1979 & 1985 & 2004 \\
\hline $\mathbf{7}$ & 1976 & 2000 & 1992 & 1981 & 1990 & 2000 \\
\hline $\mathbf{8}$ & 1990 & 1973 & 1999 & 2004 & 2002 & Avg Yr \\
\hline $\mathbf{9}$ & Avg Yr & Avg Yr & 1996 & 2002 & 1985 & Avg Yr \\
\hline $\mathbf{1 0}$ & 1990 & 1983 & 1997 & 1999 & 1978 & 1990 \\
\hline $\mathbf{1 1}$ & 2000 & 1997 & 1994 & 1977 & 1983 & 1999 \\
\hline $\mathbf{1 2}$ & 2004 & 1993 & 1996 & 1973 & 1984 & 2001 \\
\hline $\mathbf{1 3}$ & 1991 & 1985 & 1990 & 2005 & 1994 & 2003 \\
\hline $\mathbf{1 4}$ & 1991 & 2000 & 2000 & 1984 & 1985 & 2001 \\
\hline $\mathbf{1 5}$ & 1973 & 1998 & 1990 & 1999 & 1997 & 1997 \\
\hline $\mathbf{1 6}$ & 1993 & 1975 & 2003 & 2002 & 1975 & 2004 \\
\hline $\mathbf{1 7}$ & 1974 & 1978 & 2001 & 2000 & 1985 & Avg Yr \\
\hline $\mathbf{1 8}$ & 1975 & 1981 & 1973 & 1997 & 2004 & 1984 \\
\hline $\mathbf{1 9}$ & 1999 & Avg Yr & 1996 & 1999 & 2002 & 2000 \\
\hline $\mathbf{2 0}$ & 2004 & 1973 & 2004 & 1998 & 2002 & 1990 \\
\hline $\mathbf{2 1}$ & Avg Yr & 1985 & 1979 & 1985 & 1996 & 1984 \\
\hline $\mathbf{2 2}$ & 1992 & 1985 & 2002 & 2001 & 1989 & 1992 \\
\hline $\mathbf{2 3}$ & 1994 & 1989 & 1989 & 1976 & 1991 & 1981 \\
\hline $\mathbf{2 4}$ & 1981 & Avg Yr & 1999 & 2001 & 1978 & 2001 \\
\hline $\mathbf{2 5}$ & 2004 & 1990 & 1977 & 1999 & 2000 & 1979 \\
\hline $\mathbf{2 6}$ & 1979 & 1996 & 1980 & 1998 & 1977 & 1978 \\
\hline $\mathbf{2 7}$ & 2004 & 1993 & 1979 & 2003 & 1978 & 2000 \\
\hline $\mathbf{2 8}$ & 1994 & 2000 & 1997 & 1981 & 1999 & 2003 \\
\hline $\mathbf{2 9}$ & 1999 & 1983 & 1973 & 1996 & 1975 & 1996 \\
\hline & & & & & & \\
\hline
\end{tabular}

\section{CE/TTI Regression Models and Calibrated Simulations}

The CE/TTI Building has been commissioned twice. The first commissioning took place between August 1996 and September 1996. The second commissioning took place between December 2002 and August 2003.

Post-commissioning regression models and calibrated simulations are created for time periods where consumption data is available. Post-commissioning time periods are divided into full calendar years when possible. A period of missing hot water data, however, as well as the nine-month second commissioning period make this difficult to follow and consumption data period lengths are altered to lengths both shorter and longer than 12 months. The following is a list of the post-commissioning time periods for which regression models and calibrated simulations are created:

1. 1997

2. 1998

3. January 1,1999 toApril 24,2000

4. April 24, 2001to December 31, 2001

5. January 1, 2002 to November 30,2002

6. September 24, 2003 to June 22, 2004 
Table 3.12 summarizes the goodness-of-fit measures for each time period's calibrated simulation. The 1996 pre-commissioning simulation has no goodness-of-fit measures because it has no measured consumption data to be compared to.

Table 3.12 Goodness-of-fit measures for CE/TTI AirModel calibrated simulations.

\begin{tabular}{|c|c|c|c|c|c|c|c|}
\hline RMSE & $\begin{array}{l}1996 \\
\text { Pre-Cx }\end{array}$ & 1997 & 1998 & $\begin{array}{l}1 / 1999- \\
4 / 2000\end{array}$ & $\begin{array}{l}4 / 2001- \\
12 / 2001\end{array}$ & $\begin{array}{l}1 / 2002- \\
11 / 2002\end{array}$ & $\begin{array}{l}9 / 2003- \\
6 / 2004\end{array}$ \\
\hline $\begin{array}{l}\text { CHW } \\
\text { (MMBtu/day) }\end{array}$ & $\mathrm{n} / \mathrm{a}$ & 4.4687 & 4.6170 & 4.2340 & 4.6359 & 4.4325 & 3.9846 \\
\hline CHW (GJ/day) & $\mathrm{n} / \mathrm{a}$ & 4.7147 & 4.8712 & 4.4671 & 4.8912 & 4.6766 & 4.2040 \\
\hline HW (MMBtu/day) & $\mathrm{n} / \mathrm{a}$ & 2.0499 & 2.3970 & 2.3941 & 2.0091 & 2.7280 & 4.0636 \\
\hline HW (GJ/day) & $\mathrm{n} / \mathrm{a}$ & 2.1628 & 2.5290 & 2.5260 & 2.0097 & 2.8782 & 4.2873 \\
\hline MBE & $\begin{array}{l}1996 \\
\text { Pre-Cx }\end{array}$ & 1997 & 1998 & $\begin{array}{l}1 / 1999- \\
4 / 2000\end{array}$ & $\begin{array}{l}4 / 2001- \\
12 / 2001\end{array}$ & $\begin{array}{l}1 / 2002- \\
11 / 2002\end{array}$ & $\begin{array}{l}\text { 9/2003- } \\
6 / 2004\end{array}$ \\
\hline $\begin{array}{l}\mathrm{CHW} \\
\text { (MMBtu/day) }\end{array}$ & $\mathrm{n} / \mathrm{a}$ & -0.0381 & -0.1636 & 0.4876 & -0.0088 & -0.6075 & -0.1620 \\
\hline CHW (GJ/day) & $\mathrm{n} / \mathrm{a}$ & -0.0402 & -0.0173 & 0.5145 & 0.0093 & -0.6410 & -0.1702 \\
\hline HW (MMBtu/day) & $\mathrm{n} / \mathrm{a}$ & -0.2631 & -0.4496 & -0.0782 & 0.5751 & 0.2108 & 0.9088 \\
\hline HW (GJ/day) & $\mathrm{n} / \mathrm{a}$ & -0.2776 & -0.4743 & -0.0825 & 0.6068 & 0.2224 & 0.9588 \\
\hline CV-MBE & $\begin{array}{l}1996 \\
\text { Pre-Cx }\end{array}$ & 1997 & 1998 & $\begin{array}{l}1 / 1999- \\
4 / 2000\end{array}$ & $\begin{array}{l}4 / 2001- \\
12 / 2001\end{array}$ & $\begin{array}{l}1 / 2002- \\
11 / 2002\end{array}$ & $\begin{array}{l}9 / 2003- \\
6 / 2004\end{array}$ \\
\hline $\mathrm{CHW}$ & $\mathrm{n} / \mathrm{a}$ & $-0.09 \%$ & $-0.35 \%$ & $1.23 \%$ & $-0.02 \%$ & $-1.32 \%$ & $-0.49 \%$ \\
\hline $\mathrm{HW}$ & $\mathrm{n} / \mathrm{a}$ & $-2.96 \%$ & $-6.13 \%$ & $-1.05 \%$ & $8.45 \%$ & $2.12 \%$ & $9.52 \%$ \\
\hline CV-RMSE & $\begin{array}{l}1996 \\
\text { Pre-Cx }\end{array}$ & 1997 & 1998 & $\begin{array}{l}1 / 1999- \\
4 / 2000\end{array}$ & $\begin{array}{l}\text { 4/2001- } \\
12 / 2001\end{array}$ & $\begin{array}{l}1 / 2002- \\
11 / 2002\end{array}$ & $\begin{array}{l}9 / 2003- \\
6 / 2004\end{array}$ \\
\hline $\mathrm{CHW}$ & $\mathrm{n} / \mathrm{a}$ & $10.04 \%$ & $9.78 \%$ & $10.67 \%$ & $9.65 \%$ & $9.66 \%$ & $12.10 \%$ \\
\hline HW & $\mathrm{n} / \mathrm{a}$ & $23.03 \%$ & $32.66 \%$ & $32.02 \%$ & $29.51 \%$ & $27.42 \%$ & $42.56 \%$ \\
\hline
\end{tabular}

All of the baseline and post-commissioning chilled and hot water models are four parameter change point models (4P CP). Regression model goodness-of-fit measures are found in Table 3.13.

Table 3.13 Goodness-of-fit measures for CE/TTI regression models.

\begin{tabular}{|c|c|c|c|c|c|c|c|}
\hline $\mathrm{CHW}$ & $\begin{array}{l}1996 \\
\text { Pre- } \\
\text { Cx }\end{array}$ & 1997 & 1998 & $\begin{array}{l}\text { 1/1999- } \\
4 / 2000\end{array}$ & 2001 & $\begin{array}{l}1 / 2002- \\
11 / 2002\end{array}$ & $\begin{array}{l}9 / 2003 \\
6 / 2004\end{array}$ \\
\hline MBE (MMBtu/day) & $\mathrm{n} / \mathrm{a}$ & -0.0002 & -0.0002 & 0.0000 & 0.0938 & 0.0001 & -0.0692 \\
\hline MBE (GJ/day) & $\mathrm{n} / \mathrm{a}$ & -0.0002 & -0.0002 & 0.0000 & 0.0889 & 0.0000 & -0.0656 \\
\hline RMSE (MMBtu/day) & $\mathrm{n} / \mathrm{a}$ & 4.9755 & 5.2263 & 5.0009 & 4.7574 & 4.7104 & 4.1297 \\
\hline RMSE (GJ/day) & $\mathrm{n} / \mathrm{a}$ & 4.7158 & 4.9536 & 4.7399 & 4.5091 & 4.4646 & 3.9141 \\
\hline CV-RMSE & $\mathrm{n} / \mathrm{a}$ & $11.17 \%$ & $11.07 \%$ & $12.61 \%$ & $9.90 \%$ & $10.27 \%$ & $12.54 \%$ \\
\hline HW & $\begin{array}{l}1996 \\
\text { Pre- } \\
\text { Cx }\end{array}$ & 1997 & 1998 & $\begin{array}{l}1 / 1999- \\
4 / 2000\end{array}$ & 2001 & $\begin{array}{l}1 / 2002- \\
11 / 2002\end{array}$ & $\begin{array}{l}9 / 2003- \\
6 / 2004\end{array}$ \\
\hline MBE (MMBtu/day) & $\mathrm{n} / \mathrm{a}$ & 0.0005 & -0.0003 & 0.0000 & 0.0063 & 0.0000 & -0.2100 \\
\hline MBE (GJ/day) & $\mathrm{n} / \mathrm{a}$ & 0.0005 & -0.0003 & 0.0000 & 0.0060 & 0.0000 & -0.1990 \\
\hline RMSE (MMBtu/day) & $\mathrm{n} / \mathrm{a}$ & 1.7554 & 2.4857 & 2.0631 & 1.5637 & 2.2109 & 3.4344 \\
\hline RMSE (GJ/day) & $\mathrm{n} / \mathrm{a}$ & 1.6638 & 2.3560 & 1.9554 & 1.4821 & 2.0955 & 3.2552 \\
\hline CV-RMSE & $\mathrm{n} / \mathrm{a}$ & $19.72 \%$ & $33.87 \%$ & $27.60 \%$ & $22.97 \%$ & $22.22 \%$ & $35.97 \%$ \\
\hline
\end{tabular}


It is interesting to note that the goodness-of-fit measures results of the calibrated simulations and regression models in Table 3.12 and Table 3.13 show that the calibrated simulations generally have a smaller RMSE and CV-RMSE than the regression models for chilled water. The results for hot water, however, show the opposite occurs-regression models generally have lower RMSE and CV-RMSE values than calibrated simulations. The significance of this result, however, is difficult to ascertain because AirModel links the chilled water and hot water consumption together while chilled water and hot water regression models are created independent of each other.

\section{Results}

The chilled water and hot water consumption, savings, percent savings, and change in percent savings are listed in Table 3.14. These values are determined with Option C of the IPMVP using the regression models and the NAC weather normalization approach. The long-term average College Station weather year is used as the "normal" weather year.

Table 3.14 CE/TTI chilled water and hot water consumption, savings, percent savings, and change in percent savings using the NAC weather normalization approach and Option $C$ with regression models.

\begin{tabular}{|c|c|c|c|c|c|c|c|}
\hline Year/Period & $\begin{array}{l}1996 \\
\text { Pre-Cx }\end{array}$ & 1997 & 1998 & \begin{tabular}{|l|}
$1 / 1999-$ \\
$4 / 2000$ \\
\end{tabular} & 2001 & $\begin{array}{l}1 / 2002- \\
11 / 2002\end{array}$ & $\begin{array}{l}9 / 2003- \\
6 / 2004\end{array}$ \\
\hline \multicolumn{8}{|l|}{ Values in MMBtu/yr } \\
\hline CHW Use & 17356 & 16491 & 15849 & 14890 & 14767 & 15822 & 13256 \\
\hline CHW Savings & Baseline & 864 & 1507 & 2466 & 2589 & 1534 & 4100 \\
\hline CHW \% Savings & Baseline & $5.0 \%$ & $8.7 \%$ & $14.2 \%$ & $14.9 \%$ & $8.8 \%$ & $23.6 \%$ \\
\hline CHW Change in \% Savings & $\mathrm{n} / \mathrm{a}$ & $\mathrm{n} / \mathrm{a}$ & $3.7 \%$ & $5.5 \%$ & $0.7 \%$ & $-6.1 \%$ & $14.8 \%$ \\
\hline HW Use & 3625 & 2804 & 2770 & 2553 & 3127 & 3828 & 2923 \\
\hline HW Savings & Baseline & 821 & 856 & 1072 & 498 & -203 & 702 \\
\hline HW \% Savings & Baseline & $22.7 \%$ & $23.6 \%$ & $29.6 \%$ & $13.7 \%$ & $-5.6 \%$ & $19.4 \%$ \\
\hline HW Change in \% Savings & $\mathrm{n} / \mathrm{a}$ & $\mathrm{n} / \mathrm{a}$ & $0.9 \%$ & $6.0 \%$ & $-15.9 \%$ & $-19.3 \%$ & $24.9 \%$ \\
\hline \multicolumn{8}{|l|}{ Values in GJ/yr } \\
\hline CHW Use & 16450 & 15630 & 15022 & 14113 & 13996 & 14996 & 12564 \\
\hline CHW Savings & Baseline & 819 & 1428 & 2337 & 2453 & 1454 & 3886 \\
\hline CHW \% Savings & Baseline & $5.0 \%$ & $8.7 \%$ & $14.2 \%$ & $14.9 \%$ & $8.8 \%$ & $23.6 \%$ \\
\hline $\mathrm{CHW}$ Change in \% Savings & $\mathrm{n} / \mathrm{a}$ & $\mathrm{n} / \mathrm{a}$ & $3.7 \%$ & $5.5 \%$ & $0.7 \%$ & $-6.1 \%$ & $14.8 \%$ \\
\hline HW Use & 3436 & 2658 & 2625 & 2420 & 2964 & 3628 & 2770 \\
\hline HW Savings & Baseline & 778 & 811 & 1016 & 472 & -192 & 665 \\
\hline
\end{tabular}

Table 3.14 shows favorable savings results for chilled water and hot water. The chilled water and hot water each experience savings increases from the first to second and from the second to third postcommissioning periods. Overall, aggregate site savings decline sharply between the 2001 and 1/02$11 / 02$ periods, dropping from $14.6 \%$ to $7.1 \%$. Hot water savings show an especially sharp drop between these two periods, dropping from $13.7 \%$ to $-5.6 \%$. The second commissioning of the building, performed after the 1/02-11/02 period, appears to be worthwhile, as the hot water and aggregate site savings increase to $19.4 \%$ and $15.6 \%$, respectively, based on the 1996 pre-commissioning baseline. While only the first year of post-commissioning data is available for the second building commissioning, the aggregate site savings return to a level similar to the peak achieved before the $2^{\text {nd }}$ commissioning occurred. Over six post-commissioning periods, CE/TTI averages $12.5 \%$ chilled water savings, $17.2 \%$ hot water savings, $7.9 \%$ electricity savings, and $11.4 \%$ aggregate site savings. 


\section{SAVINGS AND VARIABILITY OF SAVINGS FROM DIFFERENT SAVINGS METHODOLOGIES RESULTS}

\section{Option D MBE Adjustment}

Each of the calibrated simulations has an associated mean bias error (MBE) that if left unadjusted may significantly affect the post-commissioning savings depending on the magnitude of the MBE and its sign (positive or negative). The regression models created have essentially no MBE and consequently are not adjusted. In order to avoid biased savings and persistence results, adjustments are made to each of the annual consumption values determined by the calibrated simulations to offset the MBE of the calibrated simulation. Table 3.15 shows the MBE of the calibrated simulations from the pre-commissioning period and each of the post-commissioning periods. The annual adjustment given to each period's consumption determined with the calibrated simulations is also shown. The annual adjustment represents the opposite (positive or negative) of the MBE expressed as a daily value multiplied by 365 (days/yr).

Table 3.15 Calibrated simulation MBE and corresponding annual consumption adjustment for chilled and hot water.

\begin{tabular}{|c|c|c|c|c|c|c|c|}
\hline Year/Period & $\begin{array}{l}1996 \\
\text { Pre-Cx }\end{array}$ & 1997 & 1998 & $\begin{array}{l}1 / 1999- \\
4 / 2000\end{array}$ & 2001 & $\begin{array}{l}1 / 2002- \\
11 / 2002 \\
\end{array}$ & $\begin{array}{l}\text { 9/2003- } \\
6 / 2004 \\
\end{array}$ \\
\hline \multicolumn{8}{|l|}{ Values in MMBtu } \\
\hline CHW MBE (MMBtu/day) & -0.0381 & -0.0381 & -0.1636 & 0.4876 & -0.0088 & -0.6075 & -0.1620 \\
\hline $\begin{array}{l}\text { Annual CHW Adjustment } \\
\text { (MMBtu/yr) }\end{array}$ & 13.90 & 13.90 & 59.70 & -177.96 & 3.23 & 221.75 & 59.14 \\
\hline HW MBE (MMBtu/day) & -0.2631 & -0.2631 & -0.4496 & -0.0782 & 0.5751 & 0.2108 & 0.9088 \\
\hline $\begin{array}{l}\text { Annual HW Adjustment } \\
\text { (MMBtu/yr) }\end{array}$ & 96.031 & 96.031 & 164.1 & 28.53543 & -209.925 & -76.9577 & -331.702 \\
\hline \multicolumn{8}{|l|}{ Values in GJ } \\
\hline CHW MBE (GJ/day) & -0.0361 & -0.0361 & -0.1551 & 0.4622 & -0.0083 & -0.5758 & -0.1535 \\
\hline Annual CHW Adjustment (GJ/yr) & 13.17 & 13.17 & 56.58 & -168.67 & 3.06 & 210.18 & 56.05 \\
\hline HW MBE (GJ/day) & -0.2494 & -0.2494 & -0.4261 & -0.0742 & 0.5451 & 0.1998 & 0.8614 \\
\hline Annual HW Adjustment (GJ/yr) & 91.019 & 91.019 & 155.5 & 27.04626 & -198.970 & -72.9415 & -314.392 \\
\hline
\end{tabular}

\section{NAC Versus Standard IPMVP Weather Normalization Approach}

The percent savings results from the NAC weather normalization approach generally show good agreement with the percent savings results from the standard IPMVP weather normalization approach. Chilled water consumption and savings results are shown for both the NAC and standard IPMVP weather normalization approaches in Table 3.16 with Option $\mathrm{C}$ using regression models and Table 3.17 with Option D (MBE adjusted). The NAC weather normalization approach in these tables uses the long-term average College Station weather year. The differences in percent savings between the two weather normalization approaches shown in the tables for each post-commissioning period vary but there are only two post-commissioning periods where the difference is greater than $1 \%$ and one post-commissioning period where the difference is greater than $2 \%$. However, some of these differences are relatively large compared to the percent savings of these post-commissioning periods. For example, the average 1997 percent savings between the two weather normalization approaches using Option D (MBE adjusted) are $4.34 \%$ (see Table 3.16). The difference in savings, $0.58 \%$, represents $13.4 \%$ of the average savings. In other words, while percent savings differences shown in Table 3.16 and Table 3.17 may seem small, a small difference may be significant if the overall savings is not that large. The chilled water percent savings differences between the NAC and standard IPMVP weather normalization approaches using Option D (MBE adjusted) average $0.78 \%$ over all post-commissioning periods while the differences using Option $\mathrm{C}$ with regression models average $0.64 \%$. 
Table 3.16 Chilled water consumption and savings results using Option D (MBE adjusted) of IPMVP to compare NAC and standard IPMVP weather normalization approaches. The long-term average weather year is used for the NAC weather normalization approach.

\begin{tabular}{|c|c|c|c|c|c|c|c|c|}
\hline & Year/Period & $\begin{array}{l}1996 \\
\text { Pre-Cx }\end{array}$ & 1997 & 1998 & $\begin{array}{l}1 / 1999- \\
4 / 2000\end{array}$ & 2001 & $\begin{array}{l}1 / 2002- \\
11 / 2002\end{array}$ & $\begin{array}{l}\text { 9/2003- } \\
6 / 2004\end{array}$ \\
\hline \multicolumn{9}{|c|}{ NAC Weather Normalization Approach } \\
\hline \multirow{5}{*}{$\begin{array}{l}\text { Normalized to } \\
\text { Long-Term } \\
\text { Avg Weather }\end{array}$} & CHW Use (MMBtu/yr) & 16800 & 16024 & 15409 & 14745 & 14469 & 15639 & 13069 \\
\hline & CHW Use (GJ/yr) & 15923 & 15188 & 14605 & 13976 & 13714 & 14823 & 12387 \\
\hline & CHW Savings (MMBtu/yr) & Baseline & 777 & 1392 & 2056 & 2331 & 1161 & 3732 \\
\hline & CHW Savings (GJ/yr) & Baseline & 736 & 1319 & 1949 & 2209 & 1100 & 3537 \\
\hline & CHW \% Savings & Baseline & $4.62 \%$ & $8.28 \%$ & $12.24 \%$ & $13.87 \%$ & $6.91 \%$ & $22.21 \%$ \\
\hline \multicolumn{9}{|c|}{ Standard IPMVP Weather Normalization Approach } \\
\hline \multirow{2}{*}{$\begin{array}{l}\text { Baseline } \\
\text { Consumption } \\
\text { with Post-Cx } \\
\text { Weather }\end{array}$} & CHW Use (MMBtu/yr) & 18874 & 17017 & 18610 & 17571 & 17839 & 17685 & 17983 \\
\hline & CHW Use (GJ/yr) & 17889 & 16129 & 17639 & 16654 & 16908 & 16762 & 17045 \\
\hline \multirow{5}{*}{$\begin{array}{l}\text { Post-Cx } \\
\text { Consumption } \\
\text { with Own } \\
\text { Period's } \\
\text { Weather }\end{array}$} & CHW Use (MMBtu/yr) & 18874 & 16253 & 17066 & 15685 & 15305 & 16164 & 13819 \\
\hline & CHW Use (GJ/yr) & 17889 & 15405 & 16175 & 14866 & 14506 & 15320 & 13098 \\
\hline & CHW Savings (MMBtu/yr) & Baseline & 764 & 1544 & 1886 & 2534 & 1522 & 4164 \\
\hline & CHW Savings (GJ/yr) & Baseline & 724 & 1463 & 1788 & 2402 & 1443 & 3947 \\
\hline & CHW \% Savings & Baseline & $4.05 \%$ & $8.18 \%$ & $9.99 \%$ & $13.43 \%$ & $8.06 \%$ & $22.06 \%$ \\
\hline & $\begin{array}{l}\text { CHW \% Savings } \\
\text { Difference }\end{array}$ & Baseline & $0.58 \%$ & $0.10 \%$ & $2.24 \%$ & $0.45 \%$ & $1.15 \%$ & $0.15 \%$ \\
\hline
\end{tabular}


Table 3.17 Chilled water consumption and savings results using Option C of IPMVP with regression models to compare NAC and standard IPMVP weather normalization approaches. The long-term average weather year is used for the NAC weather normalization approach.

\begin{tabular}{|c|c|c|c|c|c|c|c|c|}
\hline & Year/Period & $\begin{array}{l}1996 \\
\text { Pre- } \\
\text { Cx }\end{array}$ & 1997 & 1998 & $\begin{array}{l}\text { 1/1999- } \\
4 / 2000\end{array}$ & 2001 & $\begin{array}{l}1 / 2002- \\
11 / 2002\end{array}$ & $\begin{array}{l}9 / 2003- \\
6 / 2004\end{array}$ \\
\hline \multicolumn{9}{|c|}{ NAC Weather Normalization Approach } \\
\hline \multirow{5}{*}{$\begin{array}{l}\text { Normalized to Long- } \\
\text { Term Average } \\
\text { Weather }\end{array}$} & $\begin{array}{l}\text { CHW Use } \\
\text { (MMBtu/yr) }\end{array}$ & 17356 & 16491 & 15849 & 14890 & 14767 & 15822 & 13256 \\
\hline & $\begin{array}{l}\text { CHW Use } \\
\text { (GJ/yr) }\end{array}$ & 16450 & 15630 & 15022 & 14113 & 13996 & 14996 & 12564 \\
\hline & $\begin{array}{l}\text { CHW Savings } \\
\text { (MMBtu/yr) }\end{array}$ & $\begin{array}{l}\text { Base- } \\
\text { line }\end{array}$ & 864 & 1507 & 2466 & 2589 & 1534 & 4100 \\
\hline & $\begin{array}{l}\text { CHW Savings } \\
(\mathrm{GJ} / \mathrm{yr})\end{array}$ & $\begin{array}{l}\text { Base- } \\
\text { line }\end{array}$ & 819 & 1428 & 2337 & 2454 & 1454 & 3886 \\
\hline & CHW \% Savings & $\begin{array}{l}\text { Base- } \\
\text { line }\end{array}$ & $\begin{array}{l}4.98 \\
\%\end{array}$ & $\begin{array}{l}8.68 \\
\%\end{array}$ & $14.21 \%$ & $\begin{array}{l}14.92 \\
\%\end{array}$ & $8.84 \%$ & $23.62 \%$ \\
\hline \multicolumn{9}{|c|}{ Standard IPMVP Weather Normalization Approach } \\
\hline \multirow{2}{*}{$\begin{array}{l}\text { Baseline } \\
\text { Consumption with } \\
\text { Post-Cx. Weather }\end{array}$} & $\begin{array}{l}\text { CHW Use } \\
\text { (MMBtu/yr) }\end{array}$ & 18860 & 17142 & 18840 & 18034 & 18058 & 17841 & 18094 \\
\hline & $\begin{array}{l}\text { CHW Use } \\
(\mathrm{GJ} / \mathrm{yr})\end{array}$ & 17876 & 16247 & 17857 & 17093 & 17116 & 16910 & 17150 \\
\hline \multirow{5}{*}{$\begin{array}{l}\text { Post-Cx } \\
\text { Consumption with } \\
\text { Own Period's } \\
\text { Weather }\end{array}$} & $\begin{array}{l}\text { CHW Use } \\
\text { (MMBtu/yr) }\end{array}$ & 18860 & 16253 & 17059 & 15685 & 15298 & 16125 & 13734 \\
\hline & $\begin{array}{l}\text { CHW Use } \\
\text { (GJ/yr) }\end{array}$ & 17876 & 15405 & 16169 & 14866 & 14500 & 15283 & 13017 \\
\hline & $\begin{array}{l}\text { CHW Savings } \\
\text { (MMBtu/yr) }\end{array}$ & $\begin{array}{l}\text { Base- } \\
\text { line }\end{array}$ & 889 & 1780 & 2349 & 2760 & 1716 & 4360 \\
\hline & $\begin{array}{l}\text { CHW Savings } \\
(\mathrm{GJ} / \mathrm{yr})\end{array}$ & $\begin{array}{l}\text { Base- } \\
\text { line }\end{array}$ & 843 & 1687 & 2226 & 2616 & 1626 & 4132 \\
\hline & CHW \% Savings & $\begin{array}{l}\text { Base- } \\
\text { line }\end{array}$ & $\begin{array}{l}4.71 \\
\%\end{array}$ & $\begin{array}{l}9.44 \\
\%\end{array}$ & $12.45 \%$ & $\begin{array}{l}14.64 \\
\%\end{array}$ & $9.10 \%$ & $23.12 \%$ \\
\hline & $\begin{array}{l}\text { CHW \% Savings } \\
\text { Difference }\end{array}$ & $\begin{array}{l}\text { Base- } \\
\text { line }\end{array}$ & $\begin{array}{l}0.27 \\
\%\end{array}$ & $\begin{array}{l}0.76 \\
\%\end{array}$ & $1.76 \%$ & $\begin{array}{l}0.28 \\
\%\end{array}$ & $0.26 \%$ & $0.50 \%$ \\
\hline
\end{tabular}

While the results in Tables 3.16 and 3.17 do not show any striking differences in savings between the NAC and standard IPMVP weather normalization approaches, they do not show which approach has less variability. Figure 3.8 compares chilled water plus hot water percent savings quartiles of the NAC and standard IPMVP weather normalization approaches side by side when using the 29 different College Station weather years and random runs. Option D (MBE adjusted) of the IPMVP is used for both weather normalization approaches in Fig. 3.9. The minimum, median and maximum values are shown. Figure 3.8 is significant in that it shows an appreciably smaller variability in savings for the NAC weather normalization approach than the standard IPMVP approach for several of the post-commissioning time periods. It shows that depending on the weather years used for the standard IPMVP weather normalization approach, there may be considerably less persistence in savings over time than there would be if the NAC weather normalization approach is used. 


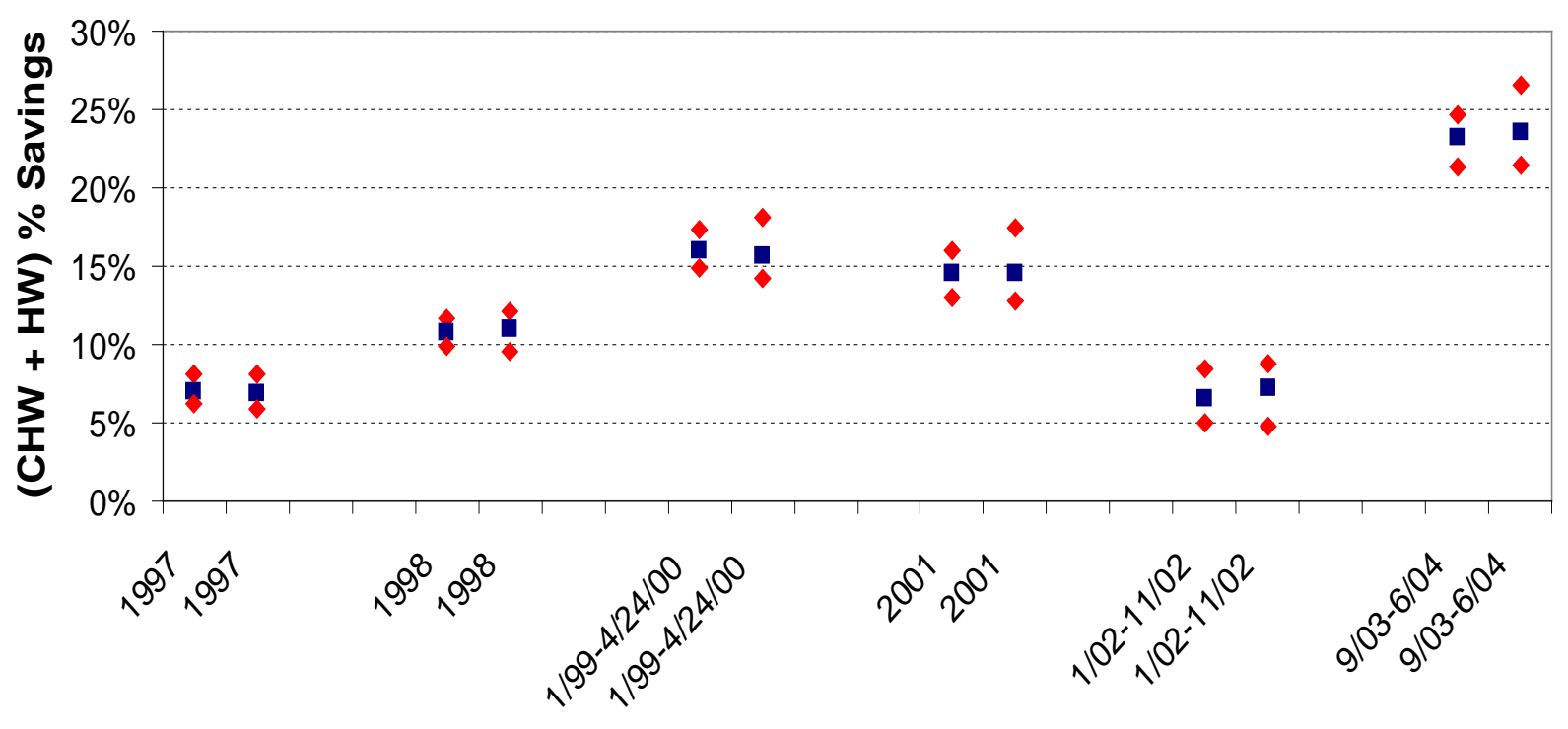

Figure 3.8 Post Commissioning Period, chilled water plus hot water percent savings variability (min, median and max) comparison between NAC (left set) and standard IPMVP (right set) weather normalization approaches when using Option C of IPMVP with regression.

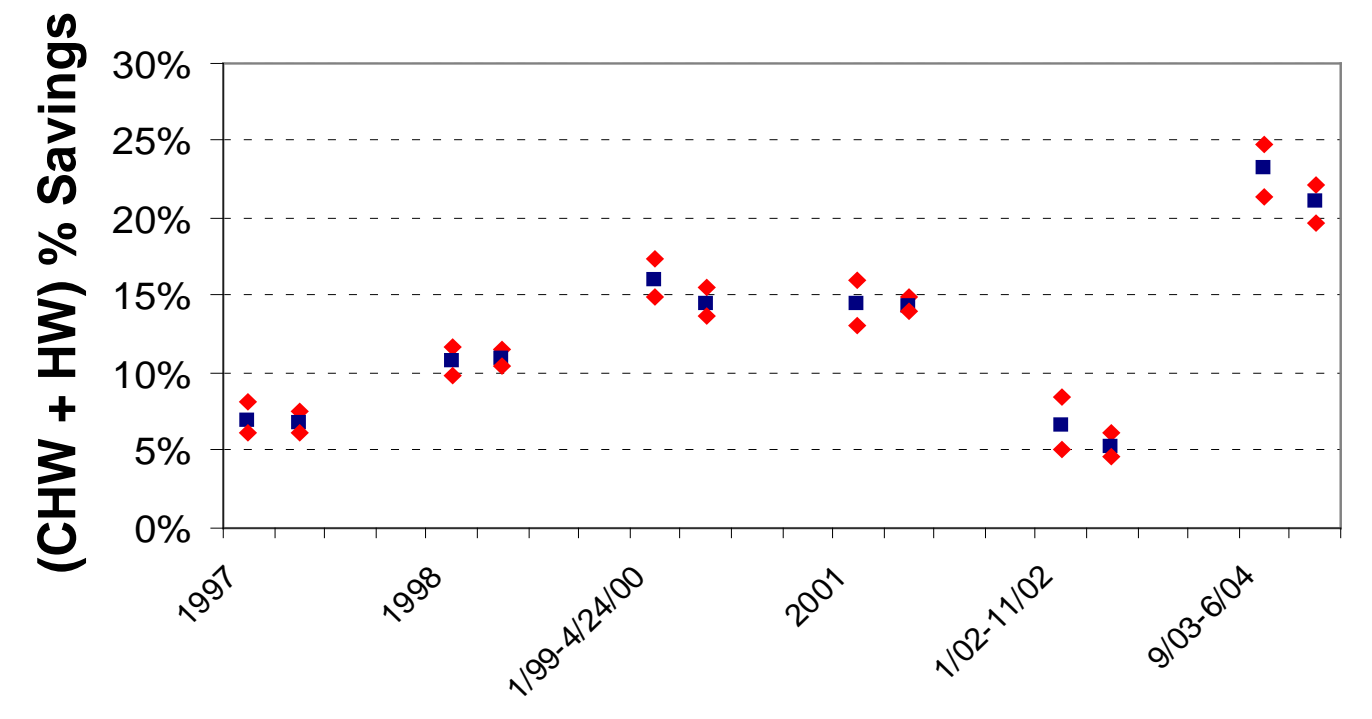

Figure 3.9 Post Commissioning Period, chilled water plus hot water percent savings variability comparison between NAC (left set) and standard IPMVP (right set) weather normalization approaches when using Option D (MBE adjusted) of IPMVP. 
Chilled and hot water savings ranges and averages across all weather years with the NAC weather normalization approach and all random runs with the standard IPMVP weather normalization approach are listed in Table 3.18. Option D (MBE adjusted) of the IPMVP is used for both weather normalization approaches in this table. The results show that the NAC weather normalization approach has a smaller average range in savings across all post-commissioning periods than the standard IPMVP weather normalization approach for both chilled and hot water. For chilled water, the mean percent savings range is $1.32 \%$ for the NAC weather normalization approach and $2.64 \%$ for the standard IPMVP weather normalization approach. For hot water, the mean percent savings range is $3.30 \%$ for NAC and $5.04 \%$ for standard IPMVP. Despite these differences, the mean of the post-commissioning period average savings is quite similar. For chilled water, the mean of the average percent savings is $11.38 \%$ for the NAC weather normalization approach versus $11.40 \%$ for the standard IPMVP weather normalization approach. For hot water, the mean of the average percent savings is $15.99 \%$ for both the NAC and standard IPMVP weather normalization approaches. The differences between the two weather normalization approaches in average percent savings across each of the post-commissioning periods are also relatively small. For chilled water, the largest difference in average savings between the two weather normalization approaches in a post-commissioning period is $0.25 \%$, occurring in the 9/03-6/04 period. For hot water, it is $0.28 \%$, occurring in 2001.

Table 3.18 Chilled and hot water percent savings range and average across all College Station weather years under NAC weather normalization approach and across all random runs under standard IPMVP weather normalization approach. Both approaches use Option D (MBE adjusted)

\begin{tabular}{|l|l|l|l|l|l|l|l|}
\hline $\begin{array}{l}\text { CHW \% } \\
\text { Savings } \\
\text { Range }\end{array}$ & $\mathbf{1 9 9 7}$ & $\mathbf{1 9 9 8}$ & $\begin{array}{l}\mathbf{1 / 9 9 -} \\
\mathbf{4 / 2 4 / 0 0}\end{array}$ & $\mathbf{2 0 0 1}$ & $\begin{array}{l}\mathbf{1 / 0 2 -} \\
\mathbf{1 1 / 0 2}\end{array}$ & $\mathbf{9 / 0 3 - 6 / 0 4}$ & Average \\
\hline NAC & $1.30 \%$ & $0.81 \%$ & $1.49 \%$ & $1.04 \%$ & $1.42 \%$ & $1.84 \%$ & $1.32 \%$ \\
\hline $\begin{array}{l}\text { Standard } \\
\text { IPMVP }\end{array}$ & $0.82 \%$ & $1.67 \%$ & $2.62 \%$ & $3.47 \%$ & $1.64 \%$ & $5.62 \%$ & $2.64 \%$ \\
\hline
\end{tabular}

\begin{tabular}{|l|l|l|l|l|l|l|l|}
\hline $\begin{array}{l}\text { HW } \\
\text { Savings } \\
\text { Range }\end{array}$ & $\mathbf{1 9 9 7}$ & $\mathbf{1 9 9 8}$ & $\begin{array}{l}\mathbf{1 / 9 9 -} \\
\mathbf{4 / 2 4 / 0 0}\end{array}$ & $\mathbf{2 0 0 1}$ & $\begin{array}{l}\mathbf{1 / 0 2 -} \\
\mathbf{1 1 / 0 2}\end{array}$ & $\mathbf{9 / 0 3 - 6 / 0 4}$ & Average \\
\hline NAC & $4.43 \%$ & $3.53 \%$ & $2.76 \%$ & $2.70 \%$ & $3.29 \%$ & $3.09 \%$ & $3.30 \%$ \\
\hline $\begin{array}{l}\text { Standard } \\
\text { IPMVP }\end{array}$ & $4.31 \%$ & $5.02 \%$ & $9.00 \%$ & $6.11 \%$ & $2.77 \%$ & $3.03 \%$ & $5.04 \%$ \\
\hline
\end{tabular}

\begin{tabular}{|l|l|l|l|l|l|l|l|}
\hline $\begin{array}{l}\text { CHW } \\
\text { Savings } \\
\text { Average }\end{array}$ & $\mathbf{1 9 9 7}$ & $\mathbf{1 9 9 8}$ & $\begin{array}{l}\mathbf{1 / 9 9 -} \\
\mathbf{4 / 2 4 / 0 0}\end{array}$ & $\mathbf{2 0 0 1}$ & $\begin{array}{l}\mathbf{1 / 0 2 -} \\
\mathbf{1 1 / 0 2}\end{array}$ & $\mathbf{9 / 0 3 - 6 / 0 4}$ & Average \\
\hline NAC & $4.33 \%$ & $8.21 \%$ & $12.12 \%$ & $14.02 \%$ & $7.18 \%$ & $22.41 \%$ & $11.38 \%$ \\
\hline $\begin{array}{l}\text { Standard } \\
\text { IPMVP }\end{array}$ & $4.32 \%$ & $8.14 \%$ & $12.03 \%$ & $14.12 \%$ & $7.16 \%$ & $22.66 \%$ & $11.40 \%$ \\
\hline
\end{tabular}

\begin{tabular}{|l|l|l|l|l|l|l|l|}
\hline $\begin{array}{l}\text { HW } \\
\text { Savings } \\
\text { Average }\end{array}$ & $\mathbf{1 9 9 7}$ & $\mathbf{1 9 9 8}$ & $\begin{array}{l}\mathbf{1 / 9 9 -} \\
\mathbf{4 / 2 4 / 0 0}\end{array}$ & $\mathbf{2 0 0 1}$ & $\begin{array}{l}\mathbf{1 / 0 2 -} \\
\mathbf{1 1 / 0 2}\end{array}$ & $\mathbf{9 / 0 3 - 6 / 0 4}$ & Average \\
\hline NAC & $18.71 \%$ & $23.50 \%$ & $25.36 \%$ & $16.04 \%$ & $-3.20 \%$ & $15.53 \%$ & $15.99 \%$ \\
\hline $\begin{array}{l}\text { Standard } \\
\text { IPMVP }\end{array}$ & $18.87 \%$ & $23.77 \%$ & $25.19 \%$ & $15.76 \%$ & $-3.18 \%$ & $15.52 \%$ & $15.99 \%$ \\
\hline
\end{tabular}




\section{Option C with Regression Models Versus Option D of IPMVP}

The previous section compares the variability in savings persistence between the NAC and standard IPMVP weather normalization approaches. It is also valuable to know whether Option $C$ with regression models or Option D of the IPMVP shows less variability in the persistence of savings and by how much. Knowing this may influence how much time one is willing to invest calibrating simulations under Option D when one could quickly create regression models.

Table 3.19 quantifies the variation in percent savings across the different weather years using the NAC weather normalization approach for both Option $C$ with regression models and Option D (MBE adjusted) of the IPMVP. The range and average percent savings across all 29 College Station weather years for each post-commissioning period are shown. Table 3.19 shows that each of the post-commissioning period calibrated simulations (Option $\mathrm{D}, \mathrm{MBE}$ adjusted) has less variation (smaller range) than the corresponding regression models (Option C) for both chilled and hot water, although some of the chilled water post-commissioning periods are quite similar. The smallest chilled water range difference between Option C and Option D is $0.03 \%$ (1997) while the largest is $1.56 \%$ (2001). The average chilled water savings range over all post-commissioning periods for Option D (MBE adjusted) is $1.32 \%$ while the average for Option $C$ with regression models is $2.14 \%$. The hot water range differences are larger, the smallest being $1.80 \%$ (2001) and the largest being $6.22 \%(1 / 99-4 / 24 / 00)$. The mean hot water savings range over all post-commissioning periods for Option D (MBE adjusted) is $3.30 \%$ and $7.16 \%$ for Option $C$ with regression models. Even though Option D (MBE adjusted) exhibits an overall lower savings range than Option $C$ with regression models across all weather years when using the NAC weather normalization approach, the average chilled water savings from the different weather years over all postcommissioning periods are somewhat similar for Option D (MBE adjusted) and Option C with regression models. The differences for average chilled water percent savings vary from $0.48 \%$ in 1997 to $1.81 \%$ in $1 / 02-11 / 02$. For hot water, the differences for average savings during the post-commissioning periods vary as two of the periods show differences between Option D (MBE adjusted) and Option C with regression models of less than $1 \%$ (1997 and 1/02-11/02) and three show differences greater than $3 \%$ $(1998,2001$, and 9/03-6/04). The differences for average hot water percent savings vary from $0.54 \%$ in 1997 up to $3.48 \%$ in 2001. 
Table 3.19 Chilled and hot water percent savings range and average across all College Station weather years under NAC weather normalization approach for Option D (MBE adjusted) and Option C with regression models.

\begin{tabular}{|l|l|l|l|l|l|l|l|}
\hline $\begin{array}{l}\text { CHW \% } \\
\text { Savings } \\
\text { Range }\end{array}$ & $\mathbf{1 9 9 7}$ & $\mathbf{1 9 9 8}$ & $\begin{array}{l}\mathbf{1 / 9 9 -} \\
\mathbf{4 / 2 4 / 0 0}\end{array}$ & $\mathbf{2 0 0 1}$ & $\begin{array}{l}\mathbf{1 / 0 2 -} \\
\mathbf{1 1 / 0 2}\end{array}$ & $\mathbf{9 / 0 3 - 6 / 0 4}$ & Average \\
\hline Option D & $1.30 \%$ & $0.81 \%$ & $1.49 \%$ & $1.04 \%$ & $1.42 \%$ & $1.84 \%$ & $1.32 \%$ \\
\hline $\begin{array}{l}\text { Option C } \\
\text { with } \\
\text { Regression }\end{array}$ & $1.33 \%$ & $1.82 \%$ & $1.82 \%$ & $2.59 \%$ & $2.69 \%$ & $2.60 \%$ & $2.14 \%$ \\
\hline
\end{tabular}

\begin{tabular}{|c|c|c|c|c|c|c|c|}
\hline $\begin{array}{l}\text { HW \% } \\
\text { Savings } \\
\text { Range }\end{array}$ & 1997 & 1998 & $\begin{array}{l}1 / 99- \\
4 / 24 / 00\end{array}$ & 2001 & $1 / 02-11 / 02$ & 9/03-6/04 & Average \\
\hline Option D & $4.43 \%$ & $3.53 \%$ & $2.76 \%$ & $2.70 \%$ & $3.29 \%$ & $3.09 \%$ & $3.30 \%$ \\
\hline $\begin{array}{l}\text { Option C } \\
\text { with } \\
\text { Regression }\end{array}$ & $9.65 \%$ & $7.14 \%$ & $8.97 \%$ & $4.49 \%$ & $6.01 \%$ & $6.70 \%$ & $7.16 \%$ \\
\hline
\end{tabular}

\begin{tabular}{|l|l|l|l|l|l|l|l|}
\hline $\begin{array}{l}\text { CHW \% } \\
\text { Savings } \\
\text { Average }\end{array}$ & 1997 & $\mathbf{1 9 9 8}$ & $\begin{array}{l}\text { 1/99- } \\
\mathbf{4 / 2 4 / 0 0}\end{array}$ & $\mathbf{2 0 0 1}$ & $\mathbf{1 / 0 2 - 1 1 / 0 2}$ & $\mathbf{9 / 0 3 - 6 / 0 4}$ & Average \\
\hline Option D & $4.33 \%$ & $8.21 \%$ & $12.12 \%$ & $14.02 \%$ & $7.18 \%$ & $22.41 \%$ & $11.38 \%$ \\
\hline $\begin{array}{l}\text { Option C } \\
\text { with } \\
\text { Regression }\end{array}$ & $4.81 \%$ & $8.79 \%$ & $13.82 \%$ & $14.91 \%$ & $9.00 \%$ & $24.08 \%$ & $12.57 \%$ \\
\hline
\end{tabular}

\begin{tabular}{|l|l|l|l|l|l|l|l|}
\hline $\begin{array}{l}\text { HW \% } \\
\text { Savings } \\
\text { Average }\end{array}$ & $\mathbf{1 9 9 7}$ & $\mathbf{1 9 9 8}$ & $\begin{array}{l}\mathbf{1 / 9 9 -} \\
\mathbf{4 / 2 4 / 0 0}\end{array}$ & $\mathbf{2 0 0 1}$ & $\mathbf{1 / 0 2 - 1 1 / 0 2}$ & $\mathbf{9 / 0 3 - 6 / 0 4}$ & Average \\
\hline Option D & $18.71 \%$ & $23.50 \%$ & $25.36 \%$ & $16.04 \%$ & $-3.20 \%$ & $15.53 \%$ & $15.99 \%$ \\
\hline $\begin{array}{l}\text { Option C } \\
\text { with } \\
\text { Regression }\end{array}$ & $18.16 \%$ & $20.07 \%$ & $26.87 \%$ & $12.56 \%$ & $-4.20 \%$ & $18.87 \%$ & $15.39 \%$ \\
\hline
\end{tabular}

\section{Variability of Savings Statistical Measures}

Two statistical measures are now shown to better quantify the variability of savings for each of the four different combinations of savings determination methods and weather normalization approaches (Option $D$ using the NAC weather normalization approach, Option $C$ with regression models using the NAC weather normalization approach, Option D using the standard IPMVP weather normalization approach, and Option $C$ with regression models using the standard IPMVP weather normalization approach). This allows for simple comparison of savings variability between the four different combinations of sets of savings obtained from the 29 different College Station weather years and random runs for the NAC and standard IPMVP weather normalization approaches, respectively. The two statistical measures used here are the standard deviation and the coefficient of variation of the percent savings.

Chilled water savings variability results are listed in Table 3.20. Both the standard deviation and coefficient of variation results show Option D (MBE adjusted) with the NAC weather normalization approach to have the least amount of savings variability $(0.32 \%$ savings average standard deviation and $3.50 \%$ average coefficient of variation for chilled water savings across all post-commissioning periods) while Option $\mathrm{C}$ with regression models using the standard IPMVP weather normalization approach has the most amount of savings variability (1.01\% savings average standard deviation and $8.36 \%$ average 
coefficient of variation for chilled water savings across all post-commissioning periods). The average chilled water savings variability measures are similar for Option D (MBE adjusted) with the standard IPMVP weather normalization approach (0.68 \% savings average standard deviation and $5.78 \%$ average coefficient of variation for chilled water savings across all post-commissioning periods) and Option $\mathrm{C}$ with regression models with the NAC weather normalization approach $(0.57 \%$ savings average standard deviation and $5.29 \%$ average coefficient of variation for chilled water savings across all postcommissioning periods). Thus the NAC weather normalization approach shows less variability in chilled water savings than the standard IPMVP weather normalization approach when comparing results using the same IPMVP savings determination method. Additionally, Option D (MBE adjusted) shows less variability in chilled water savings than Option $\mathrm{C}$ with regression models when comparing results using the same weather normalization approach.

Table 3.20 Chilled water savings variability quantification for each of the four combinations of the NAC and standard IPMVP weather normalization approaches and Option C and Option D (MBE adjusted) savings determination methods.

\begin{tabular}{|l|l|l|l|l|l|l|l|}
\hline \multicolumn{2}{|l}{ Option D (MBE Adjusted) with NAC Weather Normalization Approach } \\
\hline & $\mathbf{1 9 9 7}$ & $\mathbf{1 9 9 8}$ & $\begin{array}{l}\mathbf{1 / 9 9 -} \\
\mathbf{4 / 2 4 / 0 0}\end{array}$ & $\mathbf{2 0 0 1}$ & $\mathbf{1 / 0 2 - 1 1 / 0 2}$ & $\mathbf{9 / 0 3 - 6 / 0 4}$ & Average \\
\hline stdev & $0.29 \%$ & $0.20 \%$ & $0.39 \%$ & $0.25 \%$ & $0.36 \%$ & $0.43 \%$ & $0.32 \%$ \\
\hline coeff var & $6.76 \%$ & $2.41 \%$ & $3.19 \%$ & $1.76 \%$ & $4.95 \%$ & $1.92 \%$ & $3.50 \%$ \\
\hline
\end{tabular}

\begin{tabular}{|c|c|c|c|c|c|c|c|}
\hline \multicolumn{8}{|c|}{ Option D (MBE Adjusted) with Standard IPMVP Weather Normalization Approach } \\
\hline & 1997 & 1998 & $\begin{array}{l}1 / 99- \\
4 / 24 / 00\end{array}$ & 2001 & $1 / 02-11 / 02$ & 9/03-6/04 & Average \\
\hline stdev & $0.20 \%$ & $0.41 \%$ & $0.61 \%$ & $0.93 \%$ & $0.49 \%$ & $1.46 \%$ & $0.68 \%$ \\
\hline coeff var & $4.70 \%$ & $5.06 \%$ & $5.08 \%$ & $6.57 \%$ & $6.82 \%$ & $6.44 \%$ & $5.78 \%$ \\
\hline
\end{tabular}

\begin{tabular}{|c|c|c|c|c|c|c|c|}
\hline \multicolumn{8}{|c|}{ Option C with Regression Models with NAC Weather Normalization Approach } \\
\hline & 1997 & 1998 & \begin{tabular}{|l|}
$1 / 99-$ \\
$4 / 24 / 00$
\end{tabular} & 2001 & $1 / 02-11 / 02$ & $9 / 03-6 / 04$ & Average \\
\hline stdev & $0.35 \%$ & $0.47 \%$ & $0.48 \%$ & $0.70 \%$ & $0.73 \%$ & $0.71 \%$ & $0.57 \%$ \\
\hline coeff var & $7.20 \%$ & $5.37 \%$ & $3.46 \%$ & $4.68 \%$ & $8.06 \%$ & $2.96 \%$ & $5.29 \%$ \\
\hline
\end{tabular}

\begin{tabular}{|l|l|l|l|l|l|l|l|}
\hline \multicolumn{6}{|c|}{ Option C with Regression Models with Standard IPMVP Weather Normalization Approach } \\
\hline & $\mathbf{1 9 9 7}$ & $\mathbf{1 9 9 8}$ & $\begin{array}{l}\mathbf{1 / 9 9 -} \\
\mathbf{4 / 2 4 / 0 0}\end{array}$ & $\mathbf{2 0 0 1}$ & $\mathbf{1 / 0 2 - 1 1 / 0 2}$ & $\mathbf{9 / 0 3 - 6 / 0 4}$ & Average \\
\hline stdev & $0.40 \%$ & $0.69 \%$ & $0.97 \%$ & $1.27 \%$ & $1.02 \%$ & $1.74 \%$ & $1.01 \%$ \\
\hline coeff var & $8.75 \%$ & $7.79 \%$ & $7.09 \%$ & $8.41 \%$ & $10.97 \%$ & $7.14 \%$ & $8.36 \%$ \\
\hline
\end{tabular}

Hot water savings variability results are listed in Table 3.21. When not considering the coefficient of variation of the 1/02-11/02 where negative savings occur, hot water savings variability results are similar to those of the chilled water except that the savings variability measures are much closer for the NAC and standard IPMVP weather normalization approaches when using Option C with regression models. The average standard deviation across all post-commissioning periods is $1.83 \%$ savings for Option C with regression models using the NAC weather normalization approach versus $1.85 \%$ savings for Option C with regression models using the standard IPMVP weather normalization approach. When using Option D (MBE adjusted), however, the NAC weather normalization approach clearly shows less savings variability than the standard IPMVP weather normalization approach. The average standard deviation across all post-commissioning periods is $0.79 \%$ savings for Option D (MBE adjusted) using the NAC weather normalization approach versus $1.32 \%$ savings for Option D (MBE adjusted) using the standard IPMVP weather normalization approach. When considering the average of the coefficient of variation across all post-commissioning periods excluding the 1/02-11/02 period, the same pattern seen with the standard deviation exists. The NAC weather normalization approach (4.20\% average coefficient of variation) shows less variability in savings than the standard IPMVP weather normalization approach 
(7.36 \% average coefficient of variation) when using Option D (MBE adjusted) of the IPVMP. Also, the NAC weather normalization approach ( $9.83 \%$ average coefficient of variation) shows similar variability in savings to the standard IPMVP weather normalization approach (9.92 \% average coefficient of variation) when using Option $\mathrm{C}$ with regression models of the IPMVP.

Table 3.21 Hot water savings variability quantification for each of the four combinations of the NAC and standard IPMVP weather normalization approaches and Option C and Option D (MBE adjusted) savings determination methods.

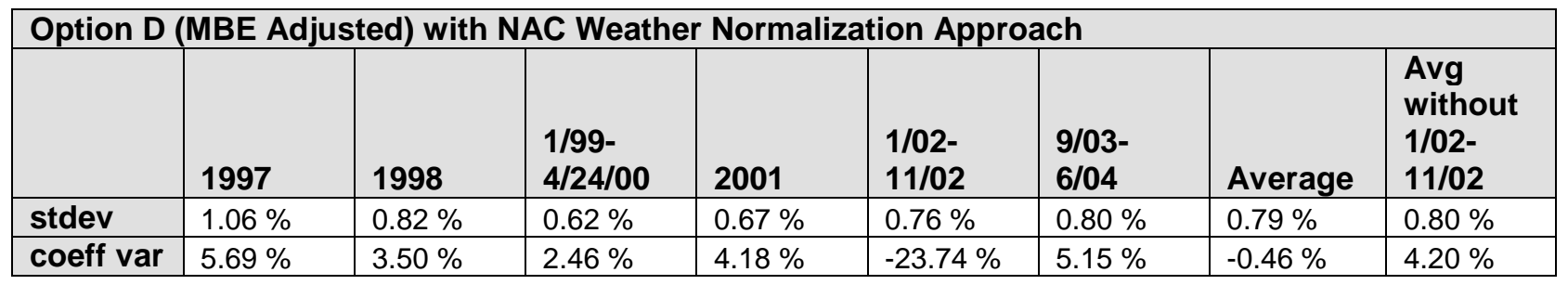

\begin{tabular}{|c|c|c|c|c|c|c|c|c|}
\hline \multicolumn{9}{|c|}{ Option D (MBE Adjusted) with Standard IPMVP Weather Normalization Approach } \\
\hline & 1997 & 1998 & $\begin{array}{l}1 / 99- \\
4 / 24 / 00\end{array}$ & 2001 & $\begin{array}{l}1 / 02- \\
11 / 02\end{array}$ & $\begin{array}{l}9 / 03- \\
6 / 04\end{array}$ & Average & $\begin{array}{l}\text { Avg } \\
\text { without } \\
1 / 02- \\
11 / 02\end{array}$ \\
\hline stdev & $1.14 \%$ & $1.34 \%$ & $2.11 \%$ & $1.70 \%$ & $0.69 \%$ & $0.93 \%$ & $1.32 \%$ & $1.44 \%$ \\
\hline coeff var & $6.05 \%$ & $5.62 \%$ & $8.39 \%$ & $10.76 \%$ & $-21.82 \%$ & $5.96 \%$ & $2.49 \%$ & $7.36 \%$ \\
\hline
\end{tabular}

\begin{tabular}{|c|c|c|c|c|c|c|c|c|}
\hline \multicolumn{9}{|c|}{ Option C with Regression Models with NAC Weather Normalization Approach } \\
\hline & 1997 & 1998 & $\begin{array}{l}\text { 1/99- } \\
4 / 24 / 00\end{array}$ & 2001 & $\begin{array}{l}1 / 02- \\
11 / 02\end{array}$ & $\begin{array}{l}9 / 03- \\
6 / 04\end{array}$ & Average & $\begin{array}{l}\text { Avg } \\
\text { without } \\
1 / 02- \\
11 / 02\end{array}$ \\
\hline stdev & $2.54 \%$ & $1.80 \%$ & $2.09 \%$ & $1.13 \%$ & $1.61 \%$ & $1.78 \%$ & $1.83 \%$ & $1.87 \%$ \\
\hline coeff var & $14.00 \%$ & $8.95 \%$ & $7.79 \%$ & $8.96 \%$ & $-38.48 \%$ & $9.46 \%$ & $1.78 \%$ & $9.83 \%$ \\
\hline
\end{tabular}

\begin{tabular}{|c|c|c|c|c|c|c|c|c|}
\hline \multicolumn{9}{|c|}{ Option C with Regression Models with Standard IPMVP Weather Normalization Approach } \\
\hline & 1997 & 1998 & $\begin{array}{l}1 / 99- \\
4 / 24 / 00\end{array}$ & 2001 & $\begin{array}{l}1 / 02- \\
11 / 02\end{array}$ & $\begin{array}{l}9 / 03- \\
6 / 04\end{array}$ & Average & $\begin{array}{l}\text { Avg } \\
\text { without } \\
1 / 02- \\
11 / 02\end{array}$ \\
\hline stdev & $2.49 \%$ & $1.72 \%$ & $2.38 \%$ & $1.58 \%$ & $1.70 \%$ & $1.22 \%$ & $1.85 \%$ & $1.88 \%$ \\
\hline coeff var & $13.45 \%$ & $8.31 \%$ & $8.91 \%$ & $12.60 \%$ & $-47.54 \%$ & $6.32 \%$ & $0.34 \%$ & $9.92 \%$ \\
\hline
\end{tabular}

\section{Variability of Persistence of Savings Statistical Measures}

Just as it is important to have some quantifiable measure of the variability of commissioning savings for each of the four different combinations of savings determination methods and weather normalization approaches, it is also valuable to quantify the variability of commissioning persistence of savings for each of these four different combinations. Persistence of savings in this case is defined as the percent savings difference between a post-commissioning period after 1997 (the first post-commissioning period) and the 1997 post-commissioning period.

Table 3.22 shows the chilled water savings and persistence of savings for both the NAC and standard IPMVP weather normalization approaches using Option D (MBE adjusted) of the IPMVP. The long-term average College Station weather year is used for the NAC weather normalization approach. The normal procedure for the standard IPMVP weather normalization approach is employed that uses the actual 
weather data of the post-commissioning periods. Table 3.22 indicates that persistence of savings results do vary depending on the weather normalization approach used just as savings results do. For two of the post-commissioning periods (1/99-4/24/00 and 1/02-11/02), chilled water persistence of savings differs by more than $1.5 \%$ between the NAC and standard IPMVP weather normalization approaches.

Table 3.22 Chilled water savings and persistence of savings results using Option D (MBE adjusted) of IPMVP for both NAC and standard IPMVP weather normalization approaches. The long-term average weather year is used for the NAC weather normalization approach.

\begin{tabular}{|c|c|c|c|c|c|c|}
\hline & 1997 & 1998 & $1 / 99-4 / 24 / 00$ & 2001 & $1 / 02-11 / 02$ & $9 / 03-6 / 04$ \\
\hline \multicolumn{7}{|c|}{ NAC Weather Normalization Approach } \\
\hline $\begin{array}{ll}\text { CHW } & \% \\
\text { Savings } & \end{array}$ & $4.62 \%$ & $8.28 \%$ & $12.24 \%$ & $13.87 \%$ & $6.91 \%$ & $22.21 \%$ \\
\hline $\begin{array}{l}\text { CHW } \\
\text { Persistence }\end{array}$ & $\mathrm{n} / \mathrm{a}$ & $3.66 \%$ & $7.62 \%$ & $9.25 \%$ & $2.29 \%$ & $17.59 \%$ \\
\hline
\end{tabular}

\begin{tabular}{|l|l|l|l|l|l|l|}
\hline \multicolumn{7}{|l|}{ Standard IPMVP Weather Normalization Approach } \\
\hline $\begin{array}{l}\text { CHW } \\
\text { Savings }\end{array}$ & $4.05 \%$ & $8.18 \%$ & $9.99 \%$ & $13.43 \%$ & $8.06 \%$ & $22.06 \%$ \\
\hline $\begin{array}{l}\text { CHW } \\
\text { Persistence }\end{array}$ & n/a & $4.13 \%$ & $5.94 \%$ & $9.38 \%$ & $4.01 \%$ & $18.01 \%$ \\
\hline
\end{tabular}

\begin{tabular}{|c|c|c|c|c|c|c|}
\hline $\begin{array}{l}\text { CHW \% } \\
\text { Savings } \\
\text { Difference }\end{array}$ & $0.57 \%$ & $0.10 \%$ & $2.25 \%$ & $0.44 \%$ & $1.15 \%$ & $0.15 \%$ \\
\hline $\begin{array}{l}\text { CHW } \\
\text { Persistence } \\
\text { Difference }\end{array}$ & $\mathrm{n} / \mathrm{a}$ & $0.47 \%$ & $1.68 \%$ & $0.13 \%$ & $1.72 \%$ & $0.42 \%$ \\
\hline
\end{tabular}

To quantify the variability of persistence of savings, sets of savings from the 29 different College Station weather years and 29 different random runs are again used for the NAC and standard IPMVP weather normalization approaches, respectively. From these sets of persistence of savings results, the standard deviation and the coefficient of variation of the persistence are found. Table 3.23 quantifies the chilled water variability of persistence of savings. Results of the variability of chilled water persistence of savings differ somewhat from the results of the variability of chilled water savings. Option $C$ with regression models using the NAC weather normalization approach (0.38\% persistence average standard deviation and $5.12 \%$ average coefficient of variation across all post-commissioning periods) shows slightly less overall variability than Option D (MBE adjusted) using the NAC weather normalization approach $(0.42 \%$ persistence average standard deviation and $7.37 \%$ average coefficient of variation across all postcommissioning periods). Option D (MBE adjusted) with the standard IPMVP weather normalization approach (0.68 \% persistence average standard deviation and $9.04 \%$ average coefficient of variation across all post-commissioning periods), however, still shows less variability than Option $\mathrm{C}$ with regression models using the standard IPMVP weather normalization approach $(1.20 \%$ persistence average standard deviation and $15.03 \%$ average coefficient of variation across all post-commissioning periods). As with chilled water variability of savings results, the NAC weather normalization approach shows less chilled water variability of persistence than the standard IPMVP weather normalization approach when comparing results using the same IPMVP savings determination method (both Option $\mathrm{C}$ with regression models and Option D). 
Table 3.23 Chilled water persistence of savings variability quantification for each of the four combinations of the NAC and standard IPMVP weather normalization approaches and Option C and Option D (MBE adjusted) savings determination methods.

\begin{tabular}{|l|l|l|l|l|l|l|}
\hline \multicolumn{6}{|l|}{ Option D (MBE Adjusted) with NAC Weather Normalization Approach } \\
\hline & $\mathbf{1 9 9 8}$ & $\mathbf{1 / 9 9 - 4 / 2 4 / 0 0}$ & $\mathbf{2 0 0 1}$ & $\mathbf{1 / 0 2 - 1 1 / 0 2}$ & $\mathbf{9 / 0 3 - 6 / 0 4}$ & Average \\
\hline stdev & $0.17 \%$ & $0.22 \%$ & $0.42 \%$ & $0.61 \%$ & $0.70 \%$ & $0.42 \%$ \\
\hline coeff var & $4.38 \%$ & $2.84 \%$ & $4.29 \%$ & $21.49 \%$ & $3.87 \%$ & $7.37 \%$ \\
\hline
\end{tabular}

\begin{tabular}{|l|l|l|l|l|l|l|}
\hline \multicolumn{6}{|l|}{ Option D (MBE Adjusted) with Standard IPMVP Weather Normalization Approach } \\
\hline & $\mathbf{1 9 9 8}$ & $\mathbf{1 / 9 9 - 4 / 2 4 / 0 0}$ & $\mathbf{2 0 0 1}$ & $\mathbf{1 / 0 2 - 1 1 / 0 2}$ & $\mathbf{9 / 0 3 - 6 / 0 4}$ & Average \\
\hline stdev & $0.30 \%$ & $0.46 \%$ & $0.80 \%$ & $0.45 \%$ & $1.38 \%$ & $0.68 \%$ \\
\hline coeff var & $7.78 \%$ & $6.02 \%$ & $8.21 \%$ & $15.65 \%$ & $7.53 \%$ & $9.04 \%$ \\
\hline
\end{tabular}

\begin{tabular}{|l|l|l|l|l|l|l|}
\hline \multicolumn{6}{|l|}{ Option C with Regression Models with NAC Weather Normalization Approach } \\
\hline & $\mathbf{1 9 9 8}$ & $\mathbf{1 / 9 9 - 4 / 2 4 / 0 0}$ & $\mathbf{2 0 0 1}$ & $\mathbf{1 / 0 2 - 1 1 / 0 2}$ & $\mathbf{9 / 0 3}-\mathbf{0 4}$ & Average \\
\hline stdev & $0.18 \%$ & $0.17 \%$ & $0.44 \%$ & $0.49 \%$ & $0.60 \%$ & $0.38 \%$ \\
\hline coeff var & $4.61 \%$ & $1.85 \%$ & $4.37 \%$ & $11.68 \%$ & $3.10 \%$ & $5.12 \%$ \\
\hline
\end{tabular}

\begin{tabular}{|l|l|l|l|l|l|l|}
\hline \multicolumn{2}{|c|}{ Option C with Regression Models with Standard IPMVP Weather Normalization Approach } \\
\hline & $\mathbf{1 9 9 8}$ & $\mathbf{1 / 9 9 - 4 / 2 4 / 0 0}$ & $\mathbf{2 0 0 1}$ & $\mathbf{1 / 0 2 - 1 1 / 0 2}$ & $\mathbf{9 / 0 3 - 6 / 0 4}$ & Average \\
\hline stdev & $0.84 \%$ & $1.01 \%$ & $1.38 \%$ & $1.07 \%$ & $1.71 \%$ & $1.20 \%$ \\
\hline coeff var & $19.39 \%$ & $11.12 \%$ & $13.07 \%$ & $22.91 \%$ & $8.65 \%$ & $15.03 \%$ \\
\hline
\end{tabular}

When assessing hot water variability of persistence of savings results (see Table 3.24), the coefficient of variation should not be considered. Due to very small average persistence values in multiple postcommissioning periods, many of the results for the coefficient of variation cannot accurately assess the variability of hot water persistence of savings. The standard deviation appears better suited as a measure of variability of hot water persistence of savings. When only considering the average value across all post-commissioning periods of the standard deviation for hot water persistence of savings, Option D (MBE adjusted) using the NAC weather normalization approach has the least variability $(0.98 \%$ persistence average standard deviation across all post-commissioning periods). This is followed by Option D (MBE adjusted) using the standard IPMVP weather normalization approach (1.12\% persistence average standard deviation across all post-commissioning periods), Option $\mathrm{C}$ with regression models using the NAC weather normalization approach ( $1.75 \%$ persistence average standard deviation across all post-commissioning periods), and Option $\mathrm{C}$ with regression models using the standard IPMVP weather normalization approach (2.61 \% persistence average standard deviation across all post-commissioning periods). 
Table 3.24 Hot water persistence of savings variability quantification for each of the four combinations of the NAC and standard IPMVP weather normalization approaches and Option C and Option D (MBE adjusted) savings determination methods.

\begin{tabular}{|l|l|l|l|l|l|l|}
\hline \multicolumn{2}{|c|}{ Option D (MBE Adjusted) with NAC Weather Normalization Approach } \\
\hline & $\mathbf{1 9 9 8}$ & $\mathbf{1 / 9 9 - 4 / 2 4 / 0 0}$ & $\mathbf{2 0 0 1}$ & $\mathbf{1 / 0 2 - 1 1 / 0 2}$ & $\mathbf{9 / 0 3 - 6 / 0 4}$ & Average \\
\hline stdev & $0.32 \%$ & $1.09 \%$ & $1.24 \%$ & $1.69 \%$ & $0.56 \%$ & $0.98 \%$ \\
\hline coeff var & $6.78 \%$ & $16.43 \%$ & $-46.25 \%$ & $-7.71 \%$ & $-17.61 \%$ & $-9.67 \%$ \\
\hline
\end{tabular}

\begin{tabular}{|l|l|l|l|l|l|l|}
\hline \multicolumn{6}{|c|}{ Option D (MBE Adjusted) with Standard IPMVP Weather Normalization Approach } \\
\hline & $\mathbf{1 9 9 8}$ & $\mathbf{1 / 9 9 - 4 / 2 4 / 0 0}$ & $\mathbf{2 0 0 1}$ & $\mathbf{1 / 0 2 - 1 1 / 0 2}$ & $\mathbf{9 / 0 3 - 6 / 0 4}$ & Average \\
\hline stdev & $0.80 \%$ & $1.59 \%$ & $1.16 \%$ & $1.61 \%$ & $0.44 \%$ & $1.12 \%$ \\
\hline coeff var & $16.30 \%$ & $25.21 \%$ & $-37.33 \%$ & $-7.30 \%$ & $-12.98 \%$ & $-3.22 \%$ \\
\hline
\end{tabular}

\begin{tabular}{|l|l|l|l|l|l|l|}
\hline \multicolumn{6}{|l|}{ Option C with Regression Models with NAC Weather Normalization Approach } \\
\hline & $\mathbf{1 9 9 8}$ & $\mathbf{1 / 9 9 - 4 / 2 4 / 0 0}$ & $\mathbf{2 0 0 1}$ & $\mathbf{1 / 0 2 - 1 1 / 0 2}$ & $\mathbf{9 / 0 3} \mathbf{0 4}$ & Average \\
\hline stdev & $0.83 \%$ & $1.31 \%$ & $2.10 \%$ & $2.98 \%$ & $1.51 \%$ & $1.75 \%$ \\
\hline coeff var & $43.68 \%$ & $15.09 \%$ & $-37.40 \%$ & $-13.31 \%$ & $214.89 \%$ & $44.59 \%$ \\
\hline
\end{tabular}

\begin{tabular}{|l|l|l|l|l|l|l|}
\hline \multicolumn{6}{|c|}{ Option C with Regression Models with Standard IPMVP Weather Normalization Approach } \\
\hline & $\mathbf{1 9 9 8}$ & $\mathbf{1 / 9 9 - 4 / 2 4 / 0 0}$ & $\mathbf{2 0 0 1}$ & $\mathbf{1 / 0 2 - 1 1 / 0 2}$ & $\mathbf{9 / 0 3 - 6 / 0 4}$ & Average \\
\hline stdev & $2.42 \%$ & $3.03 \%$ & $2.36 \%$ & $3.25 \%$ & $1.98 \%$ & $2.61 \%$ \\
\hline coeff var & $111.63 \%$ & $37.05 \%$ & $-39.69 \%$ & $-14.71 \%$ & $271.96 \%$ & $73.25 \%$ \\
\hline
\end{tabular}

\section{Summary Comparison of Savings Using Four Different Normalization Approaches}

The variability of savings and persistence of savings results from the commissioning of CE/TTI using the NAC and standard IPMVP weather normalization approaches, as well as Option C with regression models and Option D of the IPMVP are presented in this chapter. It has been shown that the savings and persistence of savings may vary greatly depending on which weather normalization approach, IPMVP Option, and weather year selected as the "normal" weather year are used.

Overall, the NAC weather normalization approach shows less variability in savings and persistence of savings than the standard IPMVP weather normalization approach. Additionally, Option D of the IPMVP generally shows less variability in savings and persistence of savings than Option $C$ with regression models. These statements hold true when considering chilled water savings. However, for hot water savings, results for the variability in the persistence of savings are mixed. Chilled water persistence of savings results differ in that Option $C$ with regression models using the NAC weather normalization approach shows slightly less overall variability of persistence than Option D using the NAC weather normalization approach. Finally, the hot water persistence of savings shows mixed variability.

For chilled water savings, the average standard deviation across all post-commissioning periods is 0.32 $\%$ savings for Option D (MBE adjusted) using the NAC weather normalization approach, $0.68 \%$ savings for Option D (MBE adjusted) using the standard IPMVP weather normalization approach, $0.57 \%$ savings for Option C with regression models using the NAC weather normalization approach, and $1.01 \%$ savings for Option C with regression models using the standard IPMVP weather normalization approach.

For hot water savings, the average standard deviation across all post-commissioning periods is $0.79 \%$ savings for Option D (MBE adjusted) using the NAC weather normalization approach, $1.32 \%$ savings for Option D (MBE adjusted) using the standard IPMVP weather normalization approach, $1.83 \%$ savings for Option C with regression models using the NAC weather normalization approach, and $1.85 \%$ savings for Option C with regression models using the standard IPMVP weather normalization approach.

For chilled water persistence of savings, the average standard deviation across all post-commissioning periods is $0.42 \%$ persistence for Option D (MBE adjusted) using the NAC weather normalization 
approach, $0.68 \%$ persistence for Option D (MBE adjusted) using the standard IPMVP weather normalization approach, $0.38 \%$ persistence for Option $C$ with regression models using the NAC weather normalization approach, and $1.20 \%$ persistence for Option $\mathrm{C}$ with regression models using the standard IPMVP weather normalization approach.

For hot water persistence of savings, the average standard deviation across all post-commissioning periods is $0.98 \%$ persistence for Option D (MBE adjusted) using the NAC weather normalization approach, $1.12 \%$ persistence for Option D (MBE adjusted) using the standard IPMVP weather normalization approach, $1.75 \%$ persistence for Option $C$ with regression models using the NAC weather normalization approach, and $2.61 \%$ persistence for Option $C$ with regression models using the standard IPMVP weather normalization approach.

\subsection{Recent Persistence Studies}

\subsubsection{Persistence of Commissioning Measures in Four Buildings in Japan}

Yamaha (2007) examined information available in Japanese for 14 buildings that had received "10 Year Awards" from the Society of Heating, Air-Conditioning and Sanitary Engineers of Japan (SHASE) for conducting system inspections and improvements over a period of at least ten years. He concluded there was sufficient information regarding energy-saving measures implemented and subsequent energy use in three of these buildings to be valuable for examining the persistence of energy savings in buildings. In these cases, the measures were primarily energy efficiency measures incorporated into the design of the buildings.

He discussed the Chubu Electric Power Co. (CEPCO) Okazaki Building, the Tokyo Electric Power Co. (TEPCO) Higashi-Murayama Building and the TEPCO R\&D Center, all of which received SHASE Ten Year Awards. These buildings used $20 \%$ to $40 \%$ less energy than reference designs. He also presents the performance of the Tonets Corp. (TONETS) Shinkawa Building.

The CEPCO Okazaki Building incorporated high levels of insulation, sun shading with controls and cubic shape to minimize surface area. The building also uses thermal energy storage, variable water volume and variable air volume control strategies and heat recovery. Figure 3.10 shows the disaggregated energy consumption of the CEPCO Okazaki Building for 20 years. The energy use ranges from a low of $50 \%$ of the reference consumption to a high of about $80 \%$ of the reference consumption. During the latter half of the 1980s, building consumption increased substantially, primarily due to increases in lighting consumption, fan energy and pumping power. But even after these increases, the building still used $20 \%$ less than the reference design.

The TEPCO Higashi-Murayama Building incorporates ventilation windows, sun shade controls, data visualization tools, thermal energy storage and large temperature differences in the distribution systems. As shown in Fig. 3.11, the consumption was relatively stable over the last 11 years shown, with consumption between a low of about $75 \%$ of the reference building (in a year with a cool summer) to a high of about $85 \%$ of the reference. Consumption was very low in 1988 since the building was not operational for the entire year.

The TEPCO R\&D Center utilizes data visualization tools to help achieve optimal operation and incorporates thermal storage and large temperature differences in the distribution systems. The energy consumption shown in Fig. 3.12 is quite stable for four of the nine years shown, has three years of abnormally high consumption (1997 to 1999) due to increased consumption of an experimental fuel cell installation in the building. During 2002 and 2003 consumption decreased by $15 \%$ and $26 \%$ due to the removal of the experimental fuel cell installation and a cool summer in 2003. 
Figure 3.13 shows the savings in $\mathrm{MJ} / \mathrm{m}^{2}$-year of the CEPCO Okazaki Building, the TEPCO HigashiMurayama Building and the TONETS Shinkawa Building. The first two saved significant energy throughout the entire period of observation along with the TEPCO R\&D building. The TONETS Shinkawa Building saved significant energy for seven years, then over the next seven years shows savings that are negative in aggregate due to a $25 \%$ increase in operating hours and additional computers and office machines.

As a group, these buildings are consistent with the commissioned buildings that have been examined in Annex 47 work - most continue to show savings over periods that in this case run from 10 years to 20 years, while generally showing some decrease in savings over time.

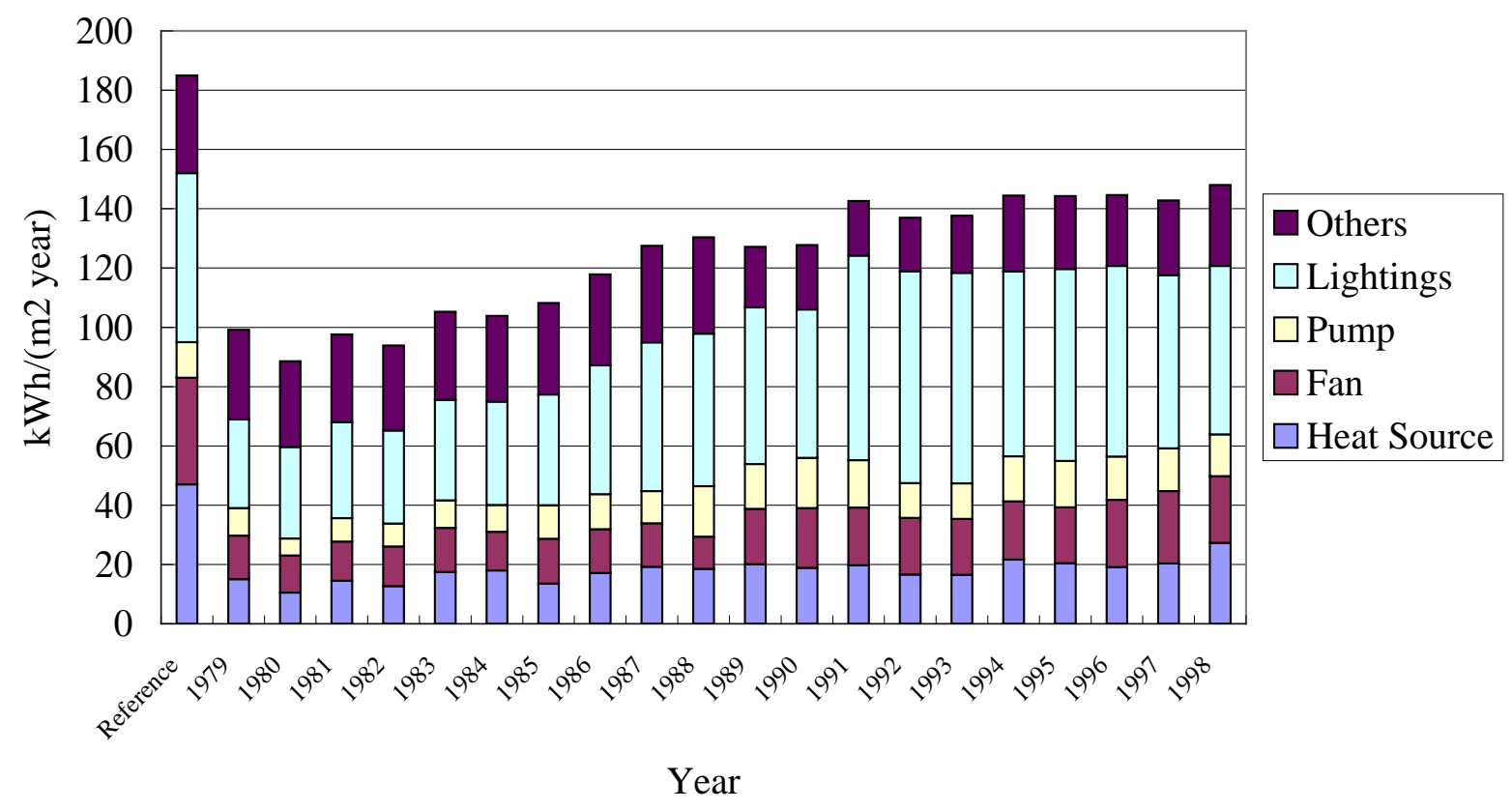

Figure 3.10 Annual energy consumption of the CEPCO Okazaki Building for years 1979 to 1998 (Source: Yamaha 2007). 


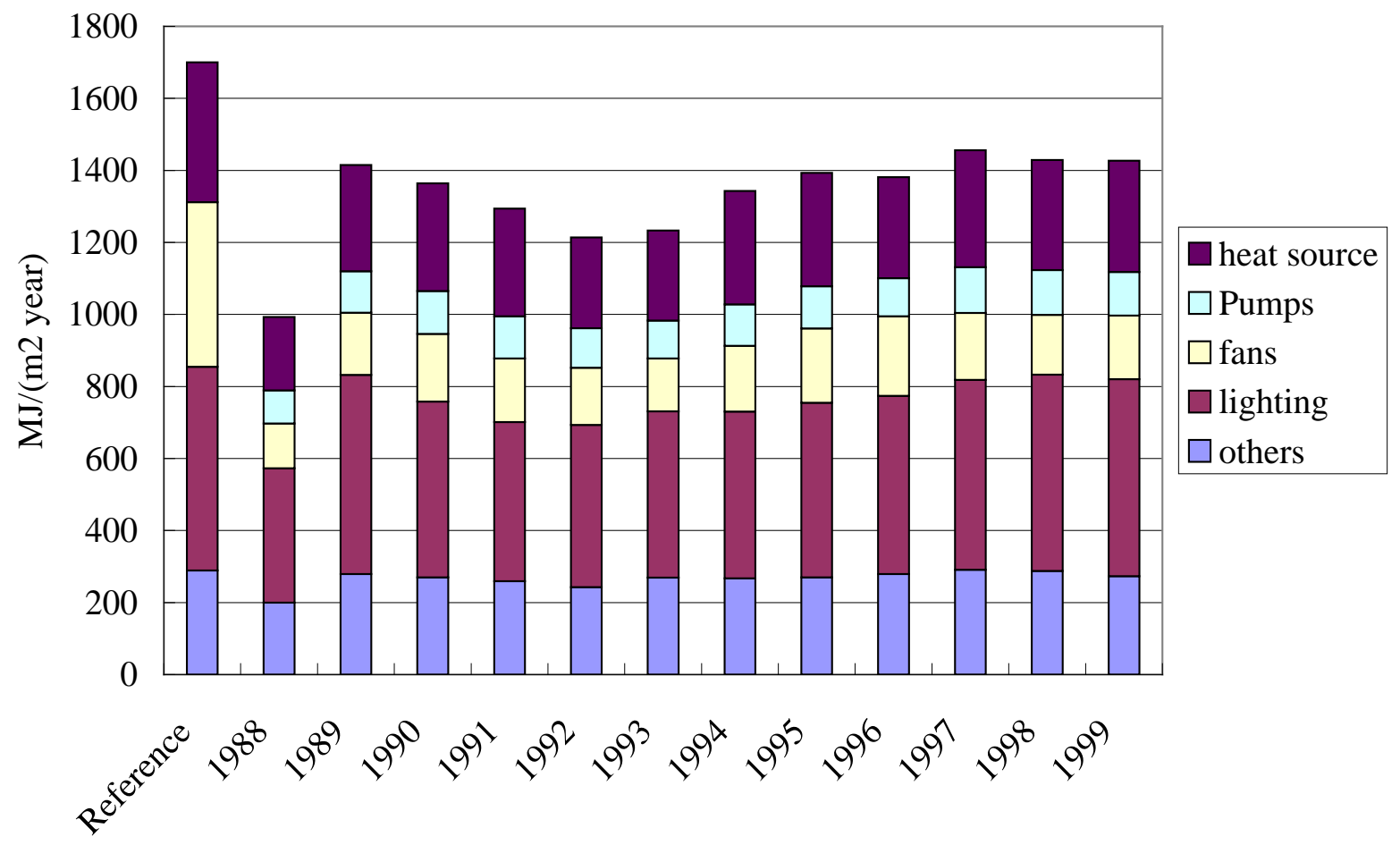

Figure 3.11 Energy consumption of the TEPCO Higashi Murayama Building for 1988 to 1999 (Source: Yamaha 2007).

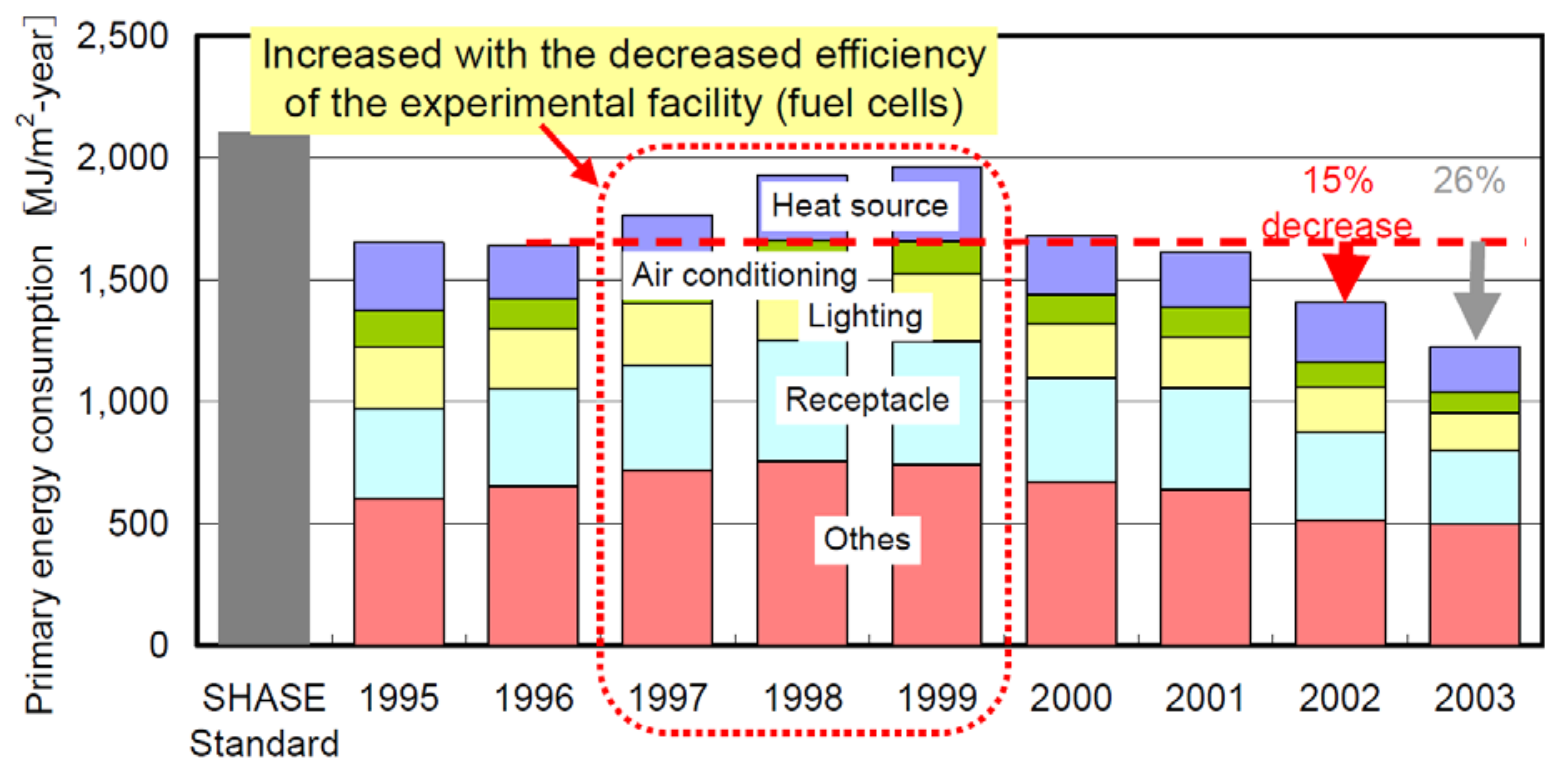

Figure 3.12 Energy consumption of the TEPCO R\&D for 1995 to 2003 (Source: Yamaha 2007). 


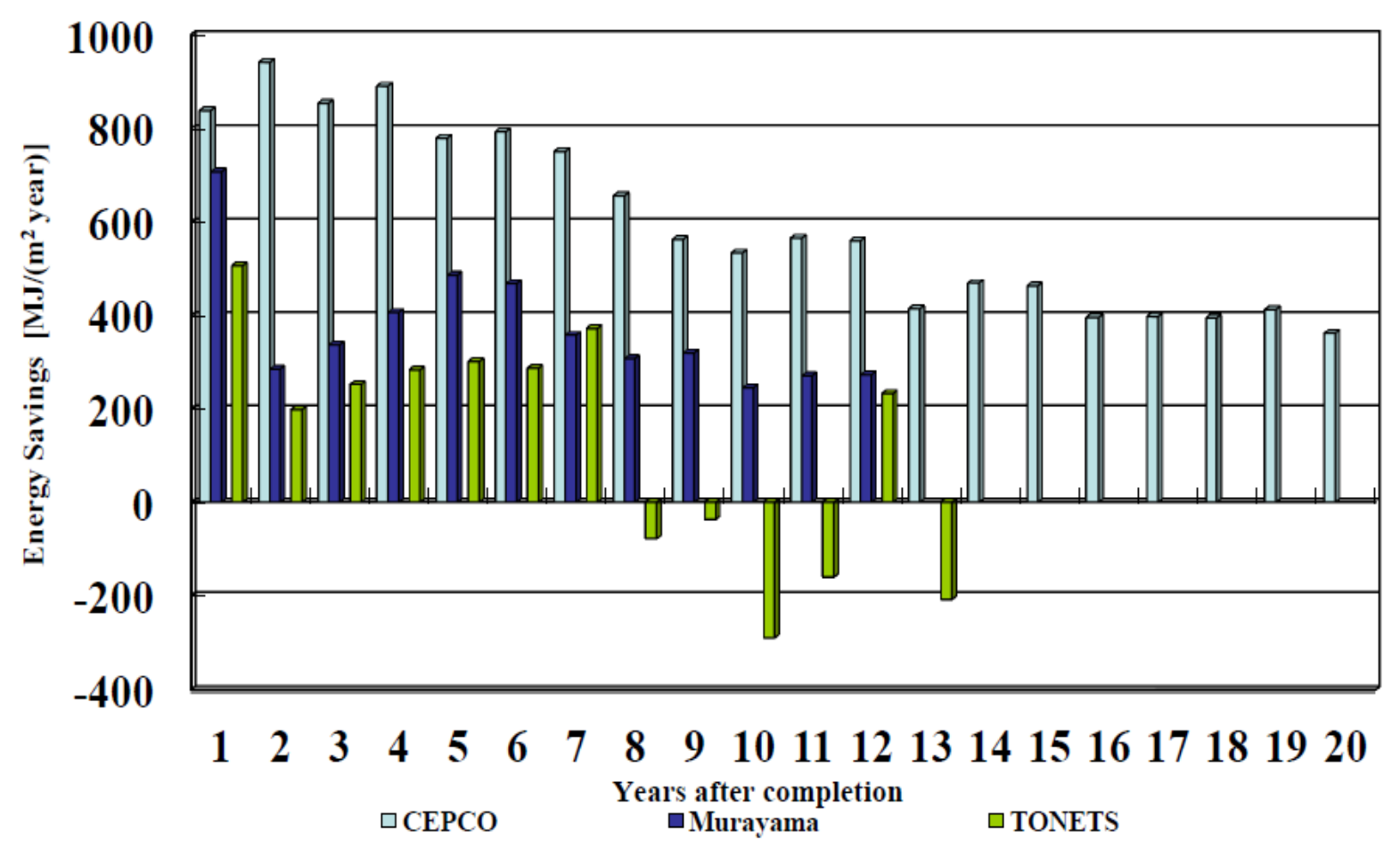

Figure 3.13. Persistence of energy savings for three buildings over a 20 year period (Source: Yamaha 2007).

\subsubsection{Persistence of Commissioning Measures in ten Buildings at Texas A\&M - An Update}

\section{Results of Previous Study}

As noted earlier, the previous study of the ten buildings by Turner et al. (2001) and Cho (2002) compared the normalized energy savings of each building over a period of four years following retro-commissioning. These results have been updated by Toole (2009). Table 3.25 details the results of this study, with the chilled water, hot water, and electricity consumption and savings shown on a yearly basis. 
Table 3.25 Energy savings results for the years examined in the previous study (Cho, 2002).

\begin{tabular}{|c|c|c|c|c|c|c|c|c|c|c|}
\hline \multirow[b]{2}{*}{$\begin{array}{l}\text { Building } \\
\text { Name }\end{array}$} & \multirow[b]{2}{*}{ Type } & \multirow{2}{*}{$\begin{array}{c}\text { Baseline } \\
\text { Use } \\
\text { (MMBtu) } \\
\text { (MWh) / yr }\end{array}$} & \multicolumn{2}{|c|}{1997} & \multicolumn{2}{|c|}{1998} & \multicolumn{2}{|c|}{1999} & \multicolumn{2}{|c|}{2000} \\
\hline & & & $\begin{array}{c}\text { Use } \\
\text { (MMBtu) } \\
\text { (MWh)/yr }\end{array}$ & $\begin{array}{c}\text { Saving } \\
\text { (\%) }\end{array}$ & $\begin{array}{c}\text { Use } \\
(\mathrm{MMBtu}) \\
(\mathrm{MWh}) / \mathrm{yr}\end{array}$ & $\begin{array}{c}\text { Saving } \\
\text { (\%) }\end{array}$ & $\begin{array}{c}\text { Use } \\
\text { (MMBtu) } \\
\text { (MWh) / yr }\end{array}$ & $\begin{array}{c}\text { Saving } \\
\text { (\%) }\end{array}$ & $\begin{array}{c}\text { Use } \\
\text { (MMBtu) } \\
\text { (MWh) / yr }\end{array}$ & $\begin{array}{l}\text { Saving } \\
\text { (\%) }\end{array}$ \\
\hline \multirow{3}{*}{ Blocker } & CHW & 22,955 & 16,723 & 27 & 19,530 & 15 & 20,164 & 12 & 21,083 & ** 8 \\
\hline & HW & 8,735 & 4,093 & 53 & 1,676 & 81 & 3,330 & 62 & 4,344 & ** 50 \\
\hline & Elec & 4,832 & 3,773 & 22 & 3,883 & 20 & 3,936 & 19 & 3,859 & 20 \\
\hline \multirow{3}{*}{ Eller O\&M } & CHW & 30,625 & 18,846 & 38 & 18,660 & 39 & 19,012 & 38 & 20,360 & 34 \\
\hline & HW & 7,584 & 2,578 & 66 & 1,154 & 85 & 1,831 & 76 & 4,712 & 38 \\
\hline & Elec & 4,891 & 3,698 & 24 & 3,675 & 25 & 3,823 & 22 & 3,874 & 21 \\
\hline \multirow{3}{*}{$\begin{array}{l}\text { G.R.White } \\
\text { Coliseum }\end{array}$} & CHW & 18,872 & 8,717 & 54 & 8,511 & 55 & 14,548 & 23 & 15,858 & 16 \\
\hline & HW & 21,155 & 6,091 & 71 & 549 & 97 & 4,923 & 77 & 10,111 & 52 \\
\hline & Elec & 1,480 & 1,297 & 12 & 1,168 & 21 & 1,171 & 21 & 1,291 & 13 \\
\hline \multirow{3}{*}{$\begin{array}{c}\text { Harrington } \\
\text { Tower }\end{array}$} & $\mathrm{CHW}$ & 14,179 & 7,109 & 50 & 8,420 & 41 & 7,660 & 46 & 9,032 & 36 \\
\hline & HW & 6,896 & 2,603 & 62 & 914 & 87 & 1,629 & 76 & 3,519 & 49 \\
\hline & Elec & 1,666 & 1,297 & 22 & 1,336 & 20 & 1,341 & 20 & 1,353 & 19 \\
\hline \multirow{3}{*}{$\begin{array}{l}\text { Kleberg } \\
\text { Building }\end{array}$} & $\mathrm{CHW}$ & 59,271 & 34,864 & 41 & 34,969 & 41 & 36,731 & 38 & 41,965 & 29 \\
\hline & HW & 40,812 & 6,523 & 84 & 1,215 & 97 & 8,030 & 80 & 10,591 & 74 \\
\hline & Elec & 5,511 & 5,458 & 1 & 5,067 & 8 & 4,778 & 13 & 4,684 & 15 \\
\hline \multirow{3}{*}{$\begin{array}{l}\text { Koldus } \\
\text { Building }\end{array}$} & CHW & 21,964 & 12,177 & 45 & 12,988 & 41 & 12,740 & 42 & 11,804 & 46 \\
\hline & HW & 2,103 & 704 & 67 & 399 & 81 & 634 & 70 & 649 & 69 \\
\hline & Elec & 2,850 & 2,511 & 12 & 2,597 & 9 & 2,624 & 8 & 2,592 & 9 \\
\hline \multirow{3}{*}{$\begin{array}{c}\text { Rich. } \\
\text { Petroleum }\end{array}$} & CHW & 28,526 & 13,599 & 52 & 15,637 & 45 & 15,078 & 47 & 17,702 & 38 \\
\hline & HW & 18,227 & 6,565 & 64 & 5,588 & 69 & 5,098 & 72 & 2,171 & 88 \\
\hline & Elec & 1,933 & 1,898 & 2 & 1,914 & 1 & 1,991 & -3 & 2,153 & -11 \\
\hline \multirow{3}{*}{ VMC Addition } & $\mathrm{CHW}$ & 40,892 & 23,115 & 43 & 24,080 & 41 & 22,915 & 44 & 23,307 & 43 \\
\hline & HW & 3,569 & 887 & 75 & 2,041 & 43 & 2,097 & 41 & 2,051 & 43 \\
\hline & Elec & 4,186 & 3,996 & 5 & 4,140 & 1 & 4,236 & -1 & 4,056 & 3 \\
\hline \multirow{3}{*}{ Wehner СВA } & $\mathrm{CHW}$ & 19,193 & 12,327 & 36 & 13,339 & 31 & 12,530 & 35 & 11,609 & 40 \\
\hline & HW & 13,393 & 10,876 & 19 & 9,715 & 27 & 6,581 & 51 & 6,350 & 53 \\
\hline & Elec & 2,555 & 2,410 & 6 & 2,446 & 4 & 2,552 & 0 & 2,581 & -1 \\
\hline \multirow{3}{*}{$\begin{array}{c}\text { Zachry Engr. } \\
\text { Center }\end{array}$} & CHW & 40,824 & 16,737 & 59 & 17,377 & 57 & 18,148 & 56 & 20,225 & 50 \\
\hline & HW & 7,676 & 1,630 & 79 & 3,230 & 58 & 2,226 & 71 & 4,271 & 44 \\
\hline & Elec & 7,502 & 6,762 & 10 & 6,793 & 9 & 7,099 & 5 & 6,955 & 7 \\
\hline \multicolumn{2}{|l|}{ Type } & Total & Total & Average & Total & Average & Total & Average & Total & Average \\
\hline \multicolumn{2}{|l|}{ Chilled Water } & 297,298 & 164,215 & 44.8 & 173,509 & 41.6 & 179,527 & 39.6 & 192,946 & 35.1 \\
\hline \multicolumn{2}{|l|}{ Hot Water } & 130,149 & 42,549 & 67.3 & 26,482 & 79.7 & 36,380 & 72.0 & 48,768 & 62.5 \\
\hline \multicolumn{2}{|l|}{ Electricity } & 37,407 & 33,100 & 11.5 & 33,018 & 11.7 & 33,552 & 10.3 & 33,399 & 10.7 \\
\hline
\end{tabular}

* The baseline energy use for these buildings was estimated from the average savings of the other buildings because insufficient data was available to create reliable baselines.

** The Blocker building had insufficient chilled water and hot water energy use data in 2000 to determine normalized annual consumption. So the savings were estimated from the average degradation that occurred between 1999 and 2000 in the other nine buildings.

\section{New Findings}

The results of the previous study were expanded upon to include normalized consumption data and savings calculations for additional years following the completion of the original study. For seven of the buildings, reliable energy consumption data were available from as recently as 2006-2007. For the other three buildings, the last year of reliable consumption data ranged from 2002 to 2004 . Table 3.26 shows the combined results of the previous study with the additional years of data for each building. 
Table 3.26 Updated results of energy savings analysis, normalized to common weather year.

\begin{tabular}{|c|c|c|c|c|c|c|c|c|c|c|c|c|c|c|c|c|c|c|c|c|c|c|}
\hline \multirow[b]{2}{*}{$\begin{array}{l}\text { Building } \\
\text { Name }\end{array}$} & \multirow[b]{2}{*}{ Type } & \multirow{2}{*}{$\begin{array}{l}\text { Baseline } \\
\text { Use } \\
\text { (MMBtu) } \\
\text { (MWh) / /yr }\end{array}$} & \multicolumn{2}{|c|}{1997} & \multicolumn{2}{|c|}{1998} & \multicolumn{2}{|c|}{1999} & \multicolumn{2}{|c|}{2000} & \multicolumn{2}{|c|}{2001} & \multicolumn{2}{|c|}{2002} & \multicolumn{2}{|c|}{2003} & \multicolumn{2}{|c|}{2004} & \multicolumn{2}{|c|}{$2005-2006$} & \multicolumn{2}{|c|}{ 2006-2007 } \\
\hline & & & $\begin{array}{c}\text { Use } \\
\text { (MMBtu) } \\
(\mathrm{MWh}) / \mathrm{yr} \\
\end{array}$ & $\begin{array}{l}\text { Saving } \\
(\%)\end{array}$ & $\begin{array}{c}\text { Use } \\
(\mathrm{MMBU}) \\
(\mathrm{MMh}) / \mathrm{yr}\end{array}$ & $\begin{array}{l}\text { Saving } \\
(\%)\end{array}$ & $\begin{array}{c}\text { Use } \\
(\mathrm{MMBtu}) \\
(\mathrm{MWh}) / \mathrm{yr}\end{array}$ & $\begin{array}{l}\text { Saving } \\
(\%)\end{array}$ & $\begin{array}{c}\text { Use } \\
\text { (MMBu) } \\
\text { (MWh)/yr }\end{array}$ & $\begin{array}{l}\text { Saving } \\
(\%)\end{array}$ & $\begin{array}{c}\text { Use } \\
(\mathrm{MMBt}) \\
(\mathrm{MWh}) / \mathrm{yr}\end{array}$ & $\begin{array}{l}\text { Saving } \\
(\%)\end{array}$ & $\begin{array}{c}\text { Use } \\
\text { (MMBtu) } \\
\text { (MWh)/yr }\end{array}$ & $\begin{array}{l}\text { Saving } \\
(\%)\end{array}$ & $\begin{array}{c}\text { Use } \\
\text { (MMBtu) } \\
(\mathrm{MWh}) / \mathrm{yr} \\
\end{array}$ & $\begin{array}{l}\text { Saving } \\
(\%)\end{array}$ & $\begin{array}{c}\text { Use } \\
\text { (MMBtu) } \\
(\mathrm{MWh}) / \mathrm{yr}\end{array}$ & $\begin{array}{c}\text { Saving } \\
(\%)\end{array}$ & $\begin{array}{c}\text { Use } \\
\text { (MMBtu) } \\
\text { (MWh)/yr }\end{array}$ & $\begin{array}{l}\text { Saving } \\
(\%)\end{array}$ & $\begin{array}{c}\text { Use } \\
(\mathrm{MMBu}) \\
(\mathrm{MNh}) / \mathrm{yr}\end{array}$ & $\begin{array}{l}\text { Saving } \\
(\%)\end{array}$ \\
\hline \multirow{3}{*}{ Blocker } & $\mathrm{CHW}$ & 22,955 & 16,723 & 27 & 19,530 & 15 & 20,164 & 12 & 21,083 & ** 8 & 19,082 & 17 & 17,887 & 22 & 20,850 & 9 & & & & & 21,179 & 8 \\
\hline & HW & 8,735 & 4,093 & 53 & 1,676 & 81 & 3,330 & 62 & 4,344 & ** 50 & 4,623 & 47 & 2,654 & 70 & 6,367 & 27 & & & & & 4,409 & 50 \\
\hline & \begin{tabular}{|l|} 
Elec \\
\end{tabular} & 4,832 & 3,773 & 22 & 3,883 & 20 & 3,936 & 19 & 3,859 & 20 & 3,639 & 25 & 3,516 & 27 & 3,583 & 26 & & & & & 3,511 & 27 \\
\hline \multirow{3}{*}{ Eller O\&M } & $\mathrm{CHW}$ & 30,625 & 18,846 & 38 & 18,660 & 39 & 19,012 & 38 & 20,360 & 34 & 24,002 & 22 & 21,120 & 31 & 19,948 & 35 & 21,805 & 29 & & & & \\
\hline & $\mathrm{HW}$ & 7,584 & 2,578 & 66 & 1,154 & 85 & 1,831 & 76 & 4,712 & 38 & 4,488 & 41 & & & & & & & & & & \\
\hline & Elec & 4,891 & 3,698 & 24 & 3,675 & 25 & 3,823 & 22 & 3,874 & 21 & 3,972 & 19 & 3,732 & 24 & 3,745 & 23 & 3,861 & 21 & & & & \\
\hline \multirow{3}{*}{$\begin{array}{l}\text { G.R.White } \\
\text { Coliseum }\end{array}$} & $\mathrm{CHW}$ & 18,872 & 8,717 & 54 & 8,511 & 55 & \begin{tabular}{ll|}
14,548 \\
\end{tabular} & 23 & 15,858 & 16 & & & & & & & & & $\begin{array}{ll}6,837 \\
\end{array}$ & 64 & 11,134 & 41 \\
\hline & HW & 21,155 & 6,091 & 71 & 549 & 97 & 4,923 & 77 & 10,111 & 52 & & & & & & & & & 3,276 & 85 & 2,216 & 90 \\
\hline & \begin{tabular}{|l|l|} 
Elec \\
\end{tabular} & 1.480 & 1,297 & 12 & 1,168 & 21 & 1,171 & 21 & 1,291 & 13 & 1,102 & 26 & 1,028 & 31 & 1,015 & 31 & 1,109 & 25 & 1,028 & 31 & 956 & 35 \\
\hline \multirow{3}{*}{$\begin{array}{l}\text { Harrington } \\
\text { Tower }\end{array}$} & $\mathrm{CHW}$ & 14,179 & 7,109 & 50 & 8,420 & 41 & 7,660 & 46 & 9,032 & 36 & 8,380 & 41 & 9,267 & 35 & 8,614 & 39 & 7,817 & 45 & 7,103 & 50 & 6,927 & 51 \\
\hline & HW & 6,896 & 2,603 & 62 & 914 & 87 & 1,629 & 76 & 3,519 & 49 & & & 3,921 & 43 & 3,538 & 49 & & & 2,966 & 57 & 2,807 & 59 \\
\hline & Elec & 1,666 & 1,297 & 22 & 1,336 & 20 & 1,341 & 20 & 1,353 & 19 & 1,319 & 21 & 1,331 & 20 & 1,390 & 17 & & & 1,293 & 22 & 1,220 & 27 \\
\hline \multirow{3}{*}{$\begin{array}{l}\text { Kleberg } \\
\text { Building }\end{array}$} & $\mathrm{CHW}$ & 59,271 & 34,864 & 41 & 34,969 & 41 & 36,731 & 38 & 41,965 & 29 & 45,187 & 24 & 37,180 & 37 & 31,911 & 46 & 33,560 & 43 & 20,964 & 65 & 28,831 & 51 \\
\hline & HW & 40,812 & 6,523 & 84 & 1,215 & 97 & 8,030 & 80 & 10,591 & 74 & & & & & & & & & 7,421 & 82 & 12,989 & 68 \\
\hline & Elec & 5,511 & 5,458 & 1 & 5,067 & 8 & 4,778 & 13 & 4,684 & 15 & 4,539 & 18 & 4,564 & 17 & 4,832 & 12 & 4,666 & 15 & 3,320 & 40 & 3,533 & 36 \\
\hline \multirow{3}{*}{$\begin{array}{l}\text { Koldus } \\
\text { Building }\end{array}$} & $\mathrm{CHW}$ & 21,964 & 12,177 & 45 & \begin{tabular}{ll|}
12,988 \\
\end{tabular} & 41 & 12,740 & 42 & 11,804 & 46 & 12,735 & 42 & & & & & & & \begin{tabular}{ll|}
12,487 \\
\end{tabular} & 43 & 13,784 & 37 \\
\hline & HW & 2,103 & 704 & 67 & 399 & 81 & 634 & 70 & 649 & 69 & 390 & 81 & & & & & & & 3,488 & -66 & 4,225 & -101 \\
\hline & \begin{tabular}{|l|l|} 
Elec \\
\end{tabular} & 2,850 & 2,511 & 12 & 2,597 & 9 & 2,624 & 8 & 2,592 & 9 & 2,603 & 9 & 2,667 & 6 & & & 2,682 & 6 & 2,553 & 10 & 2,546 & 11 \\
\hline \multirow{3}{*}{$\begin{array}{c}\text { Rich. } \\
\text { Petrol eum }\end{array}$} & CHW & 28,526 & 13,599 & 52 & 15,637 & 45 & 15,078 & 47 & 17,702 & 38 & 13,937 & 51 & 15,587 & 45 & 17,023 & 40 & 17,625 & 38 & & & & \\
\hline & HW & 18,227 & 6,565 & 64 & 5,588 & 69 & 5,098 & 72 & 2,171 & 88 & 6,568 & 64 & 6,994 & 62 & 7,391 & 59 & 8,882 & 51 & & & & \\
\hline & \begin{tabular}{|l|l|} 
Elec \\
\end{tabular} & 1,933 & 1,898 & 2 & 1.914 & 1 & 1,991 & -3 & 2,153 & -11 & 2,039 & -5 & 2,026 & -5 & 2,110 & -9 & 2,155 & -11 & & & & \\
\hline \multirow{3}{*}{ VMC Addition } & $\mathrm{CHW}$ & 40,892 & 23,115 & 43 & 24,080 & 41 & 22,915 & 44 & 23,307 & 43 & 24,380 & 40 & 25,849 & 37 & & & & & & & & \\
\hline & $\mathrm{HW}$ & 3,569 & 887 & 75 & 2,041 & 43 & 2,097 & 41 & 2,051 & 43 & 1,881 & 47 & 3,203 & 10 & & & & & & & & \\
\hline & Elec & 4,186 & 3,996 & 5 & 4,140 & 1 & 4,236 & -1 & 4,056 & 3 & 4,219 & -1 & 4,169 & 0 & & & & & & & & \\
\hline \multirow{3}{*}{ Wehner CBA } & $\mathrm{CHW}$ & 19,193 & \begin{tabular}{|l|}
12,327 \\
\end{tabular} & 36 & 13,339 & 31 & 12,530 & 35 & 11,609 & 40 & 13,490 & 30 & & & & & & & & & 13,283 & 31 \\
\hline & $\mathrm{HW}$ & \begin{tabular}{|l|l}
3,393 \\
\end{tabular} & 10,876 & 19 & 9,715 & 27 & 6,581 & 51 & 6,350 & 53 & 7,309 & 45 & & & & & & & & & 1,723 & 87 \\
\hline & \begin{tabular}{|l|l|} 
Elec \\
\end{tabular} & 2,555 & 2,410 & 6 & 2,446 & 4 & 2,552 & 0 & 2,581 & -1 & 2,529 & 1 & & & & & & & & & 2,342 & 8 \\
\hline & $\mathrm{CHW}$ & 40,824 & 16,737 & 59 & 17,377 & 57 & 18,148 & 56 & 20,225 & 50 & 19,794 & 52 & & & & & & & 20,440 & 50 & 24,296 & 40 \\
\hline $\begin{array}{l}\text { Zaciny Engr. } \\
\text { Center }\end{array}$ & HW & 7,676 & 1,630 & 79 & 3,230 & 58 & 2,226 & 71 & 4,271 & 44 & 4,467 & 42 & & & & & & & 3,623 & 53 & 4,694 & 39 \\
\hline & \begin{tabular}{|l|l|l|} 
Elec \\
\end{tabular} & 7,502 & 6,762 & 10 & 6,793 & 9 & 7,099 & 5 & 6,955 & 7 & 6,597 & 12 & 6,516 & 13 & 6,456 & 14 & & & 4,377 & 42 & 4,662 & 38 \\
\hline
\end{tabular}

Note: The consumption data used for the time period labeled "2005-2006" were from 7/25/2005 - 7/24/2006 for all of the buildings with data for this period. For the period labeled "2006-2007," the consumption data were from 7/25/2006 - 7/24/2007 for G.R. White Coliseum, Harrington Tower, and Kleberg, and were from 10/16/2006 - 10/15/2007 for Blocker, Wehner, and Zachry. These time periods were chosen due to the availability of reliable energy consumption data. 
The overall trends in chilled water, hot water, and electricity savings over the period sampled for the ten buildings are diagrammed in Figures 3.14, 3.15, and 3.16 that follow. Specifics about the savings patterns of each building are discussed thereafter.

Figure 3.14 Chilled water savings trends over time for the ten buildings studied (some data points not available). 


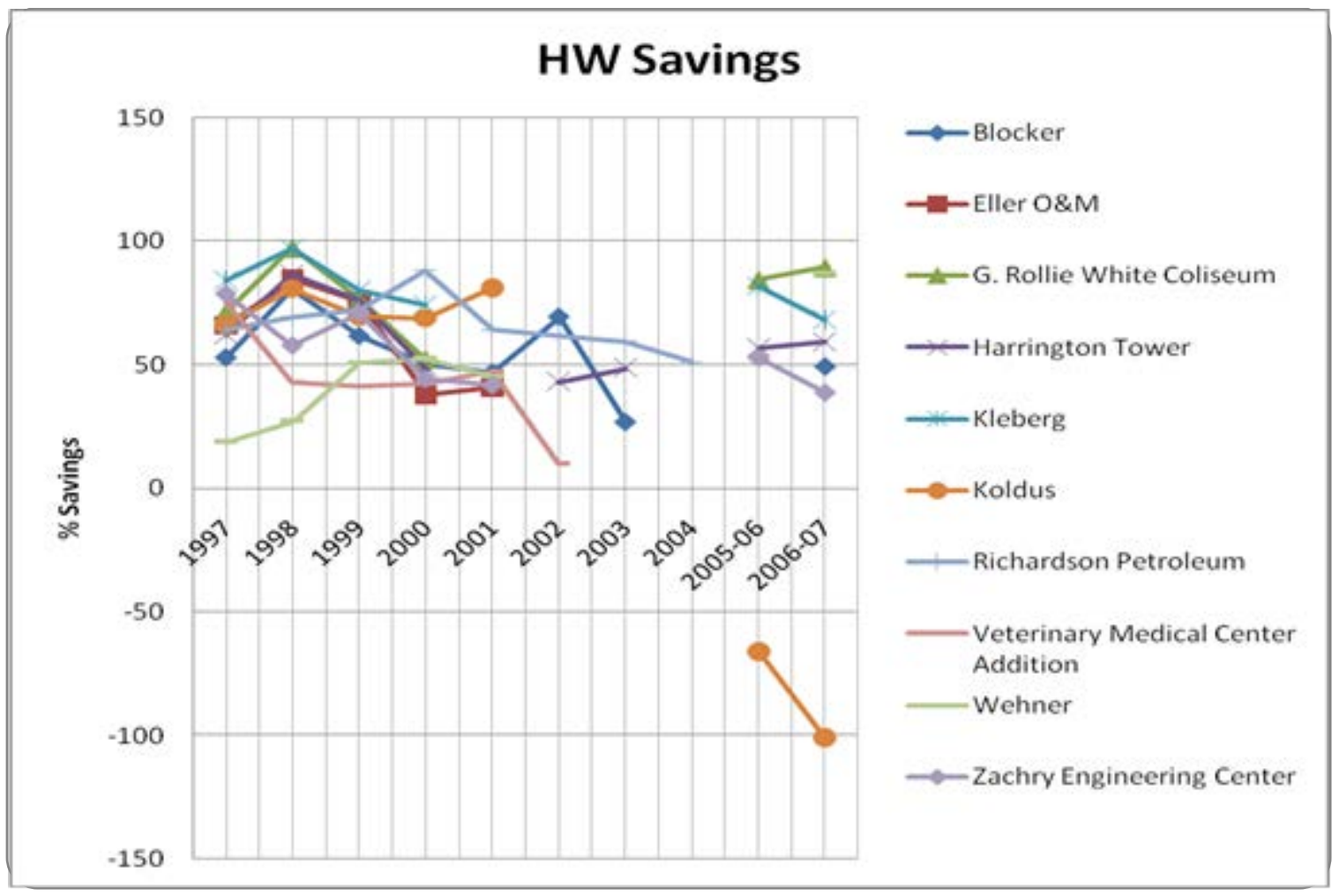

Figure 3.15 Hot water savings trends over time for the ten buildings studied.

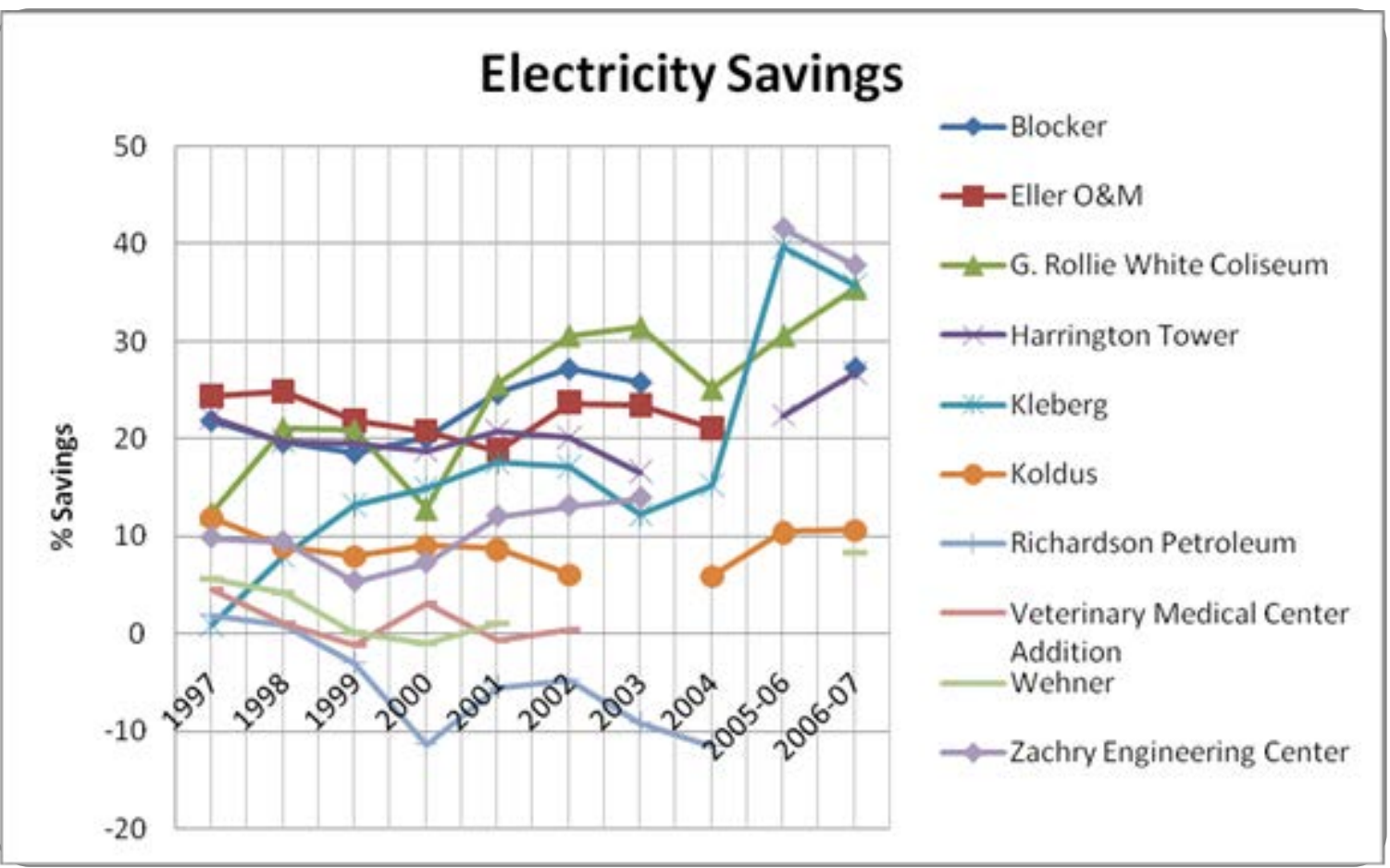

Figure 3.16 Electricity savings trends over time for the ten buildings studied. 


\section{Blocker}

The savings trends for chilled water, hot water, and electricity consumption for the Blocker Building are shown in bar graph form in Fig. 3.17.

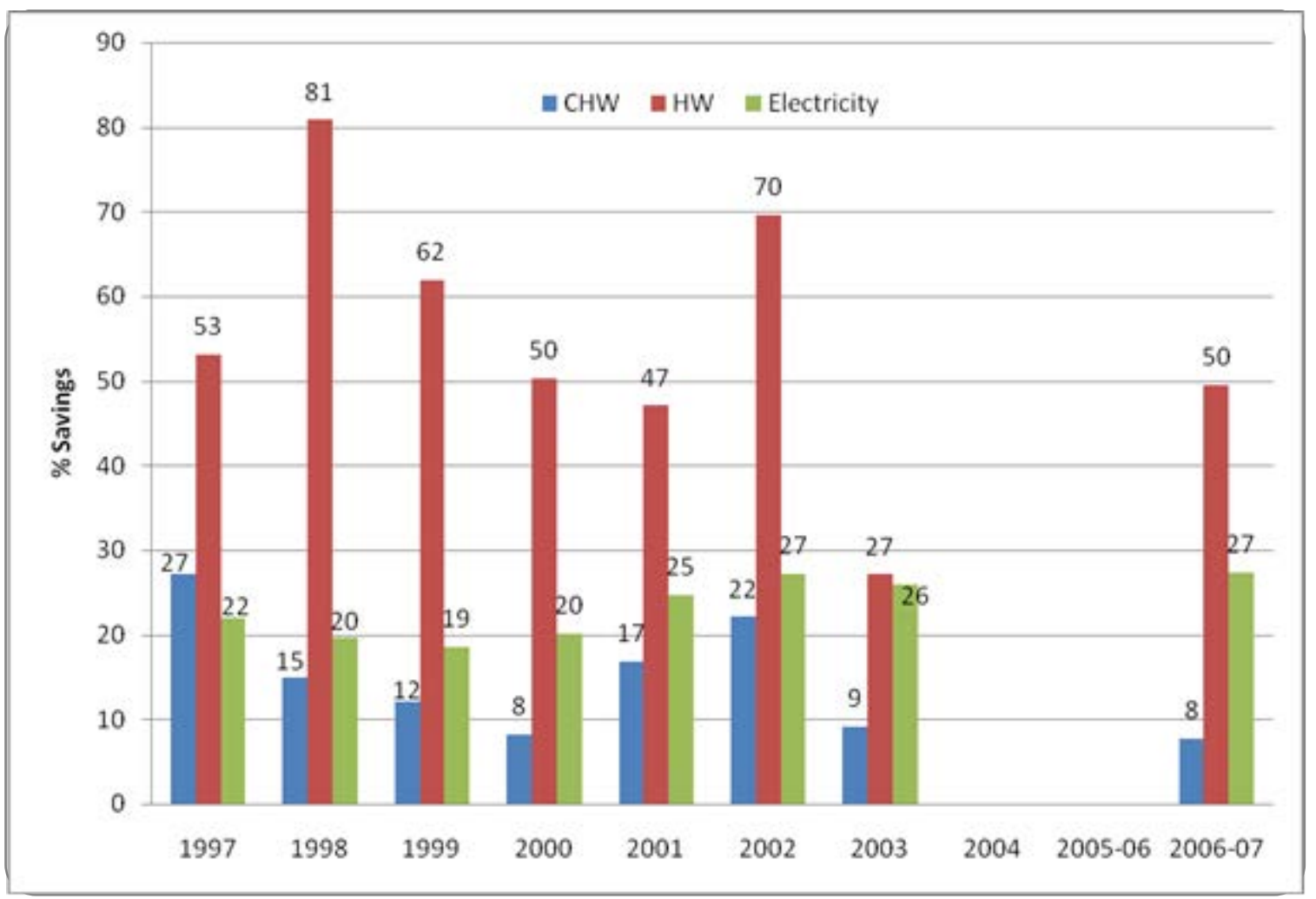

Figure 3.17 Normalized energy savings patterns for the Blocker Building.

The chilled water savings achieved in 1997 was $27 \%$, but had degraded to $8 \%$ by 2000 . However, over the next two years the chilled water savings increased, then fell again, so that by 2006-07 it had again fallen to $8 \%$. The hot water savings achieved in 1997 was $53 \%$, and in 2006-07 was a close $50 \%$. During the years between, however, it rose as high as $81 \%$, while dropping as low as $27 \%$. The electricity savings remained fairly constant in the ten year period, even rising some from $22 \%$ in 1997 to $27 \%$ in 2006-07. 


\section{Eller O\&M}

The savings trends for chilled water, hot water, and electricity consumption for the Eller O\&M Building are shown in bar graph form in Fig. 3.18.

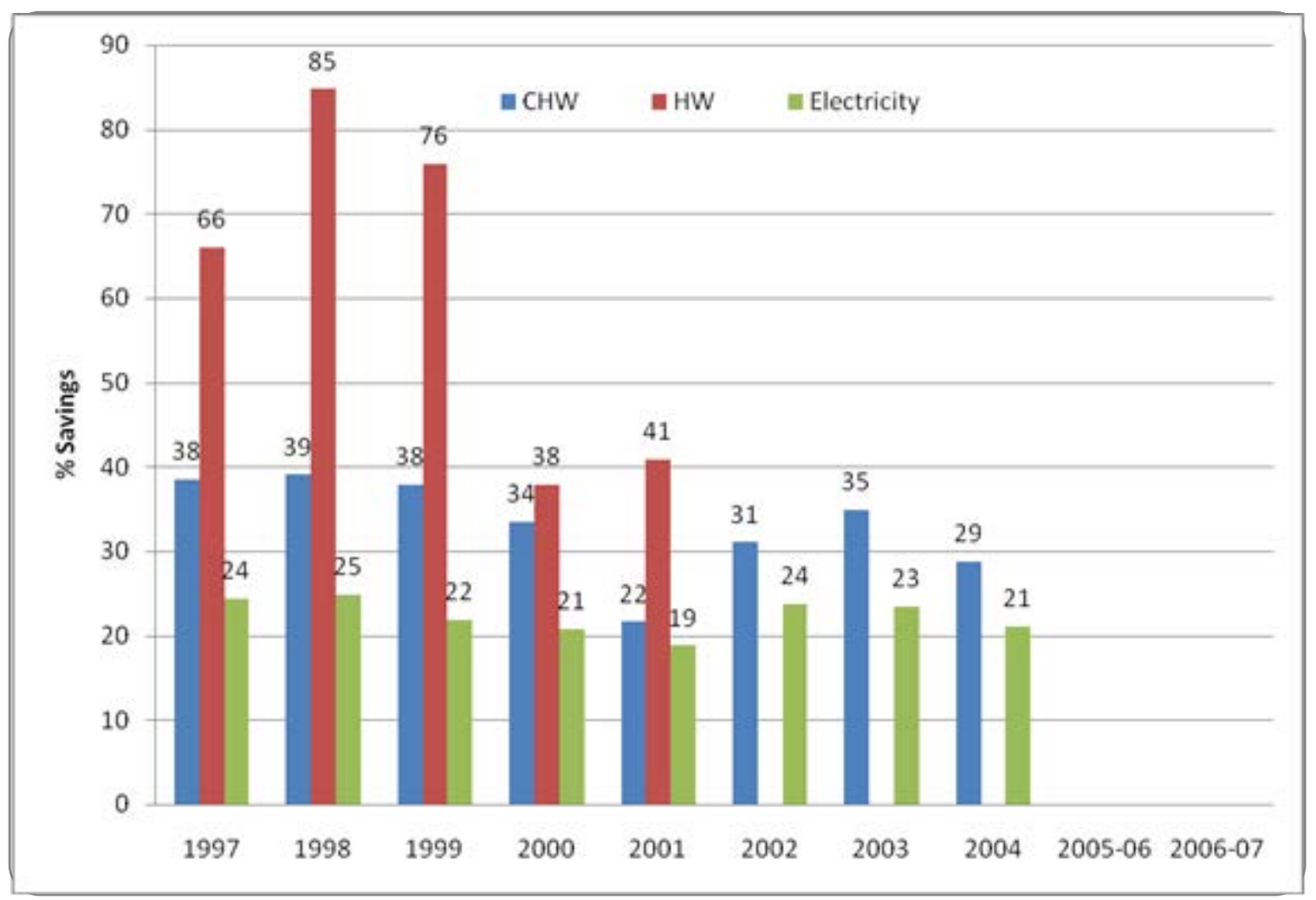

Figure 3.18 Normalized energy savings patterns for the Eller O\&M Building.

The chilled water savings achieved in 1997 was $38 \%$. By 2004, the last year of available data, the savings had degraded slightly to $29 \%$. The hot water savings achieved in 1997 was $66 \%$, increased to $85 \%$ the next year and $76 \%$ the next, and then declined sharply to $38 \%$ and $41 \%$ in the final two years of available data. The electricity savings remained fairly constant in the eight year period of available data, beginning at $24 \%$ in 1997 and falling slightly to $21 \%$ by 2004 . 


\section{G. Rollie White Coliseum}

The savings trends for chilled water, hot water, and electricity consumption for the G. Rollie White Coliseum are shown in bar graph form in Fig. 3.19.

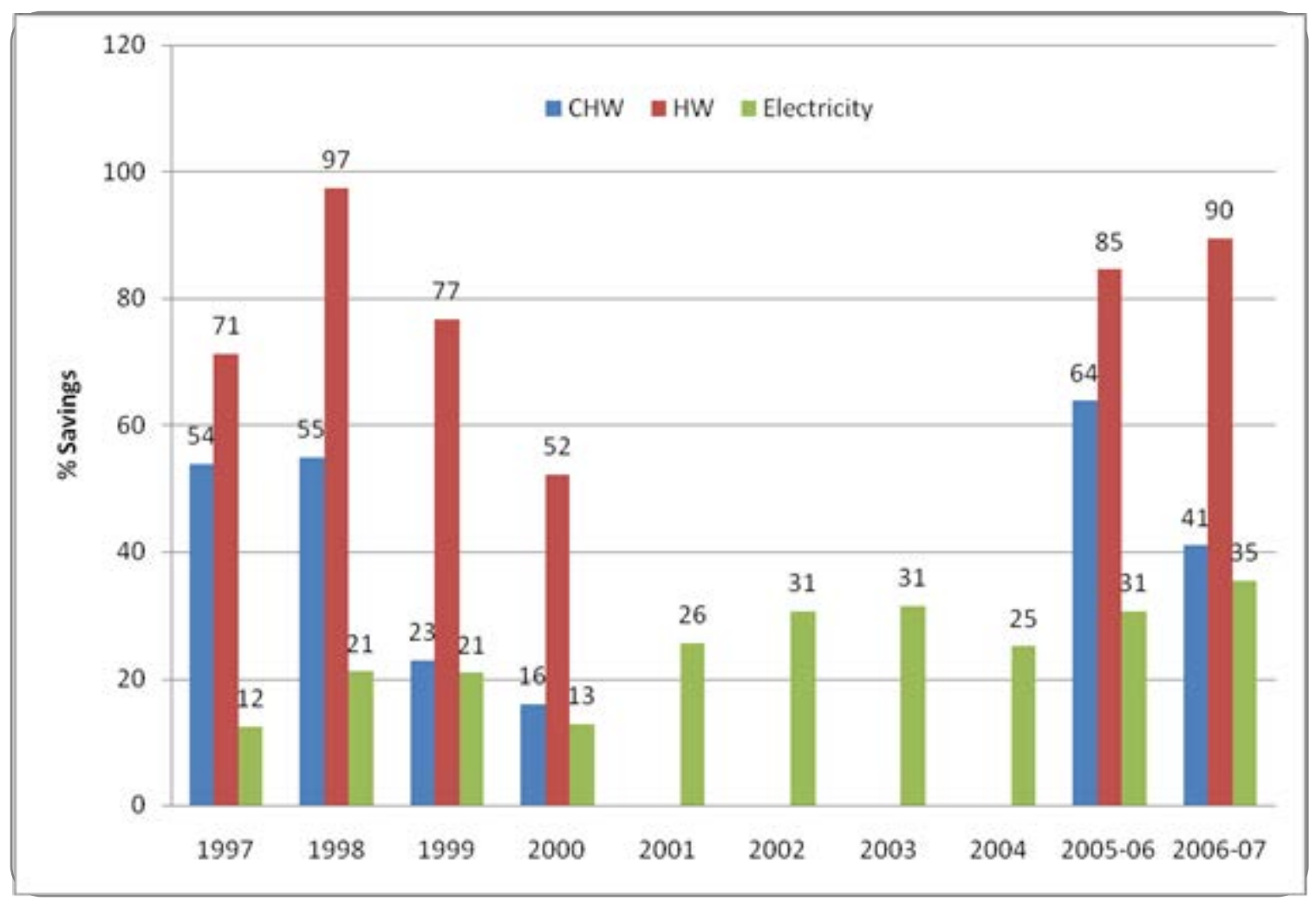

Figure 3.19 Normalized energy savings patterns for the G. Rollie White Coliseum.

The G. Rollie White Coliseum experienced some rather dramatic swings in the level of savings in both chilled water and hot water consumption, particularly in the first few years after retro-commissioning. However, by the later years (2005-2007), the level of savings for hot water was close to or exceeded previous savings, and the level of chilled water savings had risen again and settled out at a level of $41 \%$, or $13 \%$ lower than the 1997 value. The electricity savings actually increased fairly steadily over time, rising from $12 \%$ in 1997 to $35 \%$ in 2006-07. 


\section{Harrington Tower}

The savings trends for chilled water, hot water, and electricity consumption for the Harrington Tower are shown in bar graph form in Fig. 3.20.

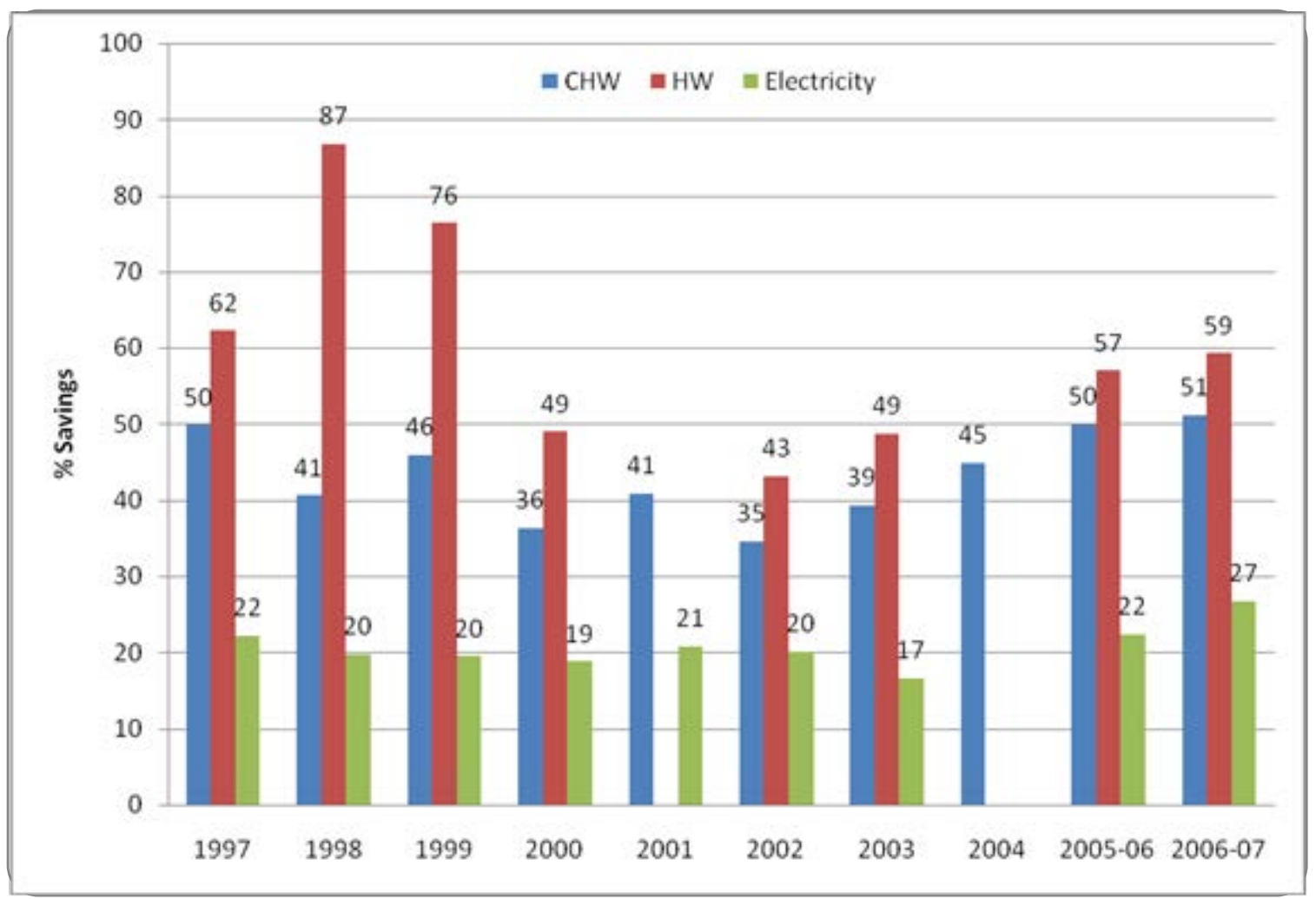

Figure 3.20 Normalized energy savings patterns for the Harrington Tower.

Harrington Tower demonstrated remarkable levels of savings persistence in both chilled water and electricity consumption, actually increasing slightly in the level of savings of each in a ten year period. While the hot water savings ended up considerably lower than the peak level achieved (down to $59 \%$ from $87 \%$ ), it had risen in later years, and ended very close to the level achieved originally in 1997 (62 $\%)$. 


\section{Kleberg}

The savings trends for chilled water, hot water, and electricity consumption for the Kleberg Building are shown in bar graph form in Fig. 3.21.

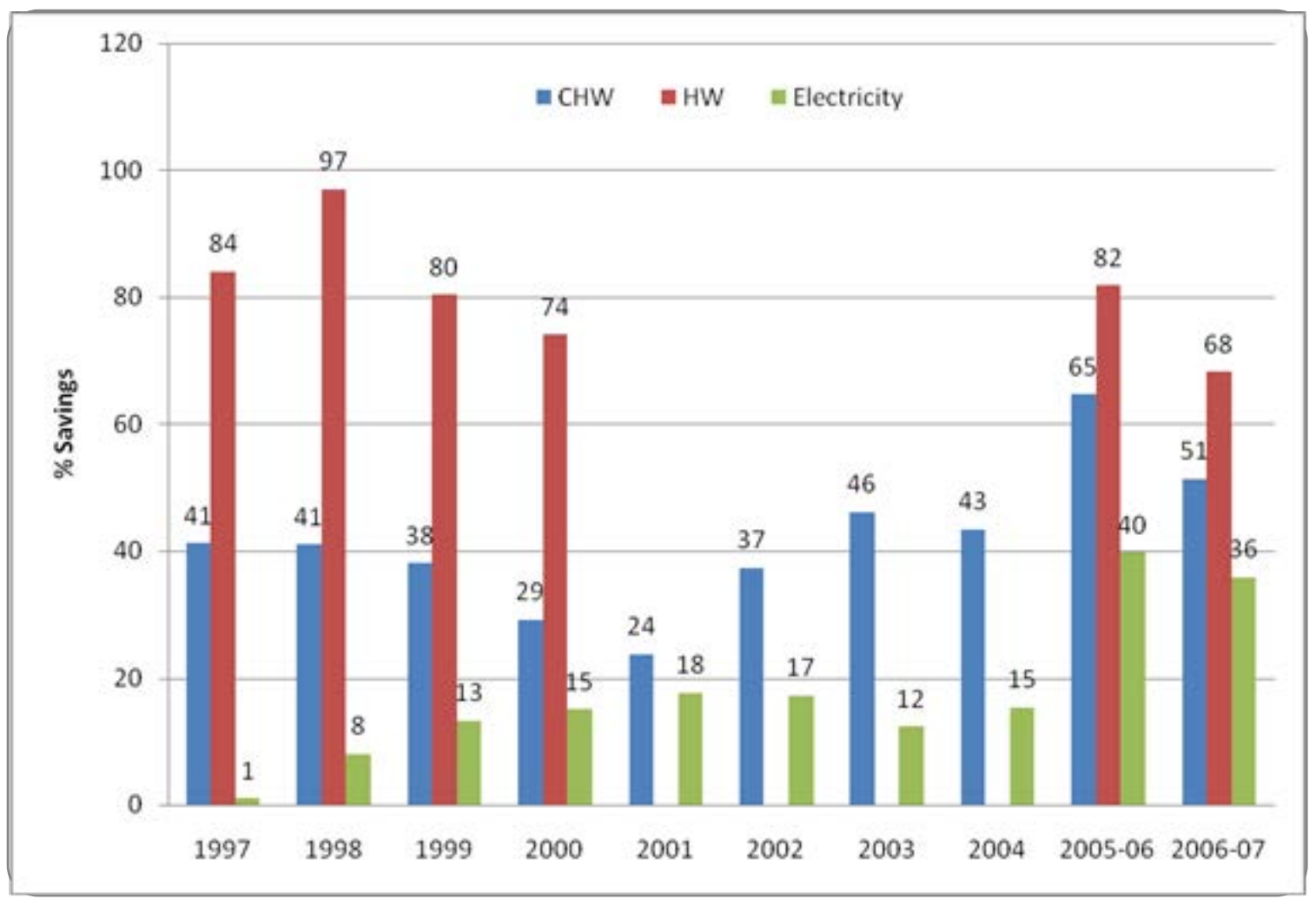

Figure 3.21 Normalized energy savings patterns for the Kleberg Building.

The level of hot water savings in Kleberg decreased from a peak of $97 \%$ in 1998 to $68 \%$ in 2006-07. However, the chilled water savings increased during the same period, rising from $41 \%$ in 1997 to as high as $65 \%$ in 2005-06, and settling back to $51 \%$ in the most recent year. Electricity savings were higher in every subsequent year following 1997, beginning at just $1 \%$ and ending at $36 \%$. 


\section{Koldus}

The savings trends for chilled water, hot water, and electricity consumption for the Koldus Building are shown in bar graph form in Fig. 3.22.

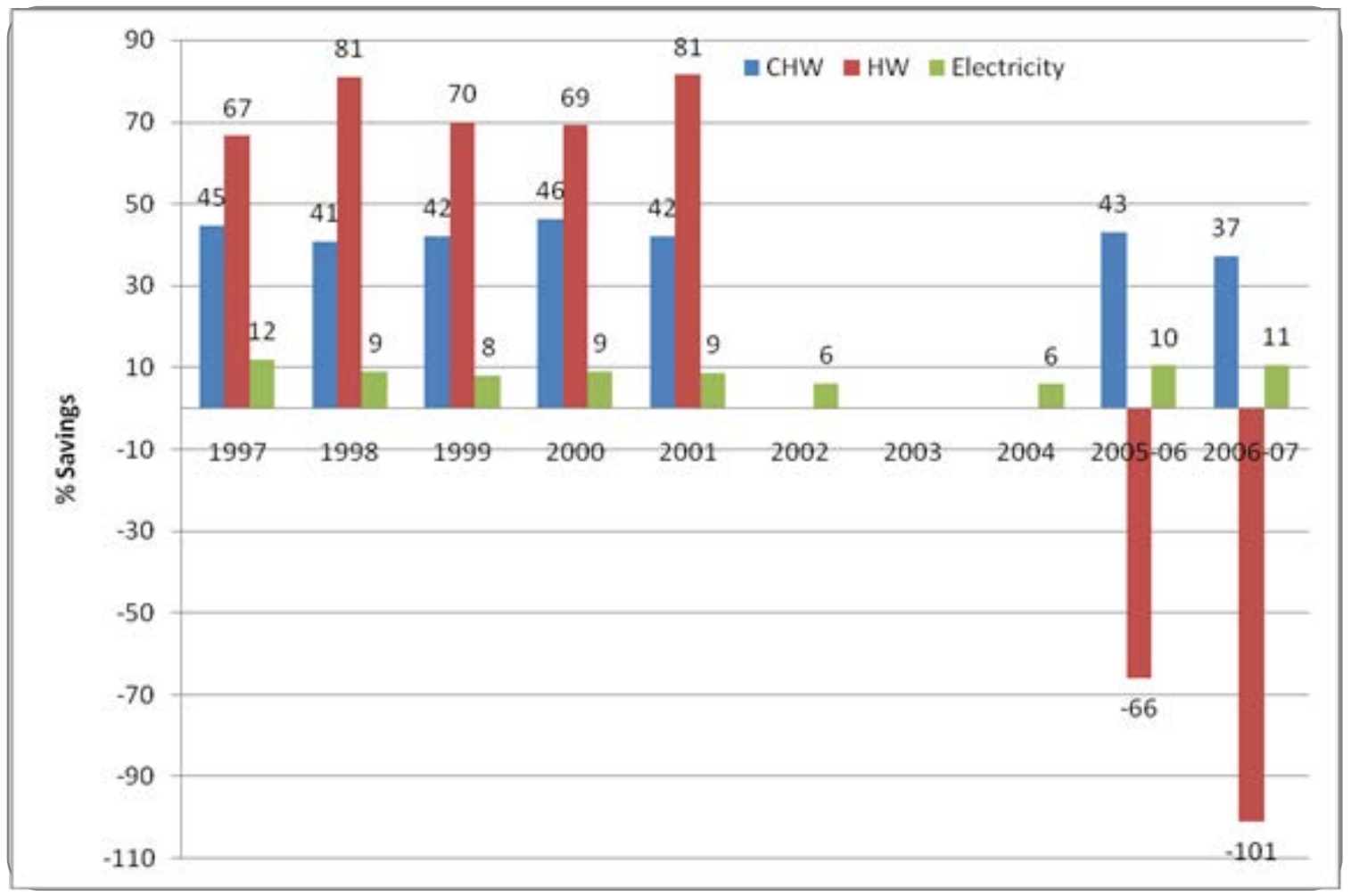

Figure 3.22 Normalized energy savings patterns for the Koldus Building.

The Koldus building demonstrated high levels of persistence in both chilled water and electricity savings over a ten year period. However, it also experienced a huge increase in hot water consumption in the most recent years, even doubling pre-retro-commissioning consumption levels. This was by far the most significant example of savings degradation noted in the ten buildings during the period studied. However, as will be discussed later, this may have been due to metering issues and not actual degradation. 


\section{Richardson Petroleum}

The savings trends for chilled water, hot water, and electricity consumption for the Richardson Petroleum Building are shown in bar graph form in Fig. 3.23.

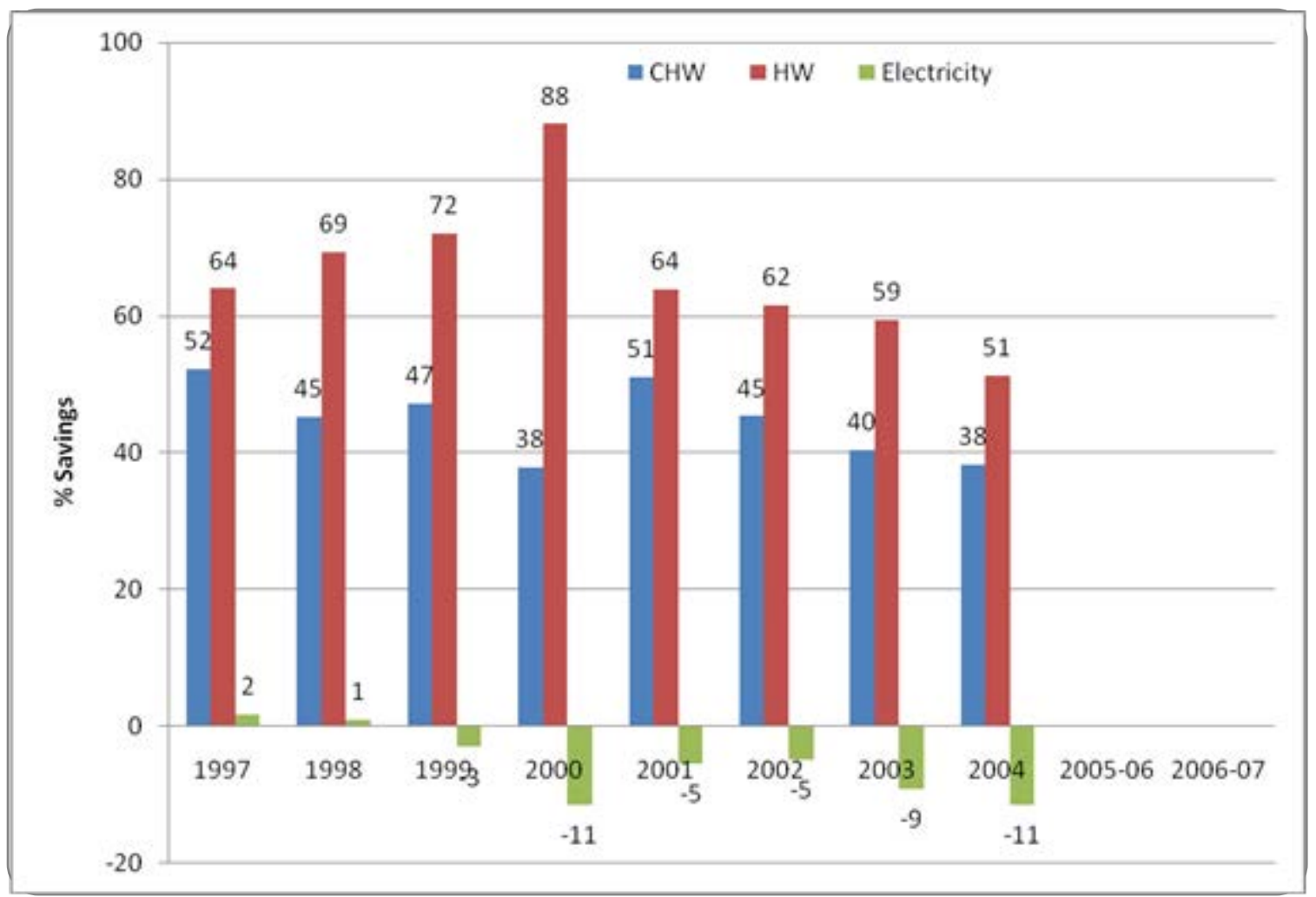

Figure 3.23 Normalized energy savings patterns for the Richardson Petroleum Building.

The chilled water savings for the Richardson Petroleum Building remained fairly steady, and in an eight year period fell only from $52 \%$ to $38 \%$. The hot water savings increased in each of the first four years after retro-commissioning, peaking at $88 \%$, but then fell in succeeding years to a level of $51 \%$ in 2004 . Electricity savings had fallen to the negative range by the third year after commissioning, and ended in 2004 at $-11 \%$, from the $2 \%$ level in 1997. 


\section{Veterinary Medical Center Addition}

The savings trends for chilled water, hot water, and electricity consumption for the Veterinary Medical Center Addition are shown in bar graph form in Fig. 3.24.

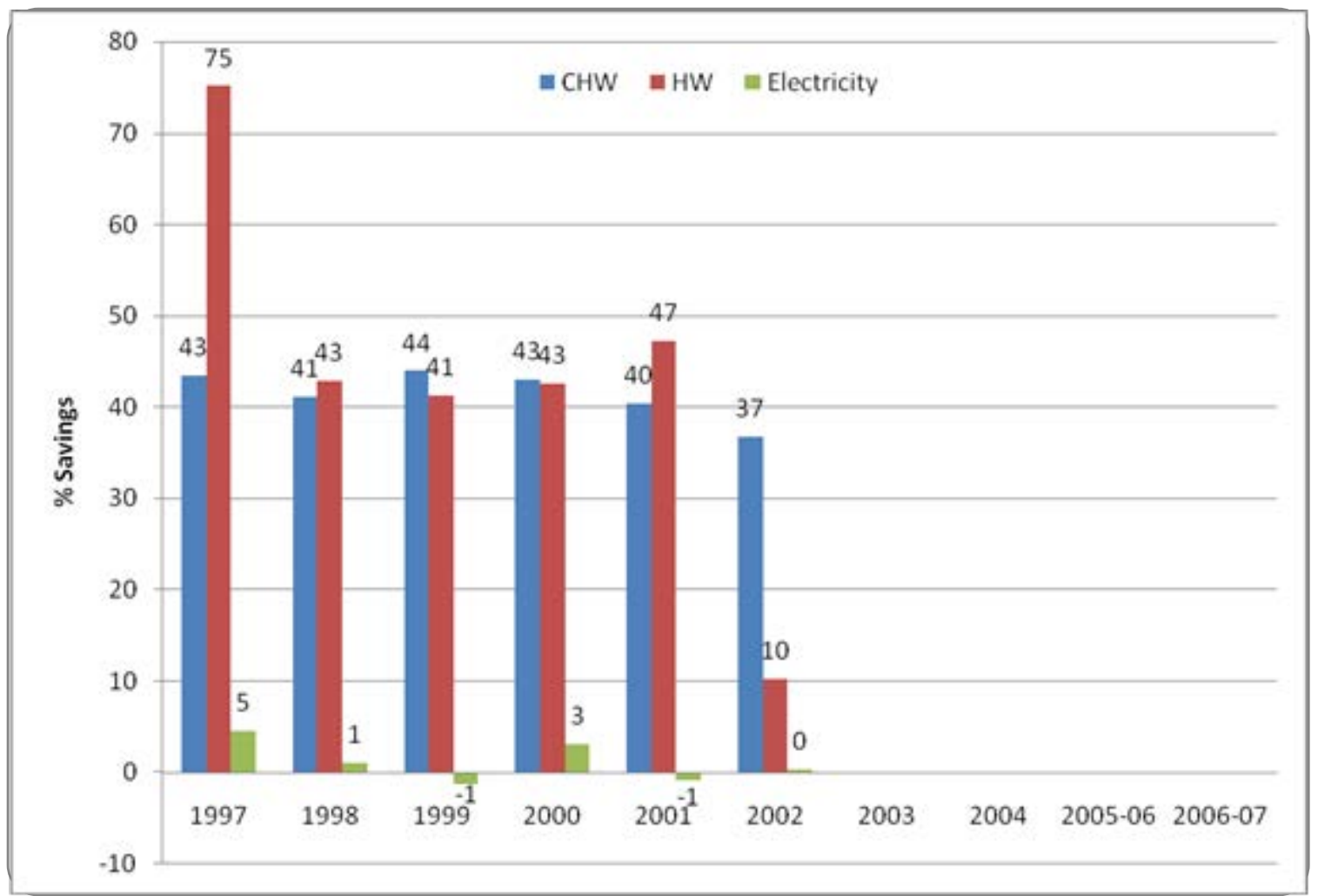

Figure 3.24 Normalized energy savings patterns for the Veterinary Medical Center Addition.

The Veterinary Medical Center Addition had the least amount of reliable energy data available, but a six year period following retro-commissioning was able to be examined. During this time chilled water savings remained consistent, falling only to $37 \%$ in 2002 from $43 \%$ in 1997 . Electricity savings essentially degraded to none after a $5 \%$ level initially. Hot water savings was $75 \%$ in 1997, fell sharply to $43 \%$ in 1998, remained very close to that level for the next three years, then fell sharply again to just $10 \%$ in 2002. 


\section{Wehner}

The savings trends for chilled water, hot water, and electricity consumption for the Wehner Building are shown in bar graph form in Fig. 3.25.

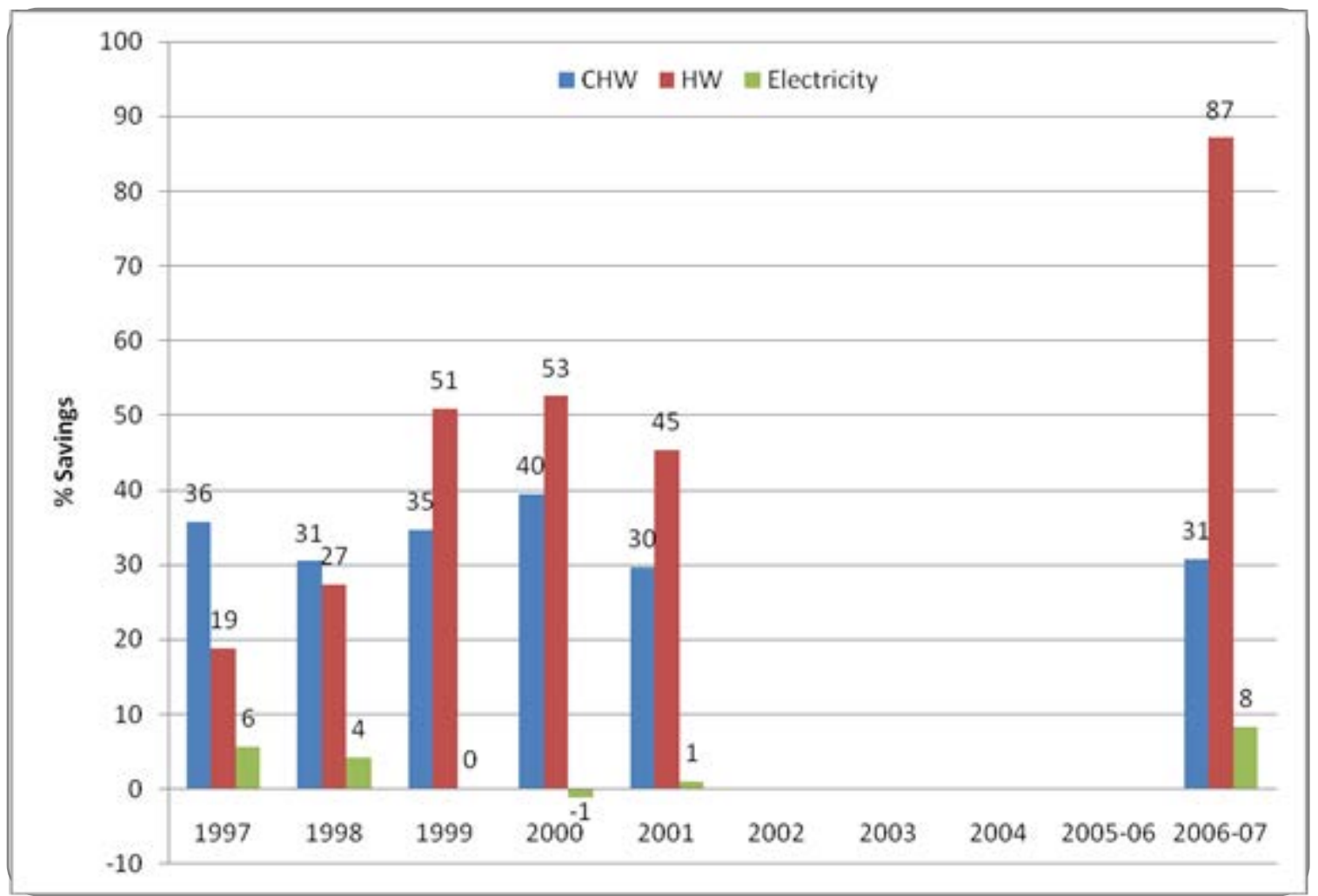

Figure 3.25 Normalized energy savings patterns for the Wehner Building.

The Wehner Building experienced good persistence in chilled water savings over time. Hot water savings increased in the years following retro-commissioning, and remained high in the most recent data year, based on the calibrated simulation model used. Electricity savings degraded some in the years following commissioning, but increased back to a level slightly higher than the 1997 level in the most recent data year, based on the calibrated simulation model. 


\section{Zachry Engineering Center}

The savings trends for chilled water, hot water, and electricity consumption for the Zachry Engineering Center are shown in bar graph form in Fig. 3.26.

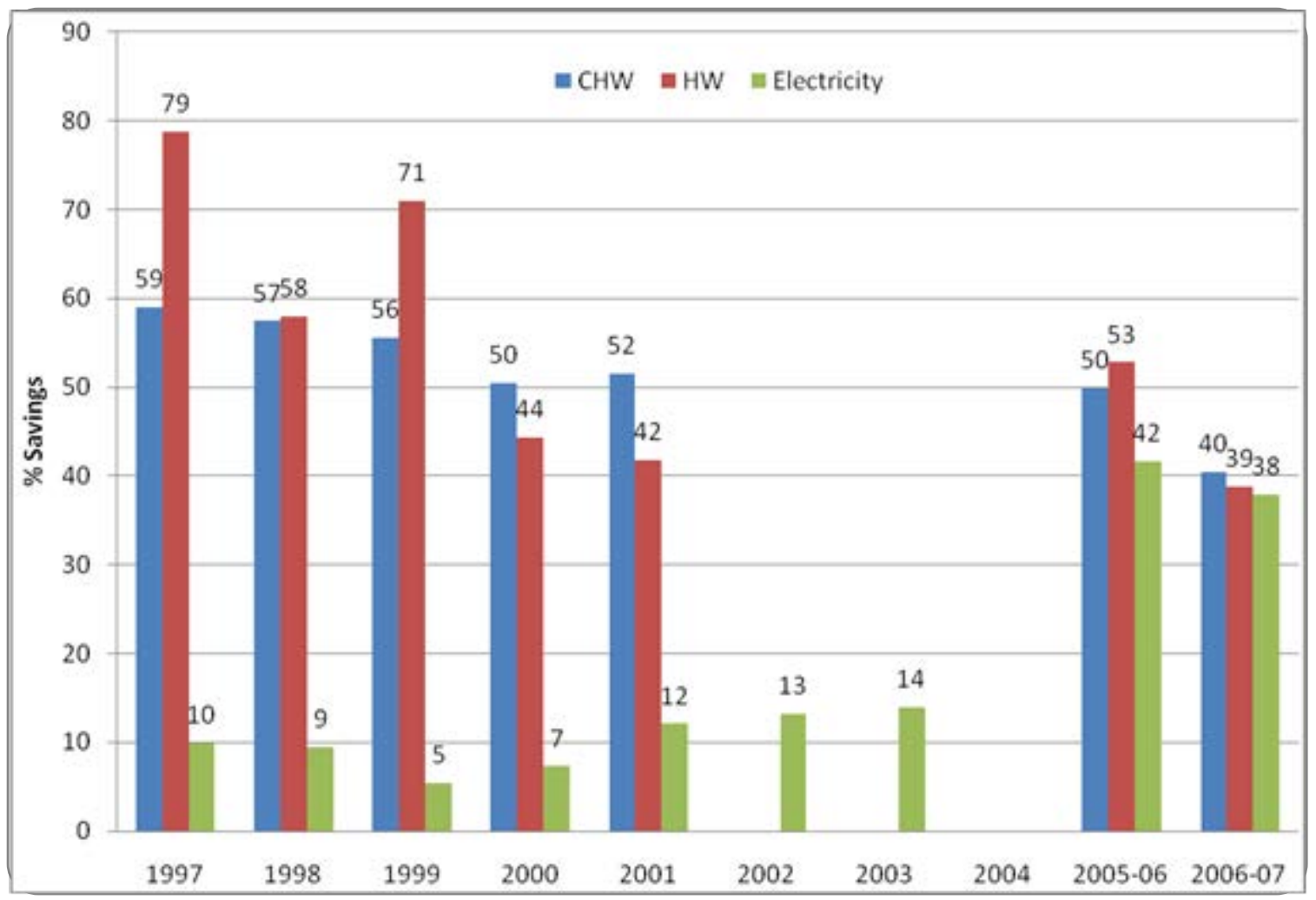

Figure 3.26 Normalized energy savings patterns for the Zachry Engineering Center.

The chilled water savings in the Zachry Engineering Center degraded from 59 \% in 1997 to $40 \%$ in 200607. The hot water savings fluctuated in the first few years after retro--commissioning. In 1997 it was at its highest level, $79 \%$, but had degraded to $39 \%$ by 2006-07. Electricity consumption was a different story, however, beginning at $10 \%$ in 1997, holding fairly constant for several years thereafter, then jumping to $42 \%$ in 2005-06, and ending at $38 \%$ in the most recent year.

\subsubsection{Summary of Recent Persistence Studies}

As a group, the four Japanese buildings studied are consistent with the commissioned buildings that have been examined in the literature review - most continue to show savings over periods that in this case run from 10 to 20 years, while generally showing some decrease in savings over time.

The fundamental conclusion from the additional study of ten buildings at Texas A\&M is that cooling and heating savings did not change appreciably during the up to seven years of additional data following the year 2000. The average cooling savings were $45 \%$ in 1997, $34 \%$ in 2000 and $36 \%$ in the last year of good data for each building (average of 2005.9). Heating savings averaged $63 \%$ in 1997, $56 \%$ in 2000 and $55 \%$ in the last year of available data (average 2005-06). It should be noted that follow-up commissioning was conducted in most of these buildings at least once. 


\subsection{References}

ASHRAE. 1996. ASHRAE Guideline 1-1996: The HVAC Commissioning Process. Atlanta: American Society of Heating, Ventilating, and Air Conditioning Engineers, Inc.

Bourassa, N.J., M.A. Piette, N. Motegi., "Evaluation of Persistence of Savings from SMUD Retrocommissioning Program - Final Report," Lawrence Berkeley National Laboratory, May 2004. LBNL54984

Chen, H., S. Deng, and H. Bruner. 2004. Continuous Commissioning ${ }^{S M}$ Report for Civil Engineering \& Texas Transportation Institute (CE/TTI) Building. Energy Systems Laboratory, Texas A\&M University, College Station, TX.

Chen, Hui, Song Deng, Homer Bruner, David Claridge and W.D. Turner, "Continuous Commissioning ${ }^{\mathrm{SM}}$ Results Verification And Follow-Up For An Institutional Building - A Case Study," Proc. $13^{\text {th }}$ Symposium on Improving Building Systems in Hot and Humid Climates, May 20-23, 2002, Houston, TX, pp. 87-95.

Cho, Sool Yeon, "The Persistence of Savings Obtained from Commissioning of Existing Buildings," M.S. Thesis, Mechanical Engineering Department, Texas A\&M University, ESL-TR-02-05-01, May, 2002, 347 pp.

Claridge, D. E., N. Bensouda, S. Lee, G. Wei, K. Heinemeier, and M. Liu. 2003. Manual of Procedures for Calibrating Simulations of Building Systems. Prepared for Lawrence Berkeley National Laboratory, Berkeley, CA.

Claridge, D.E., Turner, W.D., Liu, M., Deng, S., Wei, G., Culp, C., Chen, H. and Cho, S.Y., "Is Commissioning Once Enough?," Solutions for Energy Security \& Facility Management Challenges: Proc. Of the $25^{\text {th }}$ WEEC, Atlanta, GA, pp. 29-36, Oct. 9-11, 2002.

Claridge, D.E., Turner, W.D., Liu, M., Deng, S., Wei, G., Culp, C., Chen, H., and Cho, S.Y., "Is Commissioning Once Enough?" Energy Engineering, Vol. 101, No. 4, 2004, pp. 7-19.

Fels, M. 1986. PRISM: An Introduction. Energy and Buildings 9(1 and 2): 5-18.

Frank, M., Friedman, H., Heinemeier, K., Toole, C., Claridge, D., Castro, N., and Haves, P., 2005, "Existing Cost/Benefit and Persistence Methodologies and Data, State of Development of Automated Tools, and Assessment of Needs for Commissioning ZEB," Draft report submitted to U.S. Department of Energy under Contract No. DE-AC02-05CH11231, 78 pp., August.

Friedman, H., Potter, A., Haasl, T., and Claridge, D., "Persistence of Benefits from New Building Commissioning," Proceedings of the 2002 ACEEE Summer Study on Energy Efficiency in Buildings, Pacific Grove, CA, Aug. 19-23, 2002, pp. 3.129 - 3.140.

Friedman, H., Potter, A., Haasl, T., Claridge, D and Cho, S., "Persistence of Benefits from New Building Commissioning," Proc. Of $11^{\text {th }}$ National Conference on Building Commissioning, Palm Springs, CA, May 20-22, 2003a, 15 pp., CD.

Friedman, H., A. Potter, T. Haasl, and D. Claridge, "Report on Strategies for Improving Persistence of Commissioning Benefits - Final Report," July 2003b, 47 pp. Lawrence Berkeley National Laboratory. http://buildings.lbl.gov/hpcbs/pubs/E5P22T5c-Final.pdf

IPMVP 2001. IPMVP Committee, International Performance Measurement \& Verification Protocol: Concepts and Options for Determining Energy and Water Savings, Vol. 1, U.S. Dept. of Energy, DOE/GO-102001-1187, 86 pp., January. 
IPMVP Technical Committee. 2002. International Performance Measurement \& Verification Protocol Volume 1: Concepts and Options for Determining Energy and Water Savings. U.S. Dept. of Energy: 86.

Katipamula, S., T.A. Reddy, and D.E. Claridge. 1995. Effect of Time Resolution on Statistical Modeling of Cooling Energy Use in Large Commercial Buildings. ASHRAE Transactions 101(2).

Liu, M. 1995. Manual for AirModel. Energy Systems Laboratory, Texas A\&M University, College Station, TX.

Liu, M., Claridge, D. E. and Turner, W.D., 2002, Continuous Commissioning ${ }^{S M}$ Guidebook: Maximizing Building Energy Efficiency and Comfort, Federal Energy Management Program, U.S. Dept. of Energy, 144 pp., Available at http://www.eere.energy.gov/femp/operations_maintenance/commissioning_guidebook.cfm

Liu, C., Turner, W.D., Claridge, D., Deng, S. and Bruner, H.L., "Results of CC Follow-Up in the G. Rollie White Building," Proc. $13^{\text {th }}$ Symposium on Improving Building Systems in Hot and Humid Climates, May 20-23, 2002, Houston, TX, pp. 96-102.

Mills, E., H. Friedman, T. Powell, N. Bourassa, D. Claridge, T. Haasl, and M. Piette, "The CostEffectiveness of Commercial-Buildings Commissioning: A Meta-Analysis of Energy and Non-Energy Impacts in Existing Buildings and New Construction in the United States," December 2004. LBNL-56637.

Mills, E., N. Bourassa, M.A. Piette, H. Friedman, T. Haasl, T. Powell, and D. Claridge. "The CostEffectiveness of Commissioning New and Existing Commercial Buildings: Lessons from 224 Buildings," Proceedings of the 2005 National Conference on Building Commissioning, Portland Energy Conservation, Inc., New York, New York, May, 2005.

http://www.peci.org/ncbc/proceedings/2005/19_Piette_NCBC2005.pdf

National Climatic Data Center (NCDC). Viewed 21 September 2006. http://cdo.ncdc.noaa.gov/pls/plcimprod/cdomain.abbrev2id

Peterson, Janice, "Evaluation of Retro-commissioning Results After Four Years: A Case Study," Proceedings of the 2005 National Conference on Building Commissioning, Portland Energy Conservation, Inc., New York, New York.

Selch, M. and J. Bradford, "Re-commissioning Energy Savings Persistence," Proceedings of the 2005 National Conference on Building Commissioning, Portland Energy Conservation, Inc., New York, New York, May, 2005.

Shao, X. 2005. First Law Energy Balance as a Data Screening Tool. M.S. Thesis, Texas A\&M University, Department of Mechanical Engineering, College Station, TX.

Toole, C., "The Persistence of Retrocommissioning Savings in 10 University Buildings," M.S. Thesis, Mechanical Engineering Department, Texas A\&M University, Dec, 2009,

Turner, W.D., Claridge, D.E., Deng, S., Cho, S., Liu, M., Hagge, T., Darnell, C., Jr., and Bruner, H., Jr., "Persistence of Savings Obtained from Continuous Commissioning ${ }^{\text {SM }}$," Proc. of 9th National Conference on Building Commissioning, Cherry Hill, NJ, p. 20-1.1 - 20-1.13, May 9-11, 2001.

Wei, G., M. Liu, and D.E. Claridge. 1998. Signatures of Heating and Cooling Energy Consumption for Typical AHUs. Proceedings of the Eleventh Symposium on Improving Building Systems in Hot and Humid Climates. Fort Worth, TX.

Yamaha, Motoi, "Persistence Surveys in Japan," Powerpoint presentation A47-C2-M5- JP-CU-1 at IEA Annex 47 Meeting 5, Kyoto, Japan, October, 2007. 


\section{TOOLS TO ENHANCE PERSISTENCE}

\subsection{An Automated Building Commissioning Analysis Tool (ABCAT)}

\subsubsection{Introduction}

In the United States, slightly more than one-third of the total primary energy consumption is used in the building sector. Commercial buildings alone cost $18 \%$ of the total energy use in the U.S. in 2007 (Energy Information Administration. 2007). Energy conservation programs for the building sector would contribute to the reduction of energy sources waste. Building commissioning services, which either ensure that building systems are installed and operated to provide the performance envisioned by the designer or identify and implement optimal operating strategies for buildings as they are currently being used, have proven to be successful in saving building energy consumption. A broad and major study of 224 new and existing commercial buildings in 21 states across the country, commissioned by 18 different commissioning service providers, netted a median savings of $15 \%$ of whole building energy use (Mills et al. 2005). The Energy Systems Laboratory at Texas A\&M University (TAMU) started Continuous Commissioning $^{\circledR 1}\left(C C^{\circledR}\right)$ in 1996. The $C C^{\circledR}$ process has produced average energy savings of about 20 percent without significant capital investment in over 150 large buildings in which it has been implemented (Claridge et al. 2004).

Though commissioning services are effective in reducing building energy consumption, the optimal energy performance obtained by commissioning may subsequently degrade, as described in Chapter 3. The persistence of savings is a significant topic of concern. Claridge et al. (2004) presented the results of a study of the persistence of savings in ten university buildings that averaged an increase of chilled water (CHW) and hot water (HW) costs by $12.1 \%$ over a two year period post-commissioning. Almost $75 \%$ of this increase was caused by significant component failures and/or control changes that did not compromise comfort but caused large changes in consumption. The remainder was due to control changes implemented by the operators (Claridge et al. 2004, Turner et al. 2001). The major increases were not identified until two years had passed, and hundreds of thousands of dollars in excess energy costs had already occurred. Obviously there is a need for a simple, cost efficient automated system that can continuously monitor building energy consumption, alert operations personnel early upon the onset of significant increases in consumption and assist them in identifying the problem. The Automated Building Commissioning Analysis Tool (ABCAT) is one of several such tools for maintaining the optimal energy performance in a building.

ABCAT was originally initiated by Lee and Claridge (2003), and has developed to an advanced prototype by Curtin et al. (2007), along with demonstrating its effectiveness in live and retrospective building implementations. This report describes the functions of the advanced prototype ABCAT tool and provides a summary of its live testing results on six buildings and retrospective testing results on five buildings. The tool has not yet been commercialized.

\section{ABCAT Description}

The fault detection and diagnosis approach to be undertaken in ABCAT will be applied to the whole building energy consumption level and is simplified to aid in the practicality of its implementation outside of the university and research lab setting. First, a building energy simulation model using the American Society of Heating, Refrigerating and Air-Conditioning Engineers (ASHRAE) simplified energy analysis procedure (Knebel et al. 1983) is established and calibrated based on the building CHW and HW consumption in the baseline period chosen from a post-commissioning time period when the building's operation is considered to be optimal. Second, subsequent CHW and HW consumption is predicted by the model using future weather data and building electricity consumption. Third, both the simulated and measured consumption are passed to the data analysis routine that generates building performance 
plots, compares and performs calculations on the simulated and measured consumption data, applies fault detection methods, and reports diagnostic and energy consumption statistics. Finally, the user of the tool evaluates the data presented and determines whether or not there is a fault that requires action. If a fault is identified, the user or other experts can use the diagnostic information provided by ABCAT to help identify and correct the fault, and follow up observations should observe a return to expected performance.

The ABCAT is initially setup in a building through the following sequence of steps:

1. Define a Baseline Consumption Period and Collect Baseline Measurements

The baseline period should correspond to a time when the building mechanical systems are known to be operating correctly, typically post new building commissioning (Cx) or existing building commissioning $(E B C x)$. The length of baseline can be a minimum of four weeks if during the swing seasons where a wide range of outside air temperatures is experience and heating and cooling systems are both operating. Required measurements include whole building heating (WBHeat) whole building cooling (WBCool), whole building electric (WBElec), ambient outside air temperature and relative humidity or dew point temperature, all recorded in hourly intervals.

Figure 4.1 describes the consumption monitoring that is required for the ABCAT. Ideally the WBHeat and the WBCool would be obtained by Btu metering of chilled and hot water, but these values could also be obtained by modeling the chiller and boiler if interval meters exist that monitor chiller electric loads and natural gas consumption.

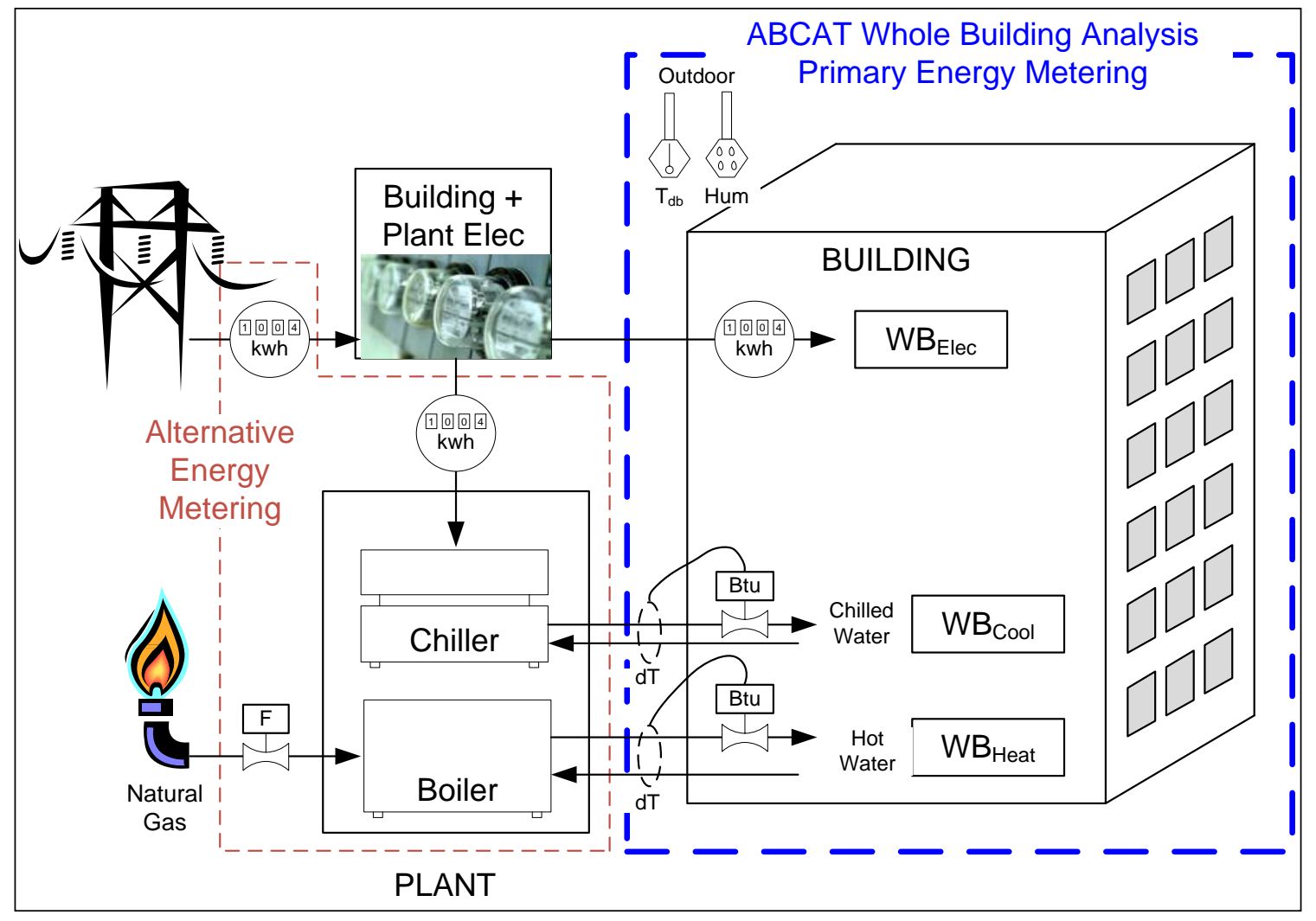

Figure 4.1. Consumption metering requirements for $A B C A T$ 
2. Obtain Building and Air Handling Unit System Details

The key characteristics of the building and its heating ventilation and air-conditioning (HVAC) systems that must be included in the model are:

(1) Envelope Area and Heat Transfer Coefficient

(2) Solar Radiation Load

(3) Internal Heat Gain from Equipment and Lighting (taken as fraction of measured electric load)

(4) Deck Temperature Schedules

(5) Maximum and Minimum Air Flow Rates,

(6) Outside Air Intake and Economizer Settings

(7) Occupancy Schedule

(8) AHU Operation Schedule

(9) Humidification Operations.

Liu et al. (1998) describes the steps for an initial value selection of these parameters in a model with similar input requirements as the ABCAT.

3. Establish Initial Values of Inputs for the Simulation Model and Calibrate the Model Generate an input file for simulation based on measured data and system information, and calibrate or tune the model inputs until desired accuracy is achieved.

\section{Correct for Bias in Model}

Provide a final adjustment to simulation model by calculating the mean bias error (MBE) and subtracting this amount from to the model so that the MBE of the model is zero for the baseline period. Even a small systematic bias in the simulation will decrease the sensitivity of the fault detection process.

\section{Program Regular Data Transfer to ABCAT}

Develop a method by which the required measured inputs can regularly be updated and passed to the ABCAT program. In the current test facilities, Visual Basic for Applications programs link the ABCAT with consumption data files, sorts, fills missing data with linear interpolation when applicable, summarizes and imports the data into the ABCAT program in its required format.

Once the ABCAT is configured for the particular building through steps 1 to 4 , the program is ready for execution.

Figure 4.2 is a process flow diagram which visually describes the following five steps to the ABCAT methodology:

\section{Import Measured Data}

Evoke the program developed in step 5 of the initial setup steps 1 to 5 from the ABCAT program.

\section{Simulate CHW and HW Consumption}

The required inputs are passed to the energy simulation routine, where the $\mathrm{CHW}$ and $\mathrm{HW}$ consumption is simulated. A detailed flow diagram of the ABCAT process through to the execution of the simulation is summarized in Appendix A.

\section{Data Analysis}

The simulated consumption and measured consumption are passed to the data analysis routine that generates the building performance plots, compares and performs calculations on the two values, applies fault detection methods, and reports diagnostic and energy consumption statistics. The current graphical layout of the ABCAT is detailed in Appendix B. 


\section{Evaluation}

The user of the tool is to evaluate the data presented and arrive at the conclusion as to whether or not a fault of enough significance exists such that action is required. The user plays an important role in defining fault triggers and manipulating the plotted data with easily adjustable parameters to suit their site specific preferences. One of the primary metrics established to aid in the user decision is the "Cumulative Energy (or Cost) Difference" plot, previously used by Haberl and Vajda (1988), which accumulates the energy residuals of persistent deviations from measured consumption by adding them to that of the total of the previous day (multiplies the accumulated energy by a user specified utility cost for the Cost Difference plot). The cost plot presents the deviations in the universally understood language of dollars and cents, which is expected to help compel users of the ABCAT to act in the case of a fault.

\section{Action}

If action is deemed necessary, the type of action taken will depend upon if the faulty condition observed is determined to be a result of a required change in operations (where the simulation model would have to be recalibrated) or if it was caused by a system or component failure or a change in control to a less than optimal setting (where repair, maintenance or a control change may be in order). If a fault is identified, the user or other experts can use the diagnostic information provided by ABCAT to help identify and correct the fault, and follow up observations should observe a return to expected performance.

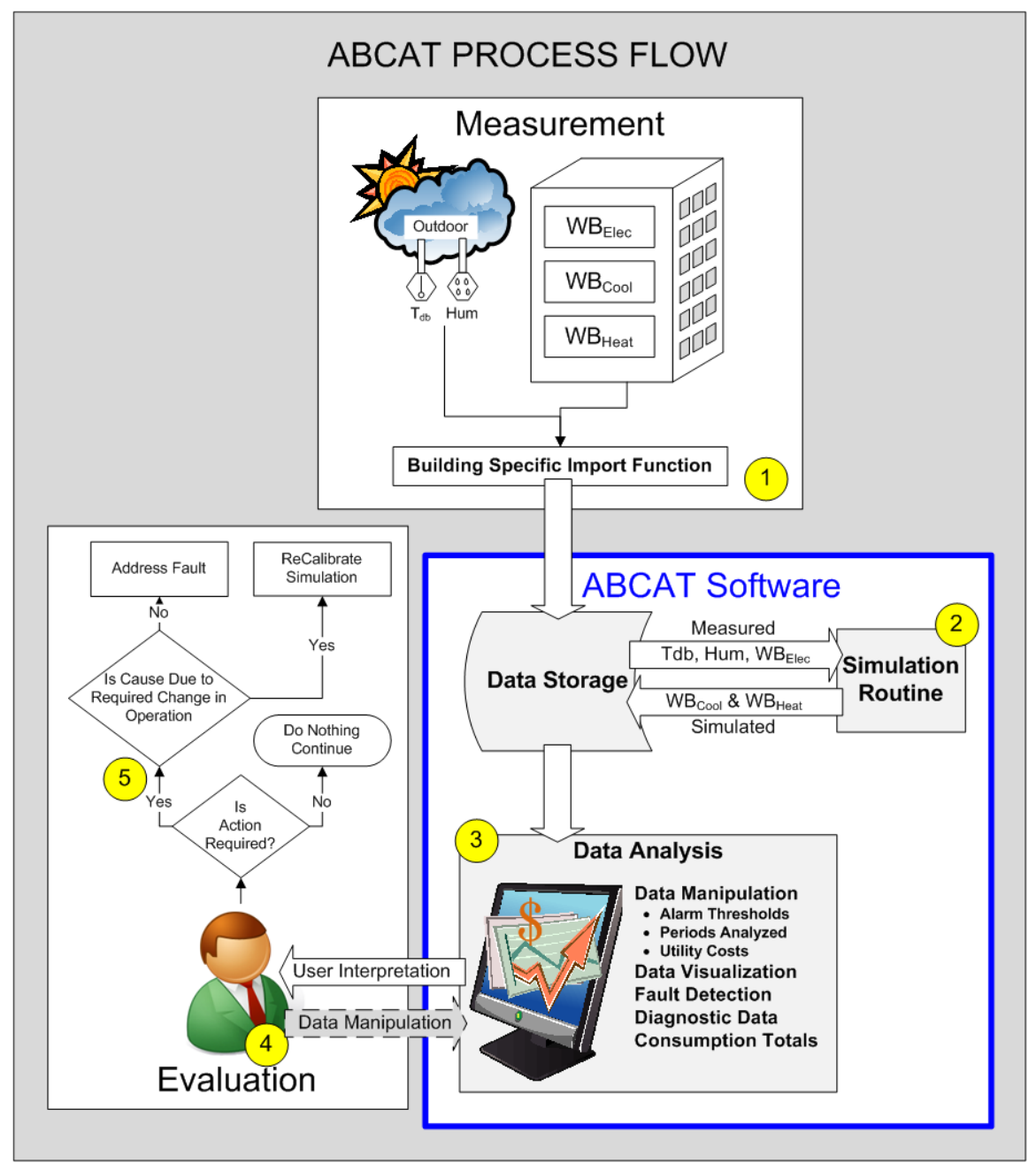

Figure 4.2 ABCAT flow diagram 


\section{Project Results}

\section{Live Test Cases}

The ABCAT was implemented in six live building situations, with various levels of automation and file manipulation were built into a specific data collection process for each building based on its unique conditions regarding data availability and format. The testing of the ABCAT in the six buildings provided a live learning scenario that helped to influence continued developments, and a summary of these test cases is provided in Table 4.1.

Table 4.1 Test buildings, results and findings from live ABCAT implementation

\begin{tabular}{|c|c|c|c|}
\hline $\begin{array}{l}\text { Building } \\
\text { Description }\end{array}$ & Location & Test Period & Results and Findings \\
\hline $\begin{array}{l}7618 \mathrm{~m}^{2} \\
82,000 \mathrm{ft}^{2} \\
\text { university dining } \\
\text { facility }\end{array}$ & $\begin{array}{l}\text { College Station, } \\
\text { Texas }\end{array}$ & $\begin{array}{l}\text { Mar } 2005- \\
\text { July } 2007\end{array}$ & $\begin{array}{l}\text { Detected excess cooling energy fault related } \\
\text { to excessive latent cooling from low } \\
\text { discharge air temperature on } 2 \text { of } 3 \text { Outside } \\
\text { Air Handling Units - Summer } 2006 \text { shown in } \\
\text { Fig. 4.3. }\end{array}$ \\
\hline $\begin{array}{l}44779 \mathrm{~m}^{2} \\
482,000 \mathrm{ft}^{2} \\
\text { computing } \\
\text { services facility }\end{array}$ & $\begin{array}{l}\text { Austin, } \\
\text { Texas }\end{array}$ & $\begin{array}{l}\text { May } 2005- \\
\text { July } 2007\end{array}$ & $\begin{array}{l}\text { - } \begin{array}{l}\text { Detected significant decrease in measured } \\
\text { cooling energy due to meter calibration - } \\
\text { Oct } 2005 \text { (Figure 4.4). } \\
\text { - A second fault, significant excess cooling } \\
\text { energy was detected in Nov } 2006 \text { Fig. 4.5). } \\
\text { - Also demonstration of successful short-term } \\
\text { adaptation of simulation to multiple baseline } \\
\text { changes. }\end{array} \\
\end{array}$ \\
\hline $\begin{array}{l}16723 \mathrm{~m}^{2} \\
180,000 \mathrm{ft}^{2} \\
\text { office building }\end{array}$ & $\begin{array}{l}\text { Albany, } \\
\text { New York }\end{array}$ & $\begin{array}{l}\text { Jan } 2007- \\
\text { July } 2007\end{array}$ & $\begin{array}{l}\text { - Successful monitoring of heating energy } \\
\text { savings following implementation of EBCx } \\
\text { measures Fig. 4.6). } \\
\text { - Training and support for two ABCAT testers. }\end{array}$ \\
\hline $\begin{array}{l}16723 \mathrm{~m}^{2} \\
190,000 \mathrm{ft}^{2} \\
\text { high-rise office } \\
\text { building }\end{array}$ & $\begin{array}{l}\text { Omaha, } \\
\text { Nebraska }\end{array}$ & $\begin{array}{l}\text { Feb } 2007- \\
\text { July } 2007\end{array}$ & $\begin{array}{l}\text { - Confirmation of optimal heating and cooling } \\
\text { energy through continued tracking. } \\
\text { - Identification of HW metering failure (Figure } \\
\text { 4.7). }\end{array}$ \\
\hline $\begin{array}{l}12356 \mathrm{~m}^{2} \\
133,000 \mathrm{ft}^{2} \\
\text { university } \\
\text { teaching building }\end{array}$ & $\begin{array}{l}\text { College Station, } \\
\text { Texas }\end{array}$ & $\begin{array}{l}\text { June 2007- } \\
\text { May } 2009\end{array}$ & $\begin{array}{l}\text { - Confirmed excess outside air increased } \\
\text { CHW use from 06/2008-08/2008 } \\
\text { - CHW increase from 9/15/2008-12/05/2008 } \\
\text { and 02/11/2009-05/18/2009 observed. } \\
\end{array}$ \\
\hline $\begin{array}{l}6625 \mathrm{~m}^{2} \\
67,000 \mathrm{ft}^{2} \\
\text { university office } \\
\text { building }\end{array}$ & $\begin{array}{l}\text { College Station, } \\
\text { Texas }\end{array}$ & $\begin{array}{l}\text { Nov 2007- May } \\
2009\end{array}$ & $\begin{array}{l}\text { - Identified apparent CHW meter problem } \\
\text { during 11/2008. } \\
\text { - Noted apparent HW meter recalibration } \\
\text { during 2008. }\end{array}$ \\
\hline
\end{tabular}




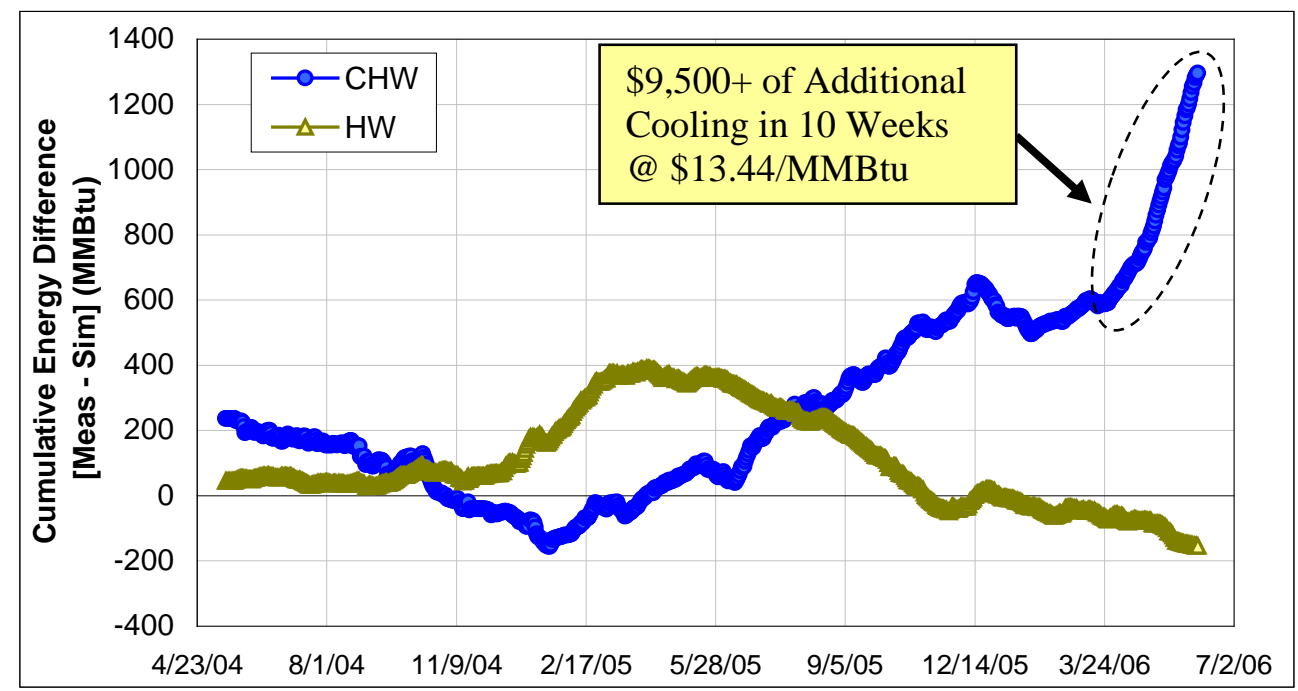

Figure 4.3 Sbisa Dining Hall cumulative energy difference meas - sim (MMBtu) with simulation calibrated to period of 5/01/2004 to $06 / 27 / 2006$

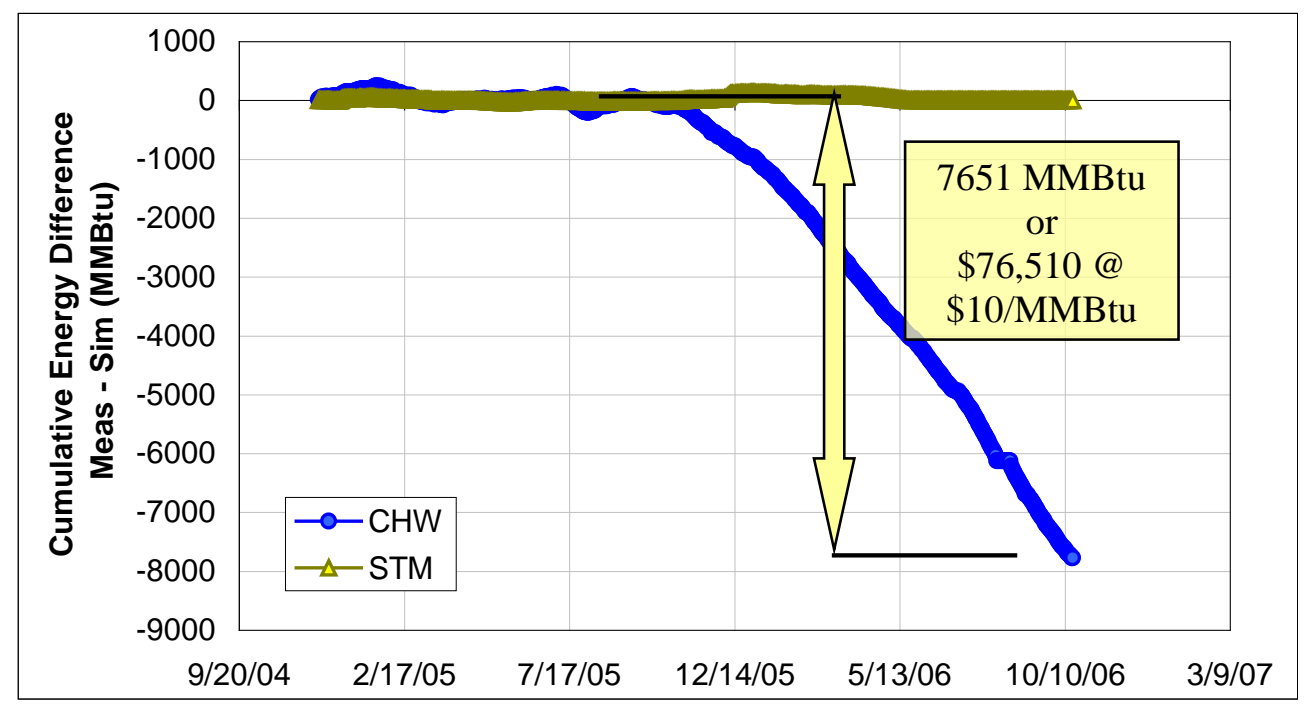

Figure 4.4 Computing Services Facility ABCAT cumulative energy difference meas - sim (MMBtu) with simulation calibrated to period of 12/01/2004 to 10/27/2005 


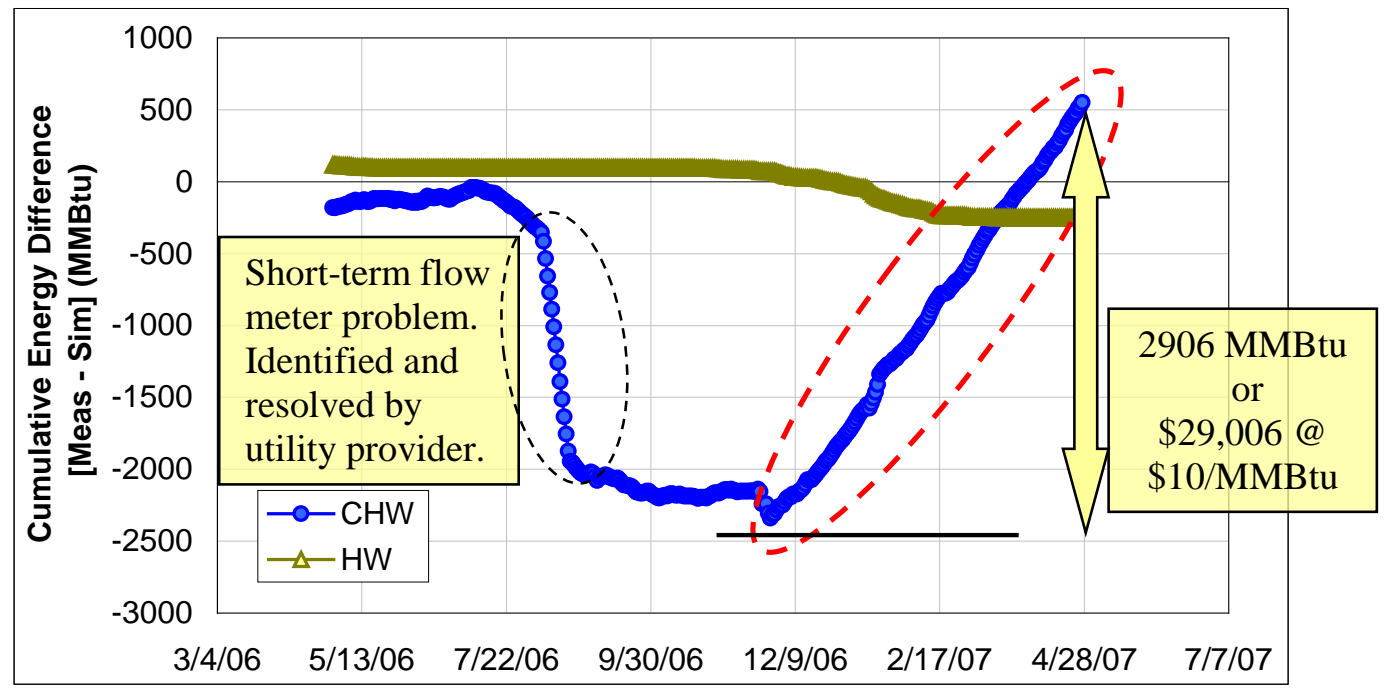

Figure 4.5 Computing Services Facility cumulative energy difference for period starting 04/29/2006 for 1 year after simulation recalibrated to period of 10/27/2005-5/19/2006

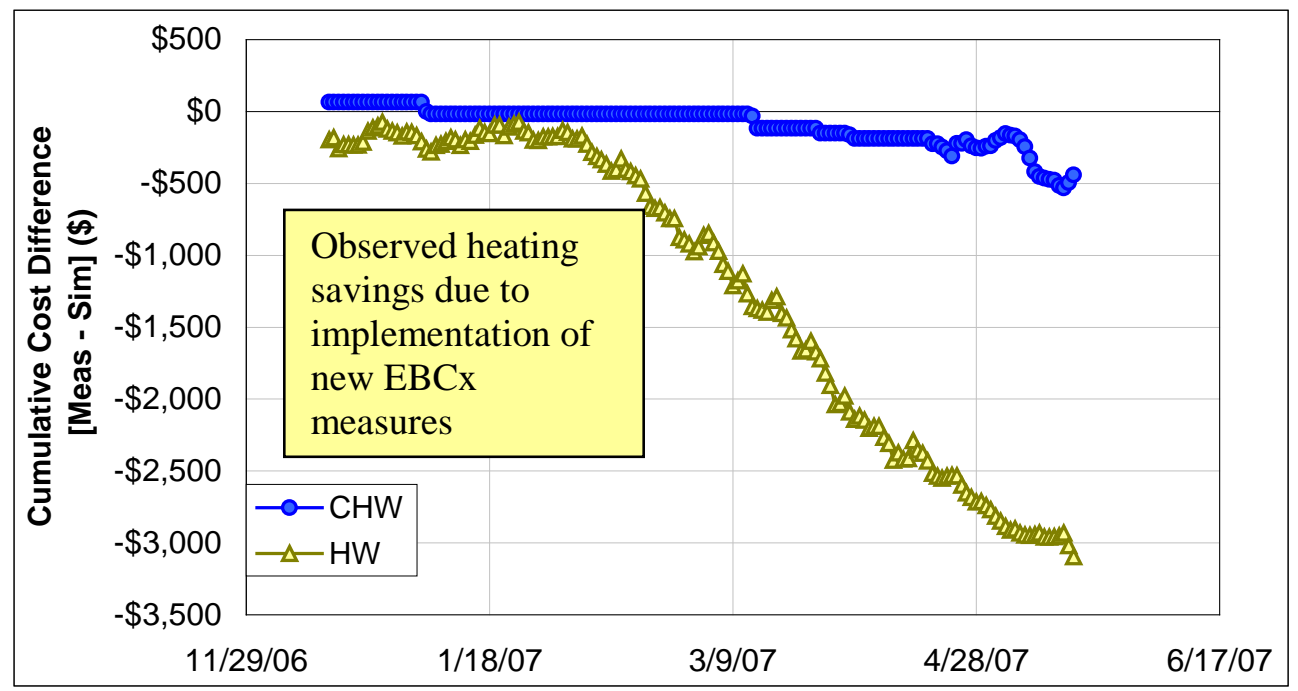

Figure 4.6 DASNY cumulative cost difference (\$15/MMBtu heating, \$10/MMBtu cooling) 


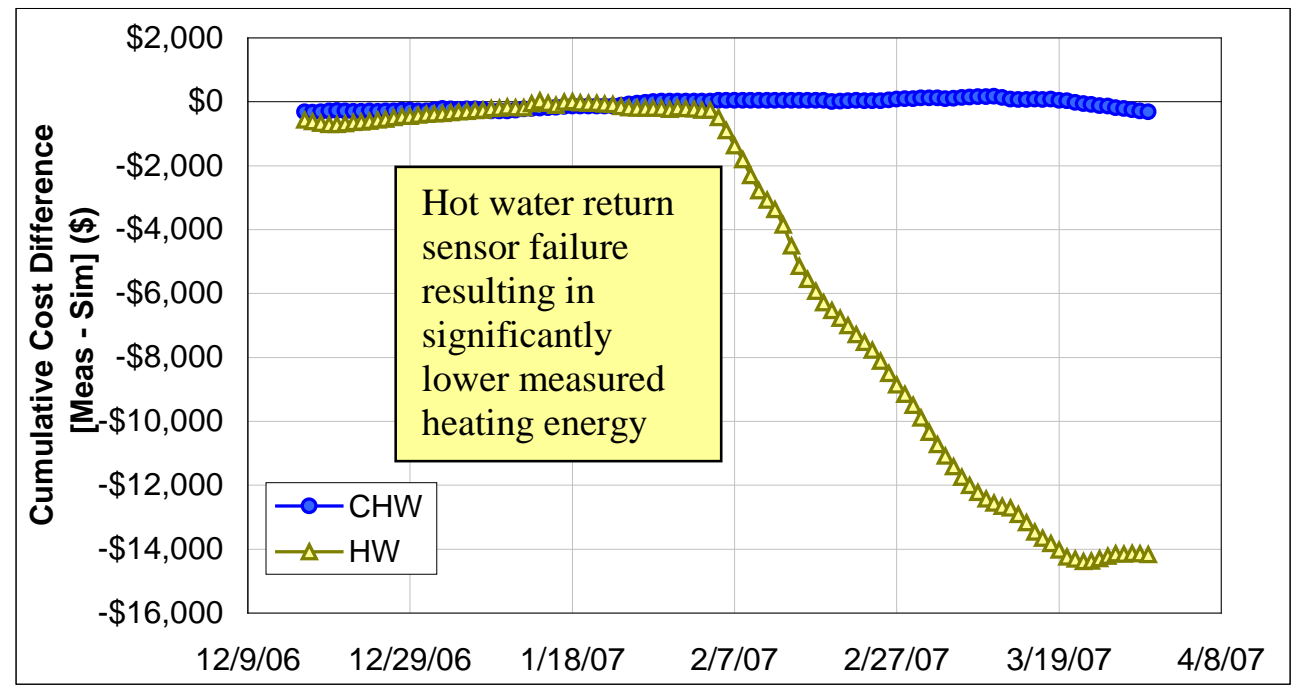

Figure 4.7 OPPD energy plaza cumulative cost difference (\$15/MMBtu heating, \$10/MMBtu cooling)

The testing of the ABCAT in these six buildings, the identification of the faults and the diagnostic reasoning that followed, helped shaped some of the specific ideas as to the developmental direction of the ABCAT. Some of the keys points to take away from these test experiences are the following:

- Whole building analysis can provide valuable diagnostic information

- Accumulated deviations from optimal performance provide the good indicator of significant faults that persist, and cost information

- The value of ABCAT does not appear to lay in daily short-term observations, but rather observations on the order of weeks to months.

- The advantage of using a first principles simulation model can be seen with occasional recalibrating requirements due to changes in building operations

\section{Retrospective Test Cases}

In order to further test the capabilities of ABCAT, a multiple building retrospective test is performed. Five buildings on the Texas A\&M University campus which had previously been studied in a commissioning persistence study (for the years of 1996 to 2000), had fairly complete consumption data sets, historical documentation as to commissioning measures implemented, and documentation of some control system set point changes during the period analyzed. It was expected that an analysis with ABCAT of a span of more than 15 building years, would provide some immediate feedback into the fault detection and diagnostic capability of the tool.

The "Cumulative Energy (or Cost) Difference" plot can visually detect a fault and show how the fault influences energy cost. Because visual fault detection depends heavily on personal subjective experience, the "Days Exceeding Threshold" plot was developed and added into ABCAT to detect faults analytically. It is drawn based on the simple standard that identifies a fault if the deviation between the measured and simulated consumption is greater than one standard deviation in the baseline period and persists for at least $30 \mathrm{~d}$. The reason for choosing $30 \mathrm{~d}$ as the fault definition is that the typical utility meter reading interval is one month. Every point in the plot represents the number of days in the next $30 \mathrm{~d}$ (including the day on which the point is plotted) where consumption has been at least one standard deviation above or below expected consumption. For example, a point at \pm 10 means there are $10 \mathrm{~d}$ of the next $30 \mathrm{~d}$ when the measured consumption is more than one standard deviation above or below the simulated consumption. Thus a fault period appears as one or more points at \pm 30 on the plot. Compared with the "Cumulative Energy (or Cost) Difference" plot, the "Days Exceeding Threshold" plot permits 
relatively precise identification of the time that a fault starts or ends and provides more objective fault detection metrics. In the retrospective cases, the "Days Exceeding Threshold" plot is used as the chief fault detection criterion.

Eighteen faults were detected in 15 building-years of consumption data with the "Days Exceeding Threshold" plot. One of the eight detected CHW faults and six of the ten detected HW faults are verified by the historical information. The remaining fault diagnoses remain unconfirmed due to data quality issues and incomplete information on maintenance performed in the buildings. A summary of these test cases is provided in Table 4.2 .

\section{Table 4.2 Building Faults Detected in five buildings}

\begin{tabular}{|c|c|c|}
\hline $\begin{array}{l}\text { Building } \\
\text { Description }\end{array}$ & Test Period & Results and Findings \\
\hline $\begin{array}{l}192,000 \mathrm{ft}^{2} \\
\text { university } \\
\text { teaching building }\end{array}$ & $\begin{array}{l}\text { Jan } 1997- \\
\text { Dec } 2000\end{array}$ & $\begin{array}{l}\text { - Detected two excess heating energy faults (HW Fault \#1 and } 2 \text { in } \\
\text { Fig. 4.8) which might be related to scaling problems on the HW } \\
\text { meter. } \\
\text { Detected one decrease in measured cooling energy (CHW Fault in } \\
\text { Fig. 4.8) which might be caused by an increase in the cold deck } \\
\text { temperature. }\end{array}$ \\
\hline $\begin{array}{l}165,000 \mathrm{ft}^{2} \\
\text { university } \\
\text { teaching building }\end{array}$ & $\begin{array}{l}\text { Nov } 1996- \\
\text { Dec } 2000\end{array}$ & $\begin{array}{l}\text { Detected significant decrease in measured heating energy (HW } \\
\text { Faults \#1 to \#4, and \#6 in Fig. 4.9) due to a HW meter problem. } \\
\text { Detected one excess heating energy fault (HW Fault \# } 5 \text { in Fig. } \\
\text { 4.9) due to the problems the Kleberg Center experienced after Apri } \\
1999 \text { as documented in Chen et al (2002) } \\
\text { Detected five excess cooling energy faults (CHW Faults \#1 to \#5 in } \\
\text { Fig. 4.9). CHW Fault \# } 1 \text { to \#3 and \#5 can't be diagnosed because } \\
\text { of the data quality issues. The reasons for CHW Fault \#4 were the } \\
\text { same as for HW Fault \# 5. }\end{array}$ \\
\hline $\begin{array}{l}180,000 \mathrm{ft}^{2} \\
\text { university } \\
\text { teaching building }\end{array}$ & $\begin{array}{l}\text { Mar } 1997- \\
\text { Dec } 2000\end{array}$ & $\begin{array}{l}\text { - Detected a significant decrease in measured heating energy (HW } \\
\text { Fault \# } 1 \text { in Fig. 4.10) which may be related to a HW meter } \\
\text { problem. } \\
\text { Detected one excess heating energy fault (HW Fault \# } 2 \text { in Fig. } \\
\text { 4.10) which may be related to an increase in minimum airflow ratio } \\
\text { and hot deck temperature. } \\
\text { The "Cumulative Cost Difference" plot (Figure 4.11) shows that the } \\
\text { CHW consumption deviation over four years The maximum CHW } \\
\text { consumption deviation over four years is approximately } 1 \% \text { of the } \\
\text { cumulative consumption. This indicates that the simulation is } \\
\text { capable of accurately predicting consumption if there are no } \\
\text { significant changes in the building. }\end{array}$ \\
\hline $\begin{array}{l}115,000 \mathrm{ft}^{2} \\
\text { university } \\
\text { teaching building }\end{array}$ & $\begin{array}{l}\text { Jan } 1998- \\
\text { Dec } 2000\end{array}$ & $\begin{array}{l}\text { - Neither a CHW fault nor a HW fault was detected on the "Days } \\
\text { Exceeding Threshold" plot (Figure 4.12). }\end{array}$ \\
\hline $\begin{array}{l}131,000 \mathrm{ft}^{2} \\
\text { university } \\
\text { teaching building }\end{array}$ & $\begin{array}{l}\text { Aug } 1996- \\
\text { Dec } 2000\end{array}$ & $\begin{array}{l}\text { - Detected two excess cooling energy faults (CHW Fault \# } 1 \text { and \#2 } \\
\text { in Fig. 4.13) which can't be diagnosed because of data quality } \\
\text { issues. }\end{array}$ \\
\hline
\end{tabular}




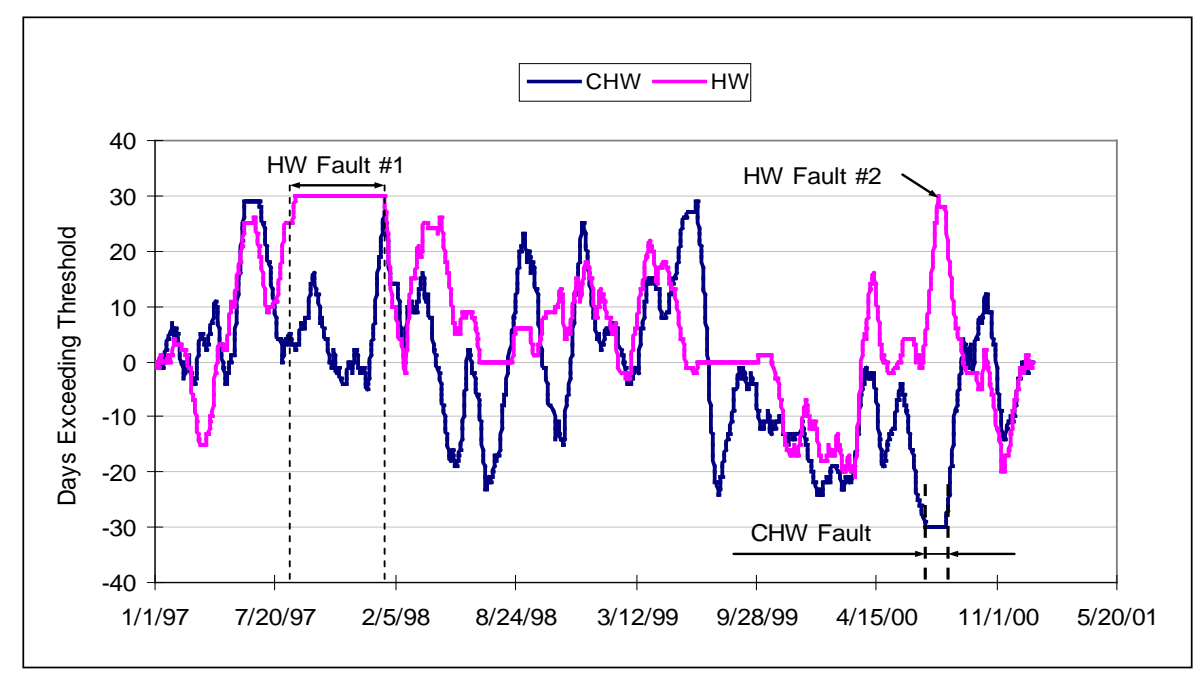

Figure 4.8 Days exceeding threshold in $\mathbf{3 0} \mathrm{d}$ periods from 01/01/1997 to 12/31/2000 for the Wehner Building

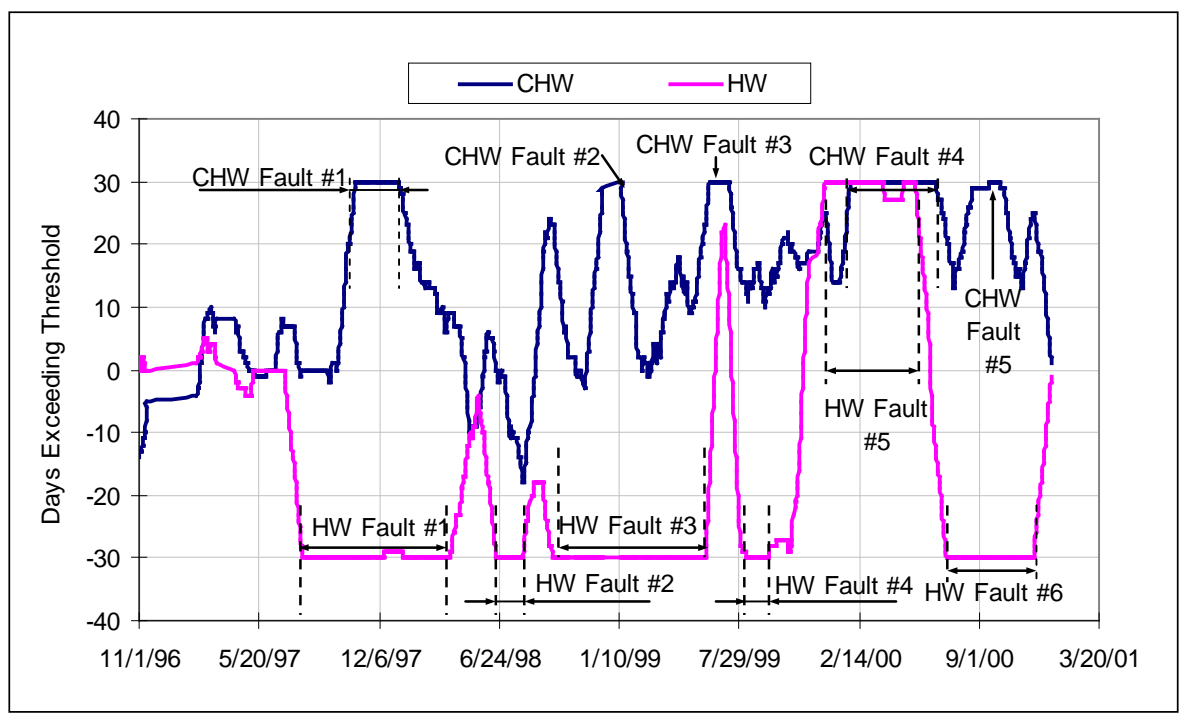

Figure 4.9 Days exceeding threshold in $\mathbf{3 0} \mathrm{d}$ periods from 11/01/1996 to 12/31/2000 for the Kleberg Center 


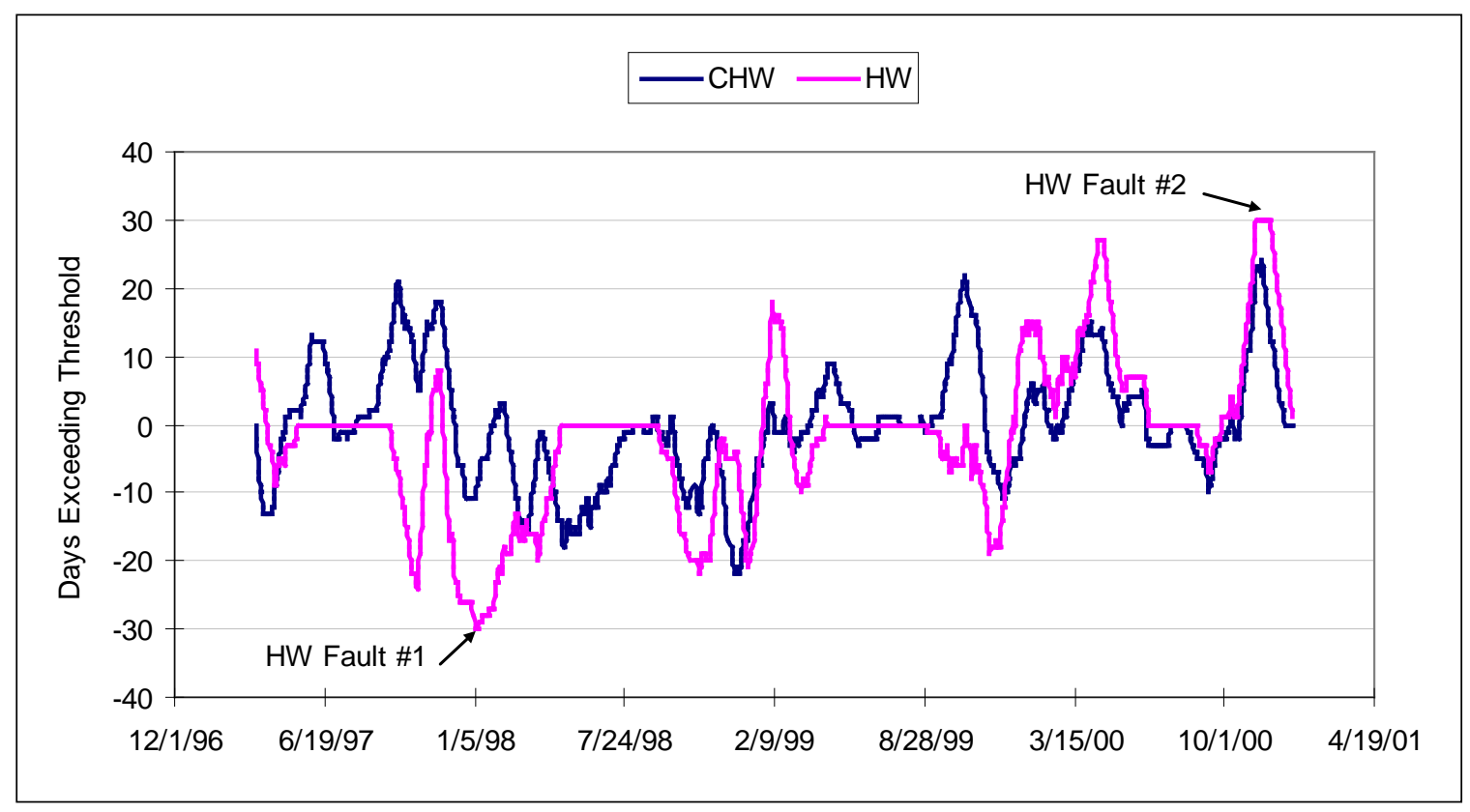

Figure 4.10 Days exceeding threshold in $30 \mathrm{~d}$ periods from 03/19/1997 to 12/31/2000 for the Eller O\&M Building

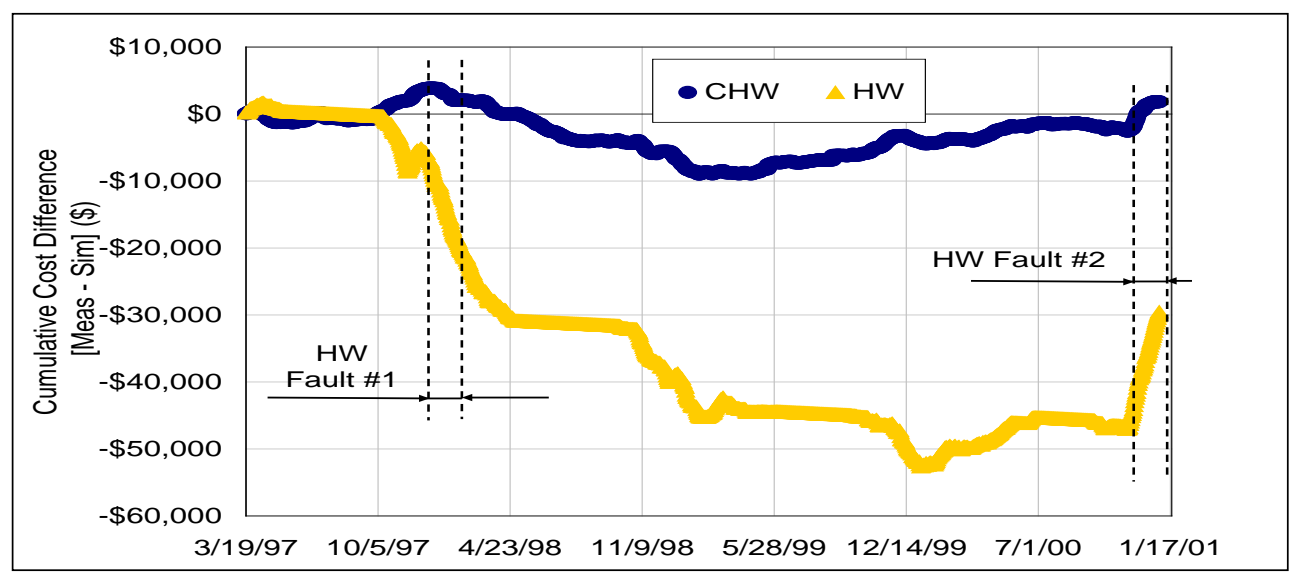

Figure 4.11 Cumulative heating and cooling cost differences for the period of 03/19/1997 to 12/31/2000 for the Eller O\&M Building (Assuming \$10 and \$15/MMBtu for CHW and HW respectively) 


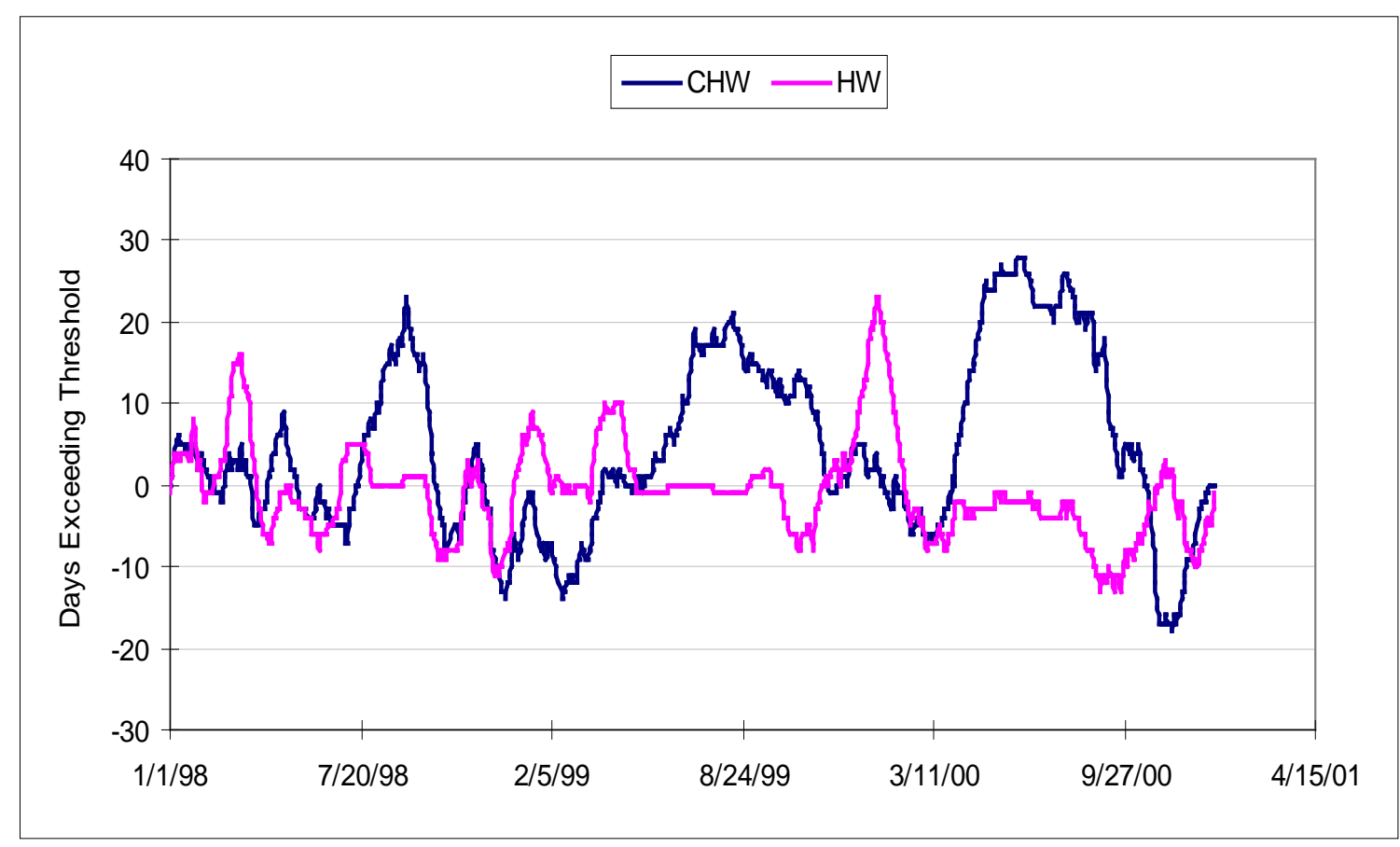

Figure 4.12 Days exceeding threshold in $30 \mathrm{~d}$ periods from 01/01/1998 to $12 / 31 / 2000$ for the Veterinary Research Building

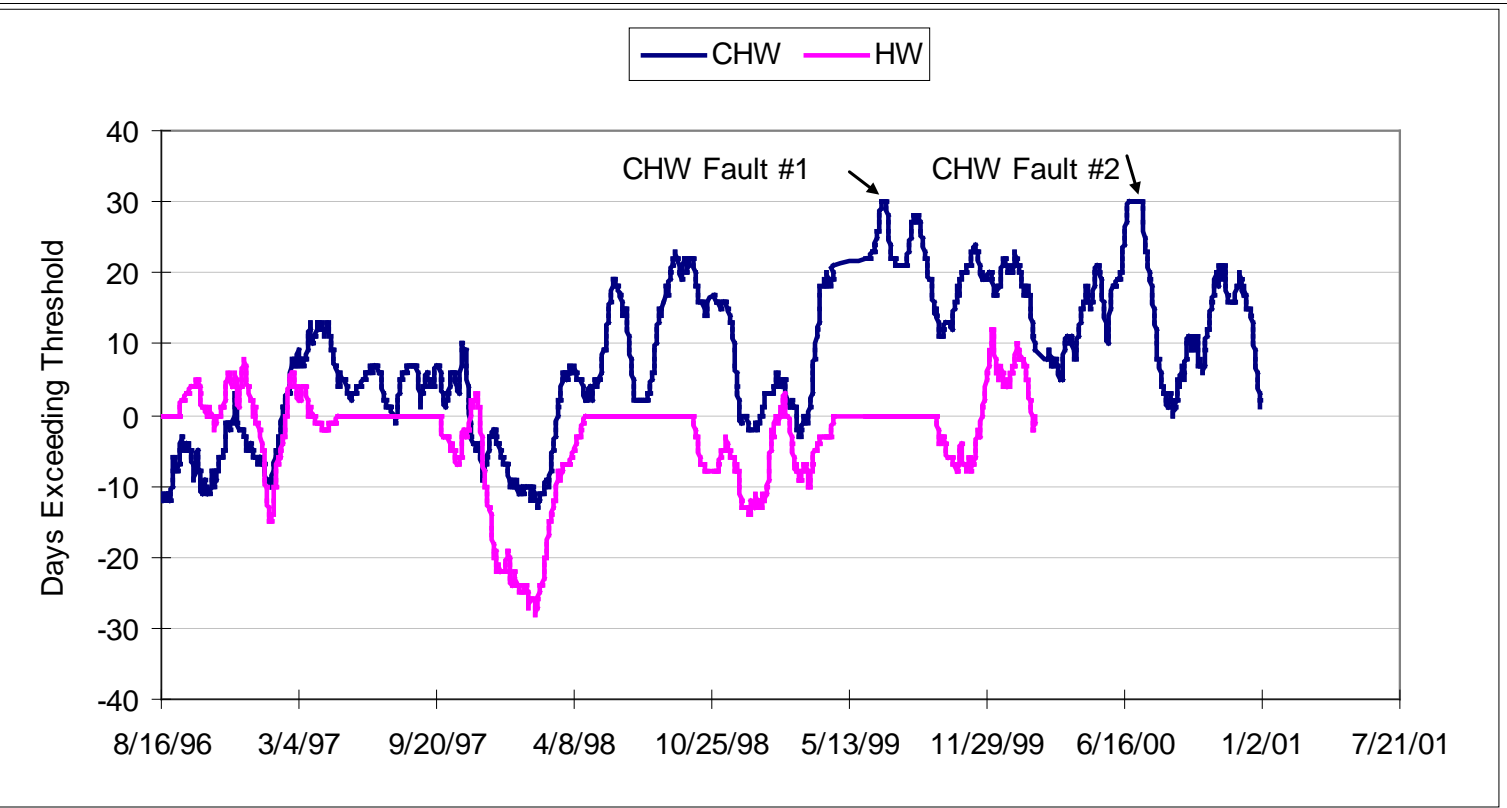

Figure 4.13 Days exceeding threshold in $30 \mathrm{~d}$ periods from 08/16/1996 to 12/31/2000 for Harrington Tower

The retrospective test cases provided an opportunity to test the simulation capabilities of the ABCAT in five additional buildings of varying types and functions, and indicate ABCAT is a promising fault detection and diagnosis tool for post-commissioning use in buildings. 


\section{ABCAT Layout}

\section{Interface}

The ABCAT is laid out as any typical Microsoft Excel file, with multiple worksheets and chart sheets accessible by the colored tabs at the bottom of the screen. The Interface sheet (Fig. 4.14) is the gateway of communication between the user and the tool, and includes the following:

- The dates of the periods analyzed can be adjusted

- Various alarm thresholds can be modified to user preferred levels

- Utility cost information can be specified

- Folder and file locations can be setup for importing and saving data files

- The calibrated simulation statistical results for the baseline

- Consumption totals and diagnostic summary of the period analyzed

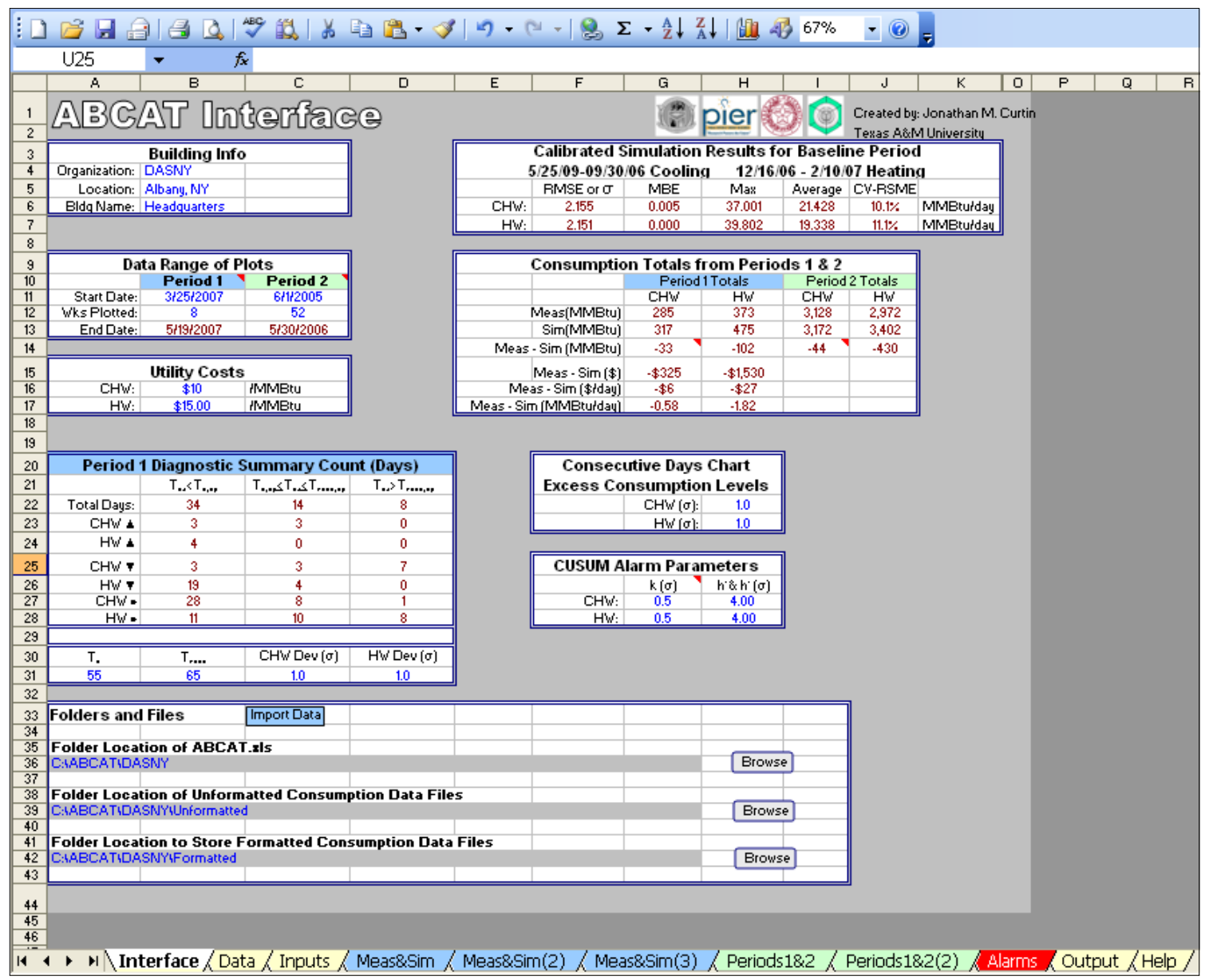

Figure 4.14 The ABCAT user interface

\section{Other Features}

- Multiple plots on each of five chart sheets providing performance data comparing measured and simulated or two periods of measured data.

- Quick day-type and date association for all plotted points with double point click

- Scroll through time with the scroll bars 
- Daily data summarized and stored in the tool such that the simulation can run for any period without user concern of reprocessing or collecting required inputs.

\section{Analysis of Comments and Feedback}

In the developmental process of the ABCAT, informal comments and feedback from users, potential users, as well as management and advisory committee members involved in the project were used to guide many choices about the features implemented in the advanced prototype tool. Although no statistical significance can be assigned to this feedback due to the small number of participants involved and no formal collection methodology was used, this feedback has nonetheless been beneficial in implementing upgrades to the tool, and setting the course for future developmental and testing steps.

\section{General Approach}

A common theme that has resonated almost universally through all those involved in testing or evaluating the ABCAT is that there is interest and a market for simple energy monitoring and fault detection and diagnostic tools. Over-complication of a tool can immediately lead to reservations from any potential future user that is not about ready to quit his day job to learn how to operate and continually manage the tool. Participants expressed general support for an adequate modeling system that could improve upon the setup complications of programs like DOE-2 or Energy-Plus.

Several positive remarks came with the presentation of the cumulative cost difference chart in the ABCAT. Thoughts were that this would provide a motive for users to act, or at least help the user in providing justification if higher level approval would first be required. It was also stated that detection, and clearly expressing the significance of faults carries a greater weight than the diagnostics, since experts will be able to find the fault if called upon, but if they don't know it exists they might not ever move to address it. One comment that is fitting for the future development is "Do you put the expert in the tool or leave the expert in the field?"

\section{Summary of New York Pilot Feedback}

The protoype tool was installed in the headquarters building of the Dormitory Authority of New York and used by the building operator and the commissioning engineers working on the building for several months. The tool was found to be "very helpful and beneficial for tracking energy consumption on a higher level" and "good for both building owners and operators", although it was stated that the tool "cannot take the place of on-site diagnostics". On weekly time intervals the required consumption data was imported into the tool, and it was perceived by one user that the optimal time interval for using the tool is weekly. Microsoft Excel as the host program was considered "Good" as far as file size, speed of execution, graphical capabilities, data storage general file layout, familiarity and ease of operation were concerned. A preference was expressed for greater clarity with labels on the Interface sheet for user manipulated fields, consumption period totals for both defined periods on the Interface sheet, and a linking to greater granularity (hourly) than daily data. One user expressed an interest in a lesson to calibrate the tool.

\section{Software Layout and Performance}

With the use of Microsoft Excel as a host to the ABCAT, speed of execution, program flow and the size of the program were concerns, although current performance capabilities were viewed as favorable.

Recommendations for linking to Microsoft Access were made, which could strengthen data storage capabilities, and allow for storage of smaller time interval and supporting data that would not be feasible to manage within Excel alone. The familiarity of most users with the general function of Excel was seen as a bonus.

As far as the graphical presentation of the tool was concerned, positive feedback was received from the multiple plots per chart sheet layout, scroll bars for zooming, and pop-up window feature for identifying day type and date of specific data points. The Interface sheet of the tool was upgraded in response to recommendations for including data summary tables, and ease of identifying user control options. 
Additional recommendations of including day typing, highlighting the most recent data on plots, and general "cleaning" of the plot areas were found to be valuable. Due to the variety of viewing preferences by user, options are provided in the ABCAT for rearranging the existing or creating new plots

\section{Conclusions}

ABCAT is a simple, cost efficient automated tool for maintaining the optimal energy performance in a building. It can continuously monitor building energy consumption, alert operations personnel early upon the onset of significant increase in consumption and assist them in identifying the problem.

In the six live building implementations, over eight building-years of operation, the "Cumulative Energy (or Cost) Difference" plot in ABCAT identified eight periods where significant energy consumption changes occurred that otherwise went undetected by the building energy management personnel. In the five retrospective building test cases, ABCAT detected 18 faults detected with "Days exceeding threshold" plots based on the simple standard that deviations greater than $+/$ - one standard deviation (as determined from the statistics of the calibrated simulation) that persisted for a period of at least one month constituted a fault.

The potential future success of the ABCAT is strongly tied to the ability of future users to obtain accurate and reliable measurements. A strong emphasis in sound engineering practices of installation, data management, calibration and data prescreening must accompany the ABCAT to ensure verification of data quality, and the likelihood for success in implementing the tool.

In addition to the originally targeted goals of tracking and ensuring energy optimization in commissioned buildings, through the course of implementing and testing the ABCAT, several other added benefits or alternative functional approaches have been identified. These include use of the ABCAT as a commissioning savings tracking tool, a simple whole building energy analysis tool (even without the simulated consumption), and providing verification of, or use in filling missing metered or billing data, both important for customers of district utility providers, and the providers themselves.

\subsection{The Diagnostic Agent for Building Operation (DABO ${ }^{\mathrm{TM}}$ ): a BEMS Assisted On-going Commissioning Tool ${ }^{15}$}

\subsubsection{Introduction}

It is accepted that the initial, retro, or ongoing commissioning of HVAC systems are proven processes that reduces energy consumption and improves occupant comfort in buildings. Claridge et al. (1998) have shown that the use of the existing building control system for commissioning resulted in $25 \%$ energy cost savings. In spite of documented benefits, commissioning is still regarded by many building owners as a minor activity in building operation and remains a one-time task that is performed during the building construction phase. Building professionals and owners attribute this situation principally to the cost associated with the commissioning process as well as the related difficulty of finding qualified resources to execute it.

The evolving capabilities of Building Energy Management Systems ${ }^{16}$ (BEMS) can help to circumvent the barriers to commissioning by offering opportunities to automate some parts of the commissioning process. Automation or semi-automation of certain aspects of the commissioning process has the potential to reduce costs for commissioning, thereby leading to more widespread application of the process. Furthermore, automating this essentially manual process could allow its application on a regular basis, generating benefits over the entire life of a building. Developing a detailed systematic automated

\footnotetext{
${ }^{15}$ This section is abridged and edited from Choiniere and Corsi (2003) and Choiniere (2004).

${ }^{16}$ Building Energy Management System may also be referred to as an Energy Management Control System (EMCS)
} 
approach will improve the quality assurance process and could even integrate energy audit capabilities that improve the overall performance of buildings. In this context, an on-going BEMS assisted commissioning tool, Diagnostic Agent for Building Operators (DABO) that verifies and optimizes the performance of building HVAC systems using the capabilities of BEMS was developed by the CANMET Energy Technology Centre. This tool is applicable mainly to commercial and institutional buildings. Commercialization is being considered.

On-going commissioning (IEA 2001a) is defined as a systematic approach used to inspect, verify and document the installations and operation of building systems to ensure that they operate at their optimum energy performance levels. This state is only achieved when buildings consume the minimum energy at the lowest cost while simultaneously considering the building's function and comfort level, available energy source(s), building energy systems and energy rates. To be efficient, many tasks must be performed continuously, an undertaking that can be facilitated by monitoring the condition of HVAC systems and building energy consumption using a BEMS.

Since 1998, the Canada Centre For Mineral And Energy Technology(CANMET) Energy Building has been used to test and demonstrate various tools developed in the context of the CANMET Intelligent Building Operating Technologies R\&D plan (Jean, G. 2004) of which DABO is the central component. In this context and principally for the last eight years an on-going commissioning process has been conducted. DABO, a software package that uses a hybrid technology composed of conventional and artificial intelligence techniques to ensure optimum operation of building systems has been used actively in the project delivery system for the continuous monitoring of all HVAC equipment and meters (e.g., terminal unit, air handling unit, plant equipment and energy meters), the analysis of the incoming information, the detection and diagnosis of major HVAC component faults, non optimum set points and sequences of operation and the monitoring of implemented measures.

The Benefits obtained through the use of the $\mathrm{DABO}^{\mathrm{TM}}$ software are summarized as follows:

\begin{tabular}{ll} 
Energy savings & Improved performance of mechanical systems \\
Reductions in greenhouse gas emissions & Rapid and automatic fault detection \\
Improved occupant comfort & Energy performance monitoring \\
Capabilities for troubleshooting of malfunctions & Reduce operation costs \\
\hline
\end{tabular}

This chapter builds on the paper "A BEMS-Assisted Commissioning tool to improve the energy performance of HVAC systems" where Choinière and Corsi (2003) described the use of BEMS assisted commissioning tools and have identified the potential to facilitate the application of initial, retro and ongoing commissioning processes.

In a subsequent paper ('Four years of On-going commissioning in CTEC-Varennes Building with a BEMS Assisted Cx Tool') Choinière (2004) presented results from the first four years of the on-going commissioning project performed in the CANMET ENERGY Building that generated a $35 \%$ reduction in the energy used. DABO has largely contributed in the verification and optimization of the performance of the building.

This section presents the functions of DABO and the results of the first eight-years of on-going commissioning conducted at the CANMET Energy- Varennes building with DABO.

\section{DABO, A BEMS-Assisted Commissioning Tool}

DABO mainly includes two parts: the commissioning-assistant module and the fault management report.

The commissioning-assistant module, designed to assist and perform some functions described in the ongoing commissioning process section is a module of DABO (Choinière 2001) which serves as the interface between the end-user (e.g., building operator, commissioning agent, and energy manager) and 
the control system (BEMS). As shown in Fig. 4.15, the tool continuously monitors the building control data and stores it in a structured database to be used on-line or upon request. Data resulting from standardized test procedures invoked manually or automatically are also stored in the database. The database functions as a server for reasoning algorithms that perform intelligent analyses of the monitored data, perform additional automated tests of components and systems, identify faults and diagnose them, and evaluate potential improvements in energy efficiency. The tool produces reports adapted to the different partners involved in the on-going commissioning process (building operators, service technicians, energy managers, commissioning agents, HVAC\&R engineers).

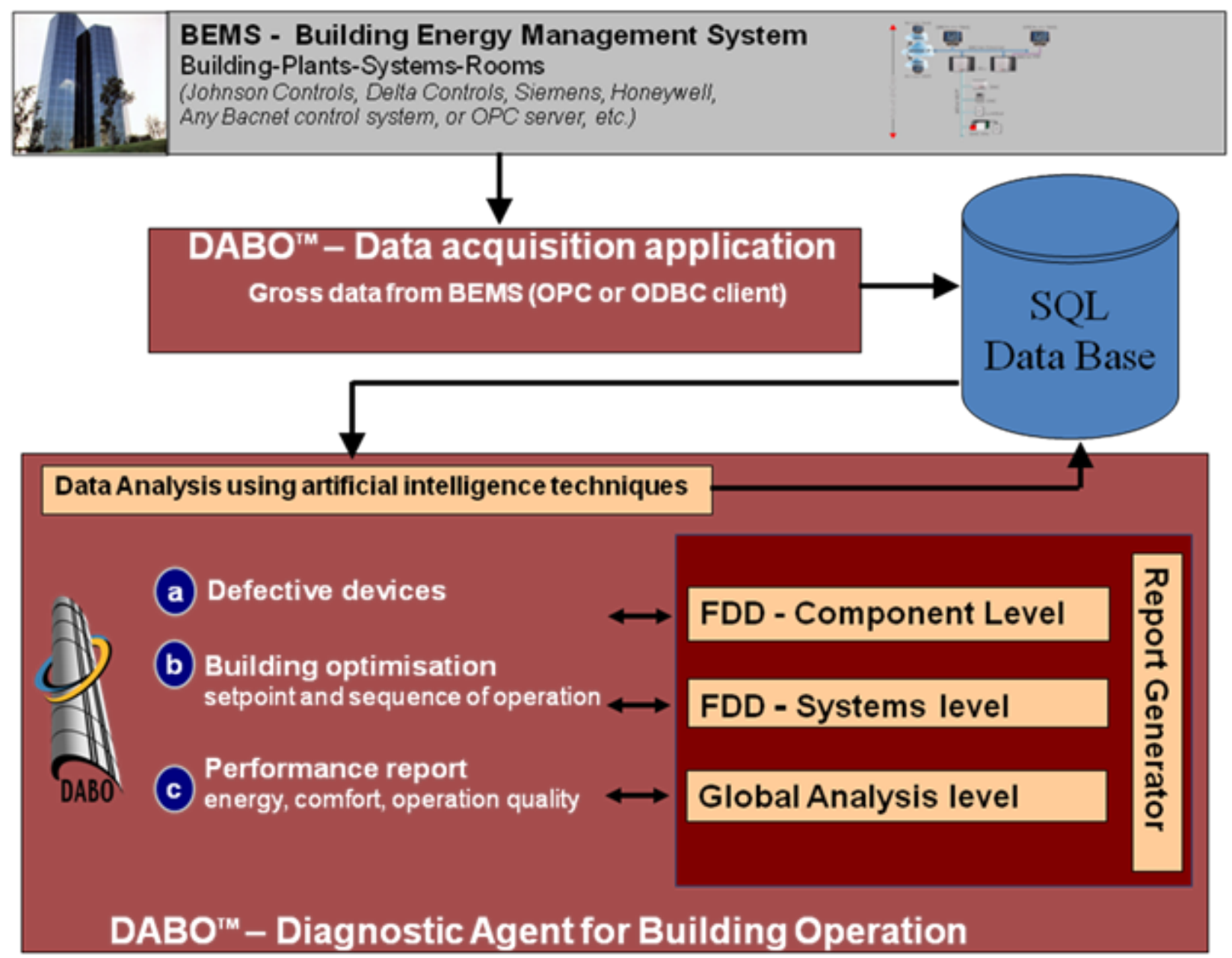

Figure 4.15 Structure of the On-going Commissioning Tool for HVAC Systems Embedded in DABO. 
The standardized test procedures are performed at three levels.

- At the first level, an hourly component analysis of individual HVAC devices and equipment is performed automatically using a combination of control loop indices and expert rules to verify their proper operation.

- The second level of testing consists of an integrated system analysis to verify the operation and energy performance of the overall HVAC system over a longer period of time (e.g., hours, days, weeks or months). At this level a set of component performance indices and expert rules is also used in the analysis.

- The third level performs basic energy performance and operation control quality reports that provide the information required to evaluate potential energy measures on specific devices. To reduce data traffic on the communication networks, the tool's steady state detectors and zone fault detectors are directly embedded in controllers. Specific applications of the fault detection and diagnostic (FDD) methods implemented in DABO are described further in Section C of IEA 2001b.

The Fault Management Report (FMR) is a tool embedded into the DABO platform. The FMR report is used by the building operator/manager to manage information concerning confirmed faults in the building's operation detected by the DABO FDD module and the subsequence operational corrective actions needed or done. In this report the user can review actual and historical data for a specific device, for all devices of the same type or for all devices of a building.

Function of the information required, the FMR report can be displayed and printed in a summary or detailed form.

The following information is reviewed in FMR reports:

- Device type, System name, Fault number, Fault description, Fault start time, Confirmation date, Fault priority, Primary benefit, Secondary benefit, Impact on energy savings, Cost, Responsible operator, Operator's comments, Confirmation of repaired fault and Repair technician's comments

Figure 4.16 shows for all air handling units in a building a summary display of all faults detected that need to be repaired. Figure 4.17 is an example of a detailed 'repaired faults' report. This report is useful to produce a status report of actions done during a specific period. 


\begin{tabular}{|c|c|c|c|c|c|c|c|c|c|c|c|c|}
\hline \multirow{2}{*}{$\begin{array}{l}\text { Graphic View } \\
\text { Family: AHU }\end{array}$} & \multicolumn{3}{|c|}{ ControlZone FDD report } & \multicolumn{2}{|c|}{1221 FDD report } & \multicolumn{7}{|l|}{ Fault Management Report CTEC } \\
\hline & _CS_H & & & $\nabla$ & Device: Al & & - Benefit & it: All & & - Timetable: & : Last week & $\nabla$ \\
\hline \multicolumn{13}{|c|}{ Confirmed failures: } \\
\hline System & & Failure \# & \multicolumn{3}{|c|}{ Failure description } & Confirmed date & Priority & Primary benefit & Secondary benefit & Energy savings & $\operatorname{Cost}(\$)$ & Operator \\
\hline M3 Bureaux 1 & & 31 & \multicolumn{3}{|c|}{ Point in manual } & 2007-04-20 08:002007-05-07 13:00 & I & Indoor emvironment & Operation and mai... & Yes & & Daniel Choinière \\
\hline \multicolumn{2}{|l|}{ M3 Bureaux 1} & 19 & \multicolumn{3}{|c|}{ Control software problem } & 2007-02-19 05:002007-03-20 15:00 & Moderate & Indoor emvironment & Operation and mai... & No & & $s$ \\
\hline \multicolumn{2}{|l|}{ M2 Laboratoires } & 19 & \multicolumn{3}{|c|}{ Control software problem } & 2007-06-19 06:002007-07-24 16:00 & Moderate & Indoor emvironment & Operation and mai... & No & & Daniel Choinière s \\
\hline \multicolumn{2}{|l|}{ M4 Corridor } & 19 & \multicolumn{3}{|c|}{ Control software problem } & 2007-02-19 11:002007-03-21 12:00 & Moderate & Indoor emvironment & Operation and mai... & No & & c \\
\hline \multicolumn{2}{|c|}{ M5 Salle électrique } & 14 & \multicolumn{3}{|c|}{ Outdoor air damper failure } & 2007-03-14 09:002007-03-21 12:00 & Low & Indoor emvironment & Operation and mai... & Yes & & 0 \\
\hline \multicolumn{2}{|c|}{ M5 Salle électrique } & 13 & \multicolumn{3}{|c|}{ Mixed air damper failure } & 2007-06-08 00:002007-07-09 10:00 & Low & Indoor emvironment & Operation and mai... & Yes & \multicolumn{2}{|r|}{ Daniel Choinière $A$} \\
\hline \multicolumn{2}{|l|}{ M4 Corridor } & 13 & \multicolumn{3}{|c|}{ Mixed air damper failure } & 2007-02-13 08:002007-03-21 12:00 & Low & Indoor emvironment & Operation and mai... & Yes & & c \\
\hline \multicolumn{2}{|c|}{ M2 Laboratoires: } & 12 & \multicolumn{3}{|c|}{ Exhaust air damper failure } & 2007-04-15 21:002007-05-16 19:00 & Low & Operation and mai... & Indoor emironment & No & & Daniel Choinière $\mathrm{K}$ \\
\hline M30 Bureaux 2 & & 128 & Return & n fan overcal & pacity & 2007-05-29 14:002007-06-26 16:00 & Low & Operation and mai... & Asset value or tena... & ... Yes & & Daniel Choinière $c$ \\
\hline M2 Laboratoires & & 6 & Return & n air humidity & y sensor & 2007-02-13 07:002007-03-21 12:00 & Very Low II & Indoor emvironment & Asset value or tena... & ... Yes & & $c$ \\
\hline M3 Bureaux 1 & & 35 & Supply & y air CO2 sen & & 2007-05-03 15:002007-05-09 15:00 & Very Low II & Indoor emvironment & Liability reduction & No & & Daniel Choinière $\mathbf{s}$ \\
\hline M20 Annexe 2 & & 116 & Supply & y fan motor 0 & or drive failu. & u...2007-07-30 09:00|2007-07-31 12:00 & Very Low & Indoor emvironment & Operation and mai... & No & & Daniel Choinière $\mathrm{v}$ \\
\hline
\end{tabular}

Figure 4.16 Typical Fault Management Report for an Air Handling Unit in DABO ${ }^{\mathrm{TM}}$ 


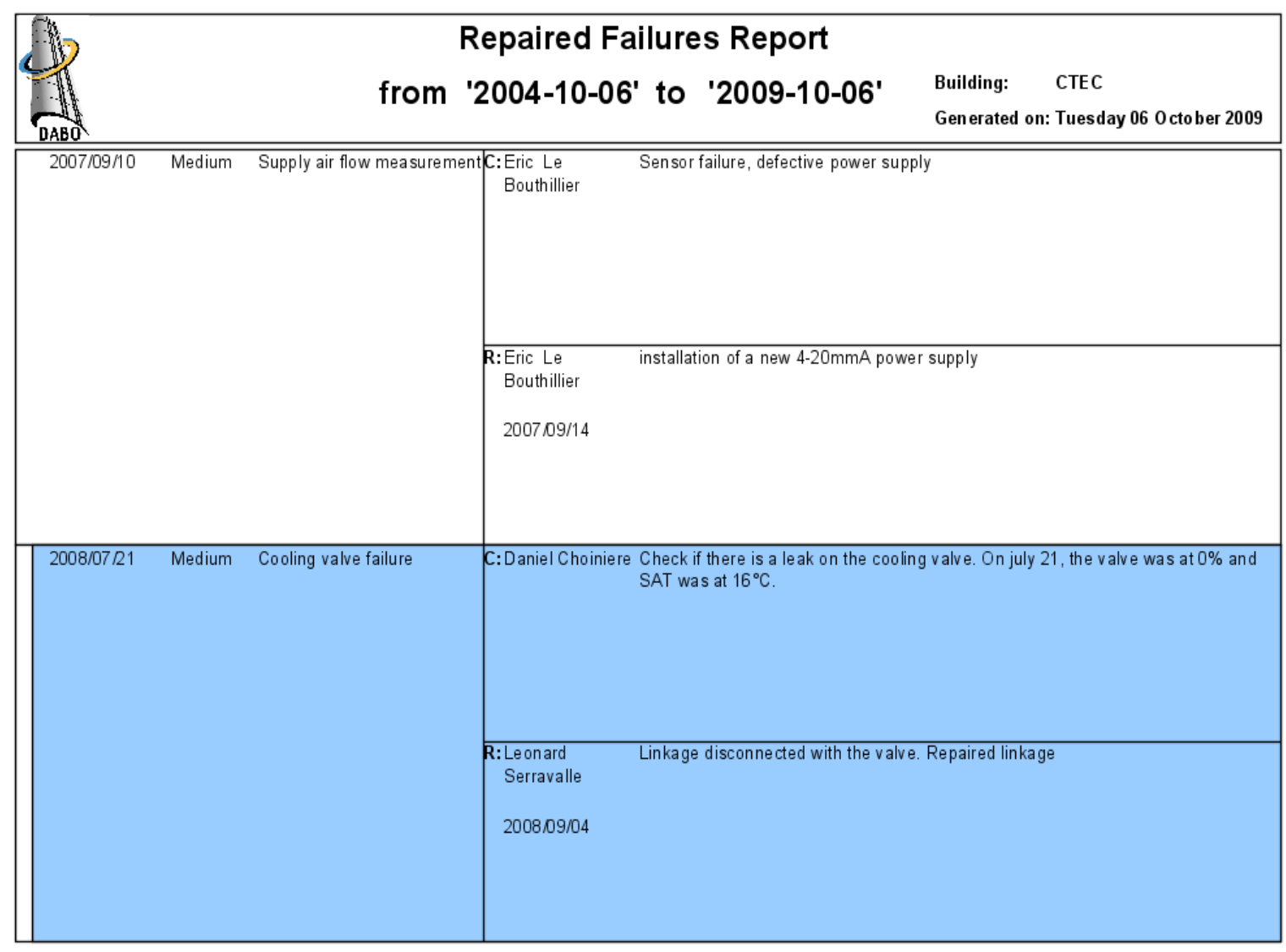

Figure 4.17 Typical Repaired Failures Report for an Air Handling Unit in DABO ${ }^{\mathrm{TM}}$

\section{On-going Commissioning Project}

The demonstration building is the CANMET Energy Building located in Varennes, Québec, Canada. Built in 1992, the single floor $3600 \mathrm{~m}^{2}$ building includes office spaces for 90 people as well as two laboratories, two industrial pilot plants, conference rooms and a cafeteria.

The building, designed to be energy efficient, incorporates low energy technologies such as a passive solar preheating device, ice bank storage, photovoltaic cells, as well as a central gas heating plant and a central electric chilled water plant. Each area of the building is served by a specific air system designed for its occupation. The HVAC systems are central controlled by a BEMS system. (Table 4.3) 
Table 4.3 CTEC-Varennes HVAC Systems

\begin{tabular}{|c|c|c|}
\hline HVAC systems & Capacity & Location \\
\hline \multicolumn{3}{|l|}{ Heating } \\
\hline Fire tube boilers (2) & $470 \mathrm{~kW}$ each & Building \\
\hline \multicolumn{3}{|l|}{$\begin{array}{l}1 \text { primary and } 5 \text { secondary hydronic } \\
\text { circuits, } 7 \text { pumps, constant volume }\end{array}$} \\
\hline \multicolumn{3}{|l|}{ Cooling } \\
\hline 1 air cooled chiller & $406 \mathrm{~kW}$ & Building \\
\hline 2 ice bank tanks & 1145 kW-hour & Building \\
\hline \multicolumn{3}{|l|}{$\begin{array}{l}1 \text { hydronic circuit, } 2 \text { pumps, constant } \\
\text { volume }\end{array}$} \\
\hline \multicolumn{3}{|l|}{ Air Handling system } \\
\hline M1 (CAV, HEA) & $2,735 \mathrm{l} / \mathrm{s}$ & Pilot plant1 \\
\hline $\begin{array}{l}\text { M2 (VAV, } 100 \% \text { fresh air, heating, } \\
\text { cooling) }\end{array}$ & $5,815 \mathrm{l} / \mathrm{s}$ & Laboratories \\
\hline M3 (VAV, heating, cooling) & $5,500 \mathrm{l} / \mathrm{s}$ & Office phase 1 \\
\hline M4 (CAV, heating) & $1,265 \mathrm{l} / \mathrm{s}$ & Storage phase 1 \\
\hline M5 (CAV) & $160 \quad \mathrm{l} / \mathrm{s}$ & Mechanical room \\
\hline M6 (CAV) & $1,030 \mathrm{l} / \mathrm{s}$ & Boiler room \\
\hline M30(VAV, HEA, CO) & $1,660 \mathrm{l} / \mathrm{s}$ & Office phase 2 \\
\hline M31(CAV, HEA) & $5,200 \mathrm{l} / \mathrm{s}$ & Pilot plant 2 \\
\hline M32(CAV) & $2,000 \mathrm{l} / \mathrm{s}$ & Mechanical room 2 \\
\hline
\end{tabular}

The on-going commissioning process started in 1999 and continued until 2009 aimed at resolving operating problems, improving comfort, optimizing energy use and recommending retrofits where necessary. Delivery of the on-going commissioning project system included a series of tasks performed in four steps: planning, investigation, implementation and hand off (Table 4.4). Tasks surveyed with DABO are shown in italics. As it is an ongoing commissioning process, the investigation and implementation have been gradually and continuously performed over the 2000 to 2006 period. Since 2006, DABO is still used on a regular basis to insure the persistence of savings and detect new deficiencies.

Results for the investigation and implementation period 2000 to 2006 were presented in 'Four Years of On-going Commissioniong in CTEC-Varennes Building with a BEMS Assisted Cx Tool' (Choinière 2004) and are summarized in the following section.

Results for the hand off and persistence period include new deficiencies that occurred during the normal operation as well as deficiencies that were not detected during the commissioning of the various optimization projects (2006 to 2009). 


\section{Table 4.4 The Ongoing Commissioning Project Delivery System Followed at CETC-V}

\begin{tabular}{|c|}
\hline PLANNING \\
\hline 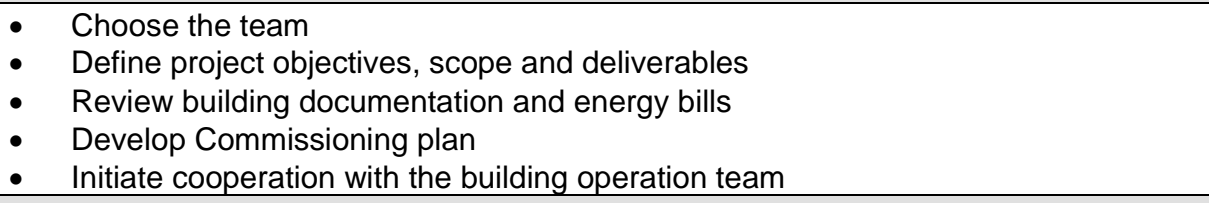 \\
\hline INVESTIGATION (continuous over 6 years, 2000 to 2006) \\
\hline $\begin{array}{l}\text { - Assessment } \\
\text { o Site, design and occupant needs assessment } \\
\text { - } \quad \text { Installation of DABO } \\
\text { - } \quad \text { Develop and carry out diagnostic tests and system monitoring } \\
\text { - } \quad \text { Analyze monitoring results } \\
\text { - Develop list of deficiencies and improvements } \\
\text { o Include capital improvement opportunities } \\
\text { o Include training recommendations } \\
\text { - Select the most cost effective opportunities }\end{array}$ \\
\hline IMPLEMENTATION (continuous over 6 years, 2000 to 2006) \\
\hline $\begin{array}{ll}\text { - } & \text { Implement improvements identified in investigation phase } \\
\text { - } & \text { Retest and re-monitor to confirm the results } \\
\text { - } & \text { Adjust, if necessary, the improvements carried out during the investigation phase } \\
\text { - } & \text { Review the energy consumption reduction estimates } \\
\text { - } & \text { Building Operator training and occupant information } \\
\end{array}$ \\
\hline HAND OFF- PERSISTENCE (continuous since 2006) \\
\hline $\begin{array}{l}\text { - Prepare and present final report } \\
\text { o As-Built Re-commissioning work } \\
\text { o New sequence of operation manual } \\
\text { o Testing and balancing (TAB) report (air, water) } \\
\text { o Energy baseline } \\
\text { o Check-up of energy bills (3 months) } \\
\text { o Proposal for EE measures with longer payback } \\
\text { Implement an on-going commissioning process and an energy management plan } \\
\text { o Ensure that the use of DABO is well understood by the operators so as to } \\
\text { maintain the re-commissioning benefits }\end{array}$ \\
\hline
\end{tabular}




\section{Results for Investigation and Implementation Step (1999 to 2006)}

- Implement a continuous energy management plan 1998 (in house staff)

- Reset operation schedules (AHU, hydronic circuits)(1999)

- Optimise controls and sequence of operation

o Function of actual needs

o Peak load management (chiller, humidification)(2003)

o Avoid simultaneous heating and cooling

- $\quad$ Reset set points (AHU, hydronic circuits)(2000 to 2005)

o Minimum fresh air

o Supply pressure and temperature

o Night set back

- Fixed minor deficiencies

o Sensor calibration

o Low heating capacity in some rooms

o Replacement of leaking valves

- Investment in measures with short payback

o Addition of DDC controls (chiller, boiler 2001)

o Link AHU M2 to solar wall (March 2003)

o VSD on 3 fans (March 2002)

- Energy efficiency project (2005 to 2006) $\$ 250,000$ CDN

o Conversion of pneumatic room controls to DDC

o Off peak electric boiler (200kW)

o AHU M2 $100 \%$ fresh air convert to a recirculation system

o Connection on AHU M4 fresh air to solar wall

o VSD on 6 pumps and fan motors

- Energy reduction

o Figure 4.17 shows the impact on the energy consumption of the on-going commissioning project implemented at the CETC-V since 1998. During this period 1999-2006, measures implemented have resulted in a $35 \%$ reduction in electricity and $45 \%$ in natural gas consumption.

\section{Energy reduction}

Figure 4.18 shows the impact on the energy consumption of the on-going commissioning project implemented at the CETC-V since 1998.

During this period, measures implemented have resulted in a $44 \%$ reduction in electricity and $78 \%$ in natural gas consumption. For 2007 to 2008 , the cost savings represented $\$ 91,861$ CDN, or $51 \%$ of the building energy bills. The Cumulative savings since 1998 are \$496,124 CDN while the global energy used drop from $2248 \mathrm{MJ} / \mathrm{m}^{2}$ to $994 \mathrm{MJ} / \mathrm{m}^{2}$. 


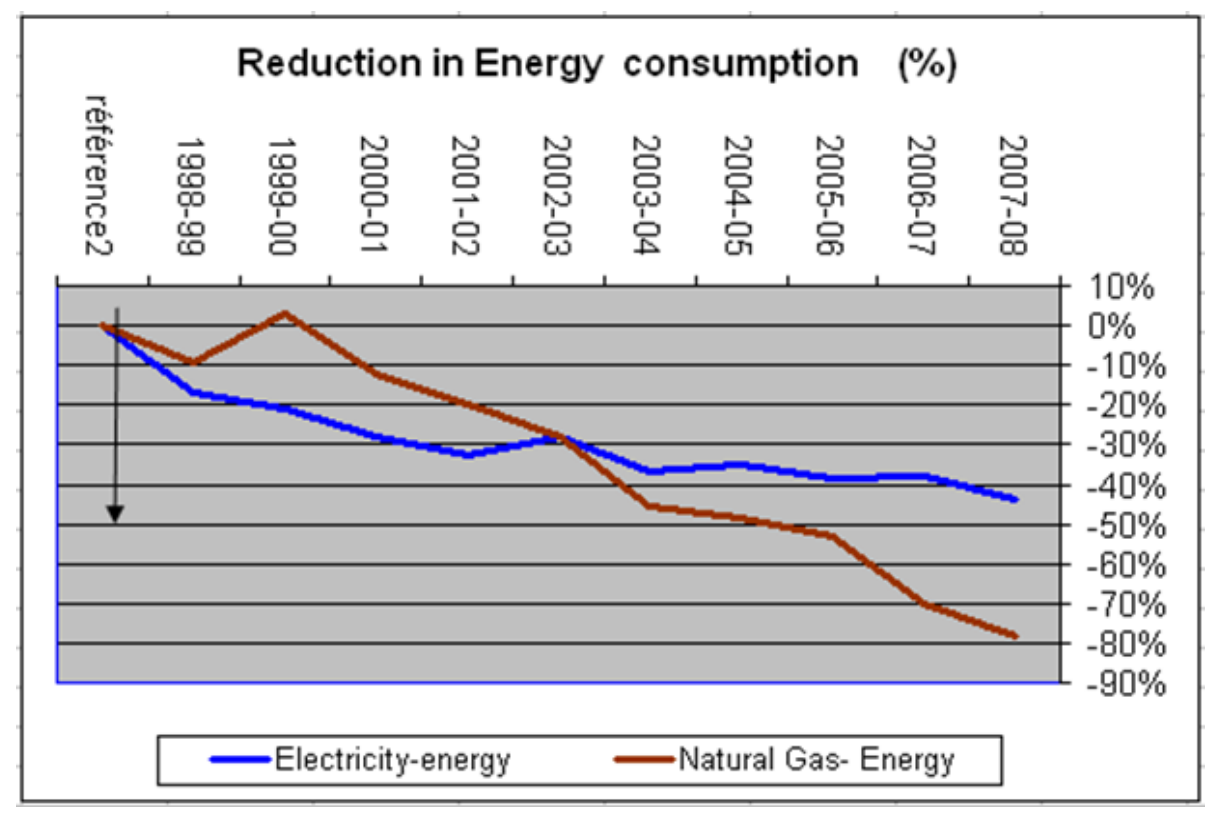

Figure 4.18 On-going commissioning impact on CETC-V Building energy consumption

\section{How to Improve the BEMS-assisted Commissioning Tool (input from 11 demonstration sites)}

The demonstration project was also used to validate the tool technology, to understand the barriers and opportunities and to identify areas for R\&D activities to improve the prototype tool.

The following sections provide feedback collected from the tool installers, the building operators, $\mathrm{Cx}$ providers and facility managers on this project as well as on 11 other buildings where the technology has been deployed. This section also provides some thoughts on the lessons learned from our R\&D projects.

\section{Feedback from the installers (Total: 12 installations)}

Perceived Strengths:

- Friendly user interface

- Most common HVAC system configurations can be set up

- Easy to install when the building information and connection to BEMS are available Perceived Barriers:

- Installation is time consuming when building information is not adequate

- Remote accessibility (internet connection of the BEMS computer) is hard to get and frequently relatively slow. (Organizational Network department)

- Control procedures and control point naming conventions are not general (function of the control supplier and installer, the consultant, the owner)

- Lack and inaccuracy of the Documentation: (control and building drawings, balancing report) 
Feedback from the building operators, Cx providers, facility managers (Total: 6 installations)

Perceived Strengths:

- Explanation and data supply for fault detected

- Powerful analysis of monitored data

- Very useful tool to secure persistence of savings

Perceived Barriers:

- The user needs basic computer knowledge

- The user needs a training period due to the number of available functions and the various acronyms used in tool reports

- Complexity to classify good and deficient devices (should have a summary report of defective components)

From facility manager, the information seems to be disparate.

\section{Feedback from Tool developers}

Perceived Barriers

- From the software aspect, DABO faced problems due to the obstacles inherent to the IT Office Network and the Building Energy Management Systems. The most common problems were: connectivity to Internet and/or control network and lack of resources from the owner for the installation of DABO.

- Also, the lack of availability and accessibility of the information on the mechanical systems and the sequences of control constrained the installation of DABO.

- From the human resources aspect, the barriers are related to the low level of knowledge of the mechanical system operator, and the insufficient time for training allocated to $\mathrm{DABO}$ and the turn-over of trained building operators.

- The absence of a consulting engineer and the activities related to re-commissioning pose a barrier to the use of DABO

- From a manager's point of view, the disparity and the quantity of information from approximately 20 different reports makes the day-to-day quantification of the tool benefits complex.

Opportunities

- The software prototype DABO is used and satisfies the user when the building owner accepts the tool and devotes satisfactory resources to ensure its installation and use

- Among the success factors we find:

- The operator of the control system devotes his time to using DABO for the detection of faults, diagnosis and for EBCx measures. The time devoted to DABO varies according to the scope of the installation.

- A consultant is hired to do the follow-up and effective management of project activities (The time devoted to DABO varies according to the scope of the installation)

- The computer support staff is involved in the implementation from the very beginning to facilitate the set up of the DABO station and the connectivity to Internet for an external station. 
- A consulting engineer is on-site and use DABO to carry out re-commissioning.

- The documentation on the mechanical systems and the sequences of control is available and up to date.

- $\quad$ The identified remedies for the detected faults are implemented.

\section{Conclusions}

An on-going commissioning process ensures that buildings achieve and operate at their optimized energy cost and performance levels, while ensuring comfort conditions for occupants. The project conducted at CANMET Energy has generated $44 \%$ reduction in the electric use and $78 \%$ in the natural gas consumption over the 1998 to 2008 period.

DABO, a BEMS-assisted commissioning tool has monitored the enormous amounts of data produced by BEMS and provided an extensive analysis of the incoming data.

The use of a BEMS assisted commissioning tool has helped to circumvent commissioning barriers by automating some parts of the process, which has reduced the costs for commissioning. Developing a detailed systematic automated approach has improved the quality assurance process and the overall performance of the building. Furthermore, automating this essentially manual process has allowed its application on an on-going basis, generating benefits over the entire life of the CETC-Varennes building.

The optimization process and the 'DABO ${ }^{\mathrm{TM}}$, tool are being demonstrated in more than ten projects. Demonstration projects include some of the first Canadian LEED buildings and the participation of major Canadian facility management firms and commissioning providers.

$\mathrm{DABO}^{\mathrm{TM}}$ is a tool in constant evolution. Current research efforts are concerned with the development of an energy predictor, new fault detection and diagnosis modules for heating and cooling networks, and new analyses of BEMS data to enhance the commissioning process.

Demonstration projects are currently in the investigation and implementation stages; however early results show that $\mathrm{DABO}{ }^{\mathrm{TM}}$ helps circumvent commissioning barriers by automating some parts of the process, which has reduced the cost of commissioning. Developing a detailed systematic automated approach has improved the quality assurance process and the overall performance of the buildings. Furthermore, automating this essentially manual process has allowed its application on an on-going basis.

\subsection{References}

Energy Information Administration (EIA), 2007, Annual Energy Review 2007, Report DOE/EIA0384(2007), U.S. Department of Energy, Washington, DC, June.

Choinière D. 2001. Un agent de détection et diagnostic de fautes pour les bâtiments. Congrès de l'Association québécoise pour la maîtrise de l'énergie. Quebec City, Quebec, Canada.

Choinière $D$, and M Corsi. 2003. A BEMS assisted commissioning tool to improve the energy performance of HVAC systems. Proceedings of ICEBO 2003. Berkely, CA.

Choinière D. 2004. Four years of On-going commissioning in CTEC-Varennes Building with a BEMS Assisted Cx Tool. Proceedings of ICEBO 2004. Paris, France. 
Claridge D. E., M. Liu, W. D. Turner, Y. Zhu, M. Abbas, and J. S. Haberl. 1998. Energy and Comfort Benefits of Continuous Commissioning in Buildings. Proceedings of the International Conference Improving Electricity Efficiency in Commercial Buildings. September 21-23.

Claridge, D. E., W. D. Turner, M. Liu, S. Deng, G. Wei, C. Culp, H. Chen and S. Y. Cho. 2004. Is Commissioning Once Enough? Energy Engineering: Journal of the Association of Energy Engineering, 101(4): 7-19.

Curtin, Jonathan M., "Development and Testing of an Automated Building Commissioning Analysis Tool (ABCAT)" M.S. Thesis, Department of Mechanical Engineering, Texas A\&M University, August, 2007.

Haberl, J. S. and E. J. Vajda. 1988. Use of Metered Data Analysis to Improve Building Operation and Maintenance: Early Results from Two Federal Complexes. Proceedings of the ACEEE Summer Study on Energy Efficiency in Building, Asilomar, California.

IEA. 2001a. International Energy Agency. Annex 40: Commissioning of Buildings and HVAC Systems for Improved Energy Performance. http://www.commissioning-hvac.org.

IEA. 2001b. International Energy Agency. Annex 34: Computer-Aided Evaluation of HVAC System Performance. Final Report. Editors Arthur Dexter and Jouko Pakanen. International Energy Agency.

Jean Gilles. 2004. A climate change solution; "Intelligent Building Operating Technologies". http://cetcvarennes.nrcan.gc.ca

Knebel, D.E. 1983. Simplified Energy Analysis Using the Modified Bin Method. Atlanta: American Society of Heating, Refrigerating and Air-Conditioning Engineers, Inc.

Lee, S. U. and D. E. Claridge. 2003. Field Tests of Whole Building Simulation for HVAC System Fault Detection, draft report of Energy Systems Laboratory, Texas A\&M University July 2003.

Lee, S.U., Painter, F.L. and Claridge, D.E., "Whole Building Commercial HVAC Systems Simulation for Use in Energy Consumption Fault Detection," ASHRAE Trans., Vol. 113, 2007, Pt. 2, pp. 52-61.

Lin, G. and Claridge, D.E., "Retrospective Testing of an Automated Building Commissioning Analysis Tool (ABCAT)," Proc. 3rd Int. Conf. on Energy Sustainability, ASME, July 19-23, 2009, San Francisco, CA, USA, CD.

Turner, W. D., D. E. Claridge, S. Deng, S. Cho, M. Liu, T. Hagge, C. J. Darnell and H. J. Bruner. 2001. Persistence of Savings Obtained from Continuous Commissioning. Proceedings of the Ninth National Conference on Building Commissioning, Cherry Hill, NJ. 


\section{INTERNATIONAL COMMISSIONING COST-BENEFIT AND PERSISTENCE DATABASE}

\subsection{Introduction}

It is generally recognized that demonstrating cost-effectiveness will remove a major barrier to the wider market acceptance of building Commissioning (CX). Between 2005 and 2009, the U.S. team for the IEA Annex 47 led efforts to increase the diversity of $\mathrm{Cx}$ project data available and to quantify Cx costs and benefits for international $\mathrm{Cx}$ projects through Task 4 of the DOE-funded IEA ECBCS Annex 47 on CostEffective Cx of Existing and Low Energy Buildings, "Technical Development and Data Population of the Cx Database (IEA Subtask C)".

- The project collected financial metrics and technical details from international commissioning projects.

- The data is intended for use to demonstrate the value of commissioning to owners and possibly to assist in government policy-making.

Table 5.1 IEA Subtask C Objectives and Desired Impacts

\begin{tabular}{|l|l|}
\hline Objective & Impact \\
\hline $\begin{array}{l}\text { Improve ability to estimate costs and benefits } \\
\text { of future commissioning projects based on } \\
\text { results of previous, similar projects }\end{array}$ & $\begin{array}{l}\text { Increase adoption of commissioning by } \\
\text { providing greater certainty about costs and } \\
\text { benefits to building owners }\end{array}$ \\
\hline $\begin{array}{l}\text { Identify commonly occurring building problems } \\
\text { or "hot spots" based on statistically significant } \\
\text { data }\end{array}$ & $\begin{array}{l}\text { Increase cost-effectiveness of commissioning } \\
\text { by helping providers focus attention on likely } \\
\text { problem areas }\end{array}$ \\
$\begin{array}{l}\text { Focus policy and technical R\&D efforts on } \\
\text { areas of opportunity for improving building } \\
\text { energy efficiency and performance }\end{array}$ \\
\hline
\end{tabular}

Foundational work began in 2005 with an initial presentation of cost-benefit methodologies and output options at the Spring 2005 Annex meeting in Munich and a survey of Annex members on the subject of a data collection protocol at the Fall 2005 meeting in Prague (Friedman et al. 2005, see Appendix A Cost Benefit Protocols Report). At this meeting, Annex participants were engaged in collaborative planning for the project and set goals for expected participants' annual submissions of $\mathrm{Cx}$ and Existing Building Commissioning (EBCx) projects to an international Cx database, as shown in Table 5.2.

Work continued in 2006 with a study of Cx cost and benefit methodologies Friedman et al. $2005^{17}$ and the first draft of the data collection tools (Excel forms). In 2006 and the first half of 2007 the data collection tools were continuously refined in collaborative processes with Annex members at the Spring 2006 Annex meeting in Trondheim, the Fall 2006 Annex meeting in Shenzhen, and the Spring 2007 meeting in Budapest, as well as the significant contributions of a specially formed Advisory Committee. The impact

\footnotetext{
${ }^{17}$ Friedman, H., M. Frank, T. Haasl, K. Heinemeier, 2006. Chapter 1 “State-of-the-Art Review for Commissioning Low Energy Buildings"
} 
of the method used to determine savings persistence was evaluated and online testing of the automated persistence enhancement tool ABCAT (Automated Building Cx Analysis Tool) was carried out in four buildings. In Spring of 2007, the final data collection tools were released, previously received data was transferred from earlier versions of the tools and additional data collection efforts were engaged.

Over the following 18 months, opportunities and interest arose for additional supplementary funding to expand the project, first through an earmark to the National Center for Energy Management and Building Technologies (NCEMBT) which would have included the creation of an online searchable data base with many more U.S. projects. This expanded research opportunity diverted the progress of the initial project plan somewhat, as schedules and work plans were adjusted to accommodate the expected development of the online database including an online data submission tool over a 6 month period in the Summer and Fall of 2007. The scope of the project was revised again back to the original work plan, when it was discovered that the 2007 NCEMBT earmark would not be funded. Although the DOE has expressed strong interest as recently as July of 2008 in funding the proposed expansion of this project, including the creation of an online searchable Cx cost-benefit database for end users and significant U.S. project data additions from strategic market sectors, no additional work was funded during the Annex project.

\subsubsection{Cost-Benefit Methodology}

The cost/benefit methodology evolved through collaboration between the Annex participants between 2005 and 2007 (Refer to Appendix A for details). Through this process the goals and data collection format were developed, along with defining the types of data that would be collected relating to costs, energy-related benefits, and non-energy benefits. This process is defined in the project's Cost-Benefit Protocols Report (see Appendix A).

The output of this process was the creation of two Commissioning Data Collection Forms - one for new buildings and one for existing buildings. The surveys were divided into four sections:

- Project

$$
\begin{array}{ll}
\text { o } & \text { Project Information } \\
\text { o } & \text { Technical Information } \\
\text { o } & \text { Cost Data }
\end{array}
$$

- Energy

$$
\begin{array}{ll}
\text { - } & \text { Resource Savings } \\
\text { o } & \text { Resource Use after Cx (Persistence of savings data) }
\end{array}
$$

- Non-Energy Benefits

- Issues \& Measures

There were "required" and "optional" elements. The required elements were intended to give enough data to perform a cost-benefit analysis, and therefore include fields such as "total cost of commissioning" and "annual energy savings from implemented measures".

Additionally, there were building characteristics that are required for analysis purposes such as floor area and year the project was completed.

\subsubsection{This Chapter}

This chapter, documenting the submission of data by participants in the IEA's Annex 47 and including an analysis of this project data, is the culmination of data collection performed from May of 2007 through November of 2008. These data collection efforts included email and phone requests for data, support of Annex members in supplying data using the data collection tools, follow up contacts with the data source 
to clarify questions related to data quality and for missing or incomplete data in required fields for costbenefit analysis.

Overview of the information presented in this chapter:

- Summary of the most relevant findings in the body of this report, related not only to the Cx/EBCx projects knowledge gained, but also lessons learned about the process of collecting data for such a study.

- Discussion around what we've learned from this study and how it relates to existing knowledge about $\mathrm{Cx}$ industry and in the $\mathrm{Cx}$ cost-benefit area

- Recommendations for the path forward for international commissioning costbenefit projects

- Appendices provide comprehensive analysis, data collection forms, and

- Interim reports created throughout the project

\subsection{Data Collection}

\subsubsection{Data Collection Goals and Outcomes}

At the Fall 2005 Annex meeting in Prague, participants agreed to goals for country submissions of new building Cx projects and existing building EBCx projects (See Table 5.2). At the Spring 2007 Annex meeting in Budapest, a schedule for submission of projects and overall goal presented called for 45 projects to be submitted by Annex members between December of 2007 and May of 2008.

Projects had been submitted slowly and infrequently by Annex members throughout this period, so a decision to extend the initial round of data collection was made by the U.S. team. A final round of data was received in the Fall of 2008 , which brought the total number of projects submitted to 54 . The final number of completed projects submitted by Annex members and included in this analysis are represented in Table 5.2. Of the surveys used to complete this study, many did not include data in all fields, and so the available dataset for analysis of each of the survey questions varies.

Table 5.2 Goals and Actual Submissions of Projects by Nov. 2008

\begin{tabular}{|l|l|l|l|l|l|}
\hline Country & Goal Cx & Actual Cx & Goal EBCx & Actual EBCx & Total Projects \\
\hline Belgium & N/A & & N/A & 6 & 6 \\
\hline Canada & $2-6$ & & $2-6$ & 2 & 2 \\
\hline Czech Republic & $2-6$ & & $2-6$ & & \\
\hline Germany & $2-6$ & 1 & $6-12$ & & 1 \\
\hline Hungary & $2-6$ & & $2-6$ & & \\
\hline Japan & $2-6$ & 6 & $2-6$ & 7 & 13 \\
\hline Netherlands & N/A & 1 & N/A & 9 & 10 \\
\hline Norway & $2-6$ & & 0 & 5 & 5 \\
\hline USA & $>12$ & 2 & $>12$ & 15 & 17 \\
\hline Total & $24-48$ & 10 & $26-48$ & 44 & 54 \\
\hline
\end{tabular}




\subsubsection{Accuracy and Completeness of Data}

\section{Cx Data Set}

Only ten new building Cx surveys were returned; Most surveys contained a completed Project Information section; however, very few of the returns included complete information on the remaining sections of the survey due to data collection limitations (see Section 5.4 Data Access Limitations for discussion).

In order to determine cost-effectiveness in terms of simple payback period of the submitted projects, the end results (savings) of the project are also required. There were six surveys with completed fields related to the estimated savings from $\mathrm{Cx}$. Of these six, only four provided the complete cost data. Therefore, the cost-effectiveness of $\mathrm{Cx}$ was not able to be determined. An underlying issue is the method for determining cost savings in new construction $\mathrm{Cx}$. Three of the six surveys with completed $\mathrm{Cx}$ savings included the method used for determining the savings.

For the purposes of this analysis Cx costs were converted to US \$ using the average exchange rate for the calendar year prior to the year of completion to estimate the timing when the decision to invest in commissioning was made.

\section{EBCx Data Set}

In examining the data from the EBCx surveys, it was found that while most projects had complete data for the project information section, fewer had the data required in order to determine cost-effectiveness (EBCx cost, pre- and post-EBCx and energy usage, energy unit cost). Simple payback was calculated for each project, which does not require conversion of currencies and allows comparison across the data set. Nineteen projects had sufficient data for calculating simple payback, and 12 of these were from the USA. As a result, this data cannot be considered a reliable basis for establishing international costeffectiveness metrics. In this analysis, it is noted in those sections where data was not available from all projects and therefore a subset of the data was used.

For this analysis, EBCx costs have been converted to US \$ using the average exchange rate for the calendar year prior to the year of project completion to estimate the timing when the decision to invest in commissioning was made.

\subsection{Cost-Benefit Analysis Summary}

\subsubsection{New Construction Commissioning}

The following section highlights the key findings following analysis of data collected on new construction commissioning:

\section{Project Characterization}

Ten new construction commissioning surveys from 4 countries were returned, as shown in Fig. 5.1. The combined floor area for all of the projects totaled nearly 2 million square feet $\left(\mathrm{ft}^{2}\right)$, with the smallest project at $9,000 \mathrm{ft}^{2}$ and the largest project at $508,853 \mathrm{ft}^{2}$. The wide variation in building size makes comparisons challenging, as the Cx process would be different for buildings at either end of the spectrum. 


\section{Netherlands, 1}

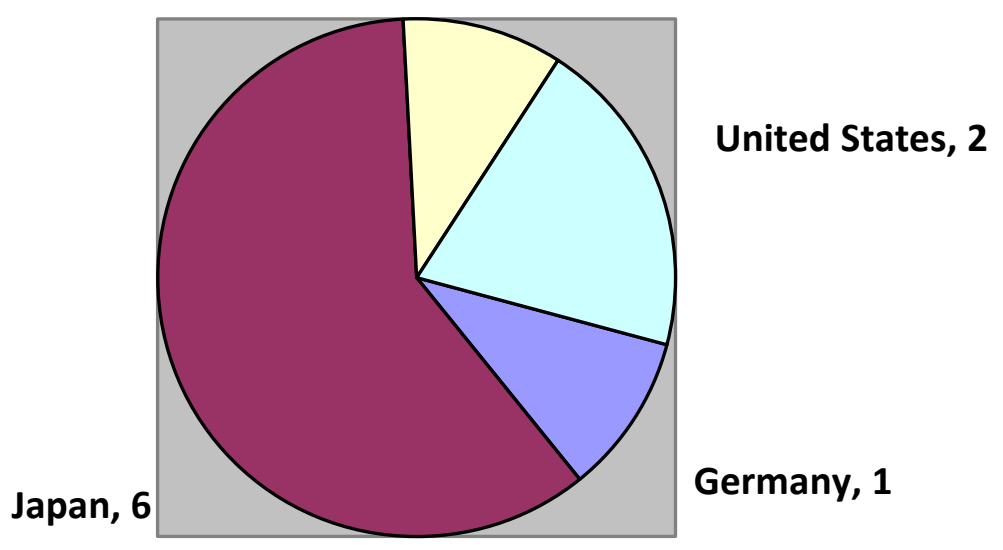

Figure 5.1 Breakdown of Cx projects by country

Owners were asked to rate their reasons for selecting Cx on a scale of 1 to 5 in a variety of categories with a score of 4 or 5 , a factor is considered "important". The results are summarized in Fig. 5.2.

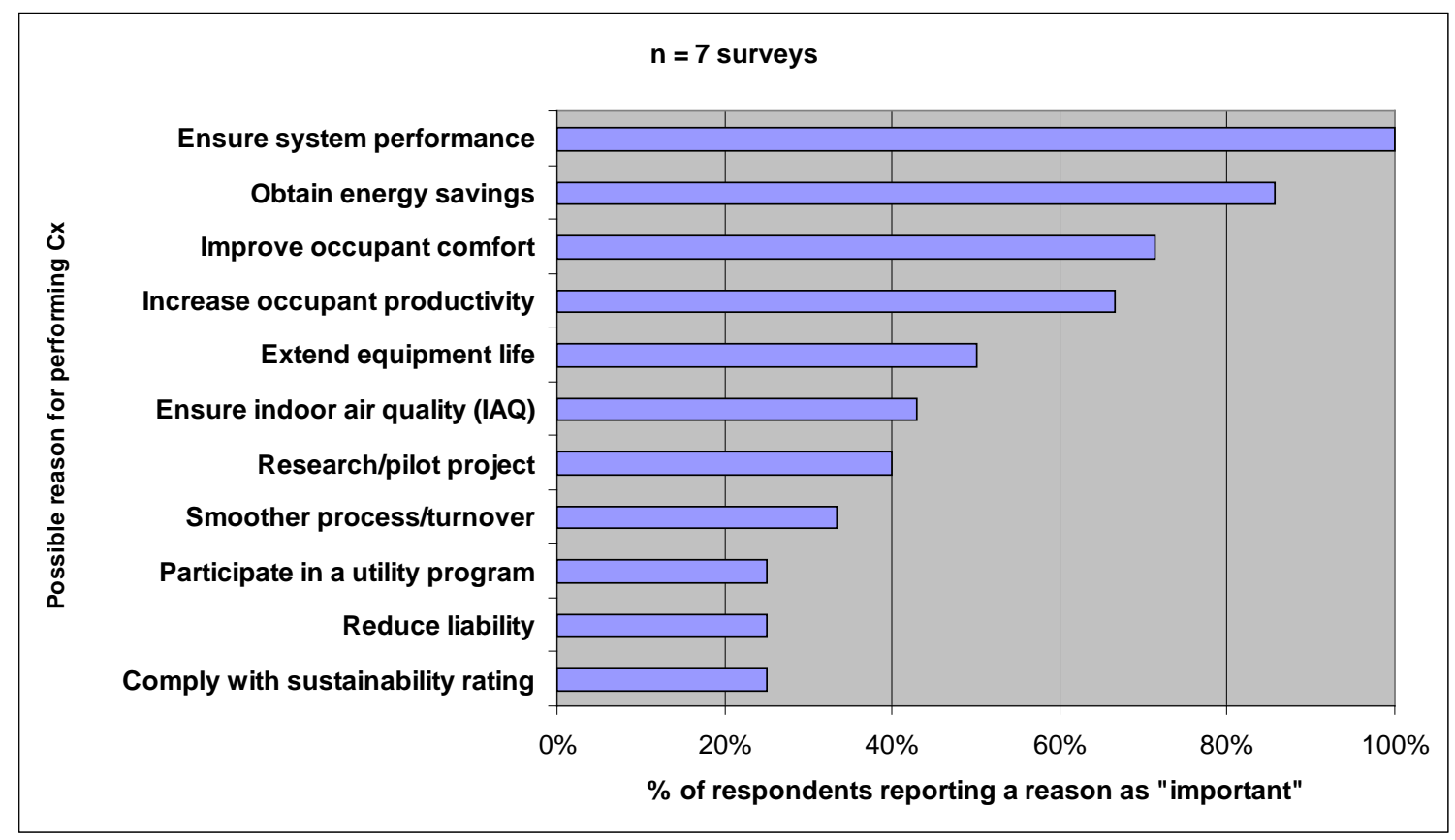

Figure 5.2 Owners' reasons for performing $\mathrm{Cx}$

All respondents stated that ensuring system performance was important. The next highest factors were to obtain energy savings, improve occupant comfort, and increase occupant productivity. It is interesting to note that while ensuring system performance can be quantified, the other three factors are harder to demonstrate for a Cx project.

Understanding the scope of the commissioning process undertaken provides a sense of how comprehensive the commissioning process was for the seven projects that reported this information. Figure 5.3 shows that scope varied widely across the small sample of projects. 


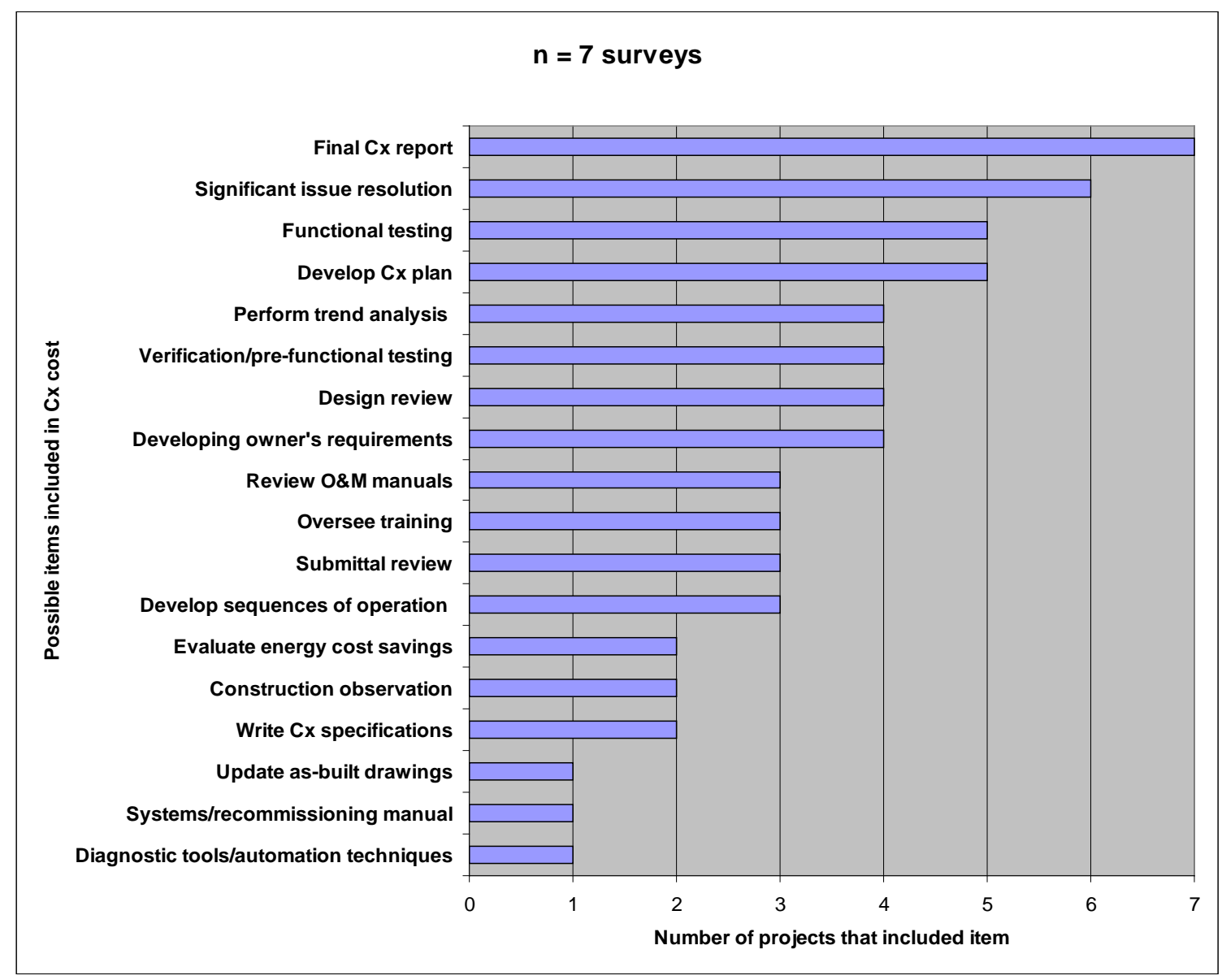

Figure 5.3 Items included in Cx cost

It is interesting to note that, while most building owners consider "obtain energy savings" as a main reason for performing Cx, only two out of the seven respondents included "evaluate energy cost savings" as part of their $\mathrm{Cx}$ process. This is likely due to the difficulties involved in evaluating energy savings for new construction projects, since there is no baseline energy use to compare against.

While no conclusions can be drawn with such limited data, the least often included items in scope (upated as-built drawing, systems/EBCx manual, and diagnostic tools) are consistent with our understanding of the U.S. experience. These items have high relevance for improving the persistence of benefits from commissioning.

\section{Issues and Measures}

A total of 55 issues compiled from six completed surveys were grouped by the type of system affected as shown in Fig. 5.4. Just over $65 \%$ of the issues were found in the central plant and the air handling systems. 


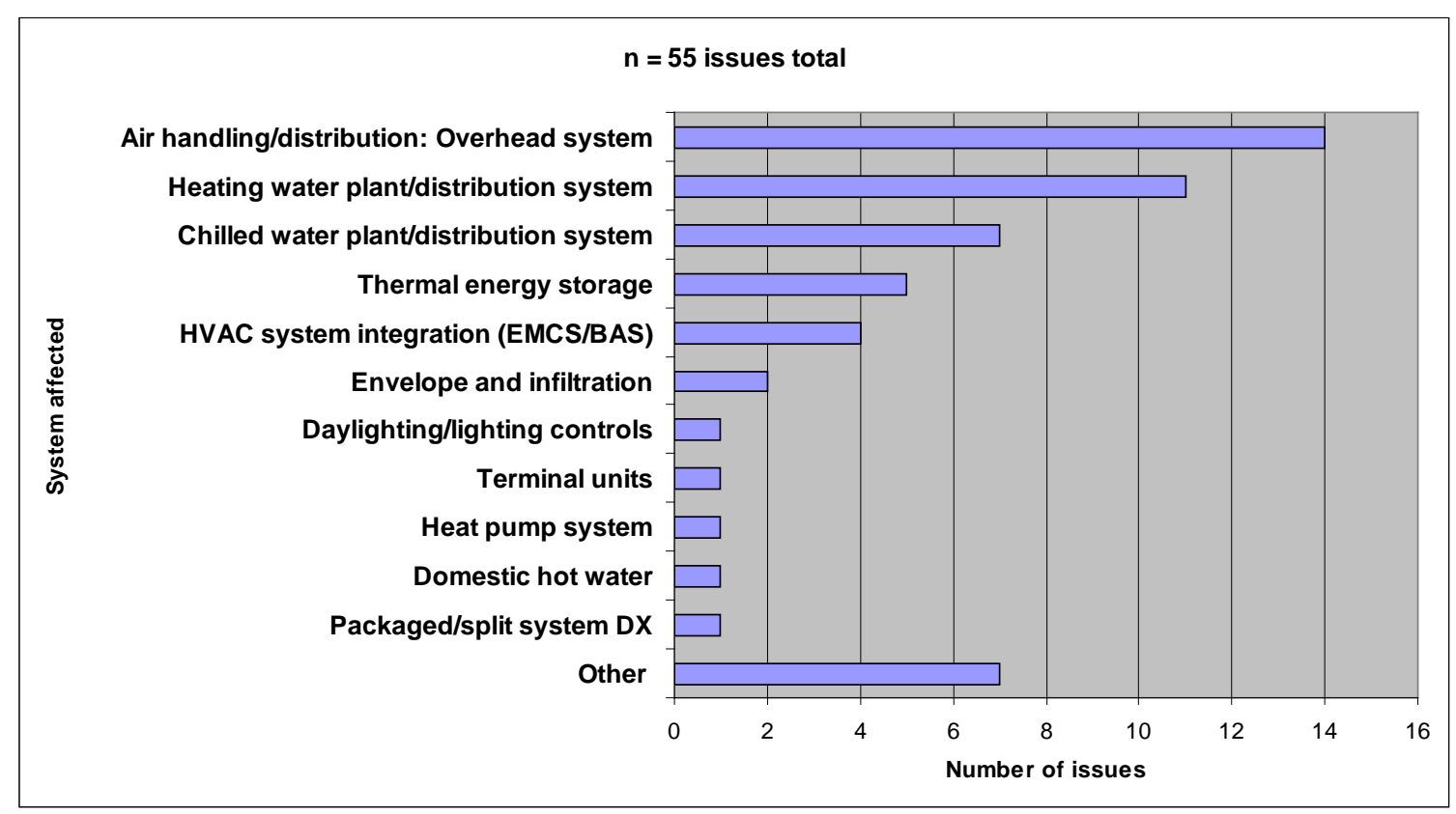

Figure 5.4 Cx Issues identified, by system type

Four surveys containing 45 of the issues listed in Fig 5.4 were classified according to four additional categories; design, construction, O\&M or capital improvement. Figure 5.5 shows the breakdown of the additional categories (there were no responses for "capital improvement"). It is interesting to note the even split between 3 categories.

\section{$n=45$ issues total}

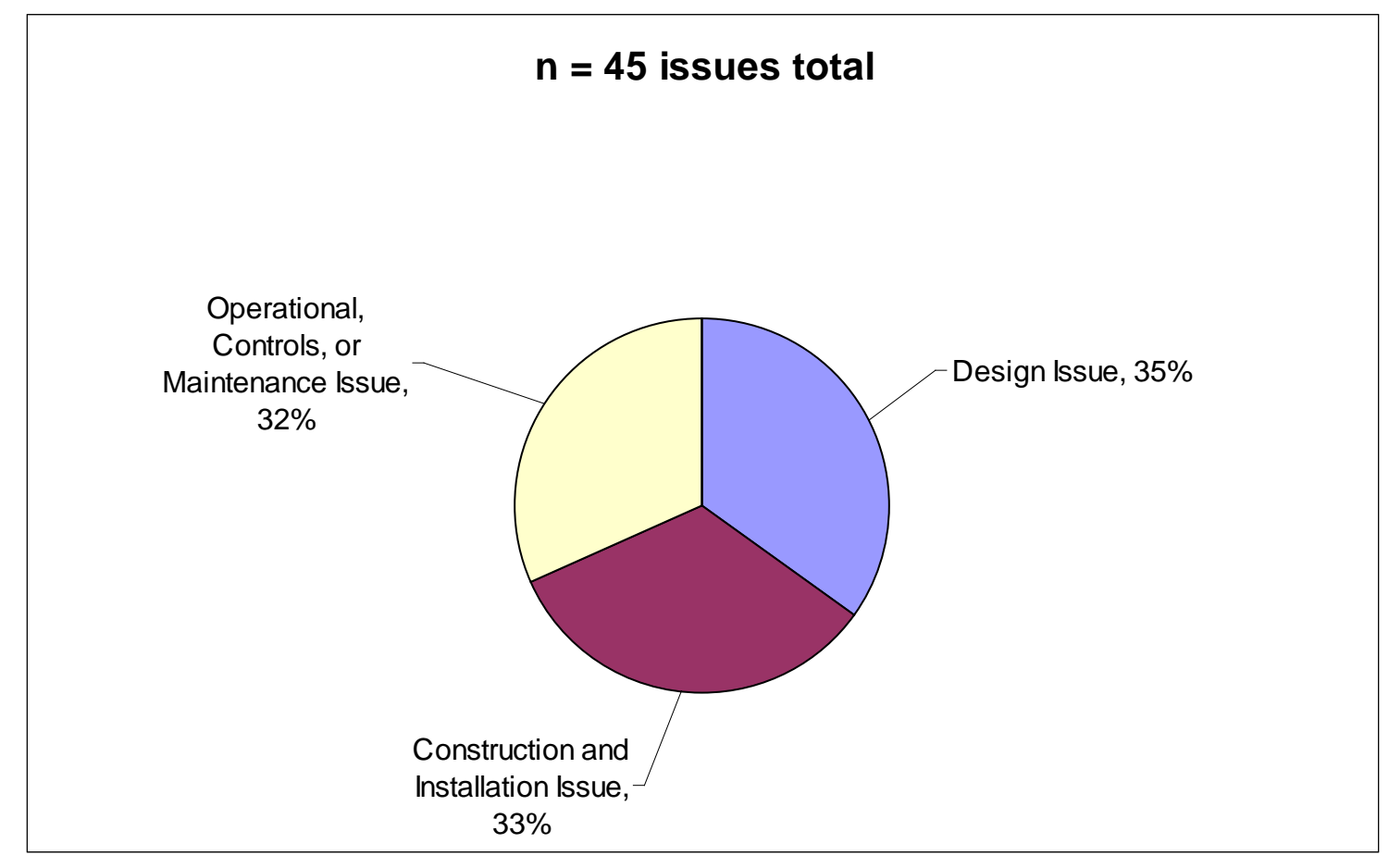

Figure 5.5 Cx Issues identified, by fault type 
Out of ten returned surveys, only three had information associated with documenting issues and the measures implemented to fix them (see Fig. 5.6). In total, there were 56 reported measures, and all measures were reported as implemented except for a single electrical issue that was listed as unknown. The categories "Other," "Installation modifications," and "Design change" account for $84 \%$ of all reported measures.

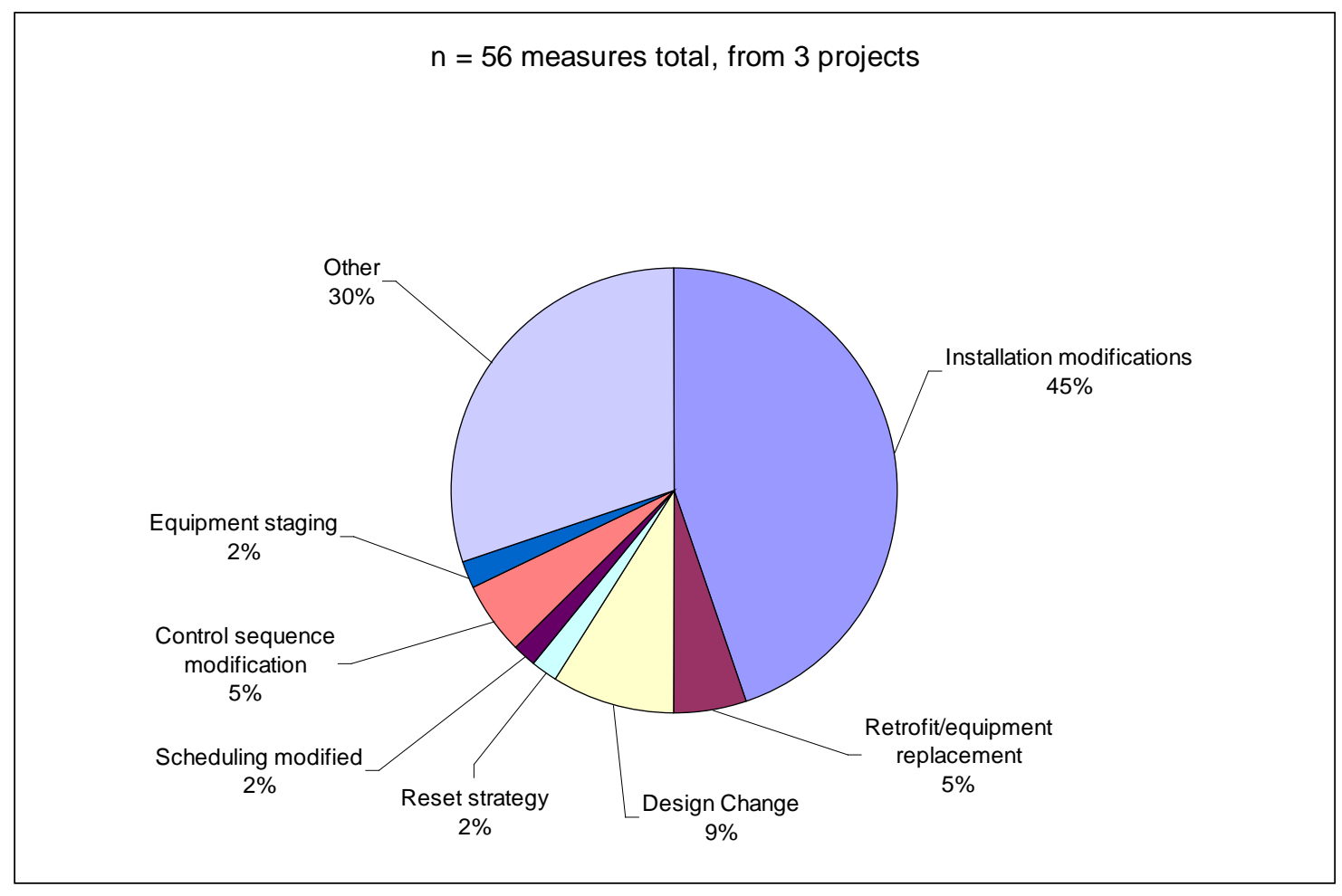

Figure 5.6 Implemented Cx measures

For the 17 survey answers with measure type "Other", the corresponding equipment categories were:

- Electrical (11)

- Security (2)

- 1 each for Ductwork, Fire/Life safety, Exhaust Fans, AHU distribution (overhead)

\section{Costs}

A total of six surveys were returned with costs reported in currency. Two additional surveys conveyed the total cost as hours of labor.

The Cx cost ranges from $\$ 0.06$ per $\mathrm{ft}^{2}$ to $\$ 2.57$ per $\mathrm{ft}^{2}$, suggesting the $\mathrm{Cx}$ process varied significantly and/or the way costs were attributed varies. This echoes earlier comments that the data set allows for little cross-comparison.

Three surveys were returned with a breakdown of fees. These results are shown in Fig. 5.7. 


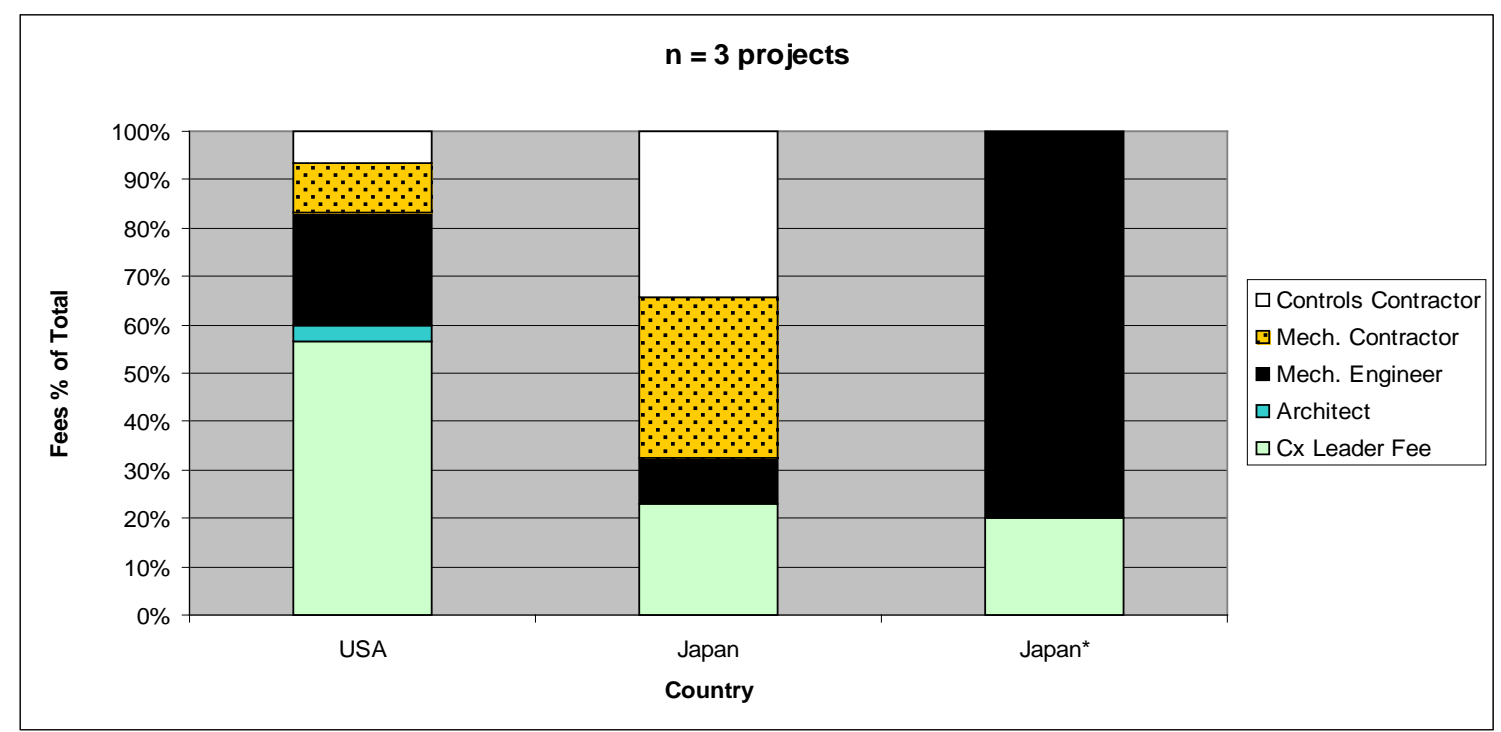

*costs reported as hours of labor for one of the Japan projects

Figure 5.7 Breakdown of fees as \% of total Cx costs

The U.S. project was the only project to include architect's fees, and one of the Japanese projects only included fees for the $\mathrm{Cx}$ leader and mechanical engineering. For the U.S. project, the $\mathrm{Cx}$ leader fees account for over $55 \%$ of the overall cost, suggesting a very active leadership role compared to the other projects where the $\mathrm{Cx}$ leader is perhaps facilitating/supporting the work of other parties.

\section{Energy Savings}

- Determining energy "savings" for a new building is challenging, and different methods may be used

- Claimed energy use may not account for the full floor area of a building, hence the EUI and savings percentage will not be accurately represented

\subsubsection{Existing Building Commissioning (EBCx)}

The complete results of the analysis of the existing building commissioning projects can be found in Fig. 5.8. The following section highlights the key findings.

\section{Project Characterization}

In total, six countries were represented in the data set. Significantly more U.S. buildings were available for inclusion in the data set, however it was decided that to retain a balance to the international data set, only 15 of these buildings would be entered. 


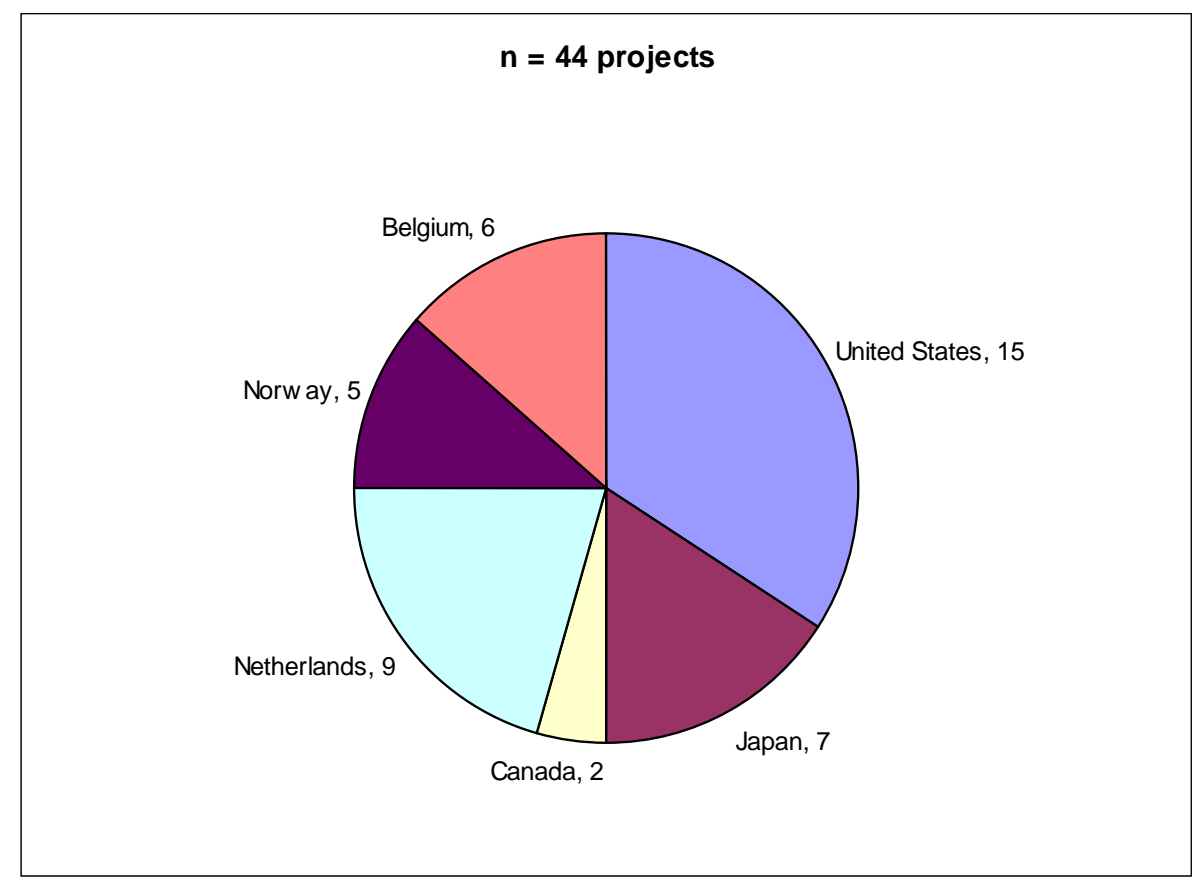

Figure 5.8 Breakdown of EBCx projects by country

The floor area from all of the projects totaled to more than 12 million $\mathrm{ft}^{2}$, with the smallest building at 11,400 feet and the largest building at 1.4 million $\mathrm{ft}^{2}$ The category with the greatest number of buildings is the range of 100,000 to $200,000 \mathrm{ft}^{2}$

The oldest building has a 1950 vintage, and the newest was built in 2006. Ten out of 44 buildings were less than five years old at the time of the EBCx project. This may be counter-intuitive for building owners, who feel that a relatively new building would not require system improvements, however it is consistent with the vintage of building often targeted in the U.S. for EBCx efforts since the control systems in these buildings often can accommodate greater energy-saving enhancements.

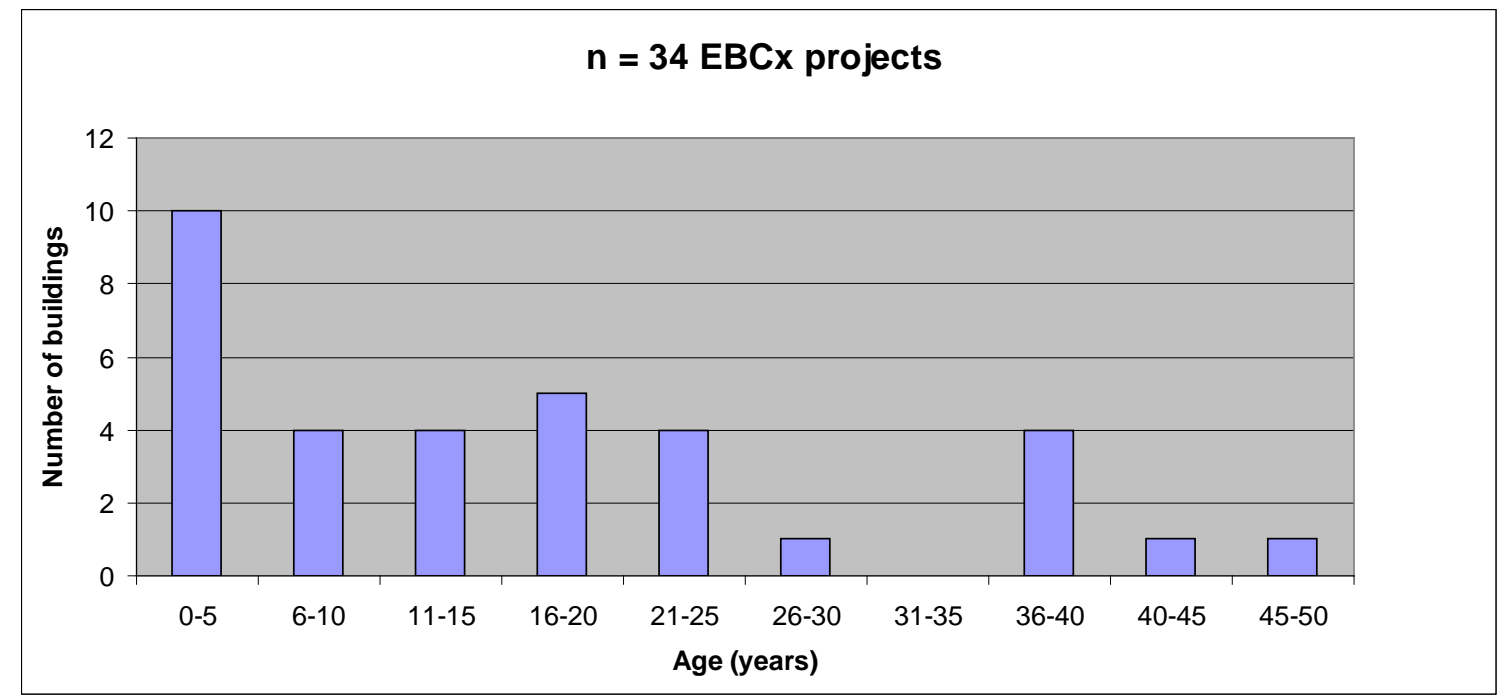

Figure 5.9 Age of building at time of EBCx project 
Publicly owned buildings comprise $49 \%$ of the data set; $51 \%$ are privately owned. Of the publicly owned buildings, all but four are universities (one public assembly, one office, one laboratory, and one office). The majority of the buildings - $65 \%$ - are owner-occupied, $28 \%$ are leased, and $7 \%$ are both owneroccupied and leased. Historically, public owner-occupied buildings are the early adopters of Cx efforts, so it is encouraging to note that private owner-occupied is gaining traction. Building leases often create disincentives for building energy improvements if all or a portion of energy costs are simply passed through to the tenants.

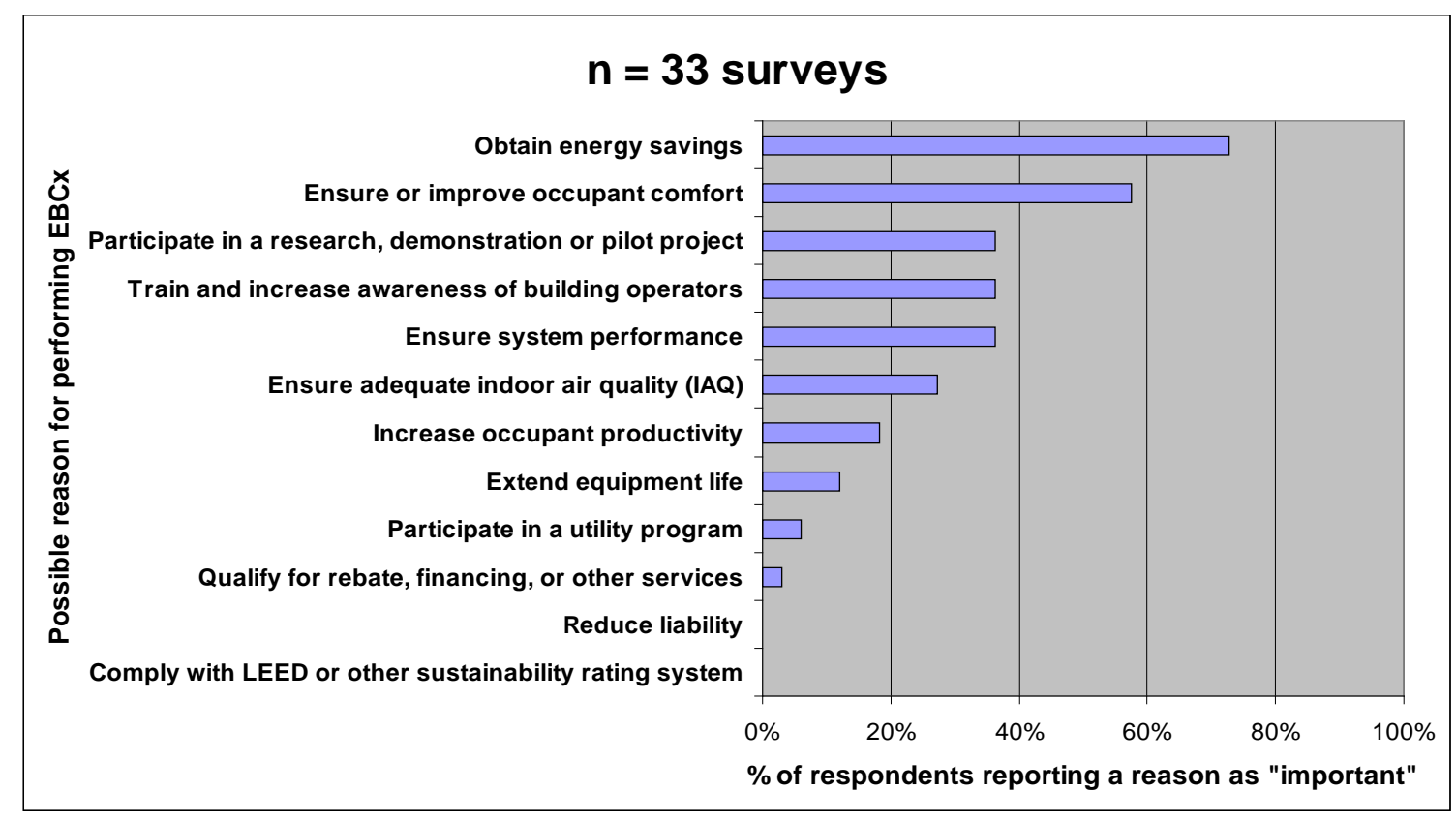

Figure 5.10 Reasons for performing EBCx

Internationally, the reasons for performing EBCx are consistent with expectations - to save energy, ensure occupant comfort, train operators, and ensure system performance. The fact that "participate in a research, demonstration, or pilot project" was also high-ranking reflects the state of the EBCx industry in many countries where EBCx is not an industry with practitioners, rather a research-grade effort.

Thirty-three out of 42 projects were led by an independent EBCx leader or energy service company. EBCX is still considered a specialized process, and so the skills have not yet been absorbed into conventional construction and mechanical engineering disciplines.

The full EBCx process includes most of the tasks included in Fig. 5.11, with a few tasks such as diagnostic tools/automation and implement capital improvements generally undertaken as an additional benefit beyond the EBCx process. Based on this data, the scope of EBCx generally includes:

- Trend analysis

- Document master list of findings

- Present a findings and recommendations report

- Implement operations and maintenance improvements

- Final report 
Almost every project presented a findings and recommendations report, and of those that did not include this report, all but one included a final report instead.

The low occurrence of updating documentation, development of a systems/EBCx manual, and monitoring persistence is a result of the cost of these activities. The lack of documentation and monitoring may result in a lack of persistence of benefits from these EBCx projects.

One surprising finding about the scope of EBCx is that utility bill analysis, benchmarking, and calculating cost savings were only performed in about half of the projects. These are common EBCx activities in the U.S., but not as common in these international projects.

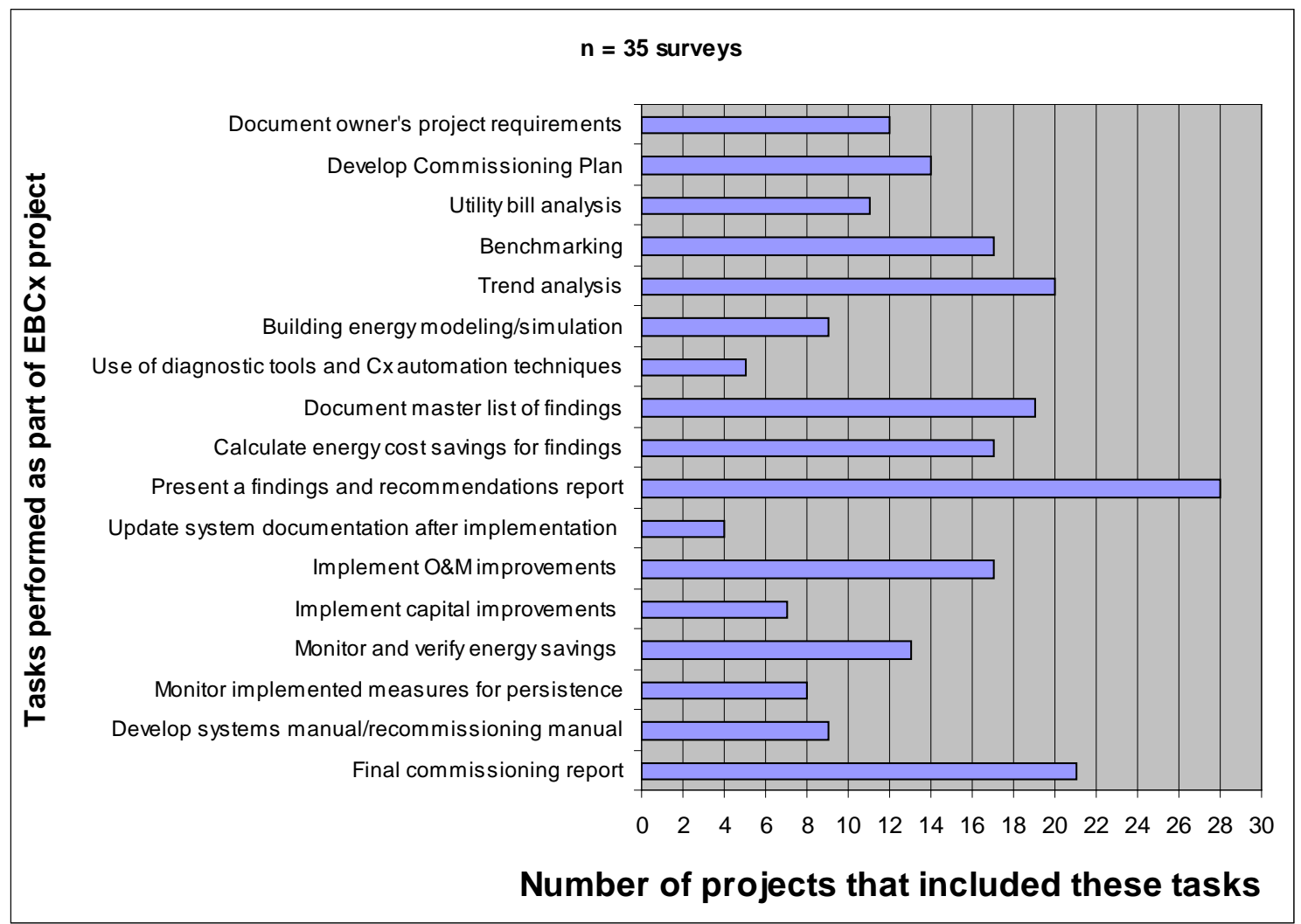

Figure 5.11 Tasks performed as part of EBCx project

\section{Issues and Measures}

The most common issues are as expected, related to integration and controls, air handling systems, and chilled and heating water plants. In order to get a better understanding of the impact of the phases of a building life-cycle on the problems found, a question was asked about where the issues originated. 


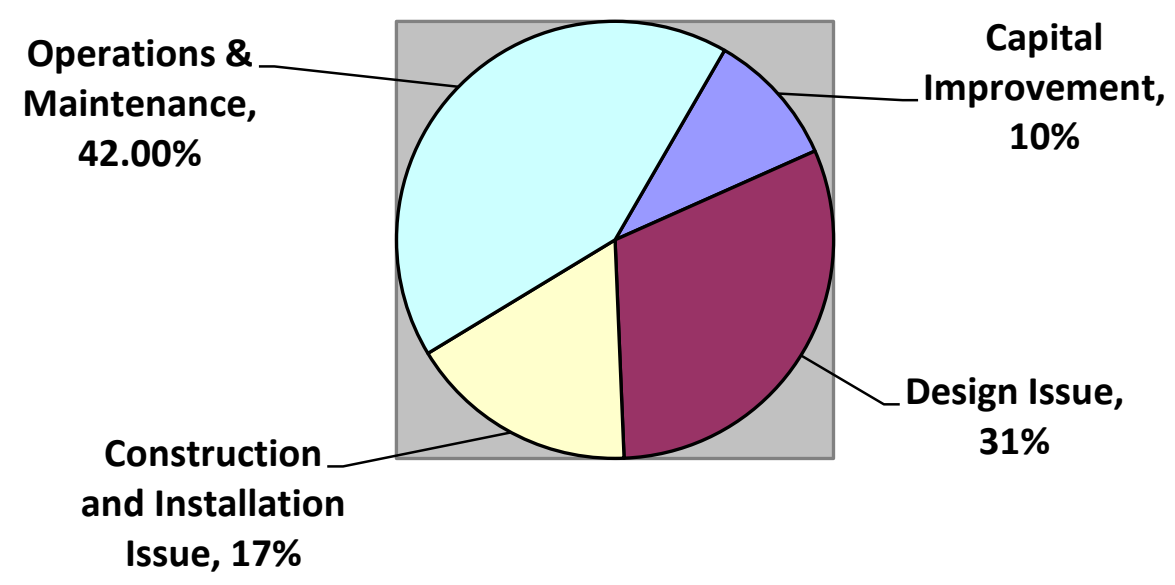

Figure 5.12 Origin of issues found through EBCx process

Here, the categories Operations and Control and Maintenance account for a large portion of the issues, areas where EBCx seeks to identify energy-saving improvements. Notably, $48 \%$ of the issues were attributed to design or construction phase decisions, which points to the benefits of commissioning for new buildings.

In 38 projects, over 203 issues were reported through the survey and categorized by issue type (see Table 5.3 for a list of issue types available for selection by survey respondents). Design/installation issues included findings related to the design or installation of equipment, rather than the operation and control of that equipment. Figure 5.13 shows the results from completed surveys for 38 EBCx projects. 
Table 5.3 List of issue types available for selection by survey respondents

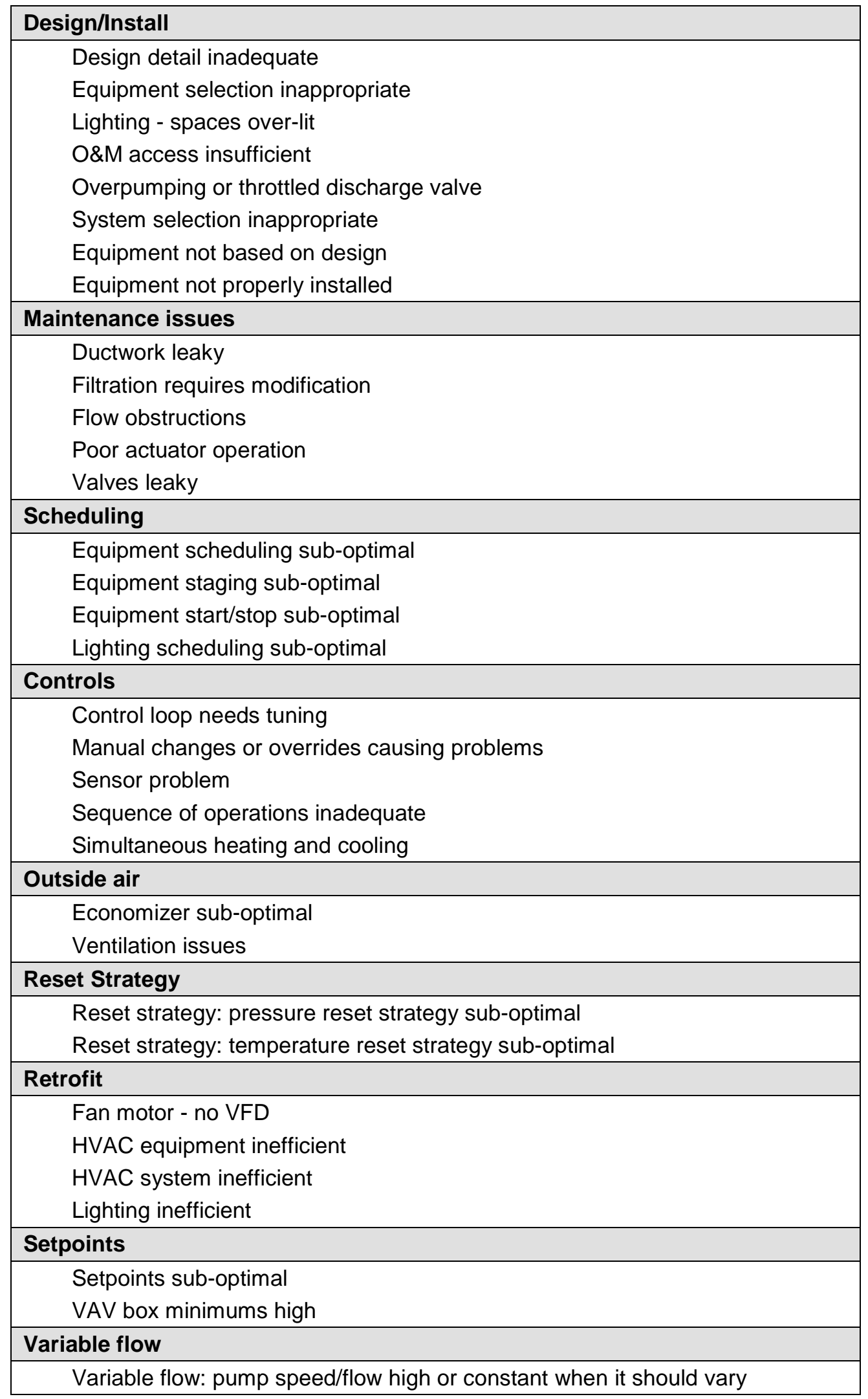




\begin{tabular}{|l|}
\hline \multicolumn{1}{|c|}{ Variable flow: fan speed/flow high or constant when it should vary } \\
\hline Other (Controls) \\
\hline Other (General) \\
\hline
\end{tabular}

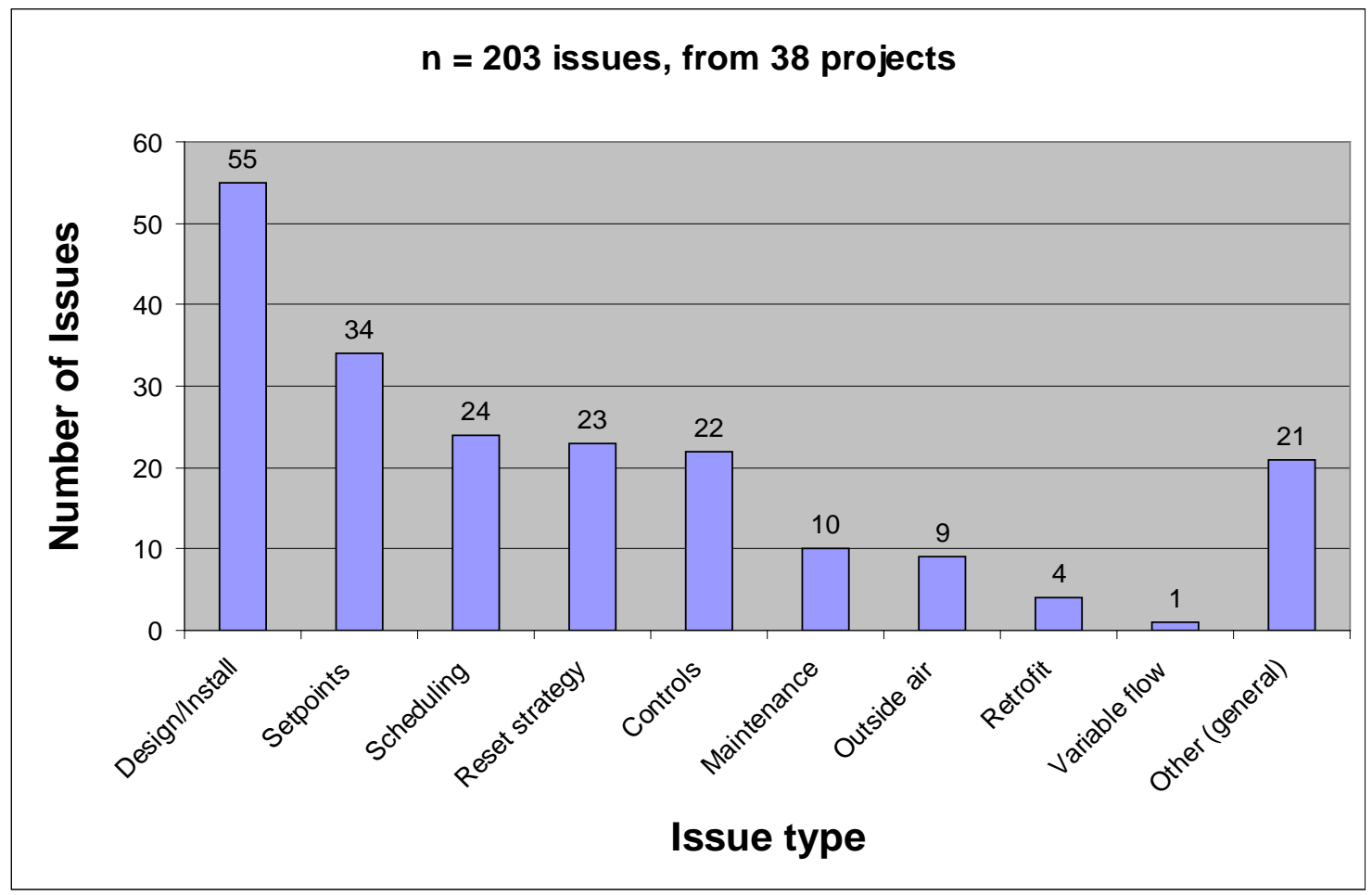

Figure 5.13 Issue types uncovered through EBCx process

One of the most unexpected findings in this report is that "Design/Install" was clearly the most common issue. This issue broke down into 9 sub-categories that were selected as follows.

- Construction/installation (24 issues)

- Equipment selection inadequate (15)

- Design detail inadequate (8)

- Space over-lit (2)

- Not properly installed (2)

- O\&M access insufficient (1)

- Over-pumping/throttled valve (1)

- System selection inadequate (1)

- Equipment not based on design (1)

This finding points to the need for design and construction-phase commissioning of new buildings, as the problems can plague a building for its life, and finally be addressed in the EBCx process.

Figure 5.14 shows the systems affected for the 203 reported issues, with more than half of the issues being attributed to the "Air handling/distribution: overhead" or "Multiple HVAC systems" categories. These responses are generally in line with expectations. 


\section{$n=203$ issues, from 38 projects}

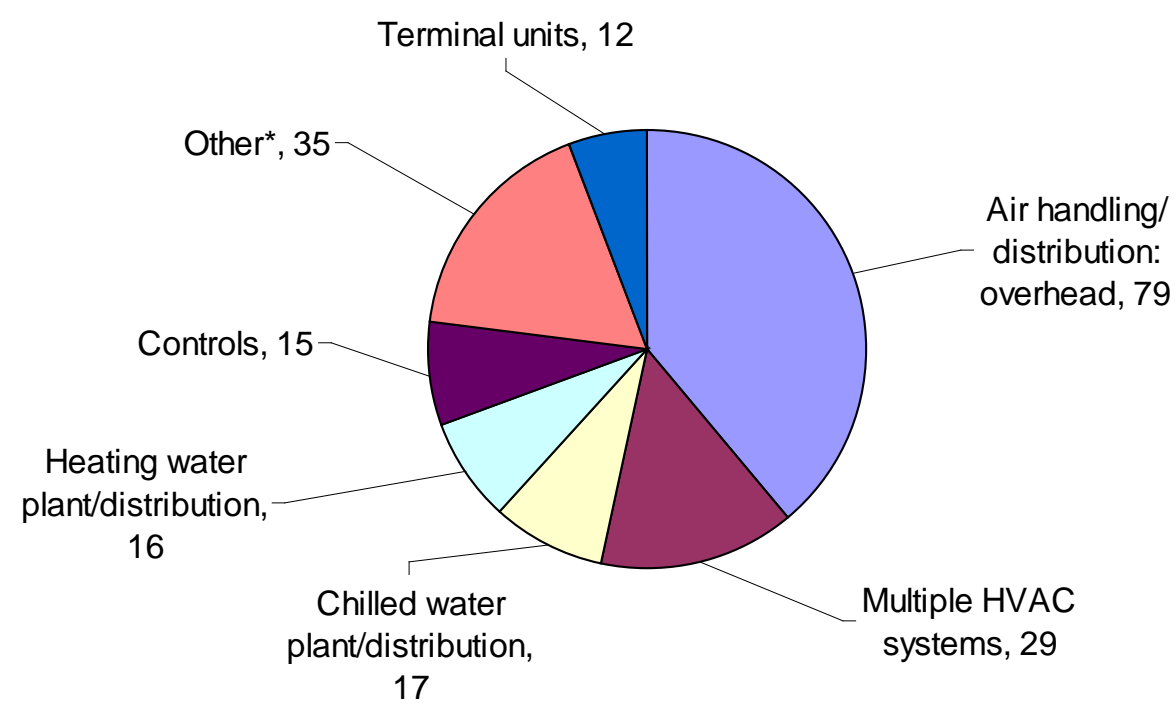

Figure 5.14 EBCx issues, system affected ${ }^{18}$

* Category "Other" includes lighting/daylighting controls, radiant heating, heat pump system, envelope/infiltration, plumbing, radiant cooling, thermal energy storage, all of which received 5 or fewer responses.

In addition to reporting the issues/problems identified through EBCX, survey respondents also reported the recommended fixes/measures for addressing those problems. Respondents gave the measure type, and for each measure indicated whether it was implemented, not implemented, or "unknown" (see Fig. 5.15).

Out of 205 recommended measures, 121 were implemented (59\%). While $59 \%$ of the recommended measures were implemented, it is not known what percentage of available energy savings this represents. It is assumed that measures with higher savings would be more likely to be implemented and that the achieved savings would be greater than $59 \%$ of the potential savings, but this cannot be verified for this study.

\footnotetext{
${ }^{18}$ Each category shown in this chart includes its associated controls. The standalone category “controls” includes general controls issues that did not fit into any other specific system type.
} 


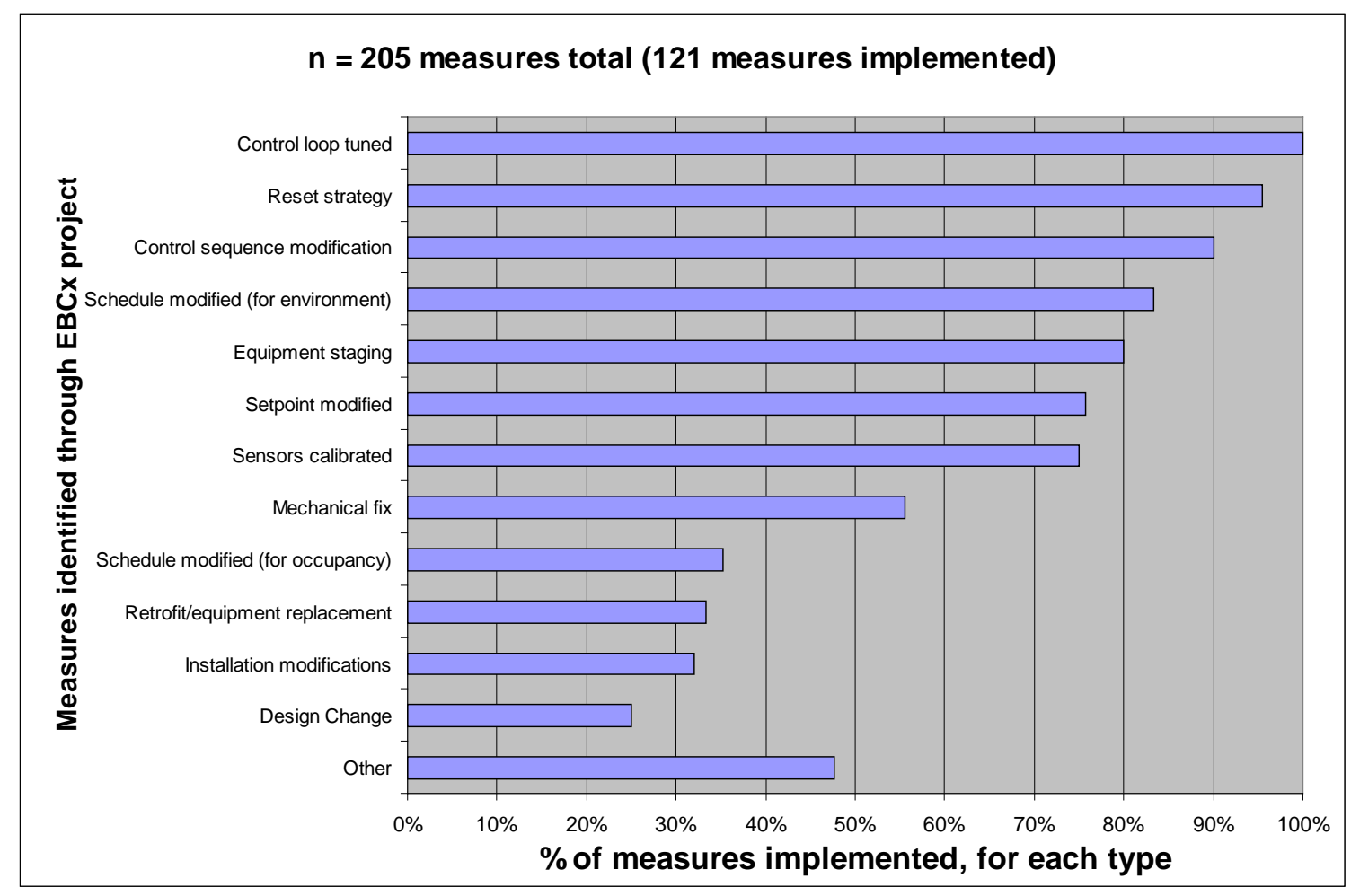

Figure 5.15 Percentage of measures implemented, by type

This data shows that a relatively small percentage of the retrofits/equipment replacements and installation modifications were implemented, whereas the majority of the setpoint modifications, reset strategies, and other modifications to the control sequence of operations were implemented. This is in line with expectations, as the items that were implemented are generally lower cost than those that were not implemented.

\section{Costs}

The cost of commissioning existing buildings in all countries was normalized into US $\$ / \mathrm{ft}^{2}$ and US $\$ / \mathrm{m}^{2}$ using the average exchange rate for the year that the EBCx project was completed. To convert from US $\$ / \mathrm{ft}^{2}$ to US $\$ / \mathrm{m}^{2}$, multiply by a conversion factor of 0.0929 . Through this analysis, median cost was found to be $\$ 3.12 / \mathrm{m}^{2}$ (US $\$ 0.29 / \mathrm{ft}^{2}$ ), with a range of US $\$ 0.11 / \mathrm{m}^{2}$ to US $\$ 17.76 / \mathrm{m}^{2}$ (US $\$ 0.01 / \mathrm{ft}^{2}$ to US $\$ 1.65 / \mathrm{ft}^{2}$ ) (see Fig. 5.16). It is important to note that cost data was not always available, especially for research-grade projects. In research projects, it is often difficult to separate out what might be deemed a typical commissioning scope.

Notes on projects with the highest and lowest unit costs per $\mathrm{ft}^{2}$ :

Highest unit cost:

Canada, EBCx cost US $\$ / \mathrm{m}^{2}$ (US $\left.\$ 1.65 / \mathrm{ft}^{2}\right)$

- $465 \mathrm{~m}^{2}\left(5,000 \mathrm{ft}^{2}\right) 65 \%$ office, $35 \%$ "Research Areas"

- The list of tasks included in the process denote this as an example of a comprehensive EBCx project

- Performing comprehensive EBCx on a small building with research areas would understandably result in a high unit cost per $\mathrm{ft}^{2}$

Japan, EBCX cost US $\$ 9.58 / \mathrm{m}^{2}$ (US $\$ 0.89 / \mathrm{ft}^{2}$ ) 
- $9383 \mathrm{~m}^{2}\left(101,000 \mathrm{ft}^{2}\right)$, office building

- There is nothing in the building size, type, or EBCx tasks list to suggest why this building had a high unit cost per $\mathrm{ft}^{2}$

Lowest unit cost:

Netherlands, EBCx cost US $\$ 0.11 / \mathrm{m}^{2}$ (US $\left.\$ 0.01 / \mathrm{ft}^{2}\right)$

- $19974 \mathrm{~m}^{2}\left(215,000 \mathrm{ft}^{2}\right)$, university

- Project cost only 2,000 Euros

- EBCx scope included only trend analysis and a final report

- The limited scope explains the low cost

Netherlands, EBCx cost US $\$ 0.65 / \mathrm{m}^{2}$ (US $\$ 0.06 / \mathrm{ft}^{2}$ )

- $30935 \mathrm{~m}^{2}\left(333,000 \mathrm{ft}^{2}\right), 80 \%$ office, $20 \%$ restaurant

- This project also had a limited scope

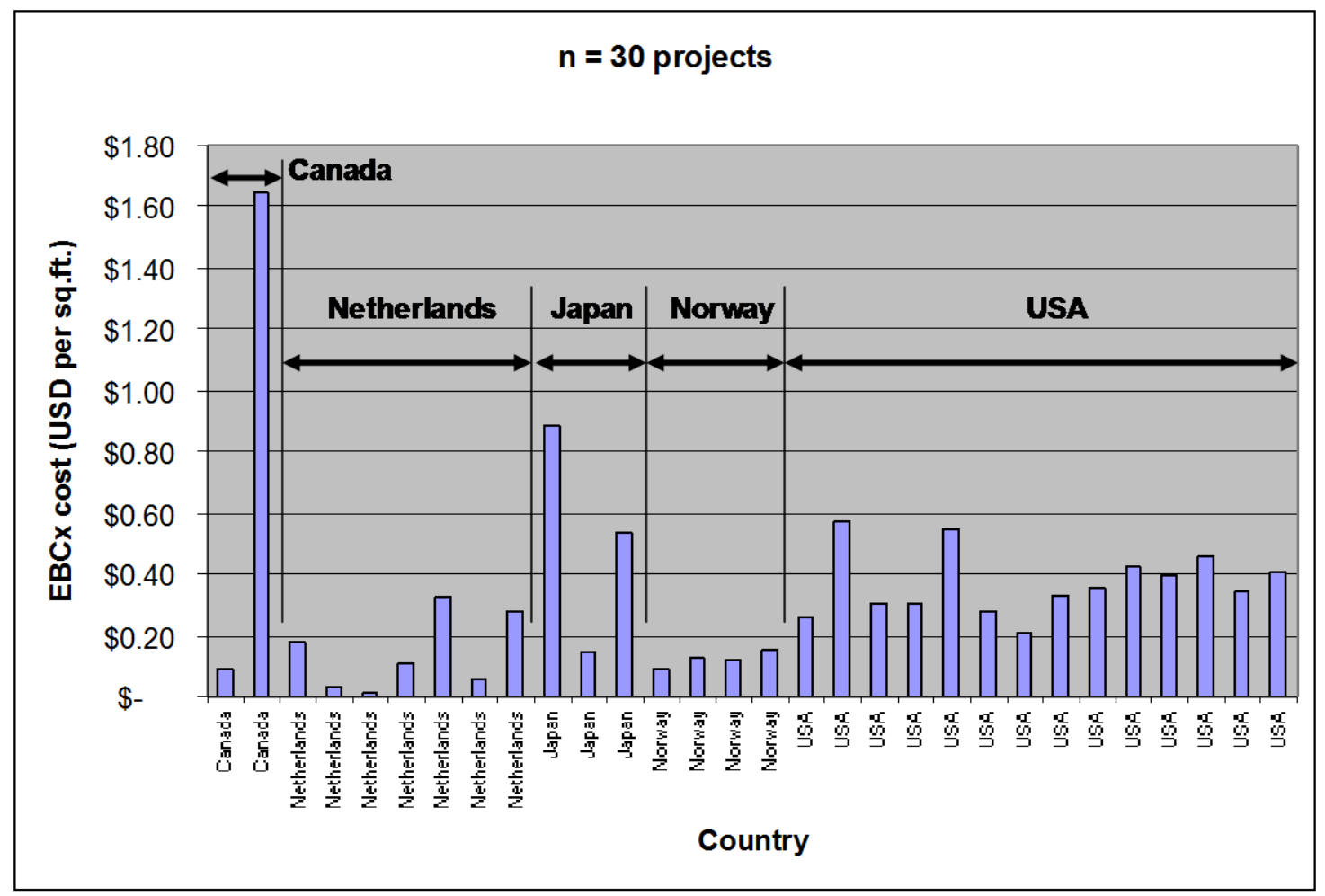

Figure 5.16 EBCx projects' cost per $\mathrm{ft}^{219}$

${ }^{19}$ To convert from US $\$ / \mathrm{ft}^{2}$ to US $\$ / \mathrm{m}^{2}$, multiply by a conversion factor of 0.0929 . 


\section{$\mathrm{n}=30$ projects}

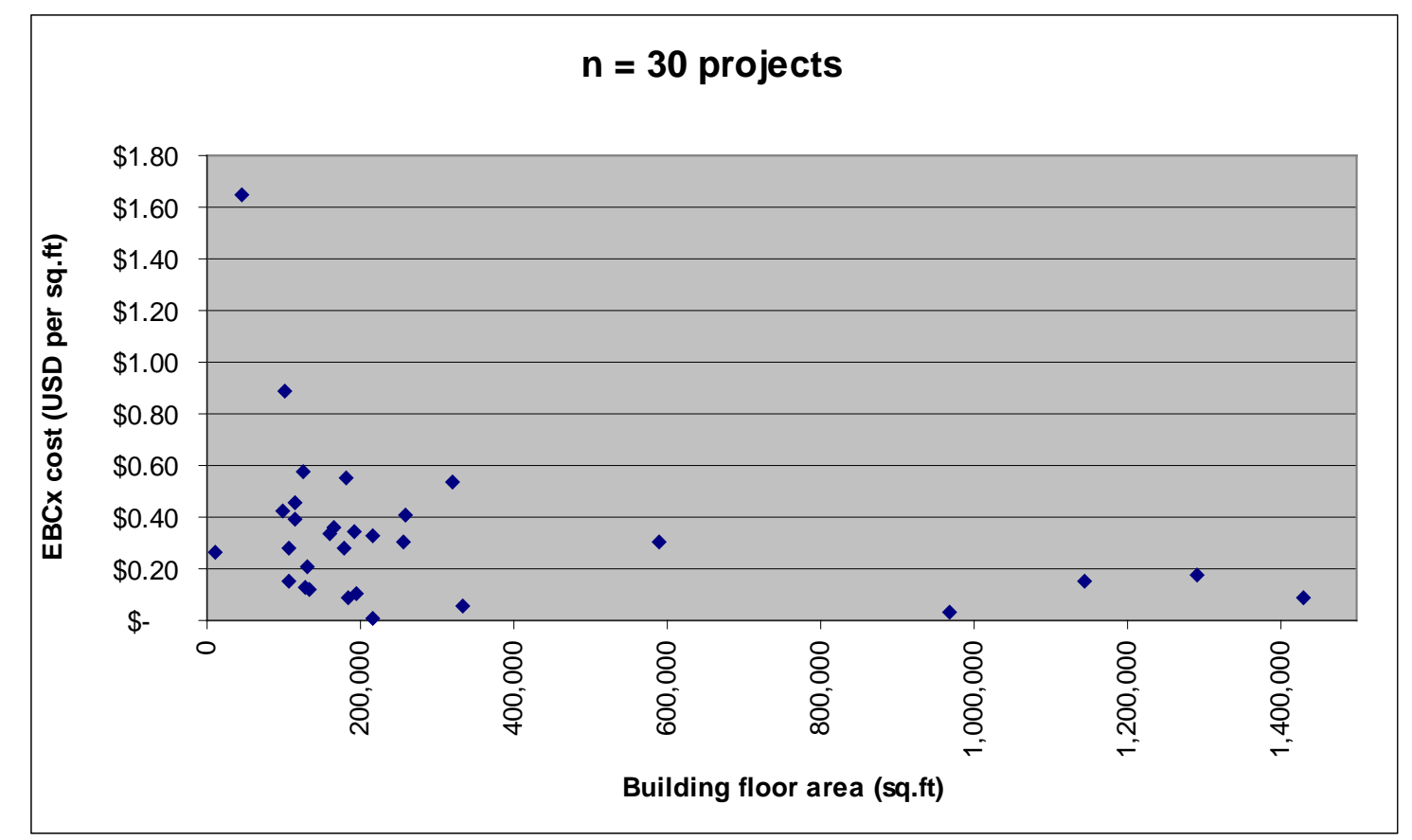

20

Figure 5.17 EBCx project cost per $\mathrm{ft}^{2}$ vs. building size

Figure 5.17 shows a slight correlation between the size of a building and the EBCx cost per $\mathrm{ft}^{2}$, but a larger dataset would be required in order to create a reliable correlation. Within the size range of $4645 \mathrm{~m}^{2}$ to $37160 \mathrm{~m}^{2}\left(50,000 \mathrm{ft}^{2}\right.$ to $\left.400,000 \mathrm{ft}^{2}\right)$, the scatter looks random.

${ }^{20}$ To convert from $\mathrm{ft}^{2}$ to $\mathrm{m}^{2}$, divide by a conversion factor of 0.0929 . 


\section{Energy Savings}

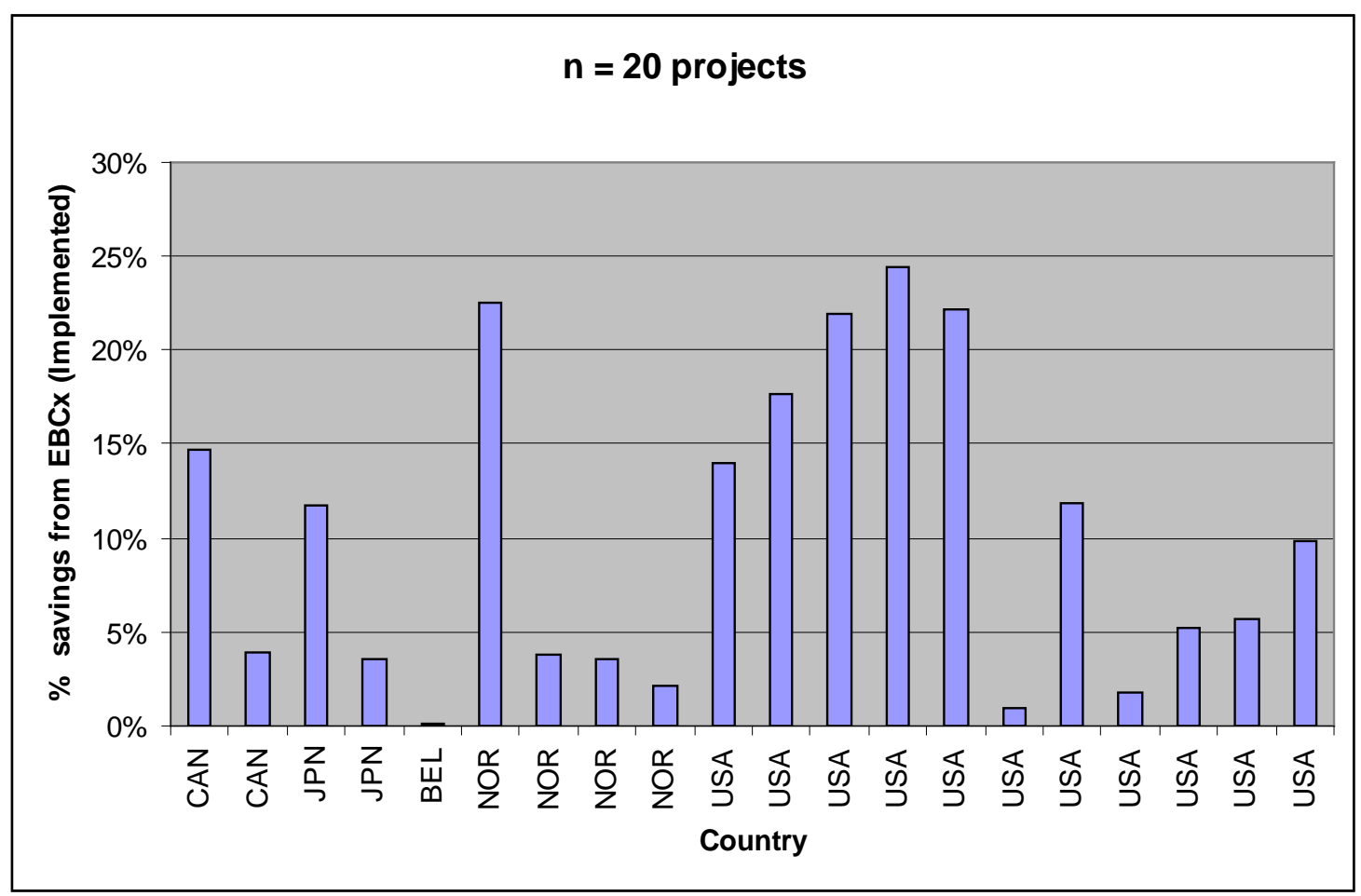

Figure 5.18 Percentage electric savings from EBCx projects

The data in Fig. 5.18 show a range of $1 \%$ to $24 \%$ electric savings (kWh), with a median value of $8 \%$. There has been no investigation into the sources of variation in these reported savings, but they could be significantly affected by the following factors:

- Scope of EBCx project

- Budget limitations resulting in efficiency improvements not being implemented

- Accuracy of estimates for claimed energy savings

- Energy efficiency of building systems prior to EBCx project

Energy Use Intensity (EUI) is one measure that may indicate the energy efficiency of building systems. Electric EUI is measured in $\mathrm{kWh} / \mathrm{ft}^{2} / \mathrm{yr}$, and Fig. 5.19 plots electric EUI against implemented $\mathrm{kWh}$ savings for this data set. 


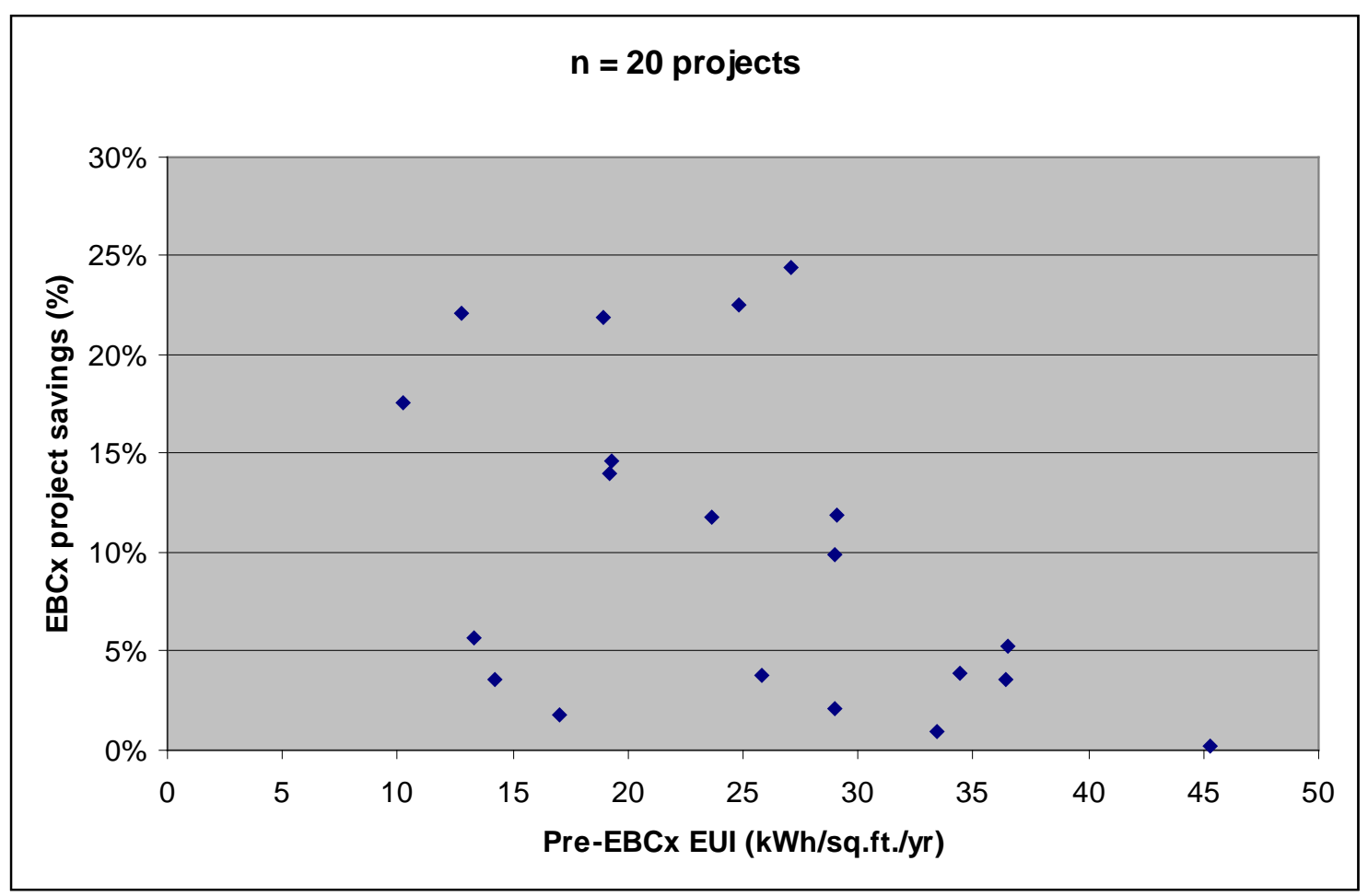

Figure 5.19 Electricity consumption vs. \% savings for EBCx projects

It is logical to assume that buildings with a higher EUI would have greater savings potential, but Fig. 5.19 suggests that there is no correlation between pre-EBCx energy use and EBCx savings percentage for this data set.

\section{Cost-effectiveness}

Common measures for cost-effectiveness are simple payback and ROI (return on investment). For this study, simple payback is used as the cost-effectiveness metric, and is calculated as the overall project cost divided by the claimed annual cost savings. A 2004 report summarizing data from 100 projects in the USA showed a median simple payback of 0.7 years, with values ranging from less than 1 month up to values in excess of 5 years. A summary of 19 projects from this study are included in Fig. 5.20. 


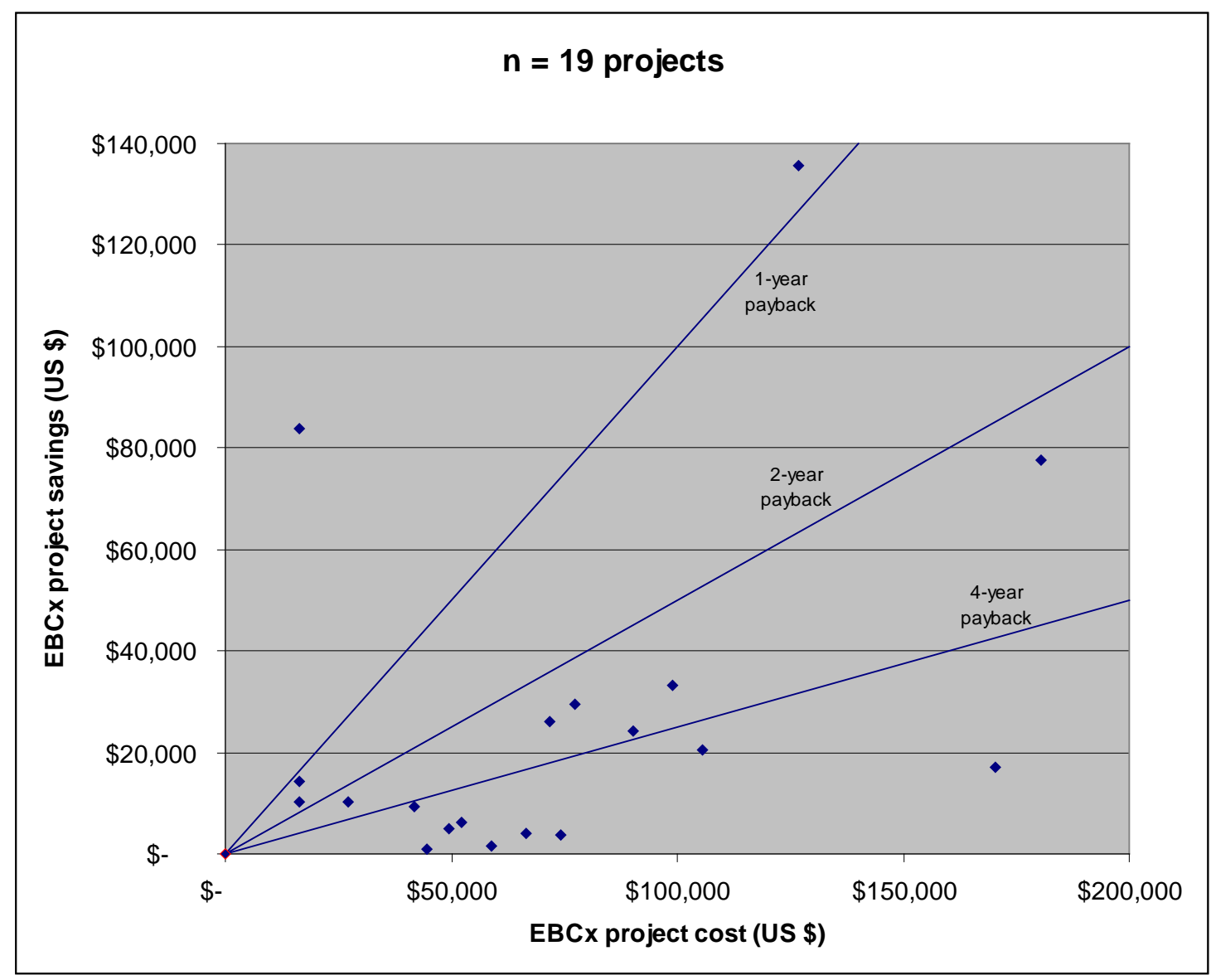

Figure 5.20 EBCx project costs vs. annual savings estimates

Project simple payback values ranged from 0.9 years to 45.7 years, with a median value of 3.7 years. Nine out of the 19 projects had a payback of greater than four years, and six had payback of between two and four years.

Higher payback is the result of either relatively high EBCx costs or relatively low resultant cost savings. For cases where payback was greater than four years in this study, the savings were relatively low (based on savings per $\left.\mathrm{ft}^{2}\right)$, as opposed the costs being relatively high.

While this data is of interest and is useful as the basis for further study, it should not be used as the basis for predicting $\mathrm{EBCx}$ project savings, for a number of reasons:

- Data is from a relatively small number of projects

- There can be a wide variation in the way that cost savings are calculated, and they may not be comprehensive (e.g.. Electric savings calculated but not gas)

- Some projects may have been undertaken in order to address non-energy issues

- The scope of EBCx varied between projects 


\section{Non-Energy Benefits}

Thirty-nine surveys were completed relating to non-energy benefits; these surveys were split under three headings, as shown in the following figures:

- Operations \& Maintenance (O\&M) - See Fig. 5.21.

- Indoor Environment - See Fig. Figure 5.22.

- Asset value and liability reduction - See Figure 5.23.

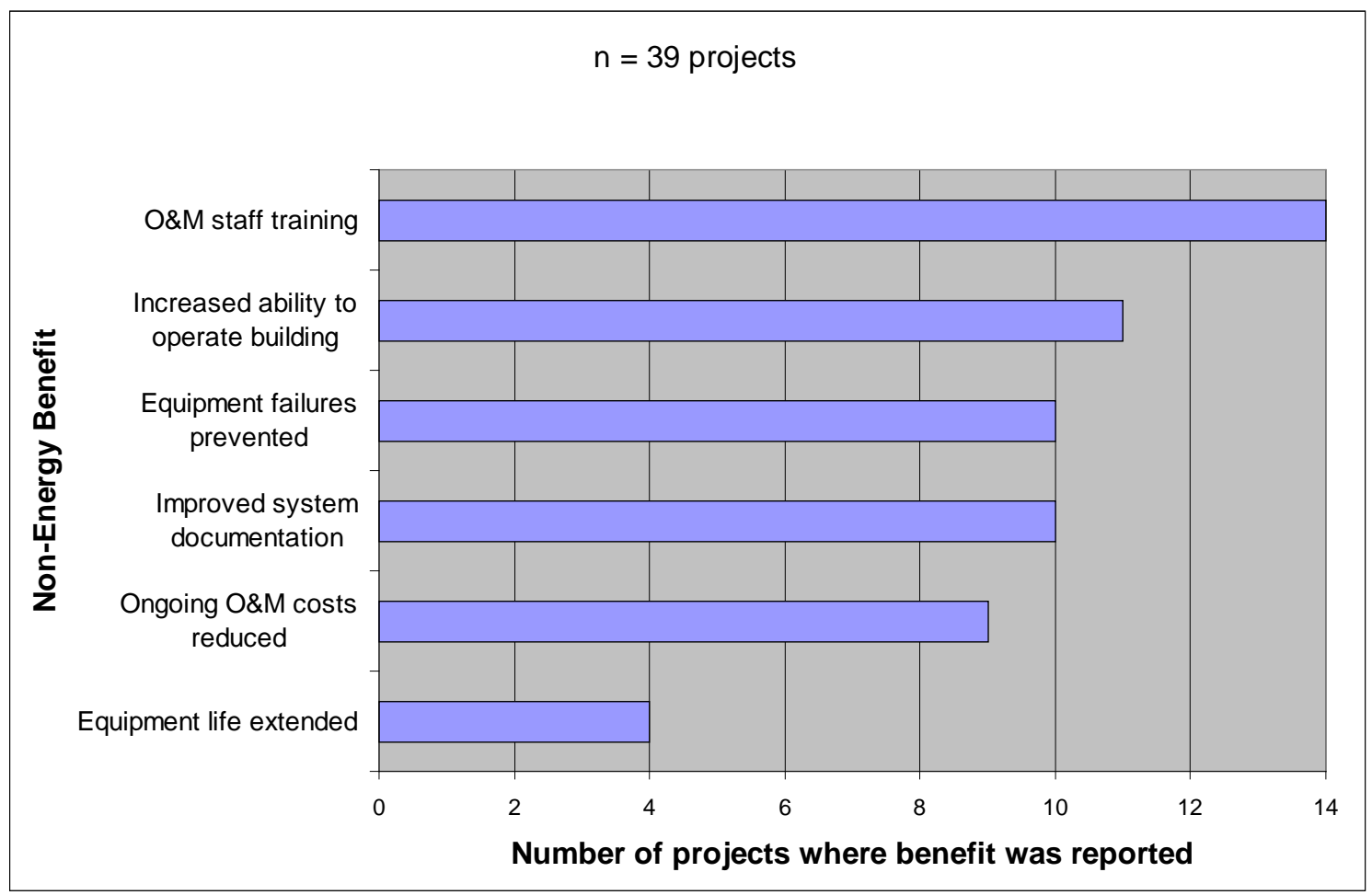

Figure 5.21 Non-energy benefits - operations \& maintenance (O\&M) 


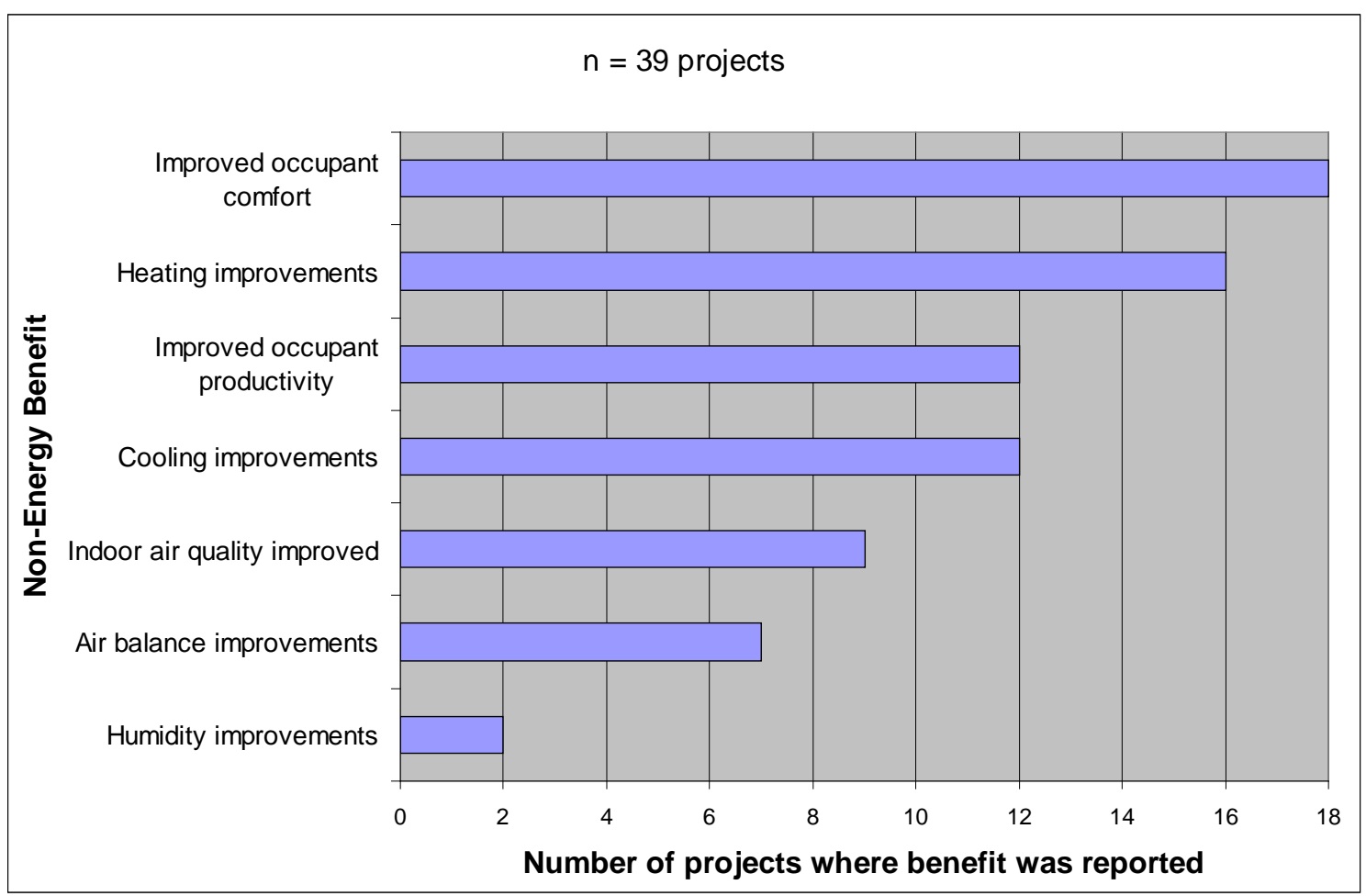

Figure 5.22 Non-energy benefits - indoor environment 


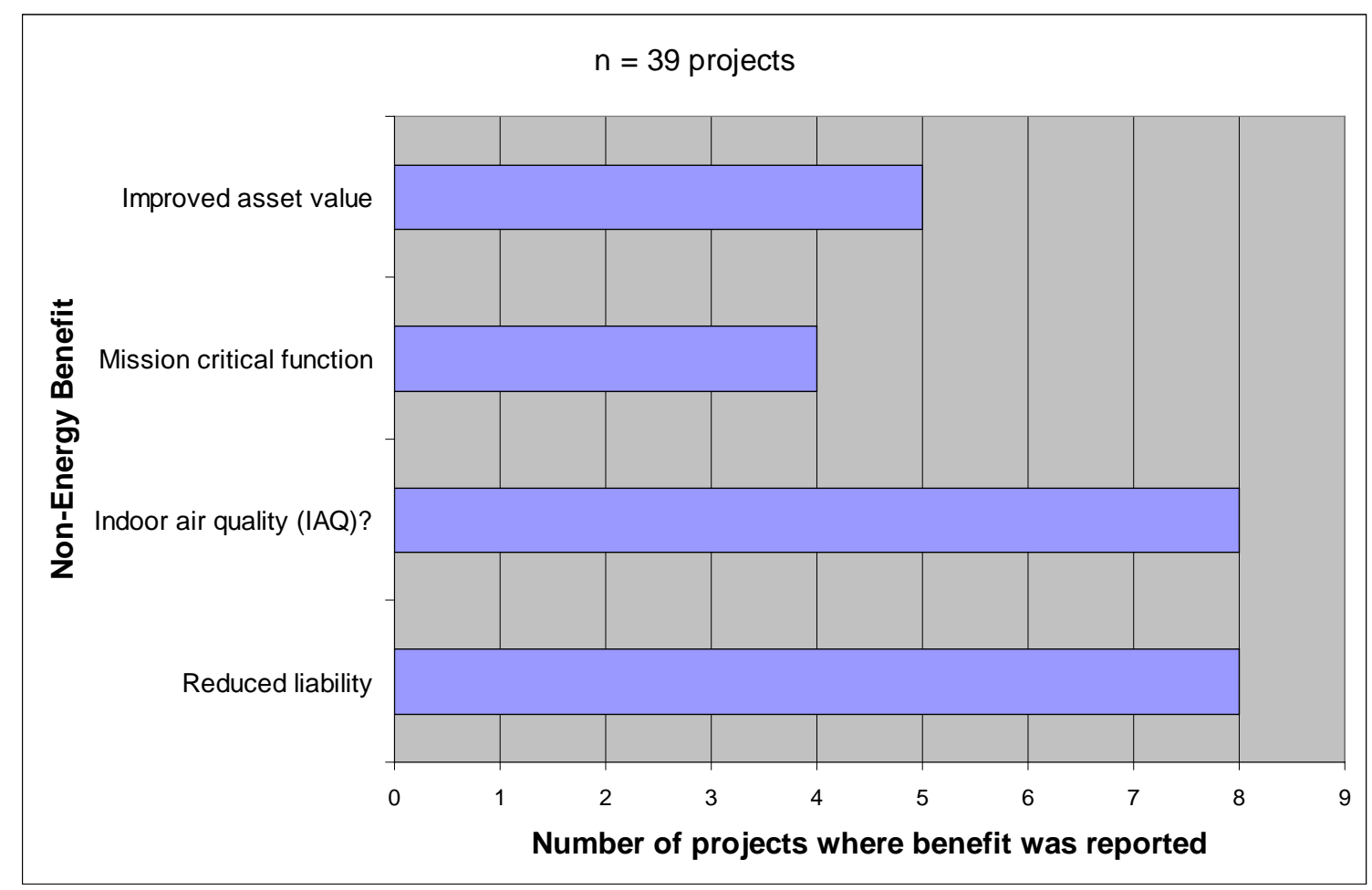

Figure 5.23 Non-energy benefits - asset value and liability reduction

There has been no attempt to quantify these benefits, but it does confirm claims that EBCx provides a number of recognizable benefits in addition to energy savings.

\subsection{Discussion}

\section{Key Results}

The data collected through this research project begins to characterize the various types of commissioning processes that are occurring in Annex member countries internationally. While data was often difficult to obtain, we expanded our knowledge in the following key areas:

- the scope of the Cx process employed for new and existing buildings

- characterization of issues discovered through the Cx process including system type, likely origin of issue (design, construction/installation, O\&M, or capital improvement), issue type, and measures implemented

While these results begin to develop a qualitative picture for how commissioning is evolving internationally, quantitative results were less apparent. For example, data on commissioning costs and energy savings were highly variable. Falling short of the data collection goals set by Annex member country representatives at the beginning of the project, we were not able to compile a large enough sample to make strong conclusions about the cost-effectiveness of $\mathrm{Cx}$ internationally.

Given the relatively small sample size and variable nature of the costs and benefits, it is interesting to note that for existing building commissioning, the median savings value of $8 \%$ corresponds well with PECl's industry experience. Further, the 3.7 year simple payback period found in this study is much higher than the LBNL 2004 study which reported a median simple payback period of 0.7 years. Industry experience has shown that typical EBCx paybacks fall in the 1year to 2 year range, which indicates that the LBNL study may not have accurately accounted for costs or counted benefits from measures that 
were not implemented. This research project simple payback is expected to be higher than the U.S. industry average due to the developing nature of the commissioning industry internationally, and the fact that many of the projects in the cost-benefit analysis were performed by researchers.

\section{Data Access Limitations}

One of the key barriers to obtaining a large set of international commissioning cost-benefit surveys was the limited data accessibility for Annex participants, especially for new building commissioning projects. The most difficult pieces of information to collect were data on costs and benefits, while qualitative data on the commissioning process and outcomes was more readily available. By setting a data collection methodology beforehand, we hoped to avoid retroactive data collection relying solely on documentation "take what you can get".

\section{Costs}

The cost of commissioning was difficult to obtain because many projects were research or demonstration projects, which have costs above and beyond what would be found in typical commissioning projects. Breaking out the research costs from the commissioning costs was not a clear process and in general, these projects reported higher costs than average. In some projects, the commissioning cost by building was not separately tracked due to the contracting relationship between the provider and a large campus of buildings. In these cases, costs by building were estimated as the percent of total fee.

When the commissioning process is not performed by a third party, as often was the case in international projects, costs can be difficult to estimate as a portion of the design or construction costs and accounted for consistently. Even when commissioning was performed by a third-party whose costs were accurately reported, we attempted to account for the cost of commissioning beyond simply tracking this

commissioning provider fee. For example, the cost to the controls contractor to assist the commissioning provider in functional performance testing may be viewed as a cost of commissioning. However, this level of detailed tracking was not generally submitted.

\section{Energy Benefits}

From the outset of the research project, it was known that energy cost savings data for new construction commissioning is difficult to report due to lack of baseline to compare the first year energy consumption against. New construction commissioning savings requires a methodology for assessing the baseline, typically through simulation that is calibrated to actual utility bills. Alternately, savings can be estimated through engineering calculations based on the measures found and fixed through the commissioning process. With only six buildings reporting energy savings for new construction commissioning, this points to the need for more focused research efforts in this area.

In tracking energy benefits, Cx providers do not always track by finding and often do not measure whole building energy savings as a result of EBCx projects. Owners often have less rigorous documentation requirements than projects that include a utility program incentive payment - utilities generally require detailed energy savings calculations up front prior to the decision to implement, then some kind of monitoring or verification that the measures were appropriately implemented. Contrasting the utilitysponsored EBCx project with an owner-sponsored one, an owner may simply provide a fee for "fixing my building", without requiring measure by measure analysis. For these cases, whole building energy consumption may be reviewed to determine total savings, which was the method performed for 26 of the buildings submitted.

Tracking and reporting the persistence of energy benefits from new and existing building commissioning generally requires a focused persistence study. While we included a section in the methodology for providing persistence data, the only instances in which it was used was for projects reported by Texas A\&M. Since those projects have already been summarized in other research findings, the results have not been included in this report. 


\section{Non-energy benefits}

Through this research, non-energy benefit data was gathered from a qualitative perspective, as it related to three areas: O\&M, indoor environment, and asset value/liability. It is difficult to quantitatively assess these benefits without developing standard methods, and this process was out of scope for the costbenefit research.

\section{State of the Commissioning Industry Internationally}

One of the results of this cost-benefit research was to develop a greater understanding of the maturity of the $\mathrm{Cx}$ industry internationally. Table 5.4 summarizes the phase of commissioning industry adoption for Annex 47 member countries that participated in this research. It was developed through discussion at Annex meetings and is based on findings from a recent research paper on the international commissioning industry development (Castro et al; 2008).

Table 5.4 Phase of commissioning industry adoption for Annex 47 member countries

\begin{tabular}{|c|c|c|c|c|c|c|c|}
\hline & \multirow[t]{2}{*}{ Research } & \multicolumn{2}{|c|}{ Early adopters } & \multicolumn{2}{|c|}{$\begin{array}{l}\text { Developing } \\
\text { industry }\end{array}$} & \multicolumn{2}{|c|}{$\begin{array}{c}\text { Different } \\
\text { framework* }\end{array}$} \\
\hline & & $C x$ & $E B C x$ & $C x$ & $E B C x$ & $C x$ & $E B C x$ \\
\hline US & $x$ & & & $x$ & $x$ & & \\
\hline Canada & $x$ & $x$ & $x$ & & & & \\
\hline Germany* & $x$ & & & & $x$ & $x$ & \\
\hline Japan & $x$ & $x$ & $x$ & & & & \\
\hline $\begin{array}{l}\text { Czech } \\
\text { Republic }\end{array}$ & $x$ & & & & & & \\
\hline Belgium & $x$ & $x$ & $x$ & & & & \\
\hline Netherlands & $x$ & $x$ & $x$ & & & & \\
\hline Norway & $x$ & $x$ & & & & & \\
\hline Hungary & $x$ & $x$ & $x$ & & & & \\
\hline
\end{tabular}

* Germany follows a different framework for implementing Cx services, where Cx activities are required by code for various parties.

All Annex countries have performed $\mathrm{Cx} / \mathrm{EBCx}$ research at universities and through country-sponsored research programs. Much of this research involved developing $\mathrm{Cx}$ guidelines specific to these countries and tools to help streamline detection of problems in buildings. A few countries can be considered "early adopters" for Cx, with a few practitioners offering Cx services as part of their service portfolio, but without any established national industry groups or guidelines.

Commissioning is developing into a recognized industry in the U.S., although Canada is moving towards this as it builds its infrastructure to deliver these services. It is interesting to note that Canada created the first guideline for the commissioning process, prior to the U.S. industry development. Existing building performance evaluation is also a well-developed field in Germany.

Germany follows a different framework for implementing new construction Cx services, where $\mathrm{Cx}$ is not considered as a separate activity. In Germany, $80 \%$ to $90 \%$ of the typical Cx tasks are regulated by (mandatory) German codes and standards. In no other country is the commissioning process so widely regulated. From the client's perspective, the quality control is part of the typical project delivery process in Germany. In the U.S., many clients hesitate to spend money for an additional Cx service, since they do not understand the value. 
For example, in Germany the contractor is required not only to perform testing, but also to document the results; to adjust actuators and optimize controls; to provide training; to compile systems manuals; etc. There is always an authority overseeing and approving these activities which is usually a construction supervisor from the design firm and the tasks and responsibilities are clearly defined within the regulations. Often, this person (or team) is on-site every day or at least several days a week during the entire construction phase. In projects in the U.S., the construction supervision, that is done by the design team (e.g. mechanical engineer), typically happens every other week or once a month, and, not every project actually has a separate $\mathrm{Cx}$ provider on board. When we consider $\mathrm{Cx}$ as a quality control during construction and start-up, this is given in Germany; however, not by an independent 3rd party, and, definitely depends on the skills of the construction supervisor.

Further, in Germany there is a requirement that starts after project completion for the involvement of the design firm for usually another two years during occupancy (or whatever the warranty period of the contractors/manufacturers is). The most important tasks within this phase is a walk-through to check functionality of the equipment and to make accordant warranty claims against the contractors. Done by experienced firms, this would includes the optimization of system operation.

\subsection{Recommendations}

Based on the results of this research project, the following potential paths forward are recommended for future international as well as U.S. commissioning cost-benefit analyses.

\section{International Commissioning Cost-Benefit Analysis}

As the commissioning process is gaining momentum internationally, each country benefits from better definition of the value proposition. In order to obtain enough relevant data to show conclusive costeffectiveness results for new construction and existing building commissioning in countries where the commissioning process is in its infancy, the cost-benefit methodology developed through this research project should be revisited when the commissioning industry is more mature. This project has set up standard methods that can be tailored to local needs going forward. For instance, if commissioning is integrated into the new building design and construction process and typically performed by the design team, then appropriate break-out percentages could be developed as guidance for accounting for Cxrelated costs and benefits.

An additional recommendation for future international commissioning cost-benefit analysis is to obtain cofunding from participating countries to have a data collection point person that is familiar with the research collect and input the commissioning data into the survey, rather than volunteer researchers and industry contacts. Each point person would be responsible for collecting and analyzing the data from their country according to this protocol, with issues such as variances in the commissioning process well-understood by the researcher. This country-level analysis would result in a well-populated international Cx costbenefit database where commonalities are analyzed.

\section{US Commissioning Cost-Benefit Analysis}

While the international commissioning process is continuing to develop, the U.S. should continue to expand its collection of commissioning data to meet current needs. One of the most pressing needs is to develop ways to scale up existing building commissioning efforts throughout the country to meet aggressive energy saving goals and mandates. There is a growing need for understanding the most common problems found through the EBCx process across the country, and the measures that have been implemented to address these problems. Existing cost-benefit analyses in the U.S. have focused on collection of total cost and savings information, rather than measure-level details.

Through this research project and other related work, obtaining accurate commissioning cost information for EBCx was difficult due to the variety of EBCx scope of work included (i.e., whole building commissioning, energy-focused commissioning, tune-up, etc.). While a true understanding of EBCx cost is important for owner acceptance of a rigorous process, we should not to let this hurdle derail our efforts to gather other commissioning data that is more readily available. 
Due to these factors, it is recommended that future research focuses on the problems found in buildings and their solutions, whether these problems were found through a whole building or less comprehensive commissioning process. Through this process, commonly problematic systems and technologies are uncovered, where changes need to be made to decrease problems or improve training. This research would help develop focused programs targeting these commonly found problems and would lead to better guidance on how to find and fix the problems in an integrated, holistic way. Further, a solid understanding of EBCx findings would help define early solutions to avoid the occurrence of these issues in the first place.

By focusing on cataloging building problems found through $E B C x$, we avoid the complexities of teasing out costs of EBCx when the process is applied differently by different providers and owners. It will also be important to collect energy savings data where it exists and clearly catalogue the methodology for estimating the savings (according to the existing cost-benefit protocol).

There are still complexities with this approach to tease out, including:

- Are these the most common problems because they are the easiest to find? Are there bigger problems that are masked?

- Are bigger problems avoided because the energy savings analysis is too difficult? Is this a consequence of the energy savings calculation review process in $\mathrm{EBCx}$ utility incentive programs?

Finally, it is worth considering this data in the context of the drivers for market growth. In the U.S. for example, utility programs are the major drivers for growth of existing building commissioning, and USGBC's LEED certification is an emerging market driver for new construction commissioning. Engaging with these market drivers should improve the integrity/volume of data collected, and should also maximize the effectiveness of research outputs.

\subsection{References}

N. S. Castro, N. Nakahara, H. Yoshida, "The International State of Building System Commissioning" 2008 ACEEE Summer Study on Energy Efficiency in Buildings, Pacific Grove, CA, (17-Aug-2008) (PubID: 861505)

Friedman, H., M. Frank, T. Haasl, K. Heinemeier, 2005. "Abbreviated Commissioning Cost-Benefit Methodology."

Friedman, H., M. Frank, T. Haasl, K. Heinemeier, 2006. Chapter 1 "State-of-the-Art Review for Commissioning Low Energy Buildings" 


\section{CONCLUSIONS ON COMMISSIONING COST-BENEFIT AND PERSISTENCE}

\section{Commissioning Cost-Benefit}

The data collected through this research project begins to characterize the various types of commissioning processes that are occurring in Annex member countries internationally. While data was often difficult to obtain, we expanded our knowledge in two key areas:

- The scope of the Cx process employed for new and existing buildings

- Characterization of issues discovered through the Cx process including system type, likely origin of issue (design, construction/installation, O\&M, or capital improvement), issue type, and measures implemented

For new construction Cx, most projects included developing a Cx plan, functional testing, issue resolution, and a final report. This finding was expected since a partial commissioning process is often employed, where commissioning begins during the construction phase. The least often included items in scope (upated as-built drawing, systems/EBCx manual, and diagnostic tools) are also consistent with our understanding of the U.S. experience. These items have high relevance for improving the persistence of benefits from commissioning.

Based on this research, the scope of EBCx internationally generally includes trend analysis, master list of findings, presentation of the findings report to the owner, implementation of operations and maintenance improvements, and a final report. The low occurrence of updating documentation, development of a systems/EBCx manual, and monitoring persistence is a result of the cost of these activities. The lack of documentation and monitoring may result in a lack of persistence of benefits from these EBCx projects.

The issues found through both new construction commissioning and existing building commissioning most often occurred in air handling systems, heating water plants, and chilled water plants. In new construction projects, the origin of these issues was evenly split between design, construction/installation, and O\&M/controls. For existing building projects, more issues were related to O\&M/controls (42\%), with the second most common being design (31\%). Additionally in existing building commissioning projects, $27 \%$ of issues were related to design/installation, $17 \%$ related to setpoints, and $11 \%$ each were related to scheduling, resets, and controls.

While these results begin to develop a qualitative picture for how commissioning is evolving internationally, quantitative results were less apparent. For example, data on commissioning costs and energy savings were highly variable. Falling short of the data collection goals set by Annex member country representatives, it was not possible to make strong conclusions about the cost-effectiveness of Cx internationally. However, progress was made towards understanding and categorizing the state of the commissioning industry for new and existing buildings in Annex member countries. While all countries have $\mathrm{Cx}$ research occurring, the majority of countries are in an early adopter phase of industry development. Only a few countries can be categorized as having a developing commissioning industry in which services are becoming more commonly obtained by owners.

\section{Persistence of Commissioning Benefits}

A review of results of studies from five projects related to the persistence of commissioning benefits, either in new or existing buildings conducted prior to the beginning of Annex 47 found that the savings in the buildings that were retro-commissioned generally showed some degradation with time. In retrocommissioned buildings, savings generally decreased with time, but there is wide variation from building to building. 
For the new buildings, well over half of the 56 commissioning fixes persisted. Hardware fixes, such as moving a sensor or adding a valve, and control algorithm changes that were reprogrammed generally persisted. Control strategies that could easily be changed, such as occupancy schedules, reset schedules, and chiller staging tended were less likely to persist. It was also found that the extent to which persistence occurs is also related to operator training.

Persistence studies conducted as part of the Annex 47 work found that as a group, four Japanese buildings studied are consistent with the commissioned buildings examined in the literature review - most continue to show savings over periods that run from 10 years to 20 years, while generally showing some decrease in savings over time. Additional study of 10 buildings at Texas A\&M found that cooling and heating savings did not change appreciably during the up to seven years of additional data following the year 2000. The average cooling savings were $45 \%$ in 1997, $34 \%$ in 2000 and $36 \%$ in the last year of good data for each building (average data went through 2006) Heating savings averaged $63 \%$ in 1997 , $56 \%$ in 2000 and $55 \%$ in the last year of available data for each building. It should be noted that ongoing commissioning follow-up was conducted in most of these buildings at least once.

A preliminary study conducted during the Annex found that determination of savings using a "normalized annual consumption" as the basis for savings determination produced less variation in savings and persistence than found when the actual weather during the baseline and post-commissioning periods was used. It also suggested that use of calibrated simulation for baseline determination may provide more stable results.

Two prototype computerized tools that can assist in maintaining the persistence of commissioning savings have been demonstrated:

- The Automated Building Commissioning Analysis Tool (ABCAT) is a simple automated tool that uses calibrated simulation to maintain the optimal energy performance in a building. It can continuously monitor building energy consumption, alert operations personnel early upon the onset of significant increase in consumption and assist them in identifying the problem. In the six live building implementations, over eight building-years of operation, ABCAT identifed eight periods where significant energy consumption changes occurred that otherwise went undetected by the building energy management personnel. In the five retrospective building test cases (approximately 20 building years of analysis), ABCAT detected 18 faults.

- The Diagnostic Agent for Building Operation (DABO), a BEMS-assisted commissioning tool monitors the enormous amounts of data produced by BEMS and provides an extensive analysis of the incoming data. The use of a detailed systematic automated approach has improved the quality assurance process and the overall performance of the building. Furthermore, automating this essentially manual process has allowed its application on an on-going basis, generating benefits over the entire life of the CETC-Varennes building. The optimization process and the 'DABO' ${ }^{T M}$ ' tool are being demonstrated in more than ten projects. These projects include some of the first Canadian LEED buildings and the participation of major Canadian facility management firms and commissioning providers.

Current information on persistence of commissioning energy savings in existing buildings may be summarized as:

- Savings persistence at the time of the study (3 years to 20 years after commissioning) ranged from about $50 \%$ to $100 \%$ in all but a handful of buildings.

- Average savings at the time of the study were about $75 \%$ of the original savings.

- The most dramatic savings degradation was caused by undetected mechanical or control component failures.

- Follow-up when needed has demonstrated persistence of commissioning savings for 7 to 20 years in a small number of buildings. 


\section{APPENDIX A: Commissioning Cost-Benefit Database}

I: Commissioning Cost-Benefit Protocols Report

II. Data Collection Form (Cx)

III: Data Collection Form (EBCx)

IV: Tabulated Survey Results (Cx)

V: Tabulated Survey Results (EBCx) 


\title{
I: Commissioning Cost-Benefit Protocols Report
}

\section{IEA Annex 47: \\ Cost-Effective Commissioning for Existing and Low Energy Buildings}

\author{
Cost-benefit Protocols Report \\ A report documenting the cost-benefit methodology and protocols \\ agreed to by the Annex participants
}

Submitted to:

Phil Haves, LBNL

Submitted by:

$\mathrm{PECl}$

May 23, 2007 


\subsection{INTRODUCTION}

\subsection{Background}

This report, documenting the cost-benefit protocols and methodology agreed to by participants in the IEA's Annex 47, represents the culmination of an 18-month process in which the goals and preferences of Annex members were ascertained and a series of data collections forms were developed, tested, revised and tested again.

\section{5}

This work began in December 2005 with the delivery of an "abbreviated methodology," based on the results of a survey of Annex members conducted at the Prague Annex meeting in October, 2005. The abbreviated methodology specified the project goals, data collection format and types of cost, energy and non-energy benefit data that Annex members wanted to collect (Friedman et al. 2005).

\section{6}

The first draft of the data collection form, an Excel spreadsheet, was completed in March 2006 and a revised version - "v2.0,"was completed in July 2006. A field test of v2.0 was conducted between July and October 2006, in which the form was distributed to approximately 1,000 recipients via email. They included Annex members, Evan Mills of Lawrence Berkeley National Laboratory and the mailing lists of the California Commissioning Collaborative, and the Building Commissioning Association.

During the field test, recipients were asked to use the form to submit data on commissioning projects. PECI received nine completed forms. Results of the field test were presented to Annex members at the Trondheim Annex meeting in April 2006 and a discussion was held to resolve a set of outstanding issues, including terminology, system types to include and normalization options.

After completion of the field test, the form was revised based on comments received and a new version - "v3.0," was presented to Annex members at the Shenzhen Annex meeting in October 2006. Another discussion was held with participants to resolve additional outstanding issues, including the extent of required data, numeral formatting, definitions of conditioned v. nonconditioned floor area, terminology and building and system types to include.

\section{7}

In March 2007 the data collection form was revised for a final time reflecting all of the comments received to-date and the final version - "v3.1," was presented to Annex members at the Budapest Annex meeting in April 2007. In comparing the final data collection form to the initial form developed in March 2006, one will observe a significant evolution. Major changes include the use of separate forms for new and existing buildings rather than a single form for both, the division of the form into four tabs to make completion easier and expanded sections for collecting data on non-energy benefits, issues and measures. 


\subsection{This report}

This report summarizes the data collection protocols agreed to by the Annex members. Its organization mirrors that of the data collection forms, and includes four sections: commissioning project, energy, non-energy benefits and issues and measures. The data collection forms themselves are attached as separate documents.

\subsection{COMMISSIONING PROJECT}

\subsection{Confidentiality}

Respondents are asked whether the building name or any other information on the form must remain confidential.

\subsection{Project information}

This section includes the name and contact information for the person completing the form, the name of the commissioning provider, the building name and location, as well as other data about the building and the project, including:

- Design temperatures

- Building type

- Occupancy type

- Performance of O\&M

- Awards received

- Year commissioning completed

- Owner's primary and secondary reasons for commissioning

- Who led the process and who contracted with the commissioning provider

New building projects include the following additional data fields:

- Year construction completed

- Project delivery method

- Whether occupancy occurred on schedule

Existing building projects include the following additional data fields:

- Did the building undergo commissioning when constructed, and if so, in what phase did commissioning begin

\subsection{Technical information}

This section provides a technical overview of the building and the commissioning project. It is the same for new and existing buildings. Data fields include:

- Floor area units

- Total floor area and that to be used in an analysis of costs and benefits 
- Number of buildings (if more than one) included in the floor area

- Number of floors and their average height

- Number of operating hours per week

- Whether the building is served by a central heating and cooling plant

This section also asks respondents to identify the number of issues found in each of the commissioned systems and to identify which percentage of issues originated in each phase of the building's history: design, construction/installation, operational/controls/maintenance, or capital improvement.

\subsection{Cost data}

This section aims to record the various costs of the commissioning project and the activities represented by the costs. Data fields include:

- Currency units

- Year costs incurred

- Commissioning provider free

- Who paid the costs

- Costs incurred in each phase of the process

- Items included in the cost estimates (list differs for new and existing buildings)

The new building form also asks for the building construction cost and costs to other parties to conduct commissioning tasks (architect, mechanical engineer, general contractor, mechanical contractor, electrical contractor, controls contractor and the owner’s O\&M staff).

The existing building form asks for slightly different costs, including the costs to other parties to conduct commissioning tasks (controls contractor and the owner's O\&M staff), the cost to implement measures and the cost of monitoring and verification.

\subsection{ENERGY}

\subsection{Source, unit and cost}

This section collects the unit type, energy source and average cost per unit for electricity, electric demand, fuel, district chilled water, district hot water, district steam and water.

\subsection{Resource savings}

In new buildings, respondents are asked to submit the first year annual resource use for each resource type and to estimate the savings obtained through commissioning, as well as the method used to determine the savings.

In existing buildings, respondents are asked the annual resource use before commissioning for each resource type, the savings from implemented measures, the estimated savings from measures recommended but not implemented and the method used to determine the savings. 
In both forms, respondents are asked whether data could have been affected by major changes in occupancy, conditioned floor area, building use and major equipment. Respondents are also asked whether the data submitted has been normalized for weather, changes in occupancy and floor area and, if so, to what year, percentage occupancy and floor area.

\subsection{Resource use after commissioning}

This section was developed in collaboration with David Claridge, Texas A\&M University. Respondents are asked about the percent resource savings for each fuel type which continued to accrue for up to six years post-commissioning and asked to submit the starting month and year of the baseline period.

This section is to be completed only if multiple years of post-commissioning data are available. All data must be weather normalized.

\subsection{NON-ENERGY BENEFITS}

\subsection{New buildings}

This form asks for data on non-energy benefits in the following areas:

- Project cost savings

- Benefits to project design

- Change orders and warranty claims

- Construction team coordination

- Project schedule

- Building start-up and turn-over

- Operations \& maintenance (O\&M)

- Indoor environment

\subsection{Existing buildings}

This form asks for data on non-energy benefits in the following areas:

- Asset value

- Liability reduction

- Operations \& maintenance (O\&M)

- Indoor environment

\subsection{ISSUES AND MEASURES}

\subsection{Issue data}

Data is requested on issues (or problems) discovered during the commissioning process, including: 
- Issue description (free response)

- System affected (drop-down list)

- Equipment affected (drop-down list)

- Issue category (drop-down list)

- Issue type (drop-down list)

- Origin of issue (drop-down list)

\subsection{Measure data}

Data is requested on measures (or solutions) recommended as a result of the issues discovered, including:

- Measure description (free response)

- Whether measure was implemented (drop-down list)

- Implementation cost (free response)

- Measure cost type (drop-down list)

\subsection{Resource savings}

Data is requested on the resource savings resulting from each measure and for each fuel type. Respondents are also asked to provide:

- Savings estimation approach (drop-down list)

- Total resource cost savings (free response)

- Number of years after commissioning that $50 \%$ or more of the resource savings continued to accrue (drop-down list)

- An explanation of why the savings did or did not continue to accrue (free response)

\subsection{Non-energy benefits}

Data is requested on the non-energy benefits resulting from each measure. For both the primary and secondary non-energy benefits (selected from a drop-down list), respondents are also asked to provide the monetary value of the benefit and the calculation method used to determine the monetary value.

\subsection{References}

Hannah Friedman, Marti Frank, Tudi Haasl and Kristin Heinemeier, "Annex 47 Abbreviated Commissioning Cost-Benefit Methodology," December 9, 2005. 


\section{Data Collection Form (Cx)}

\section{DATA COLLECTION FORM (CX) - “INSTRUCTIONS” SECTION}

\section{Commissioning Data Collection Form - New Buildings}

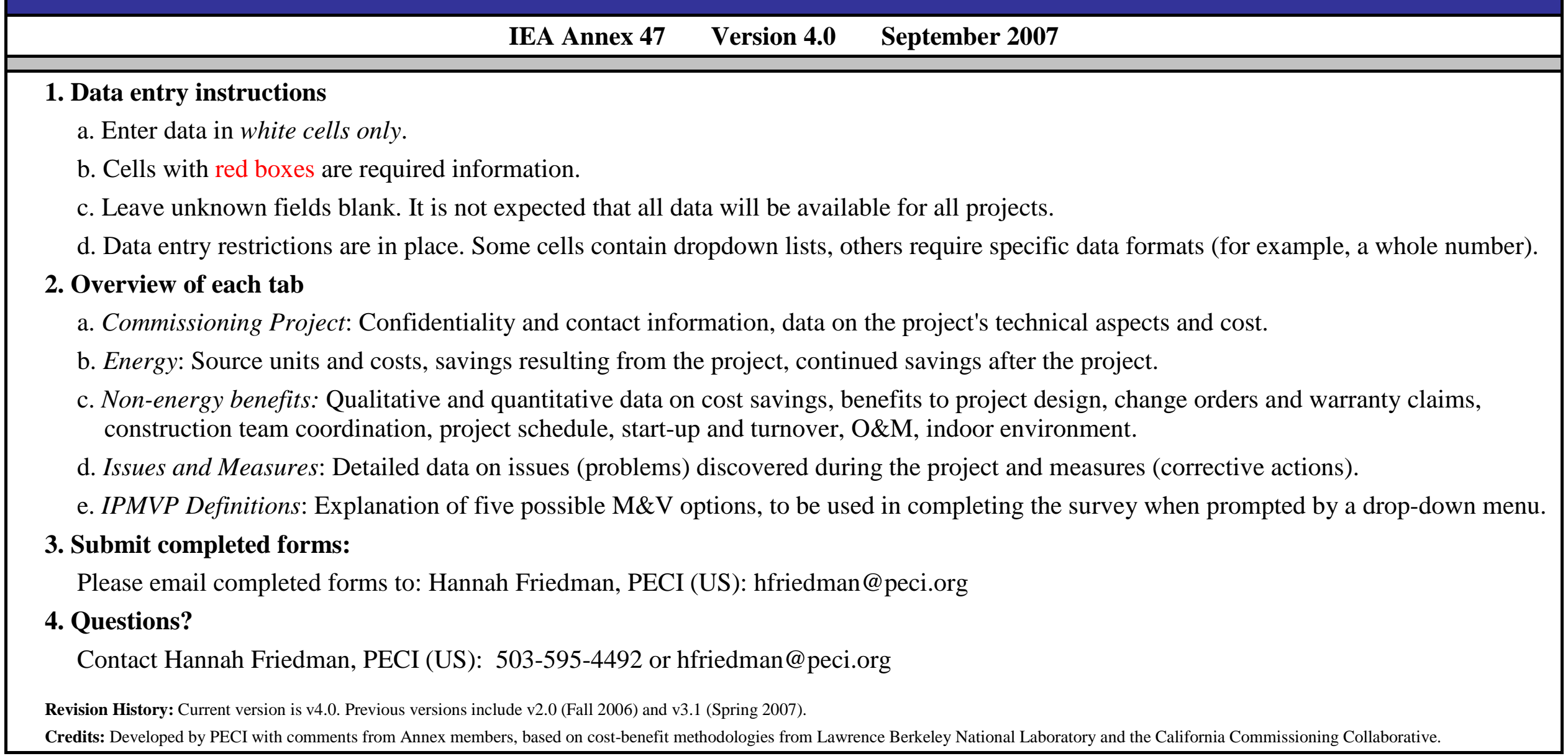


DATA COLLECTION FORM (Cx) - “COMMISSIONING PROJECT” SECTION

\section{Commissioning Data Collection Form - New Buildings}

\begin{tabular}{|c|c|c|c|c|}
\hline IEA Annex 47 & \multirow{2}{*}{$\begin{array}{l}\text { Version } 4.0 \\
\text { Notes }\end{array}$} & \multicolumn{3}{|l|}{ September 2007} \\
\hline & & Project Data & Units & Comments \\
\hline \multicolumn{5}{|l|}{ CONFIDENTIALITY } \\
\hline \multicolumn{5}{|l|}{ Is it necessary for the building name to remain confidential? } \\
\hline \multicolumn{5}{|l|}{ PROJECT INFORMATION } \\
\hline \multicolumn{5}{|l|}{ Name of person completing form } \\
\hline \multicolumn{5}{|l|}{ Contact information of person completing form: Phone } \\
\hline \multicolumn{5}{|l|}{ Contact information of person completing form: E-mail } \\
\hline \multicolumn{5}{|l|}{ Hours spent completing this form } \\
\hline \multicolumn{5}{|l|}{ Who led the commissioning process? } \\
\hline \multicolumn{5}{|l|}{ Name of commissioning leader } \\
\hline $\begin{array}{l}\text { How many other commissioning projects did the commissioning } \\
\text { leader complete prior to this project? }\end{array}$ & $\begin{array}{c}\text { Include only projects } \\
\text { completed by leader, not } \\
\text { firm }\end{array}$ & & & \\
\hline \multicolumn{5}{|l|}{ Who held the contract with the commissioning leader? } \\
\hline \multicolumn{5}{|l|}{ Name of building/project } \\
\hline \multicolumn{5}{|l|}{ Building location } \\
\hline \multicolumn{5}{|l|}{ City } \\
\hline \multicolumn{5}{|l|}{ State } \\
\hline \multicolumn{5}{|l|}{ Country } \\
\hline \multicolumn{5}{|l|}{ Year construction completed } \\
\hline Total building construction cost & $\begin{array}{l}\text { Total cost paid by owner } \\
\text { for the building or retrofit }\end{array}$ & & & \\
\hline
\end{tabular}




\section{PROJECT INFORMATION CONTINUED}

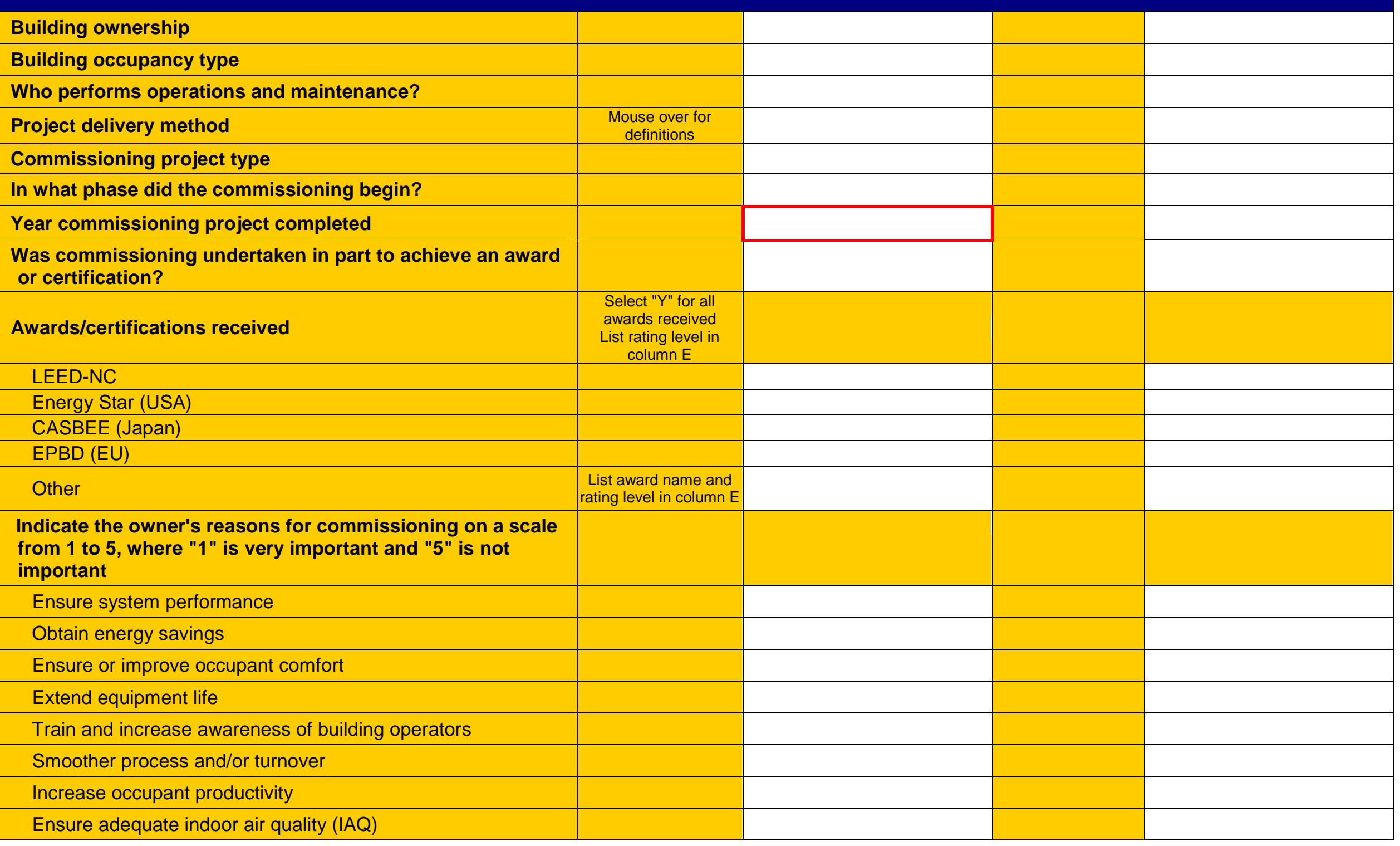




\section{PROJECT INFORMATION CONTINUED}

Comply with LEED or other sustainability rating system

Reduce liability

Qualify for rebate, financing, or other services

Participate in a research, demonstration or pilot project

Participate in a utility program

Other

\section{Level of commissioning}

Explain in column $\mathrm{E}$

f only energy efficiency

measures were

commissioned, select

"Specific systems"

\section{TECHNICAL INFORMATION}

\section{Floor area units}

Total floor area

Floor area served by commissioned systems (excludes parking)

Total floor area dedicated to each of the following uses

\section{School}

University

Hospital or health facility

Laboratory

Office

Hotel

Retail

Restaurant

Supermarket

Residential apartment building

Parking

Public assembly

Public order and safety

Religious worship

\begin{tabular}{|l|l|l|l|}
\hline & & \\
\hline & & \\
\hline Explain in column E & & \\
\hline $\begin{array}{c}\text { If only energy efficiency } \\
\text { measures were } \\
\text { commissioned, select } \\
\text { "Specific systems" }\end{array}$ & & & \\
\hline
\end{tabular}

\begin{tabular}{|l|}
\hline \\
\hline 2 \\
\hline 2 \\
\hline \\
\hline \\
\hline
\end{tabular}

\begin{tabular}{|c|c|c|}
\hline $\begin{array}{c}\text { automatically } \\
\text { calculated }\end{array}$ & $\# N / A$ & \\
\hline \multirow[t]{15}{*}{$\begin{array}{c}\text { automatically } \\
\text { calculated }\end{array}$} & $\# N / A$ & \\
\hline & $\# \mathrm{~N} / \mathrm{A}$ & \\
\hline & $\# N / A$ & \\
\hline & $\# N / A$ & \\
\hline & $\# N / A$ & \\
\hline & $\# N / A$ & \\
\hline & $\# N / A$ & \\
\hline & $\# N / A$ & \\
\hline & $\# N / A$ & \\
\hline & $\# N / A$ & \\
\hline & $\# N / A$ & \\
\hline & $\# N / A$ & \\
\hline & $\# N / A$ & \\
\hline & \#N/A & \\
\hline & $\# N / A$ & \\
\hline
\end{tabular}

Page 171 of 239 


\section{TECHNICAL INFORMATION CONTINUED}

Industrial building

Service, warehouse or storage

Vacant

Other

If the indicated floor area is for multiple buildings, how many buildings?

Is the facility served by a central heating and cooling plant that serves multiple buildings?

How many issues were found in each commissioned

system?

If the system was not commissioned, leave cell empty.

If the system was commissioned but no issues were found, enter 0 .

If the same issue occurred multiple times or places, only count as one

issue.

HVAC system integration (EMCS/BAS)

Chilled water plant and distribution system

Packaged or split system DX

Heating water plant and distribution system

Domestic hot water

Heat pump system

Air handling and distribution: Overhead system

Air handling and distribution: Underfloor system

Terminal units

Thermal energy storage

Radiant heating

Radiant cooling

Passive heating/cooling

Natural ventilation or mixed-mode ventilation

Lighting/daylighting and lighting controls

Electrical

Plumbing

Envelope and infiltration

Fire/life safety

Utility-related (electric, gas, water, emergency power)

TECHNICAL INFORMATION CONTINUED

Explain in column $\mathrm{E}$

Each system category

below includes the

controls related to the system

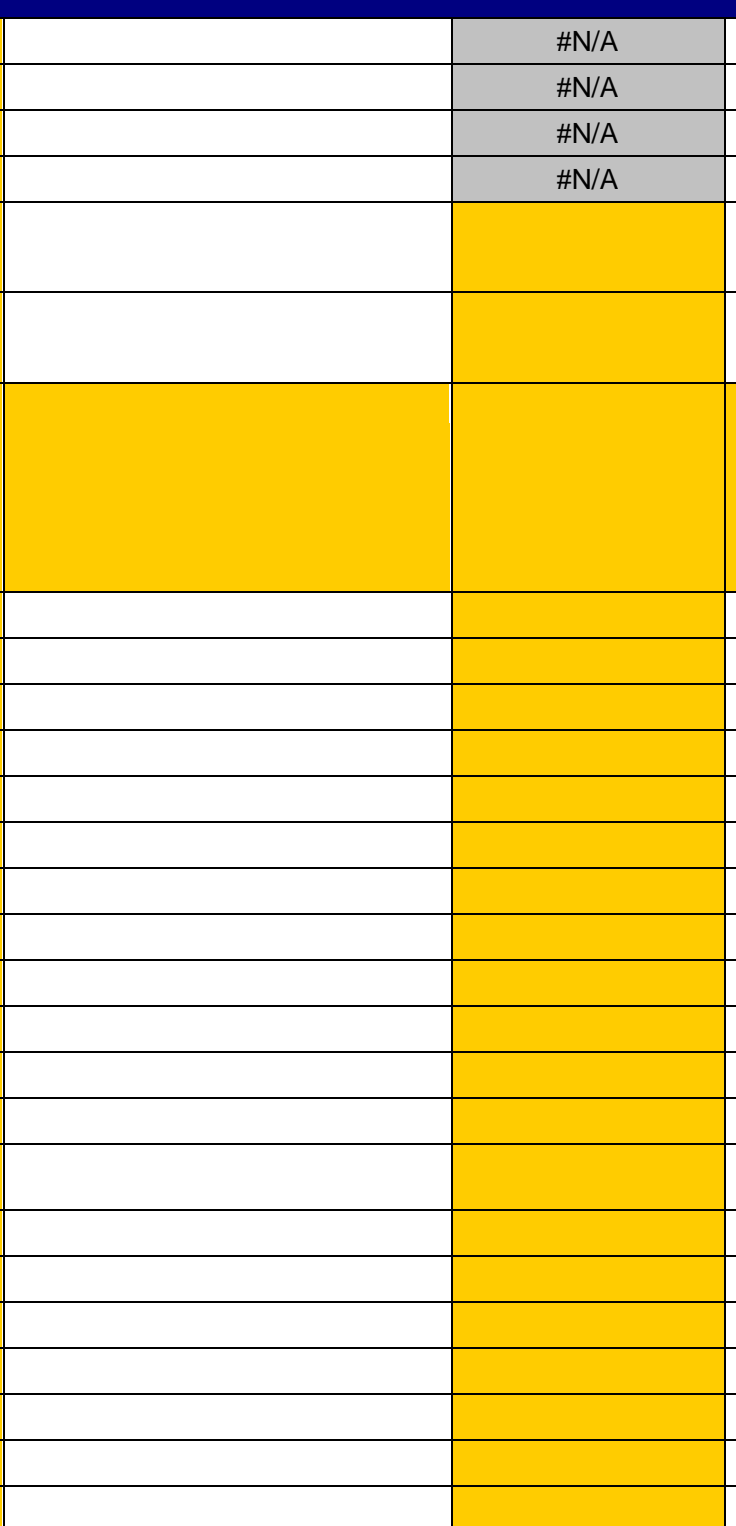




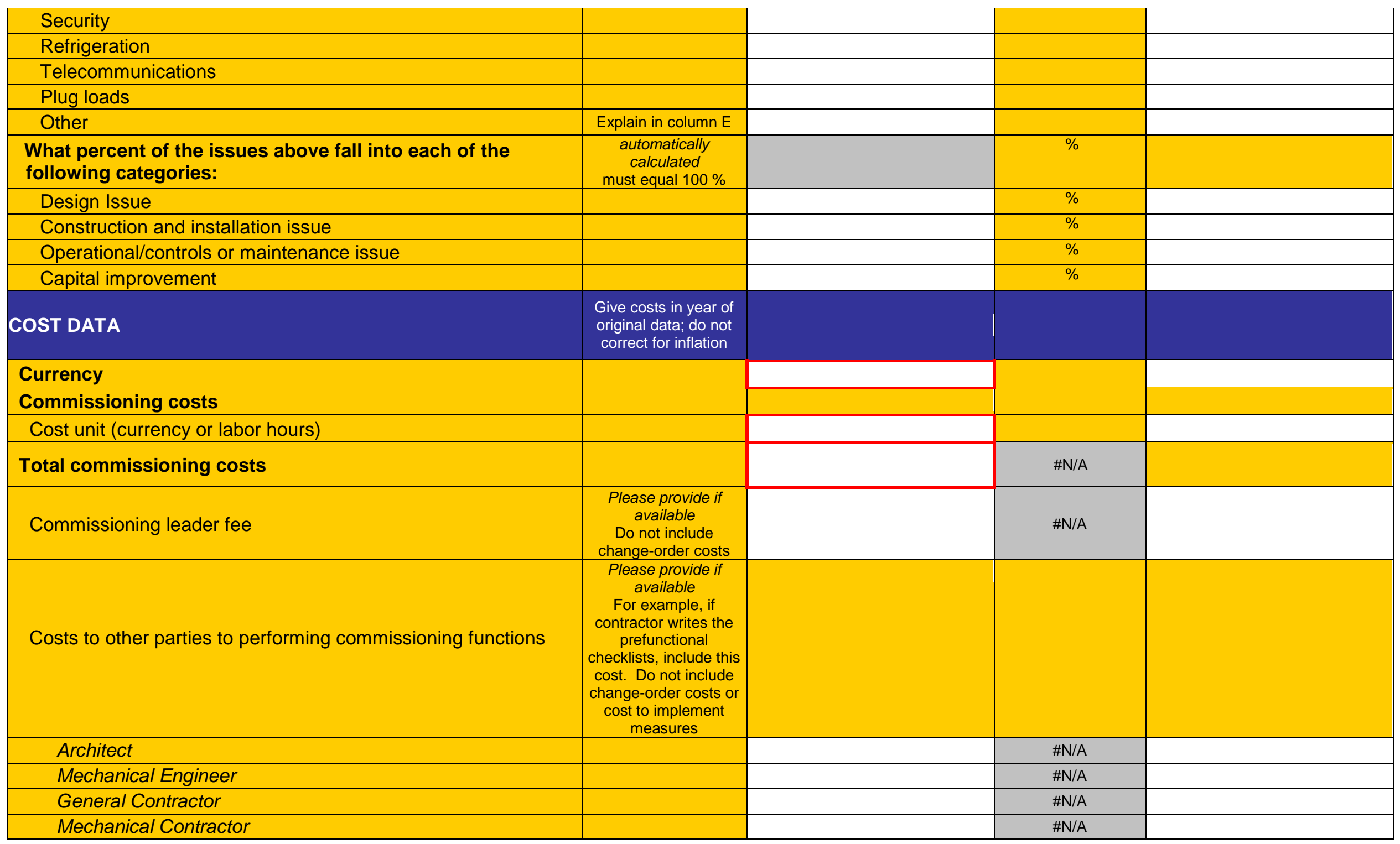




\section{COST DATA CONTINUED}

Electrical Contractor

Controls Contractor

Owner's Operation and Maintenance Staff

\section{Percent of cost paid by:}

Building owner

Utility (for example, as a rebate or incentive)

Grants/tax incentives

Other

\section{Percent of cost incurred in each phase}

Pre-design phase

Design phase

Construction phase

Warranty/occupancy phase

\section{Items included in cost estimates}

Development of owner's project requirements and basis of design (if not well-developed by designer)

Building modeling

Write commisioning specifications

Develop commisioning plan

Design review

Develop sequences of operation (if not well-developed by mechanical or controls contractor)

Submittal review

Construction observation

Verification checks/pre-functional testing

Use of diagnostic tools and Cx automation techniques

Functional testing

Significant involvement in issue resolution

COST DATA CONTINUED

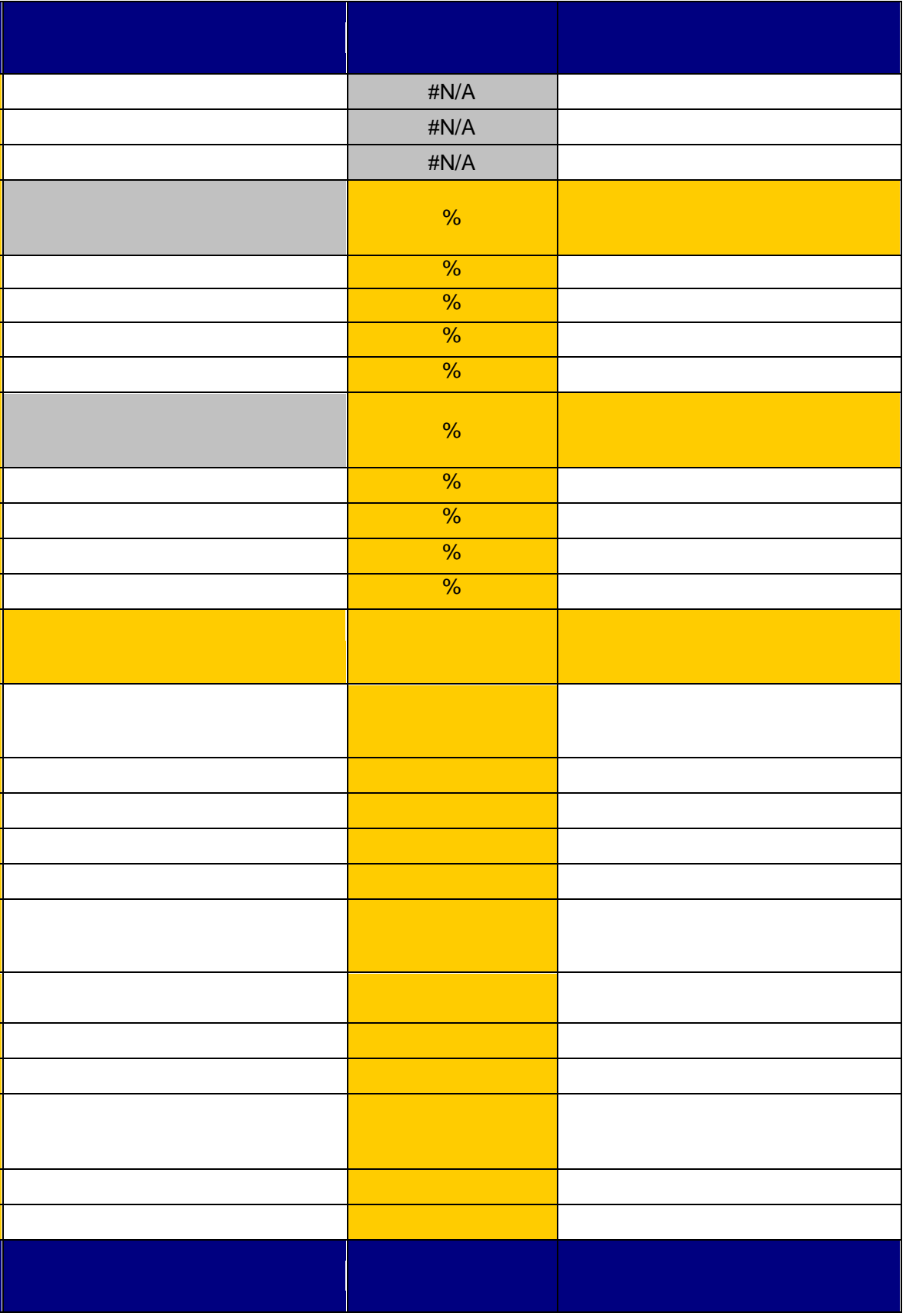


Oversee training

Review operations \& maintenance manuals

Develop systems manual/recommissioning manual

Perform trend analysis

Evaluate energy cost savings

Final commissioning report

Update as-built drawings

Other

Explain in column E 
DATA COLLECTION FORM (Cx) - "ENERGY" SECTION

\section{Commissioning Data Collection Form - New Buildings}

\begin{tabular}{|c|c|c|c|c|}
\hline IEA Annex 47 & Version 4.0 & September 2007 & & \\
\hline & Notes & Project Data & Units & Comments \\
\hline \multicolumn{5}{|l|}{ SOURCE, UNIT \& COST } \\
\hline \multicolumn{5}{|l|}{ Electricity } \\
\hline \multicolumn{5}{|l|}{ Unit } \\
\hline Average cost per unit (in the first year after commissioning) & & & \#N/A & \\
\hline \multicolumn{5}{|l|}{ Electric demand } \\
\hline \multicolumn{5}{|l|}{ Unit } \\
\hline Average cost per unit (in the first year after commissioning) & & & \#N/A & \\
\hline \multicolumn{5}{|l|}{ Fuel } \\
\hline \multicolumn{5}{|l|}{ Fuel type } \\
\hline \multicolumn{5}{|l|}{ Unit } \\
\hline Average cost per unit (in the first year after commissioning) & & & \#N/A & \\
\hline \multicolumn{5}{|l|}{ District chilled water } \\
\hline \multicolumn{5}{|l|}{ Unit } \\
\hline Average cost per unit (in the first year after commissioning) & & & $\# \mathrm{~N} / \mathrm{A}$ & \\
\hline \multicolumn{5}{|l|}{ District hot water } \\
\hline \multicolumn{5}{|l|}{ Unit } \\
\hline Average cost per unit (in the first year after commissioning) & & & $\# \mathrm{~N} / \mathrm{A}$ & \\
\hline \multicolumn{5}{|l|}{ District steam } \\
\hline \multicolumn{5}{|l|}{ Unit } \\
\hline Average cost per unit (in the first year after commissioning) & & & \#N/A & \\
\hline \multicolumn{5}{|l|}{ Water } \\
\hline \multicolumn{5}{|l|}{ Unit } \\
\hline Average cost per unit (in the first year after commissioning) & & & \#N/A & \\
\hline
\end{tabular}


To calculate savings

subtract first year

annual usage from

projected usage of

baseline building (the

original design or

building, before

commissioning began)

\section{Electric consumption}

First year annual usage

Estimated annual savings from commissioning

Describe method used to determine savings and baseline

\section{Electric demand}

First year peak demand

Estimated demand reduction from commissioning

Describe method used to determine savings and baseline

Fuel

First year annual usage

Estimated annual savings from commissioning

Describe method used to determine savings and baseline

\section{District chilled wate}

First year annual usage

Estimated annual savings from commissioning

Describe method used to determine savings and baseline

\section{District hot water}

First year annual usage

Estimated annual savings from commissioning

Describe method used to determine savings and baseline

\section{District steam}

First year annual usage

Estimated annual savings from commissioning

Describe method used to determine savings and baseline

Water

First year annual usage

(a)




\section{WHOLE BUILDING RESOURCE SAVINGS CONTINUED}

Estimated annual savings from commissioning

Describe method used to determine savings and baseline

Could data have been affected by:

Major occupancy changes?

Average \% occupied before commissioning

Average \% occupied after commissioning

Changes in conditioned floor area?

Average \% conditioned floor area before commissioning Average \% conditioned floor area after commissioning

Changes in building use

Major equipment changes

Has submitted data been normalized for:

Weather?

If yes, to what year was the data normalized?

Changes in occupancy?

If yes, to what \% occupancy was the data normalized?

Changes in floor area?

If yes, to what floor area was the data normalized?

Other$$
\text { Other }
$$

seline

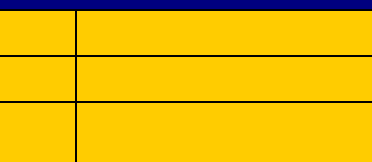

\begin{tabular}{|l|l|}
\hline & \\
\hline & \\
\hline &
\end{tabular}

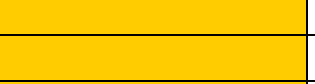

\begin{tabular}{|c|}
\hline $\begin{array}{l}\text { If yes, describe in } \\
\text { column } E\end{array}$ \\
\hline $\begin{array}{c}\text { If yes, describe in } \\
\text { column E }\end{array}$ \\
\hline
\end{tabular}

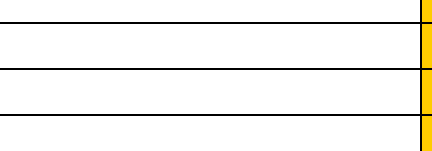

\begin{tabular}{|l|l|}
\hline \#N/A & \\
\hline & \\
\hline & \\
\hline
\end{tabular}

\section{RESOURCE USE AFTER COMMISSIONING}

Indicate the "baseline" period (must be one full year of data - usually the first full year after commissioning)

\begin{tabular}{|l|c}
\hline Start month & $\begin{array}{c}\text { Example: } \\
\text { enter January as } 1\end{array}$ \\
\hline Start year & $\begin{array}{c}\text { automatically } \\
\text { calculated }\end{array}$ \\
\hline End date &
\end{tabular}

If yes, describe in column E

Please complete this section if multiple

years of post-

commissioning use

data are available

Page 178 of 239 


\section{RESOURCE USE AFTER COMMISSIONING CONTINUED}

Electric consumption - weather normalized \% savings from

baseline

Year 1

Year 2

Year 3

Year 4

Year 5

Year 6

Electric demand - weather normalized \% savings from

baseline

Year 1

Year 2

Year 3

Year 4

Year 5

Year 6

Fuel - weather normalized \% savings from baseline

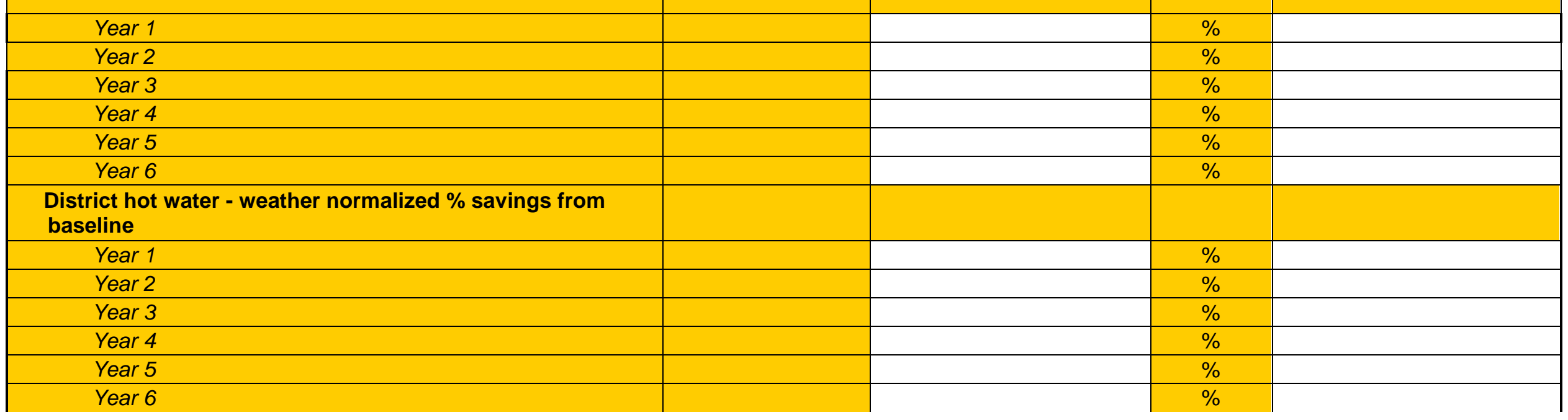

RESOURCE USE AFTER COMMISSIONING CONTINUED

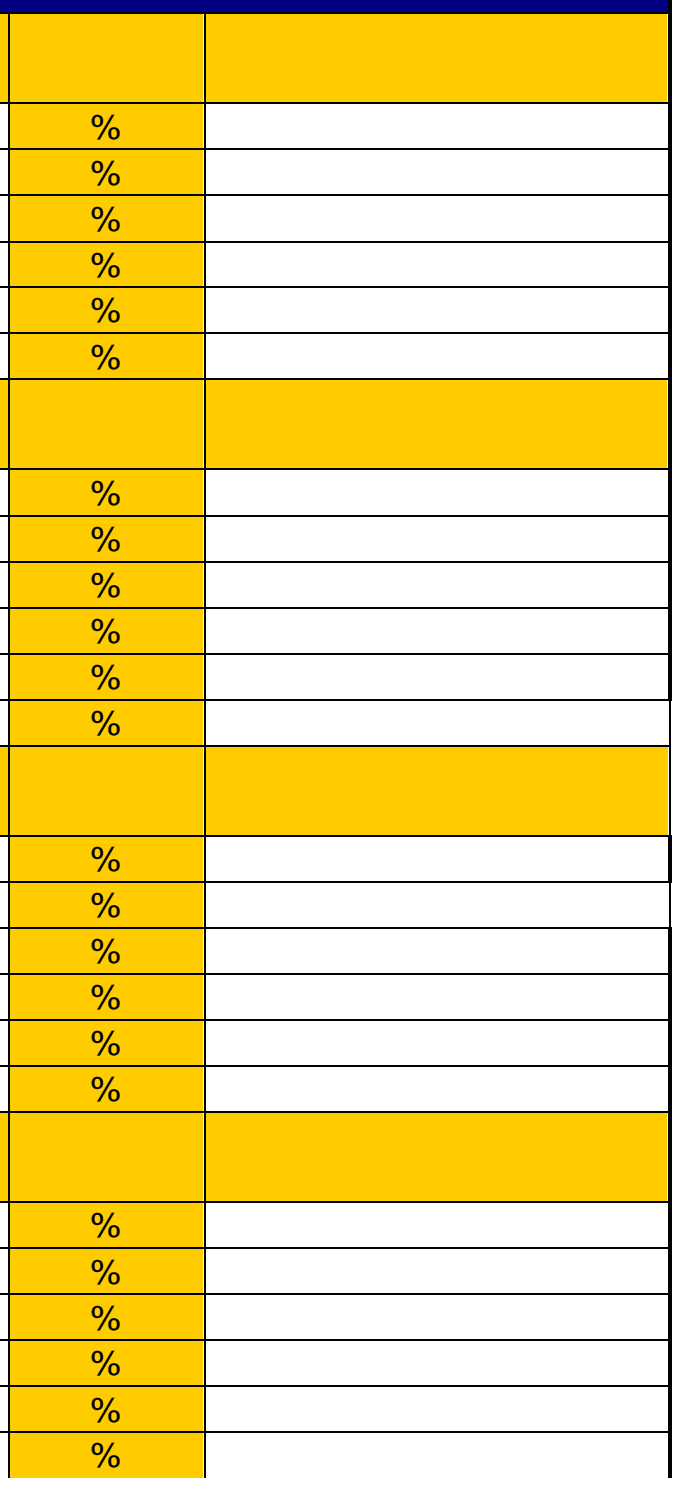




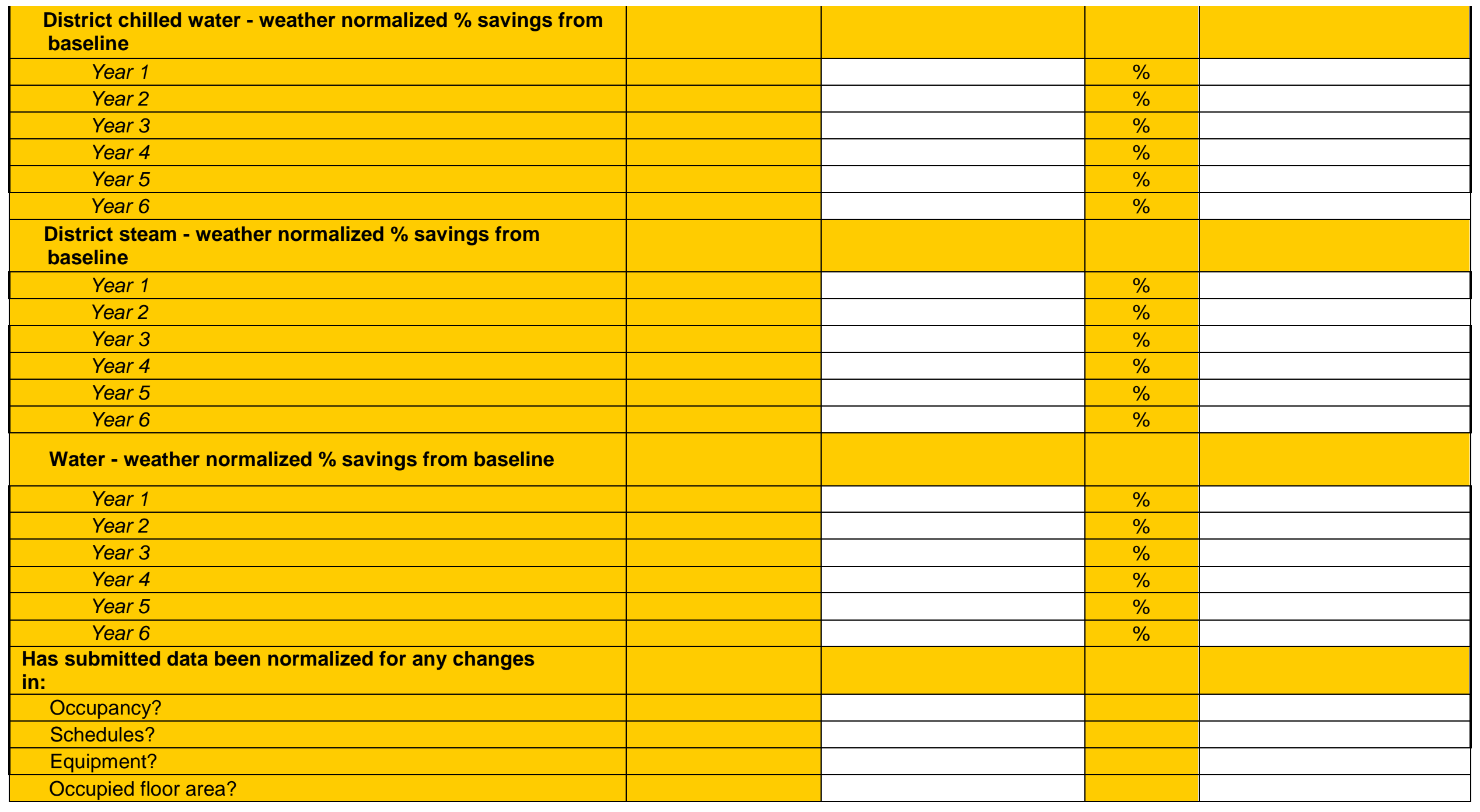

DATA COLLECTION FORM (Cx) - “NON-ENERGY BENEFITS” SECTION 


\section{Commissioning Data Collection Form - New Buildings}

\begin{tabular}{|c|c|c|c|c|}
\hline IEA Annex 47 & Version 4.0 & ber 2007 & & \\
\hline & Notes & Project Data & Units & Comments \\
\hline NON-ENERGY BENEFITS & $\begin{array}{l}\text { Describe calculations } \\
\text { in column E }\end{array}$ & & & \\
\hline \multicolumn{5}{|l|}{ Project cost savings } \\
\hline \multicolumn{5}{|l|}{$\begin{array}{l}\text { Did you achieve an overall lower project cost (or "first cost") as a } \\
\text { result of commissioning? }\end{array}$} \\
\hline What is the total value of this savings? & describe in column E & & \#N/A & \\
\hline \multicolumn{5}{|l|}{ Benefits to project design } \\
\hline \multicolumn{5}{|l|}{$\begin{array}{l}\text { Were improvements to system design made as a result of } \\
\text { commissioning? }\end{array}$} \\
\hline \multicolumn{5}{|l|}{ Was equipment sized correctly as a result of commissioning? } \\
\hline What is the monetary value of these benefits? & describe in column E & & \#N/A & \\
\hline \multicolumn{5}{|l|}{ Change orders and warranty claims } \\
\hline \multicolumn{5}{|l|}{$\begin{array}{l}\text { Did you reduce or avoid change orders as a result of } \\
\text { commissioning? }\end{array}$} \\
\hline \multicolumn{5}{|l|}{ How many change orders were avoided? } \\
\hline \multicolumn{5}{|l|}{$\begin{array}{l}\text { Did you reduce or avoid warranty claims as a result of } \\
\text { commissioning? }\end{array}$} \\
\hline What is the monetary value of these benefits? & describe in column E & & \#N/A & \\
\hline \multicolumn{5}{|l|}{ Asset value } \\
\hline \multicolumn{5}{|l|}{ Was asset value improved as a result of commissioning? } \\
\hline What is the total value of this benefit? & describe in column $\mathrm{E}$ & & \#N/A & \\
\hline \multicolumn{5}{|l|}{ Liability reduction } \\
\hline \multicolumn{5}{|l|}{ Was liability reduced as a result of commissioning? } \\
\hline \multicolumn{5}{|l|}{ Did this include reductions in liability related to: } \\
\hline \multicolumn{5}{|l|}{ Indoor air quality (IAQ)? } \\
\hline \multicolumn{5}{|l|}{ Fire/life safety? } \\
\hline \multicolumn{5}{|l|}{ Security? } \\
\hline The building's mission critical function? & & & & \\
\hline
\end{tabular}

Page 181 of 239 


\begin{tabular}{|c|c|c|}
\hline What is the monetary value of these benefits? & $\begin{array}{c}\text { describe in column } \\
\mathrm{E}\end{array}$ & $\# \mathrm{~N} / \mathrm{A}$ \\
\hline \multicolumn{3}{|l|}{ Construction team coordination } \\
\hline \multicolumn{3}{|l|}{$\begin{array}{l}\text { Was coordination among team members improved as a result of } \\
\text { commissioning? }\end{array}$} \\
\hline \multicolumn{3}{|l|}{$\begin{array}{l}\text { Were disagreements among contractors reduced or resolved } \\
\text { more quickly as a result of commissioning? }\end{array}$} \\
\hline What is the monetary value of these benefits? & \begin{tabular}{|c|} 
describe in column \\
$\mathrm{E}$
\end{tabular} & $\# N / A$ \\
\hline \multicolumn{3}{|l|}{ Project schedule } \\
\hline \multicolumn{3}{|l|}{$\begin{array}{l}\text { Did the project progress according to schedule as a result of } \\
\text { commissioning? }\end{array}$} \\
\hline \multicolumn{3}{|l|}{$\begin{array}{l}\text { Were potential problems detected and corrected earlier than they } \\
\text { would have been without commissioning? }\end{array}$} \\
\hline What is the monetary value of these benefits? & $\begin{array}{c}\text { describe in column } \\
\mathrm{E}\end{array}$ & \#N/A \\
\hline \multicolumn{3}{|l|}{ Building start-up and turn-over } \\
\hline \multicolumn{3}{|l|}{$\begin{array}{l}\text { Was the building occupied on schedule as a result of } \\
\text { commissioning? }\end{array}$} \\
\hline \multicolumn{3}{|l|}{$\begin{array}{l}\text { Were contractor call-backs reduced as a result of } \\
\text { commissioning? }\end{array}$} \\
\hline \multicolumn{3}{|l|}{$\begin{array}{l}\text { Were testing and balancing (TAB) costs reduced as a result of } \\
\text { commissioning? }\end{array}$} \\
\hline What is the monetary value of these benefits? & $\begin{array}{c}\text { describe in column } \\
\mathrm{E}\end{array}$ & $\# \mathrm{~N} / \mathrm{A}$ \\
\hline \multicolumn{3}{|l|}{ Operations \& maintenance (O\&M) } \\
\hline \multicolumn{3}{|l|}{$\begin{array}{l}\text { Was system documentation available to O\&M staff as a result of } \\
\text { commissioning? }\end{array}$} \\
\hline \multicolumn{3}{|l|}{$\begin{array}{l}\text { Were O\&M staff provided with training as a result of } \\
\text { commissioning? }\end{array}$} \\
\hline \multicolumn{3}{|l|}{$\begin{array}{l}\text { Do O\&M staff report satisfaction with their ability to operate and } \\
\text { maintain the building as a result of commissioning? }\end{array}$} \\
\hline \multicolumn{3}{|l|}{ Was equipment life extended as a result of commissioning? } \\
\hline $\begin{array}{l}\text { Were ongoing operations and maintenace costs reduced a result } \\
\text { of commissioning? }\end{array}$ & & \\
\hline
\end{tabular}




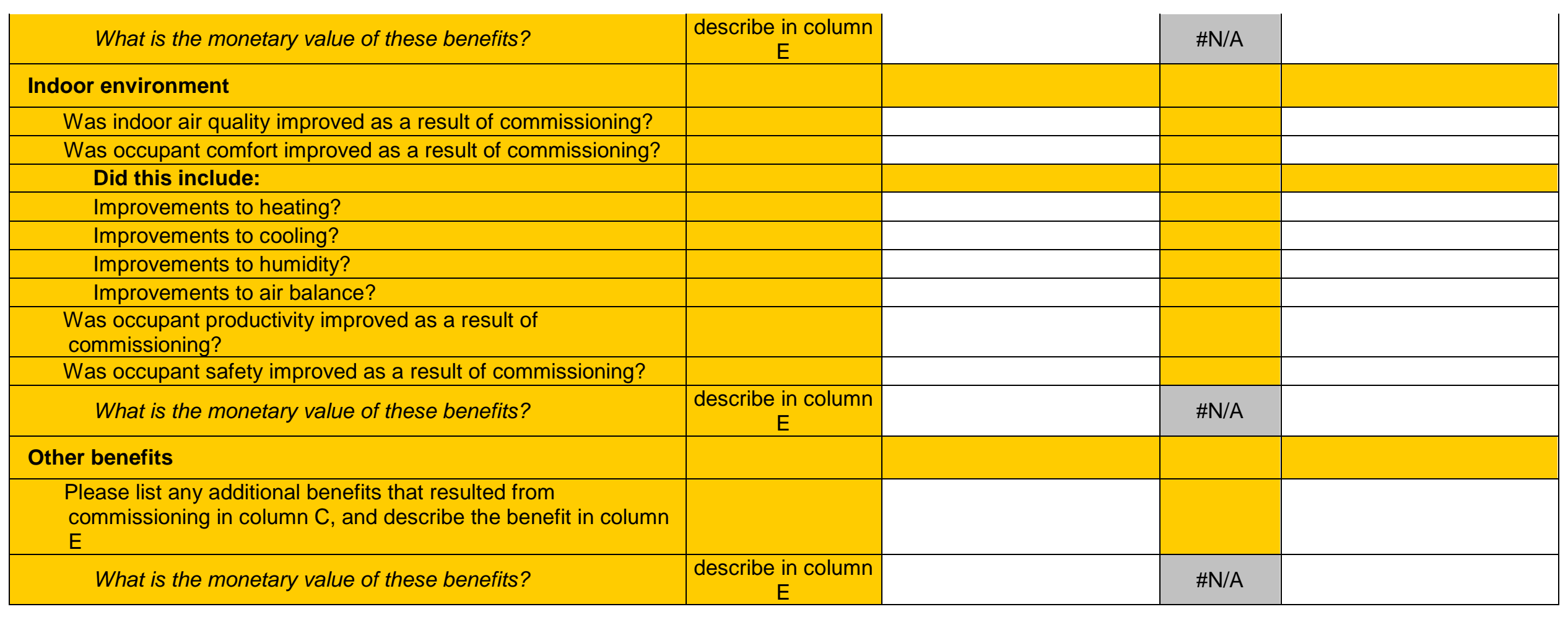




\section{Commissioning Data Collection Form}

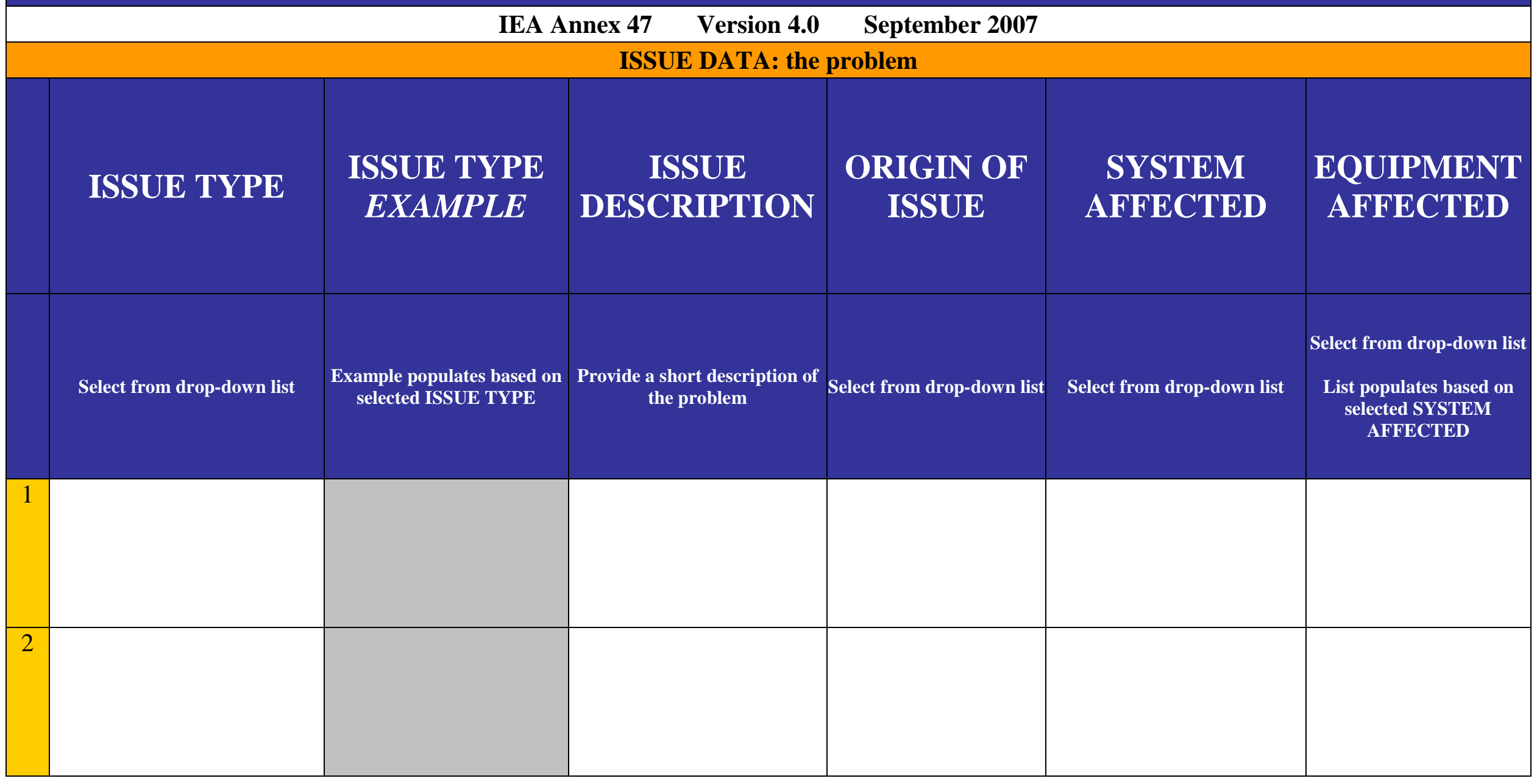




\begin{tabular}{|c|c|c|c|c|c|c|}
\hline \multicolumn{7}{|c|}{ MEASURE DATA: the solution } \\
\hline & $\begin{array}{l}\text { ISSUE } \\
\text { TYPE }\end{array}$ & $\begin{array}{c}\text { MEASURE } \\
\text { TYPE }\end{array}$ & $\begin{array}{c}\text { MEASURE } \\
\text { DESCRIPTION }\end{array}$ & $\begin{array}{c}\text { WAS MEASURE } \\
\text { IMPLEMENTED } \\
?\end{array}$ & $\begin{array}{l}\text { IMPLEMENT- } \\
\text { ATION COST }\end{array}$ & $\begin{array}{l}\text { MEASURE } \\
\text { COST TYPE }\end{array}$ \\
\hline & $\begin{array}{l}\text { Select from drop-dowr } \\
\text { list }\end{array}$ & $\begin{array}{l}\text { Select from drop-down } \\
\text { list }\end{array}$ & $\begin{array}{l}\text { Provide a short description of } \\
\text { the solution recommended to } \\
\text { correct the problem }\end{array}$ & $\begin{array}{l}\text { Select from drop-down list } \\
\text { If recommended but not } \\
\text { implemented, select "No" }\end{array}$ & \#N/A & $\begin{array}{l}\text { Select from drop-down } \\
\text { list }\end{array}$ \\
\hline 1 & & & & & & \\
\hline 2 & & & & & & \\
\hline & & & & & & \\
\hline
\end{tabular}




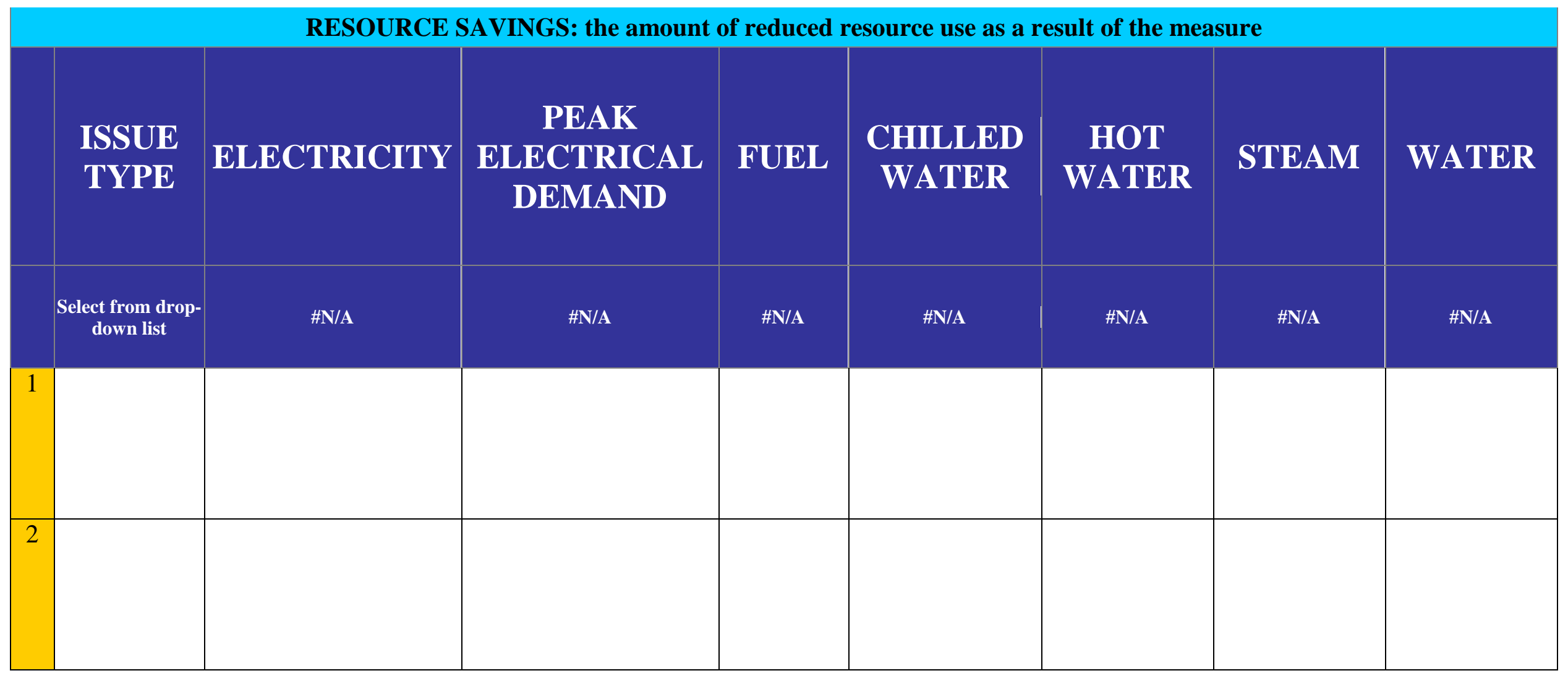




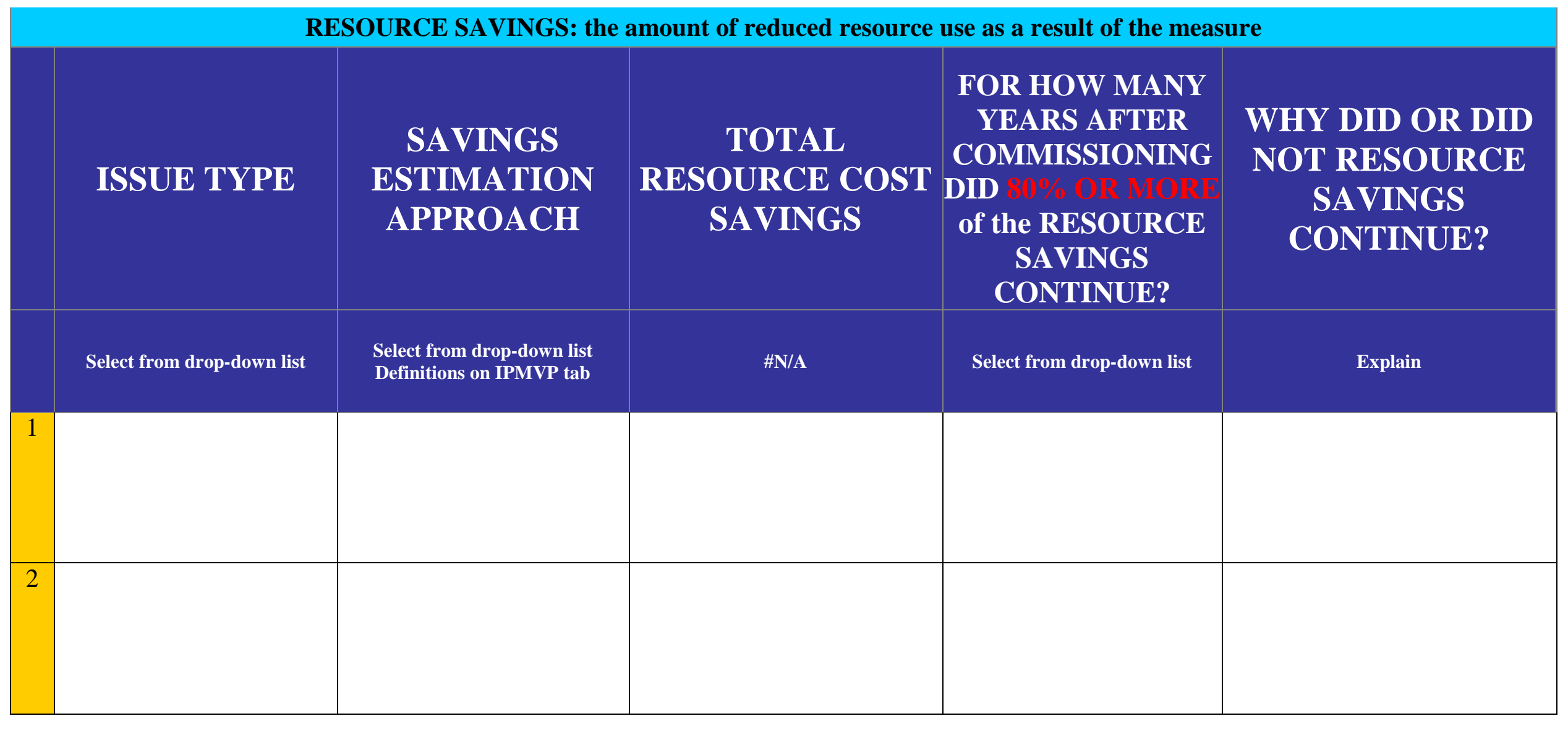




\begin{tabular}{|c|c|c|c|c|c|c|c|}
\hline \multicolumn{8}{|c|}{ NON-ENERGY BENEFITS } \\
\hline & $\begin{array}{l}\text { ISSUE } \\
\text { TYPE }\end{array}$ & $\begin{array}{l}\text { PRIMARY } \\
\text { BENEFIT: } \\
\text { TYPE }\end{array}$ & $\begin{array}{c}\text { PRIMARY } \\
\text { BENEFIT: } \\
\text { MONETARY } \\
\text { VALUE }\end{array}$ & $\begin{array}{c}\text { PRIMARY } \\
\text { BENEFIT: } \\
\text { CALCULATION } \\
\text { METHOD }\end{array}$ & $\begin{array}{c}\text { SECONDARY } \\
\text { BENEFIT: TYPE }\end{array}$ & $\begin{array}{l}\text { SECONDARY } \\
\text { BENEFIT: } \\
\text { MONETARY } \\
\text { VALUE }\end{array}$ & $\begin{array}{c}\text { SECONDARY } \\
\text { BENEFIT: } \\
\text { CALCULATION } \\
\text { METHOD }\end{array}$ \\
\hline & $\begin{array}{c}\text { Select from } \\
\text { drop-down list }\end{array}$ & $\begin{array}{l}\text { Select from drop-down } \\
\text { list }\end{array}$ & $\# \mathbf{N} / \mathbf{A}$ & $\begin{array}{l}\text { Describe method used to } \\
\text { calculate value of benefit }\end{array}$ & $\begin{array}{l}\text { Select benefit type from } \\
\text { drop-down menu }\end{array}$ & \#N/A & $\begin{array}{l}\text { Describe method used to } \\
\text { calculate value of benefit }\end{array}$ \\
\hline 1 & & & & & & & \\
\hline 2 & & & & & & & \\
\hline & & & & & & & \\
\hline
\end{tabular}




\section{III: Data Collection Form (EBCX)}

\section{EBCX DATA COLLECTION FORM - "INSTRUCTIONS" SECTION}

\section{Commissioning Data Collection Form - Existing Buildings}

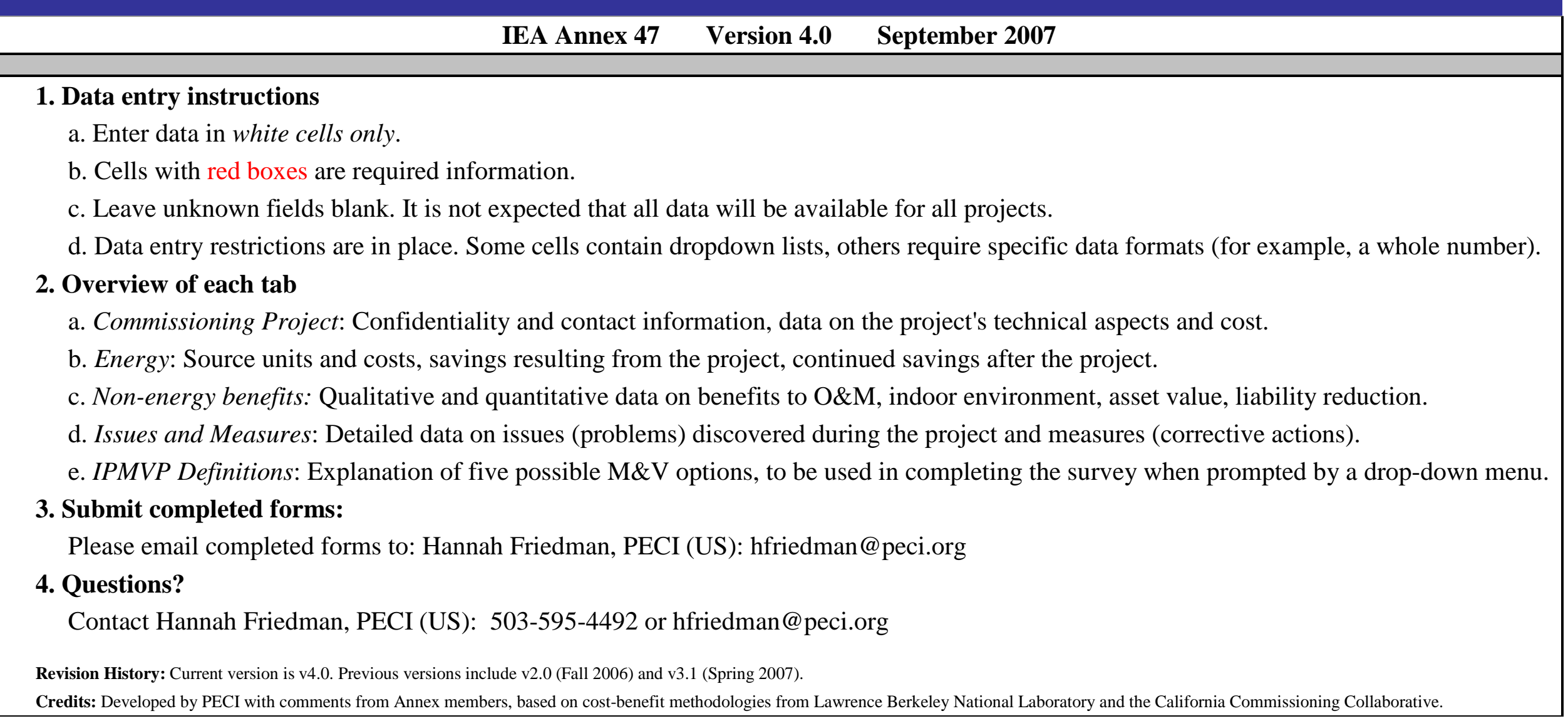


EBCX DATA COLLECTION FORM - “COMMISSIONING PROJECT” SECTION

\section{Commissioning Data Collection Form - Existing Buildings}

\begin{tabular}{|c|c|c|c|c|}
\hline \multirow[t]{2}{*}{ IEA Annex 47} & Version 4.0 & \multicolumn{3}{|l|}{ September 2007} \\
\hline & Notes & Project Data & Units & Comments \\
\hline \multicolumn{5}{|l|}{ CONFIDENTIALITY } \\
\hline \multicolumn{5}{|l|}{ Is it necessary for the building name to remain confidential? } \\
\hline \multicolumn{5}{|l|}{ PROJECT INFORMATION } \\
\hline \multicolumn{5}{|l|}{ Name of person completing form } \\
\hline \multicolumn{5}{|l|}{ Contact information of person completing form: Phone } \\
\hline \multicolumn{5}{|l|}{ Contact information of person completing form: E-mail } \\
\hline \multicolumn{5}{|l|}{ Hours spent completing this form } \\
\hline \multicolumn{5}{|l|}{ Who led the commissioning process? } \\
\hline \multicolumn{5}{|l|}{ Name of commissioning leader } \\
\hline $\begin{array}{l}\text { How many other commissioning projects did the commissioning } \\
\text { leader complete prior to this project? }\end{array}$ & $\begin{array}{l}\text { Include only projects } \\
\text { completed by leader, } \\
\text { not firm }\end{array}$ & & & \\
\hline \multicolumn{5}{|l|}{ Name of building/project } \\
\hline \multicolumn{5}{|l|}{ Building location } \\
\hline \multicolumn{5}{|l|}{ City } \\
\hline \multicolumn{5}{|l|}{ State } \\
\hline \multicolumn{5}{|l|}{ Country } \\
\hline \multicolumn{5}{|l|}{ Building ownership } \\
\hline \multicolumn{5}{|l|}{ Building type } \\
\hline Year built & & & & \\
\hline
\end{tabular}




\section{PROJECT INFORMATION CONTINUED}

Year commissioning project completed

Building occupancy type

Who performs operations and maintenance?

Was commissioning undertaken in part to achieve an award or certification?

\section{Awards/certifications received}

\section{LEED-NC}

\section{LEED-EB}

Energy Star (USA)

CASBEE (Japan)

EPBD (EU)

Other

Indicate the owner's reasons for commissioning on a scale

from 1 to 5 , where " 1 " is very important and " 5 " is not important

Ensure system performance

Obtain energy savings

Ensure or improve occupant comfort

Extend equipment life

Train and increase awareness of building operators

Increase occupant productivity

Ensure adequate indoor air quality (IAQ)

Comply with LEED or other sustainability rating ystem

Reduce liability

Qualify for rebate, financing, or other services

Participate in a research, demonstration or pilot project

PROJECT INFORMATION CONTINUED

Select "Y" for all

awards received

List rating level in

column E

List award name and
rating level in column

rating level in column$$
\mathrm{E}
$$

\begin{tabular}{|l}
2 \\
\hline
\end{tabular}

\begin{tabular}{|l|l|l|}
\hline & \\
\hline & \\
\hline & \\
\hline & \\
\hline & \\
\hline & \\
\hline & \\
\hline & \\
\hline & \\
\hline & \\
\hline & \\
\hline & \\
\hline & \\
\hline & \\
\hline & \\
\hline & \\
\hline & \\
\hline & \\
\hline
\end{tabular}


Participate in a utility program

Other

\section{Level of commissioning}

\section{Did the building undergo a new building commissioning} process?

If yes, in what phase did commissioning begin?

TECHNICAL INFORMATION

\section{Floor area units}

Total floor area

Floor area served by commissioned systems (excludes parking)

Total floor area dedicated to each of the following uses

School

University

Hospital or health facility

Laboratory

Office

Hotel

Retail

Restaurant

Supermarket

Residential apartment building

Parking

Public assembly

Public order and safety

Religious worship

Industrial building

Service, warehouse or storage

\section{Explain in column $\mathrm{E}$}

If only energy

efficiency measures

were commissioned,

select "Specific

systems"
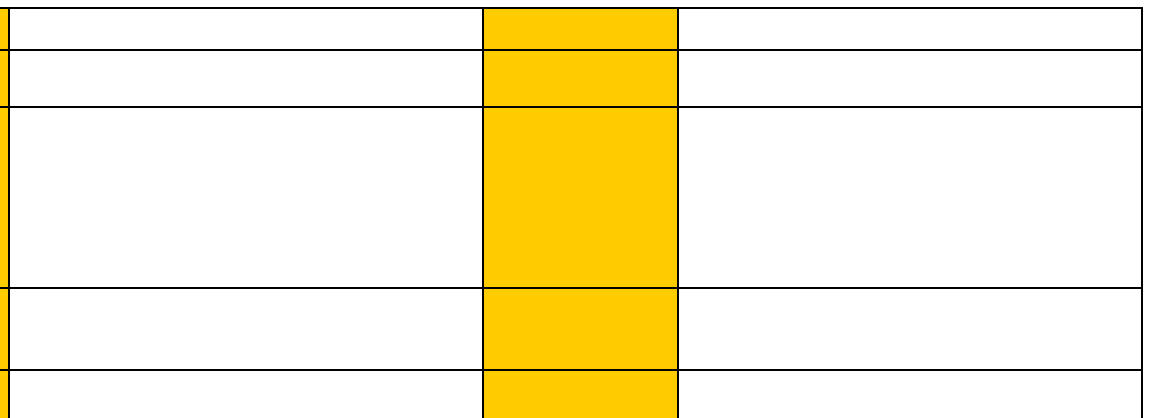

\section{TECHNICAL INFORMATION CONTINUED}


Other

If the indicated floor area is for multiple buildings, how many

buildings?

Is the facility served by a central heating and cooling plant

that serves multiple buildings?

How many issues were found in each commissioned system?

If the system was not commissioned, leave cell empty.

If the system was commissioned but no issues were found, enter 0.

If the same issue occurred multiple times or places, only count as one issue.

HVAC system integration (EMCS/BAS)

Chilled water plant and distribution system

Packaged or split system DX

Heating water plant and distribution system

Domestic hot water

Heat pump system

Air handling and distribution: Overhead system

Air handling and distribution: Underfloor system

Terminal units

Thermal energy storage

Radiant heating

Radiant cooling

Passive heating/cooling

Natural ventilation or mixed-mode ventilation

Lighting/daylighting and lighting controls

Electrical

Plumbing

Envelope and infiltration

Fire/life safety

Utility-related (electric, gas, water, emergency power)
Explain in column E

below includes the

controls related to the system

$$
\text { system }
$$

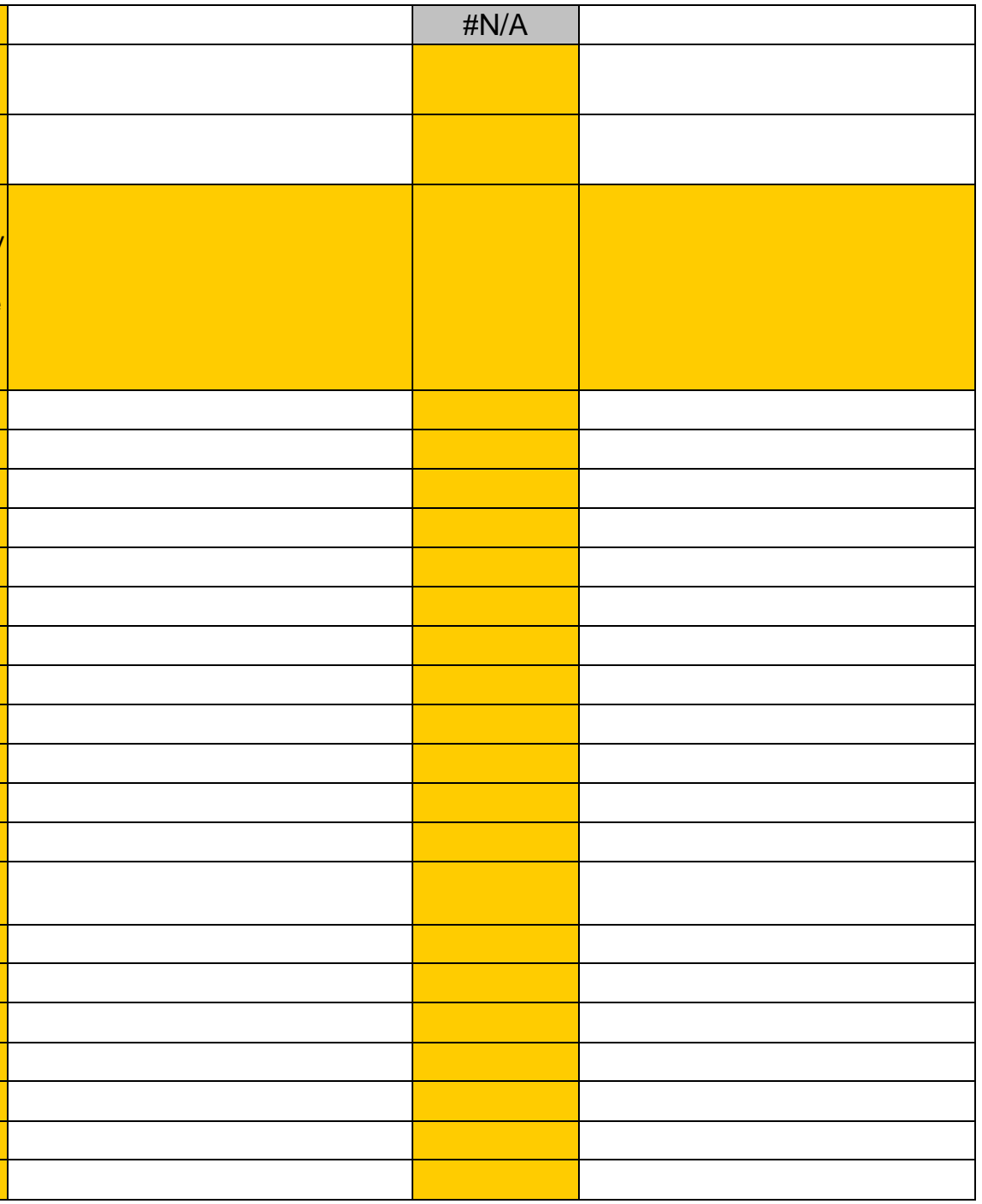

\section{TECHNICAL INFORMATION CONTINUED}

\section{Security}

Refrigeration 


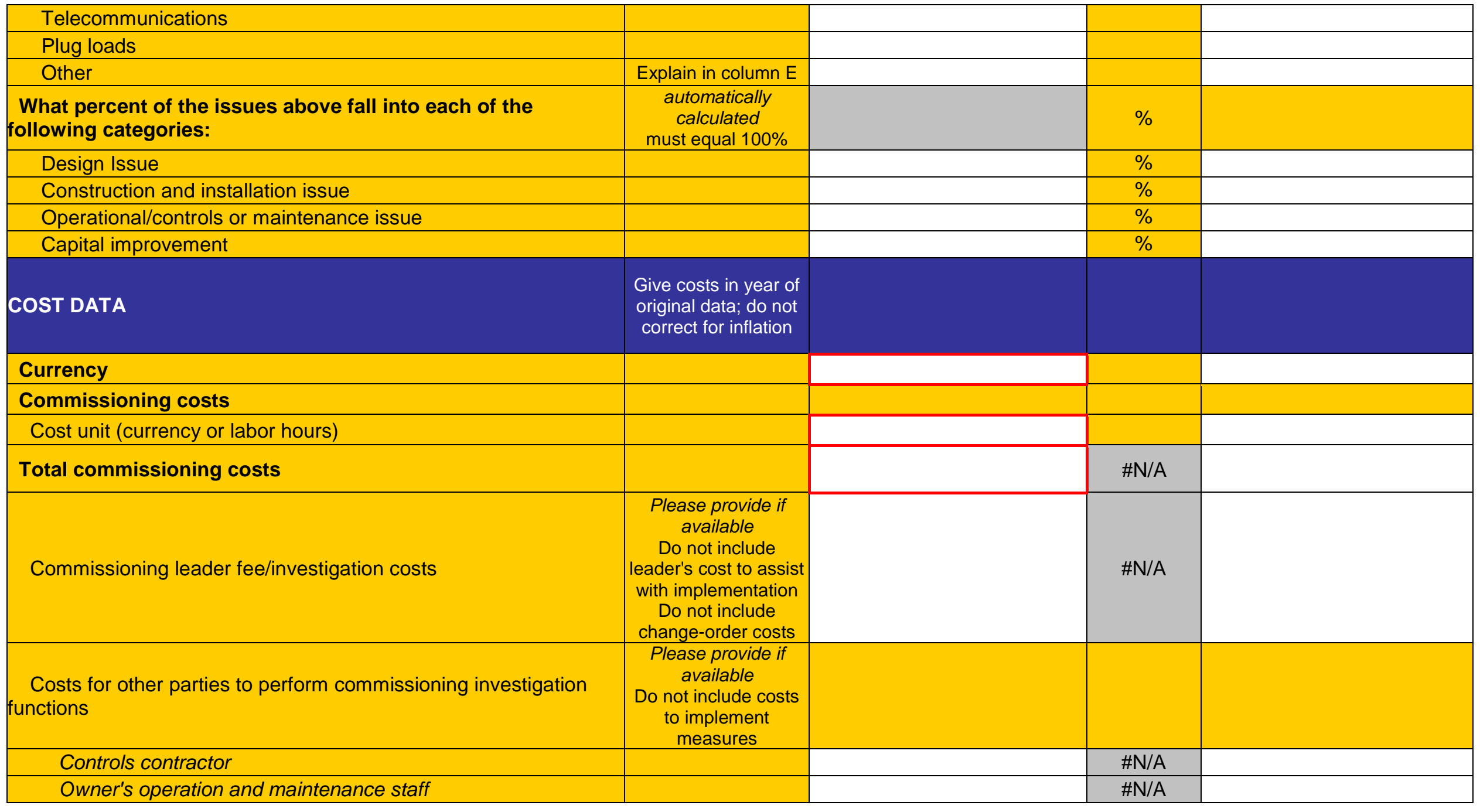

\section{COST DATA CONTINUED}

Cost to implement measures (include cost of all labor and materials)
Please provide if

available
\#N/A

Page 194 of 239 


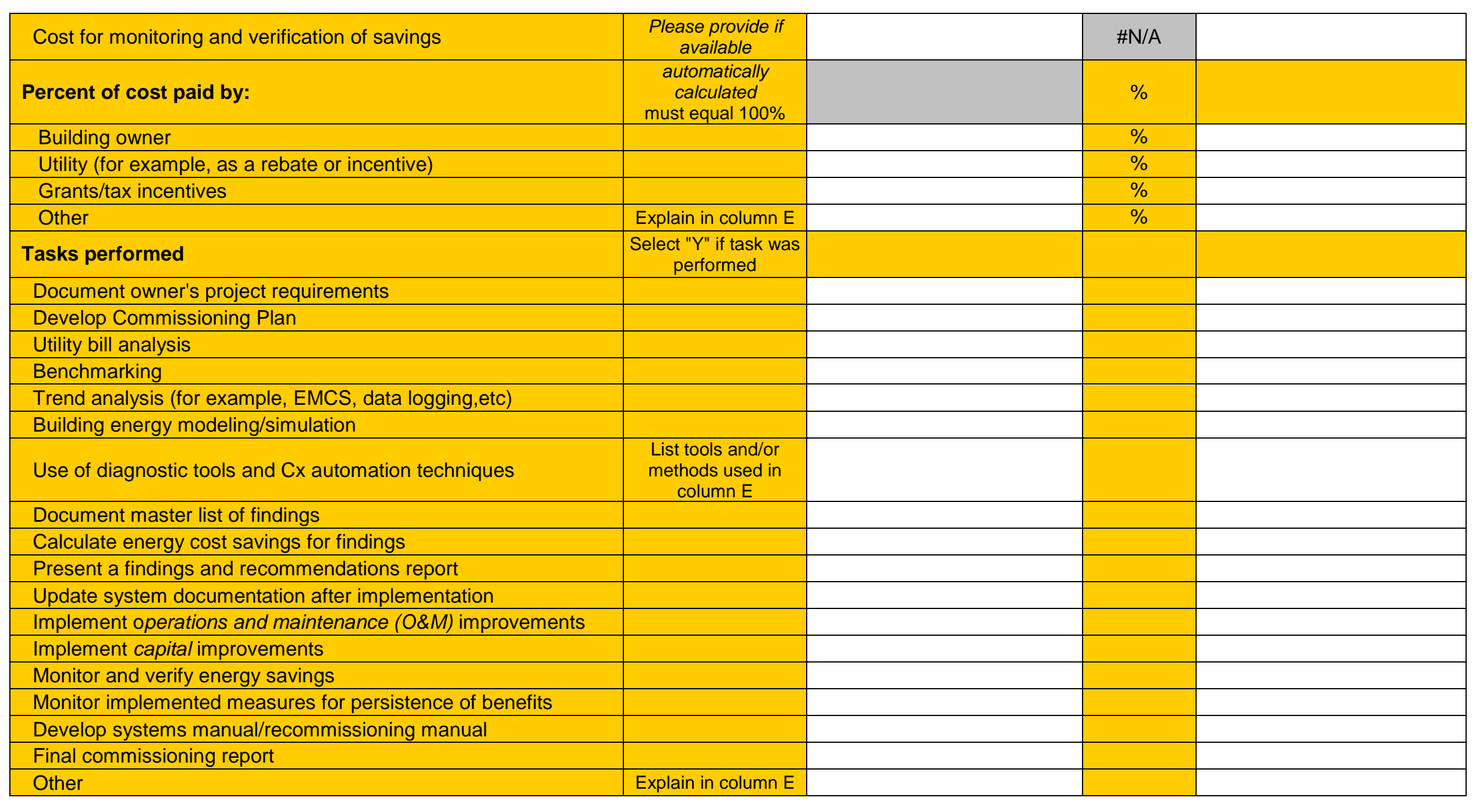


EBCX DATA COLLECTION FORM - “ENERGY” SECTION

\section{Commissioning Data Collection Form - Existing Buildings}

\begin{tabular}{|c|c|c|c|c|}
\hline IEA Annex 47 & Version 4.0 & September 2007 & & \\
\hline & Notes & Project Data & Units & Comments \\
\hline \multicolumn{5}{|l|}{ SOURCE, UNIT \& COST } \\
\hline \multicolumn{5}{|l|}{ Electricity } \\
\hline \multicolumn{5}{|l|}{ Unit } \\
\hline Average cost per unit (in the first year after commissioning) & & & \#N/A & \\
\hline \multicolumn{5}{|l|}{ Electric demand } \\
\hline \multicolumn{5}{|l|}{ Unit } \\
\hline Average cost per unit (in the first year after commissioning) & & & \#N/A & \\
\hline \multicolumn{5}{|l|}{ Fuel } \\
\hline \multicolumn{5}{|l|}{ Fuel type } \\
\hline \multicolumn{5}{|l|}{ Unit } \\
\hline Average cost per unit (in the first year after commissioning) & & & \#N/A & \\
\hline \multicolumn{5}{|l|}{ District chilled water } \\
\hline \multicolumn{5}{|l|}{ Unit } \\
\hline Average cost per unit (in the first year after commissioning) & & & $\# N / A$ & \\
\hline \multicolumn{5}{|l|}{ District hot water } \\
\hline \multicolumn{5}{|l|}{ Unit } \\
\hline Average cost per unit (in the first year after commissioning) & & & \#N/A & \\
\hline \multicolumn{5}{|l|}{ District steam } \\
\hline \multicolumn{5}{|l|}{ Unit } \\
\hline Average cost per unit (in the first year after commissioning) & & & $\# \mathrm{~N} / \mathrm{A}$ & \\
\hline
\end{tabular}




\begin{tabular}{|c|c|c|c|}
\hline \multicolumn{4}{|l|}{ Water } \\
\hline \multicolumn{4}{|l|}{ Unit } \\
\hline Average cost per unit (in the first year after commissioning) & & \#N/A & \\
\hline \multicolumn{4}{|l|}{ Electricity } \\
\hline Annual usage before commissioning & & \#N/A & \\
\hline Annual savings from implemented measures & & $\# \mathrm{~N} / \mathrm{A}$ & \\
\hline $\begin{array}{l}\text { Additional annual savings from measures recommended but not } \\
\text { implemented }\end{array}$ & & \#N/A & \\
\hline Method used to determine savings & $\begin{array}{c}\text { Definitions on IPMVP } \\
\text { tab }\end{array}$ & & \\
\hline \multicolumn{4}{|l|}{ Electric demand } \\
\hline Peak demand before commissioning & & $\# \mathrm{~N} / \mathrm{A}$ & \\
\hline Demand reduction from implemented measures & & \#N/A & \\
\hline $\begin{array}{l}\text { Additional annual savings from measures recommended but not } \\
\text { implemented }\end{array}$ & & \#N/A & \\
\hline Method used to determine savings & $\begin{array}{c}\text { Definitions on IPMVP } \\
\text { tab }\end{array}$ & & \\
\hline \multicolumn{4}{|l|}{ Fuel } \\
\hline Annual usage before commissioning & & \#N/A & \\
\hline Annual savings from implemented measures & & \#N/A & \\
\hline $\begin{array}{l}\text { Additional annual savings from measures recommended but not } \\
\text { implemented }\end{array}$ & & \#N/A & \\
\hline Method used to determine savings & \begin{tabular}{|c|}
$\begin{array}{c}\text { Definitions on IPMVP } \\
\text { tab }\end{array}$ \\
\end{tabular} & & \\
\hline \multicolumn{4}{|l|}{ District chilled water } \\
\hline Annual usage before commissioning & & \#N/A & \\
\hline Annual savings from implemented measures & & \#N/A & \\
\hline $\begin{array}{l}\text { Additional annual savings from measures recommended but not } \\
\text { implemented }\end{array}$ & & \#N/A & \\
\hline
\end{tabular}

RESOURCE SAVINGS CONTINUED 


\begin{tabular}{|c|c|c|c|}
\hline Method used to determine savings & \begin{tabular}{|c|}
$\begin{array}{c}\text { Definitions on IPMVP } \\
\text { tab }\end{array}$ \\
\end{tabular} & & \\
\hline \multicolumn{4}{|l|}{ District hot water } \\
\hline Annual usage before commissioning & & \#N/A & \\
\hline Annual savings from implemented measures & & \#N/A & \\
\hline $\begin{array}{l}\text { Additional annual savings from measures recommended but not } \\
\text { implemented }\end{array}$ & & \#N/A & \\
\hline Method used to determine savings & \begin{tabular}{|c|}
$\begin{array}{c}\text { Definitions on IPMVP } \\
\text { tab }\end{array}$ \\
\end{tabular} & & \\
\hline \multicolumn{4}{|l|}{ District steam } \\
\hline Annual usage before commissioning & & \#N/A & \\
\hline Annual savings from implemented measures & & \#N/A & \\
\hline $\begin{array}{l}\text { Additional annual savings from measures recommended but not } \\
\text { implemented }\end{array}$ & & \#N/A & \\
\hline Method used to determine savings & \begin{tabular}{|c|}
$\begin{array}{c}\text { Definitions on IPMVP } \\
\text { tab }\end{array}$ \\
\end{tabular} & & \\
\hline \multicolumn{4}{|l|}{ Water } \\
\hline Annual usage before commissioning & & \#N/A & \\
\hline Annual savings from implemented measures & & \#N/A & \\
\hline $\begin{array}{l}\text { Additional annual savings from measures recommended but not } \\
\text { implemented }\end{array}$ & & \#N/A & \\
\hline Method used to determine savings & $\begin{array}{c}\text { Definitions on IPMVP } \\
\text { tab }\end{array}$ & & \\
\hline \multicolumn{4}{|l|}{ Could data have been affected by: } \\
\hline \multicolumn{4}{|l|}{ Major occupancy changes? } \\
\hline Average \% occupied before commissioning & & $\%$ & \\
\hline Average \% occupied after commissioning & & $\%$ & \\
\hline \multicolumn{4}{|l|}{ Changes in conditioned floor area? } \\
\hline Average \% conditioned floor area before commissioning & & $\%$ & \\
\hline Average $\%$ conditioned floor area after commissioning & & $\%$ & \\
\hline Changes in building use & $\begin{array}{l}\text { If yes, describe in } \\
\text { column } E\end{array}$ & & \\
\hline Major equipment changes & $\begin{array}{l}\text { If yes, describe in } \\
\text { column } E\end{array}$ & & \\
\hline \multicolumn{4}{|l|}{ RESOURCE SAVINGS CONTINUED } \\
\hline Has submitted data been normalized for: & & & \\
\hline
\end{tabular}

Page 198 of 239 


\begin{tabular}{|c|c|c|c|c|}
\hline Weather? & & & & \\
\hline \multicolumn{5}{|l|}{ If yes, to what year was the data normalized? } \\
\hline \multicolumn{5}{|l|}{ Changes in occupancy? } \\
\hline If yes, to what \% occupancy was the data normalized? & & & $\%$ & \\
\hline \multicolumn{5}{|l|}{ Changes in floor area? } \\
\hline If yes, to what floor area was the data normalized? & & & $\# N / A$ & \\
\hline Other & $\begin{array}{c}\text { If yes, describe in } \\
\text { column } E\end{array}$ & & & \\
\hline \multicolumn{5}{|l|}{$\begin{array}{l}\text { Indicate the "baseline" period (must be one full year of data - } \\
\text { usually the first full year after commissioning) }\end{array}$} \\
\hline Start month & $\begin{array}{c}\text { Example: enter } \\
\text { January as } 1\end{array}$ & & & \\
\hline End date & $\begin{array}{l}\text { automatically } \\
\text { calculated }\end{array}$ & $12 / 1900$ & & \\
\hline \multicolumn{5}{|l|}{$\begin{array}{l}\text { Electric consumption - weather normalized \% savings from } \\
\text { baseline }\end{array}$} \\
\hline Year 1 & & & $\%$ & \\
\hline Year 2 & & & $\%$ & \\
\hline Year 3 & & & $\%$ & \\
\hline Year 4 & & & $\%$ & \\
\hline Year 5 & & & $\%$ & \\
\hline Year 6 & & & $\%$ & \\
\hline \multicolumn{5}{|c|}{ Electric demand - weather normalized \% savings from baseline } \\
\hline Year 1 & & & $\%$ & \\
\hline Year 2 & & & $\%$ & \\
\hline Year 3 & & & $\%$ & \\
\hline
\end{tabular}

\section{RESOURCE USE AFTER COMMISSIONING CONTINUED}

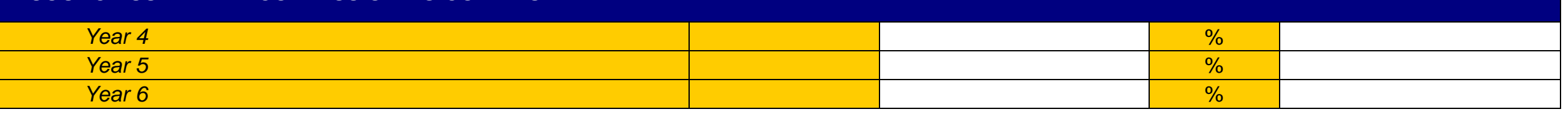

Page 199 of 239 


\begin{tabular}{|c|c|c|}
\hline \multicolumn{3}{|c|}{ Fuel - weather normalized \% savings from baseline } \\
\hline Year 1 & $\%$ & \\
\hline Year 2 & $\%$ & \\
\hline Year 3 & $\%$ & \\
\hline Year 4 & $\%$ & \\
\hline Year 5 & $\%$ & \\
\hline Year 6 & $\%$ & \\
\hline \multicolumn{3}{|c|}{$\begin{array}{l}\text { District hot water - weather normalized \% savings from } \\
\text { baseline }\end{array}$} \\
\hline Year 1 & $\%$ & \\
\hline Year 2 & $\%$ & \\
\hline Year 3 & $\%$ & \\
\hline Year 4 & $\%$ & \\
\hline Year 5 & $\%$ & \\
\hline \multicolumn{3}{|c|}{$\begin{array}{l}\text { District chilled water - weather normalized \% savings from } \\
\text { baseline }\end{array}$} \\
\hline Year 1 & $\%$ & \\
\hline Year 2 & $\%$ & \\
\hline Year 3 & $\%$ & \\
\hline Year 4 & $\%$ & \\
\hline Year 5 & $\%$ & \\
\hline Year 6 & $\%$ & \\
\hline \multicolumn{3}{|c|}{ District steam - weather normalized \% savings from baseline } \\
\hline Year 1 & $\%$ & \\
\hline Year 2 & $\%$ & \\
\hline
\end{tabular}

\section{RESOURCE USE AFTER COMMISSIONING CONTINUED}

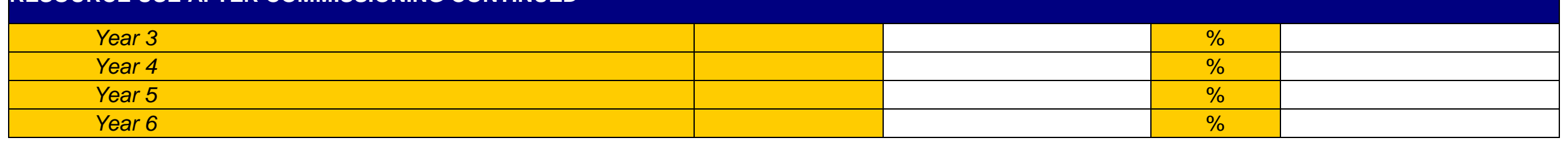

Page 200 of 239 


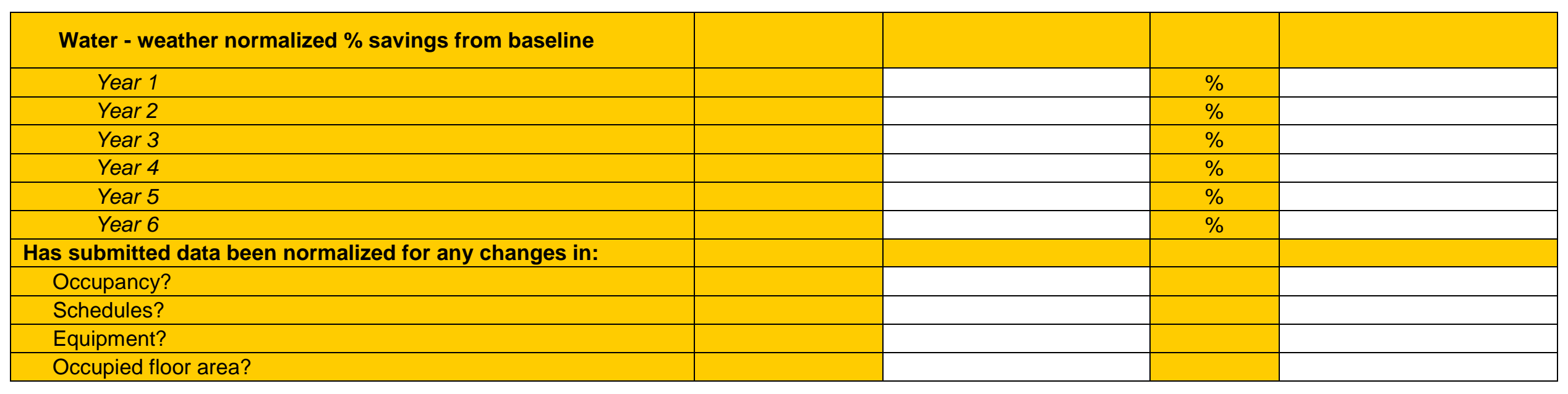


EBCX DATA COLLECTION FORM - “NON-ENERGY BENEFITS” SECTION

\section{Commissioning Data Collection Form - Existing Buildings}

\begin{tabular}{|c|c|c|c|c|}
\hline IEA Annex 47 & Version 4.0 & September 2007 & & \\
\hline & Notes & Project Data & Units & Comments \\
\hline NON-ENERGY BENEFITS & $\begin{array}{l}\text { Describe calculations in } \\
\text { column } E\end{array}$ & & & \\
\hline \multicolumn{5}{|l|}{ Operations \& maintenance (O\&M) } \\
\hline \multicolumn{5}{|l|}{$\begin{array}{l}\text { Was improved system documentation available to O\&M staff } \\
\text { as a result of commissioning? }\end{array}$} \\
\hline \multicolumn{5}{|l|}{$\begin{array}{l}\text { Were O\&M staff provided with training as a result of } \\
\text { commissioning? }\end{array}$} \\
\hline \multicolumn{5}{|l|}{$\begin{array}{l}\text { Do O\&M staff report increased ability to operate and maintain } \\
\text { the building as a result of commissioning? }\end{array}$} \\
\hline \multicolumn{5}{|l|}{ Was equipment life extended as a result of commissioning? } \\
\hline \multicolumn{5}{|l|}{$\begin{array}{l}\text { Were unexpected equipment failures likely prevented as a } \\
\text { result of commissioning? }\end{array}$} \\
\hline \multicolumn{5}{|l|}{$\begin{array}{l}\text { Were ongoing operations and maintenace costs reduced a } \\
\text { result of commissioning? }\end{array}$} \\
\hline What is the monetary value of these benefits? & describe in column $\mathrm{E}$ & & $\# \mathrm{~N} / \mathrm{A}$ & \\
\hline \multicolumn{5}{|l|}{ Indoor environment } \\
\hline \multicolumn{5}{|l|}{ Was indoor air quality improved as a result of commissioning? } \\
\hline \multicolumn{5}{|l|}{ Was occupant comfort improved as a result of commissioning? } \\
\hline \multicolumn{5}{|l|}{ Did this include: } \\
\hline \multicolumn{5}{|l|}{ Improvements to heating? } \\
\hline \multicolumn{5}{|l|}{ Improvements to cooling? } \\
\hline \multicolumn{5}{|l|}{ Improvements to humidity? } \\
\hline \multicolumn{5}{|l|}{ Improvements to air balance? } \\
\hline \multicolumn{5}{|l|}{$\begin{array}{l}\text { Was occupant productivity improved as a result of } \\
\text { commissioning? }\end{array}$} \\
\hline \multicolumn{5}{|l|}{ Was occupant safety improved as a result of commissioning? } \\
\hline What is the monetary value of these benefits? & describe in column $\mathrm{E}$ & & $\# \mathrm{~N} / \mathrm{A}$ & \\
\hline
\end{tabular}

Page 202 of 239 


\section{NON-ENERGY BENEFITS CONTINUED}

Asset value

Was asset value improved as a result of commissioning? What is the total value of this benefit?

Liability reduction

Was liability reduced as a result of commissioning? Did this include reductions in liability related to: Indoor air quality (IAQ)? Fire/life safety? Security?

The building's mission critical function? What is the monetary value of these benefits?

ing?

\begin{tabular}{|l|l|}
\hline describe in column $\mathrm{E}$ & \\
& \\
& \\
& \\
& \\
\hline describe in column $\mathrm{E}$ & \\
\hline
\end{tabular}

\section{Other benefits}

Please list any additional benefits that resulted from

commissioning in column $\mathrm{C}$, and describe the benefit in column $\mathrm{E}$

What is the monetary value of these benefits?

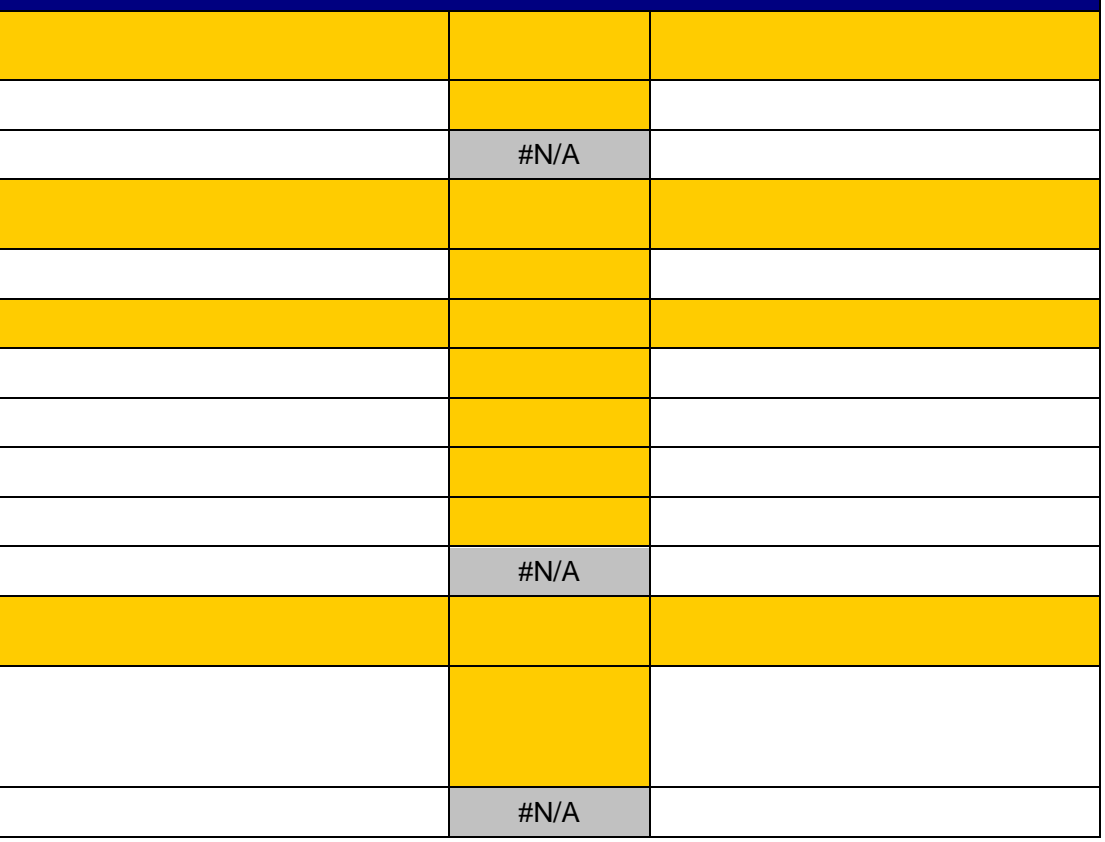




\section{Commissioning Data Collection Form}

\begin{tabular}{|c|c|c|c|c|c|c|}
\hline & & IEA A & Version 4.0 & September 2007 & & \\
\hline \multicolumn{7}{|c|}{ ISSUE DATA: the problem } \\
\hline & ISSUE TYPE & $\begin{array}{l}\text { ISSUE TYPE } \\
\text { EXAMPLE }\end{array}$ & $\begin{array}{c}\text { ISSUE } \\
\text { DESCRIPTION }\end{array}$ & $\begin{array}{l}\text { ORIGIN OF } \\
\text { ISSUE }\end{array}$ & $\begin{array}{c}\text { SYSTEM } \\
\text { AFFECTED }\end{array}$ & $\begin{array}{c}\text { EQUIPMENT } \\
\text { AFFECTED }\end{array}$ \\
\hline & Select from drop-down list & $\begin{array}{l}\text { Example populates based on } \\
\text { selected ISSUE TYPE }\end{array}$ & $\begin{array}{l}\text { Provide a short description of } \\
\text { the problem }\end{array}$ & $\begin{array}{l}\text { Select from drop-down } \\
\text { list }\end{array}$ & Select from drop-down list & $\begin{array}{l}\text { Select from drop-down list } \\
\text { List populates based on } \\
\text { selected SYSTEM } \\
\text { AFFECTED }\end{array}$ \\
\hline \multicolumn{7}{|l|}{1} \\
\hline 2 & & & & & & \\
\hline & & & & & & \\
\hline
\end{tabular}




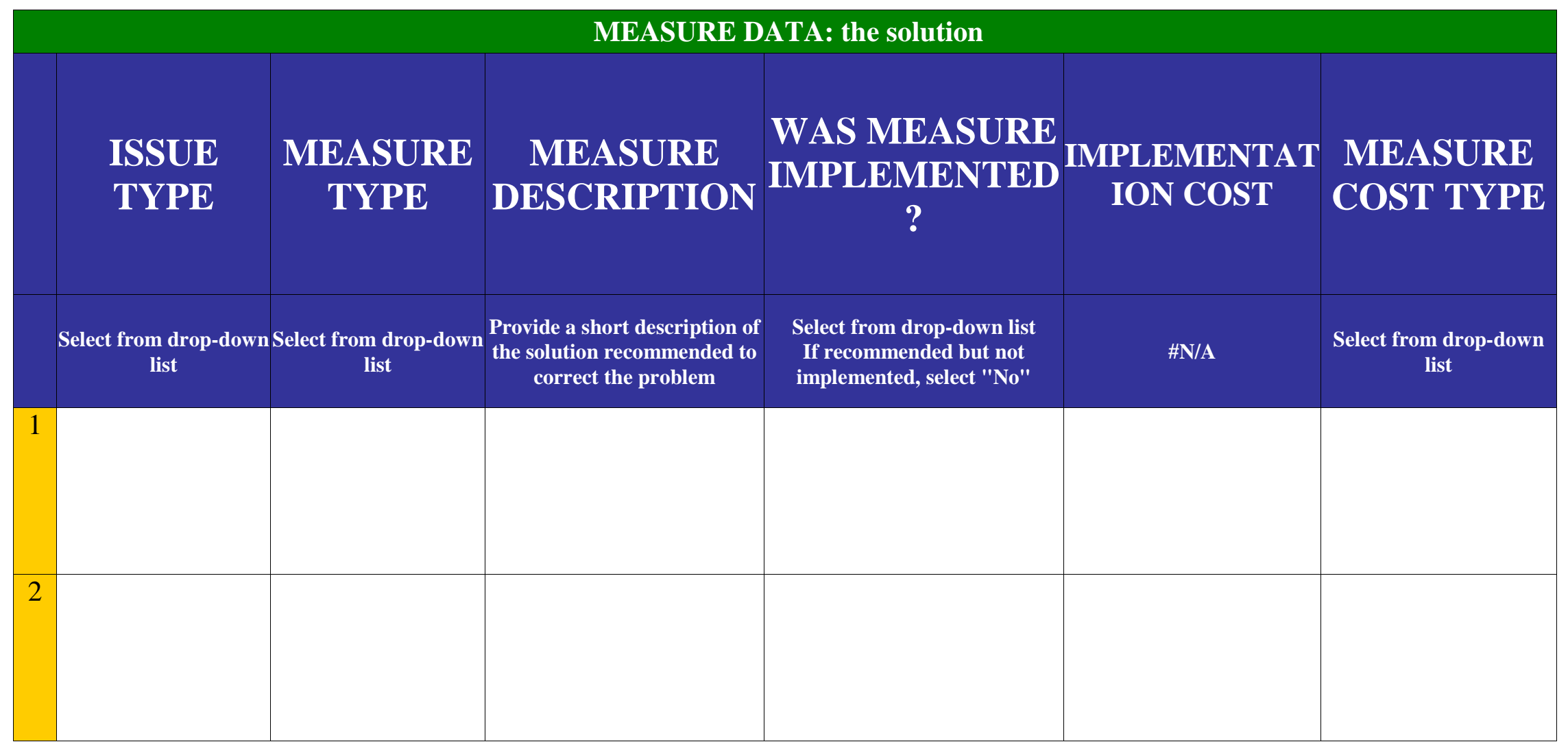




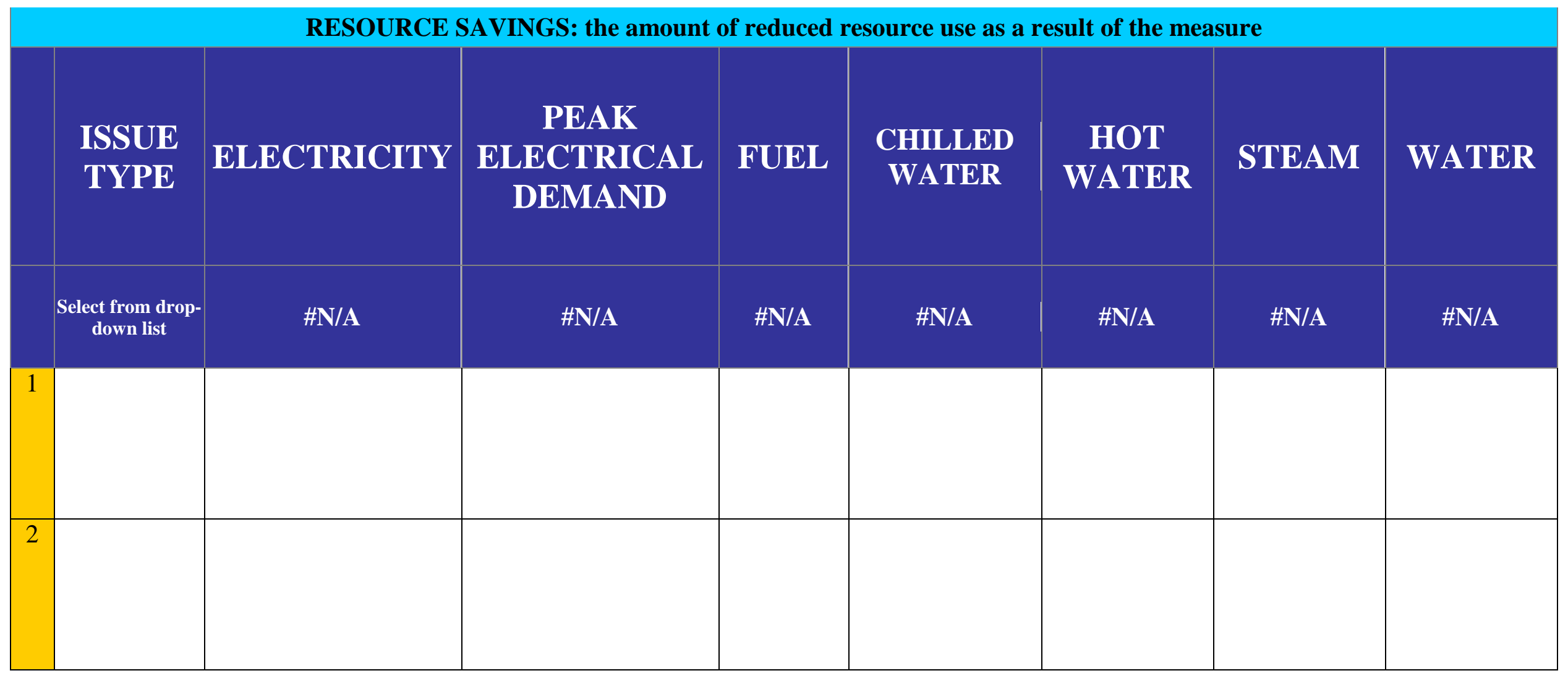




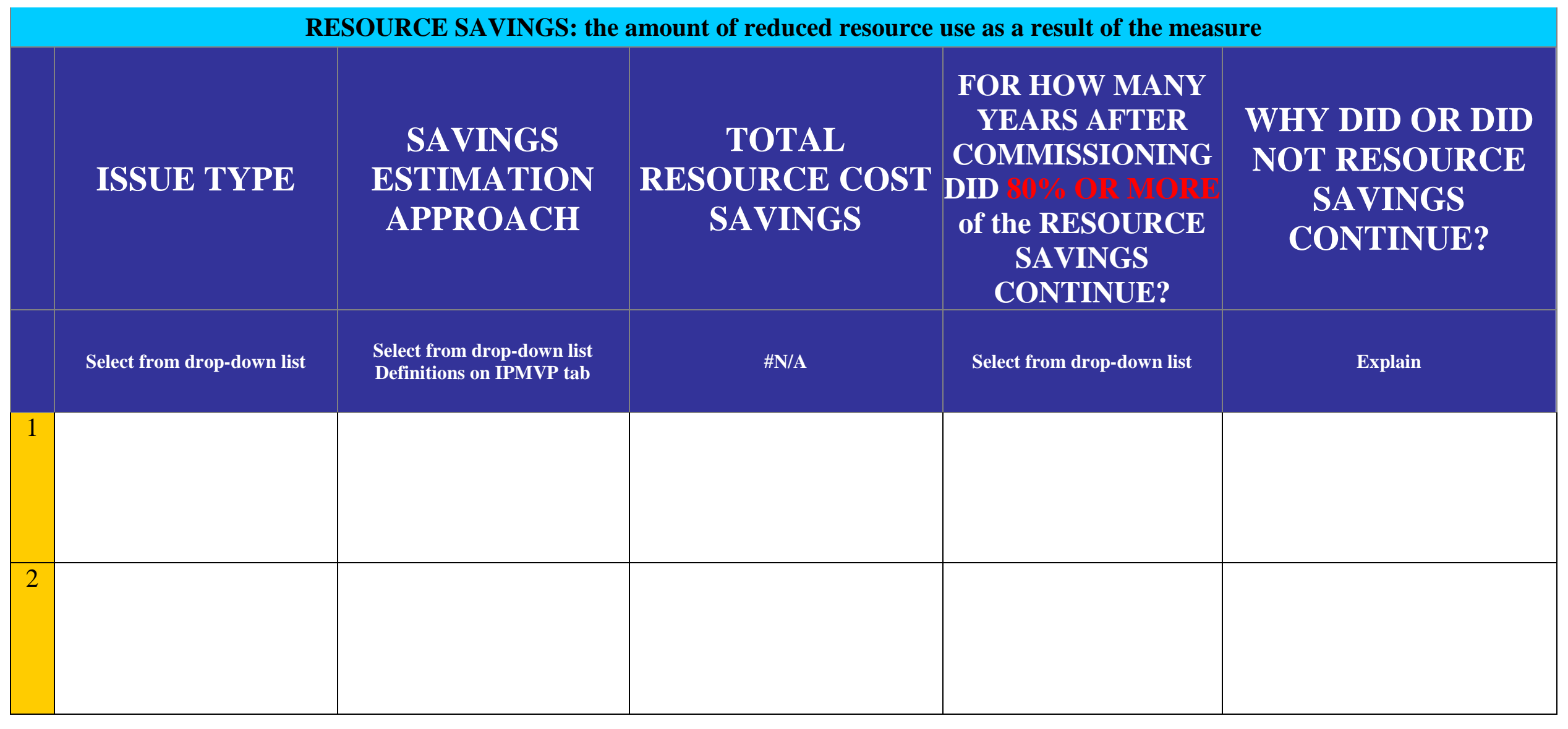




\begin{tabular}{|c|c|c|c|c|c|c|c|}
\hline \multicolumn{8}{|c|}{ NON-ENERGY BENEFITS } \\
\hline & \begin{tabular}{|l} 
ISSUE \\
TYPE
\end{tabular} & $\begin{array}{l}\text { PRIMARY } \\
\text { BENEFIT: } \\
\text { TYPE }\end{array}$ & $\begin{array}{c}\text { PRIMARY } \\
\text { BENEFIT: } \\
\text { MONETARY } \\
\text { VALUE }\end{array}$ & $\begin{array}{c}\text { PRIMARY } \\
\text { BENEFIT: } \\
\text { CALCULATION } \\
\text { METHOD }\end{array}$ & $\begin{array}{c}\text { SECONDARY } \\
\text { BENEFIT: TYPE }\end{array}$ & $\begin{array}{l}\text { SECONDARY } \\
\text { BENEFIT: } \\
\text { MONETARY } \\
\text { VALUE }\end{array}$ & $\begin{array}{c}\text { SECONDARY } \\
\text { BENEFIT: } \\
\text { CALCULATION } \\
\text { METHOD }\end{array}$ \\
\hline & $\begin{array}{c}\text { Select from } \\
\text { drop-down list }\end{array}$ & $\begin{array}{l}\text { Select from drop- } \\
\quad \text { down list }\end{array}$ & $\# \mathbf{N} / \mathbf{A}$ & $\begin{array}{l}\text { Describe method used to } \\
\text { calculate value of benefit }\end{array}$ & $\begin{array}{l}\text { Select benefit type from drop- } \\
\text { down menu }\end{array}$ & $\# \mathbf{N} / \mathbf{A}$ & $\begin{array}{l}\text { Describe method used to } \\
\text { calculate value of benefit }\end{array}$ \\
\hline 1 & & & & & & & \\
\hline 2 & & & & & & & \\
\hline & & & & & & & \\
\hline
\end{tabular}


IV: Tabulated Survey Results (CX)

\section{TABULATED SURVEY RESULTS (CX) - "CX PROJECT" SECTION}

\begin{tabular}{|c|c|c|c|c|c|c|c|c|c|c|c|}
\hline $\begin{array}{l}\text { Project } \\
\text { ref } \\
\text { number }\end{array}$ & \begin{tabular}{|l} 
PROJECT \\
INFORMATION
\end{tabular} & $\begin{array}{l}\text { Building } \\
\text { location }\end{array}$ & City & State & Country & $\begin{array}{l}\text { Year } \\
\text { commissioning } \\
\text { project } \\
\text { completed }\end{array}$ & $\begin{array}{l}\text { TECHNICAL } \\
\text { INFORMATION }\end{array}$ & $\begin{array}{l}\text { Floor area } \\
\text { units }\end{array}$ & $\begin{array}{l}\text { How many issues were } \\
\text { found in each commissioned } \\
\text { system? } \\
\text { If the system was not } \\
\text { commissioned, leave cell } \\
\text { empty. } \\
\text { If the system was } \\
\text { commissioned but no issues } \\
\text { were found, enter } 0 \text {. } \\
\text { If the same issue occurred } \\
\text { multiple times or places, only } \\
\text { count as one issue. }\end{array}$ & $\begin{array}{l}\text { HVAC } \\
\text { system } \\
\text { integration } \\
\text { (EMCS/BAS) }\end{array}$ & $\begin{array}{l}\quad \text { Chilled water } \\
\text { plant and } \\
\text { distribution } \\
\text { system }\end{array}$ \\
\hline 1 & & & Stuttgart & $\begin{array}{c}\text { Baden- } \\
\text { Württemberg }\end{array}$ & Germany & 2004 & & $\mathrm{~m} 2$ & & & \\
\hline 2 & & & Zwolle & & Netherlands & 2007 & & $\mathrm{~m} 2$ & & & 1 \\
\hline 3 & & & Davenport lowa & lowa & USA & 2006 & & $\mathrm{ft} 2$ & & & \\
\hline 4 & & & Pittsburgh & PA & USA & 2004 & & $\mathrm{ft} 2$ & & & \\
\hline 5 & & & Tachikawa & Tokyo & Japan & 2005 & & $\mathrm{~m} 2$ & & 4 & 4 \\
\hline 6 & & & Oita & Oita & Japan & 2000 & & $\mathrm{~m} 2$ & & & 1 \\
\hline 7 & & & Okazaki & Aichi & Japan & & & $\mathrm{m} 2$ & & & \\
\hline 8 & & & Yokohama & Kanagawa & Japan & & & $\mathrm{m} 2$ & & 0 & 1 \\
\hline 9 & & & $\begin{array}{l}\text { 1-5-1 Higasi } \\
\text { Shinbashi, } \\
\text { Minatoku }\end{array}$ & Tokyo & Japan & 2006 & & $\mathrm{~m} 2$ & & 0 & 0 \\
\hline 10 & & & kobei & Wakayama & Japan & 2006 & & $\mathrm{~m} 2$ & & & \\
\hline
\end{tabular}




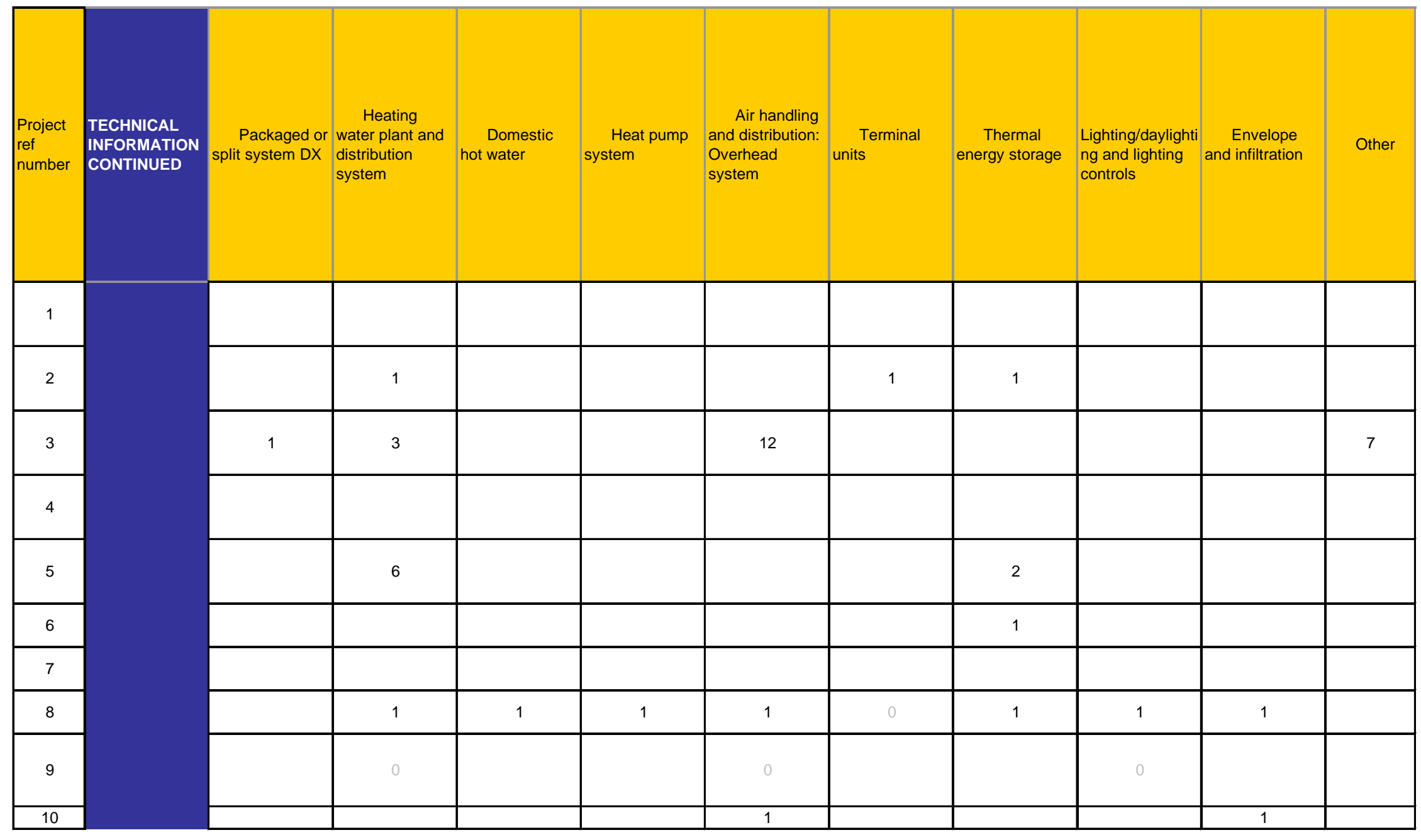




\begin{tabular}{|c|c|c|c|c|c|c|c|c|c|c|c|c|}
\hline $\begin{array}{l}\text { Project } \\
\text { ref } \\
\text { number }\end{array}$ & COST DATA & Currency & $\begin{array}{l}\text { Cost unit } \\
\text { (currency or } \\
\text { labor hours) }\end{array}$ & $\begin{array}{l}\text { Total } \\
\text { commissioning } \\
\text { costs }\end{array}$ & $\begin{array}{l}\text { Items } \\
\text { included in } \\
\text { cost } \\
\text { estimates }\end{array}$ & $\begin{array}{l}\text { Development } \\
\text { of owner's } \\
\text { project } \\
\text { requirements } \\
\text { and basis of } \\
\text { design (if } \\
\text { not well- } \\
\text { developed by } \\
\text { designer) }\end{array}$ & $\begin{array}{c}\text { Write } \\
\text { commisioning } \\
\text { specifications }\end{array}$ & $\begin{array}{l}\text { Develop } \\
\text { commisioning } \\
\text { plan }\end{array}$ & $\begin{array}{l}\text { Design } \\
\text { review }\end{array}$ & $\begin{array}{l}\quad \text { Develop } \\
\text { sequences of } \\
\text { operation (if not } \\
\text { well-developed } \\
\text { by mechanical } \\
\text { or } \quad \text { controls } \\
\text { contractor) }\end{array}$ & $\begin{array}{l}\text { Submittal } \\
\text { review }\end{array}$ & $\begin{array}{l}\text { Construction } \\
\text { observation }\end{array}$ \\
\hline 1 & & EUR (euro) & Currency & 175000 & & $Y$ & & $Y$ & & & & \\
\hline 2 & & EUR (euro) & Currency & 15000 & & & & & $Y$ & Y & Y & \\
\hline 3 & & USD (US dollar) & Currency & 15000 & & $y$ & $y$ & $y$ & $y$ & & $y$ & $y$ \\
\hline 4 & & USD (US dollar) & Currency & 18000 & & & & $\mathrm{Y}$ & & Y & & \\
\hline 5 & & $\begin{array}{l}\text { JPY (Japanese } \\
\text { yen) }\end{array}$ & Labor & 1104 & & Y & Y & Y & $\mathrm{Y}$ & Y & Y & Y \\
\hline 6 & & $\begin{array}{l}\text { JPY (Japanese } \\
\text { yen) }\end{array}$ & Currency & $30,000,000.00$ & & & & & & & & \\
\hline 7 & & $\begin{array}{c}\text { JPY (Japanese } \\
\text { yen) }\end{array}$ & & & & & & & & & & \\
\hline 8 & & $\begin{array}{l}\text { JPY (Japanese } \\
\text { yen) }\end{array}$ & Labor & 432 & & & & & & & & \\
\hline 9 & & $\begin{array}{l}\text { JPY (Japanese } \\
\text { yen) }\end{array}$ & Currency & $36,700,000.00$ & & & & & & & & \\
\hline 10 & & & & 1000 & & $y$ & & $y$ & $\underline{y}$ & & & \\
\hline
\end{tabular}




\begin{tabular}{|c|c|c|c|c|c|c|c|c|c|c|c|c|}
\hline $\begin{array}{l}\text { Project } \\
\text { ref } \\
\text { number }\end{array}$ & $\begin{array}{l}\text { COST DATA } \\
\text { CONTINUED }\end{array}$ & $\begin{array}{l}\text { Verification } \\
\text { checks/pre- } \\
\text { functional testing }\end{array}$ & $\begin{array}{l}\text { Use of } \\
\text { diagnostic tools } \\
\text { and } C x \\
\text { automation } \\
\text { techniques }\end{array}$ & $\begin{array}{l}\text { Functional } \\
\text { testing }\end{array}$ & $\begin{array}{c}\text { Significant } \\
\text { involvement in } \\
\text { issue resolution }\end{array}$ & $\begin{array}{l}\text { Oversee } \\
\text { training }\end{array}$ & $\begin{array}{l}\quad \text { Review } \\
\text { operations \& } \\
\text { maintenance } \\
\text { manuals }\end{array}$ & $\begin{array}{l}\text { Develop } \\
\text { systems } \\
\text { manual/recommi } \\
\text { ssioning manual }\end{array}$ & $\begin{array}{l}\text { Perform trend } \\
\text { analysis }\end{array}$ & $\begin{array}{l}\text { Evaluate } \\
\text { energy cost } \\
\text { savings }\end{array}$ & $\begin{array}{l}\text { Final } \\
\text { commissioning } \\
\text { report }\end{array}$ & $\begin{array}{l}\text { Update as- } \\
\text { built drawings }\end{array}$ \\
\hline 1 & & & & & $Y$ & & & & $Y$ & & $Y$ & \\
\hline 2 & & & & $Y$ & & & & & & & $Y$ & \\
\hline 3 & & $y$ & & $y$ & $y$ & $y$ & $y$ & & & & $y$ & \\
\hline 4 & & $Y$ & & $Y$ & $Y$ & & $Y$ & & & & $Y$ & \\
\hline 5 & & $Y$ & & $Y$ & $Y$ & $Y$ & $Y$ & $Y$ & $Y$ & & Y & \\
\hline 6 & & & & & & & & & & & & \\
\hline 7 & & & & & & & & & & & & \\
\hline 8 & & & & & & & & & & & & \\
\hline 9 & & & $Y$ & & $Y$ & $Y$ & & & $Y$ & $Y$ & $Y$ & \\
\hline 10 & & $y$ & & $y$ & $y$ & & & & $y$ & $y$ & $y$ & y \\
\hline
\end{tabular}


TABULATED SURVEY RESULTS (Cx) - "CX ENERGY" SECTION

\begin{tabular}{|c|c|c|c|c|c|c|c|c|c|c|c|c|c|c|c|c|}
\hline $\begin{array}{l}\text { Project } \\
\text { Ref } \\
\text { number }\end{array}$ & Country & $\begin{array}{l}\text { SOURCE, } \\
\text { UNIT \& } \\
\text { COST }\end{array}$ & Electricity & Unit & $\begin{array}{l}\text { Electric } \\
\text { demand }\end{array}$ & Unit & Fuel & Fuel type & Unit & $\begin{array}{l}\text { District } \\
\text { chilled } \\
\text { water }\end{array}$ & Unit & $\begin{array}{l}\text { District } \\
\text { steam }\end{array}$ & Unit & Water & Unit & $\begin{array}{l}\quad \text { Average } \\
\text { cost per unit } \\
\text { (in the first } \\
\text { year after } \\
\text { commissioni } \\
\text { ng) }\end{array}$ \\
\hline 1 & Germany & & & $\begin{array}{l}\text { Kilowatt-hour } \\
\text { (kWh) }\end{array}$ & & $\begin{array}{c}\text { Kilowatt } \\
\text { (kW) }\end{array}$ & & Natural gas & $\begin{array}{l}\text { Cubic } \\
\text { meters gas } \\
\text { (m3) }\end{array}$ & & & & & & & \\
\hline 2 & Netherlands & & & & & & & & & & & & & & & \\
\hline 3 & USA & & & $\begin{array}{l}\text { Kilowatt-hour } \\
\text { (kWh) }\end{array}$ & & $\begin{array}{c}\text { Kilowatt } \\
(\mathrm{kW})\end{array}$ & & Natural gas & $\begin{array}{l}\text { Hundred } \\
\text { cubic feet } \\
\text { (CCF) }\end{array}$ & & & & & & & \\
\hline 4 & USA & & & $\begin{array}{l}\text { Kilowatt-hour } \\
\text { (kWh) }\end{array}$ & & $\begin{array}{c}\text { Kilowatt } \\
(\mathrm{kW})\end{array}$ & & & & & & & & & Gallons & \\
\hline 5 & Japan & & & $\begin{array}{l}\text { Kilowatt-hour } \\
\text { (kWh) }\end{array}$ & & $\begin{array}{l}\text { Kilowatt } \\
(\mathrm{kW})\end{array}$ & & $\begin{array}{l}\text { Not used at } \\
\text { this facility }\end{array}$ & & & & & & & Liters & 0.37 \\
\hline 6 & Japan & & & $\begin{array}{l}\text { Kilowatt-hour } \\
\text { (kWh) }\end{array}$ & & $\begin{array}{l}\text { Kilowatt } \\
(\mathrm{kW})\end{array}$ & & $\begin{array}{l}\text { Not used at } \\
\text { this facility }\end{array}$ & & & & & & & Liters & \\
\hline- & Japan & & & $\begin{array}{l}\text { Kilowatt-hour } \\
\text { (kWh) }\end{array}$ & & $\begin{array}{c}\text { Kilowatt } \\
(\mathrm{kW})\end{array}$ & & $\begin{array}{l}\text { Not used at } \\
\text { this facility }\end{array}$ & & & & & & & Liters & \\
\hline 8 & Japan & & & $\begin{array}{l}\text { Kilowatt-hour } \\
\text { (kWh) }\end{array}$ & & $\begin{array}{l}\text { Kilowatt } \\
(\mathrm{kW})\end{array}$ & & $\begin{array}{l}\text { Not used at } \\
\text { this facility }\end{array}$ & & & & & & & Liters & 0.37 \\
\hline 9 & Japan & & & $\begin{array}{l}\text { Megajoule } \\
(\mathrm{MJ})\end{array}$ & & $\begin{array}{l}\text { Kilowatt } \\
(\mathrm{kW})\end{array}$ & & & & & $\begin{array}{l}\text { Megajoule } \\
\text { (MJ) }\end{array}$ & & $\begin{array}{l}\text { Megajoule } \\
\text { (MJ) }\end{array}$ & & Liters & \\
\hline 10 & Japan & & & & & & & & & & & & & & & \\
\hline
\end{tabular}


V: Tabulated Survey Results (EBCX)

\begin{tabular}{|c|c|c|c|c|c|c|c|c|c|c|c|c|}
\hline \begin{tabular}{|l} 
Project \\
Ref \\
Number
\end{tabular} & $\begin{array}{l}\text { PROJECT } \\
\text { INFORMATION }\end{array}$ & $\begin{array}{l}\text { Name of } \\
\text { person } \\
\text { completing } \\
\text { form }\end{array}$ & $\begin{array}{l}\text { Contact information of } \\
\text { person completing } \\
\text { form: Phone }\end{array}$ & $\begin{array}{l}\text { Contact } \\
\text { information of } \\
\text { person } \\
\text { completing } \\
\text { form: E-mail }\end{array}$ & $\begin{array}{l}\text { Building } \\
\text { location }\end{array}$ & City & State & Country & $\begin{array}{l}\text { Building } \\
\text { ownership }\end{array}$ & Building type & $\begin{array}{l}\text { Year } \\
\text { built }\end{array}$ & $\begin{array}{l}\text { Year } \\
\text { commissioning } \\
\text { project completed }\end{array}$ \\
\hline 1 & & Alexis Versele & & & & $\begin{array}{l}\text { Oud } \\
\text { Borgerhout }\end{array}$ & Antwerp & Belgium & & $\begin{array}{l}\text { Other (explain } \\
\text { in column E) }\end{array}$ & 1930 & \\
\hline 2 & & Alexis Versele & & & & Wondelgem & $\begin{array}{l}\text { Oost- } \\
\text { Vlaanderen }\end{array}$ & Belgium & & School & 1977 & \\
\hline 3 & & Alexis Versele & & & & Wondelgem & $\begin{array}{l}\text { Oost- } \\
\text { Vlaanderen }\end{array}$ & Belgium & & School & 1985 & \\
\hline 4 & & $\begin{array}{l}\text { Stijn Van den } \\
\text { Broecke }\end{array}$ & & & & Mechelen & $\begin{array}{l}\text { provincie } \\
\text { Antwerpen }\end{array}$ & Belgium & Private & Office & 2006 & 2008 \\
\hline 5 & & $\begin{array}{l}\text { Prof. M. De } \\
\text { Paepe }\end{array}$ & & & & Gent & Flanders & Belgium & Public & Laboratory & 2003 & 2007 \\
\hline 6 & & Hilde Breesch & & & & Gent & $\begin{array}{l}\text { Oost- } \\
\text { Vlaandere }\end{array}$ & Belgium & Public & School & & 2008 \\
\hline 7 & & André Chalifour & & & & Montréal & Québec & Canada & & $\begin{array}{l}\text { Other (explain } \\
\text { in column E) }\end{array}$ & 1983 & 2003 \\
\hline 8 & & $\begin{array}{l}\text { Daniel } \\
\text { Choiniere }\end{array}$ & & & & Varennes & Québec & Canada & Public & $\begin{array}{l}\text { Other (explain } \\
\text { in column E) }\end{array}$ & 1991 & 2006 \\
\hline 9 & & $\begin{array}{l}\text { Shigehiro } \\
\text { Ichinose }\end{array}$ & & & & Nagoya & Aichi & Japan & & Office & 1971 & 2007 \\
\hline 10 & & $\begin{array}{l}\text { Kazuhiro } \\
\text { Nakazawa }\end{array}$ & & & & Osaka & Osaka & Japan & Private & $\begin{array}{l}\text { Other (explain } \\
\text { in column E) }\end{array}$ & 2005 & 2007 \\
\hline 11 & & $\begin{array}{l}\text { Katsuhiro } \\
\text { KAMITANI }\end{array}$ & & & & $\begin{array}{l}\text { nihonbashi,chu } \\
\text { o-ku }\end{array}$ & Tokyo & Japan & Private & Office & 1968 & 2004 \\
\hline 12 & & $\begin{array}{l}\text { Katsuhiro } \\
\text { KAMITANI }\end{array}$ & & & & $\begin{array}{l}\text { sinkawa,chuo- } \\
\text { ku }\end{array}$ & Tokyo & Japan & Private & Office & 1988 & 1999 \\
\hline 13 & & $\begin{array}{l}\text { Masahiro } \\
\text { Shinozaki }\end{array}$ & & & & Oita & Oita & Japan & Private & Office & 1997 & 2007 \\
\hline 14 & & Hirobumi UEDA & & & & Nishiku & Osaka & Japan & Private & Office & 1996 & 2008 \\
\hline 15 & & Henk Peitsman & & & & Amsterdam & n.a. & Netherlands & & Office & 1999 & 2005 \\
\hline 16 & & $\begin{array}{l}\text { Henk C. } \\
\text { Peitsman }\end{array}$ & & & & Rotterdam & n.a. & Netherlands & Private & Office & 1991 & 1996 \\
\hline 17 & & $\begin{array}{l}\text { Henk C. } \\
\text { Peitsman }\end{array}$ & & & & The Hague & & Netherlands & Private & Office & & 2005 \\
\hline 18 & & $\begin{array}{l}\text { Henk C. } \\
\text { Peitsman }\end{array}$ & & & & Maastricht & & Netherlands & Private & University & 2005 & 2007 \\
\hline 19 & & $\begin{array}{l}\text { Henk C. } \\
\text { Peitsman }\end{array}$ & & & & Driebergen & n.a. & Netherlands & Public & Office & 1989 & 2008 \\
\hline 20 & & $\begin{array}{l}\text { Henk C. } \\
\text { Peitsman }\end{array}$ & & & & Hoevelaken & n.a. & Netherlands & Private & Office & 1969 & 2008 \\
\hline 21 & & $\begin{array}{l}\text { Henk C. } \\
\text { Peitsman }\end{array}$ & & & & Amsterdam & n.a. & Netherlands & Private & Office & 2002 & 2006 \\
\hline
\end{tabular}

Page 214 of 239 


\begin{tabular}{|c|c|c|c|c|c|c|c|c|c|c|c|c|}
\hline $\begin{array}{l}\text { Project } \\
\text { Ref } \\
\text { Number }\end{array}$ & $\begin{array}{l}\text { PROJECT } \\
\text { INFORMATION }\end{array}$ & $\begin{array}{l}\text { Name of } \\
\text { person } \\
\text { completing } \\
\text { form }\end{array}$ & $\begin{array}{l}\text { Contact } \\
\text { information of } \\
\text { person completing } \\
\text { form: Phone }\end{array}$ & $\begin{array}{l}\text { Contact information of } \\
\text { person completing form: E- } \\
\text { mail }\end{array}$ & $\begin{array}{l}\text { Building } \\
\text { location }\end{array}$ & City & State & Country & $\begin{array}{l}\text { Building } \\
\text { ownership }\end{array}$ & Building type & $\begin{array}{l}\text { Year } \\
\text { built }\end{array}$ & $\begin{array}{l}\text { Year } \\
\text { commissioning } \\
\text { project completed }\end{array}$ \\
\hline 22 & & $\begin{array}{l}\text { Henk C. } \\
\text { Peitsman }\end{array}$ & $\ldots$ & - & & Delft & n.a. & Netherlands & Public & Office & 2002 & 2008 \\
\hline 23 & & Henk Peitsman & & & & The Hague & n.a. & Netherlands & Private & Office & 1969 & 2008 \\
\hline 24 & & Natasa Djuric & & & & Trondheim & & Norway & & in column E) & 1958 & 2005 \\
\hline 25 & & Natasa Djuric & & & & $\begin{array}{l}\text { South Norway, } \\
\text { Cost }\end{array}$ & & Norway & Private & Hotel & 2002 & 2005 \\
\hline 26 & & Natasa Djuric & & & & $\begin{array}{l}\text { West Norway, } \\
\text { Cost }\end{array}$ & & Norway & Private & Hotel & 1987 & 2005 \\
\hline 27 & & Natasa Djuric & & & & $\begin{array}{l}\text { South Norway, } \\
\text { Cost }\end{array}$ & & Norway & Private & Hotel & 2000 & 2005 \\
\hline 28 & & Natasa Djuric & & & & $\begin{array}{l}\text { East Norway, } \\
\text { Inland }\end{array}$ & & Norway & Private & Hotel & 1992 & 2005 \\
\hline 29 & & Omer Akin & ( & & & Pittsburgh & $\mathrm{PA}$ & USA & & University & 2004 & 2005 \\
\hline 31 & & Marti Frank & & & & La Mesa & California & USA & Private & Office & 1983 & 2001 \\
\hline 32 & & $\begin{array}{l}\text { Hannah } \\
\text { Friedman }\end{array}$ & & & & Portland & OR & USA & Public & $\begin{array}{l}\text { Public } \\
\text { assembly }\end{array}$ & 1997 & 2005 \\
\hline 33 & & Cory Toole & & & & College Station & $T X$ & USA & Public & University & 1978 & 1997 \\
\hline 34 & & Cory Toole & & & & College Station & $T X$ & USA & Public & University & 1973 & 1997 \\
\hline 35 & & Cory Toole & & & & College Station & TX & USA & Public & University & 1955 & 1997 \\
\hline 36 & & Cory Toole & & & & College Station & TX & USA & Public & University & 1973 & 1996 \\
\hline 37 & & Ken Engan & & & & College Station & $T X$ & USA & Public & University & 1977 & 1999 \\
\hline 38 & & Cory Toole & & & & College Station & $\overline{T X}$ & USA & Public & University & 1978 & 1996 \\
\hline 39 & & Cory Toole & & & & College Station & $T X$ & USA & Public & University & & 1997 \\
\hline 40 & & Cory Toole & & & & College Station & $T X$ & USA & Public & University & & 1997 \\
\hline 41 & & Cory Toole & & & & College Station & $\mathrm{TX}$ & USA & Public & University & & 1996 \\
\hline 42 & & Cory Toole & & & & College Station & $T X$ & USA & Public & University & 1995 & 1997 \\
\hline 43 & & Cory Toole & & & & College Station & $T X$ & USA & Public & University & 1971 & 1997 \\
\hline
\end{tabular}




\begin{tabular}{|c|c|c|c|c|c|c|c|c|c|c|c|c|c|c|c|c|}
\hline $\begin{array}{l}\text { Project } \\
\text { Ref } \\
\text { Number }\end{array}$ & $\begin{array}{l}\text { TECHNICAL } \\
\text { INFORMATION }\end{array}$ & $\begin{array}{l}\text { Floor } \\
\text { area } \\
\text { units }\end{array}$ & $\begin{array}{l}\text { Total floor } \\
\text { area }\end{array}$ & $\begin{array}{l}\text { \# issues found } \\
\text { in each Cx'd } \\
\text { system? } \\
\text { - If no Cx, leave cell } \\
\text { empty. } \\
\text { - If Cx but no issues } \\
\text { were found, enter } 0 . \\
\text { - If same issue } \\
\text { occurred multiple } \\
\text { times or places, } \\
\text { count as } 1 \text { issue. } \\
\text { System categories } \\
\text { below include } \\
\text { controls related to } \\
\text { the system }\end{array}$ & $\begin{array}{l}\text { HVAC } \\
\text { system } \\
\text { integration } \\
\text { (EMCS/ } \\
\text { BAS) }\end{array}$ & $\begin{array}{l}\text { Chilled } \\
\text { water plant } \\
\text { and } \\
\text { distribution } \\
\text { system }\end{array}$ & $\begin{array}{l}\text { Heating } \\
\text { water plant } \\
\text { and } \\
\text { distribution } \\
\text { system }\end{array}$ & $\begin{array}{l}\text { Domestic } \\
\text { hot water }\end{array}$ & $\begin{array}{l}\text { Heat } \\
\text { pump } \\
\text { system }\end{array}$ & $\begin{array}{l}\text { Air handling } \\
\text { and } \\
\text { distribution: } \\
\text { Overhead } \\
\text { system }\end{array}$ & $\begin{array}{l}\text { Air handling } \\
\text { and } \\
\text { distribution: } \\
\text { Underfloor } \\
\text { system }\end{array}$ & $\begin{array}{l}\text { Terminal } \\
\text { units }\end{array}$ & $\begin{array}{l}\text { Thermal } \\
\text { energy } \\
\text { storage }\end{array}$ & $\begin{array}{l}\text { Radiant } \\
\text { heating }\end{array}$ & $\begin{array}{l}\text { Radiant } \\
\text { cooling }\end{array}$ & $\begin{array}{l}\text { Passive } \\
\text { heating/ } \\
\text { cooling }\end{array}$ \\
\hline 1 & & $\mathrm{~m} 2$ & 1149 & & & & & & & & & & & & & \\
\hline 2 & & $\mathrm{~m} 2$ & 1524 & 6 & $\bar{Y}$ & & & $\bar{Y}$ & & & & & & $\bar{Y}$ & & \\
\hline 3 & & $\mathrm{~m} 2$ & 1512 & 6 & $\bar{Y}$ & & & $\bar{Y}$ & & & & & & $\bar{Y}$ & & \\
\hline 4 & & m2 & 1636 & 7 & $Y$ & & & & $Y$ & $Y$ & & & $Y$ & $Y$ & $Y$ & c \\
\hline 5 & & m2 & 12900 & 4 & . & Y & & & & $Y$ & & Y & & & & \\
\hline 7 & & $\mathrm{ft} 2$ & 1431500 & 7 & $Y$ & $Y$ & $Y$ & $\bar{Y}$ & & $Y$ & & & & & & \\
\hline 8 & & $\mathrm{~m} 2$ & 4189 & & & & & & & & & & & & & \\
\hline 9 & & $\mathrm{~m} 2$ & 9446 & & & & & & & & & & & & & \\
\hline 10 & & m2 & 106363 & 2 & & $Y$ & $Y$ & & c & & & & & & & \\
\hline 11 & & m2 & & 6 & $Y$ & $Y$ & $Y$ & & $Y$ & & & & $Y$ & & & \\
\hline 12 & & m2 & 5400 & 6 & $Y$ & $Y$ & $Y$ & & $Y$ & & & & $\mathrm{Y}$ & & & \\
\hline 13 & & m2 & 29869 & 2 & & $\mathrm{Y}$ & & & & & & & $Y$ & & & \\
\hline 14 & & m2 & 41000 & 4 & & $Y$ & $\mathrm{Y}$ & $\mathrm{Y}$ & & & & & $\mathrm{Y}$ & & & \\
\hline 15 & & $\mathrm{~m} 2$ & 120000 & & & & & & & & & & & & & \\
\hline 16 & & $\mathrm{~m} 2$ & 100000 & 4 & & $\bar{Y}$ & & & & $\mathrm{Y}$ & $\mathrm{Y}$ & $\bar{Y}$ & & & & \\
\hline 17 & & $\mathrm{~m} 2$ & 90000 & 4 & & $\bar{Y}$ & $\bar{Y}$ & & & $\bar{Y}$ & & $\bar{Y}$ & & & & \\
\hline 18 & & $\mathrm{~m} 2$ & 20000 & 3 & $\bar{Y}$ & $\bar{Y}$ & & & & & & $\bar{Y}$ & & & & \\
\hline 19 & & $\mathrm{~m} 2$ & 18000 & 2 & $\bar{Y}$ & 0 & 0 & & & $\bar{Y}$ & & & & & & \\
\hline 20 & & $\mathrm{~m} 2$ & 20000 & 6 & $\bar{Y}$ & $\bar{Y}$ & $\bar{Y}$ & & & $Y$ & & $Y$ & & & & \\
\hline
\end{tabular}

Page 216 of 239 


\begin{tabular}{|c|c|c|c|c|c|c|c|c|c|c|c|c|c|c|c|c|}
\hline $\begin{array}{l}\text { Project } \\
\text { Ref } \\
\text { Number }\end{array}$ & $\begin{array}{l}\text { TECHNICAL } \\
\text { INFORMATION }\end{array}$ & $\begin{array}{l}\text { Floor } \\
\text { area } \\
\text { units }\end{array}$ & $\begin{array}{l}\text { Total floor } \\
\text { area }\end{array}$ & $\begin{array}{l}\text { \# issues found } \\
\text { in each Cx'd } \\
\text { system? } \\
\text { - If no Cx, leave cell } \\
\text { empty. } \\
\text { - If Cx but no issues } \\
\text { were found, enter } 0 \text {. } \\
\text { - If same issue } \\
\text { occurred multiple } \\
\text { times or places, } \\
\text { count as } 1 \text { issue. } \\
\text { System categories } \\
\text { below include } \\
\text { controls related to } \\
\text { the system }\end{array}$ & $\begin{array}{l}\text { HVAC } \\
\text { system } \\
\text { integration } \\
\text { (EMCS/ } \\
\text { BAS) }\end{array}$ & $\begin{array}{l}\text { Chilled } \\
\text { water plant } \\
\text { and } \\
\text { distribution } \\
\text { system }\end{array}$ & $\begin{array}{l}\text { Heating } \\
\text { water plant } \\
\text { and } \\
\text { distribution } \\
\text { system }\end{array}$ & $\begin{array}{l}\text { Domestic } \\
\text { hot water }\end{array}$ & $\begin{array}{l}\text { Heat } \\
\text { pump } \\
\text { system }\end{array}$ & $\begin{array}{l}\text { Air handling } \\
\text { and } \\
\text { distribution: } \\
\text { Overhead } \\
\text { system }\end{array}$ & $\begin{array}{l}\text { Air handling } \\
\text { and } \\
\text { distribution: } \\
\text { Underfloor } \\
\text { system }\end{array}$ & $\begin{array}{l}\text { Terminal } \\
\text { units }\end{array}$ & $\begin{array}{l}\text { Thermal } \\
\text { energy } \\
\text { storage }\end{array}$ & $\begin{array}{l}\text { Radiant } \\
\text { heating }\end{array}$ & $\begin{array}{l}\text { Radiant } \\
\text { cooling }\end{array}$ & $\begin{array}{l}\text { Passive } \\
\text { heating/ } \\
\text { cooling }\end{array}$ \\
\hline 23 & & $\mathrm{~m} 2$ & 32000 & 4 & $Y$ & $Y$ & 0 & & & TY & 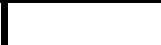 & 0 & & T & & J \\
\hline 24 & & $\mathrm{~m} 2$ & 13702 & 2 & $Y$ & & $Y$ & & & & & & & & & \\
\hline 25 & & $\mathrm{~m} 2$ & 17000 & 3 & 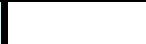 & & & & & $Y$ & & & & & & \\
\hline 26 & & $\mathrm{~m} 2$ & 12000 & 5 & $Y$ & & & & & $Y$ & & & & & & \\
\hline 27 & & $\mathrm{~m} 2$ & 12500 & 4 & 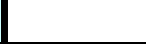 & & $Y$ & & & $Y$ & & & & Y & & \\
\hline 28 & & $\mathrm{~m} 2$ & 10000 & 4 & $Y$ & & & & & $Y$ & & & & $Y$ & & \\
\hline 29 & & $\mathrm{ft} 2$ & 11400 & & & & & & & & & & & & & \\
\hline 30 & & $\mathrm{ft} 2$ & 200460 & 1 & & & & & & Y & & & & & & \\
\hline 31 & & ft2 & 125000 & 1 & & & & & & & & & & & & \\
\hline 32 & & $\mathrm{ft} 2$ & 589140 & 0 & & & & & & & & & & & & \\
\hline 33 & & $\mathrm{ft} 2$ & 255490 & 0 & & & & & & & & & & & & \\
\hline 34 & & $\mathrm{ft} 2$ & 180316 & 0 & & & & & & & & & & & & \\
\hline 35 & & ft2 & 177838 & 0 & & & & & & & & & & & & \\
\hline 36 & & $\mathrm{ft} 2$ & 130844 & 0 & & & & & & & & & & & & \\
\hline 37 & & $\mathrm{ft} 2$ & 158979 & 4 & & & & $Y$ & & $Y$ & & $Y$ & & & & \\
\hline 38 & & $\mathrm{ft} 2$ & 165030 & 0 & & & & & & & & & & & & \\
\hline 39 & & $\mathrm{ft} 2$ & 97920 & 0 & & & & & & & & & & & & \\
\hline 40 & & $\mathrm{ft} 2$ & 113699 & 0 & & & & & & & & & & & & \\
\hline 41 & & $\mathrm{ft} 2$ & 114666 & 0 & & & & & & & & & & & & \\
\hline 42 & & $\mathrm{ft} 2$ & 192001 & 0 & & & & & & & & & & & & \\
\hline 43 & & $\mathrm{ft} 2$ & 258600 & 0 & & & & & & & & & & & & \\
\hline
\end{tabular}




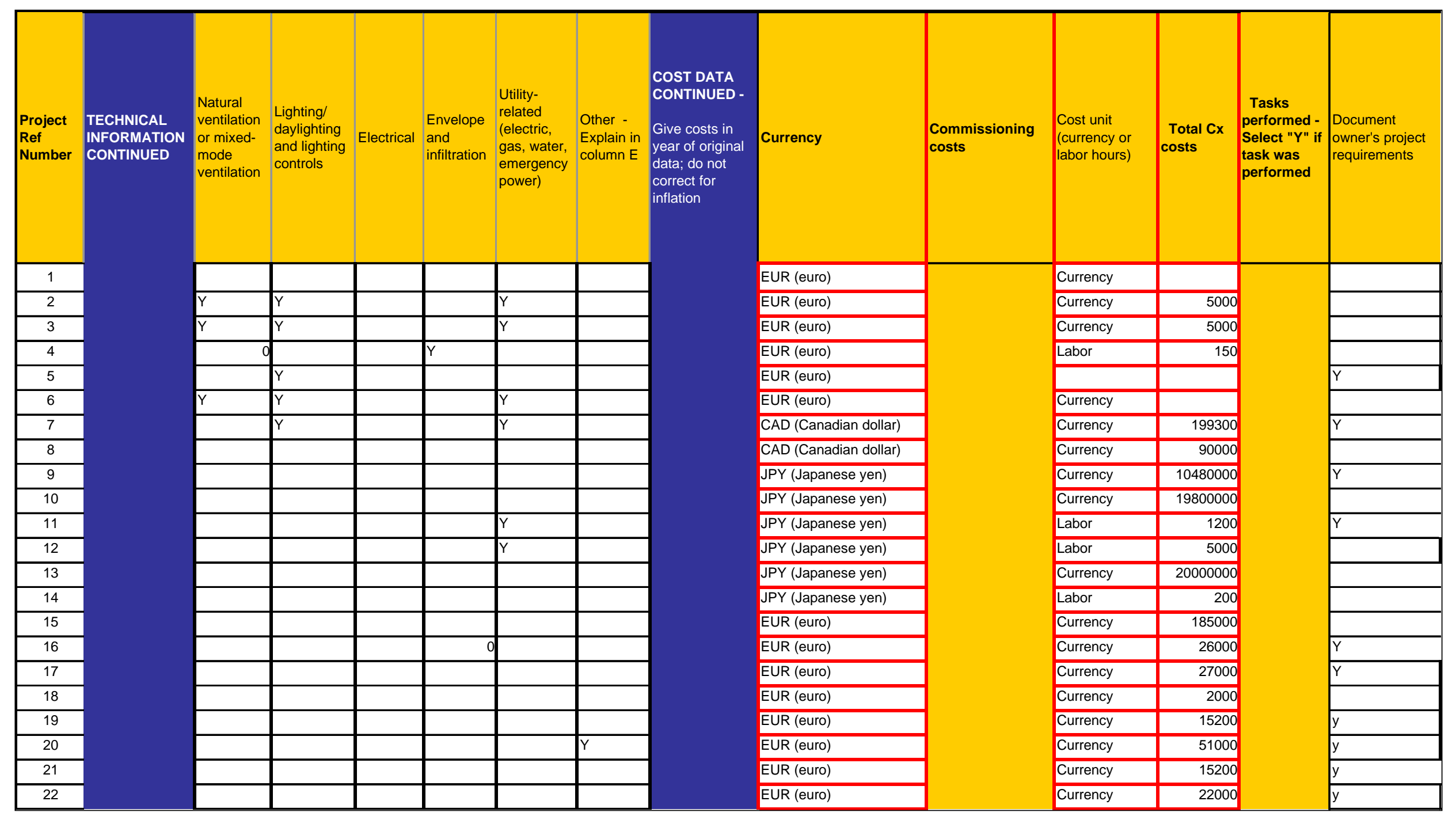

Page 218 of 239 


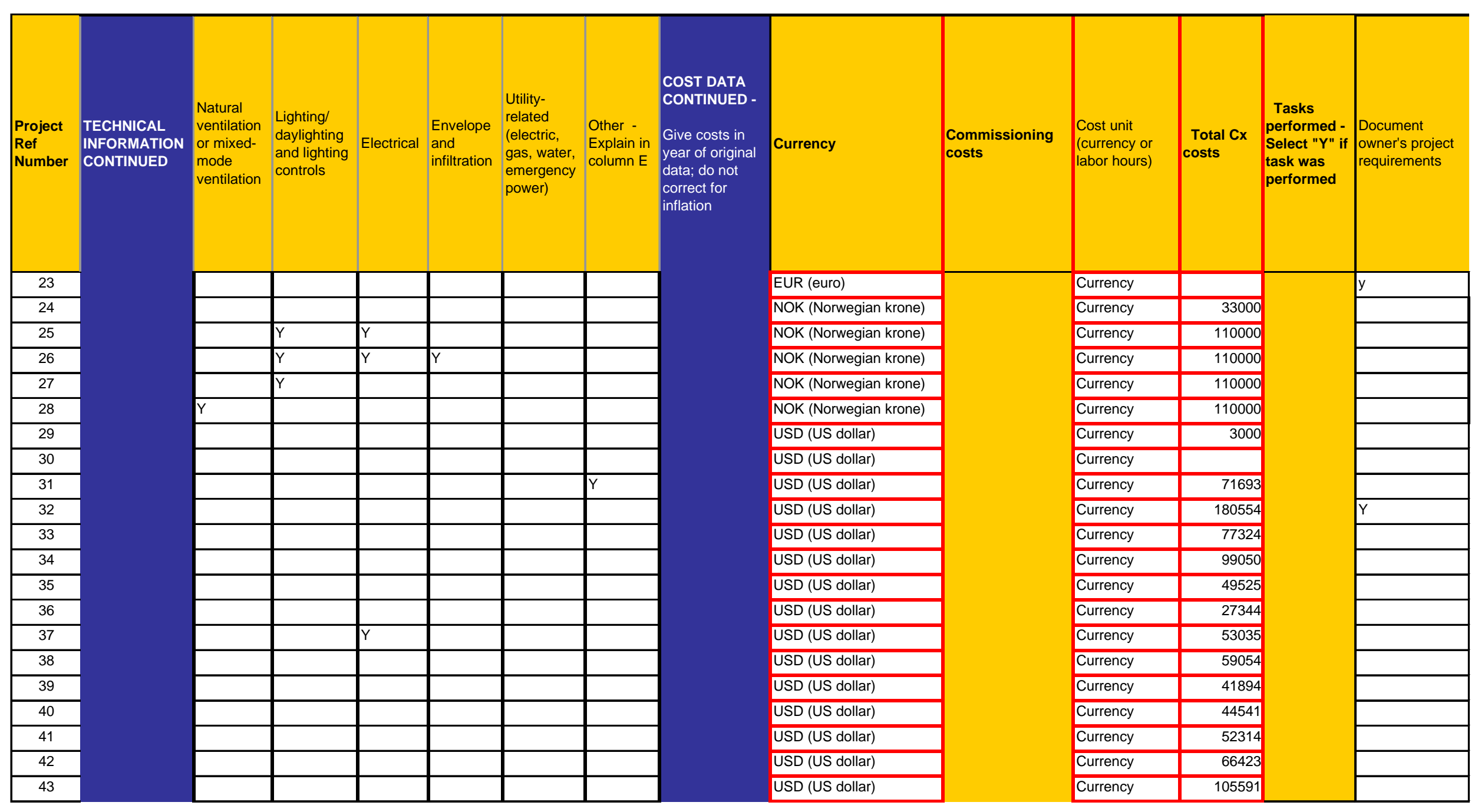

Page 219 of 239 


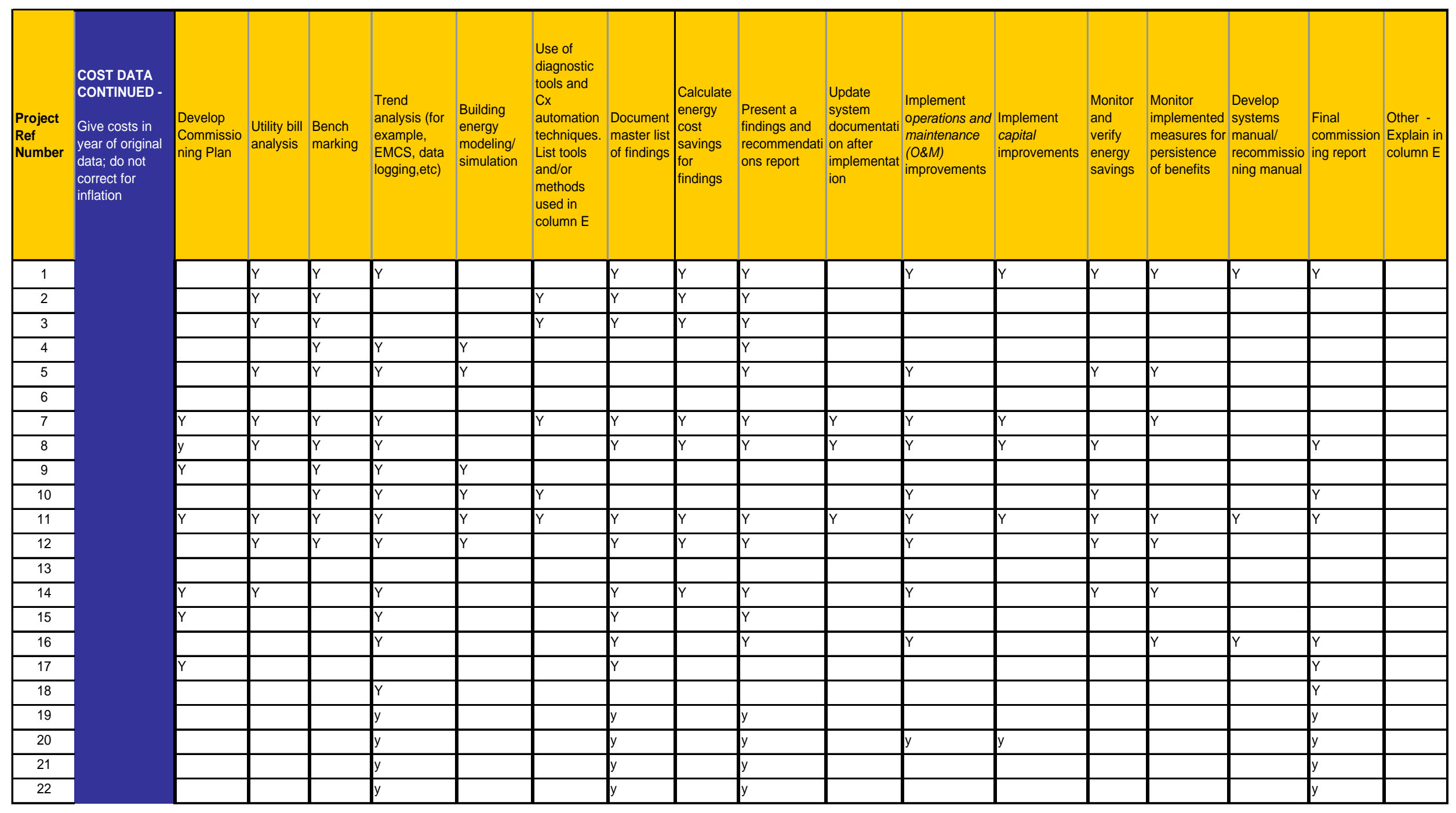

Page 220 of 239 


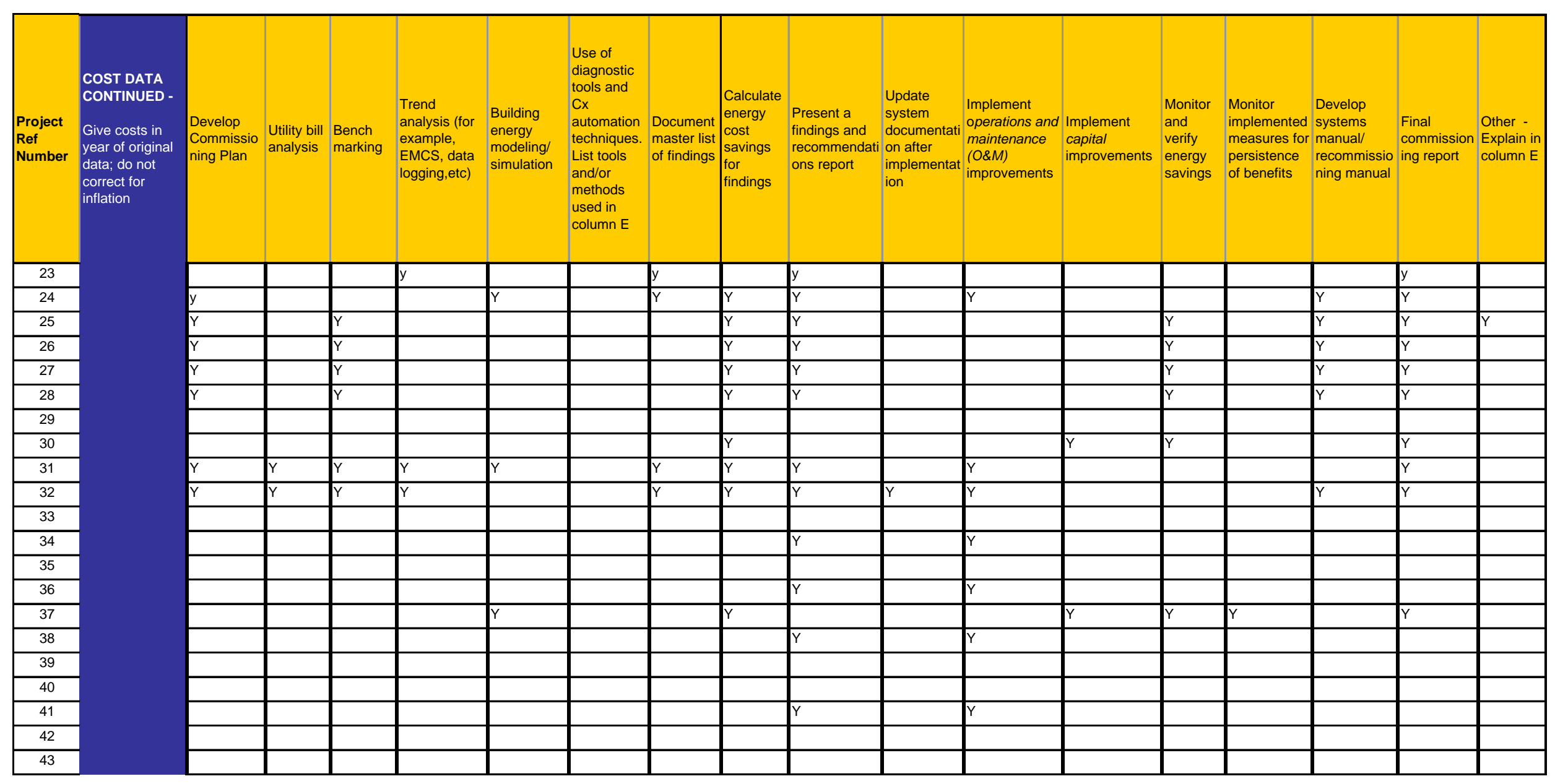




\begin{tabular}{|c|c|c|c|c|c|c|c|c|c|c|c|c|c|c|c|}
\hline \multirow[b]{2}{*}{$\begin{array}{l}\text { Project } \\
\text { Ref } \\
\text { Number }\end{array}$} & \multirow[b]{2}{*}{$\begin{array}{l}\text { SOURCE, } \\
\text { UNIT \& } \\
\text { COST }\end{array}$} & & \multicolumn{2}{|c|}{ Electricity } & \multicolumn{2}{|c|}{ Electric demand } & \multicolumn{3}{|c|}{ Fuel } & \multicolumn{2}{|c|}{$\begin{array}{c}\begin{array}{c}\text { District chilled } \\
\text { water }\end{array} \\
\end{array}$} & \multicolumn{2}{|c|}{ District hot water } & \multicolumn{2}{|l|}{ Water } \\
\hline & & & $\begin{array}{l}\text { Average cost } \\
\text { per unit (in the } \\
\text { first year after } \\
\text { commissioning) }\end{array}$ & Unit & 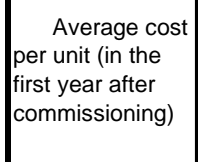 & Unit & Fuel type & $\begin{array}{l}\text { Avg cost/unit } \\
\text { (in the first } \\
\text { year after } C x \text { ) }\end{array}$ & Unit & $\left|\begin{array}{l}\text { Avg cost/unit } \\
\text { (in the first } \\
\text { year after } C x)\end{array}\right|$. & Unit & $\begin{array}{l}\text { Avg } \\
\text { cost/unit (in } \\
\text { the first year } \\
\text { after Cx) }\end{array}$ & Unit & $\begin{array}{l}\text { Average cost per unit } \\
\text { (in the first year after } \\
\text { commissioning) }\end{array}$ & Unit \\
\hline 1 & & Project Data & 14 & EUR/kWh & & & & & & & & & & & \\
\hline 2 & & Project Data & 0.155 & EUR/kWh & & & Natural gas & 0.019444444 & EUR/MJ & & & & & & \\
\hline 3 & & Project Data & 0.155 & EUR/kWh & & & Natural gas & 0.019444444 & EUR/MJ & & & & & & \\
\hline 4 & & Project Data & & & & & Natural gas & & & & & & & & \\
\hline 7 & & Project Data & 0.0526 & CAD/kWh & 11.85 & CAD/kW & Natural gas & 0.48 & CAD/m3 & & & & & & \\
\hline 8 & & Project Data & 0.074 & CAD/kWh & & & Natural gas & 0.54 & CAD/m3 & & & & & & \\
\hline 9 & & Project Data & 9.98 & JPY/kWh & 1774.5 & $\mathrm{JPY} / \mathrm{kW}$ & & & & & & & & & \\
\hline & & Project Data & 8.99 & JPY/kWh & 1517 & $\mathrm{JPY} / \mathrm{kW}$ & & & & & & & & 0.157 & JPY/Liters \\
\hline 10 & & Comments & $\begin{array}{l}\text { on Cx (but } 9.890 \\
\text { in summer } \\
\text { daylight \& } 4.500 \\
\text { at night) }\end{array}$ & & Average in 2005 & & & & & & & & & & \\
\hline 24 & & Project Data & 0.7 & NOK/kWh & & & & & & & & 0.7 & NOK/kWh & & \\
\hline 26 & & Project Data & 0.078 & USD/kWh & 0.121 & USD/kW & Natural gas & & & & & & & & \\
\hline \multirow[b]{2}{*}{30} & & Project Data & 0.55 & NOK/kWh & 460 & NOK/kW & & & & & & & & 15 & NOK/Other \\
\hline & & Comments & & & & & & & & & & & & Incoming + outlet water & \\
\hline \multirow[b]{2}{*}{31} & & Project Data & 0.55 & NOK/kWh & 460 & NOK/kW & Fuel oil & 0.5 & NOK/Therms & & & & & 151 & NOK/Other \\
\hline & & Comments & & & & & & $\begin{array}{l}\text { The cost is per } \\
k W h\end{array}$ & & & & & & Incoming + outlet water & \\
\hline \multirow[b]{2}{*}{32} & & Project Data & 0.55 & NOK/kWh & 460 & NOK/kW & Fuel oil & 0.5 & NOK/Therms & & & & & 15 & NOK/Other \\
\hline & & Comments & & & & & & & & & & & & Incoming + outlet water & \\
\hline 33 & & Project Data & 0.02788 & USD/kWh & & & & & & 4.67 & $\# \mathrm{~N} / \mathrm{A}$ & 4.75 & USD/MMBTU & & \\
\hline 34 & & Project Data & 0.02788 & USD/kWh & & & & & & 4.67 & $\# \mathrm{~N} / \mathrm{A}$ & 4.75 & USD/MMBTU & & \\
\hline 35 & & Project Data & 0.02788 & USD/kWh & & & & & & 4.67 & \#N/A & 4.75 & USD/MMBTU & & \\
\hline 36 & & Project Data & 0.02788 & USD/kWh & & & & & & 4.67 & \#N/A & 4.75 & USD/MMBTU & & \\
\hline 38 & & Project Data & 0.02788 & USD/kWh & & & & & & 4.67 & $\# N / A$ & 4.75 & USD/MMBTU & & \\
\hline 39 & & Project Data & 0.02788 & USD/kWh & & & & & & 4.67 & $\# \mathrm{~N} / \mathrm{A}$ & 4.75 & USD/MMBTU & & \\
\hline 40 & & Project Data & 0.02788 & USD/kWh & & & & & & 4.67 & $\# \mathrm{~N} / \mathrm{A}$ & 4.75 & USD/MMBTU & & \\
\hline 41 & & Project Data & 0.02788 & USD/kWh & & & & & & 4.67 & \#N/A & 4.75 & USD/MMBTU & & \\
\hline 42 & & Project Data & 0.02788 & USD/kWh & & & & & & 4.67 & \#N/A & 4.75 & USD/MMBTU & & \\
\hline 43 & & Project Data & 0.02788 & USD/kWh & & & & & & 4.67 & $\# \mathrm{~N} / \mathrm{A}$ & 4.75 & USD/MMBTU & & \\
\hline
\end{tabular}

Page 222 of 239 


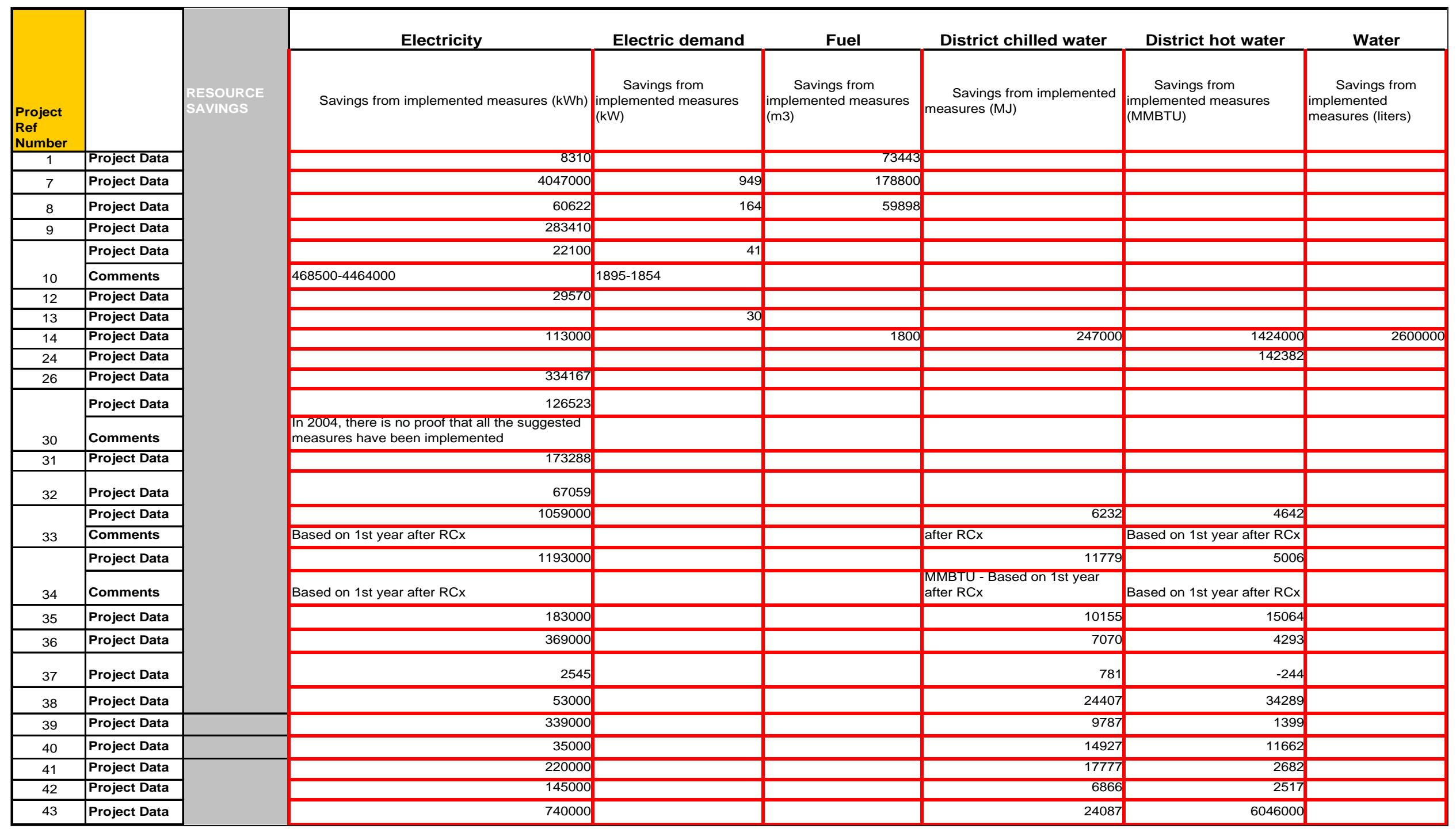




\section{APPENDIX B: The State of Building Systems Commissioning}

The following sections on the Asia Pacific, Europe, and North America regions provide an overview of the state of building systems commissioning. Each national assessment aims to present the national drivers, leading efforts and an indication of their success (if known). Fifteen countries are represented in this review.

\section{Asia Pacific}

In the Asia Pacific region, the construction industry is experiencing unparalleled growth. China alone reports the annual construction of two billion ${ }^{\mathrm{m} 2} \mathrm{~s}$ of floor space, (Qiu, 2008). The environmental impact of this growth has global repercussions. It is therefore critical that the building industry adopt building commissioning as a standard practice to improve the quality and efficiency of design, construction, and operations.

Asia Pacific countries are leveraging national energy laws, institutional mandates, and non-profit organizations to foster development of building systems commissioning. For several countries in the region, recent exposure through international symposia and conferences sparked interest that has developed into national research projects. This exchange of information is particularly useful for countries that have natural synergies, such as climate, that facilitate transfer of technologies or guidelines. Through these cooperative exchanges, countries are able to leapfrog technologies and accelerate adoption.

Australia: Indoor environmental quality assessments, rising energy costs, and a greater understanding of the link between comfort and productivity are driving the demand for improved energy efficiency of buildings in Australia. At present, most of the commissioning projects are associated with major contracts and do not address smaller projects. Furthermore, the fully integrated approaches to project commissioning, promoted by the Chartered Institution of Building Services Engineers (CIBSE) and American Society of Heating, Refrigerating and Airconditioning Engineers (ASHRAE) commissioning guidelines, are not well understood by the commercial sector, and this educational need is yet to be addressed (EcoLibrium 2006).

Awareness of the importance of the commissioning process is increasing, largely due to the market influence of voluntary, performance-based rating schemes such as the National Australian Built Environment Rating System and the Green Building Council's Green Star program. Through this mechanism, several large commercial real estate owners and governmental agencies have made commitments to achieve a certain rating in their building stock. The implementation and promotion of these rating schemes have the potential to trigger the demand for energy audits and commissioning in the existing building stock. Deakin University is developing rapid reporting techniques to facilitate building performance improvement in the commissioning process (Nakahara et al. 2007).

China: Mainland China has seen several construction booms. In the 1980's the rapid growth of residential construction prompted the Ministry of Construction to develop energyefficient building codes. These codes did not include commissioning and quality, in general, was considered poor. In the 1990s, testing and commissioning concepts diffused into the Chinese 
buildings industry as part of the western management techniques from numerous overseas, joint venture construction projects (Chow et al. 2006). International partnerships now also extend to academic research. Chinese universities, including Tsinghua University, are conducting research on building optimization, building commissioning and other related work. In 2008, China's Ministry for Construction released acceptance codes for building services equipment and building systems, though no information could be obtained regarding the administration and enforcement of these requirements.

Hong Kong was one of the first adopters and developers of the building commissioning process due to early exposure to the United Kingdom's commissioning model. As early as 1990, the Hong Kong Government published twelve booklets based on the CIBSE Commissioning Codes. The documents were developed into commissioning specifications released in 2002 and are intended to be incorporated into government building project contracts (Chow et al. 2006). Furthermore, in 2004, Hong Kong introduced a new voluntary scheme, termed the Consolidated Environmental Performance Assessment Scheme (CEPAS), to promote the design of environmentally-friendly buildings. CEPAS incorporates building commissioning as a major element for performance assessment.

The Hong Kong Building Commissioning Centre (HKBCxC) was established in December 2004 as a non-profit organization whose mission is to promote the establishment of a standardized approach to building commissioning in Hong Kong. The HKBCxC organizes programs for continuing professional development, certification services and publishes guidebooks on the management of building commissioning, field measurements, and system tuning. In the "Practical Guide to Building Commissioning Management", Chow et al (2006) report that independent contracts for commissioning and retro-commissioning are soaring in Hong Kong.

Japan: In 2006, building energy performance reporting became mandatory under the Energy Conservation Law. The reports are based on simple performance tests of the components and systems that have the largest impact on the energy consumption of heating, ventilation, and airconditioning systems. In practice, there is significant variation in the implementation approach because no standard test procedures are specified and it is unclear whether relevant problems could be investigated adequately through the data contained in the reports. Hence, aspects of the commissioning process are drawing more attention in Japan's building sector. In existing buildings, various approaches for retro-commissioning are commonly implemented, but initial commissioning for new construction is not common.

In 2005 the Society of Heating, Air-Conditioning and Sanitary Engineers of Japan (SHASE) technical committee on commissioning issued a guideline on the building services commissioning process. The Building Services Commissioning Association (BSCA), a nonprofit organization launched in 2004, provides seminars about commissioning technologies in major cities and has undertaken cooperative activities with Asian countries such as China (including Hong Kong), Taiwan, and Korea. It also continues to compile commissioning documentation and tools through actual commissioning projects and research. BSCA's strategy is to establish a certification program for commissioning engineers, including the Commissioning Authority, and to educate the construction industry and related government sectors. 
Energy policy is playing an important role. The Ministry of Economy, Trade and Industries is interested in a new business model, based on building commissioning, to enhance energy efficiency of new and existing buildings and The Ministry of Land, Infrastructure and Transportation is promoting use of lifecycle energy management with a newly developed simulation tool. Market demand for commissioning is believed to be strong but mandates, based on energy and environmental policy, are needed for building owners to apply building commissioning to new construction.

Taiwan: In Taiwan, building commissioning for new construction is considered established practice. The Taiwanese government has issued a mandate requiring that all public projects with a budget over 15 million U.S. dollars acquire the Green Building Label before a construction permit can be granted. Testing, adjusting and balancing (TAB), commissioning, and the use of a building energy management system (BEMS) are prerequisites. However, the process implemented in Taiwan does not represent the full range of actions from design to operations. The commissioning role in Taiwan for existing buildings is typically similar to that served by energy service companies in Japan and the USA. Taiwan is involved in international activities to expand national practices as deemed necessary. For example, a review of the Green Building Label (similar to Leadership in Energy and Environmental Design (LEED) for new construction in the USA and CASBEE in Japan) suggested that a commissioning plan be added.

A national-scale project was launched in 2003, by the Architecture and Building Research Institute, Ministry of the Interior, to renovate all the central heating, ventilation, and airconditioning (HVAC) systems in governmental buildings for energy conservation. The renovation process includes system diagnostics, remedial strategies, establishing engineering jobs, contracting, TAB, commissioning, and system performance validation through the BEMS. To date, 22 million USD have been spent with an overall energy-savings of $22 \%$ and an average payback of five years. The success has since led to a series of demonstration projects for civil and governmental buildings. In 2008, Taiwan will launch another five-year program where the energy savings effort will be enhanced with greater system fine-tuning and commissioning as a means to support the Kyoto Protocol and global $\mathrm{CO}_{2}$ emission reduction efforts.

Korea: The Korean Institute for Energy Research (KIER) is working to promote the commissioning process through energy conservation and quality assurance measures for new construction. Commissioning projects have been carried out by KIER as part of their research work, and have also been implemented in several buildings financed by foreigners. However, there is no recognized national standard and the Korean government has no intention to mandate the commissioning process.

Europe: The countries of the European region present significant differences in their building delivery processes as well as their emphasis on energy efficiency and measures for quality assurance. For most, with the exception of the UK, the commissioning process is quite new. However, the European Commission established the European Performance of Buildings Directive, EPBD (EC 2002), to promote the improvement of energy efficiency and building performance. Four requirements to be implemented by the Member States are to: 1) develop a framework for a methodology to calculate the integrated performance of buildings, 2) set 
minimum standards in new and existing buildings, 3) certify the energy performance of buildings, and 4) inspect and assess heating and cooling installations.

According to reports from the member states, the EPBD poses significant challenges in terms of its practical implementation, including difficulties associated with the transfer of requirements into existing building practices under a range of climates. However, because the commissioning process is well aligned with the goals of the EPBD, several national research programs are introducing commissioning tools as a means to address the requirements of the directive. In many countries, commissioning tasks are focused on the building handover, or performed as part of the facilities management. However, for commissioning to have a real impact on savings, the review must begin at the pre-design phase, where changes are easier and more cost-effective to make. It is anticipated that the increased attention to energy efficiency in buildings will lead to greater application and consistency of commissioning through the building lifecycle.

Belgium: Commissioning research has been underway in Belgium for several years, and mainstream awareness of the importance of commissioning of low-energy buildings has increased due to the implementation of the EPBD and the introduction of the passive house concept for very low energy building. Energy performance laws, which set requirements for the energy performance and indoor climate for most buildings requiring a building permit, exist in the Flemish Region and are under development in the Brussels and Walloon regions.

Czech Republic: Building commissioning is a new concept in the Czech Republic. Only some aspects of building commissioning are implemented as a part of the facility management and energy auditing processes that are related to EPBD implementation. Under the IEA Annex 47 project, researchers have developed tools that support additional aspects of the broader commissioning process, including new control system energy services.

Finland: Historically, individual contractors and builders in Finland have managed commissioning-related activities as part of their quality assurance measures. More recently, emphasis has been placed on the development and implementation of "energy auditing" procedures. In 2002, a Finnish national research program called CUBE was launched to improve the performance of building services. This program includes a national R\&D project to develop Finnish procedures for building commissioning, focusing on the indoor air quality and energy efficiency of buildings. The Finnish term and concept of "toimivuuden varmistaminen (ToVa)," an adaptation of building systems commissioning, is being promoted. Practical testing and further development of the guidebook and tools are underway. Methods and tools to support the commissioning of buildings and their subsystems throughout the phases of the building life-cycle are being developed.

France: The commissioning process is just beginning to take hold in France and a national guideline on commissioning is under development. In practice, commissioning is implemented in the operations phase, though there is greater interest from large building owners for more complete commissioning plans as a result of ongoing national research and new requirements under the EPBD. Current research is focused on automating the commissioning process to improve performance, pushing for early implementation of the commissioning process from 
design through certification, and developing tools and procedures for specific building applications (e.g., schools).

Germany: Commissioning for new construction is not established or even required as a third party service in Germany. German law (HOAI) dictates that architects and design engineers perform the following tasks within the construction administration and construction supervision:

- supervising acceptance and performance tests and statement of deficiencies;

- collecting/compiling and delivering as-built documentation, operating manuals, and acceptance protocols; and

- supervising the rectification of deficiencies that fall under the two-year contractor's warranty period or the five-year design team warranty period from date of acceptance.

This approach, initiated in 1976, presents a model for internal commissioning during the construction phase and, in conjunction with energy conservation laws, has resulted in higher performing buildings. Efforts to implement the full commissioning process beginning in predesign have been more recent. In one German national research program on energy optimization in buildings (ENOB), more than twenty demonstration buildings surpassed national energy consumption standards by $50 \%$ without incurring additional building costs. The program has been extended and now supports the design process, commissioning, and monitoring of the first two years of operation. ENOB also supports several projects focusing on improved commissioning and operation of innovative buildings. Energy agencies and utilities support energy efficiency through contracting and public private partnerships. Two other projects, ModBen and Building EQ, deal with performance evaluation of existing buildings.

The Netherlands: In the Netherlands, practitioners agree on the importance of building commissioning. However, it is currently only implemented in the installation and formal handover of selected buildings. A pilot project on functional performance tests conducted in forty buildings identified that $70 \%$ of the systems tested were malfunctioning, leading to increased energy use and reduced comfort. To improve system operation, large-building owners are investigating performance contracting for operations and maintenance, based on well-defined criteria. The commissioning process plays an important role. The Netherlands Organization for Applied Scientific Research is involved in the development of national standards concerning the energy performance of new buildings to promote the implementation of the whole commissioning process. Norway: Building commissioning is not an established practice in Norway. A draft national commissioning guideline was developed in 2007 to promote the lifelong commissioning of building HVAC systems. The guideline is currently under review and several large governmental and private building owners are involved in the effort to verify, document and implement suitable tools to provide continuous control of energy and indoor environment during the life of the building.

United Kingdom: The UK developed the earliest commissioning codes and provided the basis for similar work in many other countries. CIBSE published the first commissioning code on airdistribution systems in 1960 and subsequently released codes for other types of equipment. The emphasis of the commissioning codes was originally post-construction commissioning. Bordass (2008) reports that independent commissioning engineers were usually appointed as part of the design and build team in the late 1970's and early 1980's. However, as markets became more competitive, in the late 1980's and 1990's, commissioning was less commonly sold as a separate 
service and eventually became a subcontractor role, which had a negative impact on quality due to cost-cutting pressures. Today, initial commissioning has become routine for large projects and quality has once again improved but there are still major challenges in that the commissioning period is often squeezed when other delays impact the delivery date. The current set of CIBSE commissioning codes includes: air distribution systems, boilers, automatic controls, lighting, management (Code $\mathrm{M}$ ), refrigeration, and water distribution systems. Code M shows an important change in the approach to the initial commissioning process by stating that the commissioning manager should be appointed early in the design phase in order for the system to be designed as commissionable.

Other organizations have also been directly involved in improving the commissioning industry. The Building Services Research and Information Association (BSRIA), a non-profit consulting design, construction, and operations organization is leading the "Soft landings" development with support from the Usable Buildings Trust, a non-profit organization dedicated to improving building performance through the better use of feedback. The Soft landings procedure aims to reduce the loss of information by extending the service of the design and building (and commissioning) team to facilitate fine-tuning and debugging at building handover in order to achieve a closer match between design targets and building operation, and to allow individuals to learn from the experience (BSRIA 2008). The Commissioning Specialists Association (CSA) is focused on career development, including training and certification of individuals.

Although retrocommissioning is not widespread, there is expected to be a major increase in its implementation as demand for improved energy and carbon performance increases, driven by new requirements of the EPBD, occupants, and building owners.North America

In North America, the concept of building commissioning began with the Code of Practice for Commissioning Mechanical Systems in Buildings that was developed in 1986 by the Standing Committee of Consulting Engineers and Mechanical Contractors of British Columbia. Today there are several, industry-recognized guidelines on the commissioning process: ASHRAE Guideline 1-1989 The HVAC Commissioning Process (revised in 1996), and ASHRAE Guideline 0-2005, The Commissioning Process. Although building systems commissioning is established practice in both Canada and the USA, the process is not widespread. Many of the existing resources are focused on conventional HVAC systems and there is need for information on other types of systems, particularly due to increased interest in non-conventional, low energy systems.

In Canada and the USA, awareness has increased through professional organizations, certification programs (e.g., LEED), large-owner mandates, and energy-efficiency initiatives. However, market barriers are significant. There is a need for greater awareness of the benefits and cost of commissioning to increase demand, and a need for more training and certification of commissioning providers to increase the supply. At present, building owners lack the access to experience and lessons learned in easily accessible, creditable and persuasive formats that would facilitate their investment decisions. Furthermore, tools and standardization are needed to reduce the cost of commissioning and improve the cost-benefit ratio for greater uptake. This includes automated tools, data on cost-benefits, and clear specifications for key building performance metrics, monitoring methods, and energy calculation methods. Details of national initiatives follow. 
Canada: Existing building commissioning in Canada is at the early stage of its development. While the demand for commissioning services remains stagnant, there are encouraging signs of activity transformation favorable to the creation of a better structured and more efficient market place. As more and more building owners and managers strive for energy conservation and building sustainability, their first step consists to improve their building operation efficiency. With the increase of energy prices, low cost technology availability and their practical advantages have strengthened the demand for energy-saving HVAC controls.

In order to support institutional and commercial businesses in this shifting market, the Ministry of Natural Resources Canada and its energy science and technology organization, CanmetENERGY, provides knowledge, services and tools for recommissioning, commissioning and ongoing commissioning projects. They offer to building engineers, technicians, owners, managers and other similar stakeholders a suite of capacity-building and decision-making tools, including guides, training material, awareness seminars, pre-screening and benchmarking tools and case studies. CanmetENERGY developed an application software tool ( $\left.\underline{\mathrm{DABO}^{\mathrm{TM}}}\right)$ to continuously monitor, detect and diagnose the operation inconsistencies and poor performances of a building's electromechanical systems.

Furthermore, the Demand Side Management Working Group (DSMWG) created by Natural Resources Canada collaborates with utilities, public works, green building associations and standard organizations on energy management to accelerate the training and certification of commissioning providers and to raise stakeholders' awareness on the benefits of commissioning work. The persistence of energy savings has also attracted the interest of DSMWG and action has been undertaken to implement a new Energy Management Information System (EMIS) component to the recommissioning process.

It is also worth mentioning that the Canadian Standard Association is preparing a new standard on commissioning that should come into effect in 2011.

USA: Rising energy costs and a shift in public policy that emphasizes the need for energy independence are driving energy conservation. In the absence of national commissioning requirements, individual state codes and institutional mandates have proven to be strong market drivers, though enforcement mechanisms have been problematic.

The buildings industry is working to address market barriers and improve the quality of its services. Non-profit organizations, including ASHRAE, Portland Energy Conservation, Inc. (PECI), the California Commissioning Collaborative and the Building Commissioning Association (BCA), provide access to industry resources for both providers and building owners, including:

A library of published papers and commissioning guides for retro-, initial, and on-going commissioning; tools: design guides, operations and maintenance best practices, case studies database; Sample documents: commissioning plans, specifications, functional tests, checklists; and training and certification programs, career and provider directories.

In recent years, market indicators show growth in the number of firms offering commissioning services. In 2008, 267 commissioning provider firms and 665 members registered with the BCA. There has also been a dramatic increase in commissioning certification and training provided by 
professional organizations, which indicate a demand by engineering professionals for more knowledge.

Utilities and government agencies have also invested resources on research and technology demonstration activities in an effort to stimulate the market for commissioning. More investment is needed to significantly improve the energy efficiency of the existing building stock, to meet the low energy targets for new construction, and to address the projected shortage of skilled and certified providers. 


\section{APPENDIX C: Relevant Papers and Presentations}

Claridge, D.E., "Methodologies for Determining Persistence of Commissioning Benefits," Proc. of $7^{\text {th }}$ International Conference for Enhanced Building Operations - Maximizing Building Energy Efficiency and Comfort Permission to reprint granted on 12/1/11.

Toole, C. and Claridge, D.E., "Review on Persistence of Commissioning Benefits in New and Existing Buildings", Proc. of $7^{\text {th }}$ International Conference for Enhanced Building Operations Maximizing Building Energy Efficiency and Comfort, Part II, Paper VI-4-4, Shenzhen, China, November 6-8, 2006, 15 pp. Permission to reprint granted on 12/1/11.

Lin, G. and Claridge, D.E., "Retrospective Testing Of An Automated Building Commissioning Analysis Tool (ABCAT)," Proceedings of the 3rd International Conference On Energy Sustainability ASME, July 19-23, 2009, San Francisco, CA, USA. Copyrighted by ASME. Permission to reprint granted on 12/1/11. 
Insert PDF files of 3 papers and check page numbering.

Page 233 of 239 
Page 234 of 239 


\section{Appendix D: Annex 47 Participants}

\begin{tabular}{|c|c|c|}
\hline Name & Country & Affiliation \\
\hline Alexis Versele & Belgium & KaHo St-Lieven \\
\hline Hilde Breesch & Belgium & KaHo St-Lieven \\
\hline Stephane Bertagnolio & Belgium & University of Liege \\
\hline Daniel Choinière & Canada & Natural Resources Canada \\
\hline Zhongxiian Gu & China & TNO Beijing \\
\hline Yongning Zhang & China & Tsinghua University \\
\hline Karel Kabele & Czech Republic & Czech Technical University \\
\hline Pavla Dvorakova & Czech Republic & Czech Technical University \\
\hline Michal Kabrhel & Czech Republic & Czech Technical University \\
\hline Mika Violle & Finland & Helsinki University of Technology \\
\hline Jorma Pietilainen & Finland & Technical Research Centre of Finland (VTT) \\
\hline Hannu Keranen & Finland & Helsinki University of Technology \\
\hline Lari Eskola & Finland & Helsinki University of Technology \\
\hline Satu Paiho & Finland & Technical Research Centre of Finland (VTT) \\
\hline Hossein Vaezi-Nejad & France & Dalkia \\
\hline Oliver Baumann & Germany & Ebert \& Baumann Consulting Engineers \\
\hline Steffen Plesser & Germany & Institute of Building Services and Energy Design (IGS) \\
\hline Christian Neumann & Germany & Fraunhofer Institute for Solar Energy Systems \\
\hline Dirk Jacob & Germany & Fraunhofer Institute for Solar Energy Systems \\
\hline Anatoli Hein & Germany & Institute of Building Services and Energy Design (IGS) \\
\hline Michele Liziero & Germany/Italy & Politecnico di Milano, Guest Scientist ISE \\
\hline Jochen Schaefer & Germany & Ebert \& Baumann Consulting Engineers \\
\hline Shengwei Wang & HK/China & Hong Kong Polytechnic University \\
\hline Xinhua $\mathrm{Xu}$ & HK/China & Hong Kong Polytechnic University \\
\hline Zhenjun Ma & HK/China & Hong Kong Polytechnic University \\
\hline Zhou Cxiang & HK/China & Hong Kong Polytechnic University \\
\hline Xiao Fu Linda & HK/China & Hong Kong Polytechnic University \\
\hline Na Zhu & Hong Kong & Hong Kong Polytechnic University \\
\hline Zoltan Magyar & Hungary & University of Pecs \\
\hline Csaba Fodor & Hungary & University of Pecs \\
\hline
\end{tabular}




\begin{tabular}{|l|l|l|}
\hline \multicolumn{1}{|c|}{ Name } & \multicolumn{1}{|c|}{ Country } & \multicolumn{1}{c|}{ Affiliation } \\
\hline Harunori Yoshida & Japan & Kyoto University \\
\hline Motoi Yamaha & Japan & Chubu University \\
\hline Mingjie Zheng & Japan & Sanyo Air Conditioning \\
\hline Yasunori Akashi & Japan & Kyushu University \\
\hline Hiroo Sakai & Japan & Hitachi Plant Technologies \\
\hline Katuhiro Kamitani & Japan & Tonets Corporation \\
\hline Ryota Kuzuki & Japan & Tokyo Gas Co \\
\hline Katsuhiko Shibata & Japan & Takasago Thermal Eng. Co \\
\hline Fulin Wang & Japan & Kyoto University \\
\hline Masato Miyata & Japan & Kyoto University (student) \\
\hline Hirotake Shingu & Japan & Kyoto University (student) \\
\hline Hiromasa Yamaguchi & Japan & Kansai Electric Power Co \\
\hline Ryusi Yanagihara & Japan & Tokyo Electric Power Co \\
\hline Hideki Yuzawa & Japan & Nikken Sekkei Research Institute \\
\hline Takao Odajima & Japan & Takenaka Corp. \\
\hline hirobumi ueda & Japan & Osaka Gas CO., Ltd \\
\hline Masahiro Shinozaki & Japan & Kyushu Electric Power Co. \\
\hline Katsuhiro Kamitani & Japan & Tonets Corporation \\
\hline Mingjie zheng & Japan & SANKO AIR CONDITIONING CO.,LTD \\
\hline Katsuhiko Shibata & Japan & Takasago Thermal Engineering Co..Ltd \\
\hline Vojislav Novakovic & Norway & $\begin{array}{l}\text { Norwegian University of Science and Technology } \\
\text { (NTNU) }\end{array}$ \\
\hline Natasa Djuric & Norway & NTNU \\
\hline Marko Masic & Norway & NTNU \\
\hline Vojislav Novakovic & Norway & NTNU \\
\hline Henk Peitsman & the Netherlands & $\begin{array}{l}\text { Netherlands Organization for Applied Scientific } \\
\text { Research (TNO) }\end{array}$ \\
\hline Luc Soethout & the Netherlands & TNO \\
\hline Ipek Gursel & the Netherlands & University of Delft \\
\hline Natascha Milesi & USA & National Institute of Standards \& Technology \\
\hline David Claridge & USA & \\
\hline Hannah Friedman & USA & \\
\hline
\end{tabular}




\begin{tabular}{|l|l|l|}
\hline \multicolumn{1}{|c|}{ Name } & \multicolumn{1}{|c|}{ Country } & \multicolumn{1}{c|}{ Affiliation } \\
\hline Omer Akin & USA & Carnegie Mellon University \\
\hline Ashish Singhal & USA & Johnson Controls \\
\hline Tudy Haasl & USA & Portland Energy Conservation Inc \\
\hline Phil Haves & USA & Lawrence Berkley National Laboratory \\
\hline
\end{tabular}

